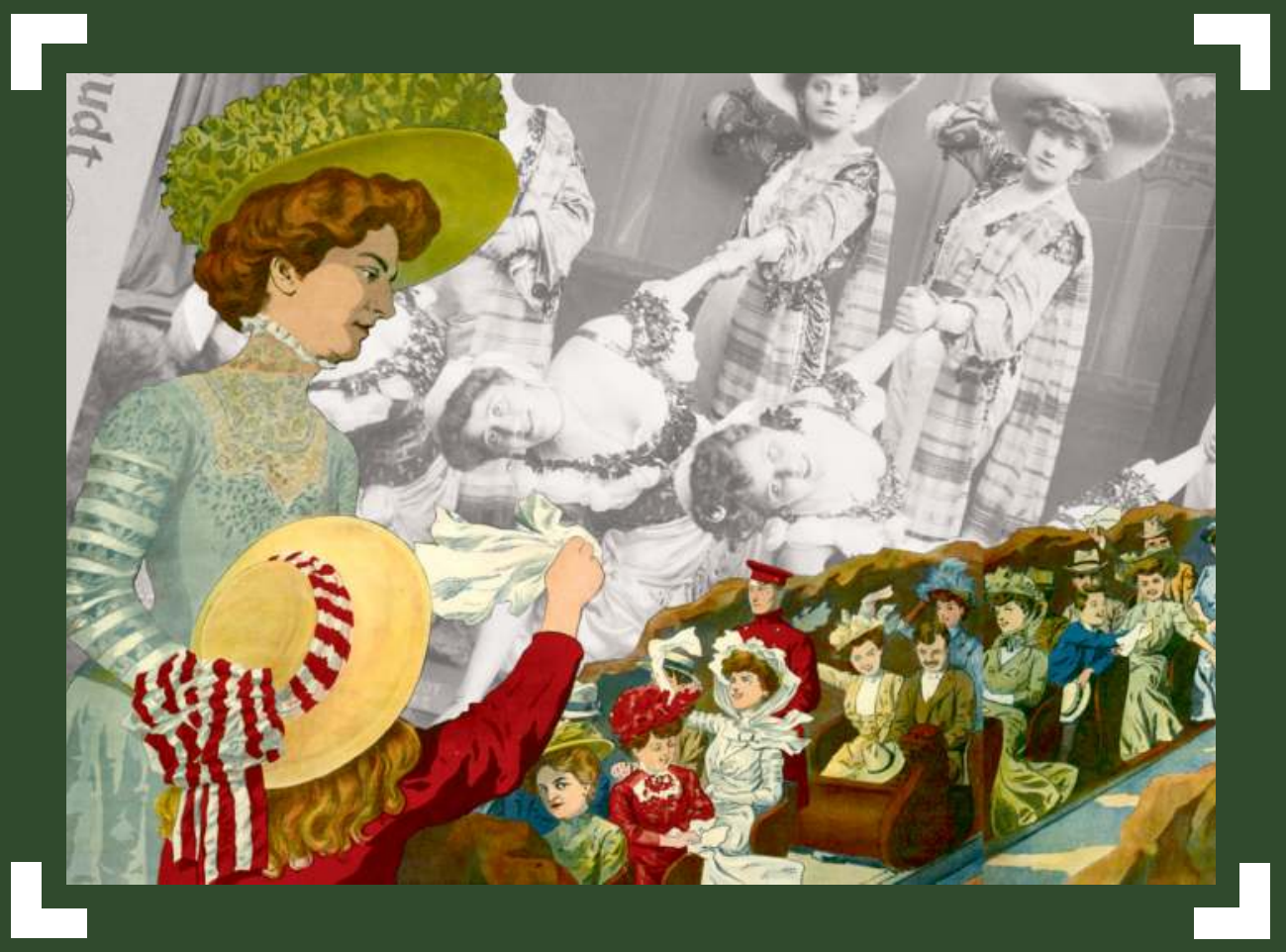

\title{
Auf die Tour!
}

Jüdinnen und Juden in Singspiellhalle, Kabarett und Varieté

Zwischen Habsburgermonarchie und Amerika 
$\frac{2}{\frac{\pi}{2}}$ 
Schriften des Centrums für Jüdische Studien

Band 35

Herausgegeben von Gerald Lamprecht und Olaf Terpitz 
Susanne Korbel

\section{Auf die Tour!}

Jüdinnen und Juden in Singspielhalle, Kabarett und Varieté

Zwischen Habsburgermonarchie und Amerika 


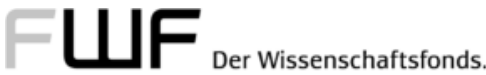

\section{Veröffentlicht mit der Unterstützung des Austrian Science Fund (FWF): PUB 712-G}

Open Access: Wo nicht anders festgehalten, ist diese Publikation lizenziert unter der CreativeCommons-Lizenz Namensnennung 4.0; siehe http://creativecommons.org/licenses/by/4.0/

Die Publikation wurde einem anonymen, internationalen Peer-Review-Verfahren unterzogen

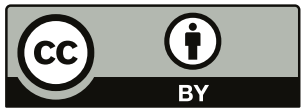

Bibliografische Information der Deutschen Nationalbibliothek :

Die Deutsche Nationalbibliothek verzeichnet diese Publikation in der Deutschen Nationalbibliografie ; detaillierte bibliografische Daten sind im Internet über http://dnb.d-nb.de abrufbar.

(C) 2021 by Böhlau Verlag Ges.m.b.H. \& Co. KG, Wien, Zeltgasse 1, A-1080 Wien

Umschlagabbildung : Emil Ranzenhofer, „Venedig 1909“, Druck Emil Weiner, Farblithographie, Albertina Wien und „Varietégirls“, Bildarchiv Austria; collagiert von Herwig Holzmann.

Korrektorat : Chris Zintzen, Wien

Einbandgestaltung : Michael Haderer, Wien

Vandenhoeck \& Ruprecht Verlage | www.vandenhoeck-ruprecht-verlage.com

ISBN (Print): 978-3-205-21187-7

ISBN (PDF): 978-3-205-21188-4

https://doi.org/10.7767/9783205211884 


\section{Inhalt}

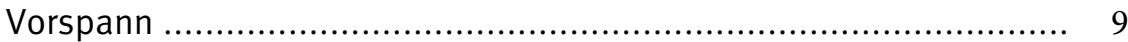

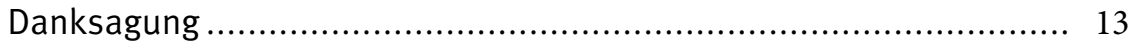

1. Jüdinnen und Juden, Mobilität und Sex - populäre Unterhaltung um 1900. Wie ,jüdisch“, wie ,transnational' und wie ,populär‘ war Amüsement im

Fin de Siècle?......................................................... 15

1.1 Neue Mobilitäten und Migrationen ................................ 21

1.2 Populäre Kultur als jüdisch-nichtjüdisches Interaktionsfeld........ 24

1.3 Raum, Differenz und Ähnlichkeit ............................... 25

1.4 Transgressive Mobilität - Perspektiven der Kapitel ................ 30

1.5 Quellen zum Eintauchen in die Welt populärer Kultur ............ 32

2. Die urbane Erfahrung in Wien, Budapest und New York. Blicke in die Metropolen ........................................... 35

2.1 Wien, Budapest und New York um 1900 .......................... 36

Wien ......................................................... 36

Budapest ...................................................... 39

New York .................................................... 42

2.2 Jüdisches Leben in den Metropolen ................................. 44

3. Amüsement in den Metropolen. Etablissement, Varieté und Singspielhalle in Wien, Budapest und New York ............... 51

3.1 Räume populärer Kultur in Wien, Budapest und New York ........ 53

$\mathrm{Zu}$ Raum und Ort................................................ 58

Jüdische Räume und Räume populärer Kultur .................... 61

3.2 Singspielhalle, Varieté und Etablissement in Wien,

Budapest und New York ....................................... 63

Wiener Spielstätten: Verortung populärer Kultur im Alltag........ 63

Intime Erfahrungen in der populären Kultur................. 67

Räumliche Überschreibung .................................. 72

Freiheit von Nation, Konzession und Konfession in den

Budapester Etablissements ................................ 75

Die Expansion der Budapester Singspielhallen ................ 76

Verortung als ,jüdische' Spielstätten .......................... 84

Transnationale Räume und Nationalismus.................... 85

Vom People's Theatre zur People's Music Hall in New York......... 94 
3.3 Global geteilte Erfahrungen und Entwicklungen in der populären Kultur 102

(K)Ein exklusiv (nicht)jüdisches Vergnügen? 106

4. Auf der Tour. Die Reisen der Volkssänger und Soubretten

4.1 Mobilität und populäre Kultur.... 113

Wachstum und Untergang?.

Organisation....

Die Distributionspraxis der Populärkultur ............................. 128

4.2 Jüdinnen und Juden auf der Tour......................................... 139

4.3 Männliche Damen, weibliche Männer und deren

Imitationen: mobile Rollenbilder 144

Volkssänger, Gesangshumoristen und Komödianten 145

Die Chantant-Regisseure.... 153

Von der „bodenständigen“ Volkssängerin zur Soubrette 154

Der Chantant-Direktor 161

Die Bühne als Zone des Übergangs zwischen Rollen. 164

4.4 Vorbehalte gegenüber der populären Kultur 170

5. Die urbanen „Busentempel“ als Möglichkeitsräume. Antisemitismus und Erotisierung, Gender-Bending und produktives Miteinander?

5.1 Singen, Spielen und Erzählen darüber, „was man

unterwegs alles erlebt" 180

Die Folie des Reisens 183

Stereotype, Vorurteile und Kolonialismus .............................. 187

Gender und gesellschaftliche Normen .................................. 190

Inszenierung von Gefahren des Unterwegsseins........................ 192

5.2 Populärkultur als interkultureller und kosmopolitischer Raum ....... 196

5.3 (Jüdischer) Humor und Ähnlichkeit.................................... 200

5.4 Beziehungen und das Intime .......................................... 213

Die jüdische Straßensängerin - Adaptionen des Bildes der Varitédame/Volkssängerin.................................. 214

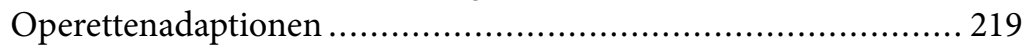

Die Volkssängerin an der Bowery? ..................................... 222

5.5 Das Private im Unterwegssein ............................................. 222

Nächtigen unterwegs - Erfundene, verhinderte oder gelebte Intimität? 
Nachspiel - Am American Scenic Railway durch Wien 233

Abkürzungsverzeichnis 239

Literaturverzeichnis 241

Personen- und Sachregister. 265 



\section{Vorspann}

Auf die Tour erforscht die Teilhabe von Jüdinnen und Juden an der populären Kultur in Wien, Budapest und New York. Spätestens seit der Vienna 1900 Ausstellung des Museum of Modern Art New York und Carl E. Schorskes Fin de Siècle Vienna war breit diskutiert, dass Juden (!) maßgeblich die sogenannte Hochkultur zur Jahrhundertwende in der Metropole der Habsburgermonarchie gestalteten. Die Euvres Ferenc Molnárs (1878-1952), Emmerich Kálmáns (1882-1953) und anderer aus Budapest bekannter Persönlichkeiten legten eine ähnliche Annahme für die zweite Residenzstadt der Monarchie nahe. Durch die enge Verbindung zwischen der Geschichte New Yorks und dem Broadway, und später vor allem mit Hollywood, ist das Wissen um Jüdinnen und Juden in der Unterhaltungsszene der Vereinigten Staaten kein kleines. Die Anfänge des Broadways an seinem südlichsten Teil, an der Bowery, wo populäre Kultur als blühendes Feld zwischen jüdischen und nichtjüdischen Migrant ${ }^{\star}$ innen und der schon länger in New York lebenden Gesellschaft geschaffen wurde, müssen allerdings erst Einzug ins Narrativ über die Millionenmetropole finden. ${ }^{1}$

Jüdinnen und Juden gestalteten auch die populäre Kultur auf Gasthausbühnen, in Singspielhallen, Varietés und Weingärten. Ebenso prominent wie Hugo von Hofmannsthal (1874-1929) oder Arnold Schönberg (1874-1951) an der Wiener Oper gespielt wurden, betrieben Jüdinnen und Juden Spielstätten, Musikhallen und kleinere Bühnen in Wien, Budapest und New York. Viele der bekanntesten Volkssänger*innen und Varietéstars waren Jüdinnen und Juden. Und ebenso waren Jüdinnen und Juden Teil des Publikums, das zur Jahrhundertwende immer stärker nach Amüsement hungerte.

Die populäre Kultur war ein Bereich des täglichen Lebens, in dem es zu besonders intensiven, regelmäßigen und facettenreichen jüdisch-nichtjüdischen Kontakten und Beziehungen kam. Sie war ein Bereich, der über sonst existierende Trennungen, etwa über soziale Klassen oder Alterskohorten hinweg, die Stadtbewohner*innen gemeinsam Zeit verleben ließ. Bettgeher*innen konnten hier dem gleichen Bühnengeschehen lauschen wie gutsituierte Kinder aus bürgerlichen Familien. Vor allem aber war die populäre Kultur jener Bereich, der durch die Massenmigration, Mobilität und Internationalität der Jahrhundertwende sein Potential und seine Wirkkraft entfaltete. In der populären Kultur waren die Habsburgermonarchie und Amerika durch ihre sich zu pulsierenden

1 Vienna 1900: Art, Architecture and Design, Museum of Modern Art New York, 3. Juli bis 26. Oktober 1986, New York. Carl E. Schorske, Fin De Siècle Vienna: Politics and Culture (New York: Vintage, 1981). 
Zentren des Amüsements entwickelnden Metropolen Wien, Budapest und New York eng verbunden.

Populäre Kultur verharrte nicht beim vermeintlichen Anspruch lediglich zu amüsieren. Sie spielte mit dem Subversivem. Sie nutzte die Möglichkeit, Theater zu machen gesellschaftspolitisch. Die populäre Kultur wollte bewegen und zum Nachdenken anstoßen. Sie war das Medium, mit dem sich Menschen täglich befassten und hatte entsprechend großen Einfluss. Umso spannender ist es - und gleichzeitig ist das der Grund, warum Jüdinnen und Juden und populäre Kultur lange nicht gemeinsam im Narrativ über die Jahrhundertwende vertreten waren - dass ein Jüdisch-Sein der Protagonist ${ }^{\star}$ innen weniger Thematisierung fand, als dies in antisemitischen Diskursen der Fall war. In den Stücken und Liedern spielten Jüdisch-Sein und Antisemitismus dahingegen sehr wohl eine Rolle. Die Inhalte der populären Kultur spiegelten die vielen kulturellen Affiliationen wider, drehten Stereotype um und gelegentlich spielten jüdische Gruppen und Schauspieler ${ }^{\star}$ innen mit antisemitischen Klischees.

Vermeintlich starre Kategorisierungen führten die Künstler*innen in der populären Kultur vor. Sie durchbrachen nicht nur jüdisch-nichtjüdische Dichotomien, sondern auch jene von Geschlechterverhältnissen. Etwa Gender-Bending, das Wechseln zwischen Geschlechterrollen, war eine gängige performative Strategie. Künstlerinnen besangen Diskriminierung und protestierten gegen den Vorwurf mit ihrer Unterhaltungstätigkeit Prostitution zu verschleiern. Deshalb lassen sich aus der populären Kultur viele Aufschlüsse über den Alltag, die Wahrnehmungen und die Erfahrungen breiter Bevölkerungsschichten jenseits vermeintlicher Gruppenkonzeptionen ziehen.

Umso bedauerlicher ist es, dass sich nicht schon viele Studien mehr der bunten Welt der populären Kultur widmeten. Auf die Tour möchte zur Erhellung beitragen und die populäre Kultur zwischen der Habsburgermonarchie und Amerika beleuchten, die mit ihren vielen Möglichkeiten, ihrer Mobilität und in ihrem innovativen Charakter eines der wichtigsten jüdisch-nichtjüdischen Interaktionsfelder um 1900 war.

\section{Bemerkungen zu Schreibweise, Transliteration und Übersetzungen}

Auf die Tour versammelt deutsch-, englisch-, hebräisch-, jiddisch- und ungarischsprachige Archivalien. Viele dieser verwendeten Quellen zeichnen besondere Eigenheiten aus. Unter diesen sei an dieser Stelle nur knapp auf die Eigenheiten der Schreibweise in Manuskripten hingewiesen: Bei den Textbüchern von Aufführungen liegen heute Abschriften jener Stücke und Lieder vor, die den Behörden vorgelegt wurden, um Genehmigungen zur Aufführung zu erhalten. Manchmal mussten die Abschriften auch als Übersetzungen in von 
den Behörden geforderten Sprache zugänglich gemacht werden. Die Künstler*innen fertigten daher ihre Manuskripte, etwa aufgrund von Zeitdruck um zeitnahe Aufführungserlaubnisse zu bekommen, häufig schnell an, Grammatik und Orthographie kam dabei keine besondere Bedeutung zu. In den Originalen gibt es auch keinerlei Stringenz betreffend Grammatiken, Orthographien und Strophenführungen. Transliterationen des Jiddischen sind oft willkürlich und inkonsistent - sogar innerhalb ein und desselben Manuskripts.

Ich habe die Schreibweise von den Manuskripten mit all ihren Eigenheiten übernommen. Bei grammatikalischen, orthographischen oder sonstigen Abweichungen weise ich aufgrund der großen Zahl nur am Ende der jeweils zitierten Passagen auf diese pauschal hin. Selbiges gilt auch für zitierte Zeitungspassagen und andere zitierte Textstellen aus Primärquellen. Die Transliterationen jiddischer Textstellen erfolgte nach YIVO Norm. Die Übersetzungen und Transliterationen sind, sofern nicht anders ausgewiesen, meine eigenen. 



\section{Danksagung}

A Room of one's own is not enough [...]

- Joan L. Bolker, $1994^{1}$

Schreiben ist über weite Strecken sehr einsam. „Ein Zimmer für sich“ zu haben, ist wichtig, aber nicht alles. Diesen Gedanken griff die Psychologin und Schreibtrainerin Joan L. Bolker auf, als sie sich auf Virginia Woolfs berühmte Feststellung darüber, was Frauen zum Schreiben bräuchten, bezog. Zu dem Zimmer, von dem Woolf sprach, fügte Bolker noch mit besonderer Betonung den kollegialen Austausch hinzu. Das gilt auch für diese Monographie. Vom ersten Nachdenken über ein Dissertationsprojekt, den ersten Tagen im Graduiertenkolleg, den Forschungsaufenthalten, dem Fertigschreiben der Dissertation bis hin zum Weiterforschen und Schreiben an der Monographie wurde ich von vielen großartigen Menschen begleitet und inspiriert. Ohne ihre Anregungen, Rückmeldungen und ihre Unterstützung wäre Auf die Tour nie zu Tinte und Papier geworden. Ihnen allen möchte ich hier danken.

Dieses Buch nahm seinen Ursprung in einer Reihe von Seminaren am Centrum für Jüdische Studien der Universität Graz, wo ich das Glück hatte, von den Arbeiten von Klaus Hödl, Joachim Schlör, Gerald Lamprecht, Petra Ernst-Kühr, Jennifer Hansen-Glucklich und Olaf Terpitz lernen zu dürfen. Diskussionen über jüdische Kultur, jüdisch-nichtjüdische Beziehungen und wie diese sich im Alltag manifestierten und in kulturellen Auseinandersetzungen Artikulation fanden, schlugen sich maßgeblich im Nachdenken über dieses Buch nieder. Ohne den prägenden Einfluss und die unzähligen Anregungen von Klaus Hödl, dem Betreuer meines Dissertationsprojektes, wäre dieses Buch nicht denkbar gewesen. Ebenso großer Dank gilt Joachim Schlör, nicht nur dafür, dass er von Southampton und Berlin aus das Projekt begleitet und stets fruchtbringend angeregt hat, sondern auch dafür, dass er es mir ermöglichte, einen Fuß in die Wissenschaft zu setzen. Ihnen beiden danke ich außerdem dafür, dass sie immer ein offenes Ohr hatten und mich ermutigten, meine eigene Stimme zu finden.

Auch viele andere schenkten mir Stunden ihrer Zeit, ein offenes Ohr und halfen mir mit Hinweisen und Anregungen weiter: Asher Biemann, Anil Bhatti, Tobias Brinkmann, Waltraud Dennhardt-Herzog, Gabriel Finder, Hildegard

1 Joan L. Bolker, A Room of One's Own Is Not Enough, in: dies. (Hg.), The Writer's Home Companion: An Anthology of the World's Best Writing Advice, from Keats to Kunitz (New York: Penguin Books, 1997), 183-200; Virginia Woolf, A Room of One's Own (London: Hogarth, 1929). 
Frübis, Pieter Judson, Dorothee Kimmich, Miklós Konrád, Michael L. Miller, Amos Moris Reich, Carsten Schapkow, Elana Shapira, Jonathan Skolnik, Frank Stern, Heidemarie Uhl, Alexander Vari, Michaela Wolf. Mein Dank gilt meinen Kolleg*innen in Graz und Budapest, Gerald Lamprecht, Olaf Terpitz, Lukas Nievoll und Orsolya Lénárt, und insbesondere Petra Ernst-Kühr und ihrer Doktorandengruppe Stefan Benedik, Thomas Stoppacher und Lukas Waltl, ohne deren Anregungen der Beginn des Projektes undenkbar gewesen wäre. Den Raum zum Schreiben gaben mir Schreibgruppen: In Wien möchte ich hier vor allem Judith Wolfsberger danken, für die regelmäßigen Treffen und den Austausch über das Schreiben Tim Corbett und in Graz Lukas Nievoll und Markus Wurzer sowie Elke Widmer für den Austausch über die Theaterstücke. Britta Badura gilt der Dank für das sorgsame Korrektorat. Für die sorgsame Auseinandersetzung mit meinem Manuskript und die gute Zusammenarbeit danke ich Ursula Huber und dem Böhlau Verlag sowie den Reihenherausgebern Gerald Lamprecht und Olaf Terpitz.

Ein Buch, das sich mit drei Städten auseinandersetzt, hätte nicht ohne die Hilfe und Anregungen von Forschungseinrichtungen und Archiven entstehen können. Ich möchte vor allem für die Unterstützung bei den Recherchen zu New York dem Center for Jewish History, und dort insbesondere dem Leo Baeck Institute und dem YIVO, Frank Mecklenburg, und Hermann Teifer, Michael Simonson sowie Leo Greenbaum, danken. Mich im Budapester Stadtarchiv zurechtzufinden, ermöglichte mir Erika Garami. Besonderer Dank gilt den Archivarinnen der Theatersammlung der National Széchényi Library. Im Wiener Stadt- und Landesarchiv eröffnete mir Georg Gänser die einmalige Möglichkeit, ungehindert in allen nur denkbar für das Projekt relevanten Beständen zu forschen. Ihm schulde ich ebenso großen Dank für unzählige Stunden Austausch.

Ich möchte mich zudem für die Kommentare von Diskutant*innen auf Konferenzen und Reviewer ${ }^{\star}$ innen, die frühere Ergebnisse dieses Projektes weiter gedeihen ließen, bedanken. Zudem hatte ich 2017 die Ehre, vom Deutschen Historischen Institut zum transatlantischen Doktorandenkolloquium eingeladen zu werden. Hier möchte ich den Teilnehmer*innen sowie Tobias Becker, Miriam Rürup und Annette Timm für ihre Anregungen danken.

Ich danke dem FWF für Finanzierung der Publikationskosten (Projektnummer PUB-712 G). Ohne die Finanzierung vom Österreichischen Bundesministerium für Wissenschaft, Forschung und Wirtschaft für die Forschungen und das Studium in Budapest sowie den Forschungsaufenthalt in Tübingen hätte ich nicht an diesem Projekt arbeiten können (Projektnummer BMWFW41.965/10-WF/V/7/2016). Die Fertigstellung der Monographie wäre ohne die Forschungsaufenthalte in den Vereinigten Staaten und in Israel, die vom DavidHerzog Fonds der steirischen Universitäten finanziert wurden, nicht möglich gewesen. Dafür möchte ich mich vielmals bedanken. 


\section{Jüdinnen und Juden, Mobilität und Sex - populäre Unterhaltung um 1900}

Wie ,jüdisch‘, wie ,transnational‘ und wie ,populär‘ war Amüsement im Fin de Siècle?

Du lieber Gott, was man unterwegs alles erlebt! - Scholem Alejchem ${ }^{1}$

Am 8. Jänner 1894 titelte die Internationale Artisten Revue „Auf die Tour!“. Damit eröffnete das „Fachorgan für Varieté- und Spezialitätenbühnen, Circus, Konzertetablissement, Schausteller und reisende Artisten“, wie sich das Blatt im Untertitel nannte, eine breite Diskussion über die Mobilität von Volkssänger ${ }^{\star}$ innen, Artist ${ }^{\star}$ innen und anderen Künstler*innen. Der Artikel sprach von der „allmählichen Ausdehnung" der populären Unterhaltungsszene und bezog sich darauf, dass im ausgehenden 19. Jahrhundert immer mehr Etablissements, Singspielhallen, Varietés, Orpheen und andere Orte des Amüsements in den urbanen Metropolen eröffnet hatten. Doch alle Artist*innen hatten keinen Platz in der Hauptstadt und mussten folglich auf Tournee gehen, so der Aufhänger des Artikels. Als paradigmatisch für eine solche Tour führte der Verfasser das Szenario eines Aufbruchs an:

Nach vieler Mühe ist die zusammengestellte Gesellschaft zur Abreise auf dem Bahnhof versammelt, die Karten sind gelöst, nur Frl. X. der Stern der Gesellschaft fehlt, das 1. Läuten ist vorüber, ängstlich haften die Augen des Directors an der Bahnhofuhr, endlich, beim 2. Läuten stürzt Frl. X. athemlos herein. Gott sei dank! Entströmt dem erleichterten Herzen des Directors, doch nur um in noch grösseren Schreck versetzt zu werden, denn Frl. X erklärt kategorisch dem Direktor, noch 25 fl. zu den erhaltenen 40 Gulden Vorschuss zu benötigen oder nicht mitfahren zu können. Der Direktor ist blank, er hat kaum $2 \mathrm{fl}$. zur eigenen Wegzehrung im Sacke, doch ein findiger Direktor weiss sich zu helfen, ohne sich eine Blösse zu geben. Wer von den Herrschaften kann mir einen Hunderter wechseln? Fragt der Herr Direktor, wohl wissend, dass das Keiner in der Gesellschaft kann, da jeder wenige Stunden vorher erst einige Gulden Vorschuss selbst vom Direktor erhalten. Niemand? Dann bitte ich Jedem mir $3 \mathrm{fl}$. zu leihen und so indem der Director sich von seinen eigenen Vorschuss $3 \mathrm{fl}$. von Jedem zurückborgt, werden die Ansprüche von Frl. X. befriedigt. Man sitzt im Wagon 3. Läuten! Pfiff! Der Zug rollt aus der Halle. $[!]^{2}$

1 Scholem Alejchem, Eisenbahngeschichten, herausgegeben, aus dem Jiddischen übersetzt und mit einem Nachwort von Gernot Jonas (Frankfurt am Main: Jüdischer Verlag, 1996), 7.

2 „Auf d.e. Tour“[!], IAR, 8.1.1894, 1-2, hier 1. 
Die Soubrette, die Sängerin der Gruppe, wollte die Tournee nicht begleiten, da ihr die Gage zu niedrig erschien. Von ihr aber hing der Erfolg der Gruppe ab. So bezahlte der Direktor - von den anderen Ensemblemitgliedern borgend - ihr schließlich den geforderten Betrag. Endlich im Zug, musste er dann hoffen, dass seine Soubrette nicht während der Tournee abspringe, da sonst das Schicksal der Gruppe besiegelt gewesen wäre.

Diese Anekdote präsentiert ein Bild von der Szene populärer Kultur, das von Mobilität geprägt war. Die Volkssänger*innen, Kabarettist ${ }^{\star}$ innen und Artist ${ }^{*}$ innen der Jahrhundertwende reisten zwischen den beiden Residenzstätten der Monarchie ebenso wie zwischen Amerika und Europa. Die Anekdote porträtiert überaus treffend die Bedeutung und die Wichtigkeit der Sängerin, der Soubrette, für das ganze Ensemble. Die Anekdote deutet auch an, wie hart das Geschäft mit der populären Unterhaltung war und dass es Mobilität, eine internationale Tätigkeit, erforderte. Indirekt weist die Anekdote zudem auf die oftmals prekären Lebensumstände der Künstler*innen hin. Ihr Leben war häufig von monetärer Not geprägt. Versicherungen gab es für ihre Berufsgruppe keine - umso wichtiger wurde es, dass sich die Szene lokal wie global selbst zu organisieren begann.

Das wachsende Unterhaltungsangebot in den Städten, das die Anekdote als Grund für die Tournee der Gruppe beschreibt, war allerdings nicht der einzige Grund, weshalb Künstlerinnen zur Jahrhundertwende mobil waren: Sie nutzten auch die neuentstandenen leichteren Reisemöglichkeiten, um ihr Repertoire in unterschiedlichen Städten zu präsentieren.

Als der Artikel in der Internationalen Artisten Revue erschien, erhob sich in Wien, Budapest und New York gerade ein Klagen nach den "guten alten Zeiten“ - nach dem Lebensgefühl der letzten Jahrzehnte -, nach „Alt-Wien“, "Alt-Budapest“ und „Old-New York“. New York sah sein Great Yiddish Theater untergehen, Wien sein altes Volkssängertum verschwinden und Budapest sein gutes altes Szinház verloren. Für all das wurden die Moderne und die mit ihr aufkommenden neuen Formen populärer Kultur wie Kabaretts, institutionalisierte Volkssänger- und Chansonbühnen, Singspielhallen oder Varietés verantwortlich gemacht: Die Attitüde „Busen- statt Musentempel ${ }^{\text {“3 }}$ und das Bedürfnis, „sich zu amüsieren“ breitete sich in den Städten aus.

Im Fin de Siècle änderte sich das urbane Lebensgefühl maßgeblich. Eine neue „Qualität an Mobilität“, wie der Kulturwissenschafter Moritz Csáky konstatiert, hatte in den letzten Jahrzehnten des 19. Jahrhunderts Wien, aber auch Budapest, zu prägen begonnen. ${ }^{4}$ Um 1900 war Migration aus sozialen, ökono-

3 Reichspost, 6.4.1899, 9.

4 Moritz Csáky, Hybride Kommunikationsräume und Mehrfachidentitäten: Zentraleuropa um 1900, in: Elisabeth Röhrlich (Hg.), Migration und Innovation um 1900: Perspektiven auf das 
mischen, politischen und/oder beruflichen Gründen allgegenwärtig. Unterwegs zu sein war leichter geworden und Mobilität Alltag jüdischen und nichtjüdischen Lebens. ${ }^{5}$ Theatergruppen, Artist ${ }^{*}$ innen und Volkssänger ${ }^{\star}$ innen gingen auf Tour. Die Künstler*innen brachten ihre Stücke in verschiedenen Städten auf die Bühne. Internationale Agenturen und eine weit vernetzte Organisation für reisende Künstler*innen zwischen den Städten der Monarchie, am europäischen Festland, aber auch nach Amerika entstanden. Fachorgane wie die Internationale Artisten Revue wurden gegründet. Darin informierten sich Künstler*innen, Theatermacher*innen und Ensembledirektor*innen über die Szene, deren Probleme, aber auch über neue Trends, Angebote, Stellen, Kostümfirmen, Textschreiber*innen und Ähnliches. Die neuen Publikationsorgane vernetzten sich auch untereinander und führten miteinander transnational wie interkontinental Korrespondenz. Neuigkeiten aus New York brauchten nach Wien oder Budapest nur noch sechs Stunden. ${ }^{6}$ In den Metropolen verbreiteten sich nicht nur Spielstätten, sondern es entstand auch die damit verbundene Infrastruktur für reisende, nichtortsansässige Künstler*innen. Artistenheime und -cafés, wo die Tag- beziehungsweise Nachtstunden abseits der Auftritte verlebt und preisgünstig gewohnt werden konnten, erleichterten die Mobilität der Künstler*innen.

Die Auftretenden waren nicht nur Reisende, sondern das Reisen beeinflusste auch die Aufführungen und das Aufgeführte. In ihren Darbietungen erzählten die Künstler*innen über das Reisen, Migration, Mobilität und Unterwegssein. Populäre Stücke und Lieder nahmen alltägliche Erfahrungen zum Ausgangspunkt. Sie jonglierten mit der sprachlichen Vielfalt, die das Unterwegssein wie auch den Alltag in plurikulturellen Migrationsgesellschaften, ${ }^{7}$ wie es jene Wiens, Budapests und New Yorks im Fin de Siècle waren, ausmachte. In der Pluralität des mit Reisen und Mobilität Verbundenen konnten Wahrnehmungen eines

Wien der Jahrhundertwende, unter Mitarbeit von Agnes Meisinger (Wien, Köln, Weimar: Böhlau, 2016), 65-97, 65-66.

5 Neben der realen Omnipräsenz von, jüdischen Reisen sei auch an die fiktive Tradition erinnert und nur kurz auf die bekannten jiddischen Erzählungen von Scholem Alejchem oder Jizchok Leib Perez, genauso wie etwa Joseph Roths Juden auf Wanderschaft verwiesen. Zu den unterschiedlichen Sujets ,jüdischer Reisen“ siehe Ezrahi Sidra DeKoven, Booking Passage: Exile and Homecoming in the Modern Jewish Imagination (Berkeley: University of California Press, 2000), 103-130.

6 „Das Vermittlungswesen“, IAR, 10.6.1894, 1-3, hier 1.

7 Anil Bhatti, Plurikulturalität, in: Johannes Feichtinger, Heidemarie Uhl (Hg.), Habsburg neu denken: Vielfalt und Ambivalenz in Zentraleuropa, 30 kulturwissenschaftliche Stichworte (Wien, Köln, Weimar: Böhlau, 2016), 171-180, 176-177. Auch Moritz Csáky verwendet das Plurikulturalitätsparadigma. Moritz Csáky, Das Gedächtnis der Städte: Kulturelle Verflechtungen - Wien und die urbanen Milieus in Zentraleuropa (Wien, Köln, Weimar: Böhlau, 2010), 357-358. Sowie Csáky, Hybride Kommunikationsräume, 72-76. 
being in-between, Lokation und Dislokation von Kultur/en widergespiegelt und verhandelt werden. ${ }^{8}$ Als Metapher diente Reisen aber auch dazu, um von der Zensur verbotene sowie kontroverse Inhalte in weitentlegenen und fremden Gegenden diskutieren zu können. ${ }^{9}$

Die neue Qualität an Mobilität prägte die Szene populärer Kultur, als sich die sogenannte Massenkultur zu entwickeln begann: Gassenhauer, Groschenromane, unzählige Varietés und andere Spielstätten, in denen man sich bei Speisen und Getränken amüsierte, erblühten. Die Massenkultur brachte verschiedenste Formen populärer Unterhaltung hervor und urbane Vergnügungsstätten verbreiteten sich rasant. Das war überhaupt erst möglich, da eine große Mehrheit der Bevölkerung erstmals Zeit - „Freizeit“ - hatte, das grenzenlose Vergnügen in Singspielhalle, Etablissement und Varieté genießen und durch Freizeitparks wie den Prater, das Budapester Városliget (Stadtwäldchen) oder den Vergnügungsgarten im New Yorker Washington Square Park spazieren konnte. ${ }^{10}$

Für den Untersuchungszeitraum von 1890 bis in die Zwischenkriegszeit einen passenden Zugang zu populärer Kultur zu finden, ist schwierig. Der Kulturanthropologe Kaspar Maase beschreibt den Zeitraum als einen Umbruch in der Populärkultur. Um die Jahrhundertwende waren die Straßen Wien, Budapest und New Yorks gefüllt mit Ständen, an denen Passant*innen Romane für wenige Heller beziehungsweise Pennys, sogenannte „Schundliteratur", kaufen konnten. Bald fanden sich Rubriken mit romanhaften Erzählungen in Tageszeitungen. Unterhaltungsstätten eröffneten überall. Vieles war leichter zugänglich; der "Schwank“, die "Schundliteratur" und „Gassenhauer", die die Bevölkerung unterhielten. ${ }^{11}$ Maases Feststellung greift Auf die Tour auf. Ihr fügt Auf die Tour eine weitere wesentliche Veränderung hinzu und konstatiert eine Schwelle in der Populärkultur hinsichtlich des besonderen Einflusses von Mobilität und Migration.

In Anlehnung an eine Definition des, Populären' vom Historiker Lawrence Levine soll unter Populärkultur das verstanden werden, was viele Menschen erreichen konnte und für viele zugänglich war, umgekehrt aber nicht nur zu-

8 Siehe hierzu im Besonderen Ansätze aus den postcolonial studies. Homi K. Bhabha, The Location of Culture (London, New York: Routledge, 2004).

9 Zur literarischen Tradition des Kosmopolitismus siehe Bill Ashcroft, Gareth Griffiths, Helen Tiffin, Postcolonial Studies: The Key Concepts (New York, Oxon: Routledge, 2013), 64-67. Im Vergleich dazu siehe Zu Aspekten „transnationaler Gesellschaftsgeschichte“ vgl. Jürgen Osterhammel, „Transnationale Gesellschaftsgeschichte: Erweiterung oder Alternative?“, Geschichte und Gesellschaft 27 (2001): 464-479.

$10 \mathrm{Zu}$ Massenkultur siehe Kaspar Maase, Grenzenloses Vergnügen: Der Aufstieg der Massenkultur 1850-1970 (Frankfurt am Main: Fischer, 1997), 19-25.

11 Maase, Grenzenloses Vergnügen, 20-29. 
gänglich war, sondern auch tatsächlich von vielen rezipiert wurde. ${ }^{12}$ Der Medienwissenschafter John Fiske betont, dass dieser populären Kultur ein interaktives und subversives Potential innewohnt. Dieses muss untersucht werden. ${ }^{13}$ Mit populärer Kultur meint Auf die Tour den Bereich alltäglichen Lebens, der dem Zeitvertreib der konsumierenden Bevölkerung diente. Eine Opposition zwischen der sogenannten Hochkultur und der Populärkultur gibt Aufdie Tour auf und sieht kulturelle Produktion als Feld des stetigen Überganges. Grenzen zwischen der populären Kultur und der sogenannten Hochkultur waren stets fließend. Damit verortet sich Auf die Tour in einem Wissenschaftsparadigma, das Levine als erstes einforderte. Levine fand beispielsweise heraus, dass Shakespeare im 19. Jahrhundert ,lowbrow' war. Heute würden die meisten Shakespeare der sogenannten Hochkultur zuordnen. ${ }^{14}$ Der Literaturwissenschafter Jonathan Hess prägte diesen produktiven Blick auf die Verknüpftheit der vermeintlich getrennten Bereiche, highbrow' und ,lowbrow' mit dem Begriff ,middlebrow'. ${ }^{15}$

Zwischen diesen beiden, beinahe gleichzeitigen Entwicklungen - der steigenden Nachfrage an populärer Kultur und der neuen Mobilität -, und den in ihnen entstehenden, neuen Möglichkeitsräumen mit ihrer engen Verknüpfung mit jüdisch-nichtjüdischen Interaktionen steht Auf die Tour. Auf die Tour thematisiert die Teilhabe von Jüdinnen und Juden an der populären Kultur zwischen Wien, Budapest und New York um 1900. Die populäre Kultur als jüdisch-nichtjüdischer Interaktionsraum zieht sich durch das ganze Buch; es beschreibt populäre Kultur als bewegliches und mobiles Interaktionsfeld von Jüdinnen und Juden mit Nichtjüdinnen und Nichtjuden. Auf die Tour fragt, wie populäre Unterhaltung in und zwischen Wien, Budapest und New York um 1900 aussah. Welche Personen beziehungsweise Ensembles wirkten in mehreren Städten? Welche Bedingungen rahmten ihr internationales Wirken? Wo fanden in den Städten Aufführungen statt? Mit welchen räumlichen Gegebenheiten und gesetzlichen Vorgaben waren die Künstler*innen konfrontiert? Wie wirkte sich Mobilität auf die Aufführungspraxis aus? Was bedeuteten Migration, Mobilität, Reisen und ein Unterwegssein für die Künstlerinnen, ihre Lieder und Theaterstücke? Veränderten, und wenn ja, wie adaptierten die Künstler*innen

12 Lawrence W. Levine, „The Folklore of Industrial Society: Popular Culture and Its Audiences“, The American Historical Review 97, no. 5 (1992): 1369-1399, 1395-1397.

13 John Fiske, Reading the Popular (London, New York: Routledge, 2011), 1-2.

14 Lawrence W. Levine, Highbrow Lowbrow: The Emergence of Cultural Hierarchy in America (Cambridge, London: Harvard University Press, 2002), 4-9 sowie 33.

15 Die Auflösung dieser Dichotomie von Hoch- und Populärkultur bzw. highbrow und lowbrow war stark von den Arbeiten des Historikers David Sorkin zur Problematisierung der Konzepte von „Minderheit“ und „Mehrheit“ beeinflusst. Jonathan M. Hess, Middlebrow Literature and the Making of German-Jewish Identity (Stanford: Stanford University Press, 2010), 11-14. 
ihre Stücke zwischen verschiedenen Städten? Gibt es Themen oder Motive, die immer wieder verwendet werden oder sich gehäuft in den Stücken finden? Wie übersetzten die Künstler*innen ihre Stücke kulturell? Wie wird das Unterwegssein, wie wird das Verlassen gewohnter Umgebungen und Gewohnheiten und sich in neuen zurechtzufinden, reflektiert? Welche Diskursfiguren und Stereotype kommen vor und wie differenzierten sie sich in den Städten aus? Welche Aufschlüsse über die Interaktionen von Jüdinnen und Juden mit Nichtjüdinnen und Nichtjuden können daraus gewonnen werden? Welche Rückschlüsse auf Identifikationen und Genderzuschreibungen sind zulässig?

Auf die Tour zeigt, was auf den Bühnen und durch die Mobilität und Transnationalität alles möglich war; wie Akteur*innen populärer Kulturen Antisemitismus gleichermaßen wie Gender-Bending zum Thema machen konnten. Auf die Tour beleuchtet die Möglichkeitsräume, die die populäre Kultur bot und gleichermaßen auch Vorwürfe, die der populären Kultur gegenüber aufkamen. Auf die Tour problematisiert Unterstellungen, die sich die Szene und deren Protagonist*innen immer wieder gefallen lassen mussten und thematisiert die scheinbar paradoxe Ambivalenz der urbanen Vergnügungsstätten - zwischen Ermöglichen und Tadeln, zwischen Amüsement und Gesellschaftskritik, zwischen kosmopolitischem und kolonialistischem Denken. Die einzelnen Kapitel beleuchten diese produktive Ambivalenz aus jeweils anderer Perspektive: Zwischen welchen Entwicklungen sich populäre Kultur überhaupt ereignete (Kapitel 2); wie sich Möglichkeitsräume als Orte des Amüsements in den Städten Wien, Budapest und New York etablierten und Wirkung entfalteten (Kapitel 3); wie populäre Kultur mit ihren Protagonist*innen auf Tour ging und wie diese Mobilität organisiert war (Kapitel 4); mit welchen Strategien brisante Themen anzusprechen, zu diskutieren und zu reflektieren vermocht wurden (Kapitel 5); und wie schließlich damit die populäre Kultur und das in ihr Aufgezeigte (all-)zu visionär erschien (Nachspiel). Anders gesprochen: Es geht in diesem Buch darum, wie vor dem Hintergrund der Mobilität und im internationalen Licht populärer Kultur jüdische und nichtjüdische Künstler*innen einerseits alle unterhalten und gleichzeitig auf der Bühne subversive Strategien benutzen konnten, um brisante Themen wie Antisemitismus zu diskutieren, ja sogar Geschlechterrollen zu tauschen und zu hinterfragen, sich aber andererseits gerade die populäre Kultur immer wieder Vorwürfe wie Obszönität, Seichtheit und Schleier für Prostitution zu sein gefallen lassen musste. ${ }^{16}$

16 Zum subversiven Potential populärer Kulturen vgl. John Fiske, Reading the Popular, 1-2. 


\subsection{Neue Mobilitäten und Migrationen}

Wie kam es zu dieser neuen Qualität an Mobilität, die die populäre Kultur derartig beeinflusste? ${ }^{17}$ Warum konnten so viele Sänger ${ }^{\star}$ innen, Artist ${ }^{\star}$ innen und Ensembles in verschiedenen Städten auftreten? Ein Blick auf Migrationsbewegungen, die ihren Ausgang in den vorhergegangenen Jahrzehnten nahmen, erklärt Entwicklungen, die wichtige Voraussetzungen dafür schufen. Die jüdische Massenmigration ${ }^{18}$ ließ in den letzten Jahrzehnten des 19. Jahrhunderts rund zwei Millionen Jüdinnen und Juden aus den östlichen Gebieten der Monarchie westwärts wandern. Verschiedene Faktoren bedingten diese Bewegung: Die Erschließung Galiziens und der Bukowina, den östlichsten Provinzen der Monarchie, durch die Eisenbahn ${ }^{19}$ beeinflusste die ökonomische Ausgangslage innerhalb wie auch außerhalb der Monarchie nachhaltig. ${ }^{20}$ Die leichtere Erreichbarkeit der Märkte mit dem Zug führte dazu, dass Händler*innen von auswärts mit der Bahn anreisten. Das Angebot und damit der Wettbewerb nahmen zu und Ansässige konnten ihre Produkte nicht mehr verkaufen. Viele verarmten. ${ }^{21}$ Die große Zahl an in Armut Lebenden resultierte zudem aus einem vorangegangenen Bevölkerungswachstum, das seit der zweiten Hälfte des 19. Jahrhunderts die Demographie geprägt hatte. ${ }^{22}$

17 Csáky, Hybride Kommunikationsräume und Mehrfachidentitäten, 65-67.

18 Tobias Brinkmann, Points of Passage: Reexamining Jewish Migration from Eastern Europe after 1880, in: ders. (Hg.), Points of Passage: Jewish Transmigrants from Eastern Europe in Scandinavia, Germany, and Britain 1880-1914 (New York, Oxford: Berghahn, 2013), 1-26.

191836 wurde die Errichtung der ersten Dampfeisenbahn für Galizien genehmigt und das Netz schließlich bis 1861 ausgebaut. Neben einer bedeutenden Verbesserung der Infrastruktur für den Handel bewirkte dies, dass Menschen nun vermehrt die Eisenbahn nutzen konnten und bald auch Händlerandelnde auf dieses Verkehrsmittel zurückgriffen. Klemens Kaps, Ungleiche Entwicklung in Zentraleuropa: Galizien zwischen überregionaler Verflechtung und imperialer Politik, 1772-1914 (Wien, Köln, Weimar: Böhlau, 2015), 328-334.

20 Julius Twardowski, Industrialisierung Galiziens, in: Wirtschaftliche Zustände Galiziens in der Gegenwart: 6 Vorträge gehalten aus Anlass der Studienreise der Wiener Freien Vereinigung für staatswissenschaftliche Fortbildung nach Krakau und Galizien (Wien: Braumüller, 1913).

21 Andlauer geht davon aus, dass spätestens ab der Jahrhundertwende die ökonomische Ausgangslage beinahe einziger migrationsauslösender Faktor gewesen sei. Teresa Andlauer, Die jüdische Bevölkerung im Modernisierungsprozess Galiziens 1867-1914 (Menschen und Strukturen, Historisch-Sozialwissenschaftliche Studien 11) (Frankfurt am Main, New York: Peter Lang, 2001), 54. Zur Berufsschichtung siehe Klaus Hödl, Als Bettler in die Leopoldstadt: Galizische Juden auf dem Weg nach Wien (Wien, Köln, Weimar: Böhlau, $\left.{ }^{2} 1994\right), 19$; sowie Klaus Hödl, Vom Shtetl an die Lower East Side: Galizische Juden in New York (Wien, Köln, Weimar: Böhlau, 1991), 23-26. Siehe auch Wolfgang Schivelbusch, Geschichte der Eisenbahnreise: Zur Industrialisierung von Raum und Zeit im 19. Jahrhundert (Frankfurt am Main: Fischer Taschenbuch Verlag, 2000); Kaps, Ungleiche Entwicklung in Zentraleuropa.

22 Andlauer gibt an, dass die jüdische Bevölkerung seit den 1860er Jahren bis zum Ende des 19. Jahrhunderts um das 1,4-fache zunahm. Dieses Wachstum begünstigten ein natürlicher 
Dass ein überproportionaler Teil der jüdischen Bevölkerung emigrierte, hing mit deren beruflichen Tätigkeitsfeldern zusammen. In Galizien war der Haupterwerbsbereich von Jüdinnen und Juden der Handel: Während nur drei Prozent der nichtjüdischen Bevölkerung in diesem Sektor ihren Lebensunterhalt bestritt, waren es 36 Prozent der jüdischen. ${ }^{23}$ Im Vergleich zu den anderen Ländern der Monarchie waren Jüdinnen und Juden in Galizien auch überdurchschnittlich oft in der Landwirtschaft tätig. ${ }^{24}$ Deshalb trafen die skizzierten Entwicklungen, die als „Industrialisierung“ Galiziens subsummiert werden, die jüdische Bevölkerung besonders stark. ${ }^{25}$ Fehlende Perspektiven, vor allem innerhalb der jüdischen Bevölkerung, führten schließlich dazu, dass viele eine Migration als einzige Möglichkeit sahen. Der überproportional große Anteil an Jüdinnen und Juden in dieser Migrationsbewegung war ein Grund dafür, dass diese als ,jüdische ${ }^{c}$ Massenmigration bezeichnet wird. ${ }^{26}$ In der Geschichte der Jüdinnen und Juden, so konstatiert der Historiker Lloyd Gartner, „[m]igration is not part of Jewish history, it is Jewish history itself." ${ }^{\text {"27 }}$

Zieldestinationen der zunächst vorherrschenden Binnenmigration waren die größeren Städte der Bukowina und Galiziens. Nach und nach zogen die Menschen auf,Wanderschaft' immer weitere Kreise und gelangten in die Metropolen der Monarchie. Wirkliche Zukunftsperspektive aber sahen die meisten der Migrant*innen in den Vereinigten Staaten von Amerika und da vor allem in New York - in der goldenen Medine. Goldene Medine stand für die vermeintlich unbegrenzten Möglichkeiten und Straßen voller Gold, die die Migrant*innen in Amerika zu finden hofften. ${ }^{28}$ Bedingt durch den Verlauf der Ostfront während

Geburtenzuwachs und eine geringe Sterberate. Andlauer, Die jüdische Bevölkerung im Modernisierungsprozess Galiziens, 52-63. Zur Armut im Allgemeinen siehe die zeitgenössische Schilderung o.A., Wirtschaftliche Zustände Galiziens in der Gegenwart.

23 Hödl, Als Bettler in die Leopoldstadt, 18. Siehe auch Andlauer, Die jüdische Bevölkerung im Modernisierungsprozess Galiziens 1867-1914, 170-171 sowie 282-283.

24 Andlauer gibt hier an, dass 6,7 Prozent der Jüdinnen und Juden in Galizien in der Landwirtschaft aktiv waren. Andlauer, Die jüdische Bevölkerung im Modernisierungsprozess Galiziens, 166.

25 Hödl, Als Bettler in die Leopoldstadt, 20.

26 Hödl, Als Bettler in die Leopoldstadt, 33-45.

27 Lloyd P. Gartner, „The Great Jewish Mass Migration - Its East European Background“, Tel Aviver Jahrbuch für Deutsche Geschichte 27 (1998): 107-133, 107.

28 Goldene Medine ist Jiddisch; das Wort medine kommt aus dem Hebräischen und bedeutet Land oder Staat; wörtlich übersetzt heißt goldene medine also „goldenes Land“. Im Kontext der Massenmigration um 1900 wurde das Sprechen von der goldenen Medine zur Metapher für Amerika und zum Synonym für das Land der Freiheit, Gerechtigkeit und unbegrenzten Möglichkeiten. „Der reiche Onkel in Amerika“ und „Straßen mit Gold gepflastert“ wurden zu Idiomen der goldenen medine. Ironisch gebraucht, meint goldene medine auch „Paradies der Narren“. 
des Ersten Weltkriegs dauerte diese Migration in Form von Fluchtbewegungen an. ${ }^{29}$ Der Historiker Tobias Brinkmann betont, dass im Kontext der Migrationsbewegungen des späten 19. Jahrhunderts und der ersten Jahrzehnte des 20. Jahrhunderts eher von Transmigrationen gesprochen werden sollte, da sich die Mobilität der Menschen oft - früher oder später - fortsetzte. ${ }^{30}$

Vilém Flusser (1920-1991), der selbst flüchten musste und sich theoretisch mit verschiedenen Migrationen und Exil auseinandersetzte, beschrieb Mobilität als permanente Konfrontation zwischen "Gewohntem und Ungewohntem“ - ein Ausloten von ,Lokationen und ,Dislokationen. ${ }^{\text {‘1 }}$ Dislokation und das Wechselspiel zwischen bekannten und unbekannten Situationen gehen über die geographische Veränderung hinaus: Migration bedeutet soziale, politische, lebensweltliche, sprachliche, kulturelle und ökonomische Veränderungen. ${ }^{32}$ $\mathrm{Zu}$ migrieren ist nicht nur ein Weggehen von einem und ein Ankommen an einem anderen Ort. Vielmehr sind die Prozesse der Migration und Mobilität hochreflexiv: Man denkt darüber nach, von wo man weggegangen ist, wo man ankommen wird und was einen dort erwartet. Der Kulturwissenschafter Joachim Schlör betont nachdrücklich, dass man gerade die Reise als Praxis in Migrationsprozessen berücksichtigen muss. ${ }^{33}$

Migration, Mobilität und die populäre Kultur waren mehrfach miteinander verwoben. In Europa wie auch den Vereinigten Staaten boten Populärkultur und Unterhaltungsszene der Jahrhundertwende vielfach erste Verdienstmöglichkeiten für neu Ankommende. Migrant*innen verdienten ihren Lebensunterhalt damit, andere zu unterhalten. Sie besuchten allerdings auch Aufführungen durch die große Anzahl an Migrant*innen gab es auch ein potentiell größeres Publikum. Und dann waren natürlich auch Künstler*innen in der Ausübung des Artisten-, Komiker- oder Schaustellerberufs mobil oder migrierten ihrer Kunst wegen.

29 Peter Gatrell, Philippe Nivet, Refugees and Exiles, in: Jay Winter (Hg.), The Cambridge History of the First World War, Civil Society 3 (Cambridge: Cambridge University Press, 2014), 186-215.

30 Brinkmann, Points of Passage, 1-5.

31 Vilém Flusser ist jedoch mehr als Medien denn als Migrations- und Exilforscher bekannt. Vilém Flusser, Von der Freiheit des Migranten: Einsprüche gegen den Nationalismus (Hamburg: CEP Europäische Verlagsanstalt, 2013).

32 Olaf Terpitz, An Enclave in Time? Russian-Jewish Berlin Revisited, in: Jörg Schulte, Olga Tabachnikova, Peter Wagstaff (Hg.), The Russian Jewish Diaspora and European Culture 1917-1937 (Leiden, Boston: Brill, 2012), 179-199, 180-182.

33 Joachim Schlör, ",Solange wir auf dem Schiff waren, hatten wir ein Zuhause': Reisen als kulturelle Praxis im Migrationsprozess jüdischer Auswanderer“, Voyage - Jahrbuch für Reiseund Tourismusforschung 10 (2014): 226-246. 


\subsection{Populäre Kultur als jüdisch-nichtjüdisches Interaktionsfeld}

Beeinflusst von der Annahme, Jüdinnen und Juden hätten vorwiegend die ,Hochkultur' mitgestaltet und konsumiert, kam der Teilhabe von Jüdinnen und Juden an der allgemeinen Populärkultur lange wenig Interesse zu. Allgemein ist zu konstatieren, dass einander die sogenannte Hochkultur und die Populärkultur lange scheinbar diametral gegenüberstanden. Der populären Kultur haftete im deutschsprachigen Wissenschaftsraum gewissermaßen der Geruch des Defizitären und Minderwertigen an. Mit den aufkommenden Kulturwissenschaften hat dieses Erbe der Kritischen Theorie an Einfluss verloren. Im Windschatten der immer stärker an Einfluss gewinnenden Kulturwissenschaften konnte die Populärkultur zu einem wichtigen Forschungsgegenstand avancieren. ${ }^{34}$

Aufgrund der Unterpräsenz des Themas Populärkultur in der Forschung zur Geschichte der Jüdinnen und Juden herrschte vielfach die Annahme vor, sie habe keine große Rolle gespielt. ${ }^{35}$ Seit 2015 sind erste Publikationen zu Jüdinnen und Juden in der populären Kultur erschienen. Die Historikerin Mary Gluck konstatiert für die Unterhaltungsszene in Budapest, dass dort trotz der großen jüdischen Bevölkerung Jüdinnen und Juden in den meisten Bereichen „unsichtbar" waren. Die populäre Kultur sei dahingegen jener Bereich gewesen, in dem das sonst unsichtbare jüdische Budapest sichtbar werden und auf den Bühnen eine Stimme finden konnte. ${ }^{36}$ Der Historiker Klaus Hödl zeigt, dass die Teilhabe von Jüdinnen und Juden in der Wiener Kultur der Jahrhundertwende vor allem in der populären Kultur eine besonders lebendige war. ${ }^{37}$ Die Theaterwissenschafterin Edna Nahshon legt in einem Ausstellungsprojekt im Museum of the City of New York dar, welche Dynamiken die urbanen Räume des New Yorker jiddischen Theaters ermöglichten. ${ }^{38}$ Diese auf einzelne Städte

34 Reihen wie „Alltag und Kultur“, in der Wolfgang Kaschuba und Kaspar Maase „Schund und Schönheit. Populäre Kultur um 1900“ herausgaben, etablierten sich. Zur Vernachlässigung des Forschungsfeldes sowie zur Reihe siehe Maase, Grenzenloses Vergnügen, 11. Wie auch Alexa Geisthövel, Bodo Mrozek, Einleitung, in: dies. (Hg.), Popgeschichte, Band 1: Konzepte und Methoden (Bielefeld: Transcript, 2014), 8. Zur Unterpräsenz einer wissenschaftlichen Auseinandersetzung mit populärer Kultur allgemein siehe John Fiske, Understanding Popular Culture (London, New York: Routledge, 2011); sowie Lawrence Grossberg, What's going on? Cultural Studies und Popularkultur (Wien: Turia + Kant, 2000).

35 Klaus Hödl, Zwischen Wienerlied und Der kleine Kohn. Juden in der Wiener populären Kultur um 1900 (Jüdische Religion, Geschichte und Kultur 27) (Göttingen: Vandenhoeck \& Ruprecht, 2017), 48.

36 Mary Gluck, The Invisible Jewish Budapest: Metropolitan Culture at the Fin de Siècle (Wisconsin: University of Wisconsin Press, 2016).

37 Hödl, Zwischen Wienerlied und Der kleine Kohn.

38 Edna Nahshon (Hg.), New York's Yiddish Theater: From Bowery to Broadway (New York: Columbia University Press, 2016). 
fokussierten Studien erweitert Auf die Tour und wirft einen transnationalen Blick auf Jüdinnen und Juden in der populären Kultur.

Alle diese Publikationen betonen, dass die populäre Kultur vielschichtige Interaktionen von Jüdinnen und Juden mit Nichtjüdinnen und Nichtjuden ermöglichte. Die Untersuchungen zeigen, dass Austausch und gemeinsames Handeln stattfanden, wo lange davon ausgegangen worden ist, dass dies nicht der Fall gewesen sei: Jüdinnen und Juden besuchten Varietés, Singspielhallen und Etablissements. Sie traten dort gemeinsam mit Nichtjüdinnen und Nichtjuden als Sänger ${ }^{\star}$ innen, Artist ${ }^{\star}$ innen und Akrobat ${ }^{\star}$ innen auf. Sie waren Agent ${ }^{\star}$ innen, leiteten Spielstätten und managten Ensembles, Buden in Freizeitparks oder Artistenheime. Auch in den populären Gassenhauern, Possen und Couplets gab es - positiv wie antisemitisch - als ,jüdisch' ausgewiesene Anspielungen und Charaktere. Auch flossen sprachliche Facetten jüdischer Kulturen in die Konzeption verschiedener Darbietungen mit ein - hebräische oder jiddische Zwischenrufe, „Jargon“ oder Referenzen auf religiöse wie literarische Texte oder Motive. Rezeptionen, Interpretationen und Lesarten dieser signifier $^{39}$ (Stuart Hall) des ,Jüdischen' waren verschiedenste. Diese Offenheit brachte einerseits Popularität, anderseits aber auch Kritik. Aber nicht nur das Spielen mit Codierung, Sichtbarkeit und Unsichtbarkeit des, Jüdischen, sondern auch andere Identifikationen waren in der populären Kultur der Jahrhundertwende allgegenwärtig: Interpretationen von Gender und Geschlecht wurden ebenso wie nationale Stereotype oft aufgegriffen und diskutiert. Immer bleibt aber für die konkrete Situation zu fragen, was Teil der urbanen Erfahrung im jeweiligen Aufführungserlebnis war. Waren es Antisemitismus, Misogynie, nationalistische Ideologie oder gerade, sich über Antisemit ${ }^{*}$ innen lustig zu machen, das Ermöglichen neuer Zuschreibungen von Geschlecht und das Lachen über nationalistisch-stereotype Vorstellungen, was das Publikum amüsierte?

\subsection{Raum, Differenz und Ähnlichkeit}

Dass Populärkultur in den Jüdischen Studien erst unlängst eine Konjunktur erlebte, hängt damit zusammen, wie ,jüdische Geschichte gedacht und folglich be- und geschrieben worden ist. Die Geschichte der Jüdinnen und Juden wurde als eine der ,Assimilation' oder, wie die Forschung dies später benannte, ,Akkulturation' an das Bürgertum erzählt. Dem dieser Erzählung des Aufstiegs aus

39 Stuart Hall, Ethnizität: Identität und Differenz, in: Jan Engelmann (Hg.), Die kleinen Unterschiede: Der Cultural Studies-Reader (Frankfurt am Main, New York: Campus, 1999), 83-98. Siehe besonders Kapitel 4 und Kapitel 5 in diesem Buch. 
der Tradition in die Bourgeoise zugrundeliegenden Verständnis nach , assimilierten' sich Jüdinnen und Juden, indem sie Traditionen und Kultur vollständig aufgaben und danach strebten, sich der sie umgebenden Mehrheit anzupassen, um ins Bürgertum „aufgenommen zu werden“. 40 ,Akkulturiert" meint ein ähnliches Streben, unter einer allerdings nur „äußerlichen“ Anpassung an eine solche Mehrheit. Bei dieser ,äußerlichen Anpassung‘ seien Traditionen im „Inneren“ bewahrt worden. ${ }^{41}$ Gemeinsam ist den Konzepten der ,Assimilation“ wie der ,Akkulturation' eine grundlegende konzeptuelle Prämisse, die sowohl das Denken über jüdische Geschichte und Kultur wie über Kulturen generell betrifft: Beide Konzepte setzen ein Vorhandensein von homogenen, abgrenzbaren Kollektiven voraus. ${ }^{42}$ Diese Kollektive definieren sie sodann als - nationale, religiöse, ethnische oder wie auch immer kategorisierte - Mehrheiten und

40 Marsha Rozenblit prägte die Beschreibung der ,Identität ‘ der ,assimilierten jüdischen Bevölkerung" der Habsburgermonarchie als eine „dreifache“: nämlich eine ,österreichische politische und nationale Fragen betreffend, eine ,deutsche', tschechische` oder , ungarische etc. kulturelle und eine ,jüdische ethnische Fragen betreffend. In ihren Arbeiten bezog sich Rozenblit hauptsächlich auf Zeitungsartikel und Lebenserinnerungen, die auf Deutsch verfasst worden waren. Das von ihr verwendete Quellenmaterial beinhaltete zwar auch Lebenserinnerungen von Migrant ${ }^{\star}$ innen aus Galizien, jedoch ebenso auf Deutsch verfasst. Das lässt Marsha Rozenblit zu einem einheitlichen Bild kommen, demzufolge die jüdische Bevölkerung der Habsburgermonarchie zumindest entlang politischer und ethnischer Identitätsfacetten ein homogenes Ganzes gewesen sei, was in jüngerer Forschungsliteratur zur Disposition steht, weil es ein zumindest unvollständiges Bild ergibt. Marsha L. Rozenblit, Reconstructing a National Identity: The Jews of Habsburg Austria during World War I (Oxford: Oxford University Press, 2004) hier speziell 24-25. Rozenblit Marsha L., Jews of Vienna 1867-1914: Assimilation and Identity (Albany: State University of New York Press, 1983), 161-174. Rozenblit, Jewish Ethnicity in a New Nation-State, 135. Zur Vielschichtigkeit ,jüdischer ' Selbstverständnisse um 1900 siehe Jana Schumann, Von „judischem Humor“ und „verjudeter Kunst“: Konzeptionen judischer Identität und der Populärkulturdiskurs, in: Klaus Hödl (Hg.), Nicht nur Bildung, nicht nur Burger: Juden in der Populärkultur (Schriften des Centrums fur Judische Studien 23) (Bozen, Innsbruck, Wien: Studienverlag, 2013), 91-102.. Zu Erfahrungen von Jüdinnen und Juden in Wien siehe in Barbara Eichinger, Frank Stern (Hg.), Wien und die jüdischen Erfahrungen 1900-1938: Akkulturation - Antisemitismus - Zionismus (Wien, Köln, Weimar: Böhlau, 2009). Zu ,Identität' und Wahrnehmung siehe Robert S. Wistrich, Die Juden Wiens im Zeitalter Kaiser Franz Josephs (Wien, Köln, Weimar: Böhlau, 1999). Für eine kritische Replik auf Assimilation und Akkulturation siehe Till van Rahden, „Juden und die Ambivalenz der bürgerlichen Gesellschaft in Deutschland von 1800-1933“, Transversal 1 (2004): 33-61.

41 Klaus Hödl, „From Acculturation to Interaction: A New Perspective on the History of the Jews in Fin-de-Siècle Vienna“, Shofar 25, no.2 (2007): 82-103; sowie Klaus Hödl, Wiener Juden jüdische Wiener: Identität, Gedächtnis und Performanz im 19. Jahrhundert (Schriften des Centrums für Jüdische Studien 9) (Bozen, Innsbruck, Wien: Studienverlag, 2006), 28-31.

42 Rogers Brubaker, Ethnicity without Groups (Cambridge, London: Harvard University Press, 2006), 12. 
Minderheiten und sprechen von „Identität(en)“433 Austausch beziehungsweise Adaption erfolge einseitig von der Minderheit hin zur Mehrheit. ${ }^{44}$ Es handelt sich dabei um ein monolithisches Kategorisieren, das im übrigen auch vielfach aliquot auf andere Bereiche, wie die Vorstellung darüber, wie Gender artikuliert und Geschlechterrollen ausgehandelt werden, angewandt worden ist. ${ }^{45}$ Deshalb lenken der Historiker Frederick Cooper und der Soziologe Rogers Brubaker bei der Erforschung von „Identitäten“ den Schwerpunkt auf deren Beweglichkeit und Abhängigkeit von konkreten Situationen. Sie geben Identität als eine Kategorisierung, die komplexe Zugehörigkeitsartikulationen vereinfacht, auf und analysieren Identifikationen. Identifikation rückt Prozesse in den Fokus, die von Akteur*innen in konkreten Situationen generiert werden. ${ }^{46}$ Von kategorisierbaren Kollektiven als gegebene Größen mit mehr oder weniger starren Grenzen ausgehend, hat die Historiographie sodann ihre Quellen gewählt und entsprechende Narrative entwickelt. Das führte, so Jonathan Hess und Klaus Hödl, zu einem unvollständigen Bild über die Teilhabe von Jüdinnen und Juden an Kulturen. ${ }^{47}$ Anstelle der häufig verwendeten Konzepte der ,Assimilation' und ,Akkulturation' sollte der Blick auf indifference, Gleichgültigkeiten, gegenüber den zugrundeliegenden Konzepten gelenkt werden, so die Historikerin Tara Zahra, um sich so produktiver mit gesellschaftlichen Prozessen auseinandersetzen zu können. ${ }^{48}$

43 Rogers Brubaker, Frederick Cooper, „Beyond ,Identity“ “, Theory and Society 29 (2000): 1-47, $1-15$.

44 David Biale (Hg.), Cultures of the Jews: A New History (New York: Schocken Books, 2002). CoConstitution von jüdisch-nichtjüdischer Geschichte hat David Biale bereits 1994 als Grundlage nicht-monolithischer Ansätze beschrieben. David Biale, „Confessions of an Historian of Jewish Culture“, Jewish Social Studies, New Series 1, no.1 (1994): 40-51. Am Parkes Institute der University of Southampton werden Jüdische Studien unter diesem Aspekt betrieben. University of Southampton, Parkes Institute, Research, Migration. URL: http://www.southampton.ac.uk/ parkes/research/migration.page (letzter Zugriff: 5.1.2017).

45 Judith Butler, Performative Akte und Geschlechterkonstitution, in: Uwe Wirth (Hg.), Performanz: Zwischen Sprachphilosophie und Kulturwissenschaften (Frankfurt am Main: Suhrkamp, 2002), 301-320.

46 Brubaker, Cooper, „Beyond ,Identity“', 1-47.

47 Hödl, Zwischen Wienerlied und Der klpeine Kohn, 16, 22 sowie 34-35. In der Geschichtsschreibung über die Jüdinnen und Juden nach dem Holocaust wurde lange vor allem deren „Beitrag" zur Hochkultur und der Verlust dieses, der mit der Vertreibung und Ermordung der jüdischen Bevölkerung einherging, betont. Partizipation, Austausch und Interaktion im Alltag und folglich alltäglicher populärer Kultur erfuhren dabei kaum Beachtung. Hödl, Wiener Juden - jüdische Wiener, 84-86.

48 Tara Zahra, „Imagined Noncommunities: National Indifference as a Category of Analysis“, Slavic Review 69, no. 1 (2010): 93-119, 116. 
Das Betonen von Kollektiven fußte in Benedict Andersons (Politikwissenschafter) weitrezipierten Paradigma imagined communities ${ }^{49}$ - das, die Basis von Gemeinschaftsentwürfen hinterfragend, das Interesse der Forschung auf Gruppen und Kollektive lenkte. ${ }^{50}$ Mittlerweile haben Wissenschafter*innen außerhalb wie innerhalb der Jüdischen Studien begonnen, diesen engen Blick zu differenzieren und die Relevanz von lokalen Studien, Mikrogeschichten und das Einbeziehen verschiedenartiger Quellen zu forcieren, um bereits bestehende Narrative zu erweitern. ${ }^{51}$ Basierend auf frühen Arbeiten des Historikers Gary Cohen entwickelten der Historiker Pieter Judson und Tara Zahra das Konzept der national indifference und zeigen, dass aufkommende Nationalismen klar politischen Diskursen und Eliten zugeschrieben werden können, wohingegen ein Blick auf die tägliche Praxis an verschiedenen Orten völlig andere Befunde liefert und so das Verständnis von Nationalismus erweitert. ${ }^{52}$ Das lässt sich auch für den Blick auf jüdische und nichtjüdische Beziehungen, Kulturen und kulturelle Praxis konstatieren. Hödl legt dar, dass Performativität und zwischenmenschliche Beziehungen Jüdisch-Sein ausdrücken. ${ }^{53}$ Die Historikerin Lisa Silverman zeigt mit dem Ansatz der Jewish Difference, wie reale wie imaginierte Differenzvorstellungen jüdisches und nichtjüdisches Leben prägten und Jüdisch-Sein vielfach eine implizite Identifikation bedeutete. ${ }^{54}$ Dass

49 Benedict Anderson, Imagined Communities: Reflections on the Origin and Spread of Nationalism (London: Verso, 2016); sowie Eric Hobsbawm, Terence Ranger, The Invention of Tradition (Cambridge, New York: Cambridge University Press, ${ }^{22} 2013$ ).

50 Zahra, Imagined Noncommunities, 112.

51 Hess, Middlebrow Literature, 12-17; Hödl, Zwischen Wienerlied und Der kleine Kohn, 22-26.

52 Judson Pieter M., Zahra Tara, „Introduction“, Austrian History Yearbook 43 (2012): 21-27.

53 Hödl Klaus, From Acculturation to Interaction, 82-97.

54 Der Historiker David Biale hinterfragt die Bezeichnung von kulturellen Adaptionen: „How should we label such adaption [das Übernehmen griechischer Symbolik in jüdische Beerdigungsritual, SK.] of non-Jewish culture? Does it suggest , assimilation' or, use a less loaded term, ,acculturation'? [...] This interaction demonstrates how the culture of a minority group like the Jews can never be separated from that of the majority surrounding it." David Biale, Preface, in: ders. (Hg.), Cultures of the Jews: A New History (New York: Schocken, 2002), xvii-xxxiii, xix-xx. Weiters verweist Biale auf die Evidenz von Jewish Difference in derartig vielschichtigen Prozessen und expliziert gleichzeitig - gewissermaßen als Quintessenz seiner Übersicht über die (Kultur-)Geschichte der Jüdinnen und Juden -, dass „[...] the street was not exclusively one-way." Biale, Preface, xxiii. Den Ansatz Jewish Difference entwickelten Daniel und Jonathan Boyarin. Daniel Boyarin, Jonathan Boyarin, „Diaspora: Generation and the Ground of Jewish Identity“, Critical Inquiry 19, no. 4 (1993): 693-725; Daniel Boyarin, Jonathan Boyarin, Introduction - So What's New? in: dies. (Hg.), Jews and other Differences: The New Jewish Cultural Studies (Minneapolis: University of Minnesota Press, 1997), vii-xxii. Klaus Hödl und Lisa Silverman erweiterten dieses Konzept. Hödl, From Acculturation to Interaction, 84-87; Lisa Silverman, „Reconsidering the Margins: Jewishness as an Analytical Framework“, Journal of Modern Jewish Studies 8, no.1 (2009): 103-120. 
Jüdisch-Sein sich immer nur kontextbezogen interpretieren lässt, illustriert der Historiker Moshe Rosman in How Jewish is Jewish History beeindruckend. ${ }^{55}$

Auf die Tour untersucht Jüdisch-Sein und jüdisch-nichtjüdische Begegnungen in der populären Kultur auf Basis dieser skizzierten Überlegungen. Um die einzigartigen Charakteristika der Erfahrungen verstehen zu helfen, beschreibt Auf die Tour populäre Kultur als Möglichkeitsraum für Interaktionen von Jüdinnen und Juden mit Nichtjüdinnen und Nichtjuden und für die Artikulation von Jüdisch-Sein und ebenso von anderen Identifikationen wie Geschlecht. Dabei greift Auf die Tour kulturwissenschaftliche Fragestellungen des spatial und postcolonial turn auf. Auf die Tour argumentiert, dass die populäre Kultur Räume bot, in denen jüdisch-nichtjüdische Beziehungen ebenso wie eine diskursive Auseinandersetzung mit Jüdisch-Sein von Differenzen bis Ähnlichkeiten reichen konnten.

Ähnlichkeit ist ein von dem Kulturwissenschafter Anil Bhatti und von der Literaturwissenschafterin Dorothee Kimmich entwickeltes „kulturtheoretisches Paradigma“, das von binären Gegensätzen abrückt. ${ }^{56}$ Ähnlichkeit soll in diesem Buch dabei helfen, das auf Unterschiede fokussierte Narrativ der Geschichte über Jüdinnen und Juden zu erweitern. ${ }^{57}$ Während Jewish Difference differenzorientiert Ausdrücke und Aushandlungen von Jüdisch-Sein in öffentlichen Diskursen interpretiert, möchte das Paradigma Ähnlichkeit die Dichotomie eines „Entweder-Oder“ überkommen und betont das „Sowohl-Als-Auch“ von Ähnlichkeit und Differenz in Interaktionen sowie deren Repräsentation. ${ }^{58}$

55 Hödl, From Acculturation to Interaction, 82-86. Moshe Rosman, How Jewish is Jewish History? (Oxford: The Littman Library of Jewish Civilization, 2007), 106-107. Silverman, Reconsidering the Margins, 105.

56 Anil Bhatti, Dorothee Kimmich (Hg.), Ähnlichkeit: Ein kulturtheoretisches Paradigma (Konstanz: Konstanz University Press, 2015).

57 Zu Ansätzen einer Geschichte der Jüdinnen und Juden als Teil einer allgemeinen Historiographie siehe Klaus Hödl, ,,Jewish history' as part of ,general history': A comment“', Medaon 12, no. 22 (2018): 1-4.

58 Anil Bhatti, Dorothee Kimmich, Einleitung, in: dies. (Hg.), Ähnlichkeit: Ein kulturtheoretisches Paradigma (Konstanz: Konstanz University Press, 2015), 7-32, 9; Anil Bhatti, Dorothee Kimmich, Introduction, in: dies. (Hg.), Similarity: A Paradigm for Culture Theory (New Delhi: Tulika Books, 2018), 1-24, 12. Zu Ähnlichkeit siehe Assmann Aleida, Ähnlichkeit als Performanz: Ein neuer Zugang zu Identitätskonstruktionen und Empathie-Regimen, in: Anil Bhatti, Dorothee Kimmich (Hg.), Ähnlichkeit: Ein kulturtheoretisches Paradigma (Konstanz: Konstanz University Press, 2015), 167-186. Dorothee Kimmich, Ins Ungefähre: Ähnlichkeit und Moderne (Konstanz: Konstanz University Press, 2017); Albrecht Koschorke, Ähnlichkeit: Valenzen eines post-postkolonialen Konzepts, in: Anil Bhatti, Dorothee Kimmich (Hg.), Ähnlichkeit: Ein kulturtheoretisches Paradigma (Konstanz: Konstanz University Press, 2015), 35-46, 35-45; Jürgen Osterhammel Jürgen, Ähnlichkeit - Divergenz - Konvergenz: Für eine Historiographie relationaler Prozesse, in: Anil Bhatti, Dorothee Kimmich (Hg.), Ähnlichkeit: Ein kulturtheoretisches Paradigma (Konstanz: Konstanz University Press, 2015), 75-92. 
Ähnlichkeit negiert Differenz nicht. Vielmehr betrachtet Ähnlichkeit die Bandbreite, die Begegnungen, Interaktionen und Artikulationen jüdischnichtjüdischer Wechselbeziehungen aufwiesen. ${ }^{59}$ Ähnlichkeit nuanciert das Bild, wie jüdische und nichtjüdische Artist*innen gemeinsam populäre Kultur gestalteten und in ihr Identifikationen wie Jüdisch-Sein und Gender steuerten.

Mobilität und ein transnationaler Blick auf die populäre Kultur als jüdisches und nichtjüdisches Interaktionsfeld zwischen der Habsburgermonarchie und Amerika versprechen aus mehrerlei Hinsicht, ein vielversprechendes Beispiel zu sein: Mobilität war Praxis und Strategie in der populären Kultur. Am gemeinsamen Reisen von Künstler ${ }^{\star}$ innen, an deren transnationaler Kommunikation und am globalen Austausch im Bereich populärer Kultur wird sichtbar, wie wechselseitig, vernetzt und vielschichtig Jüdinnen und Juden und Nichtjüdinnen und Nichtjuden operierten. Auch waren die politischen Entwicklungen und der vielfach als omnipräsent beschriebene Rahmen der Nationalismen nicht ausschließlich oder vorranging, das, woran sich die alltägliche Unterhaltung orientierte. Darüber hinaus thematisierte die internationale Populärkultur interkulturelle Transferprozesse. ${ }^{60}$

Auf die Tour sieht sich in diesem Sinne als ein Beitrag zu dem nicht abschließbaren, wunderbaren Fundus an kulturellen Produkten und möchte anhand ausgewählter Beispiele explizieren, was eine postmoderne Historiographie über Jüdinnen und Juden in der populärer Kultur bedeuten kann.

\subsection{Transgressive Mobilität - Perspektiven der Kapitel}

Wie beeinflusste also Mobilität populäre Kultur und die Beziehungen von Jüdinnen und Juden mit Nichtjüdinnen und Nichtjuden in ihr in Wien, Budapest und New York? Die zunehmende Mobilität und Internationalisierung bewirkte zum einen eine räumliche Veränderung populärer Unterhaltungskultur und zum anderen performative Strategien, die eine inhaltliche Beweglichkeit durch Mobilität inszenierten.

Diese neue Art sich zu amüsieren entwickelte sich parallel mit den Veränderungen der Städte. Ihre Bewohner*innen nahmen diese Veränderungen als

59 Bhatti, Kimmich, Einleitung, 14-17.

60 Doris Bachmann-Medick, Cultural Turns: Neuorientierungen in den Kulturwissenschaften (Hamburg: Rowohlt, ${ }^{6} 2014$ ), 240; Doris Bachmann-Medick, The Trans/national Study of Culture: A Translational Perspective, in: dies. (Hg.), The Trans/national Study of Culture: A Translational Perspective (Berlin, Boston: De Gruyter, 2016), 1-22, 8-11; Matthias Middell, Kulturtransfer und transnationale Geschichte, in: ders., Hannes Siegrist (Hg.), Dimensionen der Kultur- und Gesellschaftsgeschichte (Festschrift für Hannes Siegrist zum 60. Geburtstag) (Leipzig: Leipziger Universitätsverlag, 2007), 49-69, 53. 
markant wahr. Die bauliche Umgestaltung war ebenso Teil dieser Veränderung wie Mobilität und Migration. Mit den wachsenden Metropolen veränderte sich das urbane Lebensgefühl. Was (jüdisches) Leben in den Städten bedeutete, unterlag einem stetigen Wandel. Dieser Wandlungsprozess bildete den Rahmen, innerhalb dessen sich die populäre Kultur als urbanes Phänomen zu entfalten begann (Kapitel 2).

Hatte in den vorangegangenen Jahrzehnten populäre Unterhaltung vielfach in Tavernen, Gastgärten und Restaurants stattgefunden, fand sie im Fin de Siècle zunehmend in für Unterhaltungsvorstellungen konzessionierten Räumen, die mitunter auch auf die Mobilität der Auftretenden ausgerichtet waren, statt. Die Spielstätten sahen vor, dass „hauseigene" Ensembles auf Tour gingen, während Künstler*innen von auswärts ihre Säle füllten. Freizeitparks richteten im Sommer spezielle Bühnen, wie das Sommeretablissement im Kaisergartenareal des Wiener Praters, für reisende Ensembles auf Sommergastspiel ein. Die gastierenden Schauspieler*innen und die anderen Künstler*innen benötigten aber auch Unterkünfte. Sie wurden wurden zum Teil im Haus, zum Teil in eigens eingerichteten Artistenheimen untergebracht. Es ist auch kein Zufall, dass viele der neuentstandenen Varietés ohnehin in Hotels untergebracht waren, sodass die Künstler*innen in den Hotelzimmern nächtigen konnten. Die Mobilität bedeutete aber auch, dass Gruppen und einzelne Akteur*innen, die nicht mobil sein wollten, um ihren Erfolg fürchten mussten. Denn zum einen gab es zwar immer mehr Spielstätten, zum anderen aber auch zunehmende Konkurrenz (Kapitel 3).

Der Tourneebetrieb erforderte angepasste Formen der Organisation: Agenturen, Management und Zeitungen, die einen internationalen Austausch ermöglichten und damit das Reisen und die Tour erleichterten. In Budapest gründete ein Mitglied der Wiener populären Unterhaltungsbranche die eingangs zitierte Internationale Artisten Revue. Nach und nach korrespondierte diese immer stärker mit ihrem amerikanischen Pendant, dem New York Clipper. Die Zeitungen ermöglichten zudem Künstler*innen der verschiedensten Sparten, ihr Können international zu bewerben. Für Künstleragenturen stellten solche Organe Kontakt zu potentiellen neuen Ensemblemitgliedern, aber auch zu Ensembles, für die eine Tour außerhalb ihrer Heimatstadt organisiert werden sollte, her. Gleichzeitig machten sich durch die Schaffung von Räumen wie Artistenheimen - bezogen auf den nächtlichen Aufenthalt und den „privaten" Charakter der Zimmer - Gerüchte breit, denen zufolge die populären Spielstätten Orte geheimer Prostitution gewesen seien. Die Mobilität brachte der populären Kultur somit auch Vorwürfe ein. Ebenso lag allerdings in der Mobilität und dem ,Fremden', mit dem die Auftretenden von außerhalb vielfach assoziiert wurden, auch deren Faszination. Diese Attraktion versuchten jüdische wie nichtjüdische Künstler*innen nicht nur mittels tatsächlicher Mobilität, 
sondern auch mit der Wahl von Künstlernamen zu generieren. Diese vielfach als vermeintlich jüdisch interpretierte Praxis illustriert die Komplexität der populären Kultur als jüdisch-nichtjüdisches Interaktionsfeld. Mit dem Mobilen und Internationalen der populären Kultur entwickelten sich Rollenverständnisse der Volkssängerin, der "Chantant-Mutter“, des Etablissementdirektors und des Humoristen. Die Bühnenluft ließ aber auch mit performativen Strategien eines Gender-Bendings herkömmliche Zuschreibungen von Gender abseits der Bühnen fraglich erscheinen (Kapitel 4).

Die Soubretten und Gesangsakrobaten bereiteten ihre Inhalte so auf, dass ihnen das Publikum in der jeweiligen Stadt zu Füßen lag. Nachdem Mobilität die populäre Kultur maßgeblich beeinflusste, ist es auch wenig verwunderlich, dass sie sich metaphorisch wie praktisch auf die Inhalte auswirkte. Zum einen zeigt das permanente Adaptieren von gewissen Themen eindrucksvoll gelebte kulturelle Übersetzungspraxis. Zum anderen erwies sich in diesem Vermitteln zwischen Kulturen gerade die Metapher von Mobilität als besonders nützlich, um umkämpfte Themen und strittige Inhalte aufgreifen und verhandeln zu können. Die Künstler*innen spielten mit nationalen, ethnischen, sozialen, religiösen u. a. Stereotypen und Identifikationen. Wenn Jüdinnen und Juden mit scheinbar antisemitischen Stereotypen unterhielten, „Böhmen“, „Ungarn“ oder "Afrikaner" darstellten oder bourgeoisen Attitüden nachfühlten, war ein Publikumshit beinahe sicher. Der vermeintlich seichte Humor beinhaltete jedoch auch verstecktere Interpretationen und Lesarten. Mobilität sollte für deren Entschlüsselung eine Beweglichkeit in den Köpfen des Publikums herbeiführen. Reisen fungierte als Metapher, ,jüdisch konnotierte Räume zu entwerfen und angelehnt an antisemitische Diskurse der Zeit neue Rollen zu entwickeln, um mit ihnen den dahinterstehenden Antisemitismus kritisch zu hinterfragen. Grenzen von Geschlecht konnten aufgelockert werden und Nationalismen verloren im Gelächter an Boden. Die Künstler*innen nutzten die Metapher des Reisens und der Mobilität, um dem Publikum Ähnlichkeiten in Differenzen vor Augen zu führen (Kapitel 5). In der Transformation von Geschlechterrollen, Stereotypen und Kategorisierungen wie ,jüdisch und ,nichtjüdisch ' war die populäre Kultur visionär (Nachspiel).

\subsection{Quellen zum Eintauchen in die Welt populärer Kultur}

Um derartige Aspekte beleuchten zu können, basiert Auf die Tour auf unterschiedlichem historischem Quellenmaterial: ${ }^{61}$ Manuskripte von auftretenden

61 Wiener Stadt- und Landesarchiv (WStLA), Österreichisches Staatsarchiv (OeStA), Niederösterreichisches Landesarchiv (NÖLA), Archiv des Volksliedwerkes, Österreichisches Kabarettar- 
Protagonist*innen und Gruppen, Ankündigungen von und Zeitungsberichte ${ }^{62}$ über Aufführungen sowie Programmhefte. Zur Analyse inhaltlicher Auswirkungen von Mobilität auf Aufführungen dienten in erster Linie in Jiddisch, Deutsch, Englisch und teilweise Ungarisch verfasste Textbücher. In der Habsburgermonarchie musste für beide Reichshälften (und auch noch bis 1928) der Behörde für Theaterzensur alles, was aufgeführt werden sollte, vorgelegt werden. ${ }^{63}$ In New York waren für die Erteilung von Aufführungserlaubnissen die Actors Unions zuständig. ${ }^{64}$ Aus den von diesen Behörden erhaltenen Unterlagen ist eine große Zahl Textbücher überliefert.

Aufführungen sind etwas Performatives, das heißt, sie bestehen im Moment des Aufführens in der Interaktion zwischen Schauspieler*innen, Publikum und allen anderen zu diesem Zeitpunkt im Raum befindlichen Objekten. Aufführungen sind daher flüchtig. ${ }^{65}$ Um der Performativität nahezukommen, bezieht Auf die Tour Kritiken und Rezensionen über die Aufführungen wie auch die Kommentare der Zensurbehörde in die Analyse mit ein. Deshalb sind ebenso Bildmaterial von Aufführungen, so dieses greifbar war, Teil der Analyse. Oft ist die Aufführungspraxis aufgrund fehlender Korrespondenzen oder Markierungen in Manuskripten nicht rekonstruierbar. Für feste Spielstätten können derartige

chiv, Exilbibliothek im Literaturhaus, Österreichische Nationalbibliothek, Leo-Baeck-Institute General Archive (LBI), Institute for Jewish Research (YIVO), Lincoln Center for Performing Arts, New York Public Library Dorot Jewish Devision (NYPL), Library of Congress Washington Marwick Collection (LoC), National Széchényi Library (NSL), Central Archives for the History of the Jewish People in Jerusalem (CAHJP).

62 Ich beziehe mich auf jüdische und nichtjüdische Zeitungen aus den drei Städten mit jeweils unterschiedlichem Leserkreis: Egyenlöség, Pester Lloyd, Internationale Artisten Revue, Caprice Humoristisch-Satyrisches Wochenblatt, The American Jewish Messenger, The Jewish Messenger, The New York Jewish Tribune, Die Idishe Bühne, The Big Stick, Kikeriki, The New York Times, New Yorker, Neue Freie Presse, Der Humorist, Die Presse, Neues Wiener Tagblatt.

63 NÖLA, NÖ Reg. Präs Theater Textbücher. Széchényi Library, Theatercollection, Manuscripts. Zur Tätigkeit der Theaterzensur siehe u. a. Norbert Bachleitner, Paul Ferstl, Österreichische Theaterzensur im 20. Jahrhundert: Ein Abriss ihrer Entwicklung und eine Fallstudie zur Zensur englischer Stücke während des Ersten Weltkriegs, in: Ewald Mengel, Ludwig Schnauder, Rudolf Weis (Hg.), Weltbühne Wien 2: Rezeption anglophoner Dramen auf Wiener Bühnen des 20. Jahrhunderts (Trier:WVT, 2010), 27-50; Norbert Bachleitner, Michaela Wolf, ÜbersetzerInnen als „gatekeepers"?: (Selbst-)Zensur als Voraussetzung für die Aufnahme in das literarische Feld der späten Habsburgermonarchie, in: Denise Merkle, Carol O’Sullivan, Luc Van Doorslaer, dies. (Hg.), The Power of the Pen: Translation \& Censorship in Nineteenthcentury Europe (Representation - Transformation 4) (Wien, Berlin: LIT, 2010), 29-54; Carl Glossy, Zur Geschichte der Wiener Theatercensur (Wien: Carl Konegen, 1896).

64 NYPL, Dorot Jewish Division, Yiddish Theater Manuscript Plays. YIVO, RG 118, Yiddish Theater. YIVO, RG 1843, Hebrew Actors Union.

$65 \mathrm{Zu}$ Performativität siehe Erika Fischer-Lichte, Performativität: Eine Einführung (Edition Kulturwissenschaften 10) (Bielefeld: Transcript, 2012). 
Überlegungen aber in den Bauakten gefunden werden. Einblicke in räumliche Aspekte der Aufführungsstätten und -praxis können auch aus sicherheits- und baupolizeilichen Unterlagen gewonnen werden. Die feuerpolizeilichen Auflagen beinhalten Informationen über den Erhalt von Konzessionen, sowie über die technischen Möglichkeiten, die Spielstätten mit dem Einsatz von Licht etc. bei der Inszenierung nutzen konnten. ${ }^{66}$ Zudem finden sich Informationen zu Betreibenden von Spielstätten und zu bestimmten Adressen in diesen Archivalien. ${ }^{67}$ Biografische Hinweise stammen aber auch aus Meldeunterlagen und Verlassenschaftsabhandlungen sowie Berichterstattungen über die jeweiligen Personen. ${ }^{68}$

66 WStLA, M.Abt. 104, A8 - Feuer- und Sicherheitspolizei: Theater, Lokale. WStLA, M.Abt. 114, A1 - Baupolizei: EZ - Reihe: Allgemeine baurechtliche Angelegenheiten. Budapest Föváros Levéltára, IV 1420 Budapest Székesfőváros tanácsi majd polgármesteri ügyosztályainak gyüjteményes iratai, c Színházi és közművelődési iratok gyüjteménye [Stadtarchiv Budapest, Dokumente des Stadtrates und Bürgermeisters, Theater und Kultur Sammlung]. YIVO, RG 112: General Music Collection. YIVO, RG 289: Perlmutter Collection. YIVO, RG 1843: Hebrew Actor's Union.

67 WStLA, M.Abt. 114, A1 - Baupolizei: EZ - Reihe: Allgemeine baurechtliche Angelegenheiten [geordnet nach Bezirken und Adressen].

68 WStLA, Historische Meldeunterlagen. 


\title{
2. Die urbane Erfahrung in Wien, Budapest und New York
}

Blicke in die Metropolen

\author{
Während die Künstler der Josefstadt / Unter Reinhardts \\ Hinüberführung / In Amerika spielten sich satt, Klopfte mein \\ Herz in Wiener Rührung \\ - Julius Bauer, Redakteur des Illustrirten Wiener Extrablattes und \\ „Beherrscher der Theaterwelt“, $1928^{1}$
}

Wien, Budapest und New York ähnelten sich in vielen Entwicklungen, die in den letzten Jahrzehnten des 19. Jahrhunderts ihren Ausgang nahmen. Alle drei Städte kennzeichnete ein enormes Bevölkerungswachstum. Zudem prägte eine neue Mobilität das Leben. Soziale, ökonomische, politische, berufliche Bewegung und Migration bestimmten die Gesellschaft. Um 1900 kulminierten Zuwanderung, demographisches Wachstum, Eingemeindungen und Umstrukturierungen. Außerdem veränderten sich Gebäude und Straßen und damit das äußere Erscheinungsbild der Städte. Die Großstädte der zweiten Hälfte des 19. Jahrhunderts verwandelten sich in Millionenmetropolen des neuen Jahrtausends (Abb. 1).

Nicht nur Stadtbild, Demographie und Lebensgefühl entwickelten sich ähnlich. Wien, Budapest und New York teilten zahlreiche Gemeinsamkeiten im Bereich des alltäglichen Amüsements. Zum einen verband die drei Städte die Mobilität in der Populärkultur. Ein intensiver Austausch im künstlerischen Schaffen fand statt. Dieser betraf das Aufkommen neuer Aufführungsräume und -formen ebenso wie das Inszenieren und Adaptieren von beliebten Motiven, Stücken, Liedern und Repertoires der Künstler*innen. Zum anderen reduzierte die geradezu explodierende Zahl an Menschen in den Städten private Sphären. Das Vermieten der eigenen Schlafstätte an sogenannte Bettgeher*innen wurde eine weitverbreitete Praxis um $1900 .^{2}$ Deshalb war es zunehmend üblich, den Alltag im Öffentlichen zu gestalten.

1 Carl Hollitzer, Alfred Gerstenbrand, Wiener Köpfe in der Karikatur: Worte von Julius Buer (Wien: Elbmühl Papierfabriken und Graphische Industrie, 1928), o. S., Teil „Bard“. Zu „Beherrscher der Theaterwelt" siehe Reichspost, 6.4.1899, 9.

2 Michael John, Vielfalt und Heterogenität: Zur Migration nach Wien um 1900, in: Elisabeth Röhrlich (Hg.), Migration und Innovation um 1900: Perspektiven auf das Wien der Jahrhundertwende (Wien, Köln, Weimar: Böhlau, 2016), 23-64, 58. 


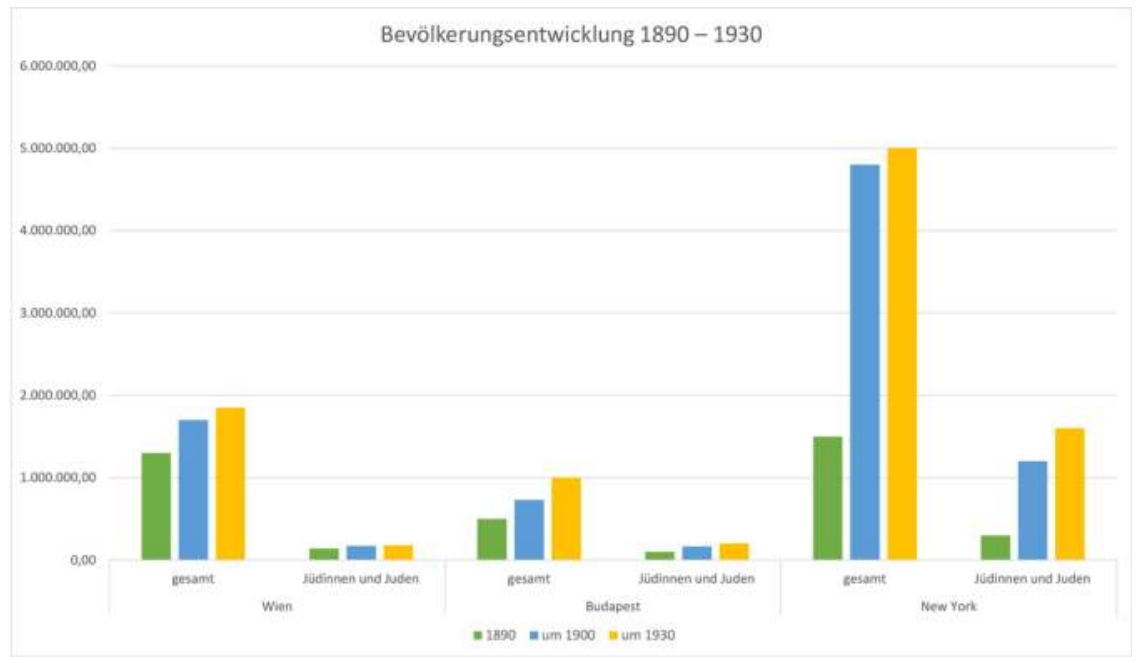

Abb. 1 Bevölkerungsentwicklung in Wien, Budapest und New York 1890 bis 1930

Ein Teil dieser Alltagsgestaltung war die Partizipation an der Populärkultur. In kleinen Theatern, Gasthäusern und an öffentlichen Plätzen tauchten (reisende) Auftretende mit (reisenden) Stücken die Städte in ein künstlerisch unterhaltendes Ambiente. Die Spielstätten sprossen förmlich aus dem Boden. Varietés an den Straßenecken, Tages- und Nachtlokale für Künstler*innen sowie Cafés, in denen man von den Aufführungen schwärmte oder über sie erfuhr und debattierte, prägten das Stadtbild und waren Dreh- und Angelpunkt gesellschaftlichen Lebens. Die Tageszeitungen lieferten ein lebendiges Bild dessen, was ab den Nachmittagsstunden in den populären Etablissements dem Publikum die Zeit versüßte.

Um die Besonderheiten populärer Kultur in einem nächsten Schritt nachvollziehen zu können, werden in diesem Kapitel zunächst Entwicklungen und Diskussionen in den Städten skizziert. Vor dem historischen Kontext beschreibt das Kapitel deshalb, woraus das Lebensgefühl in den Metropolen schöpfte. Vor welcher Kulisse gestalteten sich der Alltag und damit auch der Konsum von Unterhaltungskultur in den drei Städten? Was waren die Rahmenbedingungen für künstlerisches Wirken?

\subsection{Wien, Budapest und New York um 1900}

\section{Wien}

Innen sprachen die alten Paläste des Hofs und des Adels versteinerte Geschichte; [...]. Dazwischen erhob sich stolz und prunkvoll mit blinkenden Avenuen und blitzenden Ge- 
schäften die neue Architektur. Aber das Alte haderte hier so wenig mit dem Neuen wie der gehämmerte Stein mit der unberührten Natur. Es war wundervoll hier zu leben, in dieser Stadt, die gastfrei alles Fremde aufnahm und gern sich gab, es war in ihrer leichten, wie in Paris mit Heiterkeit beschwingten Luft natürlicher das Leben zu genießen. Wien war, man weiß es, eine genießerische Stadt, aber was bedeutete Kultur anderes, als der groben Materie des Lebens ihr Feinstes, ihr Zartestes, ihr Subtilstes durch Kunst und Liebe zu entschmeicheln? Feinschmeckerisch im kulinarischen Sinne, sehr um einen guten Wein, ein herbes frisches Bier, üppige Mehlspeisen und Torten bekümmert, war man in dieser Stadt anspruchsvoll auch in subtileren Genüssen. Musik machen, tanzen, Theater spielen, konversieren, sich geschmackvoll und gefällig benehmen wurde hier gepflegt als eine besondere Kunst. Nicht das Militärische, nicht das Politische, nicht das Kommerzielle hatte im Leben des einzelnen wie in dem der Gesamtheit das Übergewicht; der erste Blick eines Wiener Durchschnittsbürgers in die Zeitung galt allmorgendlich nicht den Diskussionen im Parlament oder den Weltgeschehnissen, sondern dem Repertoire des Theaters, das eine für andere Städte kaum begreifliche Wichtigkeit im öffentlichen Leben einnahm. ${ }^{3}$

Die „blinkenden Avenuen“, die Stefan Zweig in der zitierten Passage beschreibt, waren um die Jahrhundertwende im Entstehen. ,Alt-Wien ${ }^{4}$ sollte von ,NeuWien ' mit breiteren Straßen und weniger ausgeschmückten, geradezu kahlen Fassaden ersetzt werden. ${ }^{5}$ Dass, wie Zweig sagte, das Alte mit dem Neuen nicht haderte, traf vielleicht auf die Kulisse, nicht aber auf die Bewohner ${ }^{\star}$ innen der Stadt zu. Unter ihnen war von einer räumlichen „Demolierung“,Alt-Wiens die Rede. ${ }^{6}$ Gebautes wurde abgerissen, leere Plätze befüllt, enge Gassen dem Verkehr geöffnet und Denkmäler mitunter entfernt, um Raum gewinnen zu können. ${ }^{7}$ Auf Plätzen wurden neue Häuser errichtet, Märkte neugestaltet und erweitert sowie Straßen verbreitert. Das Schleifen der Stadtmauern zugunsten des Ringstraßenprojekts war das bekannteste Beispiel. „For these and other like characteristics Vienna might be called ,The ringed city. To drive around it on these annular oughfares is just the finest of city drives to be had anywhere [...]“, schrieb The Jewish Messenger (New York) über die Wahrnehmung von

3 Stefan Zweig, Die Welt von Gestern [1942] (Frankfurt am Main: S. Fischer, 2014), 29-30.

4 Zum Mythos ,Alt-Wien“ als die „Stadt, die niemals war“ siehe Wolfgang Kos, Christian Rapp (Hg.), Alt-Wien: Die Stadt, die niemals war (Wien: Czernin, 2004).

5 Adolf Loos, Ornanment und Verbrechen, herausgegeben von Peter Stuiber (Wien: Metroverlag, 2012), 118-169.

6 Die „Demolierung Wiens“ wird Karl Kraus als Zitat zugeschrieben. Zum Diskurs über die räumliche Demolierung siehe Renata Kassal-Mikula, Alt-Wien unter dem Demolierungskrampen: Wiens Innenstadt nach 1858, in: Wolfgang Kos, Christian Rapp (Hg.), Alt-Wien: Die Stadt, die niemals war (Wien: Czernin, 2004), 46-61. „Der Demolierer schreitet in der Inneren Stadt, in unserem Urwien, keck vorwärts [...]“. IWE, 24.3.1888, zitiert in ebda., 58. Die „Demolierung“ ,Alt-Wiens" war auch ein breit aufgegriffenes Thema in der Literatur. Siehe etwa Theodor F. Meysels, Bummel durch Alt-Wien (Wien: Franz Leo, 1936), 12.

7 Etwa der Stock am Eisernen Tor, der dem Palais Equitable weichen musste. 
Reisenden in „this Paris of Eastern Europe“. 8 Die Bevölkerung Wiens aber sehnte sich nach den "guten alten Zeiten“. Die Sehnsucht nach ,Alt-Wien“, dem nostalgisierten Flair der vergangenen Jahrzehnte, wuchs und sollte in den 1920er Jahren an ihren Höhepunkt gelangen. ${ }^{9}$ Die räumliche Veränderung der Stadt führte schließlich dazu, dass, Alt-Wien' vom real gewordenen ,Neu-Wien' überlagert wurde. Was Nostalgie und Wehmut evozierte, eröffnete aber auch neue Nutzungsmöglichkeiten: Straßenecken boten in den letzten Jahrzehnten des 19. Jahrhunderts plötzlich mehr Raum - nicht zuletzt auch für Kunst und Kultur. ${ }^{10}$

Wien um 1900 war gewissermaßen zwischen und in zwei verschiedenen Wahrnehmungen von Zeit gefangen. Zudem war das Wien der Jahrhundertwende von verschiedenen Wahrnehmungen des ,Eigenen' und des ,Fremden geprägt. In der Residenzstadt der Monarchie lebten Menschen mit einer Vielzahl unterschiedlicher Sprachen alltäglicher Kommunikation und mindestens 17 verschiedenen Religionsbekenntnissen. ${ }^{11}$ Wien war plurikulturell. ${ }^{12}$ Zuwandernde aus allen Gebieten der Monarchie bedingten ein enormes Bevölkerungswachstum: Zwischen 1890 und 1930 verdreifachte sich die Bevölkerung beinahe. Während 1880 etwa 730.000 Menschen in Wien lebten, war 1890 die Millionengrenze überschritten und 1900 lebten bereits 1,6 Millionen in der Residenzstadt. Zehn Jahre später, 1910, hatte sich die Zahl nochmal um ein Viertel vergrößert. Nun lebten 2 Millionen Menschen, darunter rund 175.000 Jüdinnen und Juden, in der Metropole. ${ }^{13}$

Die Straßen jener Stadt, die mit Zweig „gastfrei alles Fremde aufnahmen“, waren ein wichtiger Bereich des alltäglichen Lebens, auf den die Tagespolitik wiederholt Bezug nahm. Ob auf die jüdischen Migrant*innen aus Osteuropa oder die Marktszenen rekurriert wurde: Alles spielte sich vor den Kulissen des vermeintlich neuen Wien ab; ein Wien, dass immer stärker von Vielfalt

8 TJM, 10.3.1888, 1.

9 Verschiedenste Publikationen bedauern den Verfall der Metropole, zum Beispiel Ludwig Hirschfeld, Wo sind die Zeiten ...: Zehn Jahre Wien in Skizzen (Wien: Anstalt, 1921).

10 Die Ausstellung „Alt-Wien“ des Wien Museum im Künstlerhaus argumentierte, dass die räumliche Neugestaltung wesentlich zur Mythisierung Alt-Wiens betrug. Siehe Kos, Rapp, Alt-Wien.

11 John, Vielfalt und Heterogenität, 38: Die Religionsstatistik um 1900 wies 17 Kategorien auf, jedoch subsumierte sie die unter den 16 explizit ausgewiesenen Religionsbekenntnissen nicht vorkommenden Glaubensrichtungen unter ,andere Konfession“, weshalb eine exakte Zahl an Religionsbekenntnissen nicht genau eruiert werden könne.

12 Csáky, Hybride Kommunikationsräume und Mehrfachidentitäten, 65-97.

13 Ivar Oxaal, Die Juden im Wien des jungen Hitler: Historische und soziologische Aspekte, in: Gerhard Botz, ders., Michael Pollak, Nina Scholz (Hg.), Eine zerstörte Kultur: Jüdisches Leben und Antisemitismus in Wien seit dem 19. Jahrhundert (Wien: Czernin, 2002) 46-64, 52. Allgemein siehe Rozenblit, Jews of Vienna. 
und Heterogenität geprägt sein sollte. Eine plurikulturelle Gesellschaft, in der Migrant*innen das Leben und den Alltag, Kultur und Politik wesentlich beeinflussten und mitgestalteten. 1900 war mehr als die Hälfte der in Wien lebenden Bevölkerung nicht in Wien geboren: Von den rund 1,6 Millionen Menschen, die in Wien lebten, waren 875.000 nicht dort zur Welt gekommen (rund 54 Prozent). Von ihnen kam etwa die Hälfte aus Böhmen und Mähren, gut zehn Prozent aus den Ländern der ungarischen Krone und je knapp drei Prozent aus Galizien und aus dem Süden der Monarchie. ${ }^{14}$ Wien war ein Magnet für Zuwandernde. $^{15}$

\section{Budapest}

Auch in Budapest waren in den letzten Jahrzehnten des 19. Jahrhunderts viele Prachtstraßen erbaut worden. ${ }^{16}$ Anders aber als in Wien, wurden in Budapest die „Demolierer“ nicht brüskiert, sondern die Neubauten gepriesen. ${ }^{17}$

14 John, Vielfalt und Heterogenität, 27. Der Historiker Michael John wertet hier die statistischen Jahrbücher aus; die Zahlen, auf die an dieser Stelle Bezug genommen wird, betreffen die Erhebungen der Volkszählung nach Herkunft. Zur genauen Entwicklung der Bevölkerungszahlen: 1890 lebten in Wien 1,34 Millionen Menschen (140.000 Jüdinnen und Juden), 1900 rund 1,7 Millionen, 1910 rund 2 Millionen und 1928 rund 1,85 Millionen. Statistische Abteilung des Wiener Magistrats, Statistisches Jahrbuch der Stadt Wien für das Jahr 1890 (Wien: Magistrat, 1892), 34. Statistische Abteilung des Wiener Magistrats, Statistisches Jahrbuch der Stadt Wien für das Jahr 1900 (Wien: Magistrat, 1902), 32. Statistische Abteilung des Wiener Magistrats, Statistisches Jahrbuch der Stadt Wien für das Jahr 1910 (Wien: Magistrat, 1912), 45. Statistische Abteilung des Wiener Magistrats, Statistisches Jahrbuch der Stadt Wien für das Jahr 1929 (Wien: Magistrat, 1931), 3.

15 Heinz Faßmann, Die Bevölkerungsentwicklung 1850-1910, in: Helmut Rumpler, Peter Urbanitsch (Hg.), Die Habsburgermonarchie 1848-1918, Band 9/1 Lebens- und Arbeitswelten in der industriellen Revolution (Wien: Verlag der österreichischen Akademie der Wissenschaften, 2010), 159-184, 173. Zoran Kastantinovíc, Vom Werden einer Metropole: Anmerkungen zum Thema „Wien als Magnet“, in: Gertraud Marinelli-König, Nina Pavlova (Hg.), Wien als Magnet? Schriftsteller aus Ost-, Ostmittel- und Südosteuropa über die Stadt (Wien: Verlag der österreichischen Akademie der Wissenschaften, 1996), 21-33, 31-33.

16 Katalin Csontos, Az elsö székesfövárosi múzezn [Das erste Museum in der Landeshauptstadt], in: Dozsa Katalin F., Egy nagyváros születése: Pest, Buda, Obuda az egyesites idejen [Die Geburt der Großstadt: Oder Pest, Buda und Óbuda zur Zeit der Vereinigung] (Budapest: Budapesti Torteneti Muzeum, 1998), 123-133. Sowie Reinhard Pohanka, „Der Väter Burgen liess sie schleifen...": Stadtplanung 1848-1918 in Wien und Budapest, Legitimation und Nationalismus, in: Wolfgang Kos, Christian Rapp (Hg.), Alt-Wien, 71-76.

17 Géza Buzinkay, Budapesti Karikatúrák [Budapest in Karikaturen], in: Dozsa Katalin F., Egy nagyváros születése: Pest, Buda, Obuda az egyesites idejen [Die Geburt der Großstadt: Oder Pest, Buda und Óbuda zur Zeit der Vereinigung] (Budapest: Budapesti Torteneti Muzeum, 1998), 101-103. 
Einem der neuen Boulevards, der Kerepesi út, ${ }^{18}$ war ein Gedicht des jüdischen Schriftstellers Jenő Heltai gewidmet. ${ }^{19}$ Die Straße, die von der Erzsébet híd (Elisabethbrücke) am Keleti pályaudvar (Ostbahnhof) zum Tor des Fiumei temető (Fiume Friedhof) und zum östlichen Ende der Stadt führte, ${ }^{20}$ war typisch für das Budapest der Jahrhundertwende: Die Kerepesi út nahm den Ausgang an einer der Brücken, die 1873 mit der Vereinigung der Stadtteile und in den beginnenden architektonischen Umgestaltungen, die die Buda mit der Pester Seite verbanden und zu Budapest werden ließen. ${ }^{21}$ Diese Eingemeindung machte Budapest zwischen 1867 und 1914 zur am schnellsten wachsenden Stadt in Europa. Die Kerepesi út begann somit an der Donau und an einer der Brücken, die den Fluss überspannten und das Stadtbild der werdenden Metropole prägten. ${ }^{22}$ Die Kerepesi út war - wie alle diese „modernen Straßen“ - gespickt mit Theatern, Künstlerheimen und bald auch mit den verspielten Varietés der ungarischen Hauptstadt. Eines davon, in Kerepesi út 21, war das Folies Caprice. ${ }^{23}$ Ein Etablissement, das zum „Mustervarieté“ schlechthin avancieren sollte und dessen Betreiber Antal Orozzy einer der bekanntesten Liederschreiber der Etablissementszene war. ${ }^{24}$ Und schließlich führt die Kerepesi út an einem Bahnhof vorbei in die vorstädtischen Bezirke.

$\mathrm{Zu}$ einem weiteren Herzstück der Residenzstadt gelangt man über einen anderen Prachtboulevard Budapests: Die Andrássy út auf der Pester Seite entlanggehend, sich von der Donau abwendend, kam man an zahllosen Cafés und Orpheen, an der königlichen Oper, an Schaufenstern voller Kostüme und

18 Heute beginnt die Straße als Kossuth Lajos út an der Erzsébet híd (Elisabeth Brücke), geht dann am Astoria tér (Astoria Platz) in die Rákóczi út über, ehe sie schließlich ab dem Keleti Bahnhof noch den ehemaligen Namen, Kerepesi út, führt.

19 Jenö Heltai, A kerepesi út, in: A Hét, Társaldalmi, Irodalmi és Müvészeti Közlöny 4, no.25 (1893), 18.6.1893, 391: „Szeretlek edes Budapestem / Te pajkos kis cocotte / Mint a kaczer lanyt, kit bolondos/ Szivunk mar megszokott.“ [„Mein geliebtes Budapest / du ungezogenes kleines Mädchen / als kokettes Mädchen, das albern / unsere Herzen bereits gewöhnt."]

20 Heltai, A Kerepesi út, 391. Ab 1906 wurde der erste Teil vom Donauufer weg in Rákóczi út umbenannt.

21 Dozsa Katalin F., Egy nagyváros születése: Pest, Buda, Obuda az egyesites idejen [Die Geburt der Großstadt: Oder Pest, Buda und Óbuda zur Zeit der Vereinigung] (Budapest: Budapesti Torteneti Muzeum 1998).

22 Zur Bedeutung der Zusammenlegung der drei Gemeinden für das Leben in der Stadt siehe John Lukacs, Budapest, 1900: A város és kultúrája [Von der Stadt und ihrer Kultur] (Budapest: Európa, 1991), 46; sowie John Lukacs, Ungarn in Europa: Budapest um die Jahrhundertwende (Berlin: Siedler, 1990), 90-96.

23 Das war nicht die permanente Adresse; zwischen 1897 und 1905 waren die Folies Caprice in der Révay utca 18. Siehe NSLB, Színháztörténeti Tár, Mulatók Folies Caprice, 1897-1905.

24 Siehe in Kapitel 3 Folies Caprice und Anton Orozzy (Antal Oroszi). 
eleganter Schuhe, an Apotheken mit Perücken und Puderquasten und an Parfümerien vorbei, bis sich einem schließlich ein grüner Wald eröffnete. Hier war man im bunten Herzen der Stadt, dem Stadtwäldchen, Városliget, angelangt.

Das Budapester Stadtwäldchen (ein Volksbelustigungsort ähnlich dem Wiener Prater). Frühlingsnachmittag. [...] reges Leben. Soldaten, Dienstmädchen, Wachleute. Budenausrufer halten pathetische Ansprachen an das Publikum. Drehorgeln erzeugen eine lärmende Musik; Glockensignale der Ringelspiele, Gelächter und Geschrei. [...] Und dann sieht man viele ins Ringelspiel der Frau Muskat eintreten. Rufe: ,Noch ein Schaukelpferd ist frei!' ,Wer von den Damen' etc. etc. ,Noch ein Platz auf dem Hirschen!' ,Erwachsene zehn Heller, Kinder fünf, Soldaten, vom Feldwebel abwärts, die Hälfte!' Es wird dunkel, Lampen werden angezündet. Man hört den Pfiff einer fernen Eisenbahn [vom von Gustav Eiffel geplanten unweit gelegenen Nyugati Pályaudvar] ${ }^{25}$

So präsentierte der szenische Anfang des im Dezember 1909 im Budapester Vígszínház Theater uraufgeführten Stückes Lilliom von Ferenc Molnár ${ }^{26}$ das Stadtwäldchen. Ferenc Molnár kam am 12. Januar 1878 als Ferenc Neumann, Sohn eines jüdischen Physikers, in Budapest auf die Welt. Er begann, Jus in Budapest und Genf zu studieren, schlug jedoch sehr bald den Karriereweg als Journalist und Schriftsteller ein. In der Szene junger internationaler Literat*innen, die in den Budapester Cafés und Varietés verkehrten, gelang es auch Molnár, den künstlerischen Internationalismus der Zeit zu inhalieren und in sein literarisches Werk aufzunehmen. In Liliom verband Molnár drei wichtige Versatzstücke der Diskurse über die Stadt um 1900: Nämlich die Bedeutung der „Volksbelustigungsorte“, die in den baulichen Umgestaltungen in den beiden letzten Jahrzehnten das Stadtbild wesentlich zu prägen begannen. Zweitens wirft Molnár auf, dass diese Orte des Amüsements ähnlich jenen Wiens und den Wiener Entwicklungen waren. Schließlich verflocht Molnár mit dem Thema implizit die Verankerung Budapests in Zentraleuropa mit Bahnhöfen in allen Himmelsrichtungen, die Verbindungspunkte zu allen Städten Europas und Asiens, und damit der ganzen Welt, waren.

Der sogenannten Moderne, die über bauliche Neuerungen ausgedrückt werden sollte, begegnete die Stadt offen: Sie hatte als erste ein öffentliches Telefonnetz und überhaupt das erste U-Bahn-Netz am europäischen Festland. ${ }^{27}$ Als Stadt, die bis 1867 immer nur "Stadt und nicht Hauptstadt" gewesen sei, habe Budapest (im Gegensatz zu Wien) die baulichen Veränderungen und

25 Ferenc Molnár, Liliom: Vorstadtlegende in sieben Bildern und einem szenischen Prolog (Wien, Leipzig: Deutsch-österreichischer Verlag, 1912), 7-8. [Hervorhebungen im Original]

26 István Várkonyi, Ferenc Molnár and the Austro-Hungarian „Fin de siècle“ (New York: Peter Lang, 1992), 24-25 und 107-110.

27 Peter Csendes, András Sipos, Budapest und Wien: Technischer Fortschritt und urbaner Aufschwung im 19. Jahrhundert (Budapest, Wien: Franz Deuticke, 2003). 
räumliche Neuorientierung willkommen geheißen. ${ }^{28}$ Um 1890 zählte Budapest rund 500.000 Bewohner*innen, 1900 dann bereits 730.000 und 1930 hatte es die Millionengrenze überschritten. ${ }^{29} 1890$ lebten über 100.000 Jüdinnen und Juden in Budapest, das machte rund 20 Prozent der Bevölkerung aus. Der Bevölkerungsanteil von Jüdinnen und Juden blieb auch in den nächsten Jahrzehnten konstant bei 20 bis 23 Prozent. ${ }^{30}$

\section{New York}

Von Mendel Singer aber wissen wir, daß er nach einigen Monaten in New York zu Hause war. Ja, er war beinahe heimisch in Amerika! Er wußte bereits, daß old chap auf amerikanisch Vater hieß und old fool Mutter, oder umgekehrt. Er kannte ein paar Geschäftsleute aus der Bowery, mit denen sein Sohn verkehrte, die Essex Street, in der er wohnte, und die Houston Street, in der das Kaufhaus seines Sohnes lag, [...]. Er wußte, daß Sam bereits ein American boy war, daß man good bye sagte, how do you do und please, wenn man ein feiner Mann war, [...]. Man hatte ihm gesagt, daß es das Land Gottes war, wie

28 Pohanka, „Der Väter Burgen liess sie schleifen...", 74.

29 József Körösy, Budapest Székesföváros Halandósága az 1901-1905 években és annak okai [Die Sterblichkeit in Budapest in den Jahren 1901-1905 und ihre Ursachen] (Budapest: Grill, 1902), 2: Nach den Zahlen der Volkszählung vom 1. Jänner 1901 lebten 703.448 Menschen, davon 166.198 Jüdinnen und Juden in Budapest (das entspricht 23,6 Prozent). L'Office Central Royal Hongrois de Statistique, Annuaire Statistique Hongrois (Budapest: Athenaeum, 1932), 8: 1920 lebten 930.000 Menschen in Budapest (216.000 Jüdinnen und Juden), und 1.004.000 dann 1930 (204.000 Jüdinnen und Juden). Siehe Kinga Frojimovics, Géza Kormoróczy, Viktória Pusztai, Andrea Strbik, Jewish Budapest: Monuments, Rites, History (Budapest, New York: Central European University Press, 1999), 263.

30 Ungarisches statistisches Zentralamt, Ungarisches statistisches Jahrbuch, neue Folge 18, im Auftrage des kön. Ung. Handelsministers (Budapest: Athenaeum, 1910), 13: 1890505.763 Einwohner*innen, 1900732.322 und 1910 880.371. Budapest statisztikai évkönyve, 12. [Zentrales Statistikbüro Budapest] Jüdinnen und Juden sind in den statistischen Jahrbüchern miterfasst. Zur Bevölkerungsentwicklung siehe Frojimovics et al., Jewish Budapest, 262-264. Nach den antisemitischen Ausschreitungen im sogenannten „Ansiedlungsrayon“ flüchteten viele Jüdinnen und Juden in die Gebiete der ungarischen Krone, da hier das Gesetz seit 1867 Jüdinnen und Juden Bewegungsfreiheit zusicherte. Zu Migration in Budapest fehlen bislang detaillierte statistische Studien. Obwohl um 190023 Prozent der Bevölkerung mindestens zwei-, meist dreisprachig war, ist der Einfluss von Migration auf das Bevölkerungswachstum (was zu dieser Zeit, wie die Zahlen zeigen, bei knapp 40 Prozent lag) nicht explizit untersucht worden. Dies betont John, Vielfalt und Heterogenität, 26. Insbesondere Analysen zur Migration von Jüdinnen und Juden nach Budapest enden mit der ersten Hälfte des 19. Jahrhunderts. Julia Richers, Jüdisches Budapest: Kulturelle Topographien einer Stadtgemeinde im 19. Jahrhundert (Wien, Köln, Weimar: Böhlau, 2009), 144-146. Julius von Farkas, Die Strukturen der geistig führenden Schicht Ungarns, 1867-1900, in: Ungarische Jahrbücher 19 (1939), 11-50. Farkas verortet dabei die Jüdinnen und Juden Budapests explizit im Bürgertum und unter den ,hochkulturellen` Phänomenen. Ebda., 30. 
einmal Palästina, und New York eigentlich wonder city, die Stadt der Wunder, wie einmal Jerusalem.[! $]^{31}$

Was Joseph Roth (1894-1939) aus der Perspektive des fiktiven Mendel Singer schildert, galt für den Großteil der Bevölkerung New Yorks: „bald waren sie heimisch“. Auch für New York waren die letzten Dezennien des 19. Jahrhunderts der Ausgangspunkt für einen (demographischen) Wandel hin zur Millionenmetropole. Während vor 1870 die Stadt die Millionen-Einwohnergrenze noch nicht überschritten hatte, ${ }^{32}$ lebten 1890 bereits 1,5 Millionen Menschen in ihr. ${ }^{33}$ In Wien war die Hälfte der Stadtbewohner*innen nicht dort geboren; in New York waren es im Jahr 190076 Prozent. ${ }^{34}$ Vor 1890 war New York Hafen für irische, deutsche, italienische und nach und nach osteuropäische Migrant ${ }^{*}$ innen gewesen. Ab den 1890er Jahren tauchten vermehrt die sogenannten „Polish Jews“, was als Sammelbegriff für alle aus Osteuropa immigrierten Jüdinnen und Juden verwendet wurde, auf.

In Zahlen gefasst, bedeutet das: Von 1,5 Millionen Menschen, die 1890 in New York lebten, lag der Anteil der jüdischen Bevölkerung mit etwa 300.000 bei rund einem Fünftel..$^{35} 1910$ war die Millionengrenze überschritten; es lebten 1,2 Millionen Jüdinnen und Juden - damals ein Viertel der gesamten Stadtbevölkerung - da. ${ }^{36} 1930$ lebten fünf Millionen Menschen in New York, ${ }^{37}$ davon 1,6 Millionen Jüdinnen und Juden, was ein Drittel der Bevölkerung ausmachte. ${ }^{38}$ Verantwortlich für diese Bevölkerungsexplosion war die Immigration.

Joseph Roth erzählt im Roman Hiob von einem der Stadtteile New Yorks, der am stärksten mit Einwanderung und den jüdischen Immigrant*innen verbunden waren, die Lower East Side. Sie war geprägt von dieser neuen Bevölkerung,

31 Joseph Roth, Hiob: Roman eines einfachen Mannes, in: ders., Werke in drei Bänden, Bd. 2, [1930] (Köln, Berlin: Kiepenheuer \& Witsch, 1956), 79.

321870 lebten in New York etwa 80.000 Jüdinnen und Juden. Moses Rischin, The Promised City: New York's Jews 1870-1914 (Cambridge, London: Harvard University Press, 21977), 94.

33 John S. Billings, Department of the Interior, Vital statistics of New York City and Brooklyn: covering a period of six years ending May 31, 1890 (Washington: US GPO, 1894), 2: 1,515 Millionen.

34 Rischin, The Promised City, 9.

35 Walter Laidlaw, Population of the City of New York 1890-1930 (New York: The Cities Census Committee, 1932), 270. Diner erwähnt, dass rund 60.000 Jüdinnen und Juden zu diesem Zeitpunkt an der Lower East Side gelebt hätten. Dinner, Yiddish New York, 52.

36 Hasia Diner, Yiddish New York, in: Edna Nahshon (Hg.), New York's Yiddish Theater: From Bowery to Broadway (New York: Columbia University Press, 2016), 50-63, 52-54.In den 1930er und 1940er Jahren stieg die Zahl auf (über) zwei Millionen in New York lebende Jüdinnen und Juden an; ein Viertel der New York Bevölkerung. Rischin, The Promised City, ix. Der Zensus gab jedoch eine Zahl von 1,876545 Jüdinnen und Juden an.

37 Laidlaw, Population of the City of New York 1890-1930, 270-277.

38 Diner, Yiddish New York, 52-54. 
die in ein „neues versprochenes Land“, ein „neues Jerusalem“ aufgebrochen war. Roth beschrieb das Zusammenspiel von Migration, verschiedenen Sprachen und Kulturen. Das Bild der Immigration nach Amerika steht dabei relativ zu jenem der Diaspora in Europa, mit der sie Roth verglich. Im Unterschied zur Diaspora stellte Roth die Immigration ins ,neue Jerusalem' als schnelle und gewissermaßen außerzeitliche Re-Lokation und Neuidentifizierung mit den New Yorker Lebensumständen dar. Diese neuen New Yorker*innen, die sogenannte „andere Hälfte“, wie Jacob Riis (1849-1914) sie nannte, lebte vorwiegend im Süden Manhattans, an der Lower East Side. Viele Menschen wohnten hier auf engsten Verhältnissen in den sogenannten tenements. ${ }^{39}$ Über das Leben der Migrant*innen habe die „andere Hälfte“ nichts gewusst und sich nicht dafür interessiert, so Riis in einer zeitgenössischen Darstellung: „Long ago it was said that, one half of the world does not know how the other half lives. That was true then. It did not know because it did not care. [...] Of one thing New York made sure at that early stage of inquiry: the boundary line of the Other Half lies through the tenements. "40

\subsection{Jüdisches Leben in den Metropolen}

Um die Jahrhundertwende war jüdisches Leben in den Metropolen zum einen mit dem Bürgertum und zum anderen mit den Massen an - meist ärmlicheren - Zuwander*innen verbunden. Auch wenn es in Wien, in Budapest und in New York einzelne Bezirke gab, die besonders stark mit jüdischem Leben in Verbindung gebracht wurden, lebten Jüdinnen und Juden in allen Gegenden der Städte. Es gibt daher weder urbane Räume, die als ausschließlich jüdisch, noch als ausschließlich nichtjüdisch gelten konnten. ${ }^{41}$

Wie kommt es also zu als ,jüdisch' konnotierten urbanen Räumen? Ein Grund dafür waren Stadtteile mit einem relativ hohen Anteil jüdischer Bevölkerung. In New York fand ein Großteil der neu angekommenen Jüdinnen und Juden in der Lower East Side erste Wohnungen. Die Migrant*innen, und mit ihnen

39 Richard Plunz, A History of Housing in New York City (New York: Columbia University Press, 1990).

40 Jacob Riis, How the Other Half Lives: Studies among the Tenements of New York. Herausgegeben von Leviatin David (Boston: Bedford \& St. Martin's, 2011), 59-60.

41 Simone Lässig, Miriam Rürup, Introduction: What Made a Space „Jewish“? Reconsidering a Category of Modern German History, in: dies. (Hg.), Space and Spatiality in Modern GermanJewish History (New York: Berghahn, 2017), 1-20, 2-8. Lisa Silverman, Jewish Memory, Jewish Geography: Vienna before 1938, in: Arjiit Sen, dies. (Hg.), Making Place: Space and Embodiment in the City (Bloomington, Indianapolis: Indiana University Press, 2014), 173-197, 175-180. 
die Populärkultur, bewegten sich aber auch nordwärts. Eine andere Nachbarschaft, in der Migrant*innen und Nichtmigrant*innen gemeinsam ein buntes Kulturleben konstituierten, war Harlem und zunehmend auch die Bronx. ${ }^{42}$ Mit der Eröffnung der Brooklyn Bridge 1883 und schließlich der Williamsburg Bridge 1903 war die Verbindung in die Stadtteile auf der anderen Seite des East Rivers und eine gute Anbindung an Manhattan gegeben, was diese Stadtteile attraktiver werden ließ. Die Lower East Side mit dem Broadway, entlang dem nach Jacob Riis vermeintlich die Trennung zwischen der einen und der anderen Hälfte verlaufen sei, erstreckte sich von der Bowery im Westen bis zum East River. Riis war jener New Yorker Polizeibeamte, der für seine Fotodokumentation über die beengten Lebensumstände der Migrant*innen noch heute bekannt ist. Innerhalb der Lower East Side verortete Riis einen Teil mit vorwiegend jüdischen Migrant*innen, den er als „hebrew quarter“ oder „Jewish ghetto“ bezeichnete. In diesem sogenannten „hebrew quarter“ lebten zwischen 1880 und 1890 drei Viertel der jüdischen Bevölkerung New Yorks. ${ }^{43}$

The man who was born in New-York and has not seen the city for fifteen or eighteen years would become bewildered if he were to take a walk through the great East Side. The streets are much the same as they were in those days, [...] [b]ut it is the population that has changed - a class entirelly[!] different in manners and costumes and political ideas and beliefs from the old-timers, who have moved up town, east and west. The district bounded by Catherine Street, the Bowery, Houston Street, and the East River, which was formerly divided up between the Irish in the lower and more eastern portion and the Germans in the upper part, and a fair sprinkling of Americans, who were still able to support several churches there, has almost entirely changed hands. A certain proportion of the Irish element still holds the fort on the river front, where the rough work is done along shore, but the others have been steadily pushed upward and outward by the children of Israel in their new exodus, [...]. A different language is now heard there. Neither German nor English nor yet Gaelic, but what is called the Yiddish, or Jewish, a jargon of old German, Hebrew, Polish and Russian, with the addition of Hungarian, where the Jews come from Hungary. ${ }^{44}$

Der Artikel aus der New York Times begann damit, zu beschreiben, wie sich die Nachbarschaft veränderte, und endete in der Feststellung, der Alltag habe die verschiedenen Sprachen, Kulturen und Menschen zusammengebracht. Der zeitnahe Diskurs nahm folglich wahr, dass das Leben der Migrant*innen sich

42 Harlem und die Bronx wurden in der Forschung zu Immigration und vor allem zum kulturellen Schaffen bislang völlig ignoriert- vermutlich aufgrund des Mythos „Broadway“, der seinen Anfang im Süden und nicht Norden Manhattans hatte. Zur Kabarettszene in Harlem ab den 1910er Jahren siehe Shane Vogel, The Scene of Harlem Cabaret: Race, Sexuality, Performance (Chicago: University of Chicago Press, 2009).

43 Diner, Yiddish New York, 52.

44 NYT, 27.8.1895, 13. 


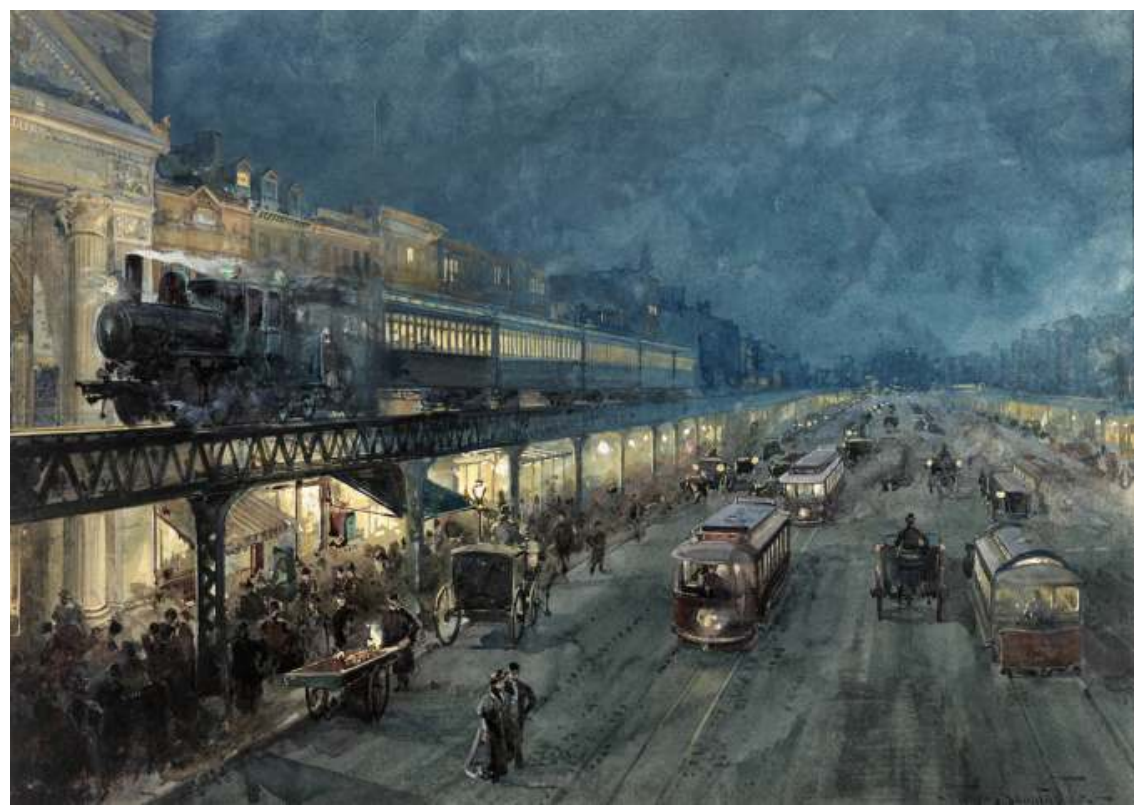

Abb. 2 Nächtliche Straßenszene an der Bowery. Die Bowery, war jener Teil New Yorks, wo Migrant ${ }^{\star}$ innen populäres Theater aufbauten, William Louis Sonntag Jr. (1869-1898), Museum of the City of New York 32.275.2

nicht in abgeschlossenen Milieus abspielte; eine Beobachtung, die Roth mit „bald war er heimisch“ auf den Punkt brachte.

In Budapest lebte mit rund 166.000 Jüdinnen und Juden um 1900 nach Warschau die größte jüdische Gemeinde Europas. ${ }^{45}$ Als ,jüdische Stadt“ war Budapest vielfach denunziert worden, zum Beispiel vom Wiener Bürgermeister Karl Lueger (1844-1910), der die Stadt spöttisch „Judapest“ nannte. So führte etwa die Andrássy út hin zum Stadtwäldchen durch den siebten Budapester Gemeindebezirk, Erzsébetváros (Elisabethstadt), wo um 1900 siebzig Prozent der jüdischen Bevölkerung Budapests lebte. ${ }^{46}$ Die Antisemit ${ }^{*}$ innen in Budapest versuchten, sich diesem Diktum zu entledigen. Obwohl im Budapest der Jahrhundertwende ein Jude das Amt des Vizebürgermeisters und mit Ferenc Heltai 1913 ein Jude den Bürgermeister bekleidete, war das ,jüdische ${ }^{`}$ Budapest nicht Teil eines öffentlichen Diskurses. ${ }^{47}$ Gerade „Judapest“ sei unsichtbar

45 L'Office Central Royal Hongrois de Statistique, Annuaire Statistique Hongrois, 8.

46 Lukács, Ungarn in Europa, 64.

47 Rolf Fischer, Entwicklungsstufen des Antisemitismus in Ungarn 1867-1939: Die Zerstörung der magyarisch-jüdischen Symbiose (München: R. Oldenburg, 1988), 9-10. 


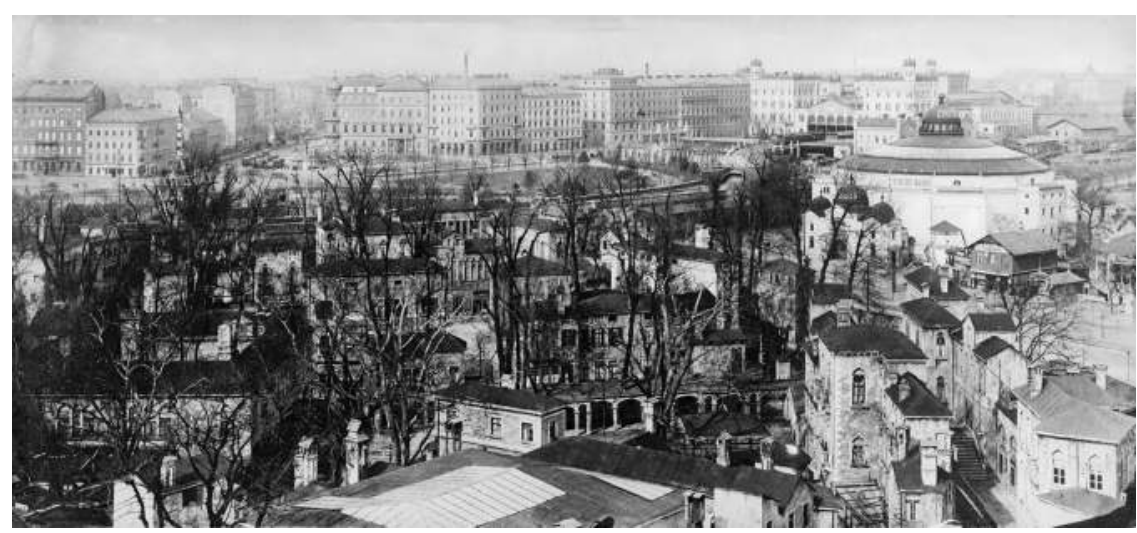

Abb. 3 Blick aus dem Prater auf die Wiener Leopoldstadt mit der Rotunde, dem Nordbahnhof und der Praterstraße, Bildarchiv Austria, 293.543

gewesen, so Mary Gluck, und nur die Populärkultur jener Bereich, wo das jüdische Budapest sichtbar war. ${ }^{48}$

Die jüdischen Zuwanderer*innen, die aus den östlichen Gebieten der Monarchie nach Wien gekommen waren, migrierten aus wirtschaftlichen und sozialen Gründen oder in Folge der Nachrichten über Pogrome im russischen Ansiedlungsrayon. ${ }^{49}$ Um 1900 war Wien nach Warschau und Budapest die drittgrößte jüdische Stadt Europas, es lebten rund 147.000 Jüdinnen und Juden in ihr. ${ }^{50}$ Sie siedelten sich vorwiegend im zweiten und zwanzigsten Wiener Gemeindebezirk, Leopoldstadt und Brigittenau, an, wo zwischen 1890 und 1910 rund 40 Prozent der Wiener jüdischen Bevölkerung lebte. ${ }^{51}$ Jüdinnen und Juden aus den östlichen Gebieten der Monarchie waren damit die größte Gruppe von Zuwandererinnen, die aus tschechisch-sprachigen Gebieten der Monar-

48 Mary Gluck, „The Budapest Flâneur: Urban Modernity, Popular Culture, and the ,Jewish Question in Fin-de-Siècle Hungary“, Jewish Social Studies 10, no. 3 (204): 1-22, 4.

49 Siehe hierzu die einleitenden Bemerkungen.

50 John, Vielfalt und Heterogenität, 39.

51 Michael John, Albert Lichtblau, Schmelztiegel Wien einst und jetzt: Zur Geschichte und Gegenwart von Zuwanderung und Minderheiten (Wien, Köln, Weimar: Böhlau, $\left.{ }^{2} 1993\right), 145$ und 207-208. 
chie die zweitgrößte. ${ }^{52}$ Die Leopoldstadt erhielt den Beinamen „Mazzesinsel ${ }^{\star 53}$ und Joseph Roth sprach von der Leopoldstadt als „freiwilliges Ghetto“. Hier, zwischen Prater und Kaiser Ferdinand Nordbahnhof, so Roth, könnten die vom Osten kommenden jüdischen Migrant ${ }^{\star}$ innen vom Frohsinn leben. ${ }^{54}$ Sie lebten aber nicht abgeschlossen. Ihr Alltag und die Unterhaltungskultur fanden nicht in isolierten ,Milieus' statt. ${ }^{55}$ Zum Leben in meist nur allzu ärmlichen Verhältnissen gehörte auch „Musik zu machen, tanzen und Theaterspielen“ oder ein Besuch im Prater.

Allgemein spielte sich jüdisches Leben in Wien wie auch in Budapest und New York nicht abgeschlossen ab: Jüdinnen und Juden wohnten in Wien nicht exklusiv in der Leopoldstadt, sondern ebenso in allen anderen Stadtteilen. ${ }^{56}$ Die Leopoldstadt war allerdings jener Gemeindebezirk, der aufgrund seiner starken Verbindung zur jüdischen Massenmigration der Jahrhundertwende auch in der Gegenwart noch immer am stärksten mit jüdischem Leben verbunden ist. Wie die Gesellschaft Wiens plurikulturell war, so war das auch die vermeintlich und nur zu häufig kollektivierte ,jüdische ' Bevölkerung. ${ }^{57}$

Neben positiven Beispielen fanden sich auch immer wieder Berichte über Konflikte in diesen plurikulturellen Verhältnissen. Die sogenannte „amerikanische Bevölkerung" etwa stand den (jüdischen) Migrant*innen in New York nicht ausschließlich positiv gegenüber. Bald berichteten jüdische Tageszeitungen von Vorbehalten, die nicht religiöser, sondern „ethnologischer" Natur gewesen seien. Folgendes schrieb etwa der Jewish Messenger im Juni 1881. Als tolerant gegenüber Religionen, jedoch weniger tolerant gegenüber vermeintlichen sozialen Charaktereigenschaften stünden die Amerikaner*innen Jüdinnen und Juden gegenüber:

The ordinary American citizen looks on the Jewish religion with tolerant curiosity, but not with condemnation; nor would he hesitate to sit at meat with a Mohamedan out

52 Der Zensus in der Habsburgermonarchie unterschied Sprachgebrauch und Religion. Damit ist natürlich klar, dass Jüdinnen und Juden zu allen Sprachgruppen zählen konnten. In den Angaben, die Immigrant ${ }^{\star}$ innen in Ellis Island machen mussten, wurde zwischen Religion und Herkunft wie auch nach Sprache differenziert. Zu jüdischen Migrant*innen aus Galizien in Wien siehe Hödl, Als Bettler in die Leopoldstadt, 129-162; Marsha Rozenblit, „A Note on Galician Jewish Migration to Vienna“, Austrian History Yearbook 19 (1983): 143-152.

53 Ruth Beckermann, Die Mazzesinsel: Juden in der Leopoldstadt 1918-1938 (Wien: Löcker, 1992), 9.

54 Joseph Roth, Juden auf Wanderschaft [1927] (München: Dtv, $\left.{ }^{5} 2015\right), 52$.

55 Klaus Hödl, Galizische Juden und Jüdinnen in Wien: Einige Gründe für deren Stereotypisierung, in: Elisabeth Röhrlich (Hg.), Migration und Innovation um 1900: Perspektiven auf das Wien der Jahrhundertwende (Wien, Köln, Weimar: Böhlau, 2016), 221-241, 234.

56 Hödl, Als Bettler in die Leopoldstadt, 10-20.

57 Hödl, Galizische Juden und Jüdinnen in Wien, 225-230. 
of mere religious exclusiveness. The larger part of the present dislike to Jews is due to social characteristics. Ethnological differences have a practical power which neither the Christian principle of human brotherhood nor the modern political doctrine of equality has been able to neutralize. ${ }^{58}$

Dieser Artikel aus dem Jewish Messenger bildet jenen Diskurs ab, der auch den Antisemitismus in Europa im ausgehenden 19. Jahrhundert zu prägen begann: einen rassistisch-biologistisch argumentierenden, neuen Antisemitismus. Nicht mehr Religion war das Unterscheidungsmerkmal, sondern etwas biologistisch Bedingtes, und damit natürlich unmöglich zu Überkommendes. ${ }^{59}$ Georg von Schönerer, Führer der Deutschnationalen und der Alldeutschen Bewegung, prägte die Grundzüge dieses modernen Antisemitismus. Der spätere Wiener Bürgermeister aus dem Christlichsozialen Lager, Karl Lueger machte Politik damit. ${ }^{60}$ Lueger verband wie kein anderer vor ihm Antisemitismus mit Populismus; eine politische Agitation, aus deren Kontext auch „Judapest“ stammte. $^{61}$ Während Kaiser Franz Joseph bei der ersten Wahl Luegers zum Bürgermeister dessen Ernennung verhinderte - ,ich dulde in meinem Reich keine Judenhetze“ - konnte er den Christlich-Sozialen nicht mehr beikommen und Lueger wurde ab November 1897 Bürgermeister der kaiserlichen Residenzstadt. ${ }^{62}$

Dieser neue Antisemitismus richtete sich, wie auch der zitierte Artikel aus dem Jewish Messenger illustriert, häufig gegen die jüdischen Migrant*innen aus den östlichen Gebieten der Habsburgermonarchie oder aus dem russischen Ansiedlungsrayon. Sie wurden als kaftantragende, arme Exoten stigmatisiert, die besonders kinderreiche Familien hätten. Die Stadtbevölkerung fürchtete sie als Gefahr; die schon länger in Wien lebenden Jüdinnen und Juden hatten Angst, dass der Antisemitismus aufgrund der Sichtbarkeit der jüdischen Migrant*innen stiege. ${ }^{63}$ Die massenhafte Präsenz der Migrant ${ }^{\star}$ innen prägte gerade auch

58 TJM, 21.6.1881, 5.

59 Shulamit Volkov, Antisemitismus und Antifeminismus, in: dies. (Hg.), Das jüdische Projekt der Moderne: Zehn Essays (München: Beck, 2001).

60 Peter G. J. Pulzer, Die Entstehung des modernen Antisemitismus in Deutschland und Österreich 1867-1914 (Göttingen: Vandenhoeck \& Ruprecht, 2004), 181-199; Victor Karady, Gewalterfahrung und Utopie: Juden in der europäischen Moderne, aus dem Französischen von Judith Klein (Frankfurt am Main: Fischer, 1999), 203-216.

61 Robert Wistrich, Laboratory for World Destruction: Germans and Jews in Central Europe (Lincoln, London: University of Nebraska Press, 2007), 363.

62 Robert S. Wistrich, The Jews of Vienna in the Age of Franz Joseph (New York, Oxford: Oxford University Press, 1989), Wistrich, Die Juden Wiens im Zeitalter Kaiser Franz Josephs, 149. Gerald Stieg, Sein oder Schein: Die Österreich-Idee von Maria Theresia bis zum Anschluss (Wien, Köln, Weimar: Böhlau, 2016), 103-106 sowie 131.

63 Steven E. Aschheim, „Between East and West: Reflections on Migration and the Making of German-Jewish Identity, 1800-1880“, Studia Rosenthalia 23 (1989): 77-87. 
das Bild jener Stadtteile, in denen die populäre Kultur besonders lebendig war: New Yorks Lower East Side, Wiens Leopoldstadt und Budapests Józsefváros und Erzsébetváros (Josef- und Elisabethstadt). Letztere waren schon aufgrund des Wiener Nordbahnhofs und Budapests Keleti Pályaudvar (Bahnhof) die Ankunftsorte von Migrant*innen wie auch reisenden Künstler*innen in den Städten. Den besonders von der Massenmigration geprägten Stadtteilen waren viele Berichte über die katastrophalen, vermeintlich von den Migrant*innen verursachten Lebensumstände dort, gewidmet. How the Other Half Lives, der Bericht des New Yorker Polizeibeamten Jacob Riis, ist der Bekannteste. ${ }^{64}$

Während zum einen mehr oder weniger seriöse soziopolitische Berichte über die Bevölkerungsentwicklung in Folge der Migration den Diskurs determinierten, entwarfen zum anderen antisemitische Medien zunehmend die stereotypisierte Bilder über jüdische Migrant ${ }^{\star}$ innen. Die Wiener karikierte Wochenschrift Kikeriki etwa, die ursprünglich ein liberales Medium gewesen war und bis zur Mitte der 1890er Jahre immer vehementer antisemitisch wurde, ${ }^{65}$ verlegte neben eigenen Postkartenserien auch ein „Lexikon“, das sie süffisant als „Kohn-Lexikohn“ betitelte. 1895 erstmals erschienen, erlebte das Pamphlet innerhalb von zehn Jahren drei Auflagen. ${ }^{66}$ Es rühmte sich, in 24 Abbildungen den „edlen Kohn in allen Lebenslagen graphisch zu illustrieren“. Je ein lateinisches bzw. französisches Wort herausgreifend und auf ein antisemitisches Stereotyp metaphorisch anspielend, stellte das Pamphlet Karikaturen über die sogenannten „Ostjuden“ neben jene über die „assimilierte Bevölkerung “ 67 Zur raschen Verteilung nutzte der Verlag einen Aspekt neuer populärer Kultur nämlich das neue Druckschriftenformat, das es auch ermöglichte, Zeitungsromane und kurze Geschichten für wenig Geld - wenige Groschen - zu erwerben („Groschenromane"). ${ }^{68}$

64 Riis, How the Other Half Lives; siehe auch für Wien und Budapest. Zur Bevölkerungsverteilung siehe Michael K. Silber, Budapest. YIVO Encyclopedia of Jews in Eastern Europe. http://www. yivoencyclopedia.org/article.aspx/Budapest (letzter Zugriff: 12.11.2018).

65 Sarah Holzinger, Die Darstellung von Juden und Jüdinnen im Humoristischen Volksblatt „Kikeriki“ (Dipl. Arbeit, Universität Graz, 2015).

66 Kikeriki, Kohn-Lexikon. [im Verlag beim Kikeriki erschienen; erste Auflage 1895, zweite Auflage 1900 und dritte Auflage 1904].

67 Kohn-Lexikon, 3-4; sowie die Gesamtdarstellung. Zu „Ostjuden“ siehe Philipp Mettauer, Barbara Staudinger (Hg.), „Ostjuden“: Geschichte und Mythos (Bozen, Innsbruck, Wien: Studienverlag, 2015).

68 Kaspar Maase, Einleitung: Schund und Schönheit: Populäre Kultur um 1900, in: ders., Wolfgang Kaschuba (Hg.), Schund und Schönheit: Populäre Kultur um 1900 (Wien, Köln, Weimar: Böhlau, 2001), 9-28. 


\section{Amüsement in den Metropolen}

Etablissement, Varieté und Singspielhalle in Wien, Budapest und New York

Die allmähliche Ausdehnung des Artistenwesens...

- Die Internationale Artisten Revue, November 1891

Als die in Budapest herausgegebene Internationale Artisten Revue 1891 von der „allmählichen Ausdehnung des Artistenwesens“ schrieb, resümierte sie über eine Entwicklung, die im vorhergegangenen Jahrzehnt ihren Ausgang nahm und die urbanen Räume in den nächsten Jahren prägen sollte: Vergnügungsstätten - ob Varieté, Singspielhalle oder andere Etablissements - breiteten sich rasant in den Städten Europas und Amerikas aus und säumten zum Fin de Siècle die Straßen in allen Stadtteilen der Metropolen. Die Tatsache, dass die populäre Kultur einer jener urbanen Räume war, den Jüdinnen und Juden gestalteten, wurde im zeitgenössischen Diskurs weithin nicht thematisiert. Stattdessen stand die Attraktion der Vergnügungsstätten im Mittelpunkt der Berichterstattung. Zeitungen schrieben über die Chat Noir de Paris und Harry's New York Bar im zweiten Pariser Arrondissement. Künstler*innen versuchten, sich mit französischen Namen den Flair der Pariser populären Kultur und Bohème zu verleihen. ${ }^{1}$

Namensgebungen wie „New York Bar“ für ein Lokal in Paris lassen vermuten, dass es einen regen Austausch zwischen Europa und Amerika gab. In Europa war Paris vielleicht das bekannteste, aber keineswegs einzige Referenzobjekt, an dem sich die anderen Metropolen der Jahrhundertwende betreffend Innovationen in der Unterhaltungskultur orientierten: Die Szene der ungarischen Hauptstadt hatte eigentlich jene von Paris längst an Beliebtheit überholt. Neidvoll blickte die Welt auf Budapest, das, so hieß es, nie schlief. Um schlafen zu können, müsste man nach Wien fahren - so die Degradierung der Residenzstadt. Wien versuchte dafür, sich mit technischer Innovation einen Namen zu machen. Auch Freizeitparks entwickelten und beeinflussten sich global. Kopenhagens Tivoli als älteste Freiluftvergnügungseinrichtung oder Schwedens Gröna Lund inspirierten die Buden und Raumarrangements in Freizeitparks

1 Zum Chat Noir de Paris und zur Bohème siehe Mary Gluck, Popular Bohemia: Modernism and Urban Culture in Nineteenth Century Paris (Cambridge: Harvard University Press, 2008), 111. 
weltweit. ${ }^{2}$ Das Budapester Varieté Folies Caprice prägte die Entwicklung der sogenannten Rauchtheater - Varietés in denen geraucht werden durfte - in Triest gleichermaßen wie in Tarnopol, Prag und Wien. Aufgrund ihrer enormen Beliebtheit, die weit über die Grenzen der ungarischen Hauptstadt hinausreichte, bedingten die Folies Caprice sogar einen „Krieg“ unter den Künstler*innen, wenn die Gruppe ankündigte, in anderen Städten Spielstätten zu eröffnen. ${ }^{3}$ Die Weltausstellungen waren ein weiteres Paradebeispiel urbaner Innovation von internationaler Reichweite. Mit den ersten Weltausstellungen in Übersee - von New York, über Melbourne und Sydney, Philadelphia und Chicago - lässt sich auch hier ein zunehmend außereuropäischer, globaler Trend erkennen. Das dort Präsentierte griff die Unterhaltungsszene nur zu gern auf. Eine jener Erfindungen, die sich am stärksten im Sprechen und Amüsieren über die globale Innovation niederschlugen, war das rollende Trottoir („Straße der Zukunft“, „Rue de l'Avenir“). Für die Chicagoer Weltausstellung von 1893 entworfen und schließlich 1900 in Paris präsentiert, ${ }^{4}$ fand es sich als Referenzobjekt in populären Liedern und Stücken. ${ }^{5}$

In diesem Kapitel geht es darum wie die Räume populärer Kultur all das möglich machten; darum, wie diese Räume aussahen, wo sie entstanden und um die Umgebung, in der sie sich konstituierten. Welche Spielstätten etablierten sich in den Städten? Wie oft wurden Vorführungen gespielt und zu welchen Eintrittspreisen? Wer war das Publikum? Und was machte die urbane Erfahrung in Varieté, Singspielhalle und Etablissement aus? Am Beispiel von Wien, Budapest und New York zeigt dieses Kapitel, wie sich die Räume populärer Kultur entwickelten und gleichermaßen auch, wie populäre Kultur, metaphorisch gesprochen, zwischen den drei Städten bestand und sich gerade nicht im "nationalen“, sondern im internationalen Licht die Besonderheit der populären Kultur ergab. Die Frage, weshalb ein Aspekt dieser Besonderheit die Funktion populärer Kultur als jüdischer-nichtjüdischer Interaktionsraum war, steht dabei immer im Zentrum.

2 Verschiedene Aspekte zur Entstehung von Freizeitaktivitäten siehe im Sammelband von Lukas A. Scott (Hg.), A Reader in Themed and Immersive Spaces (Pittsburgh: Carnegie Mellon ETC Press, 2016).

3 Siehe den Abschnitt zu den Folies Caprice und zum Volkssängerkrieg in diesem Kapitel.

4 White Trumbull, WM. Igelhart, The World's Columbian Exhibition: Chicago 1893 [Katalog zur Weltausstellung in Chicago 1893] (Philadelphia, St. Louis: P. W. Ziegler \& Co., 1893).

5 Siehe hierzu Kapitel 5. 


\subsection{Räume populärer Kultur in Wien, Budapest und New York}

Im letzten Jahrzehnt des 19. Jahrhunderts etablierten sich nach und nach Räume populärer Kultur im Stadtbild. Sie konstituierten und entwickelten sich schnell weiter. Gemeinsam war den Räumen populärer Kultur in Wien, Budapest und New York, dass sie sich nahe am täglichen Leben auftaten - neben Einkaufsmöglichkeiten, Gebetshäusern und Schulen. Sie waren dementsprechend in Aktivitäten des Alltages eingebunden. Varieté, Etablissement und Orpheum waren Treffpunkt und ermöglichten Begegnungen und Kontakte. Die Besucherinnen suchten die Spielstätten auf, um sich zu amüsieren, eventuell, um zu essen oder zu trinken und um in geselliger Runde unterhalten zu werden.

Die neue mobile Praxis und der zunehmend internationale Charakter populärer Kultur konterkarrierten gelegentlich Vorwürfe, denen nach die „Volkskultur“ in früher Zeiten noch „regional“ gewesen sei. Im Wien der zweiten Hälfte des 19. Jahrhunderts war es gerade die Volkssängerszene, die besonders stark an ,eigenen' Traditionen, Alt-Wiens' festhielt und sich exklusiv präsentierte. Zeitgenössische Darstellungen über die Wiener Volkssänger*innen proklamierten einen Bruch zwischen der ,alten und neuen Zeit des Volkssängerthums“. Die "neue Zeit" hätte den Untergang der Volkssängerinnen bedeutet. Man trauerte somit nicht nur dem alten Erscheinungsbild von ,Alt-Wien' selbst nach, sondern auch der "guten alten Zeit“ des Volkssängertums. ${ }^{6}$ In einer Darstellung des Wiener Volkssängers Josef Koller (1872-1945) kam das Miterleben der Veränderung populärer Kultur prägnant zum Ausdruck. Volkssänger*innen traten nicht mehr allein in Gasthäusern auf, sondern waren Teil von größeren Programmen, die in neuentstandenen Varietés, Singspielhallen und anderen Etablissements dargeboten wurden. Sie bestanden meist aus Zuschauerbereich, in dem Stühle um kleine Tische herum arrangiert waren, und Bühne. Geöffnet hatten diese Einrichtungen oft ab den frühen Nachmittagsstunden, Programme wurden mehrmals täglich wiederholt und wechselten im Wochenrhythmus. Die Zusammenstellung der Programme war so konzipiert, dass der Varietébesuch für das Publikum eine Routine sein konnte, ohne dass sich das Dargebotene wiederholte.

Ein großer Teil der populären Unterhaltungsszene befand sich in den drei Städten in als jüdisch konnotierten Stadtteilen. Allerdings, wie jüdisches Leben nicht auf einzelne Stadtteile reduziert werden konnte, verteilten sich auch die Räume populären Amüsements über die ganze Stadt. Besonders dicht gedrängt

6 Josef Koller, Das Wiener Volkssängertum in alter und neuer Zeit: Nacherzähltes und Selbsterlebtes, mit Biographien, Episoden, Liedern, zahlreichen Abbildungen und Porträts nach zeitgenössischen Bildern aus dem Volkssängerleben (Wien: Gerlach und Wiedling, 1931), 190. 
waren Etablissements, Varietés, Orpheen und Singspielhallen in der Wiener Leopoldstadt, im Budapester Bezirk Erzsébetváros (Elisabethstadt) und an der Bowery der New Yorker Lower East Side. Sie fanden sich genauso in den anderen Stadtteilen. Auch waren, wie Vorbehalte suggerierten, die Stätten populärer Kultur nicht ausschließlich an der Peripherie angesiedelt, sondern gleichermaßen in den Stadtzentren wie in den äußeren Bezirken präsent. Die Programme, die die Künstler*innen darboten, gestalteten sich bunt. Sie reichten von Possen (Komödien, die mit Übertreibung und Witz spielten), Couplets (mit einprägsamen Liedern unterlegte Kurzpossen) und pikanten Liedern über artistische und akrobatische Nummern bis hin zu Imitationskunst oder „Drahtseilakten“. 7 Was zählte, war das Außergewöhnliche: Das Publikum fragte nach Mimikerinnen, Komiker*innen und „knochenlosen“ Menschen sowie anderem Skurrilen wie „kleinste Zwerge“ oder Babys mit Schnurrbärten. ${ }^{8}$

Zur Szene populärer Kultur konnten verschiedenste Räume gehören: Zum einen natürlich die Spielstätten selbst. Zum anderen aber auch Lokale, in denen die Stars ihre Zeit verbrachten und mit ihren Fans sprachen, wenn sie gerade nicht auftraten. Außerdem entstanden Unterkünfte für Artist*innen und Künstler*innen sowie Vereinslokale, in denen Zusammenkünfte unter den Szenemitgliedern abgehalten wurden. Das Amüsement und die Räume, in denen es stattfand, waren in das tägliche Leben eingebettet. Sie befanden sich an den Hauptrouten der jeweiligen Nachbarschaften, unweit von Einkaufsmöglichkeiten. Die Spielstätten befanden sich nicht selten auch in den Sälen von Hotels. Das war praktisch, bot die Hotelgastronomie wichtige Infrastruktur wie Verpflegung und einen Schlafplatz für Künstler*innen und Artist ${ }^{*}$ innen von auswärts.

Die Frage der Versorgung von den Künstler*innen gewann mit deren Reisen an Bedeutung. Nun traten Menschen auf, die an den Aufführungsorten über keinen Wohnsitz verfügten und auf eine Unterbringung angewiesen waren. Die Nächtigungsmöglichkeiten, die in Wien mit der Hotelinfrastruktur gegeben waren, mussten in Budapest und New York in anderer Form bereitgestellt werden. In der ungarischen Hauptstadt entstanden rund um die Aufführungsstätten sogenannte Artistenheime. Untertags waren die Budapester Artistenheime wichtige Aufenthalts- und Austauschorte. Zudem prägten Artistencafés, die für "Rendezvous aller Artisten [und Artistinnen] “ dienten, ${ }^{9}$ bald die Umgebung der Etablissements. Auch in Wien etablierten sich „Artistenheime“, allerdings

7 Siehe hierzu die Inserate, IAR, 1.8.1894, 4.

8 Inserat des „kleinsten Zwerges“, IAR, 1.11.1891, 4; Inserat der „Miniatur Athleten und Akrobaten“, IAR 1.11.1894, 17. Siehe allgemein Joseph Philippi, „Das Picante in der Kunst“, IAR, 1.8.1892, 1-2.

9 Siehe etwa die Hinweise auf Herzmanns Artistencafé. „Herzmann's Artistencafé, IAR, 8.11.1891, 10 . 
hatten die Wiener Artistenheime einen anderen Zweck: Hier waren derartige Unterbringungen zur Versorgung von kranken oder alten Szeneangehörigen gedacht, wohingegen die Heime in Budapest entstanden, damit auswärtige Künstler*innen zu guten Konditionen nächtigen und leben konnten. Aber auch die Budapester Erfindung von caféartigen Taglokalen für Künstler*innen griff sodann auf Wien ${ }^{10}$ und New York über. In New York eröffneten allein an der Bowery innerhalb kürzester Zeit über 22 solcher Cafés, in denen die Künstler*innen auch immer wieder Einblicke in ihr Können gewährten und einen Vorgeschmack auf die Aufführungen in den Varietés und Singspielhallen gaben. ${ }^{11}$

Orte zum Verweilen waren auch die Spielstätten selbst. Eine Praxis, die sich beim Publikum enormer Beliebtheit erfreute, war die Konsumation von Speisen und Getränken während der Aufführungen. Die Verpflegung sicherte die Zufriedenheit des Publikums und sorgte für eine besondere Atmosphäre. Zu einer Zeit, als für einen Großteil der städtischen Bevölkerung private Räume, so überhaupt vorhanden, enorm gedrängt waren und häufig mit einer großen Zahl an Mitbewohner*innen geteilt werden mussten, konnte in den Spielstätten die Freizeit - ein Phänomen, das zu dieser Zeit erstmals überhaupt vorhanden war allein oder auch gemeinsam mit der ganzen Familie verbracht werden. ${ }^{12}$ Dabei auch noch eine gewisse Gemütlichkeit zu erleben, amüsiert zu werden und sich gegebenenfalls auch Verpflegung zu leisten, manifestierte sich in der Phrase köstliches Amüsement. Wenn das Programm gefiel, die Gäste dieses in guter Gesellschaft mit Speisen und Getränken genießen konnten, kommentierten sie es mit den Worten „ich habe mich köstlich amüsiert“; die Kritiken um 1900 erkoren dies zunehmend als Gütekriterium aus:

Das neue Karnevallsprogramm des Kolosseums erzielte bei seiner Premiere einen wahren Sensationserfolg, der diesem Vergnügungsetablissement eine Reihe ausverkaufter Häuser sichert. Aus dem glänzenden Programm sind besonders hervorzuheben: [...] die tollkühnen Akrobaten auf der Luftleiter, [...] die ausgezeichnete Parodistin, mit ihrem

10 Diese Entwicklung ist für New York etwas zeitversetzt ab dem ersten Jahrzehnt des 20. Jahrhunderts nachweisbar.

11 Edna Nahshon, Café Royal, in: dies. (Hg.), New York's Yiddish Theater: From Bowery to Broadway (New York: Columbia University Press in Association with the Museum of the City of New York, 2016), 37.

12 Zum parallelen Aufkommen von Freizeit (als weite Kreise der Gesellschaft umfassendes Phänomen) und Massenkultur siehe Maase, Grenzenloses Vergnügen, 20-26. Zur soziale Klassen übergreifenden Wirkung der Räume populärer Kultur siehe Gluck, The Invisible Jewish Budapest, 149; sowie Judith Thissen, Should a Married Woman Visit a Yiddish Music Hall? in: Digital Yiddish Theatre Project 2016,

https://web.uwm.edu/yiddish-stage/should-a-married-woman-visit-a-yiddish-music-hall (letzter Zugriff: 13.4.2020). 
neuen Repertoire und [...] zwei brillante Kunstradfahrer, [...] die graziösen Tänzer, die stimmbegabte Vortragssängerin und noch eine Serie lustiger Nummern finden ebenfalls die Anerkennung des Publikums, das sich bei den Darbietungen der Künstler köstlich amüsiert. ${ }^{13}$

"Sich köstlich amüsiert zu haben“ war damit die Krönung des gelungenen Abends, wie dieser Kommentar in der Illustrierten Zeitschrift für die vornehme Welt Sport \& Salon zum neuen Programm im Colosseum, ${ }^{14}$ einem der unzähligen Varietés in Wien um 1900, unterstrich.

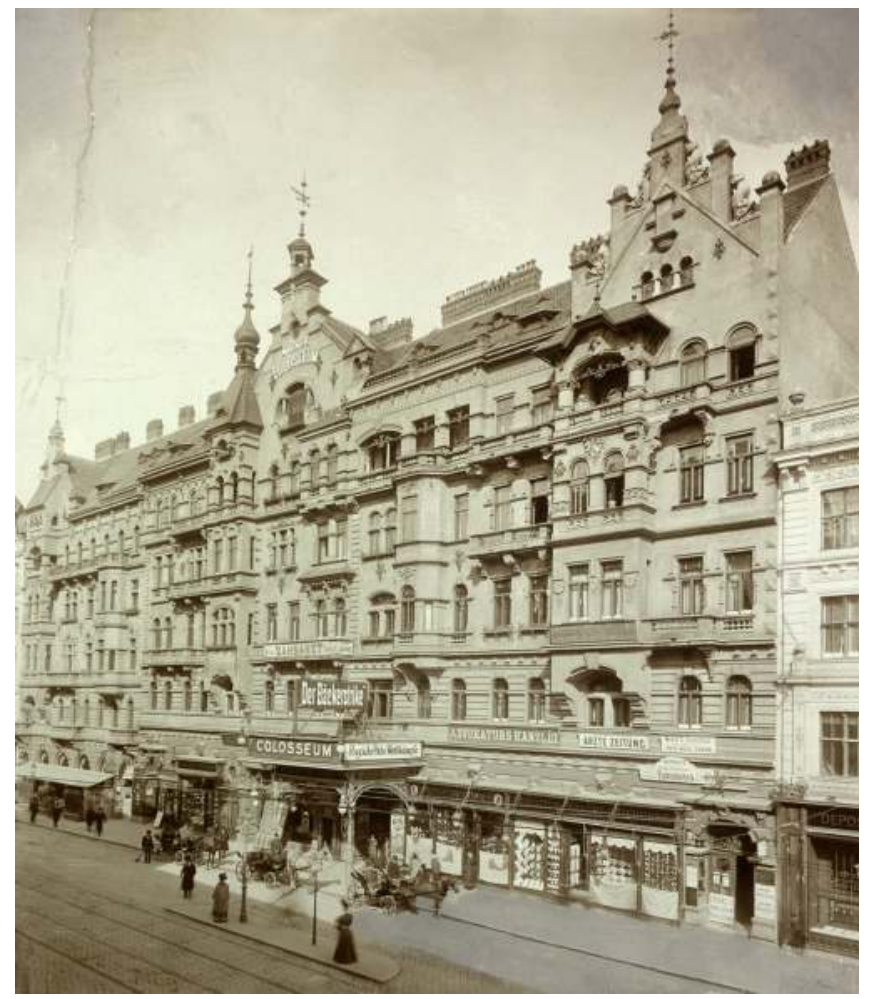

Abb. 4 Blick aus der Wiener Nussdorferstraße auf das Varieté Kolosseum um 1900, Charles Scolik, Bildarchiv Austria, Pk5152,68

13 Hervorhebung der Autorin; „Theater, Kunst und Literatur“, Sport und Salon, 10.2.1906, 8-10, 9.

14 Das Colosseum (auch Kolosseum) war mit rund 500 Sitzen ein mittelgroßes Rauchtheater in der Nußdorfer Straße 4 im neunten Wiener Gemeindebezirk (Alsergrund). Zur Zeit dieser Kritik leitete bereits Artur Brill und nicht mehr Ben Tieber das Colosseum. Professor Artur Brill war mit Ruth Brill verheiratet und lebte gleich im Nebenhaus des Varietés in Nußdorfer Straße 6. Adolph Lehmann's Allgemeiner Wohnungsanzeiger, 1906, Bd. 2. 
Das Verlangen, „sich köstlich zu amüsieren“, wirkte sich auf die Gestaltungsmöglichkeiten in der populären Kultur aus. In Varietés, Etablissements, Singspielhallen, Rauchtheatern und anderen Spielstätten kamen Menschen mit unterschiedlichsten Interessen wie auch sozialen Hintergründen in Kontakt miteinander. ${ }^{15}$ Die Stätten fungierten als Räume, in denen sich die von der neuen Mobilität geprägte plurikulturelle Gesellschaft sammelte und gemeinsam aufhielt. $^{16}$ Ihr Aufenthalt dort galt dem Ziel sich köstlich zu amüsieren. Im Verfolgen dieses Ziels verhielten sich die Besucher ${ }^{\star}$ innen indifferent gegenüber politischen, religiösen oder ethnischen Differenzen; Differenzen waren in der gemeinsamen Raumnutzung, ob lediglich im Anwesendsein oder bei Interaktionen, nicht vordergründig. ${ }^{17}$ Die dargebotenen Stücke und Lieder verhandelten kontroverse Inhalte, hochpolitische Debatten wie auch soziale Normen. Es ist anzunehmen, dass das Publikum über diese Inhalte durchaus unterschiedlich dachte. Das Amüsement ließ allerdings inhaltliche Diversitäten überbrücken und sich über - die in anderen Diskursen populistisch ausgeschlachteten - Differenzen hinweg gemeinsam „köstlich amüsieren“" ${ }^{18}$ Die Räume populärer Kultur wirkten somit als soziopolitischer Katalysator über vermeintliche religiöse, ethnische, nationale, politische oder soziale Differenzen und Identifikationen hinweg. ${ }^{19}$

15 Maase unterscheidet zwischen ,popular ‘ und ,populär`, ,Popular ‘ verwendet er für Phänomene, die man der Unterschicht zuordnete. Maase, Grenzenloses Vergnügen, 20-26.

16 Bhatti, Plurikulturalität, 171-180.

17 Unlängst hat eine Vielzahl an Studien in der Soziologie die Bedeutung derartiger Mikrokosmen für interethnische, religiöse wie auch kulturelle Interaktionen betont:. Pierre Bourdieu, „The Social Space and the as Genesis of Groups“, Theorie and Society 14, no. 6 (1985): 723-744; Till van Rahden, Weder Milieu noch Konfession: Die situative Ethnizität der deutschen Juden im Kaiserreich in vergleichender Perspektive, in: Olaf Blaschke, Frank-Michael Kuhlemann (Hg.), Religion im Kaiserreich: Milieu, Mentalitäten, Krisen (Gütersloh: Gütersloher Verlagshaus, 1996), 409-434.

18 In diesem Sinne war den Stätten populärer Kultur nicht nur eine Qualität von sogenannten Nicht-Orten nach Marc Augé inne, sondern ebenso jene des dritten Raumes als Möglichkeitsraum. Marc Augé, Nicht-Orte (München: C. H. Beck, 2014); Homi K. Bhabha, The Location of Culture. London, (New York: Routledge, 2004). Siehe auch Foucaults „Theater als Heterotopie“. Michel Foucault, „Of Other Spaces,” Diacritics 16, no. 1 (1986): 22-27; Henri Lefebvre, The Production of Space (Oxford, Cambridge: Wiley-Backwell, 1991).

19 Die Überlegungen zu Differenz und Identifikation - üblicherweise mit dem kategorisierenden Prinzip „Identität“ vereinfacht abgehandelt - beruhen in diesem Buch auf Brubaker und Rogers. Rogers Brubaker, Frederik Cooper, „Beyond ,Identity“, Theory and Society 29 (2000): $1-47$. 
Um besser verstehen zu können, wie köstliches Amüsement funktionieren konnte, wird zunächst die Qualität der Räume populärer Kultur in den Blick genommen. $^{20}$

\section{Zu Raum und Ort}

Was sind Räume und was meint Räume populärer Kultur? In den vergangenen Jahrzehnten hat das raumgeprägte Selbstverständnis der Postmoderne die zeitbeherrschte Ausrichtung der Moderne abgelöst. ${ }^{21}$ Im spatial turn rückten Fragestellungen zu Raum und Ort ins Interesse der Forschung. Studien näherten sich diesen Begriffen mit verschiedensten Konzeptionen. ${ }^{22}$ Nach dem Soziologen Henri Lefebvre sind Räume Produkte sozialer Prozesse. Raum wird dementsprechend als eine relationale, also auf Beziehungen aufbauende, Kategorie interpretiert: ${ }^{23}$ Zum einen als Produkt jener Verhandlungen, Diskussionen und Interaktionen, in denen sein Entstehen geplant wird (Stadtverwaltungen, Zensur etc.). ${ }^{24}$ Zum anderen sind es aber auch die sozialen Prozesse in den Räumen, wenn diese sodann bestehen, die Räume gestalten. ${ }^{25}$ Das heißt, wo sich ein Raum befindet und die physische Bedingtheit des Gebäudes tragen ebenso zum Erleben eines Raumes bei, wie die Begegnungen in ihm. Die physische Lage einer Spielstätte und die Kontakte, die sich in den Spielstätten ergaben, beeinflussten gleichermaßen die Konstitution der Räume populärer Kultur, wie die Stücke und Nummern, die Schauspieler ${ }^{\star}$ innen und Artist ${ }^{\star}$ innen dort aufführten.

Räume sind somit flüchtige Produkte: Sie ergeben sich immer wieder neu, abhängig davon, wer auf wen trifft ebenso wie welche Inhalte die Varietékünstler*innen darboten oder was das Publikum diskutierte. Die Soziologin Martina Löw betont gerade diese Interdependenz zwischen Subjekten, Objekten und dem physischen Ort für das Konstituieren von Räumen. ${ }^{26}$ Diese Überlegung

20 Zum Beispiel das Café Royal: An der 12th Ecke ${ }^{\text {nd }}$ Avenue hatte es 1908 noch nach dem Betreiber des Cafés „Breslau“ geheißen und wurde 1910 in Café Royal umbenannt. Nahshon, Café Royal, 37.

21 Doris Bachmann-Medick, Cultural Turns: Neuorientierungen in den Kulturwissenschaften (Hamburg: Rowohlt, $\left.{ }^{6} 2014\right), 285$.

22 Bachmann-Medick, Cultural turns, 285-318.

23 Lefebvre, The Production of Space, 26-27.

24 Die Machtverhältnisse, aus denen Räume entstehen (Stadtplanung etc.), betonten vor allem die stark am Marxismus orientierten Raumtheoretiker wie Lefebvre.

25 Aktion und Handlungen von Menschen für die Bedeutung von Raumkonstitutionen betonte vor allem Martina Löw, „The Constitution of Space: The Structuration of Spaces Through the Simultaneity of Effect and Perception“, European Journal of Social Theory 11, no. 1 (2008): 25-49, 26-35.

26 Martina Löw, Raumsoziologie (Frankfurt am Main: Suhrkamp, 2015), 63-68. 
ähnelt jener zu Performativität. Auch für Performativität wird das Zusammenwirken von allen im Raum befindlichen Akteur*innen (auf Bühnensituationen bezogen Schauspieler ${ }^{\star}$ innen gemeinsam mit dem Publikum), den für die Handlung relevanten Dingen und dem Raum der Spielstätten konstatiert. ${ }^{27}$ Räumen werden also immer wieder bestimmte Werte oder Ereignisse und Erinnerungen zugeschrieben.

In Betreff der Überlagerung von Beziehungen und Bedeutungen an einer physischen Lokation hat die Forschung lange Ort und Raum unterschieden. Die lange proklamierte vermeintliche Opposition von Ort und Raum ergab sich aus zwei Lesarten: Für die eine bietet Ort die Grundlage, auf der sozialer Raum produziert wird. ${ }^{28}$ Lefebvre etwa konstatiert, „[e]very space is already in place before the appearance in it of actors [...]. ${ }^{29}$ Der Historiker und Soziologe Michel de Certeau unterscheidet den relational konstituierten Raum von dem Ort als seiner (physischen) Lagebestimmung. ${ }^{30}$ Dahingegen sind für die zweite Lesart Räume lediglich ein Behältnis, ${ }^{31}$ das durch Überlagerung mit Bedeutungen und Beziehungen zu einem relationalen Produkt - zum Ort - werden ( - Stichwort making a sense of place). ${ }^{32}$ Löw unterscheidet diese dichotome Kategorisierung als absolutistisches und relativistisches Raumverständnis. ${ }^{33}$

Das Verhältnis der Kategorien „Ort“ und „Raum“ zueinander ist ambivalent und nicht immer eindeutig. ${ }^{34}$ Obwohl Ort und Raum in vielen Auseinandersetzungen einander lange diametral gegenübergestellt worden sind, beziehen sich ihre Definitionen doch aufeinander. ${ }^{35}$ Etwa verschränkt der Humangeograph Yi-Fu Tuan die beiden Kategorien, wenn er darlegt, dass auch soziale Räume

27 Fischer-Lichte, Performativität, 10-16.

28 Das ist die von Lefebvre vorgeschlagene Lesart. Lefebvre, The Production of Space, 57.

29 Lefebvre, The Production of Space, 57.

30 Michel de Certeau, Praktiken im Raum, in: Jörf Dünne, Stephan Günzel (Hg.), Raumtheorie: Grundlagentexte aus Philosophie und Kulturwissenschaften (Frankfurt am Main: Suhrkamp, 2015), 343-353, hier 345-347. Für de Certeau waren die Begriffe „Ort“ und „Raum“ dennoch keine Gegensätze. Für ihn ist ein Raum sei ein „Ort, mit dem man etwas macht“ und „ein Geflecht von beweglichen Elementen“.

31 Löw, The Constitution of Space, 26.

32 Gerade die jüngere Literatur schließt sich dieser Interpretation des Verhältnisses von Ort zu Raum an. Barbara E. Mann, Space and Place, in: Laurence Roth, Nadia Valman (Hg.), The Routledge Handbook of Contemporary Jewish Cultures (London, New York: Rutgers University Press, 2015), 183-194. Arijit Sen, Lisa Silverman (Hg.), Making Place: Space and Embodiment in the City (Bloomington: Indiana University Press, 2014).

33 Löw, Raumsoziologie, 63-68.

34 Julia Brauch, Anna Lipphardt, Alexandra Nocke, Exploring Jewish Spaces: An Approach, in: dies. (Hg.), Jewish Topographies: Visions of Space, Traditions of Place (Burlington, Hampshire: Routledge, 2008), 1-26, hier 3-4.

35 Für die Soziologie etwa ist „Ort“ die in Zeit und Raum lokalisierte Kultur. Marcel Mauss, Sociologie et anthropologie (Paris: Presses Universitaires de France, 1966). Tuan in der Human- 
$\mathrm{zu}$ Orten werden, wenn „[...] we get to know [them] better and endow it with value. ${ }^{\text {"36 }}$ Löw betont, dass Ort und Raum einander nicht ausschließen, sondern einander gegenseitig bedingen. ${ }^{37}$ Das sieht die Literatur- und Kulturwissenschafterin Doris Bachmann-Medick als den produktiven Gedanken des spatial turns - nämlich gerade den Blick auf Räume als etwas Bewegliches, Gestaltbares und Dynamisches zu lenken. ${ }^{38}$

Die (sozialen) Produkte der Räume - Theaterstücke ebenso wie Interaktionen, Kontakte und Beziehungen in Spielstätten - stehen im Wechselspiel zu räumlichen Praktiken, Repräsentationen (von Räumen) und Repräsentiertem (repräsentierten Räumen). ${ }^{39}$ Durch ineinandergreifende Prozesse, für die der Raum physische Grundlage ist, erhält er neue Bedeutungen: Er ist ein gelebter Raum. ${ }^{40}$ Mit anderen Worten: Der physische Ort wirkt mit dem in ihm Repräsentierten und Gelebten zusammen (Denkmäler, Aufführungsstätten, Institutionen gleichermaßen wie Beziehungen, Interaktionen und Austausch). In der jeweiligen Komposition der Räume - in der Anordnung der zum Raum gehörenden Objekte und in den Rollen, die Akteur*innen einnehmen - spiegelt ein Raum die sozialen Prozesse seiner Konstitution wider. Der Raum ist somit immer auch Spiegel der Machtverhältnisse und der Beziehungen in ihm. ${ }^{41}$ All das muss bei einem Blick in die Räume populärer Kultur mitgedacht werden.

geographie betont dahingegen, dass Raum abstrakter sei als Ort. Denn, sich in Redewendungen wie „there is no place like home“ manifestierend, werde Ort gewissermaßen mit Sicherheit, Raum aber mit Freiheit gleichgesetzt und ermögliche dadurch erst die Ausgestaltung verschiedener Schaffensspielräume. Yi-Fu Tuan, Space and Place: The Perspective of Experience (Minneapolis: University of Minnesota Press, 2001), 1. „From the security and stability of place we are aware of the openness, freedom, and threat of space, and vice versa. Furthermore, if we think of space as that which allows movement, then place is pause; each pause in movement makes it possible for location to be transformed into place." Ibid., 6 .

36 Tuan Yi-Fu, Space and Place, 6.

37 Martina Löw, Gunter Weidenhaus, „Borders that relate: Conceptualizing Boundaries in Relational Spaces“, Current Sociology 65, no. 4 (2017): 553-570; Löw, Raumsoziologie, 67-68.

38 Bachmann-Medick, Cultural turns, 286, 290-295.

39 Bei Lefebvre spatial practices, representations of space und representational spaces. Lefebvre, The Production of Space, 38-39.

40 Löw, Raumsoziologie, 67.

41 Auf dieser Lesart von Räumen als gelebte Orte und soziale Produkte basiert Bourdieus Beschreibung soziologischer Felder. Für ihn produziert sich sozialer Raum immer in habitualisierten Praxisformen, die für ihn Spiegel der Hegemonien und Machtverhältnisse sind. Pierre Bourdieu, Soziologische Fragen: Über einige Eigenschaften von Feldern (Frankfurt am Main: Suhrkamp, 1993), 107-114; sowie Pierre Bourdieu, Sozialer Raum und „Klassen“, in: ders., Sozialer Raum und „Klassen“. 2 Vorlesungen (Frankfurt am Main: Suhrkamp, 1995), 7-46. 


\section{Jüdische Räume und Räume populärer Kultur}

Inwiefern können die Räume populärer Kultur als jüdische Räume verstanden werden? Die „Wende zum Raum“ kam in den Jüdischen Studien spät an. ${ }^{42}$ Bedingt durch Narrative, die sich mit Diaspora und der Geschichte, jüdischer Identitätsbildung' befassten, haben sich Fragen zu Jewish spaces lange auf Territorialität bezogen oder waren auf religiöse Aspekte fixiert. Das, so Barbara Mann, hänge damit zusammen, dass dem hebräischen Terminus makom (Ort) neben der Referenz auf physische Orte auch eine auf Gott innewohnt. ${ }^{43}$ Obwohl seit Jahrzehnten in den Jüdischen Studien Kultur auch abseits von Religion zum Forschungsgegenstand avanciert, hat das Wissenschaftsparadigma eine Wende hin zu einem breiteren Raumverständnis nur zäh vollzogen. ${ }^{44}$ Die Frage nach relationalen Räumen ist in den Jüdischen Studien, so Miriam Rürup und Simone Lässig, noch immer unterrepräsentiert. ${ }^{45}$ Die beiden Historikerinnen konstatieren, dass sich im Besonderen historische Forschungen innerhalb der

42 Seit den ausgehenden 1990er Jahren haben sich in den Jüdischen Studien verschiedene Forschungen mit Raum und Ort aus unterschiedlichen Perspektiven beschäftigt. Barbara E. Mann, Space and Place in Jewish Studies (Piscataway: Rutgers University Press, 2012), 2-3. Barbara Mann widmete den Referenzialitäten zu Gott und die Interdependenz zu den Kategorien Ort und Raum eine Monographie und einen Aufsatz im Routledge Handbook of Contemporary Jewish Cultures. Ibid., 11-15; Mann, Space and Place, 183-194. Julia Brauch und Anna Lipphardt bieten eine breite Übersicht über Konferenzen, die sich seit den 1990er Jahren dem spatial turn in den Jüdischen Studien verschrieben haben. Julia Brauch, Anna Lipphardt, Gelebte Räume - Neue Perspektiven auf jüdische Topographien, in: Petra Ernst, Gerald Lamprecht (Hg.), Jewish Spaces: Die Kategorie Raum im Kontext kultureller Identitäten (Schriften des Centrums für Jüdische Studien 17) (Innsbruck, Wien, Bozen: Studienverlag, 2010), 13-32, hier 19-22. Jüngst erschien ein von Miriam Rürup und Simone Lässig herausgegebener Sammelband zu „space und spatiality“ in der modernen deutsch-jüdischen Geschichte. Simone Lässig, Miriam Rürup (Hg.), Space and Spatiality in Modern German-Jewish History (New York: Berghahn, 2017) sowie eine Sondernummer des Journals Jewish Culture and History. Susanne Korbel, Lukas Nievoll, Thomas Stoppacher (Hg.), Rethinking Jewish and non-Jewish Relations, Jewish Culture and History 21, no. 1 (2020).

43 „Makom“, der hebräische Terminus für „Ort“, ist als eine Referenz auf Gott konnotiert: „Why is the Holy One, blessed be he, called makom? Because he is the place of the World." Genesis, Rabbah, 68, 8 .

44 Mann, Space and Place in Jewish Studies, 17-18. Beispiele für diese Wende waren etwa das Themenheft zu Historic Jewish Spaces in Central and East Europe 42 (2015). Siehe Erika Szívós, „Introduction: Historic Jewish Spaces in Central and Eastern European Cities“, East Central Europe 42 (2015): 139-162.

45 Simone Lässig, Miriam Rürup, Introduction: What Made a Space „Jewish“?: Reconsidering a Category of Modern German History, in: dies. (Hg.), Space and Spatiality in Modern GermanJewish History (New York: Berghahn, 2017), 1-20. 
Jüdischen Studien durch beinahe völlige Ignoranz gegenüber der Kategorie "Raum" abseits von Erinnerung auszeichnen. ${ }^{46}$

Im Folgenden seien einige konzeptionelle Annäherungen zu jüdischen Orten (Jewish places) und jüdischen Räumen (Jewish spaces) kurz vorgestellt: Für die Kulturwissenschafterinnen Julia Brauch, Anna Lipphardt und Alexandra Nocke sind Jewish places alles, was geographisch verortet und so einer bestimmten, irgendwie als jüdisch assoziierten Lage zugehörig ist. ${ }^{47}$ Jewish spaces definieren sie vor allem über Performanz. ${ }^{48}$ Wie Martina Löw in der allgemeinen Forschung zu Raum versuchen die Religionswissenschafterin Charlotte Elisheva Fonrobert und die Literaturwissenschafterin Vered Shemtov die vermeintliche Kluft zwischen den Kategorien Ort und Raum (place und space) in den Jüdischen Studien aufzuheben und fragen basierend auf Texten, die sie als Produktionsfläche von Politik und Gesellschaft voraussetzen, nach Konzeptionen von und Praktiken in Jewish spaces. ${ }^{49}$ Und auch Barbara Mann betont die Unhaltbarkeit der Binarität zwischen jüdischen Orten und Räumen am Verhältnis von makom zu Raum. ${ }^{50}$

Allen Definitionen von jüdischen Räumen und Orten gemeinsam ist ein Bezug zu Interaktion, Begegnung oder Austausch. ${ }^{51}$ In diesem Buch verstehe ich dementsprechend jüdische Räume als jüdisch-nichtjüdische Interaktionsräume, Begegnungsorte, Zonen des Austausches sowie gemeinsamer Anwesenheit. Ebenso verstehe ich jüdische Räume in einem kulturellen Verhandeln von ,Jüdisch-Sein sowie durch diskursive Referenzen. Entscheidend ist: $\mathrm{Ob}$ ein Raum als ,jüdischer Raum“ wahrgenommen wurde, war immer auch von den Rezipierenden abhängig, von zeitlicher Verfasstheit und Wahrnehmung. "Jüdische Räume“ meinen weder etwas Exklusives oder Partikuläres noch Essentialistisches.

Auf einer Wechselseitigkeit und Dynamik von Raum, Objekten und Akteurinnen aufbauend sind für mich in diesem Buch ,jüdische Räume“ populä-

46 Lässig, Rürup, Introduction, 8. Aus einer erinnerungshistorischen Perspektive setzte sich Lisa Silverman mit der Kategorie Raum und Jüdinnen und Juden in der Zwischenkriegszeit in Wien auseinander. Silverman, Jewish Memory, Jewish Geography.

47 Also eine der absolutistischen Raumtheorie zugeordnete Definition. Löw, Raumsoziologie, 63-65.

48 Brauch, Lipphardt, Nocke, Exploring Jewish Spaces, 4.

49 Ein Ansatz, der in engem Zusammenhang mit der kulturwissenschaftlichen Wende im linguistic und interpretive turn entwickelt und in der Erzählraumtheorie in den Literaturwissenschaften umgesetzt wurde. Charlotte Elisheva Fonrobert, Vered Shemtov, „Introduction: Jewish Conceptions and Practices of Space“, Jewish Social Studies 11, no.3 (2005), 1-8, hier 2. $\mathrm{Zu}$ interpretive und linguistic turn siehe Bachmann-Medick, Cultural Turns, 7-71.

50 Mann, Space and Place in Jewish Studies.

51 Joachim Schlör, „Auf der Suche nach dem Ort des Judentums“, Kritische Berichte 24, no.3 (1996): 6-12. 
rer Kultur Aufführungsstätten und auch Stücke und Lieder. Aufführungsräume werden wiederum determiniert vom Aufführungserlebnis, dem Aufgeführten, den Schauspieler ${ }^{\star}$ innen und Artist ${ }^{\star}$ innen, dem Publikum und allen anderen beteiligten Personen. Gleichermaßen konstituiert die Einbettung der Aufführungsstätten im Alltag den Raum mit. Das bedeutet auch, dass das Produkt als Ergebnis stetig neuer Konstellation und sozialer Interaktion - flüchtig ist. Jedoch lassen sich Eigenschaften benennen, die kontinuierlich wieder zur sich neukonstituierenden Raumerfahrung beitragen und diese mitbestimmen: das Miteinander-Kommunizieren während der Aufführungen an den Tischen vor und um die Bühnen, die Aufführungen selbst, deren Inhalte, das räumliche Arrangement der Bühne, des Zuschauerraumes und anderer Bereiche, die zu den jeweiligen Vergnügungseinrichtungen gehörten, sowie deren Einbettung in den Alltag. Konkret meint das, die Populärkultur hinsichtlich einer Aushandlung zwischen Ortsentwürfen, Raumkonstitutionen, Zwischen-, Austauschund Interaktionsräumen und der Übersetzung symbolischer (vermeintlicher) Grenzen zu untersuchen.

\subsection{Singspielhalle, Varieté und Etablissement in Wien, Budapest und New York}

In Wien, Budapest und New York entstand in den letzten Jahrzehnten des 19. Jahrhunderts eine Vielzahl neuer Bühnen. Mit ihnen breiteten sich auch neue Genres und Formen wie das Kabarett, die Stereoskopie und die Kinematographie aus. In den vormals als Spielstätten von Volkssänger*innen genutzten Räumen oder den Aufführungsstätten des „großen jiddischen Theaters“ entstanden Singspielhallen, Varietés und ab 1910 auch Rauchtheater - Varietés, in denen es erlaubt war, zu rauchen. Diese Entwicklung repräsentierte das Heranwachsen von Hauptstädten der Jahrhundertwende zu Metropolen des neuen Jahrtausends ebenso wie das Entstehen von Freizeit und urbanen Denkräumen im internationalen Licht.

\section{Wiener Spielstätten: Verortung populärer Kultur im Alttag}

Die Wiener Leopoldstadt - die sogenannte Mazzesinsel - war nicht nur jenes Viertel, in welchem besonders viele Jüdinnen und Juden (sowie Migrant ${ }^{\star}$ innen) lebten. Der zweite Wiener Gemeindebezirk mit dem Prater sowie der Prater- und Taborstraße als seinen Hauptstraßen galt als das Vergnügungsviertel schlechthin. Die Praterstraße war jene Straße, von der Joseph Roth schrieb: „Sie führt direkt ins Vergnügen. “52 In diesem Herzen des Vergnügens

52 Roth, Juden auf Wanderschaft, 62. 
lag Fürsts Singspielhalle, die erste Singspielhalle Wiens. Der Volkssänger Johann Fürst (1825-1882), der das vormalige Schreyersche Affentheater gekauft hatte und später auch das Theater in der Josefstadt leiten sollte, etablierte mit seiner Singspielhalle nahe des Nordbahnhofes eine erfolgreiche Bühne für Künstler*innen von nah und fern. ${ }^{53}$ Das Vergnügen lag aber nicht nur am Ende der Praterstraße, nämlich im Prater selbst; die Straße führte auch an vielen Räumen des Amüsements vorbei.

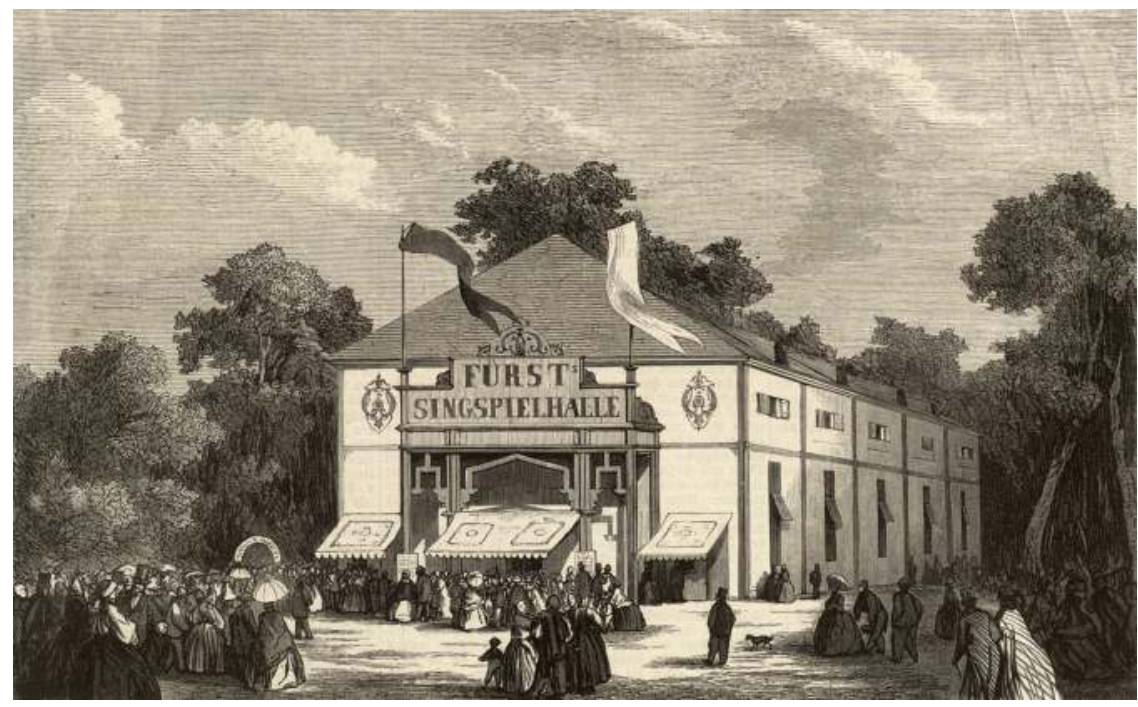

Abb. 5 Fürsts Singspielhalle im Wiener Prater, Xylografie nach einer Zeichnung von Leopold Müller um 1862, Bildarchiv Austria, Pk 2659

Mitten im Herzen der Leopoldstadt liegt der sogenannte Nestroyhof. Zur Jahrhundertwende war der Nestroyhof ein gewaltiger Gebäudekomplex: Ein Eckgebäude, das sich über einen Innenhof erstreckte und mehrere abgeteilte Gebäudebereiche, die von der Straße aus zugänglich waren, beherbergte. Diese Außenbereiche umgaben den im Inneren befindlichen Saal, der wiederum zu mehreren Nebenräumen führte. Der Nestroyhof beheimatete über die Jahre unter verschiedenen Namen konzessionierte Spielstätten und Ensembles - die Nestroysäle, die Folies Comiques, das Intime Theater und das Café Reklame. Das Gebäude beziehungsweise die zahlreichen Gruppen, die hier über die

53 WStLA, M.Abt. 104, A8/49 - Feuer- und Sicherheitspolizei: Theater, Lokale: Jantschtheater. Die Singspielhalle Fürst war unter verschiedensten Namen eingetragen, u. a. Jantschtheater, Fürsttheater, Singspielhalle Fürst und Lustspieltheater. Zu Fürst siehe Gunter Duriegl, Nini Lackner, Hans Pemmer, Der Prater einst und jetzt: Von den Anfängen bis zur Gegenwart (Wien: Jugend und Volk, 1974), 140-143. 
kommenden Jahre auftreten sollten, illustrieren die Schnelligkeit des Wandels der Etablissementkultur. Der Nestroyhof steht zudem paradigmatisch für die räumliche Ausgestaltung und die veränderte Nutzung von Räumen populärer Kultur und deren Einbettung im Alltag. ${ }^{54}$

Der Nestroyhof befindet sich in der Praterstraße 34, Ecke Czerningasse und Tempelgasse. Der Leopoldstädter Tempel, die größte Synagoge des zweiten Bezirks, grenzte unmittelbar an das Gebäude. Die erste „Bewilligung zur Benutzung der Parterre- und Souterrainrealitäten im Haus 2 Praterstraße $34 \mathrm{zu}$ Veranstaltungen verschiedener Unterhaltungen“ 1899 zeigt, wie sich die Aufführungen im Nestroyhof und die Gottesdienste in der Synagoge aufeinander bezogen, was vor allem auch deshalb spannend ist, weil der Leopoldstädter Tempel das orthodoxe Pendant zum Stadttempel war. Grundsätzlich stünde der Genehmigung einer Spielstätte im Nestroyhof nichts im Wege, wies die Baupolizei hin, allerdings durften „[...] insbesonders die im anstoßenden israelitischen Tempel stattfindenden Gottesdienste in keiner Weise durch Geräusch oder Lärm gestört werden ${ }^{\text {“ }}{ }^{55}$ Die erste Genehmigung, eine Spielstätte im Nestroyhof zu eröffnen erhielten 1899 die sogenannten Nestroysäle. Der Leiter, Emanuel Adler, war vor seiner Direktorenkarriere „Damenimitator“. Adler hatte Erfahrung als Schauspieler, jedoch fehlte ihm das unternehmerische Geschick. Nach zweimaligem Konkurs schlossen die Nestroysäle nach nur einjähriger Spielzeit bereits Ende 1900. Wenig später nutzte das Ensemble Folies Comiques die Räumlichkeiten weiter. ${ }^{56} 1905$ pachtete der Verein Intimes Theater, der seit 1904 bestanden und sich zuvor in anderen Lokalitäten eingemietet hatte, den Saal und eröffnete am 1. November 1905 das sogenannte Dilettantentheater. 1907 übernahm Emil Richter-Roland die Spielstätte unter dem Namen Varieté Reklame - diesen sollte die Bühne bis 1938 behalten. Die Nationalsozialist*innen mauerten unmittelbar nach dem „Anschluss“ die Eingangsportale zu, um schließlich den Aufführungen, die moderne Ansichten betreffend Sexualität darboten, ein Ende zu bereiten und den als ,jüdisches“ Theater bekannten Raum verschwinden zu lassen. ${ }^{57}$

54 Auf die Spielstätten im Nestroyhof wird unter verschiedensten Namen Bezug genommen. Immer noch unklar ist, wie viele verschiedene Etablissements tatsächlich im Laufe der Zeit hier geführt wurden, da zum einen die Adresse entweder die Czerningasse, die Praterstraße 34 oder der Nestroyplatz 1 (mit dem Kino später auch Tempelgasse) lautete, da die Anordnung von Lokalen und später einem Kino im Außenbereich mehrere parallele Nutzungen ermöglichte.

55 WStLA, M.Abt. 104, A8/49 - Feuer- und Sicherheitspolizei: Theater, Lokale: Varieté Reklame, Schreiben der Baupolizei an das Varieté Reklame 334278/1900 vom Jänner 1900.

56 Hödl, Zwischen Wienerlied und Der kleine Kohn, 52-54.

57 Franz Hadamowsky, Wien - Theatergeschichte: Von den Anfängen bis zum Ende des Ersten Weltkrieges (Wien: Jugend und Volk, 1988), 762-768. Als „Jüdische Künstlerspiele“ schlossen die Nationalsozialist ${ }^{\star}$ innen den Nestroyhof. Nachdem die Spielstätte in den 1950er Jahren 


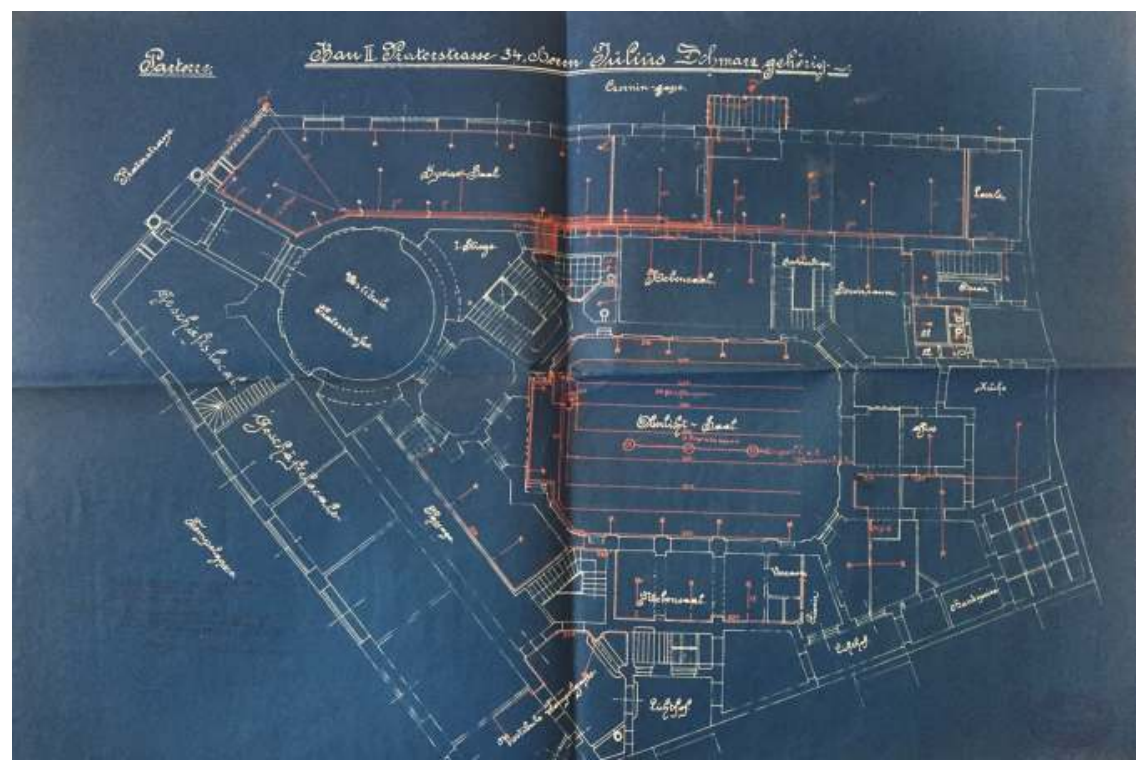

Abb. 6 Plan vom Nestroyhof, Wiener Stadt- und Landesarchiv, M.Abt. 104, A8/49 - Feuer- und Sicherheitspolizei: Theater, Lokale: Varieté Reklame, 1011/1934: Plan Praterstrasse 34

Beim Eintreten in den Gebäudekomplex beeindruckte das Entrée mit einer Glaskuppel, unter der hindurch sich den Besucher*innen der Weg in den Vorsaal bahnte. Durch ihn betraten sie den eigentlichen Spielsaal, von dem zwei, um die Jahrhundertwende als Küche und Servierraum genutzte, Nebenzimmer abgingen. Von da aus servierte die Varietébedienung Speisen und Getränke an die Tische. ${ }^{58}$ Am Theatersaal im Nestroyhof zeichnete sich eine für die Zeit typische Entwicklung zu kleineren Theatersälen ab: Im Gegensatz zu den bislang üblichen mehreren tausend Sitzen in Theatern wurde es nach und nach

kurzfristig wiedereröffnet hatte, geriet sie schließlich bis in die 1990er Jahre in Vergessenheit. Der Innenbereich des Gebäudekomplexes (eben der Saal) wurde zugemauert und fungierte als Lager. Seit der Wiedereröffnung fand eine rege Auseinandersetzung mit der Geschichte des Vergnügungsetablissements statt.

58 WStLA, M.Abt 104, A8/49 - Feuer- und Sicherheitspolizei: Theater, Lokale: Varieté Reklame, 1011/34: Plan Praterstraße 34. Hierbei handelt es sich um den Plan von ca. 1910, der 1934 für neue Deckeninstallationen eingereicht wurde. Das über viele Jahre in einen der Räume im Außenbereich untergebrachte Kino hieß ebenfalls Reklame. WStLA, M.Abt. 114, A1 Baupolizei: EZ - Reihe: Allgemeine baurechtliche Angelegenheiten: II. Bezirk - EZ 1375, Schreiben vom 20.1.1920. Die Betreiber*innen der Gastronomie wechselten hier regelmäßig und können aufgrund der überaus unvollständigen Überlieferung nur teilweise rekonstruiert werden. 1919 übernahm das Café im Außenbereich etwa Adolf Brett. WStLA, M.Abt. 114, A1 - Baupolizei: EZ - Reihe: Allgemeine baurechtliche Angelegenheiten, II. Bezirk - EZ 1375, Schreiben Adolf Brett an den Magistrat vom 27.12.1919. 
beliebter, ein kleines Publikum zu unterhalten. Weniger Zuseher*innen, dafür aber „intimere“ Erfahrungen während der Aufführungen galten als das angestrebte Ideal, das schließlich auch dem ,intimen Theater" seinen Namen geben sollte..$^{59}$

\section{Intime Erfahrungen in der populären Kultur}

Dieser neuen Form intimer Theatererfahrung widmete der ungarisch-jüdische Philosoph György Lukacs (1885-1971) 1909 einen Aufsatz. ${ }^{60}$ In der Auseinandersetzung mit der Soziologie moderner Dramaturgie bezog Lukacs die Entwicklung des „intimen Theaters“ auf die Debatte um Populärkultur und ihre räumliche Ausgestaltung. Das Bestreben des ,intimen Theaters“ bestand nach Lukacs darin, den „primitiven, unintellektuellen Massencharakter des Theaters" zu überkommen - inhaltlich wie räumlich. ${ }^{61}$ Aus der Perspektive dieses Anspruches passte sich das Intime Theater in Wien ideal in die Räumlichkeiten des Nestroyhofs ein. Die Aufführungsstätte im Nestroyhof durfte um 1900 insgesamt nicht mehr als 400 Personen aufnehmen, davon höchstens 200 Personen im Aufführungssaal. ${ }^{62}$ Eine Loge kostete nachmittags 12 Kronen und 60 Heller und abends rund 20 Kronen, der günstigste Platz am Balkon war tagsüber für 80 Heller und abends für eine Krone erhältlich. ${ }^{63}$ Der Überschaubarkeit des Aufführungsraumes wegen denunzierten die Wiener Caricaturen das Intime Theater als „billiges kleines Heim“.64

Das Intime Theater spielte ein breites Repertoire. Mit dem Anspruch, gehobene Klassiker in neuer Inszenierung auf die Bühne zu bringen, standen sehr bekannte Werke jüdischer und nichtjüdischer Autorinnen auf dem Programm. Für eine Aufführung 1908 reichte der damalige Direktor des Intimen Theaters,

59 Diese Form des Theaters etablierte sich um die Jahrhundertwende in Europa. Wien kam in dieser Entwicklung eine gewisse Vorreiterrolle zu. Einerseits bezieht sich die Bezeichnung „intim“ auf den kleineren Raum, andererseits auf die Aufführungen. Annette Delius, Intimes Theater: Untersuchungen zu Programmatik und Dramaturgie einer bevorzugten Theaterform der Jahrhundertwende (Kronberg: Scriptor, 1976), 7-10.

601909 verfasste Lukacs diesen Aufsatz als Einführungskapitel zu seinem Buch A modern dráma fejlödésének története, das 1912 in Budapest erschien. Als deutschsprachiger Aufsatz wurde die Schrift 1914 im Archiv für Sozialwissenschaft und Sozialpolitik verlegt.

61 Georg Lukacs, Schriften zur Literatursoziologie: Ausgewählt und eingeleitet von Ludz Peter (Neuwied: H. Luchterhand, 1961),273.

62 WStLA, M.Abt. 104, A8/49 - Feuer- und Sicherheitspolizei: Theater, Lokale: Varieté Reklame, Schreiben der Baupolizei an das Varieté Réclame 334278/1900.

63 Lehmann, Wiener Theater- und Konzertsäle (1911), 35. Die Bedeutung der Sitzarrangements und intimer Erfahrung in Aufführungen und wie sich das in der räumlichen Entwicklung in Salons und Clubs in Harlem (Stadtteil von New York) ab den 1910er Jahren widerspiegelte, beschreibt Shane Vogel. Vogel, The Scene of Harlem Cabaret, 65-73.

64 Wiener Caricaturen, 10.12.1911, 6. 
Emil Roland-Richter, ${ }^{65}$ eines der bedeutendsten Stücke der Aufklärung ein: Gotthold Ephraim Lessings Die Juden sollte am 29. November 1908 in der Praterstraße $34 \mathrm{zu}$ sehen sein. ${ }^{66}$ Lessings Die Juden handelt vom Überfall auf einen Reisenden. Bei den Bestrebungen, den genauen Tathergang zu rekonstruieren, tauchen starke antisemitische Abwertungen auf. Dem Reisenden kommt hierbei eine Mittlerrolle zu. Geschickt führt er die Abwertungen ad absurdum und versucht so Sensibilität für die Falschheit der ohne weiteres angeführten Vorurteile zu schaffen. Das gelingt dadurch, dass das Stück das moralisch verwerfliche Verhalten klar darlegt, was im Ambiente des Intimen Theaters besonders gut inszeniert werden konnte. In der Inszenierung im Intimen Theater waren Psyche und Sexualität zentrale Themen, die im besonders gemütlich und privat gestalteten Publikumsraum pointiert diskutiert werden konnten. Es traten hier Mitglieder vieler bekannter Ensembles auf. ${ }^{67}$ Die Eröffnung als Dilettantentheater 1905 ermöglichte aber auch Amateur ${ }^{*}$ innen, bei den Aufführungen mitzuwirken. ${ }^{68}$

Dass diese kleineren Spielstätten „intimere Erfahrungen“ - intensivere Kontakte, das Ansprechen prekärer Themen wie Geschlechternormen und sexuelle Begierden - zuließen und sich deshalb immer größerer Beliebtheit erfreuten, brachte ihnen verschiedene bürokratische Restriktionen ein. Die kleineren, „intimeren“ Spielstätten mussten vielfach mit härteren Vorschriften, was Kostümierung und Dekoration betraf, zurechtkommen. Das Argument der feuerpolizeilichen Sicherheit vorgeschoben, wurden auf diese Weise nichtstaatlich subventionierte Theater häufig zu benachteiligen versucht. Während die großen Theater meist nur monatlich kontrolliert wurden, sahen Beamte in den Etablissements mehrmals wöchentlich nach dem Rechten. Lokalaugenscheine beanstandeten dann regelmäßig die mangelnde Umsetzung der Sicherheitsbestimmungen: Nach dem Ringtheaterbrand von 1881, einer der größten Brandkatastrophen des 19. Jahrhunderts in der Habsburgermonarchie, mussten Etablissements um die Jahrhundertwende die Gasbeleuchtungen regelmäßig warten und von Rauchfangkehrbetrieben überwachen lassen. ${ }^{69}$

65 Emil Roland-Richter betrieb später auch die Rolandbühne gegenüber.

66 NÖLA, NÖ Reg. Präs. Theater TB - Textbücher der Theaterzensur TB K 655/13, Intimes Theater 1908, Lessing, Die Juden.

67 Zum Beispiel Alfred Spitzer.

68 Die Theaterordnung von 1850 sah für alle Spielstätten, die nicht als Dilettantenbühnen kategorisiert waren, vor, dass die Auftretenden professionelle Schauspieler*innen, Gesangsartist*innen etc. sein mussten. Allgemeines Reichs-Gesetz- und Regierungsblatt für das Kaiserthum Österreich 1849-1852, RGBl. 454/1850, Verordnung des Ministeriums des Inneren vom 25. November 1850, hier 1976.

69 Vergleiche etwa den Spielstättenbericht zum Hotel Stefanie in Wien, in dem die Budapester Orpheumgesellschaft um 1900 spielte. WStLA, M.Abt. 258, A1/3 - Technische Sicherheitsund Vergnügungsangelegenheiten: Theaterakten: Budapester Orpheum 3184/1911, 24.8.1911. 
Die Dekoration war regelmäßig zu imprägnieren, was penibel genau mittels sogenannter „Kerzenproben“ überprüft wurde. ${ }^{70}$ Bei Überprüfungen setzte die Feuerpolizei Probestücke den Öllampen aus. 1910 beispielsweise wurde die Dekoration der Budapester Oprheumgesellschaft durch diese Überprüfung beanstandet: „Bei der am 7. Oktober 1910 vorgenommenen Untersuchung der Imprägnierung der Dekoration im Budapester Orpheum, Wien, II. Taborstrasse 8 erwiesen sich 10 der einer Oellampe ausgesetzte[n] Probestücke fünf nicht als flammensicher. ${ }^{\text {"71 }}$ Zudem gab es generelle Bestimmungen wie vorgeschriebene Rettungskästen $^{72}$ oder die Auflage, dass vor jeder Saison der Dachstuhl und die Tramkonstruktionen einer Sicherheitswartung unterzogen werden mussten. ${ }^{73}$

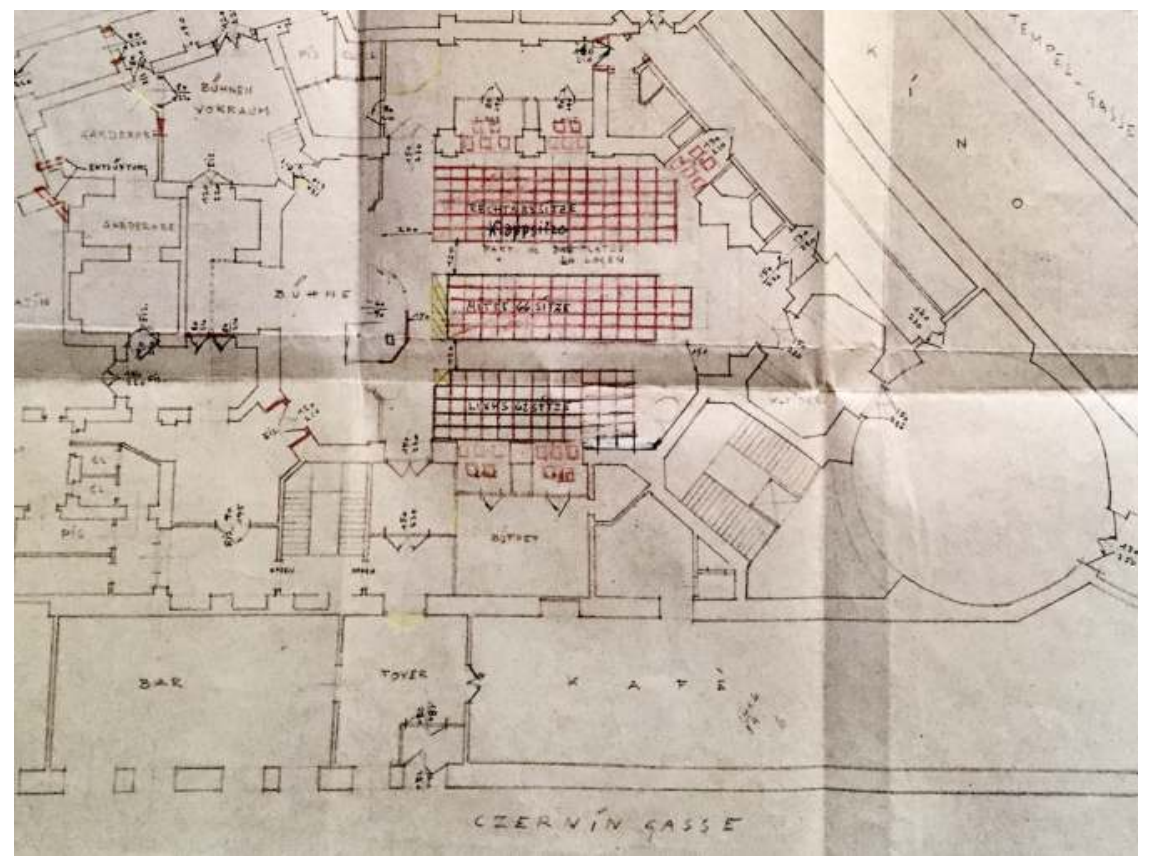

Abb. 7 Plan vom Publikumsraum des Nestroyhofes um 1920, HaMakom, WStLA, M.Abt. 114, A1 - Baupolizei: EZ - Reihe: Allgemeine baurechtliche Angelegenheiten: II. Bezirk - EZ 1375, Kino Praterstraße 34

70 WStLA, M.Abt. 258, A1/3 - Technische Sicherheits- und Vergnügungsangelegenheiten: Theaterakten: Budapester Orpheum, 3320/1910, Schreiben vom 1.9.1910.

71 WStLA, M.Abt. 258, A1/3 - Technische Sicherheits- und Vergnügungsangelegenheiten: Theaterakten: Budapester Orpheum, 3756/1910, Schreiben vom 12.10.1910.

72 WStLA, M.Abt. 258, A1/3 - Technische Sicherheits- und Vergnügungsangelegenheiten: Theaterakten: Budapester Orpheum, 230/1908, Schreiben vom 22.1.1908.

73 WStLA, M.Abt. 258, A1/3 - Technische Sicherheits- und Vergnügungsangelegenheiten: Theaterakten: Budapester Orpheum, Schreiben vom 21.9.1910. 
Der Blick in den Publikumsraum zeigt, dass das Sitzarrangement um die Bühne zu einer gesprächigen Atmosphäre einlud. Als besonderer Teil des Alltags konnte vor oder nach dem Theaterbesuch in den von der Straße aus zugänglichen Geschäften im Gebäudekomplex eingekauft oder in den Kaffeehäusern und Lokalen verweilt werden. Außen untergebracht waren Geschäftslokale, wie Birnmanns Bankinstitut, das von Ernestine Klein geführte Café Nestroyhof, ${ }^{74}$ in dem sich um 1900 Mittwochvormittags der „literarisch-wissenschaftliche Verein Kosmos" traf, ${ }^{75}$ Gottfried Weiss Tanzlehranstalt, ein Restaurantbereich und eine Bar. ${ }^{76}$ Im Leopoldstädter Tempel nebenan konnte der Gottesdienst besucht werden. Nicht nur verschiedene Bereiche alltäglichen Lebens gingen in den Räumlichkeiten rund um das Varieté im Nestroyhof ineinander über, sondern es fanden auch verschiedene Formen populärer Unterhaltung unter einem Dach Platz. Ab den 1920er Jahren ersetzte das Kinematographentheater Nestroy-Bio einen Teil der Geschäfte. Der Nestroyhof war fortan intimes und kinematographisches Theater - eine Entwicklung, die er mit vielen anderen Varietés teilte. $^{77}$

Nur unweit des Nestroyhofs, auf der zweiten „Vergnügungsstraße“ Wiens, der Taborstraße, war die Budapester Orpheumsgesellschaft, eine weitere der bekanntesten Varietéadressen Wiens, untergebracht. Zu Beginn ihres Bestehens quartierte sich die Budapester Orpheumgesellschaft im Hotel Stefanie ein. ${ }^{78}$

74 Ernestine Klein hatte das Café Nestroyhof inne, bis sie im Jänner 1905 Konkurs anmelden musste.

75 Vereinskalender, NWT, zum Beispiel 18.12.1901, 34.

76 WStLA, M.Abt 104, A8/49 - Feuer- und Sicherheitspolizei: Theater, Lokale: Varieté Reklame, 1011/34: Plan Praterstraße 34. Hierbei handelt es sich um den Plan von ca. 1910, der 1934 für neue Deckeninstallationen eingereicht wurde. Das über viele Jahre in einen der Räume im Außenbereich untergebrachte Kino hieß ebenfalls Reklame. WStLA, M.Abt. 114, A1 Baupolizei: EZ - Reihe: Allgemeine baurechtliche Angelegenheiten: II. Bezirk - EZ 1375, Schreiben vom 20.1.1920. Die Betreiber*innen der Gastronomie wechselten hier regelmäßig und können aufgrund der überaus unvollständigen Überlieferung nur teilweise rekonstruiert werden. 1919 übernahm das Café im Außenbereich Adolf Brett WStLA, M.Abt. 114, A1 Baupolizei: EZ - Reihe: Allgemeine baurechtliche Angelegenheiten, II. Bezirk - EZ 1375, Schreiben Adolf Brett an den Magistrat vom 27.12.1919.

77 Im vormals als Geschäftslokal genutzten Außenraum betrieb Eleonora Dieckler in den 1920er Jahren das Kinematographentheater Nestroy-Bio. WStLA, M.Abt. 114, A1 - Baupolizei: EZ Reihe: Allgemeine baurechtliche Angelegenheiten: II. Bezirk - EZ 1375, Kino Praterstraße 34, Schreiben vom 7.3.1924. WStLA, M.Abt. 114, A1 - Baupolizei: EZ - Reihe: Allgemeine baurechtliche Angelegenheiten: II. Bezirk - EZ 1375, Kino Praterstraße 34, Plan Nestroy Kino, Mai 1927.

78 Über die Budapester Orpheumgesellschaft gab Georg Wacks eine Monographie heraus, in der er die Geschichte der Gruppe gelungen aufarbeitete. Wacks, Die Budapester Orpheumgesellschaft (Wien: Holzhausen, 2002). Ebenfalls wurde das Ensemble in der Ausstellung „Alle meschugge?“” 2013 im jüdischen Museum in Wien berücksichtigt. Marcus P. Patka, Die 
Konzessioniert für Matthias Bernhard Lautzky (1819-1901) und später seinen Neffen, Carl Lechner, war das Ensemble eines der Herzstücke der Wiener Etablissementkultur. ${ }^{79}$ Die Budapester Orpheumgesellschaft war das bekannteste jüdische Volkssängerensemble. ${ }^{80}$ Hier, „,[b]ei Papa Lautzky in der Budapester Orfeum-Gesellschaft[!]“, so die Internationale Artisten Revue, „versammelt sich täglich die elegante Welt von Wien, um das Programm, welches an Gediegenheit nichts zu wünschen übrig lässt, durchzukosten. ${ }^{\text {"81 }}$ Lautzky, der Direktor des Ensembles, war ein bekannter Wiener Volkssänger und Singspielhallenkonzessionär. Er galt als unangefochtener „König“ unter den Theaterdirektoren. Mit seinem „Direktionszepter“ führte er große Etablissements zu den beachtlichsten Erfolgen, würdigte ihn zu seinem 75. Geburtstag 1894 die Internationale Artisten Revue. ${ }^{82}$ M. B. Lautzky, wie ihn seine Gäste nannten, kam zu einer derartigen Würdigung nicht zuletzt durch die künstlerische Brillanz der Budapester Orpheumgesellschaft.

"Gefunden" hatte Lautzky sein Budapester Orpheum auf einer Reise im Frühjahr 1889. Er machte sich von Wien nach Budapest auf, um Ausschau nach geeigneten Talenten für eine neue Gruppe zu halten. Es war ein offenes Geheimnis, dass in der Habsburgermetropole weiter flussabwärts die Varietészene blühte. Wegen des regen Austausches zwischen den beiden Städten hoffte er, bald eine vielversprechende Gruppe zusammenstellen zu können, was ihm auch tatsächlich gelang. In Budapest traf Lautzky alsbald auf den populären Wiener Komiker Josef Modl (1863-1915), der dort zu diesem Zeitpunkt Mitglied von Somossys Orpheum war. „Dem Muthigen gehört die Welt“, soll er sich gedacht, dem Plan Lautzkys eingewilligt und fortan die artistische Leitung übernommen haben. ${ }^{83}$ Noch vor Saisonende 1889 hatte Lautzky mit Hilfe seines Agenten und Impressarios Freiwirth in Budapest auch weitere geeignete Talente gefunden und das neue Ensemble war gegründet. ${ }^{84}$

Budapester Orpheumgesellschaft, in: ders., Alfred Stalzer (Hg.), Alle meschugge? Jüdischer Witz und Humor (Wien: Jüdisches Museum Wien, 2013), 84-89.

79 Zur Beschreibung als Stefanien-Teater siehe Alweltlikher idishn kultur-kongres, Idisher teater in aeirupe zwishn beide welt-malkhmot, 242. Zum jiddischen Theater in Wien Brigitte Dalinger, „Verloschene Sterne“: Geschichte des jüdischen Theaters in Wien (Wien: Picus, 1998),46-64.

80 Hödl, Zwischen Wienerlied und Der kleine Kohn, 73.

81 IAR, 10.10.1893, 5.

82 Lautzky stand als Spielstättenleiter auch lange dem Kaffeehaus im Prater und Münstedts Centralhalle vor. IAR, 1.11.1894, 2.

83 Der Humorist, 5.7.1889, 5.

84 Der Name der Gruppe variierte zwischenzeitlichig immer wieder; auch spalteten sich gelegentlich Subgruppen (zwischenzeitlich) ab. 1896 existierten beispielsweise zwei getrennte Ensembles, die beide aus der Budapester Orpheumgesellschaft hervorgingen und über einige 
Das neu zusammengestellte Ensemble erprobte sein Programm vorerst in der ungarischen Hauptstadt, ehe es für ein "Sommergastspiel“ nach Wien reiste. Schnell hatte sich die junge Gruppe einen angesehenen Namen gemacht. Noch im Juli 1889 mussten die Kritiken „[...] offen gestehen, die Gesellschaft ist nach jeder Richtung hin, sowohl bezüglich ihrer Zusammensetzung, als auch hinsichtlich der Impresari, eine so vortreffliche, daß sie wirklich aller Anerkennung würdig ist.“ Und explizit verwies die Kritik: „Und dabei kommt diese Spezialitäten-Gesellschaft auch zu gelegener Zeit. “85 Besonders günstig war der Zeitpunkt, weil über die Sommermonate alle übrigen Theater und Spielstätten geschlossen und die anderen Gruppen auf Tournee waren. ${ }^{86}$ Ein Jahr später sollte die Budapester Orpheumgesellschaft schließlich dauerhaft in Wien sesshaft werden. Künftig reiste sie dann von dort aus nach Budapest für Sommergastspiele. ${ }^{87}$ Ab 1896 war das Hotel Stefanie in der Taborstraße 12 die feste Spieladresse der Budapester. ${ }^{88}$ Nach Streitigkeiten und einer internen Abspaltung eines Teils des Ensembles zog Lautzky und mit ihm die Konzession 1903 ein paar Häuser weiter ins Hotel Central in der Taborstraße $8{ }^{89}$ Das Hotel Central bot der Budapester Orpheumgesellschaft einen mittelgroßen Spielsaal in guter Lage. Je nach Arrangement der Tische standen 450 bis 780 Plätze zur Verfügung. ${ }^{90}$ Die Stühle konnten in Reihen oder zu Tischgruppen arrangiert werden. Für die Verpflegung während der Aufführungen war durch die im Haus befindliche Hotelküche gesorgt.

\section{Räumliche Überschreibung}

Die Bühne des Hotel Stefanie, die die Budapester Orpheumgesellschaft zwischen 1896 und 1903 bespielte, war auch in der jiddischen Theaterszene bekannt. Auch die Jüdische Bühne trat immer wieder im Hotel Stefanie auf. ${ }^{91}$ Auf der Jüdischen Bühne in Wien kamen weltbekannte Stars der jiddischen Theaterszene

Monate parallel auftraten, ehe sie sich wieder zusammentaten. Siehe hierzu Wacks, Budapester, 101-105.

85 Der Humorist, 5.7.1889, 5.

86 Der Humorist, 5.7.1889, 5.

87 Wacks, Budapester, 1-9.

88 Wacks, Budapester, 1-9. WStLA, M.Abt. 104, A8/5, Feuer- und Sicherheitspolizei: Theater, Lokale: Budapester Orpheum.

89 WStLA, M.Abt. 104, A8/5 - Feuer- und Sicherheitspolizei: Theater, Lokale: Budapester Orpheum, 2339/1903, Schreiben vom 24.8.1903.

90 WStLA, M.Abt. 104, A8/5 - Feuer- und Sicherheitspolizei: Theater, Lokale: Budapester Orpheum, Plan Tische und Logen Einteilung. WStLA, M.Abt. 258, A1/3 - Technische Sicherheitsund Vergnügungsangelegenheiten: Theaterakten: Budapester Orpheum, 376/1915, Schreiben von 21.11.1914.

91 Alweltlikher idishn kultur-kongres, Idisher teater in aeirupe zwishn beide welt-malkhmot, 242. 
wie Moshe Hurwitz (1864-1910) oder Ida Kaminska (1899-1980) zusammen. Hurwitz war für die Karriere als Schauspieler aus seiner Geburtsstadt in Galizien emigriert und setzte nach Auftritten in den Metropolen der Monarchie Mitte der 1880er Jahre seinen Weg nach New York fort. In New York leitete er das Windsor Theatre, eines der vier großen jiddischen Theater an der Bowery. ${ }^{92}$ Ida Kaminska wiederum ging den umgekehrten Weg. Die amerikanische Filmikone war die Tochter von der mit der Vilna Trupe (jiddisch Wilna Gruppe) weltbekannt gewordenen Schauspielerin Ester Rokhl Kaminska (1870-1925), die drei Jahrzehnte zuvor mit dem jiddischen Theater von Galizien nach Amerika gekommen war. Ida Kaminska ging dann zurück nach Europa, um dort die Szene zu beleben. ${ }^{93}$

Dass die Räume populärer Kultur Gleichzeitigkeiten ermöglichten, zeigt die Erinnerung an die Spielstätte im Hotel Stefanie in einer Studie vom Alweltliken Idishen Kultur-Kongress (Allweltlichen Jiddischen Kultur-Kongress). Diese Studie beschrieb das Hotel Stefanie als Heim des jiddischen Theaters in Wien: „Das hiesige Stefanien-Theater ist über viele Jahre das ständige Heim von einer großen Zahl jiddischer Akteure und Akteurinnen gewesen, für heimische und für die aus der Fremde, die in verschiedenen jiddischen Theatern der Welt später berühmt werden sollten. "94 Während der Großteil des Publikums der Budapester Orpheumgesellschaft den Raum keineswegs als jiddisches Theater wahrnahm, sondern manchmal sogar als antisemitisches Theater auslegte, ${ }^{95}$ existierte parallel dazu der Raum als Spielstätte der Jüdischen Bühne. Es überlagerten sich folglich mehrere Raumvorstellungen über populäre Unterhaltung im Hotel Stefanie (welche weiteren Raumvorstellungen noch durch die Interpretation der Inhalte hinzukamen, ist Teil des fünften Kapitels). Jedenfalls illustriert die mehrfach variierende Nutzung der Räume deren Wahrnehmungen und zusätzlich die individuellen Lesarten dessen, was in diesen Räumen zur Darbietung kam. Eine paradoxe räumliche Gleichzeitigkeit, die sich auch bei

92 Judith Thissen, Early Yiddish Vaudeville in New York City, in: Edna Nahson (Hg.), New York's Yiddish Theater: From Bowery to Broadway (New York: Columbia University Press, 2016), 248-254, 250. Zu Hurwitz in Wien siehe Dalinger, Verloschene Sterne, 38. Zur Funktion der Wiener Bühnen als Sprungbrett in die Welt des jiddischen Theaters siehe auch Eva Krivanec, „Sammelbecken und Sprungbrett: Die Freie jüdische Volksbühne in Wien - Lebenswege ihrer ProtagonistInnen zwischen Theater und Film, zwischen Europa und Übersee“, Transversal 8, no.2 (2007): 37-50, 40-44.

93 Dalinger, Verloschene Sterne, 48. Der Nachlass von Ida Kaminska befindet sich im YIVO. YIVO, RG 994: Ida Kaminska and Meir Melman. Siehe auch Mirosława M. Bułat, KaminskiTheater, in: Dan Diner (Hg.), Enzyklopädie jüdischer Geschichte und Kultur 3 (Stuttgart, Weimar: Metzler, 2012), 313-316. Der Nachlass von Ester Rohkel Kaminska bildete eine der ersten Sammlungen des YIVO (YIVO, RG 8: Ester Rohkel Kaminska).

94 Alweltlike Idishe Kultur-Kongress, Jidisher teater, 242.

95 Etwa Jüdische Volksstimme, 15.6.1906, 5-6. Siehe hierzu in Kapitel 5. 
anderen Spielstätten erkennen lässt: Im Nestroyhof befanden sich die Nestroysäle, das Varieté Reklame, die Dilettanten und das Intime Theater. Das Intime Theater spielte außerdem in der Praterstraße 25, in jener Adresse, die später als Rolandbühne eröffnete. Die Gruppe von Richter-Roland wechselte temporär immer wieder in den Spielsaal der Taborstraße 8 (wo auch die Budapester einst eingemietet waren) und die Jüdische Bühne wechselte wiederum für Gastspiele in die Praterstraße 25. Im Rahmen eines solchen Gastspiels traten unter anderem die weltberühmte, amerikanische Schauspielerin Molly Picon (1898-1992) und ihr Mann Jacob Kalich (1891-1975) 1921 auf der Rolandbühne auf, was schließlich auch der Rolandbühne den Ruf als jiddisches Theater einbrachte. ${ }^{96}$

Die Mannigfaltigkeit der Spielstätten, Truppen und Protagonist ${ }^{\star}$ innen, die auf ihren Tourneen in die Stadt kamen, erzeugte den Eindruck, dass Wien als ,überschwemmt" von dem "ganzen Tingel-Tangel“ - gemeint sind die Etablissements und Vergnügungseinrichtungen - bezeichnet wurde.

Ganz Wien war plötzlich überschwemmt von derlei Talmi-Kunst-Instituten, und eine Armee von englischen, spanischen, französischen, amerikanischen und afrikanischen zigeunernden ,Artisten' und marodierenden Athleten ähnlichen Virtuosen, eine Legion von singenden, pironettirenden, balancirenden, musicirenden, kugelwerfenden und schlittschuhlaufenden Künstlerinnen (sämtliche laut Programm ,Sterne erster Größe ), erschien als jüngste Invasion.[! ${ }^{97}$

Immer wieder fanden sich die Ensembles in anderen Zusammensetzungen und suchten neue Bühnen für ihre Darbietungen. Eine Folge der „Überschwemmung“ mit den „Tingel-Tangeln“ war, dass sich die Suche nach einem passenden Soiréelokal nicht immer einfach gestaltete. Die Inhaberinnen von Gaststätten konnten es sich aufgrund der großen Nachfrage nach Spielstätten leicht leisten, kleinen und unbekannten Ensembles ihre Räumlichkeiten vorzuenthalten, und so bekamen die Gruppen von den „kleinsten Beiseln“ Absagen, mit der Begründung, dass diese für „derartige Produktionen“ ihre Räume nicht zur Verfügung stellen würden..$^{98}$ Über die Sommermonate allerdings - wenn sich die Stadtbevölkerung auf Sommerfrische ${ }^{99}$ begab oder vorzugsweise die Heurigen in den

96 IKZ, 21.10.1921, 7 sowie 14.12.1921, 5. Zu Molly Picon siehe außerdem Gender-Bending in Kapitel 4.

97 Friedrich Schlögl, Wienerisches: Kleine Culturbilder aus dem Volksleben der alten Kaiserstadt an der Donau (Wien, Teschen: Prochaska, 1883), 228.

98 IAR, 20.11.1893, 1-2.

99 Nicht nur die Gäste, sondern auch die Auftretenden wanderten mit in die Sommerfrische-Orte. Iris Fink, Roland Knie, Überlandpartie! Kabarett auf Sommerfrische (Wien, Köln, Weimar: Böhlau, 2018). 
Wiener Weinbergen frequentierte - standen die meisten (überdachten) Spielstätten leer. „[D]ie renommierten Ensemble waren auf Gastspieltouren[...] “"100 oder gastierten in „Sommer-Etablissements“ im Prater.

\section{Freiheit von Nation, Konzession und Konfession in den Budapester Etablissements}

Eine andere Form der Überschreibung von Räumen beziehungsweise der Praxis räumlicher Gleichzeitigkeit beschreibt Mary Gluck mit der Metapher Invisible Jewish Budapest. Gluck meint damit die relative Unsichtbarkeit von Jüdinnen und Juden in der Donaumetropole. Obwohl Budapest um 1900 die zweitgrößte jüdische Gemeinde Europas war, seien Jüdinnen und Juden in der Metropole nicht sichtbar gewesen. Die Populärkultur in Budapest konstituierten Jüdinnen und Juden zu einem wesentlichen Teil - sie sei deshalb, so Gluck, das Sichtfenster in das „unsichtbare jüdische Budapest" gewesen. ${ }^{101}$

Die Internationale Artisten Revue verzeichnete für 1891 in Budapest neun „Varieté-Bühnen und Konzert-Etablissements“: Somossys Orpheum, Herzmanns Orpheum, Folies Caprice, Etablissement Armin, Blaue Katze, Café Imperial, Café Tarcianu, Hókóm Theater und Fischs Varieté. ${ }^{102}$ Zudem listete das Fachorgan elf reisende ungarische „Gesellschaften“: „Barokáldi, Budapest. Dubsky Babtist, Vörösvár. Enders Josef, Temesvár. Hadji, Ungarn. Nagy János, Ungarn. Reich, Ungarn. Stöckel, Ungarn. Siaoli Wittwe, Ungarn. Wollner Franz, Ödenurg. Wollner E.H.M., Vósárhely. Winkler Hugo, Ungarn. “103 Unter „Agenturen", worunter das Blatt auch etwa Ausstellungsspediteure und andere für das Artistenwesen wichtige Sparten subsumierte, listete es sieben: „Henry Huline. Rrd. Wildmann. - M. Bátori. - F. Steiner. - J. Ziegler. - J. Schwarz. - E. Wetzler. Spediteur für Aussteller. “104 Zehn Jahre später hatte sich die Zahl beinahe verdoppelt. ${ }^{105}$ Die populäre Kultur in der ungarischen Hauptstadt blühte. Während Wien schlief, amüsierte man sich in Budapest, so eine viel zitierte Phrase aus den „Zechenführern“ und den Tageszeitungen, die über das rege Amüsement berichteten. ${ }^{106}$ Dieser Teil Budapests, die Etablissementkultur, stand für den Journalisten Adolf Ágai stellvertretend für den Wandel der Stadt von Pest zu

\footnotetext{
100 Der Humorist, 5.7.1893, 5.

101 Gluck, Invisible Jewish Budapest, 3. Gluck, The Budapest Flâneur: 4.

102 IAR, 8.11.1891, 4.

103 IAR, 8.11.1891, 5.

104 IAR, 8.11.1891, 5.

105 Die Internationale Artisten Revue listete in jeder Ausgabe eine aktuelle Liste von Etablissements, Agenturen sowie Künstler*innen, mit denen sie in Korrespondenz stand.

106 Gluck, The Invisible Jewish Budapest, 141.
} 
Budapest. ${ }^{107}$ Und auch Mary Gluck konstatiert: „The music hall stage was the public forum where the transformative energies of metropolitan life were crystallized, performed, and made visible to a newly constituted urban public. “108

\section{Die Expansion der Budapester Singspielhallen}

Obwohl sich mehrere Spielstätten in Budapest rühmten, das erste Orpheum Budapests zu sein, gebührte diese Ehre der Blauen Katze in der Pester Kaisergasse und den Folies Caprices in der Kerepesi út 21. Mit ihnen hielt die Etablissementkultur in Budapest Einzug und mit ihnen wandelten sich vormalige Gaststätten in Varietés und Räume des Amüsements, die sodann in andere Metropolen expandierten.

Benannt nach ihrem Besitzer Katzer und in Anspielung auf die Chat Noir de Paris hatte die Blaue Katze als „Gasthaus-Lokalität" seit den 1850er Jahren Bekanntheit erlangt und sich in den 1880er Jahren in ein geschätztes Soiréelokal verwandelt. ${ }^{109}$ In der Blauen Katze gaben sich die bekanntesten Volkssänger*innen Wiens die Klinke in die Hand: Franz Kriebaum trat hier regelmäßig gemeinsam mit seiner Frau, der Volkssängerin Marietta Kriebaum, auf. ${ }^{110}$ Das Etablissement war weit über die Grenzen Budapests bekannt; so bekannt, dass George, Prince of Wales, Kronprinz Rudolf und andere Aristokraten - inkognito - gemeinsam mit den anderen Gästen wiederholt die Blaue Katze beehrten. ${ }^{111}$

Die Blaue Katze war aber auch eine der ersten Spielstätten in der Donaumetropole, die der wachsenden Konkurrenz im Zuge des rasanten Ausbreitens der Populärkultur zum Opfer fiel:

Diese einen gewissen ,Weltruf' geniessende Stätte der picanten Muse wurde ein Opfer der Zeit und hat aufgehört zu existieren. Solange dies Etablissement das einzige war, in welchem exotische Genüsse geboten wurden, war es im höchsten Flor und der Sammelplatz des hohen Adels und der Intelligenz. Als aber ,Folies caprice' eröffnete und man in demselben dem Publicum pikantere Bilder in herrlichstem Rahmen vorführte und eine dem Zeitgeist entsprechende mit höchster Eleganz und grösstem Komfort ausgestattete Heimstätte der Satyre und des Humors gegründet wurde, verödete die blaue Katze $[\ldots] .[!]^{112}$

107 Mary Gluck beschreibt die Zusammenstellung mit dem Titel „Voyage from Pest to Budapest" als populärhistorische Darstellung, Reiseführer und Bildchronik. Gluck, The Budapest Flaneur, 1 sowie 15.

108 Gluck, Invisible Jewish Budapest, 142.

109 Pest-Ofner Lokalblatt, 17.7.1860, 1.

110 Deutsches Volksblatt (Abendausgabe), 20.7.1900, 2. Auch Josef Koller verwies darauf, dass Kriebaum immer wieder in Budapest in der Königsgasse auftrat, ohne explizit auf die Spielstätte zu rekurrieren. Koller, Das Wiener Volkssängertum in alter und neuer Zeit, 97.

111 Gluck, Invisible Jewish Budapest, 150.

112 IAR, 24.11.1891, 4-5. 


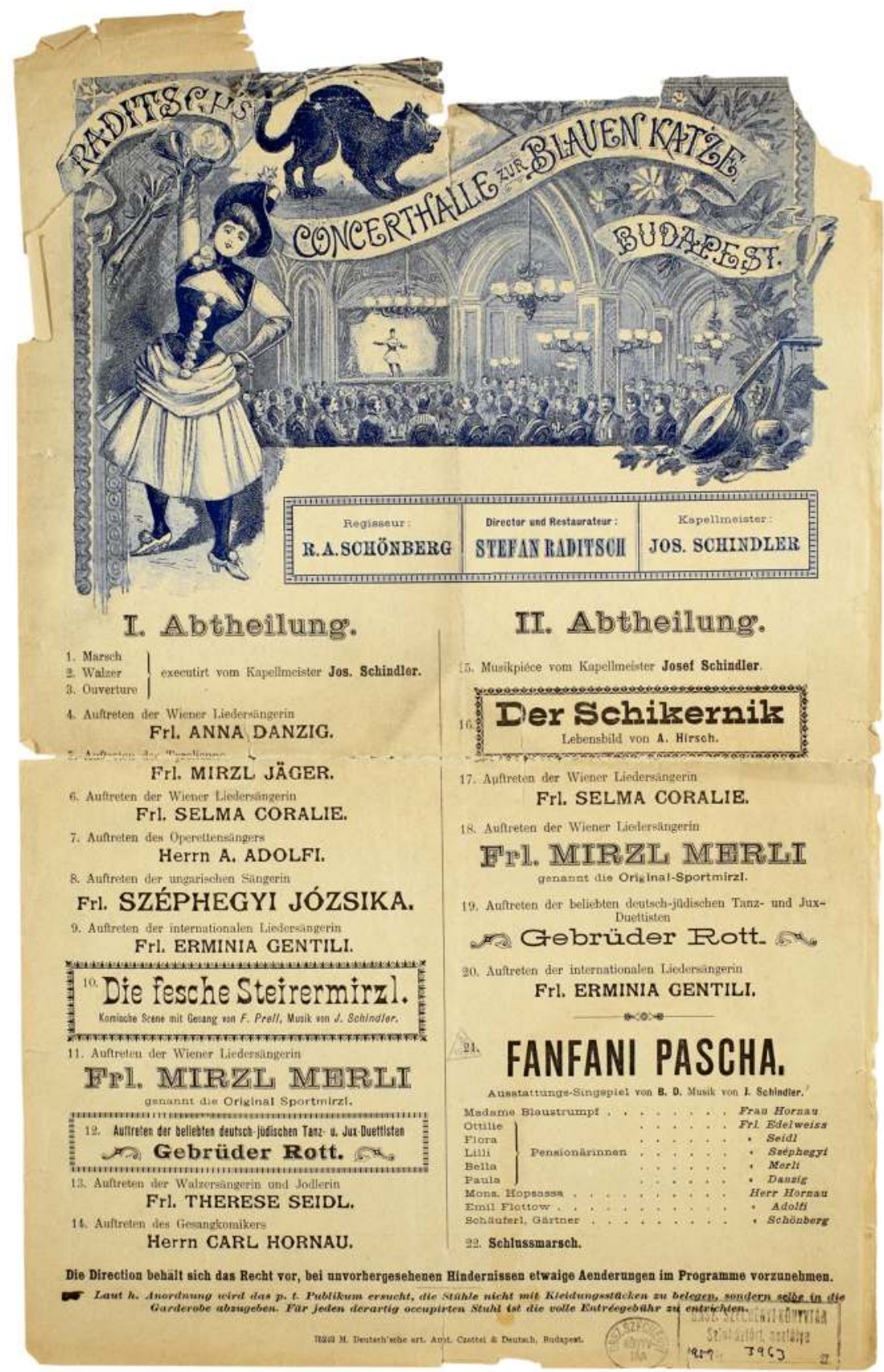

Abb. 8 Programm der Blauen Katze mit Illustration des Auffühurngsraums um 1890, Sammlung für Theatergeschichte der ungarischen Nationalbibliothek Széchényi 
Im Dezember 1891 musste die Blaue Katze mit der Produktion Neu Jerusalem den Vorhang endgültig schließen - man munkelte, weil der beliebteste Autor der Einrichtung, Caprice, die Aufführungserlaubnis für die von ihm geschriebenen Stücke entzogen und sein eigenes Etablissement gegründet hatte. ${ }^{113}$

Der „Weinreisende“, der früher für die Blaue Katze „pikante Operetten“ geschrieben hatte, ${ }^{114}$ eröffnete im Dezember 1889 mitten in Budapest sein eigenes Varieté. ${ }^{115}$ Konzipiert „im Genre der Pariser Vaudeville-Theater“, ${ }^{116}$ erfreuten sich die Folies Caprice nur zwei Jahre später eines weltweiten Rufs. Der Direktor der Folies Caprice war Anton Orozzy (Orossi/Antal Oroszi). Anton Orozzy schrieb auch unter Antal Oroszi für die Budapester Orpheumgesellschaft Wien. ${ }^{117}$ In der Kerepesi út $21^{118}$ leitete er gemeinsam mit „Mit-Direktor“ Heinrich Leitner das Etablissement. Oroszi war zudem der Hauptschreiber der Folies Caprice und schrieb unter dem Pseudonym Caprice einige der meistgespielten Stücke Europas, unter anderem Romeo Kohn und Julie Lewi, ${ }^{119}$ Der kleine Kohn oder Die Klabriaspartie. ${ }^{120}$ „Der Mann ist ein wahrer Klassiker in Zweideutigkeiten und müßte nach Wiener Censurbegriffen für Lebensdauer in Eisen geschlagen werden. ${ }^{\text {"121 }}$ Neben den Folies Caprice leitete Caprice gemeinsam mit Josef Armin (1858-1925) ein weiteres Budapester Lokal: das Etablissement Armin. ${ }^{122}$

Der Witz, die Brisanz, die Pointen und die Schlagfertigkeit der Stücke, die in den Folies Caprice das Publikum zum Lachen brachten, garantierten der Spielstätte ihre Beliebtheit.

Aber, der Wahrheit die Ehre, man amuesirt sich vortrefflich bei seinen [Caprices] Sachen, und das scheint auch unserem königlich ungarischen Sitten-Engel, dem Herren Ober-Stadthauptmann, einzuleuchten, da die Concession für ,Folies Caprice' intact bleibt, trotz des citierenden Zetergeschreies der Theater-Directoren, daß die Aufführung

113 Die Presse, 15.12.1889, 15 (Beilage 1); IAR, 20.11.1891, 14.

114 Die Presse, 15.12.1889, 15 (Beilage 1).

115 HU BFL - VII.175 - 1896 - 1043 Folies Caprice Cég (1896).

116 IAR, 1.11.1894, 6.

117 In der Internationalen Artisten Revue schien er als Anton Orozzy wie auch Antal Oroszi auf. IAR, 8.11.1891, 2 im Vergleich zu IAR, 24.11.1891, 3. Siehe hierzu etwa Hödl, Zwischen Wienerlied und Der kleine Kohn, 25. Sowie Gluck, Invisible Jewish Budapest, 168-170.

118 NSLB, Színháztörténeti Tár, Mulatók, Folies Caprice.

119 Nikola Roßbach, Wien parodiert: Theatertexte um 1900 (Wien: Praesens, 2007), 99-134.

120 Hödl, Zwischen Wienerlied und Der kleine Kohn, 25; Hödl, Der kleine Kohn; Susanne Korbel, Populärkultur und Antisemitismus um 1900 oder: Warum „Kohn zehrt“?, in: Réka Sentyváni, Béla Teleky (Hg.), Brüche, Kontinuitäten, Konstruktionen. Mitteleuropa im 20. Jahrhundert (Wien: New Academic Press, 2017), 17-37.

121 Die Presse, 15.12.1889, 15 (Beilage 1).

122 IAR, 24.12.1891, 3. 
von abschließenden Stücken statutarisch verboten sei auf Tingl-Tangl-Bühnen. Und eine wirkliche Bühne mit Courtine, Soffiten, Versetzstücken, Coulissen, Vorder- und Hintergründen haben diese Folies Caprice und ihre Primadonnen unbeschreiblich schöne Costume. Großartig ist's, wie nach jeder Pièce der Verfasser und Director Herr Caprice von dem jubelnden Haufen ,gerufen ' wird und wie ihn, den ,Widerstrebenden', die Darsteller hereinzerren und er sich glückstrahlend verbeugt.[! $]^{123}$

Das Gebiet der Satire eroberten die Folies Caprice mit dem Stück Palästina. Am 16. November 1891 feierte dieses Premiere. ${ }^{124}$ Die Kritiken mutmaßten, dass das Stück eine derartige Zugkraft besäße, sich über die nächsten Monate im Programm zu halten. Und sie sollten richtig liegen. ${ }^{125}$

Das Publikum zählte die Folies Caprice zu den „Besten unter den Besten“. 126 Die Mischung aus brisanten Stücken und internationaler Zusammensetzung der Auftretenden ließ die Folies Caprice im letzten Jahrzehnt des 19. Jahrhunderts zum „Musteretablissement“ schlechthin werden. Unter dem Titel „Budapester Brief“"war im August 1892 ein Feuilleton in der Wiener Montagszeitung den Folies Caprice gewidmet. Der etwas neidvolle Feuilletonist berichtete, dass sich die Budapester Bevölkerung ebenso an den Programmen erfreute wie internationale Gäste. „Wie einst in Wien zum Sperl“ ging in die Folies Caprice „jeder Fremde“ hin. ${ }^{127}$ „Die beste Gesellschaft. Ganz vorne, nicht unähnlich einem eleganten Menschenstall, die Creme in Logen, zwischen den Elegants wohl auch niedliche Damen, die zu den unmöglichsten Dingen herzhaft lachen, dahinter dicht gedrängt die Durchschnitts-Herrenwelt. “"128

Bei der Besetzung der Programme interagierten die Folies Caprice besonders intensiv mit der Wiener Budapester Orpheumgesellschaft. Die Mitglieder beider Gruppen traten regelmäßig in Budapest wie in Wien auf. ${ }^{129}$ Max Rott (1862-1922), der später seine eigene Spielstätte in Wien gründete, war hierfür nur ein Beispiel unter vielen. ${ }^{130}$ Die Folies Caprice wurden zum Interessensobjekt schlechthin und von Theaterkritiken vieldiskutiert. Eine gab eine zynische Zusammenfassung eines Programmablaufs in den Folies Caprice:

123 Die Presse, 15.12.1889, 15 (Beilage 1).

124 IAR, 24.11.1891, 3.

125 IAR, 24.12.1891, 3. IAR, 24.1.1892, 2.

126 IAR, 8.11.1891, 2.

127 WMJ, 15.8.1892, 1; Az Ujság, 20.7.1905, 7; Színház Hét, 23.9.1911, 30.

128 WMJ, 15.8.1892, 1.

129 IAR, 10.11.1894, 3-4.

130 In den einzelnen Programmen sind immer wieder Auftritte der sogenannten Damenkapellen ausgewiesen. NSLB, Színháztörténeti Tár, Mulatók Folies Caprice, VI. Révay utca 18, 1897-1905. Zu den Damenkapellen siehe Kapitel 5. 
Zuerst jagt man einige Chansonettensängerinnen heraus, die ihre paar Strophen absingen und verschwinden, der Vorhang rauscht fortwährend auf und nieder. Dann kommt der erste Schwank: ,Das unschuldige Wesen'. Nun, solche Unschuld kennt man: unerwartet dabei nur die politische Untermalung des saftigen Schwanks, der Dualismus im kurzen Röckchen. Die Scherze und Anspielungen mehr als aristophanisch; anderswo müßte man nach der Polizei rufen. Die aber dreht sich hier schmunzelnd den glänzenden gewichsten Bart und lacht mit. Eine hübsche Idee liegt dem zweiten Stück zu Grunde: wir kommen nach Pantalonien, wo die Weiber regieren und die Männer im Unterrock stecken. Man hält hier um die Hand der Männer an, denn leider braucht man sie doch zu einigen Dingen nothwendig. Das Stückchen schwimmt in unartigen Witzen.[!] ${ }^{131}$

Der Ruf des Erfolgsrezeptes von dieser Singspielhalle hallte schnell über die Grenzen Budapests hinaus. Jeder wollte die Folies Caprice sehen. Betrüger ${ }^{\star}$ innen witterten ihre Chance und versuchten, die Folies Caprice zu kopieren. 1903 etablierte sich eine Gruppe Folies Caprices in Wien, ${ }^{132} 1905$ eine weitere in Linz. ${ }^{133}$ Dagegen wehrte sich das Original. Warnungen, die darauf hinwiesen, dass die Gruppen in Wien und Linz nur „billige Kopien“ waren, wurden in Zeitungen geschaltet. Außerdem begab sich ein Teil der Gruppe auf permanentes Sommergastspiel nach Wien, um gegenüber ihren vermeintlichen Pendants auch örtlich präsent zu sein. Nachdem lange diskutiert wurde, einen Teil der „original Folies Caprice“ fix nach Wien zu holen, was aber zu einem sprichwörtlichen Krieg innerhalb der Szene führte, gastierte ab der Saison 1904 ein Teil der Budapester Folies Caprice im Theater Bijou im Sommeretablissement Venedig in Wien (Prater). ${ }^{134}$

Neben den als Varietés ausgewiesenen Lokalen boomten auch die Orpheen. Károly Somossy (auch Carl Somossy), der einst als Carl Singer seine Volkssängerkarriere in suburbanen Lokalen Budapests begonnen hatte, leitete ab den 1880er Jahren in einer Seitengasse der Andrássy Straße jenes Etablissement,

131 WMJ, 15.8.1892, 1.

132 Hödl, Zwischen Wienerlied und Der kleine Kohn, 120. Die mediale Debatte stellte äußerst diffus dar, was darunter zu verstehen war. Das Neue Wiener Tagblatt schrieb von einer „Filiale der Budapester Folies Caprice“. NWT, 25.5.1903, 8. Die Internationale Artisten Revue schrieb dahingegen von einer „Kopie“. IAR, 10.12.1903, 2. Es muss somit offenbleiben, ob tatsächlich Mitglieder der Folies Caprice planten, mit einer eigenen Gruppe in Wien sesshaft zu werden oder ob es sich um den Versuch einer Kopie des Budapester „Musteretablissements“ von Albert Hirsch handelte.

133 IAR, 20.5.1905, 4.

134 Anders als bei dem Streit um die vermeintlichen Wiener Folies Caprice handelte es sich bei den Ankündigungen für das Sommeretablissement um die, wie geschrieben wurde, „[o]riginal Folies Caprice aus Budapest“, die beinahe jedes Jahr im Prater auf Sommergastspiel waren. Zum Rummel um das Ensemble siehe auch der „Volkssängerkrieg“ in Kapitel 4. 
dass sich rühmte, „das erste hauptstädtische Orpheum in Budapest“ gewesen zu sein. ${ }^{135}$ Das Gebäude für Somossys großes Orpheum sollte zwischen 1890 und 1893 in der Nagymezö utca 17 (heute Operettentheater) entstehen. Der zweistöckige Bau, den die prominentesten Theaterarchitekten der Monarchie Ferdinand Fellner (1847-1916) und Hermann Helmer (1849-1919) entwarfen und realisierten, soll ein derart hohes Budget verschlungen haben, wie keine der populären Spielstätten zuvor. ${ }^{136}$

Großer Beliebtheit erfreuten sich die Vorstellungen in Somossys Orpheum wegen ihrer internationalen Zusammensetzung und des bunten Arrangements. Somossy sei besonders um „reichhaltiges als [auch] amüsantes“ Programm bemüht gewesen. Unter ihm habe das "Specialitätenwesen“ in Budapest großen Aufschwung genommen. ${ }^{137}$ Innerhalb eines Programmes, das von Humorist*innen über Soubretten bis hin zu Geschicklichkeitskünstler*innen reichen konnte, fanden sich bekannte Größen aus unzähligen Städten.

Das Ensemble recrutirt sich aus den hervorragendsten Koryphäen der Künstlerwelt und ist besonders erwähnenswerth die Piéce der les 4 Eduardos, deren Leistungen zu den Besten in diesem Gebiet zählen; die Billard Excentrique Pantomisten the Slopers; die Pantomimetruppe Bajade; die Jougleurfamilie Onatis; Mr. und Mdme. Boutin mit ihren les Nabots; die engl. Tänzer- und Sänger-Duettisten Sisters Vivian.[!] ${ }^{138}$

Beim Rekrutieren internationaler Talente unterstützte den Direktor Somossy Henry Huline, „der Agent des ersten hauptstädtischen Orpheums“ und so gelang es, der Spielstätte einen dauerhaften Publikumssegen zu verschaffen. ${ }^{139}$

Aber auch unter den internationalen Künstler*innen waren die Spielstätte und deren Direktor beliebt. Mit Somossys Orpheum sei den reisenden Künstler ${ }^{\star}$ innen ein Heim geschaffen worden. ${ }^{140}$ Der berühmte Volkssänger Heinrich Eisenbach (1870-1923) von der Budapester Orpheumgesellschaft heiratete sogar nach einem Gastauftritt am 17. November 1893 in Somossys Orpheum seine langjährige Partnerin, die Sängerin Anna Ferry. ${ }^{141}$ Nicht nur der gewinnende Charakter des Direktors ließ Künstler*innen von nah und fern immer in Somossys Orpheum auftreten. Károly Somossy schuf als einer der ersten

135 Siehe Berichte über das Orpheum, zum Beispiel IAR, 8.11.1891, 2.

136 Fellner und Helmer waren auf Theaterbauten spezialisiert und u. a. für den Wiederaufbau des Wiener Ringtheaters nach dem Ringtheaterbrand von 1881 verantwortlich.

137 IAR, 24.12.1891, 1.

138 IAR, 8.11.1891, 2.

139 IAR, 8.11.1891, 10.

140 IAR, 1.11.1894, 4.

141 IAR, 1.11.1893, 9. 
auch Infrastruktur für die reisenden Künstler*innen: Im Dezember 1893 expandierte das hauptstädtische Orpheum. Nur unweit der Spielstätte eröffneten Somossys Artistenheim und Kaffeehaus am 16. Dezember 1893 in der Feldgasse 17 (mehr zu Artistenheimen im vierten Kapitel). Das Gebäude beeindruckte mit seiner noblen Erscheinung und war eine Aufenthaltsmöglichkeit für mobile Künstler*innen. ${ }^{142}$ Mit dieser „baulichen Spezialität allerersten Ranges“ habe Direktor Somossy „[...] hier der Muse ein Heim geschaffen, wie man sich es prunkvoller und behaglicher kaum denken kann [...]“. Nicht nur der Kunst habe er ein Denkmal gesetzt, auch seinen eigenen Namen habe er in den "Annalen der Residenzstatt bleibend verewigt. “143

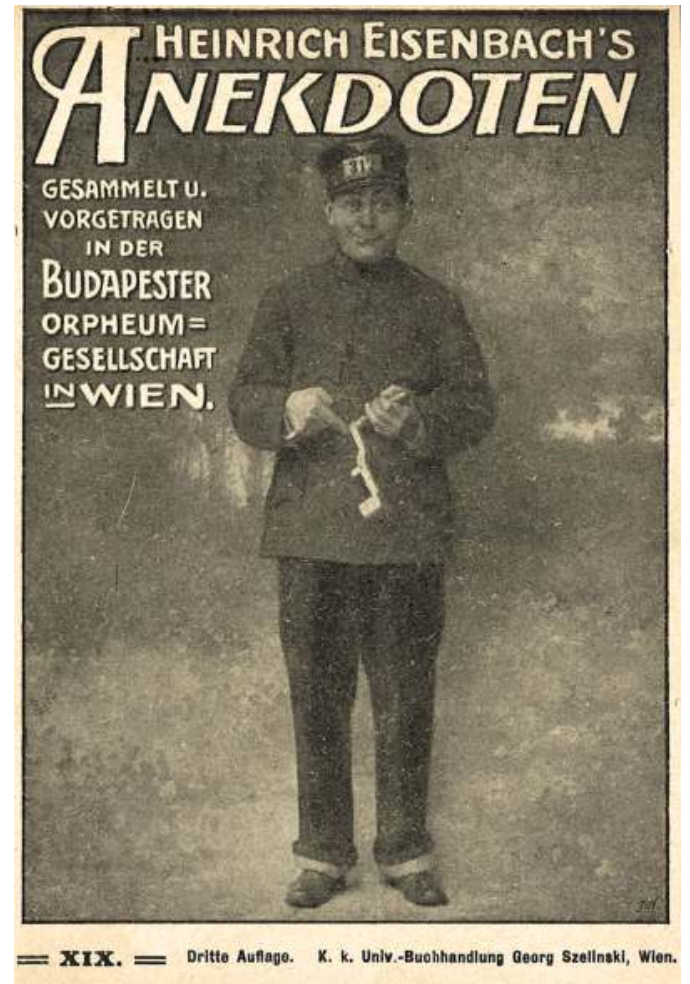

Abb. 9 Heinrich Eisenbach 1911 am Titelbild einer seiner Anekdotensammlungen, Archiv Susanne Korbel

142 IAR, 1.11.1894, 4.

143 IAR, 20.12.1893, 3. 
Auch Herzmanns Orpheum warb mit dem Pracht-Café Herzmann und dessen Artistenheim. ${ }^{144}$ Der Inhaber und Direktor Carl Herzmann war ein Konzessionär mit Weltkenntnis und geschäftlichem Geschick, der um die Bedeutung von Internationalität im Orpheum wusste. ${ }^{145}$ Deshalb sollten auch in Herzmanns Orpheum internationale, außergewöhnliche künstlerische Darbietungen den Programmen „Glanz und Beliebtheit“ verleihen; „täglich grosse internationale Künstler-Vorstellung" lautete das Motto. Die „prachtvoll ausgestatteten Singspiele“ sollten stets auf das Neueste und "Tageserlebnisse“ bezugnehmen. ${ }^{146}$ Etwa gelang es dem Etablissementdirektor im Winter 1891, den weltberühmten Mimiker Henry de Vry nach Budapest zu holen,. ${ }^{147} \mathrm{Zu}$ den „alten Lieblingen“ gehörten der Wiener Volkssänger Heinrich Eisenbach, der immer wieder Possen im Orpheum Herzmann zur Aufführung brachte, ${ }^{148}$ und Josef Armin, ein weiterer Hausautor der Budapester Orpheumgesellschaft Wien. ${ }^{149} 1892$ engagierte Herzmann Josef Müller für die artistische Leitung der Spielstätte. ${ }^{150}$ Müller hatte sich zuvor im Wiener Ronacher einen Namen gemacht, ehe ihn Herzmann nach Budapest holte. Das Highlight der ersten Saison unter der künstlerischen Leitung von Müller war ein „Miniaturcircus“. Bei dieser Nummer wechselte die bekannte ungarische Soubrette Cäcilie Carola ${ }^{151}$ die Rolle und wurde zur Dompteurin von 17 Hunden und vier Pferden. Dieses Gespann erzeugte „[...] einen solch ergötzlichen Anblick [...], daß selbe gleich nach ihrem Debut die erklärten Lieblinge des Publikums wurden [... ““ ${ }^{152}$ Derartige Darbietungen machten Herzmanns Orpheum zu einem der erfolgreichsten Etablissements in der „Hauptstadt des Vergnügens“. 1892 konnte es sogar expandieren und Herzmann gründete im nahegelegenen Budapester Stadtwäldchen ein Hippodrom, zu dem eine Bühne, eine Manege sowie Buffet und Küche gehörten. ${ }^{153}$

144 IAR, 10.12.1893, 16.

145 IAR, 1.11.1894, 3.

146 Beispielsweise Inserat IAR, 10.12.1893, 16; Budapesti Napoló, 7.1.1898, 3.

147 IAR, 24.11.1891, 1. „Henry de Vry zeigt uns seine rechte Gesichtshälfte lachend, während die linke Hälfte weint; [...] Wir können dem stets rührigen Direktor des Herzmann Orpheums nicht genug für den Genuss danken, den er uns durch die Aquisition dieses genialen Künstlers geboten."

148 IAR, 24.1.1892, 2.

149 IAR, 8.1.1892, 3.

150 IAR, 8.1.1892, 2.

$151 \mathrm{Zu}$ Cäcilie Carola siehe Abschnitt Akteur*innen (Soubretten) in Kapitel 4.

152 IAR, 24.1.1892, 2.

153 IAR, 8.2.1892, 2. 


\section{Verortung als ,jüdische‘ Spielstätten}

Benannt waren die neuen öffentlichen Orte gesellschaftlicher Transformationsprozesse nach ihren Betreibern. Carl Singer als Károly Somossy leitete das Sommossy Orpheum, Herzmann leitete das gleichnamige Orpheum, das Etablissement Armin leitete der vor allem später in der Budapest Orpheumgesellschaft als Hausautor bekannt gewordene Josef Armin, ${ }^{154}$ und den Folies Caprice stand der unter dem Pseudonym Caprice schreibende Autor Antal Oroszi vor. Bei dieser Aufzählung wird ein Umstand evident, nämlich dass es sich bei manchen der Namen um Künstlernamen und bei anderen um „magyarisierte" Namen handelte. Für die Einordnung der Budapester Etablissements scheinen die Betreibenden auf verschiedene Strategien gesetzt zu haben. Zum einen galt im ausgehenden 19. Jahrhundert der Name aus antisemitischer Perspektive als Signifikant für ein vermeintliches ,Jüdisch-Sein. ${ }^{\text {‘ }}{ }^{15}$ Es ist folglich davon auszugehen, dass mit der Wahl des Namens eine bewusste Verortung von ,jüdischer' Populärkultur vollzogen wurde. Zum anderen zeigt etwa das Beispiel von Carl Singer, der als Károly Somossy sein Orpheum eröffnete, dass es auch eine bewusste Tendenz gab, nicht als „anti-magyarische“ Einrichtung gelten zu wollen. Zudem illustrieren unter Künstlernamen geführte Etablissements eine andere gängige Praxis, das Zurückgreifen auf Bezeichnungen aus dem Französischen wieder eine weitere.

Das Thema Künstlernamen unter - jüdischen wie nichtjüdischen - Künstler*innen und Direktor*innen war ein derart komplexes, dass sich ihm auch einige Fachartikel um 1900 widmeten. Die Historiographie neigte bislang dazu, gerade bei Jüdinnen und Juden die Wahl von Künstlernamen als Marker für deren ,Assimilation' oder ,Akkulturation` zu werten. Der für seine „Wiener Culturbilder" bekannte Autor Karl Kutschera betonte allerdings in einem Artikel, dass es sich bei der Wahl von Künstlernamen keineswegs um ein Spezifikum jüdischer Künstlerinnen handelte, sondern unter allen Künstler*innen gängige Praxis war. „Sängerinnen mit echt französischen Namen

154 Josef Armin, der 1858 in Budapest geboren wurde, ging 1875 nach Wien. Später begann er als Sänger mit Gruppen in Galizien umherzureisen, ehe er wieder nach Budapest gelangte, wo ihn Herzmann engagierte. Josef Armin probierte sich zunächst noch selbst als Singspielhallenbetreiber, ehe er in Wien für die Budapester zu schreiben begann. Zu Josef Armin siehe Wacks, Budapester Orpheumgesellschaft, 65-66. Wacks merkt an, dass Armin als Josef Rottenstein geboren worden war.

155 Dietz Bering, Der ,jüdische“ Name, in: Julius Schoeps, Joachim Schlör (Hg.), Antisemitismus: Mythen und Vorurteile (München, Zürich: Piper, ${ }^{2} 1996$ ), 153-166. Fraglich und umso problematischer ist die weitverbreitete Forschungspraxis, Jüdinnen und Juden aufgrund ihrer Namen zu identifizieren. Hödl, Zwischen Wienerlied und Der kleine Kohn, 21-3 sowie 56. 
entpuppen sich als dralle Bähminen, englische Serpentinentänzerinnen verwandeln sich oft genau besehen in Tarnopoler Angehärige, eine Arabertruppe mit unaussprechlichen Namen recrutiert sich aus Söhnen der neuösterreichischen Provinz Bosnien, und ein orientalischer Zauberkünstler hat gar wieder das Bier-Eldorado Bayern zur Heimath.[!] "156 Kutschera betonte auch, dass es gerade das Publikum war, das es von allen seinen Unterhalter*innen forderte, schon mit ihrem Namen Internationalität auf die Bühne zu bringen. ${ }^{157}$ Taten sie das nicht, so Kutschera, bliebe irgendwann ihr Erfolg aus. Diese Behauptung illustrierte Kutschera, der sich selbst als „ein Beispiel unter Tausenden“ anführte - hatte er doch ein Wiener Café in Berlin eröffnet -, mit folgender Anekdote:

In einem kleinen sogenannten Mittel-Circus waren drei Athleten engagirt, welche unter ihren wirklichen - aufrichtig gesagt keineswegs poetischen - Namen vorzügliche Proben ihrer Kraft und Gewandtheit ablegten. Trotz ihres Könnens brachte man ihnen in letzterer Zeit nicht jene Sympathie entgegen die sie wirklich verdienten. Da veränderte der Circus eines Tages sein Domizil und schlug seine Wirkstätte in einem anderen Theile der gleichen Stadt auf. Die drei Athleten fassten nun den guten Gedanken, auch ihre Namen zu wechseln, und siehe da, als Osman Trio errangen sie glänzende Erfolge, und das Publikum drängte sich zu den Cassen, wenn es hiess, heute werden die Brs.[Brothers] Osman auftreten.[!] $]^{158}$

Diese unterschiedlichen Praxen, Spielstätten mit deren Namensgebung zu verorten, spiegeln daher weniger einen sich nationalisierenden Diskurs oder die ,Assimilation ' jüdischer Etablissementdirektor*innen als vielmehr den facettenreichen, internationalen Charakter populärer Kultur wider.

\section{Transnationale Räume und Nationalismus}

Gerade der internationale Charakter und der enorme Zuspruch, den dieser der Szene populärer Unterhaltung einbrachte und damit ihre Wirkmächtigkeit in breiten Kreisen der Bevölkerung ermöglichte, waren den politischen Akteur ${ }^{\star}$ innen ein Dorn im Auge. Wegen ihrer transnationalen Ausrichtung galten die Varietés, Singspielhallen und Etablissements den ungarischen Nationalist ${ }^{*}$ innen als Hochburgen der Anti-Magyarisierung. Die Räume populärer Kultur wurden von der sich nationalisierenden Politik und Regierung zunehmend als Gefahr gesehen. Mit gesetzlichen Restriktionen sollte deshalb das - „nicht ungarische“ - Varietéwesen eingedämmt werden. 1895 gab die ungarische

156 Karl Kutschera, „Artisten Namen“, IAR, 1.4.1894, 1-2.

157 Karl Kutschera, „Artisten Namen“, IAR, 1.4.1894, 1-2.

158 Karl Kutschera, „Artisten Namen“, IAR, 1.4.1894, 1-2. 
Regierung eine neue Theaterordnung heraus. Demnach hatte die Hälfte aller Aufführungen in öffentlichen Spielstätten auf Ungarisch stattzufinden. ${ }^{159} \mathrm{Zu}$ nächst war Sprache der herangezogene Indikator zur „Messung“ des nationalen Charakters populärer Unterhaltung.

Die Historiographie hat diese Praxis als Anzeichen für die Nationalisierung der populären Kultur in Budapest interpretiert. Aus dieser Auslegung und Darstellung der Theaterordnung von 1895 wie auch späteren Stellungnahmen von mit nationalen Agitationen vorgehenden Politikern zu den Budapester Etablissements hat die Forschung argumentiert, dass gerade in Budapest die deutschsprachig-jüdischen Etablissements abgeschafft werden sollten und die Entwicklung der Varietés in Folge lediglich deren Nationalisierung widerspiegle. ${ }^{160}$ Ein tieferer Blick in diese Debatten - vor allem unter dem Aspekt der räumlichen Qualität von Stätten populärer Unterhaltung - legt eine facettenreichere Interpretation nahe. ${ }^{161}$

Lange vor dieser Theaterordnung war Mehrsprachigkeit und Aufführungen in verschiedenen Sprachen alltägliche Erfahrung in den Varietés. Und auch nach dem Erlass der Theaterordnung kam es in der Praxis vielfach zu Abweichungen von der Intention der Normierung beziehungsweise ergaben sich gerade aus den gesetzlichen Richtlinien Zwischenbereiche. Die Budapester Theaterordnung von 1895 beabsichtigte eine Homogenisierung, Nationalisierung und Magyarisierung. Die Praxis in den Varietés gestaltete sich jedoch anders: Auch nach diesem Erlass für Ungarn bestanden die einzelnen Stücke innerhalb eines Programms nicht getrennt voneinander. Vielmehr stimmten die Protagonist ${ }^{\star}$ innen das gemischtsprachige Programm gekonnt ab. Die Umsetzung der gesetzlichen Norm führte im alltäglichen Vorgehen dazu, dass eine noch stärkere Interaktion zwischen den ungarischen und fremdsprachigen Darbietungen bestand. Die Schauspieler*innen tauschten sich vorab über das

159 Gluck, Invisible Jewish Budapest, 147.

160 Zur Interpretation der deutschsprachigen Orpheen in Budapest als Bedrohung des Nationalismus siehe Gluck, Invisible Jewish Budapest, 142-168. Alexander Vari, Nation-Building and Globalization in the Budapest Orpheum and Cabaret World (1890-1914): Vortrag, gehalten auf der Konferenz der Association for Slavic, East European and Eurasien Studies. Washington 2016.

161 Zur Relevanz einer perspektivenreicheren Interpretation des sogenannten „Nationalismus“ innerhalb der Habsburgermonarchie und der Bedeutung, gerade auf die Handelnden den Blick zu richten sowie Vorgänge wider die von politischen Akteur*innen proklamierten Narrative zu lesen, siehe Pieter M. Judson, The Habsburg Monarchy: A New History (Cambridge: Cambridge University Press, 2016); Judson, Zahra, Introduction 21-27; Tara Zahra, „Imagined Noncommunities: National Indifference as a Category of Analysis“, Slavic Review 69, no. 1 (2010): 93-119; sowie sämtliche Beiträge im Austrian History Yearbook 49 (2018). 
bestmögliche Arrangement aus und stellten in den Stücken Querverweise her. Damit erlangten auch jene unter den Zusehenden, die der anderen Sprache nicht mächtig waren, Einblicke. Durch die gemischtsprachigen Aufführungen entstanden somit Begegnungsräume für verschiedensprachiges - als national different konstruiertes - Publikum.

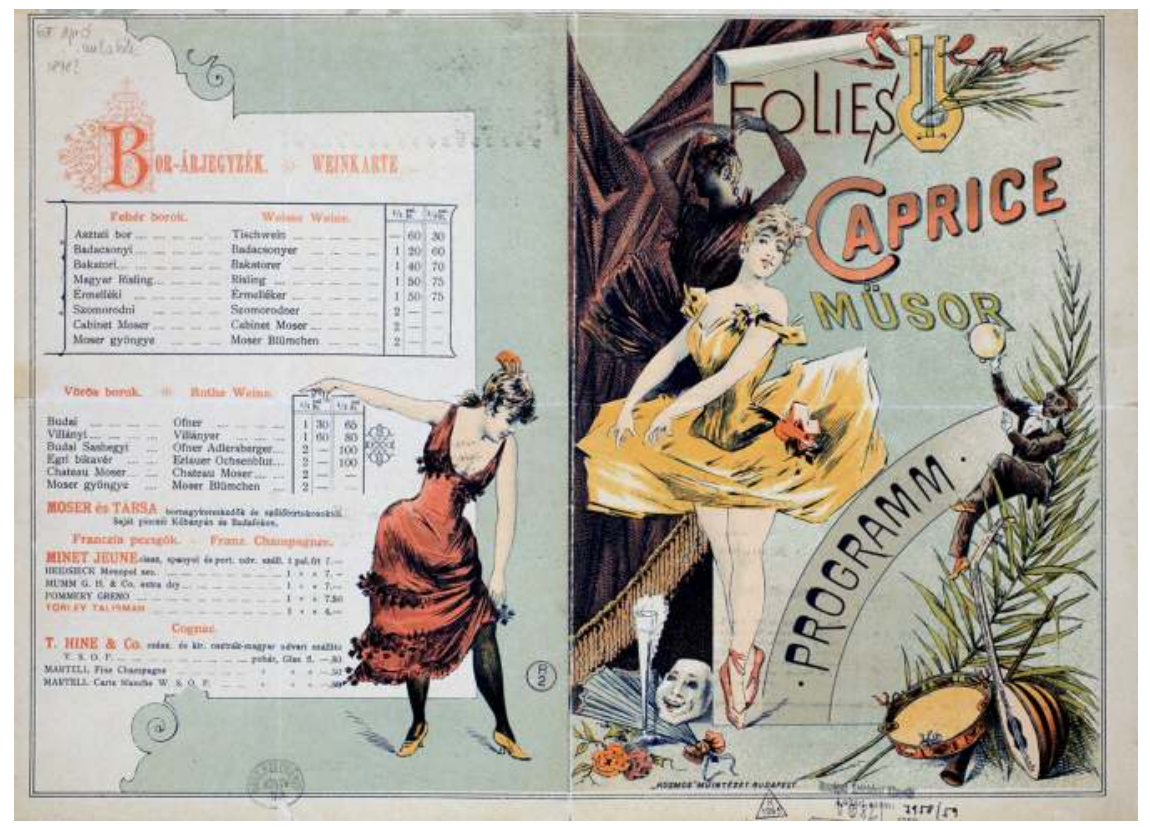

Abb. 10 Titel- und Rückseite eines Programmes der Folies Caprice mit u. a. der Klabriaspartie auf Deutsch und Ungarisch um 1900, Sammlung für Theatergeschichte der ungarischen Nationalbibliothek Széchényi

Dazu ein Beispiel: Das Wiener Fiakerlied ist nicht nur eines der bekanntesten Wienerlieder, es kann auch als Paradebeispiel für die vielschichtigen Interaktionen zwischen Jüdinnen und Juden mit Nichtjüdinnen und Nichtjuden in der Populärkultur gesehen werden. Der jüdische Autor Gustav Pick (1832-1914), der aus Ungarn nach Wien migrierte, verfasste 1885 das Fiakerlied aus der Perspektive eines nach Wien gekommenen Migranten. Popularität erlangte es durch den Vortrag des Volkssängers Alexander Girardi (1850-1918). Ein ,Jüdisch-Sein' des Autors spielte in der Rezeption keine Rolle. ${ }^{162}$ Auch tat es

162 Klaus Hödl, „The Quest for Amusement: Jewish Leisure Activities in Vienna circa 1900“, Jewish History and Culture 14, no.1 (2014): 1-17, 3. Auch nicht der Umstand, dass Baron Nathaniel Rotschild die erste Produktion in der Prater-Rotunde finanzierte. NWJ, 6.5.1918, 2. Zu Pick siehe auch Gertraud Pressler, Jüdisches und Antisemitisches in der Wiener Volksun- 
seiner Popularität in Budapest keinen Abbruch. Als Konsequenz der Budapester Theaterordnung wollte ein Budapester Orpheum das Fiakerlied dennoch nicht aus dem Programm nehmen. Um die gesetzliche Auflage zu erfüllen, übersetzte und adaptierte es das populäre Wienerlied auf Ungarisch. Im Régi Orfeum erklangen somit nicht die Zeilen „Mei' Stolz is, i' bin halt an echt's Weanakind, / A Fiaker, wie man net alle Tag' find't, “163 sondern „Ezt büszkén mondhatom / [...] Mert pesti fiakker vagyok, “ also „ein Pester Fiaker “. ${ }^{164}$ Und auch der zuvor bereits erwähnte Max Rott beteiligte sich tatkräftig am Austausch zwischen ungarisch- und deutschsprachigen Aufführungen und inszenierte Stücke in beiden Sprachen. ${ }^{165}$

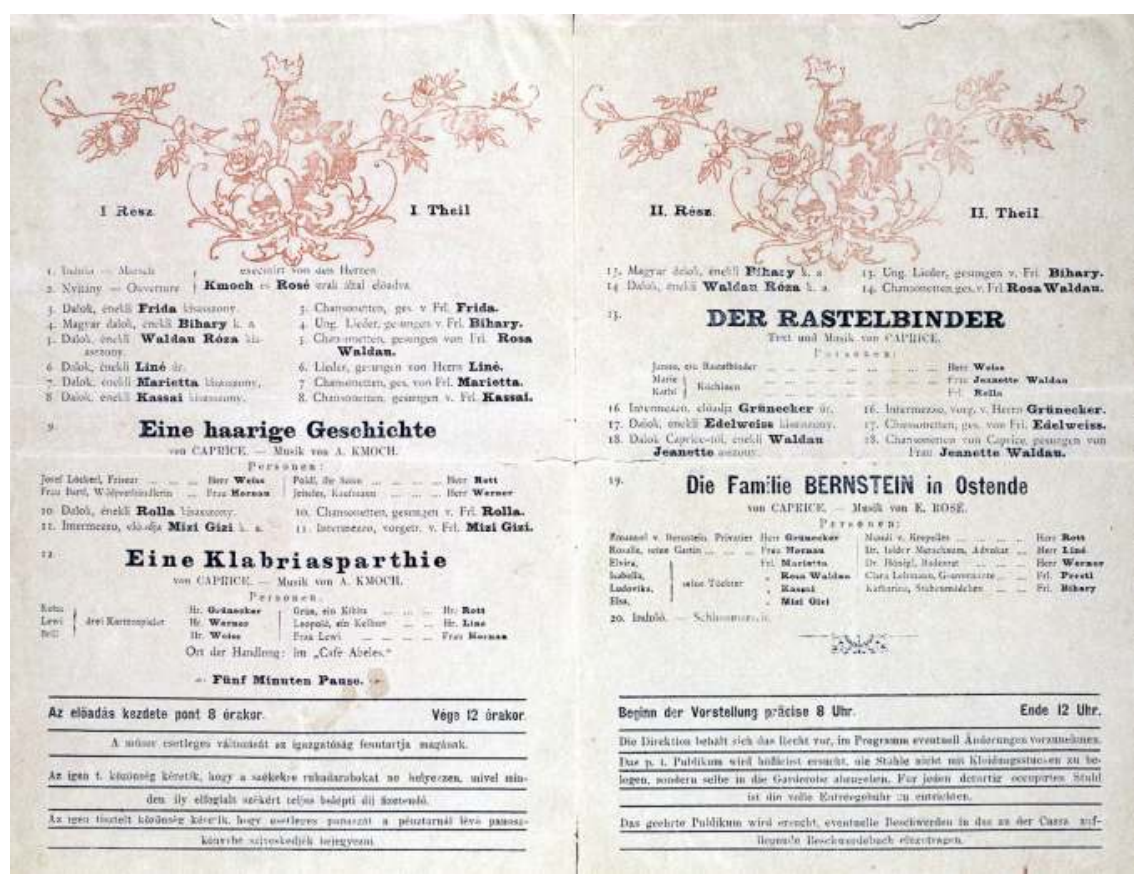

Abb. 11 Innenseite des Programmes - Darbietungen in den Folies Caprice, Sammlung für Theatergeschichte der ungarischen Nationalbibliothek Széchényi

terhaltung, in: Michael Weber, Thomas Hochrader (Hg.), Identität und Differenz: Beiträge zur vergleichenden und systematischen Musikwissenschaft (Musicologica Austriaca 17) (Wien: Musikwissenschaftlicher Verlag, 1998), 63-82, 88.

163 ÖVLA, 138173, Pick Gustav, Fiakerlied. In: So singt Österreich, 193.

164 NSLB, Theatersammlung, Programme, MM 11.417 Regi Orfeum.

165 PL, 3.9.1913, 7. 
Die Etablissements fungierten als Bindeglied zwischen den zwei scheinbar binären Positionen des deutschen und ungarischen Nationalismus. In der Forschung zu Nationalismen in der Habsburgermonarchie wird mittlerweile die These vertreten, dass Nationalismus als singuläres Erklärungsmodell für das soziopolitische Gefüge des sogenannten Vielvölkerstaates und der ihn auflösenden Prozesse unzureichend ist. Das wird an den skizzierten Debatten um die Varietés augenscheinlich. Pieter Judson und Tara Zahra illustrieren mit Überlegungen zu nationaler Indifferenz beeindruckend, wie es in Alltagssituationen vielfach zu Verhalten kam, das sich in die herkömlichen Narrationen nicht einfügt. Judson und Zahra sprechen daher von national indifference - einer Gleichgültigkeit im Sinne indifferenten Verhaltens gegenüber nationalen Kategorien, die von politischen Akteuerinnen betrieben wurden. Damit haben Judson und Zahra ein Analyseinstrument vorgelegt, das zeigt, wie in konkreten Situationen Akteur ${ }^{*}$ innen national indifferent handeln. ${ }^{166}$ Das lässt auch die vermeintlich vorwiegend nationalen Gründe, die zur Verabschiedung der Sprachauflage in der Theaterordnung führten, hinterfragen.

Eine genauere Analyse des Zustandekommens der Theaterordnung zeigt, dass sie nicht ausschließlich zum Verbreiten der ungarischen Sprache im Nationalismus motiviert war. Ebenso entstand die Theaterordnung als Widerstand gegen die Zunahme der Mobilität in der Varietészene und gegen die mit der Mobilität einhergegangene Internationalisierung. Im Zuge der Verabschiedung der Theaterordnung handelten die Akteuer*innen in der Varietészene national indifferent. Sie gaben der politischen Debatte keinerlei Widerhall. Die Akteur*innen in den Varietés widersetzten sich mit ihrer Praxis dem politischen Oktroyat national homogenere Räume in der populären Kultur schaffen zu sollen. Bot die populäre Kultur stets plurilinguale Räume, nutzten die Auftretenden in Budapest nach 1895 die dann bestehende gesetzliche Vorschrift, um noch intensiver zwischen den sogenannten "fremdsprachigen“ Aufführungen und jenen auf Ungarisch zu vermitteln. Die Theaterprogramme der Budapester Spielstätten illustrierten die Kooperation unter vermeintlich national verschiedenen Auftritten. Zudem gestalteten die Varietés alle Programme zweisprachig, ebenso wie Speisekarten und andere Informationen. Die Theaterordnung trug damit mehr zur Schaffung pluraler Räume des Austausches bei, als dass sie die Intentionen der politischen Nationalist ${ }^{*}$ innen bestätigte. ${ }^{167}$

166 Judson, Zahra, Introduction, 21-27.

167 Gluck, Invisible Jewish Budapest, 168. 


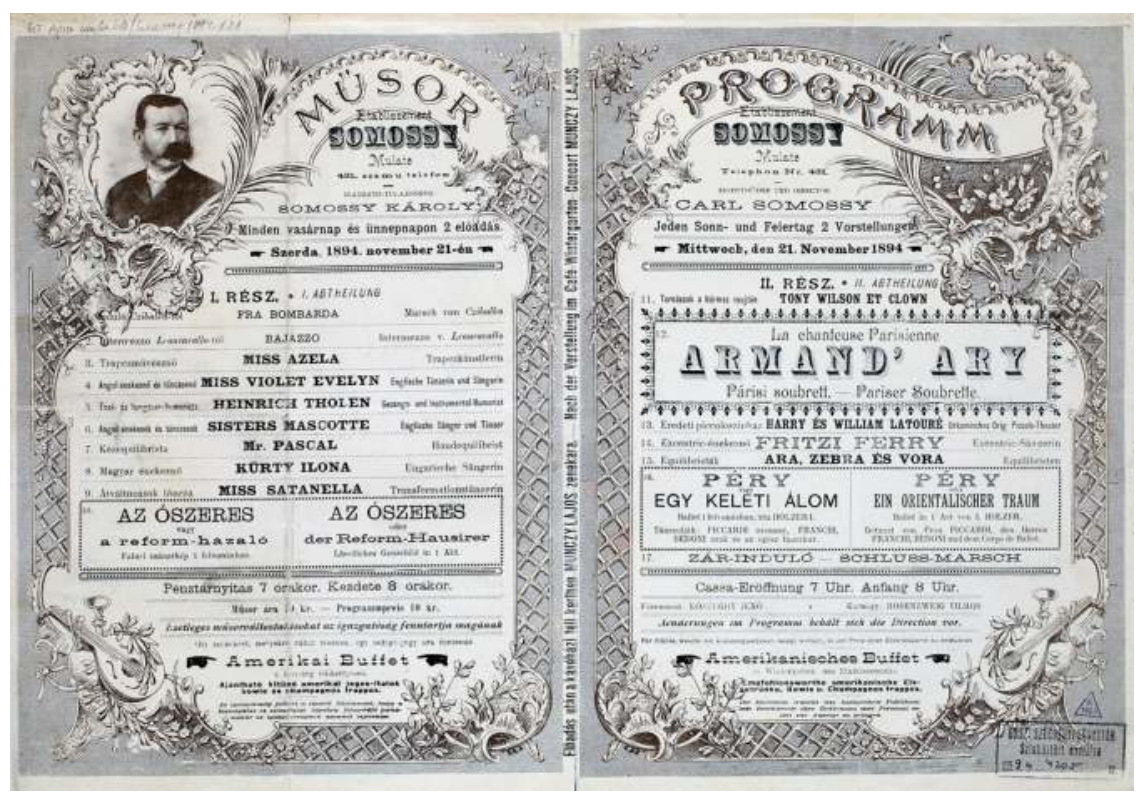

Abb. 12 Zweisprachiges Programm aus Somossys Orpheum vom 21. November 1894, Sammlung für Theatergeschichte der ungarischen Nationalbibliothek Széchényi

Auch die Proponenten der Theaterordnung von 1895 erkannten, dass anstelle von Nationalisierung im internationalen Raum populärer Kultur noch mehr Pluralität geschaffen wurde. In einem nächsten Schritt versuchten die politischen Akteur ${ }^{\star}$ innen, eine kulturelle und soziopolitische Homogenisierung dem Konzept Magyarisierung gemäß dadurch zu erwirken, dass nichtungarische Auftretende keine sozialen Unterstützungen (Krankenschutz etc.) mehr erhielten. ${ }^{168}$ Die Artistenszene selbst plädierte wiederum dafür, dass „[s]olange Jemand anständig und ehrenhaft wirkt", ihm niemand „verbieten“ dürfe, aufzutreten. ${ }^{169}$ Deshalb gründete die Szene fortan Organisationen, die derartige sozialpolitische Anliegen vertraten. ${ }^{170}$ So bewirkte der gesetzliche Rahmen, der nationalisieren sollte, vielmehr Transnationalität auch in den Netzwerken und der Organisation der Szene. Zudem wurden die Nationalsprachen und die Debatten um Nationalisierungen, wie das fünfte Kapitel zeigen wird, im internationalen Licht populärer Kultur durchaus subversiv inszeniert.

168 IAR, 1.12.1899, 1.

169 IAR, 1.12.1899, 1.

170 Siehe hierzu Kapitel 4. 
Die ein Jahr nach der Theaterordnung entstandene Posse des deutschjüdischen Autors Oscar Blumenthal (1852-1917) und seines österreichischungarischen Kollegen Gustav Kadelburg (1851-1925) Im weißen Rößl ist ein anderes Beispiel, um diese Praxis transnationaler Mittelung nachzuvollziehen. Der Schwank Blumenthals und Kadelburgs erfreute sich zeitgenössisch einer breiten globalen Rezeption. Überall kam es zu neuen Interpretationen der Posse. Schon unmittelbar nach ihrer Publikation gelangte sie in Amerika zur Aufführung. Im Winter 1898 spielte sie als At the White Horse Tavern im Irving Place Theatre am Union Square, ein deutsch- und später jiddischsprachiges Theater. Ab Februar 1899 konnte das Stück am Wallack Theatre Broadway 844 Ecke $30^{\text {th }}$ Street, produziert von Daniel und Charles Frohman, gesehen werden. Hier betonten die Kritiken, dass gerade die wiedererkennbaren Charakterzüge und der Humor des Stückes eine gesonderte örtliche Anpassung an den New Yorker Raum unnötig machten. Das Publikum, so schrieb die New York Times, konnte durch die Komposition des Humors anknüpfen. ${ }^{171}$ Seine große Beliebtheit brachte dem Schwank allerdings gleichzeitig Unterstellungen ein. ${ }^{172}$ 1901 machte sein enormer internationaler Erfolg das Stück zur Angriffsfläche von antisemitischen Hetzkampagnen gegen deren Autoren, die das „weiße Rößl“ lediglich als einen „Goldesel“ intendiert hätten. ${ }^{173}$ Wieder eine andere Version, eine kürzere Fassung des Rößls reichte der Gesangskomiker Berthold Schmied am 22. Mai 1905 für die Singspielhalle Kirnbaumer im neunten Bezirk in Wien ein. ${ }^{174}$ Nicht im Salzkammergut, sondern in einem Hotel in Wien spielt diese Fassung und handelt statt von dem Berliner Geschäftsmann von Frau Stangelmeier und deren Nichte Rosa. Die beiden kommen im Wiener Hotel an, nicht um das Land zu genießen, sondern die Stadt kennenzulernen und sich in der Stadt zu erholen. ${ }^{175}$ In dieser und weiteren Adaptionen wurde Im weißen Rößl auf Deutsch und Ungarisch in den Folies Caprices aufgeführt und

171 NYT, 5.2.1899, 17.

172 Siehe hierzu etwa einen Leserbrief, der auf eine negative Kritik einer Rößl-Aufführung verteidigend Bezug nimmt. Die Jugend, 25.2.1901, 144.

$173 \mathrm{Zu}$ antisemitischen Darstellungen des „Rößl“ sowie zu dessen medialer Rezeption siehe Julia Menzel, „Meine Frau hat sich göttlich amüsiert“: Das weiße Rößl im Spiegel zeitgenössischer Satirezeitschriften, in: Nils Grosch, Carolin Stahrenberg (Hg.), „Im weißen Rößl“: Kulturgeschichtliche Perspektiven (Populäre Kultur und Musik 19) (Münster, New York: Waxmann, 2016), 117-132.

174 Schmied Berthold, Im weissen Rössel. NÖLA, NÖ Reg. Präs. Theater TB - Textbücher der Theaterzensur 28/4.

175 Schmied Berthold, Im weissen Rössel. NÖLA, NÖ Reg. Präs. Theater TB - Textbücher der Theaterzensur 28/4. 
fungierte in Budapest als Mittler zwischen den Sprachen und war Schaubild einer trans- und internationalen Kultur. ${ }^{176}$

Auch zeigt ein Zwischenfall, der Auslöser des „Volkssängerkrieges“ war und beinahe zu einer Auseinandersetzung zwischen der Wiener und Budapester Szene geführt hätte, dass die Akteur*innen der Szene populärer Kultur wider die proklamierte Nationalisierung handelten. 1901 verboten, wie das Illustrirte Wiener Extrablatt am 24. Dezember 1901 berichtete, Budapester Behörden einer deutschsprachigen Gruppe aus Wien einen Gastauftritt in der Stadt. Noch bevor die Wiener Zunft zu ihrem Treffen am 27. Dezember 1901 zusammenkam, hatten die Budapester Kolleg*innen schon interveniert und das Verbot war aufgehoben worden. Zum wirklichen Konflikt kam es allerdings unter den ständig in Wien ansässigen Varietékünstler*innen und Singspielhallenbetreibenden. Die zunehmende Konkurrenz und wachsende Mobilität, die zu immer mehr Gastspielen führte, setzte sie wirtschaftlich unter Druck. Der Konkurrenzdruck ließ die Wiener Szene über die nächsten zwei Jahre in eine immer verfahrenere Diskussion geraten, im Rahmen derer es zu mehreren Ehrenbeleidigungen kam, die bis zur gerichtlichen Verfolgung führten. Im Narrativ hielt diese Kontroverse über den Austausch zwischen der Wiener und Budapester Szene als „Krieg“ Einzug. Es handelte sich zwar um eine Restriktion der ungarischen Behörden, die Ungarisch protegieren wollten, allerdings war ein wirklicher Konflikt aufgrund des aktiven Einschreitens der Budapester Kolleg*innen vor Ort schon längst abgewendet worden, bevor das Gesetz überhaupt gegriffen hätte. ${ }^{177}$ Bei der gerichtlichen Behandlung der Ehrenbeleidigungen, zu denen es unter den Wiener Singspielhallenbetreibern gekommen war, wurde explizit festgehalten, dass sich „9/10 der Volkssängerschaft“ gegen die Parole „Schutz den Einheimischen“ ausgesprochen hatte. ${ }^{178}$

Die Forderung nach politischer Nationalisierung über Sprache und Kultur kam in Debatten über die Szene populärer Kultur in Budapest besonders stark im Umgang mit dem jiddischen populären Theater zum Ausdruck. Der Alweltlikher idishn Kultur-Kongres (Allweltlicher Jiddische Kulturkongress) betonte, dass zur Jahrhundertwende „[d]ie Winer gzireh hot zikh in glikhn aribergeworfen oif budapesht" (die Wiener Szene hat sich nach Budapest ausgebreitet). Trotz des enormen Drucks zur ,Assimilation' habe sich die Szene jiddischen Theaters zunehmend von Wien nach Budapest verlagert. ${ }^{179}$ In der auf diese Feststellung

176 Zum Beispiel Programm, Folies Caprice, 1902. NSLB, Theatersammlung, Programme: Folies Caprice.

177 Hödl, Zwischen Wienerlied und Der kleine Kohn, 100-109.

178 „Der Volkssängerkrieg“, IWE, 26.5.1903, 9.

179 Alweltlikher idishn kultur-kongres, Idisher teater in aeirupe zwishn beide welt-malkhmot, 265. 
folgenden Beschreibung der Szene des jiddischen Theaters in Budapest wird sodann augenscheinlich, dass es so etwas wie ausschließlich und gattungsspezifisches jiddisches Theater ebenso wenig gab wie eine klare Trennung zwischen dem Spielen in beziehungsweise mit „Jargon“ oder Tätigkeitsbereiche, in denen Jüdinnen und Juden nicht gemeinsam mit Nichtjüdinnen und Nichtjuden agiert hätten. Gerade aus der Pluralität der Unterhaltungsszene heraus und in ihrer Mobilität trotzte jüdische und nichtjüdische Akteur*innen gemeinsam dem Bestreben der Nationalist*innen. Jiddische Theaterstücke waren auch in Form (mehrerer) Einzelnummern in Potpourris zusammen mit anderssprachigen Aufführungen Teil der Etablissementprogramme. Besonders im Kabarett gab es eine starke Präsenz von jiddischen Nummern. ${ }^{180}$ In den Folies Caprice wurden in den 1890er Jahren noch vielfach Stücke auf Jiddisch gespielt. So etwa 1889 Die Klabriasparthie, Caprices vielleicht bekanntestes Stück. ${ }^{181}$ Bis in die 1910er Jahre waren jiddische Stücke, so Miklós Konrád, nur noch vereinzelt zu finden gewesen. $^{182}$

Der Beginn des Ersten Weltkrieges bedeutete gewissermaßen eine rechtliche Besserstellung, denn jiddische Aufführungen waren erlaubt gewesen, mussten aber von ungarischen Schauspieler*innen aufgeführt werden. Die Regierung habe natürlich gewusst, dass nach dem Druck der Magyarisierung sich hierfür keine Gruppe „Aktoiren und Aktreises“ fände. Bald jedoch fand sich eine Kompromisslösung, die jiddische Theatervorführungen ermöglichte: „Di helfte jidishe akoiren un aktreises megn zein auislendishe birger, ober di andere helft mozn zein madiarishe birger" (Die Hälfte der Schauspieler und Schauspielerinnen mögen ausländische Bürger sein, aber die andere Hälfte müssen ungarische Bürger sein). ${ }^{183}$ Die Migrationsbewegungen während der Kriegsjahre hatte eine derartige Fülle an möglichem Publikum gebracht, das die Theatersäle stets füllte. ${ }^{184}$ Während der Regierung von Béla Kun hatte das jiddische Theater eine eigene Spielstätte an einer der Budapester Prachtstraßen erhalten. Mit der Machtergreifung Admiral Miklós Horthys wurde dieses allerdings wieder aufgelöst. Deshalb wanderten die Schauspieler ${ }^{\star}$ innen nach Wien, Transsilvanien, in die Slowakei und in den Karpatenraum, Sokowitza (Botshka Provinz).

180 Alweltlikher idishn kultur-kongres, Idisher teater in aeirupe zwishn beide welt-malkhmot, 265-266.

181 IAR, 1.1.1894, 5.

182 Miklós Konrád, Music Halls and Jewish Identities in Budapest at the Turn of the Century, in: Jurgita Šiaučiūnaitė-Verbickienė, Larisa Lempertienè (Hg.), Jewish Space in Central and Eastern Europe: Day-to-Day History (Cambridge: Cambridge Scholars Publishing, 2009), 143-155, 148-149.

183 Alweltlikher idishn kultur-kongres, Idisher teater in aeirupe zwishn beide welt-malkhmot, 266.

184 Ebda.. 


\section{Vom People's Theatre zur People's Music Hall in New York}

Das unsichtbare jüdische Budapest konterkariert das schon fast deutlich sichtbare jüdische New York. In New York waren Migration im Allgemeinen und die jüdischen Migrant ${ }^{*}$ innen im Besonderen mit der Lower East Side verbunden. Das sogenannte „Hebrew quarter“ oder die „Jewtown“ erstreckte sich von der Houston Street im Norden vom East Village abgekoppelt und vom East River im Westen und der Allen Street im Osten begrenzt. Ab den 1870er Jahren kamen hier jüdische Migrant*innen aus Europa in der "goldenen Medine“ (Amerika) an. Viele von ihnen arbeiteten in der Textilindustrie. Sie lebten in engen Stockhäusern, den sogenannten tenements. Die Kellergeschosse der Häuser boten aber auch einer großen Barszene Platz. Die Souterrains wurden zu kleinen Bars umgebaut, hier versammelten sich die Bewohner*innen abends, wenn sie nicht in einem der anderen Räume populärer Kultur zu finden waren. ${ }^{185}$

Der Fotograf und Journalist Jacob Riis dokumentierte in den 1890er Jahren das Leben der „neuen Amerikaner“ in den New Yorker tenements. Als Riis damit begann, nahm er die Lower East Side als einen der am dichtesten besiedelten Plätze der Welt wahr. Riis glaubte nicht an das, was heute Plurikulturalität genannt wird. Auch wollte er keine Studie über das Migrantenleben per se anfertigen. Vielmehr wollte Riis den Ursachen für Probleme wie der hohen Kriminalität an der Lower East Side auf den Grund gehen. Die Lösung der Probleme sah der Fotoreporter in der „vollständigen Assimilation“ durch Christianisierung der Immigrant ${ }^{*}$ innen. ${ }^{186}$ Nichtsdestoweniger prägte seine Reportage - vermutlich nicht intendiert - ein Bild der Vielschichtigkeit der Lower East Side, die in den vielen kleinen Cafés, den großen Theatern und bald auch den Singspielhallen augenscheinlich wurde.

Riis schrieb auch von diesen Unterhaltungslokalitäten, die sich nach und nach zwischen den Synagogen ansiedelten. Edmund James, ein anderer Beobachter der Zeit, schrieb in The Immigrant Jew in America über die Kultur, die sich hier zwischen religiöser Tradition und neuen Trends unter den Migrant*innen ausbreitete: „It is almost a desecration of the joy of the Sabbath not to have a little brandy before the fish course, once with the course, and once after. ${ }^{\text {"187 Damit }}$ beschrieb James, dass sich Sitten, wie am Shabbat nicht Alkohol in großen Mengen zu konsumieren, mit neuen Gewohnheiten veränderten. Es war keine Seltenheit sein Shabbatmahl zu einem Unterhaltungsangebot einzunehmen. ${ }^{188}$

185 Diner, Yiddish New York. 52.

186 Riis, How the Other Half Lives, 132-134.

187 Edmund James, The Immigrant Jew in America (New York: B.F. Buck \& Company, 1907), 222, siehe außerdem 223-226.

188 Robert W. Snyder, Voice of the City: Vaudeville and Popular Culture in New York (New York, Oxford: Oxford University Press, 1989). 


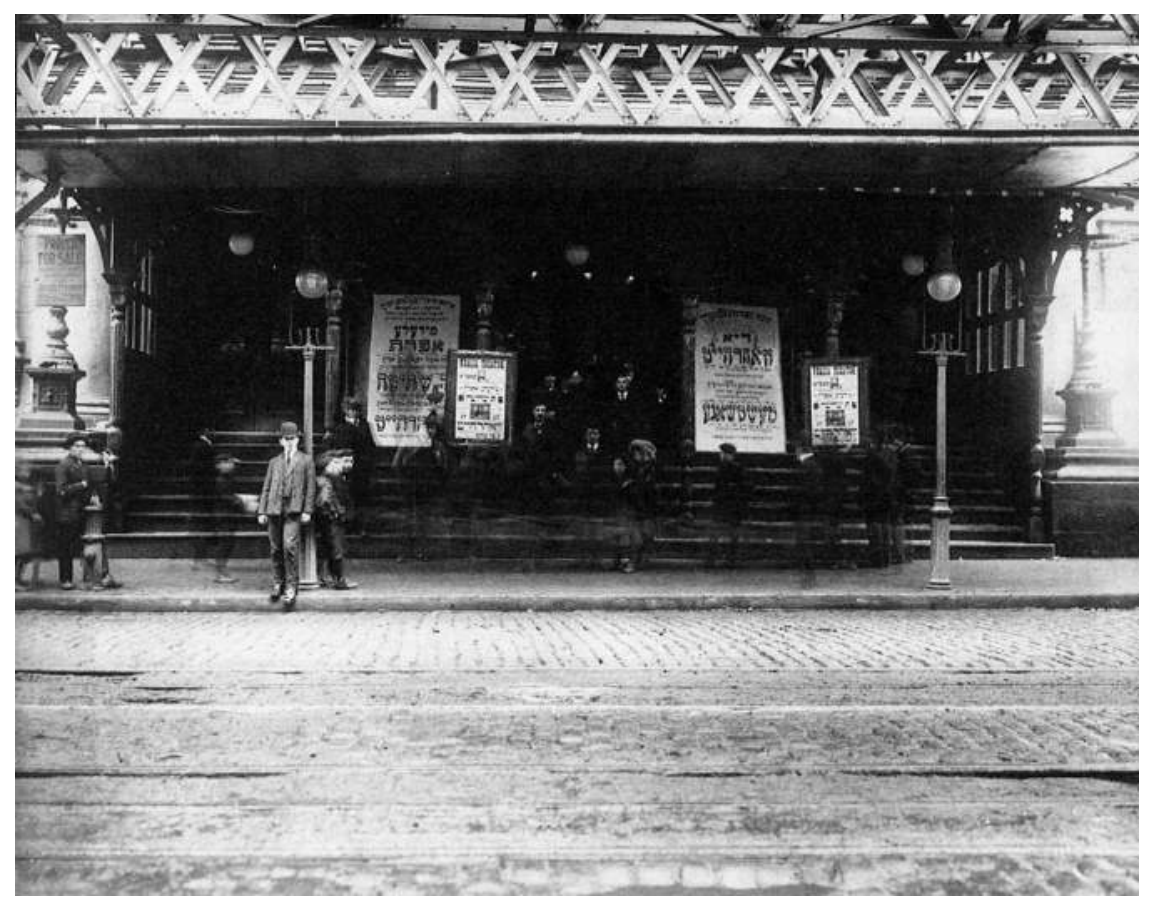

Abb. 13 Blick von der Straße auf das Thalia Theater an der Bowery um 1904, Nahshon, From Bowery to Broadway, 53

Es ist bekannt, dass die Bowery von einer Vielzahl an Theatern geprägt wurde. Riis verwies aber auch auf die in der "Jewtown“ neu entstehenden anderen Formen populärer Unterhaltung, etwa die unzähligen „Tanzschulen“. Gewöhnlich geführt von Männern, die tagsüber in Schneidereibetrieben oder in der Zigarettenherstellung arbeiteten, erstreckten sich die Tanzschulen zwischen dem unteren Ende der Ludlow Street, der Baxter Street und der Bayard Street. „The young people in Jewtown are inordinately fond of dancing [...]". Teil der alltäglichen Routine war es, dass sie „[... ] after their day's hard work will flock to these ,schools" for a night's recreation. “189 Neben den Tanzschulen interessierten sich die jüdischen Migrant ${ }^{\star}$ innen vor allem für die neu entstehenden „music halls“ und „vaudevilles“. Die Aufführungen konnten häufig ohne Eintritt besucht werden. Während der Darbietungen in den Singspielhallen konnte das Publikum Speisen und Getränke genießen. ${ }^{190}$ Man unterhielt sich, während

189 Riis, How the Other Half Lives, 138.

190 Die in den Music Halls und Varietés bedienenden Kellnerinnen ließen in den letzten Jahrzehnten des 19. Jahrhunderts ein besonders Bild der „Bardamen“ entstehen. Peter Bailey, 
man unterhalten wurde: Ein Vergnügen, zu dem die Bewohner*innen New Yorks üblicherweise die ganze Familie mitbrachten. ${ }^{191}$ Die Singspielhallen und Varietés gewannen zunehmend an Beliebtheit, was allerdings bedeutete, dass das Publikum in den großen Theatern ausblieb. Aus diesem wachen Interesse an neuen Formen resultierte, laut den Kritikern, der Untergang des jiddischen Theaters und der großen jiddischen Dramaturgie. Die Schuld daran und die daraus resultierende vermeintliche kulturelle Degeneration des Theaters hätten die Migrant*innen getragen. ${ }^{192}$ Was in Budapest also von den Nationalist ${ }^{\star}$ innen angestrebt worden war, nämlich die Zerstörung der Plurikulturalität, war auch in New York im modernen Charakter populärer Kultur als zerstörend wahrgenommen worden.

Diese Interpretation basiert zum einen auf einer dichotomen Vorstellung darüber, was „populäre“ und was „hohe“ Dramatik sei. Die Interpretation basiert aber vor allem auch auf dem indirekt fortgeführten Schluss, dass sich zwischen den populären Vaudevilles und der Dramaturgie weder eine gemeinsame Entwicklung zu neuen Formen überlappte, noch dass diese Entwicklung ein gesamtgesellschaftliches Phänomen gewesen war. Das hängt bis zu einem gewissen Teil mit der Verortung der Populärkultur an der Lower East Side zusammen. Es beruht jedoch auch auf einem Narrativ, demzufolge nur Jüdinnen und Juden das potentielle Publikum für die Aufführungen gewesen seien: Neben den

Popular Culture and Performance in the Victorian City (Cambridge, New York: Cambridge University Press, 2003), 155-166.

191 Thissen, Should a Married Woman visit a Yiddish Music Hall?

192 Diese Interpretation nimmt ihren Ausgang in der zeitgenössischen Debatte um die „Massenkultur", wie sie in New York von den sozialistischen jiddischen Zeitungen geführt wurde. Bernard Gorin, der die erste Geschichte des Migrantentheaters in New York in Jiddisch vorlegte, vertrat ebenso die These, dass die Singspielhallen Schuld am Untergang und an der ausgebliebenen Weiterentwicklung des jiddischen Dramas gehabt haben. Gorin Bernhard, Di geshikhte fun yidshen teater: zwei tausend yahr 2 (New York: Literarischer Ferlag, 1918), 178-180. Judith Thissen weist darauf hin, dass die Geschichte der Spielstätten der jüdischen Migrant*innen bislang nur hinsichtlich deren Bedeutung für die Entwicklung des Dramas untersucht worden sind. Thissen untersucht die ökonomische Ausgangssituation und ihren Zusammenhang mit den theatralen Entwicklungen an der Bowery und legte eine Diskussion der Rahmenbedingungen vor. Darin vertritt sie die These, dass allgemeinere ökonomische Entwicklungen für den Untergang des jiddischen Theaters verantwortlich gewesen seien. Die sonst überaus rezente Studie hält aber implizit unhinterfragt an der Annahme fest, dass nur die Immigrant*innen das ökonomische Potential der jiddischen Theater waren. Thissen argumentiert, dass die Produktionen auf einem „ethnic limited market“ Abnehmer*innen finden mussten, was die Erklärung der ökonomischen Umstände beschließt. Judith Thissen, „Reconsidering the Decline of the New York Yiddish Theatre in the Early 1900s", Theatre Survey 44, no.2 (2003): 173-197, 182. Für die Beschreibung der Entwicklungen in der Populärkultur ist aber, so möchte ich konstatieren, gerade das Argument der Abgeschlossenheit und einer ethnischen Exklusivität zu hinterfragen. 
Hilfsvereinen für Migrant*innen, die ganze Aufführungen als Benefizveranstaltungen aufkauften und somit subventionierten, hätten die Aufführungen nur die jüdischen Migrant ${ }^{*}$ innen interessiert. ${ }^{193}$ Bei einem näheren Blick in die Berichterstattung über die Aufführungen ergibt sich allerdings ein differenzierteres Bild: Migrant ${ }^{\star}$ innen wie Nichtmigrant ${ }^{\star}$ innen, Jüdinnen und Juden und Nichtjüdinnen und Nichtjuden besuchten gemeinsam die Aufführungen. Und auch wenn die häufig in einer späteren Beschreibung der bunten kulturellen Szene beigefügten Attribute- ,jiddisches“ Theater, etc. - anderes suggerieren, waren die Theater und Spielstätten nicht chronologisch aufeinanderfolgende kulturell homogene Räume.

Das erste sogenannte ,jiddische Theater", das in New York gegründet wurde, war das Grand Theatre an der Bowery 225, Grand Street und Ecke Chrystie Street. ${ }^{194}$ Über die Jahre entstanden das Windsor Theatre, das Thalia Theatre und schließlich das People's Theatre. ${ }^{195}$ Letzteres übernahmen Jacob Adler (1855-1926) und Boris Thomashefsky (1868-1939) von Tony Pastor (1837-1908) und seiner „traveling company“. Die jiddischen Theater entstanden an der Bowery in Theatern, die zuvor als irische und deutsche und danach als italienische und chinesische Theater geführt worden waren. Die jiddische Dramatik vor der Jahrhundertwende schöpfte aus dem Erbe des Purimspiels (traditioneller populärer Volksstücke, die Esthers Triumph über den Erzfeind der Juden Haman erzählen) und entwickelte sich entlang der Werke der drei großen jiddischen Literaten Scholem Alejchem (1859-1916), Jizchok Leib Perez (1852-1915) und Mendele Moicher Sforim (1835/6-1917). ${ }^{196}$ In New York prägten vor allem die Werke von Boris Thomashefsky und Joseph Lateiner ihre Dramaturgie. ${ }^{197}$

Das People's Theatre war das einzige unter den vier jiddischen Theatern, das, wie häufig argumentiert wird, aufgrund seiner überdurchschnittlichen Offenheit gegenüber einem breiteren Kanon populärer Stücke als einziges nicht

193 Gorin, Di geshikhte fun yidshen teater 2, 178-180. Thissen, Reconsidering, 182.

194 Es war das erste Theater New Yorks, das spezifisch als jiddisches Theater gebaut wurde. Es eröffnete 1903, zu einem Zeitpunkt, an dem der Hype um die Music Halls schon begonnen hatte. Nahshon, Overture, 32 und 43. Thissen, Liquor and Leisure, 184-185.

$195 \mathrm{Zu}$ der Etablierung der einzelnen Theater siehe Thissen, Reconsidering, 175-180.

196 Als biblisches Thema in (religiös-)populärer Unterhaltung und sehr beliebtes Motiv ist die Geschichte von Esther und Hamam, der Triumph der Juden im babylonischen Exil, an den Purim erinnert. Zum Motiv des Purimspiels im Theater siehe Shari Troy, On the Play and on the Playing: Theatricality as Leitmotif in the Purimshpil of the Bobover Hasidim (Ungedr. Diss.: City University New York, 2002).

197 Nahma Sandrow, Popular Yiddish Theatre: Music, Melodrama and Operetta, in: Edna Nahson (Hg.), New York's Yiddish Theater: From Bowery to Broadway (New York: Columbia University Press, 2016), 64-83, hier 64-72. Zu Thomashefsky siehe Boris Thomashefsky, Mayn lebns-geshikhte [Meine Lebensgeschichte] (New York: Trio Press, 1937). 
immer wieder an englischsprachige Gruppen vermietet werden musste. ${ }^{198}$ Die anderen, vor allem das Windsor Theatre und das Thalia Theatre, die einander gegenüberlagen, machten einander das Bestehen nicht einfach. Schikanen und harter Konkurrenz machten ein Überleben beinahe unmöglich. ${ }^{199}$ In der Unterhaltungsszene an der Lower East Side, hob die New York Times hervor, herrschte ein enormer Konkurrenzkampf. Was das eine Theater als Vorführung anpries, hatte das gegenüberliegende Theater schon kopiert und adaptiert und ersteres war gezwungen, etwas Neues anzuschlagen:

'Was and was not'? Yes; and in this wise. The management of the theatre visited heard the dark secret that the opposition house had in active preparation a translation of a wonderful London and Parisian success - a play to be called 'Die Gassen Kinder'. No more was needed. Vincent Crummles, whether in Portsmouth or on the Bowery, is ever a man of resource and prompt action. The services of Mr. Feinman were called into requisition. He was told to write a play round the ideas suggested by the name, et voilà tout! $!^{200}$

Bis in die 1920er Jahre eröffneten permanent neue Spielstätten und andere mussten ihre Tore schließen. Gleich mehrmals eröffnete das National Theatre - zuerst an der $10^{\text {th }}$ und Ridge Avenue, ${ }^{201}$ später das Jacob \& Katzs National Theatre an der Houston Street und $2^{\text {nd }}$ Avenue ${ }^{202}$ und schließlich Thomashefskys National Theatre in der Houston Street $111 .{ }^{203} \mathrm{Zu}$ einem der letzten, die eröffneten, zählte Das Naye Yidisher Teater. Es eröffnete 1919 als Teil des Madison Square Gardens im vormaligen Garden Theatre an der $27^{\text {th }}$ Street. $^{204}$

Im Umstand, dass es sich die meisten nicht leisten konnten, mehrmals wöchentlich in die Theater zu gehen, erkannten Jacob Adler, Joseph Edelstein (1858-1940) und Boris Thomashefsky ein Potential und entwickelten neben der Konkurrenz unter den jiddischen Theatern ein neues Format: die Yiddish Music Hall. ${ }^{205}$ Nachdem im September 1901 das Eldorado Theatre als erste

198 Thissen, Reconsidering, 178 und 182-184.

199 Nina Warnke, Patriotn and Their Stars: Male Youth Culture in the Galleries of the New York Yiddish Theatre, in: Joel Berkowitz, Barbara Henry (Hg.), Inventing the Modern Yiddish Stage: Essays in Drama, Performance, and Show Business (Detroit, Michigan: Wayne State University Press, 2012), 161-183, 169.

200 NYT, 25.12.1898, 13.

201 AJHS, P-978 Theater and Film Poster Collection of Abram Kanof, 1967-001-163 Poster „A Mothers Heart" at the National Theatre, 16.10.1914.

202 Nahshon, From the Bowery to Broadway, 35.

203 Das Thomashefsky National Theatre eröffnete 1912. Nahshon, From the Bowery to Broadway, 31.

204 Nahshon, Maurice Schwartz and the Yiddish Art Theater Movement, 156.

$205 \mathrm{Zu}$ Yiddish Music Halls siehe Nina Warnke, „Immigrant Popular Culture as Contested Sphere: Yiddish Music Halls, the Yiddish Press, and the Process of Americanization, 1900-1910“, Theatre Journal 48 no.3 (1996): 253-277. 
Yiddish Music Hall an der Bowery eröffnet hatte, gründeten Adler, Edelstein und Thomashefsky nur wenige Monate später die People's Music Hall gewissermaßen als Ableger des vormaligen People's Theatre. ${ }^{206}$ Dieser Typ populärer Kultur habe den „neuen“ New Yorker*innen entsprochen, schrieb Jacob Gorin 1918 in seiner Geschichte des jiddischen Theaters: „Zu der Zeit [um 1900] entstanden die Music Hallen. [...] Die Unterhaltung in der Singspielhalle war wie gemacht für die neu Eingewanderten [...] Was die Theater mehr an Talent, Möglichkeiten und Erfahrung hatten, konnten die Musik Hallen an Jugend aufweisen. “207 Nachdem 1901 die erste Yiddish Music Hall eröffnet hatte, gab es in New York 1906 bereits 14 jiddische Music Halls, deren Erfolgskonzept Programm-Potpourris wie in den Wiener und Budapester Varietés waren. ${ }^{208}$

Gorins Vergleich zwischen den Theatern und den Music Halls und seine Einschätzung derer Popularität war nicht nur scharfsinnig beobachtet, sondern verwies explizit auf den Wettbewerb zwischen großen Theatern und Singspielhallen. Nur vier Monate nach der Eröffnung der ersten Music Hall an der Bowery gab es bereits drei Spielstätten dieses neuen Formats: das Eldorado Theatre, das London Theatre und die People's Music Hall. Für viele Aufführungen musste kein Eintritt bezahlt werden; die Music Halls machten mit der Bewirtung der Besucher*innen ihren Umsatz. Bald unterschied die amerikanische Szene zwischen sogenannten „big-time-variétés“ und „small-time-variétés“. „Bigtime-variétés“ waren große Varietétheater mit nur zwei Vorstellungen täglich und wöchentlichem Programmwechsel. „Small-time-variétés“ spielten fünfmal am Tag, boten ab den 1910er Jahren auch zunehmend Kinovorführungen an und änderten das Programm halbwöchentlich. Der Besuch mit der ganzen Familie war nicht nur geduldet - das Familienvarieté als Marktkonzept war entdeckt. ${ }^{209}$ Bis 1910 hatten die Music Halls die Theater schließlich an Beliebtheit weit übertroffen. ${ }^{210}$ Verschiedene Organisationen, etwa das Committee of Entertainment, versuchten immer wieder, die Aufführung jiddischer Dramen zu fördern, indem sie sie anregten und die gesamten Spielzeiten aufkauften, um mit Schulklassen hinzugehen. ${ }^{211}$

Mit Europa standen um die Jahrhundertwende drei Music Halls in regem Austausch: die Imperial Music Hall, die Toni Pastor's Music Hall und die Koster

206 Thissen Judith, Early Yiddish Vaudeville in New York City, 248.

207 Gorin, Geshikhte fun idishn teatr 2, 179-80. Anfänglich warnte Gorin vor den Singspielhallen und auch in der jiddischen Presse gab es eine heftige Kampagne, die vor dem Besuch dieser Stätten abriet.

208 Thissen, Reconsidering, 185. Thissen, Liquor and Leisure, 184-187.

209 IAR, 10.8.1913, 5.

210 Thissen, Liquor and Leisure, 185-187.

211 Zum Beispiel TJM, 28.11.1902, 7. 
and Bials Concert Hall. ${ }^{212}$ Erstere zählte zu den ersten Singspielhallen, die auf amerikanischem Boden eröffnet hatten. Aufgrund der schnell steigenden Besucherzahlen musste die Imperial Music Hall bereits im Herbst des Jahres 1892 saniert werden und sich räumlich vergrößern. Bevor die Türen wieder für das Publikum öffneten, wurden die Presse und Kolleg*innen aus der Szene zu einer Premierenvorstellung eingeladen. Die Kritiken vermerkten, dass das räumliche Arrangement noch immer sehr stark an das vorherige erinnere und dabei aber weniger praktisch war. Die neu angeschafften Stühle könnten nicht für rasche und flexible Raumgestaltung verwendet und damit dem, was das Publikum sucht, gerecht werden. ${ }^{213}$ Rund zehn Jahre später hatten sich die räumlichen Ansprüche des Publikums an die Orte des Amüsements gesteigert. Pompöse Dekorationen und luxuriöse Raumgestaltung wurden nun vom Publikum gefordert. Edmund James beschrieb 1907 in "Amusement and Social Life" diese Entwicklungen wie folgt:

Ten years ago, it would have been impossible for even one of these restaurants, the acme of social life on the East Side, to have paid even running expenses; today there are a half-dozen taxed to their utmost capacity daily and nightly, and more preparing to make a bid for the profitable approval of the East Side with brighter illuminations, gaudier trimmings, more aesthetic furnishings than those which now ride on the golden crest of popularity. $^{214}$

Um den Ansprüchen des Publikums inhaltlich trotzdem zu genügen, machten sich die Music Hall Direktoren vor den Sommersaisonen auf den Weg nach Europa, um dort neue Stars zu engagieren. Für die Sommersaison 1893 in Koster and Bials Concert Hall, die Anfang Juni eröffnet werden sollte, reiste einer der beiden Direktoren nach Europa. Die New York Times berichtete, dass Albert Biale, der nun auf seinem Weg zurück von Europa war, eine große Zahl an neuen Engagements lukrierte. ${ }^{215}$ Der Bericht sprach auch eine mögliche Konkurrenzsituation zwischen zugereisten Künstler*innen und der heimischen Szene an. Sogleich beruhigten die Berichte aber auch die heimischen Akteur ${ }^{*}$ innen, dass, [...] the American girl has not lost her power to attract, in spite of the great inroad of foreign variety artists“.216

212 Diese drei schienen zumindest sowohl in der IAR als auch NYT immer wieder auf. Zum Beispiel IAR, 1.11.1894, 13.

213 NYT, 22.10.1892, 4.

214 James, The Immigrant Jew in America, 223.

215 NYT, 4.6.1893, 13: „[...] Albert Biale, who is now on his way home from Europe, having made a large number of new engagements."

216 NYT, 4.6.1893, 13. 


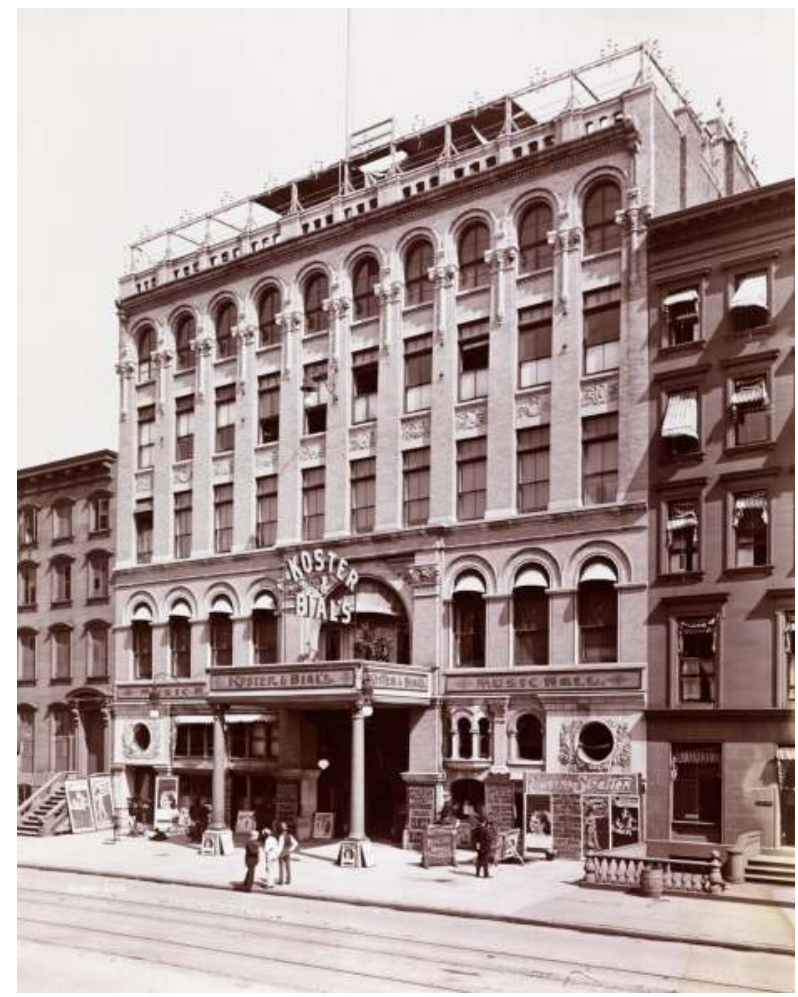

Abb. 14 Koster \& Bial's Concert Hall, Byron Company, Museum of the City of New York, 41.420 .487

Zurückkommend auf das vorherrschende Narrativ, dass die Immigrant*innen und ihre Vorliebe für diese neue Form populärer Kultur den Untergang des jiddischen Theaters bedeuteten, ist zusammenfassend festzuhalten: Zeit- und raumübergreifend zwischen Wien, Budapest und New York frequentierten niemals ausschließlich Jüdinnen und Juden oder Migrant*innen die Tanzschulen, Theater oder anderen Etablissements. Wie zahlreichen Berichte in Zeitungen zu entnehmen ist, besuchten auch breite Kreise des amerikanischen Publikums die Aufführungen. Zeitungsartikel berichteten nicht nur darüber; sie forderten explizit zu Besuchen der Spielstätten an der Bowery auf. ${ }^{217}$ „Have you ever witnessed a Yiddish play?" - fragte etwa die New York Times 1898 in einem Artikel. Fortfahrend betonte der Autor des Artikels, dass die Theater an der Bowery nicht nur hervorragende Aufführungen spielten, sondern auch ein 
wunderbarer Ort seien, um mit den jüdischen (und anderen) Migrant ${ }^{\star}$ innen in Kontakt zu kommen. ${ }^{218}$ Zudem könne, so die New York Times weiter, der „process of evolution of language" durch die Entstehung neuer Wörter aus anderen Sprachen beobachtet werden. Aber auch Stereotype blieben nicht aus. Nach expliziter Diskussion der „Minderwertigkeit“ des sogenannten ,jiddischen Jargons“ schlugen Antisemitismus und Vorbehalte gegenüber den „Down-Town Jews" in New York im Fazit durch: „There may have been great curved noses, Cossack brows, and cheekbones there, but they were not discernible. Refinement and regularity of outline, both in men's faces and women's prevailed“', so Jacob Goldstein, der Verfasser des Artikels. Im Erstaunen des Autors darüber, die pathologischen Zuschreibungen vermeintlich ,jüdischer 'Attribute der Migrant ${ }^{\star}$ innen gar nicht erkennen zu können, ist besonders auffallend, dass etwa die „Kosaken Augenbrauen“ genannt werden: Ausgerechnet die stark mythologisierten Reiterverbände der „Kosaken“ galten im russischen Zarenreich als Ausführende der Pogrome und wurden zum ultimativen Feindbild von Jüdinnen und Juden. Mit den genannten physischen Merkmalen konstruierte Goldstein somit das ultimativ Gefürchtete als Teil des Fremden, im Konkreten verkörpert durch die jüdischen Migrant ${ }^{\star}$ innen. Es wird gewissermaßen auch als Teil des ,Jüdischen' konstruiert; dieses Überlappen von Differenzen und Ähnlichkeiten, das in dem Zitat evident ist, war auch in den Stücken im Kontext von Migration die übliche Praxis (siehe das fünfte Kapitel). ${ }^{219}$ Nichtsdestoweniger kam Goldstein zu dem Fazit, dass der Besuch der jiddischen Spielstätten an der Bowery überaus empfehlenswert sei. ${ }^{220}$

\subsection{Global geteilte Erfahrungen und Entwicklungen in der populären Kultur}

Die sich neu formierenden Räume populärer Kultur in Wien, Budapest und New York hatten einige Charakteristika gemein. Sie waren Räume, in denen Jüdinnen und Juden mit Nichtjüdinnen und Nichtjuden interagierten. In dem in ihnen Dargebotenem stellten sie einen Raum, um Jüdisch-Sein zu artikulieren, zu diskutieren und zu verhandeln, zur Verfügung. Zudem standen die neu entstehenden Räume populärer Kultur für die urbane Erfahrung der Jahrhundertwende: Mobilität und Plurikulturalität, Innovation und gleichzeitig rückblickende Wehmut.

218 NYT, 25.12.1898, 13.

219 Siehe hierzu die Überlegungen zur Ähnlichkeit der Differenz siehe Kapitel 5.

220 NYT, 25.12.1898, 13. 
Die in diesem Kapitel vorgestellten Spielstätten repräsentierten die vielschichtigen Interaktionen von Jüdinnen und Juden mit Nichtjüdinnen und Nichtjuden in der populären Kultur. Ob Josef Modl und Carl Lechner in Wien, Carl Singer als Károly Somossy und Antal Oroszi als Caprice in Budapest oder Boris Thomashefsky als Direktoren von Spielstätten, oder die Vielzahl an Jüdinnen und Juden unter den Schauspieler*innen, die im folgenden Abschnitt im Mittelpunkt stehen - alle Bereiche der populären Kultur gestalteten Jüdinnen und Juden gleichermaßen wie und gemeinsam mit Nichtjüdinnen und Nichtjuden und verhandelten dabei verschiedenste Identifikationen (jüdische, deutsche, österreichische, ungarische, amerikanische, etc.).

Auch der Einfluss von Mobilität auf die populäre Kultur spiegelte sich in der Etablierung von saisonalen Räumen für reisende Ensembles in allen drei Städten wider. Eigens eingerichtete Freiluftbühnen boten den gastierenden Truppen Aufführungsorte. Der Englische Garten war ein großes Gelände nach dem Eingang des Wiener Praters vor den Buden und südlich der Ausstellungsstraße. $^{221}$ Das war jener Bereich, der sich (auch heute noch) vor dem Riesenrad befindet und die größte Konkurrenz für den damaligen Wurstelprater darstellte. Die thematische Gestaltung des Englischen Gartens wechselte jährlich. Die Lagunenstadt wurde zur „,internationalen Stadt“ (1901), dann zur „Blumenstadt“ (1902) und zur „Elektrischen Stadt“ (1903). Die bekannteste Gestaltung war die Verwandlung des Areals zu Venedig in Wien. Ein Teich blieb davon auch nach dem Abbau der Flächengestaltung als Lagunenstadt bestehen. Zuerst als Eislaufplatz neben dem Riesenrad genutzt, wurde dieses Relikt von Venedig in Wien später zur asphaltierten Rollschuhbahn. Neben Venedig in Wien war die Rekonstruktion ,Alt-Wiens' eines der Highlights der Widmungen des Englischen Gartens. ${ }^{222}$

221 Nachdem der Prater unter Maria Theresia noch ausschließlich Jagdgebiet des Kaiserhauses gewesen war, öffnete Joseph II. 1775 das Gelände für die Öffentlichkeit. Eine erste Gaststätte entstand unmittelbar aus dem zuvor vom Kaiser genutzten Gebäude. Die Prater-Hauptallee entwickelte sich nach und nach. Die Etablierung von Gebäuden nahm ihren Lauf; 1786 wurden die drei Kaffeehäuser und später das Lusthaus errichtet. Parallel entstanden mehrere „Schaubuden“, der sogenannte „Wurstelprater“. 1867 kam es mit der Verlängerung der Hauptallee und der Anlage des „Constantin-Hügels“ zur sogenannten „Prater-Reform“. Lackner, Pemmer, Der Prater, 2-10 sowie 18.

222 Die bekanntesten waren Venedig in Wien, Alt-Wien und die Kriegsausstellung. WStLA, M.Abt. 104, A8/33 - Feuer- und Sicherheitspolizei: Theater, Lokale: Wiener Vergnügungspark Kaisergarten - Venedig in Wien: 2516/1914, Plan von der Festspielarena (die bei der Umgestaltung der Fläche zu Alt-Wien erbaut wurde), 22.5.1914. Zur „,internationalen Stadt“ siehe WStLA, M.Abt. 104, A8/16 - Feuer- und Sicherheitspolizei: Theater, Lokale: Wiener Vergnügungspark Kaisergarten, Plan Kaisergarten 1901. 


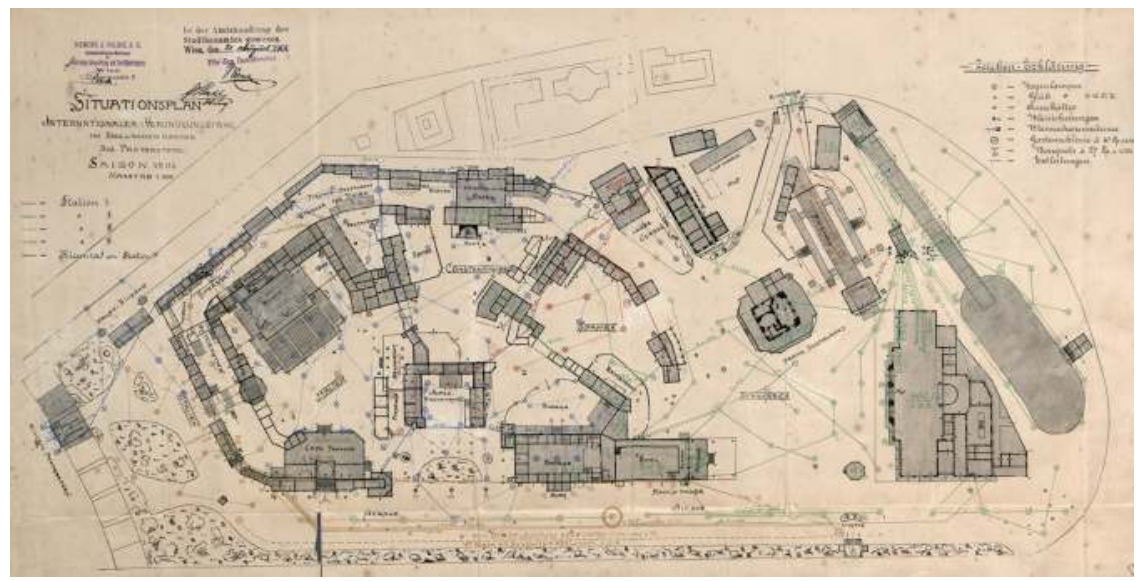

Abb. 15 Die „internationale Stadt“ im Wiener Prater 1901, Wiener Stadt- und Landesarchiv

Bei allen thematischen Ausrichtungen gab es einen Bühnenbereich für Sommergastspiele von internationalen Gruppen. Mit dem raschen Wechsel und den jährlichen thematischen Neuorientierungen war das Freiluftetablissement eine attraktive Örtlichkeit für Ensembles und Künstler*innen auf Sommergastspiel. Nachdem, am Vorbild der Budapester Folies Caprice orientiert, 1901 auch in Wien eine Spielstätte mit dem Namen Folies Caprice gegründet werden sollte, erhöhte das „Original“ seine Präsenz mit jährlichen Gastauftritten im Sommeretablissement im Wiener Prater. 1904 gastierte ein Teil der Budapester Folies Caprice im „Sommertablissement Venedig“ im Theater Bijou im Prater und konnte so selbst ihr Monopol halten. ${ }^{223}$ Die anderen Gruppen mussten sich nach eigenen, neuen Aufführungsorten umschauen und mit Attraktionen aufbieten.

Nur durch ständige Innovation war ein Überleben in der populären Kultur in Budapest, Wien und New York gewährleistet. 1902 etwa suchte die Budapester Orpheumgesellschaft um eine Erweiterung ihrer Spielstättenkonzession an. Nicht mehr nur Vorträge und Lieder, sondern auch Tanz und artistische Aufführungen sollten in das Programm aufgenommen werden dürfen. ${ }^{224}$ Nachdem entschieden war, dass ihre Budapester Konkurrenz, die Folies Caprice, definitiv für nicht mehr als Gastspiele nach Wien kommen würde, bekam die Budapester Orpheumgesellschaft die derartige Erweiterung ihrer Konzession 1904

223 Inserat von den „Original Folies Caprice aus Budapest“ aus dem WMJ, 23.5.1904, 4. Inserat in: Der Floh, 29.5.1904, 8.

224 WStLA, M.Abt. 104, A8/49 - Feuer- und Sicherheitspolizei: Theater, Lokale: Budapester Orpheumgesellschaft, 59232/1902, Schreiben vom 2.6.1902. 
- vorerst für neun Jahre - zugesprochen. ${ }^{225}$ Unter dieser erweiterten Aufführungserlaubnis erprobte die Budapester Orpheumgesellschaft - wie auch andere Ensembles - verschiedenste, aus neuen, technischen Innovationen schöpfende Darbietungen. Unterschiedliche technische Weiterentwicklungen von Aufführungen in der Populärkultur verliefen parallel. Unter der Linse des „neuen Sehens", die Fotografien und erste bewegte Bilder brachten, kombinierten die Stars populärer Unterhaltung in ihren Bühnenvorstellungen zeitgenössische Erfindungen und versuchten die von ihnen produzierten Szenen noch stärker zu animieren. Erste Programme setzten Stereoskope ein, um in den Aufführungen bewegte Bilder nutzen zu können. Um eine neuerliche „SingspielhallenKonzessionserweiterung" suchte die Budapester Orpheumgesellschaft noch im selben Jahr des Erhalts der letzten, 1904, an. Das Ziel der Gruppe war es „[...] auch Bilder mittels eines Stereoskopes vorzuführen $[\ldots] “{ }^{226}$ Die Einigung mit den Folies Caprice brachte bei dieser Anfrage neuerlich der Budapester Orpheumgesellschaft Erfolg ein. Unter der Auflage, dass die Bilder, die mit dem Skioptikon, einem auch „Zauberlaterne“ genannten Projektionsgerät, vorgeführt werden sollten, vorher beim Leopoldstädter Polizeikommissariat vorgelegt werden mussten, erhielten die Budapester die Erlaubnis. ${ }^{27}$

In den folgenden Jahren lösten Kinematographen die Stereoskope ab. Aufgrund der engen Parallelen und der von zahlreichen Wechselwirkungen geprägten Entwicklung von Varieté und Film ist es wenig verwunderlich, dass vor allem in den 1910er Jahren schließlich die Varietés zu „Varieté und KinematographenUnternehmen" expandierten und so bald Singspielhalle und Kino unter einem Dach vereinigten. Im Nestroyhof wurde ab den 1910er Jahren der Nebenraum des Intimen Theaters als „Kinematographisches Varieté“ genutzt. ${ }^{228}$

Das Wiener Apollo ist einerseits ein anderes Beispiel für die Kombinationen des animierten Sehens in der performativen Aufführungspraxis und andererseits das Ineinanderübergehen von Varieté und Kino. Am 1. September

225 WStLA, M.Abt. 104, A8/49 - Feuer- und Sicherheitspolizei: Theater, Lokale: Budapester Orpheumgesellschaft, 1319/2 vom 18.9.1904.

226 WStLA, M.Abt. 104, A8/5 - Feuer- und Sicherheitspolizei: Theater, Lokale: Budapester Orpheum, 128/1904, Schreiben vom 7.1.1904.

227 WStLA, M.Abt. 104, A8/5 - Feuer- und Sicherheitspolizei: Theater, Lokale: Budapester Orpheum, 1845/1910 ex 1904, Erlass vom 5.1.1904.

228 Die entsprechenden Serien des WStLA zeigten die Kontinuität beziehungsweise den Wechsel zwischen der Nutzung von Theatersälen für Aufführungen und Kinovorstellungen. Bei Durchsicht dieser Unterlagen finden sich zu vielen Theatersälen in den ersten Jahrzehnten des 20. Jahrhunderts bei der Baupolizei eingereichte Pläne für den Umbau oder die Adaption der Säle für kinematographische Vorstellungen. WStLA, M.Abt. 104, A8 - Feuer- und Sicherheitspolizei: Theater, Lokale. Sowie WStLA, M.Abt. 104, A11 - Feuer- und Sicherheitspolizei: Kinos. Und die Serie WStLA, M.Abt. 114, A1 - Baupolizei: EZ - Reihe: Allgemeine baurechtliche Angelegenheiten. 
1904 nach amerikanischen Vorbild als Vergnügungsetablissement eröffnet, ${ }^{229}$ verwandelte sich das Apollo basierend auf verschiedenen internationalen Vorbildern bis Ende der 1920er Jahre in das erste Tonfilmtheater Wiens: ${ }^{230}$ In Amerika begannen sich ab den 1880er Jahren in verschiedenen Bundesstaaten Apollo Varietés zu etablieren. ${ }^{231}$ Ben Tieber (1867-1925), der zunächst das Wiener Colosseum leitete ehe er in New York mit der Leitung eines Etablissements betraut worden war, kehrte nach einem Amerikaaufenthalt mit der Idee, ein solches Etablissement zu gründen, nach Wien zurück. Der Architekt Eduard Prandl (1871-1922) plante für ihn einen Neubau, der über ein Restaurant, ein Kaffeehaus, ein Hotel und ein Nebengebäude mit Wohnungen verfügte. Das Vergnügungsetablissement eröffnete schließlich in der Gumpendorfer Straße 63 im sechsten Wiener Gemeindebezirk (Mariahilf). Tieber stand stets in engem Kontakt mit der amerikanischen Szene und buchte immer wieder gefragte internationale Künstler*innen. ${ }^{232}$ Zudem eröffnete Tieber im Wiener Prater einen Lunapark nach amerikanischem Vorbild. ${ }^{233}$ Oft wollte der Entrepreneur die anderen Etablissementleiter ${ }^{\star}$ innen mit derartigen Innovationen ausbieten, was ihn häufig in Streitigkeiten mit seinen Mitbewerber*innen geraten ließ. ${ }^{234}$

\section{(K)Ein exklusiv (nicht)jüdisches Vergnügen?}

Herkömmliche Narrative ordneten populäre Kultur bislang dichotom zwischen Zentrum und Peripherie, sozialen Klassen und jüdisch-nichtjüdischen Tätigkeitsbereichen ein. Während die sogenannte Hochkultur in den Zentren der Metropolen zu finden gewesen sei, wäre die populäre Kultur in deren Randbereichen zu verorten gewesen. ${ }^{235}$ Eine Zuordnung von jüdischen und nichtjüdischen Tätigkeits- und Aktivitätsbereichen hat lange suggeriert, dass Jüdinnen und Juden beinahe ausschließlich die Hochkultur geprägt und konsumiert hätten. Das geht mit der impliziteren Zuordnung von Jüdinnen und Juden zu den Zentren von Städten einher. Gaststätten in ländlicheren Gegenden, etwa

229 WStLA, M.Abt. 104, A8/3 - Feuer- und Sicherheitspolizei: Theater, Lokale: Apollo, 27397/1904, Protokoll vom 1.9.1904.

230 Das Parterre war lange mit Tischgruppen gestaltet. Die Loge war für 30 Kronen abends (bzw. 15 Kronen nachmittags), die Tische bereits ab 1 Krone (bzw. 60 Heller nachmittags) zu erwerben. Lehmann, Wiener Theater- und Konzertsäle (1908), 43.

231 Das wohl bekannteste im New Yorker Stadtteil Harlem entstand 1913.

232 Hödl, Zwischen Wienerlied und Der kleine Kohn, 82-83.

233 NYC, 3.3.1906, 49. 1910 übernahm Tieber nach einem amerikanischen Konsortium auch den Lunapark im Prater, der dann Teil des Geländes von Venedig in Wien wurde. IAR, 1.10.1910, 1.

234 WStLA, M.Abt. 104, A9 - Theaterlokalkommission: S-Saaltheater: Apollotheater 15, 1229/1912, Plan Apollo Theater Erdgeschoss 1904.

235 Allgemein zur problematischen Diskussion von ,Hochkultur' und ,Populärkultur siehe Kapitel 1. 
Wiener Heurigen, hätte die jüdische Bevölkerung dahingegen nicht aufgesucht. Auch hätten sie an der dort stattfindenden Populärkultur weder partizipiert noch diese mitgestaltet. Gerade aber die Etablissementszene zeigte, dass Jüdinnen und Juden und Nichtjüdinnen und Nichtjuden populäre Kultur gemeinsam konstituierten. Eine ausschließliche Verortung in den Zentren der Städte oder in den sogenannten ,jüdischen' Stadtbezirken führt, wie auch die Forschungen von Gluck und Hödl darlegen, zu einem nicht vollständigen Bild darüber, wie und mit wem sich die Menschen zur Jahrhundertwende amüsierten. ${ }^{236}$ Populäre Kultur lässt sich folglich nicht als auf einige wenige Stadtteile begrenztes Phänomen lesen. Das veranschaulichte auch der Blick auf die Spielstätten in diesem Kapitel. In Budapest fanden sich Etablissements besonders häufig im Zentrum des vormaligen Pests, genauso aber auch in den anderen Stadtteilen. Während an der Bowery in New York besonders viele Singspielhallen zu finden waren, fanden sich diese aber gleichermaßen bis nach Harlem und später auch in Williamsburg. Populäre Kultur wuchs mit den Stadtentwicklungen. In Wien waren viele bekannte Gast- und Spielstätten - das Hotel Stefanie, das Hotel Central, der Nestroyhof, das Carltheater und natürlich der Prater in jenem Bezirk um den Nordbahnhof, der zum einen mit einer großen Zahl an jüdischen Migrant*innen aus dem östlichen Europa und zum anderen als eine hohe jüdische Bevölkerung aufweisend bekannt war - angesiedelt. Das Max und Moritz im ersten Bezirk, das Apollo im sechsten Bezirk ${ }^{237}$ und die Vielzahl an Spielstätten im neunten Bezirk zeigen aber, dass die populären Etablissements in Wien auch in anderen Bezirken verortet waren.

Ein Varietégründung von zwei der bekanntesten Autoren der Budapester Orpheumgesellschaft ist ein weiteres Beispiel dafür, dass Populärkultur auch keineswegs ausschließlich in den vorwiegend als jüdisch konnotierten Stadtteilen angesiedelt betrachtet werden kann: ${ }^{238}$ Otto Taussig (1870-1925) und Adolf Glinger (1873-1944) gründeten Anfang September 1910 das Max und Moritz im ersten Wiener Gemeindebezirk in der Annagasse 3, gleich am Eck beim berühmten Hotel Sacher. ${ }^{239}$ Die künstlerische Leitung übernahm der selbst als großartiger Schauspieler bekannt gewordene Ferdinand Gruenecker. Mitwirkender war außerdem der berühmte „Groteskkomiker“ Josef Fleischmann. ${ }^{240}$ Unmittelbar nach der Gründung berichteten die Zeitungen über die gute Aufnahme des neuen Varietés vom Publikum. ${ }^{241}$ Das Max und Moritz sei

236 Hödl, The quest for amusement, 1-4.

237 Das Apollo wurde von Ben Tieber nach amerikanischem Vorbild gegründet.

238 IAR, 1.9.1910, 1.

239 NWJ, 19.9.1910, 4.

240 IAR 1.9.1910, 1.

241 NWJ, 31.10.1910, 6. 
der Budapester Orpheumgesellschaft sehr ähnlich, „[...] mit dem Unterschied, daß die Budapester das derbpikante, die Max und Moritzer das feinpikante Genie pflegten“. ${ }^{242}$ Ab 1914 schloss sich auch Heinrich Eisenbach dem Max und Moritz mitten im Herzen Wiens an. ${ }^{243}$

Zudem waren die Räume populärer Kultur keineswegs statisch, sondern veränderten sich ständig und waren vielerorts zu finden. Auch die Budapester Orpheumgesellschaft übersiedelte, wie dargestellt, bereits in den ersten Jahren (aufgrund interner Streitigkeiten) in das Hotel Central und später wieder zurück. Zeitweise gaben die Gruppen immer wieder Gastspiele in den Pratercafés. Die Budapester und das Intime Theater kamen in den 1910er Jahre temporär auch in der Praterstraße 25 unter. Hier sollte später zudem noch ein weiteres Etablissement entstehen: Unter der Bedingung, dass Josefine Richter-Roland, die in den Räumen zwischenzeitig das Intime Theater betrieben hatte, ihre Konzession zurücklege, erhielt 1919 Emil Richter-Roland, ihr Ehemann, die Konzession für die Spielstätte als Rolandbühne. ${ }^{244}$ Richter-Roland dürfte die überschaubare Größe des dortigen Aufführungsraums bald als nicht rentabel genug erachtet haben, sodass die Rolandbühne ein paar Häuser weiter in die Räumlichkeiten des Hotel Central übersiedelte. Für den großen Saal, in den sich auch die Budapester schon einmal eingemietet hatten, beantragte RichterRoland eine Erlaubnis zur Erweiterung der Raumkapazität. ${ }^{245}$ Anstelle der bislang maximal zulässigen 750 Personen erstrebte er die Ausweitung auf bis zu 900 Personen. Diese räumliche Veränderung interpretierten die Besucher*innen jedoch als negative Neuerung und die dadurch entstandene Atmosphäre wurde als „Menschenhalle“ empfunden und abgelehnt und bald auch geschlossen. ${ }^{246}$

Populäre Kultur um 1900 prägte also verschiedenste Stadtteile und war eine wichtige Kontaktzone von Jüdinnen und Juden und Nichtjüdinnen und Nichtjuden. Ein anderer Vorbehalt gegenüber populärer Kultur und mit ein Grund für deren Vernachlässigung in der Historiographie über Jüdinnen und Juden war lange, dass populäre Kultur kulturell minderwertig sei. Aus diesem vermeintlichen Umstand wurde wiederum das Argument geschöpft, nur bestimmte soziale Klassen hätten populäre Kultur verfolgt. ${ }^{247}$ Der Soziologe Pierre

242 Wiener Montagblatt, 18.11.1912, 2.

243 Koller, Das Wiener Volkssängertum in alter und neuer Zeit, 157-158. Koller merkt fälschlich an, dass das Max und Moritz erst 1914 entstanden sei. Da Eisenbachs Gesellschaft infolge des Weltkrieges nicht mehr auftreten wollte, habe Eisenbach gemeinsam mit Taussig und Glinger das Varieté gegründet, so Kollers Darstellung.

244 WStLA, M.Abt. 104, A8/5 - Feuer- und Sicherheitspolizei: Theater, Lokale: Budapester Orpheum, 455/1919, Schreiben vom 27.4.1919.

245 WStLA, M.Abt. 104, A8/5 - Feuer- und Sicherheitspolizei: Theater, Lokale: Rolandbühne.

246 Der Montag, 8.10.1923, 2.

247 Storey, Cultural Theory and Popular Culture, 5. 
Bourdieu zeigt, dass der Vorwurf des schlechten "Geschmacks" der populären Kultur als sozialer Marker fungierte. ${ }^{248}$ Nachdem Jüdinnen und Juden lange vorwiegend mit der Hochkultur assoziert wurden, schienen sie deshalb von vornherein für eine Studie über populäre Kultur nicht in Frage zu kommen. ${ }^{249}$ In Kombination mit dem Akkulturations- und Verbürgerlichungsnarrativ über die jüdische Bevölkerung, demnach Jüdinnen und Juden nach der Aufklärung in der bürgerlichen Mehrheitsgesellschaft aufgegangen seien, bildet der Vorwurf der Minderwertigkeit den Nährboden dafür, Jüdinnen und Juden und populäre Kultur nur getrennt zu diskutieren.

Diese Vorbehalte halten allerdings einer Prüfung nicht stand: Das Publikum vermochte die Qualitäten dieser vermeintlich wertlosen Unterhaltungsstätten sehr wohl zu erkennen. Sogenannte „hervorragende Gäste“ besuchten die Etablissements. Und mitunter fanden sie sogar am meisten Gefallen an diesem Teil der Stadt - so etwa der Prinz von Wales bei einem Besuch selbiger 1907. ${ }^{250}$ In Budapest wohnten verschiedenste Kreise der städtischen Bevölkerung den Aufführungen bei, betont Mary Gluck. Die Singspielhallen, für die die ungarische Hauptstadt internationale Bekanntheit erlangte, war nicht auf bestimmte soziale Klassen begrenzt, nicht ausschließlich ,deutsch oder, ungarisch, und schon gar nicht auf exklusiv jüdische oder nichtjüdische Akteur ${ }^{*}$ innen begrenzt. ${ }^{251}$ Für New York legt Judith Thissen ebenfalls dar, dass sogar die "gehobene“ Bevölkerung den lebendigen Music Halls der Lower East Side etwas abgewinnen konnte und diese Freizeiträume für die ganze Familie waren. ${ }^{252}$ Die ersten Fotografien, die von der Unterhaltungsszene New Yorks existieren, veranschaulichen dieses Bild. Klaus Hödls räumliches Argument zur Wiener populären Kultur und die in diesem Kapitel ausgeführten Beobachtungen zur städtischen Verortung populärer Kultur in Wien, Budapest und New York demonstrieren ihre soziale Nicht-Gebundenheit und Funktion als sozial vermittelndes Medium, die vor allem auch in ihren Inhalten und Diskussionen evident wird (siehe fünftes Kapitel). Die in diesem Kapitel vorgestellten Räume populärer Kultur der Jahrhundertwende entstanden und bestanden im Spannungsfeld von Migration, Mobilität, Nationalismen, Antisemitismus und jüdisch-nichtjüdischen Interaktionen. Sie waren Räume gesellschaftlicher Transformationsprozesse, urbaner Innovation sowie Kontaktzonen und wesentlicher Teil der Alltagserfahrung in Wien, Budapest und New York. Ihr internationales Flair war Nährboden für eine stetig steigende Nachfrage danach, sich in den Räumen „köstlich zu amüsieren“.

248 Pierre Bourdieu, Distinction: A Social Critique of the Judgment of Taste (Cambridge: Harvard University Press, 1984), 5.

249 Hödl, Zwischen Wienerlied und Der kleine Kohn, 19-21.

250 NFP, 2.8.1907, 7.

251 Gluck, Invisible Jewish Budapest, 148-150.

252 Thissen, Should a Married Women Visit a Yiddish Music Hall? 



\section{Auf der Tour}

Die Reisen der Volkssänger und Soubretten

In der That, die ungarische Hauptstadt ist ein Venusberg mit

großer Kundschaft.

- Wiener Montags Journal über die Folies Caprice $1892^{1}$

Die Zentralstelle für die Überwachung des Mädchenhandels in Wien wandte sich am 5. Oktober 1912 mit einer Beschwerde über den Künstleragenten Jacques Weiser ${ }^{2}$ an das k.k. Ministerium des Inneren: „Das Hotel Varieté Opera in Belgrad ist den Erhebungen zufolge ein Lokal letzten Ranges, in welchem unter dem Deckmantel artistischer Produktionen Mädchen mit Wissen der sie wirtschaftlich ausbeutenden sogenannten Direktoren und artistischen Leiter der Prostitution zugeführt werden. ${ }^{\text {“3 }}$ Wiener Künstleragenturen hatten wiederholt minderjährige Mädchen an derartige Varietés, die sich nur als solche ausgaben, eigentlich aber Bordelle gewesen seien, vermittelt. Im konkreten Fall der in Budapest ansässige Jacques Weiser, dessen Namen „richtig Jakob Weiss“ lautete und als Hinweis auf dessen ,Jüdisch-Sein ' beigefügt wurde. ${ }^{4}$

Künstleragenturen waren seit der Jahrhundertwende vermehrt aufgekommen, denn ab den 1880er Jahren hatte eine "allmähliche Ausdehnung des Artistenwesens" eingesetzt und ab den 1890er Jahren schließlich die populäre Kultur bestimmt. ${ }^{5}$ Nicht nur Künstlernamen und Benennungen von Spielstätten verliehen der Chantant-, Varieté- und Etablissementszene ein internationales Licht. ${ }^{6}$ "Auf die Tour" lautete das Gebot der Stunde. Eine neue Qualität an Mobilität bestimmte die Gesellschaft und das Leben in der Habsburgermonarchie und der Varietés, Etablissements, Singspielhallen und Kabaretts. Am 8. Januar

1 Schrieb das Wiener Montags Journal über die Darbietungen im Folies Caprice. WMJ, 15.8.1892, 1.

2 Jacques Weiser war der Direktor der Elite Orpheum Gesellschaft und arbeitete dort u. a. mit der Lieder- und Walzersängerin Margit Lengyel und dem Gesangshumoristen Max Martini zusammen. NSZL, Színháztörténeti Tár, Mulátok, Elite Orpheum Gesellschaft.

3 OeStA, AVA, Ministerium des Inneren, Allgemein 2122: Mädchenhandel und Prostitution in genere 1908-1918, 37587/1912: Schreiben der Zentralstelle für die Überwachung des Mädchenhandels an das k.k. Ministerium des Inneren, 5. Oktober 1912.

4 OeStA, AVA, Ministerium des Inneren, Allgemein 2122: Mädchenhandel und Prostitution in genere 1908-1918, 37587/1912: Rundschreiben des Ministeriums an alle politischen Überwachungsbehörden, 27. November 1912.

5 Die Redaktion [Ferdinand Steiner], „An unsere geehrten Leser!“, IAR, 8.11.1891, 1.

6 Siehe hierzu Kapitel 3. 
1894 rief die Internationale Artisten Revue, das Sprachrohr der Varieté- und Etablissementkünstler*innen in der Habsburgermonarchie, Ensembles dazu auf, auf Gastspiel zu gehen, da in den Hauptstädten nicht mehr genug Platz für alle sei.

Die wachsende Szene erforderte also von denen, die in ihr wirken wollten, Mobilität. Diese brachte allerdings auch Gefahren mit sich. Dass eben Wiener und Budapester Künstleragenturen Artistinnen und Musikerinnen engagierten, um sie der „Prostitution zu zuführen“, war eines der gängisten Klischees, mit denen sich die Varieté-, Singspielhallen- und Etablissementszene konfrontiert sah. Noch bevor es in der Habsburgermonarchie ein eigenes Fachorgan und Sprachrohr für Künstlerinnen in der populären Kultur gab, hatte Der Artist, die Fachzeitung für das Deutsche Kaiserreich, 1887 auf Entführungen von Wiener und Budapester Künstlerinnen in Bordelle nach Belgrad aufmerksam gemacht. "Schon oft wurde im ,Artist' vor Engagements nach diesem oder jenem Lande gewarnt, aber unbegreiflicherweise finden sich immer noch Leichtsinnige, welche den verlockenden Schilderungen gewissenloser Agenten Gehör schenken und zu spät einsehen, dass sie die bedauernswerthen Opfer geldgieriger Menschen geworden. ${ }^{\text {"7 }}$ Mit dieser resignierenden Feststellung eröffnete Der Artist die Berichterstattung darüber, wie in „Wien und Pest" Verträge für Engagements in Belgrad abgeschlossen wurden, die dann nie entlohnt wurden oder, schlimmer noch, für Künstlerinnen in der erzwungenen Prostitution endeten. ${ }^{8}$ Bei derartigen Warnungen handelte es sich einerseits um reale Gefahren, die mit der künstlerischen Tätigkeit verbunden waren, andererseits aber auch um Denunziationen der populären Kultur und ihrer Akteur*innen. Ob begründet oder nicht, ergaben sich derartige Vorwürfe aus drei Umständen, die mit der Mobilisierung der Szene zusammenhingen: Erstens hatte die Mobilität von Künstler*innen sowie die Internationalität der Szene neue Rollenbilder hervorgebracht. ${ }^{9}$ Zweitens überschattete die weitverbreitete Panik vor (jüdischen) Mädchenhändlern und dem Verschleppen von Frauen ${ }^{10}$ die selbstständige Tä-

7 „Warnungen“, Der Artist, 21.8.1887, 1-2, 1.

8 „Warnungen“, Der Artist, 21.8.1887, 1-2.

9 Schon die frühe Form reisender Musikerinnen in Damenkapellen war oft permanent als „Trittbrett in die Prostitution“ denunziert worden. Siehe hierzu die Ausführungen in diesem Kapitel; sowie Margaret Myrs, Searching for Data about Ladies' Orchestras, in: Pirkko Moisala, Beverly Diamond (Hg.), Music and Gender (Illinois: University of Illinois Press, 2000), 189-213. Die Damenkapellen, die im deutschsprachigen Raum entstanden, spielten hauptsächlich, wie Scott schreibt, Unterhaltungsmusik. Scott weist nach, dass diese Kapellen bereits in den 1870er Jahren auch Tourneen bis New York unternahmen. Derek B. Scott, Sounds of the Metropolis: The $19^{\text {th }}$ Century Popular Music Revolution in London, New York, Paris and Vienna (New York, Oxford: Oxford University Press, 2008), 21-24.

10 Keely Stauter-Halsted, The Devil's Chain: Prostitution and Social Control in Partitioned Poland (Ithaca, London: Cornell University Press, 2015). 
tigkeit von Künstlerinnen in Varietés fern von ihren Heimatstädten. Drittens eröffneten die neuen Räume populärer Kultur, insbesondere Schlafstätten für Künstler*innen, Möglichkeiten, evozierten aber auch Spekulationen.

In diesem Kapitel geht es darum, wie populäre Kultur auf Tour ging. Die reisenden Künstler*innen formten zum einen ein völlig neues Geschäftsfeld. Das brachte neue Organisation mit sich. Agenturen, Management und Zeitungen, sowie die im dritten Kapitel beschriebenen speziellen Räumlichkeiten, in denen die Künstler*innen von auswärts nächtigen konnten und die so den internationalen Austausch ermöglichten, wurden gegründet. Die Mobilität brachte der populären Kultur ihre Anziehungskraft. Die international klingenden Künstlernamen und neue Rollenverständnisse, die den Rahmen für das Agieren auf der Weltbühne aufspannten, ließen die Gäste in die Spielstätten strömen. Damit eröffnete die neue Mobilität der populären Kultur Möglichkeiten. Zum anderen brachten die Mobilität und die mit ihr verbundene Infrastruktur Gefahren mit sich, nährten Stereotype und schürten Vorbehalte und Ängste, wie etwa, dass Varietés als Deckmantel für heimliche Prostitution fungierten. Das Zusammenwirken von all dem - also Organisation, Rollenausprägungen, Vorwürfe und nicht zuletzt deren Dynamik für die populäre Kultur als komplexes Interaktionsfeld von Jüdinnen und Juden wird im Folgenden dargestellt.

\subsection{Mobilität und populäre Kultur}

Der eingangs zitierte Gerichtsfall rund um den Künstleragenten Jacques Weiser verwies eindringlich auf eine der Gefahren, die Mobilität für Künstler*innen bedeuten konnte. Dennoch, so stellte es etwa die Internationale Artisten Revue dar, gab es für Künstler*innen in der Varietészene um 1900 keine Alternative zur Mobilität. „Doch alle Artisten haben keinen Platz in der Hauptstadt und folglich: auf d.e Tour!"[!], ${ }^{11}$ zeigte die Internationale Artisten Revue eine allgemeine Beobachtung auf.

Die Internationale Artisten Revue verwies mit diesem Artikel nicht nur auf die Mobilität der Szene populärer Kultur. Sie umriss auch lebendig die Rolle, die den Künstlerinnen, vor allem den Sängerinnen, die sich Soubretten nannten, innerhalb der Szene zukam. In diesem Artikel hatten die reisenden Sänger*innen und Artist ${ }^{\star}$ innen zudem die Gelegenheit, zu berichten, wie hart ihr Geschäft war und konnten ihre prekären Lebensumstände unterwegs aufzeigen. Doch nicht nur das sich „ausdehnende Artistenwesen“, sondern auch explizit das Publikum, das internationale Künstler*innen sehen wollte, forderte förmlich die Mobilität der Szene ein. „Auf die deutschsprechenden Staaten angewendet

11 IAR, 8.11.1891, 1. 
findet das Sprichwort, dass, der Profet in seinem Vaterlande nichts gilt' die vollste Berechtigung, und daher kommt es auch, dass Artisten welche oft durch $\mathrm{u}[$ nd] durch Deutsche sind, gezwungen werden unter ausländischer Firma zu arbeiten"[!], berichtete Karl Kutschera, ein Kenner der Szene. ${ }^{12}$

Es musste regelrecht der Traum von Künstler*innen sein, in ein Engagement außerhalb der Heimat gerufen zu werden. Dieses Diktum nahm Arthur Schnitzler (1862-1931) zum Ausgangspunkt einer Erzählung, die er 1895 mit dem Titel Der Empfindsame - eine Burlesque zu Papier brachte. Schnitzler nahm die Lebensgeschichte einer Sängerin zum Anlass, Einblick in potentielle Sängerkarrieren um die Jahrhundertwende zu geben: Die junge Frau und ihre Leidenschaft für die Varietékunst sind der Grund dafür, dass der „arme Fritz Platen“ sich sein Leben nimmt, nachdem er einen Brief von seiner Liebe gelesen hat. Der Brief beginnt mit den Worten: „Eine Reisetasche steht neben dem Bett, und im Vorzimmer rumort Mama, packt noch, denn morgen Früh, Fritz, [...] morgen früh reisen wir ab, Mama und ich, und in acht Tagen steh ich das erstemal auf der Bühne. Ja, Fritz, ich hab ein Engagement. “13 Die junge Frau, die in Schnitzlers Erzählung ihrem Liebhaber zum Abschied schreibt, studiert Gesang bei vielen Lehrenden. Die ganze Mühe hat ihr aber nichts geholfen, denn sie hat ihre Stimme vermeintlich unwiederbringlich verloren. Sie sucht einen Arzt nach dem anderen auf, doch keiner kann ihr helfen; bis der „24. Arzt“ ihr „einen Liebhaber“ verschrieb. Keine andere Rettung ihrer Karriere sehend, kommt sie dieser Empfehlung nach. Am Heimweg von „Arzt 24 “ erblickt sie auf der Terrasse des Café Imperials Fritz, der auch unverzüglich an ihr Gefallen findet. Die beiden durchleben eine erfrischende Romanze, die allerdings einen bitteren Beigeschmack hat, nämlich, dass nur die Sängerin um deren Vergänglichkeit weiß. Mit jeder Zärtlichkeit, die sie mit Fritz austauscht, komme ihre Stimme ein Stück zurück. Beim nächsten Vorsingen schon bekommt sie unverzüglich ein Engagement auf „drei Jahre mit steigender Gage für erste Partien" angeboten. ${ }^{14}$

Schnitzler umriss mit der Erzählung Der Empfindsame viele Diskurse um Sängerinnen in der populären Kultur: von der Wichtigkeit, ein Engagement zu bekommen, über die damit unabdingbar verbundene Reisetätigkeit, bis hin zu Rollenbildern wie der "Chantant-Mutter", die ihre Tochter begleiten musste, um zu verhindern, dass diese alleine reist, und schließlich das Bild der Soubrette, die nur auf ihre Karriere bedacht, Männern das Herz bricht. Auf einer anderen Ebene deutete Schnitzler aber auch auf das dahinterstehende Vorurteil

12 Karl Kutschera, „Artisten Namen“, IAR, 1.4.1894, 1-2.

13 Arthur Schnitzler, Der Empfindsame [1895], in: ders., Die griechische Tänzerin: Frühe Erzählungen (Berlin: Verlag der Nation, 1985), 78-85, 80.

14 Schnitzler, Der Empfindsame, 78-85. 
hin, dass talentierte Sängerinnen immer Liebhaber hätten oder haben müssten. All diese Motive rund um die populäre Kultur griff Schnitzler nicht nur in Der Empfindsame auf. In der Erzählung Das neue Lied steht die Genesung der erblindeten Soubrette Maria Ladenbauer, „genannt die weiße Amsel“, und ihr Auftritt samt Präsentation eines neuen Couplets rund um den Versuch, ihren verlorenen Liebhaber Karl von Breiteneder zurückzuerobern. ${ }^{15}$ Selbst in seiner Autobiografie Jugend in Wien berichtet Schnitzler über eine Beziehung mit einer jüdischen Sängerin, die er bald beenden musste, weil sie zunächst als „Choristin in ihr Sommerengagement an eine österreichische Provinzbühne" ging und ihn dann in einem „vergnügten Schreiben“ wissen ließ, „[...] daß sie eine künstlerische Tournee als Tanzsängerin angetreten habe, worauf sie für mich [Arthur Schnitzler] endgültig verschollen blieb“. ${ }^{16}$ Schnitzlers Erzählungen illustrieren, dass Mobilität die Ausprägung von Geschlechterrollen in der populären Kultur beeinflusste; ein Punkt, auf den das Kapitel später zurückkommt.

In der Mobilität von Künstler*innen und Ensembles überlagerten sich Bilder und Stereotype über Reisende. Dass in Schnitzlers Erzählung die Mutter ihre Tochter begleitete, war kein Zufall. Um die Jahrhundertwende migrierten noch immer tausende Menschen aus den östlichen Gebieten der Monarchie und dem russischen Ansiedlungsrayon, was nicht zuletzt gewissermaßen einen mobilen Sog der Anonymität für den Mädchenhandel bot. Die Gefahr wurde so omnipräsent, dass sich bald eine regelrechte Panik entwickelte. Die Gesellschaft fürchtete, dass allein reisende Frauen - Töchter, Ehegattinnen, Freundinnen Opfer des Menschenhandels würden. Teil der Panik war das Stereotype vom „jüdischen Mädchenhändler" - ein Bild eines von einer oder mehreren Frauen begleiteten Juden, das im antisemitischen Diskurs der Zeit entstand. ${ }^{17}$

15 Die Erzählung Das neue Lied publizierte Schnitzler in der „Osterbeilage“ der Neuen Freien Presse am 23. April 1905. Arthur Schnitzler, Das neue Lied, Neue Freie Presse, 23.4.1905, 31-34.

16 Arthur Schnitzler, Jugend in Wien: Eine Autobiografie [1968] (Frankfurt am Main: Fischer Taschenbuch Verlag, 2012).

17 Zum antisemitischen Hintergrund dieses Stereotyps siehe John W. Boyer, Political Radicalism in Late Imperial Vienna: Origins of the Christian Social Movement, 1848-1897 (Chicago: University of Chicago Press, 1981), 225-227; sowie Keely Stauter-Halsted, „A Generation of Monsters: Jews, Prostitution, and Racial Purity in the 1892 L'viv White Slavery Trail“, Austrian History Yearbook 38 (2007): 25-35. Der antisemitische Diskurs überlagerte sich auch mit Diskussionen über Menschenhandel, ,whiteness' and ,Jewishness' unter kolonialer Perspektive und separierte sogenannte „weiße Sklav`innen“ von Opfern aus Südosteuropa. Petra de Vries, „White Slaves' in a Colonial Nation: The Dutch Campaign Against the Traffic in Women in the Early Twentieth Century", Social and Legal Studies 14, no. 1 (2005): 39-60, 45-48; Stauter-Halsted, The Devil's Chain, 132; Nancy M. Wingfield, The World of Prostitution in Late Imperial Austria (New York, Oxford: Oxford University Press, 2017), 145-155, 193-202; 
Dieses Stereotyp des „reisenden jüdischen Mädchenhändlers“ zeichnete Scholem Alechjem in seinen Eisenbahngeschichten - er nannte sie Erzählungen über "Handlungsreisende“ - nach. Als "reisenden, jüdischen Mädchenhändler" beschrieb Scholem Alechjem eine beinahe mythische Gestalt. Er selbst begegnet einer solchen einmal im Zug, so die fiktive Ausgangssituation in der sechsten Eisenbahngeschichte. Der Jude, der durch sein besonders gepflegtes Äußeres in der dritten Klasse des Zuges auffällt, geht offenherzig auf seine Mitreisenden zu. Er spendiert ihnen unterwegs großzügig Alkohol und Speisen und weiß sich mit jedem und jeder anzufreunden. Scholem Alechjem nennt ihn den „Mann aus Buenos Aires“, denn er ist nicht nur Reisender im Zug, sondern selbst Migrant, der sich in Südamerika, aber auch in New York und London, wie er erzählt, ein Leben mit seinem „Unternehmen“ aufgebaut hat. Diese Zugreise führt ihn nun zurück nach „Soschmaken“, um zu heiraten. ${ }^{18}$ Im Sprechen über sein „Unternehmen“ in Buenos Aires bleibt er allerdings vage. Schließlich muss Scholem Alejchem deshalb den Mann fragen: „Ich wollte Euch fragen ... oh, sie pfeifen schon! Also: Was ist eigentlich Euer Geschäft? Mit was handelt Ihr?" Die Antwort macht den Reisenden dann umso verdutzter, bekam er nur ein „[m]it frommen Artikeln jedenfalls handele ich nicht, lieber Freund, nicht mit frommen Artikeln!“19

Das Stereotyp von umherreisenden Mädchenhändlern und deren Erscheinung mit ihren Opfern als bunte Reisegruppe ähnelte dem Bild von umherreisenden Varietégruppen. Die neue Qualität an Mobilität in der Gesellschaft und in der populären Kultur entwickelte sich parallel zur explosionsartigen Vermehrung der städtischen Bevölkerung sowie mit der baulichen Umgestaltung der Metropolen. Gleichzeitig mit diesen Vorgängen expandierte die populäre Kultur zu dem, was als Massenkultur beschrieben (und häufig auch als solche denunziert) wird - verschiedene Formen von Unterhaltung, die das Verlangen der Bevölkerung nach Amüsement befriedigten, und gleichermaßen auch zugänglich und Teil des Alltags vieler Menschen waren. ${ }^{20}$ Die Menschen erlebten diese Veränderungen ihres urbanen Umfeldes bewusst mit. Sie beklagten die

siehe außerdem die Bestandsgruppe OeStA, AVA, Inneres, MdI, Allgemein, Mädchenhandel und Prostitution.

18 Die Sosch war ein Fluss im russischen Reich, heute großteils Ukraine, Weißrussland und Russland.

19 Scholem Alechjem, Eisenbahngeschichten, zitiert nach 81, für die gesamte Erzählung 66-81.

20 Die Bezeichnung der Massenkultur ist in der Forschung breit diskutiert. Ich beziehe mich, wie in der Einleitung dargelegt, hier lediglich auf Massenkultur als eine alltägliche Kultur, die für viele Menschen Teil der nun verfügbaren Freizeit war. Maase, Grenzenloses Vergnügen, 19-25. Für eine kritische Auseinandersetzung mit der Bezeichnung siehe die Frankfurter Schule. Theodor W. Adorno, Max Horkheimer, Dialektik der Aufklärung: Philosophische Fragmente. (Frankfurt am Main: Suhrkamp, 2016), 128-176. 
vermeintlich besseren, alten Zeiten, die urbanen Lebensumstände der vorangegangenen Jahrzehnte. Dieses Klagen, ein nostalgisiertes Herbeisehnen der Vergangenheit, war ein internationales Phänomen. ${ }^{21}$ Für die populäre Kultur brachte es der Wiener Volkssänger Josef Koller auf den Punkt und sprach von der populären Kultur in Wien um 1900 sogar als einer „neuen Zeit“ des Volkssängertums. ${ }^{22}$ Gibt es Verbindungen zwischen diesem Klagen nach einem vermeintlich besseren Gestern im Amüsement und dessen zunehmender Internationalisierung und Mobilität? Oder, anders gefragt, bekam das Publikum Angst vor der Mobilität populärer Kultur?

Zur Jahrhundertwende reiste eine Vielzahl an Volkssängern, Soubretten und Artist*innen zwischen Städten - innerhalb der Habsburgermonarchie, aber auch zu weiter entlegenen Destinationen wie den Vereinigten Staaten - um ihr Repertoire zum Besten zu geben. Jüdische wie nichtjüdische Varietéstars waren Reisende. Zwischen Wien und Budapest zu reisen war alltäglich. Die Berichterstattungen über die populären Aufführungen zeigen, dass die Künstler*innen häufig im Wochenrhythmus in den beiden Residenzstädten auftraten. Aber auch der Wechsel über den Atlantik, war längst nichts Außergewöhnliches mehr. ${ }^{23}$ Eine Überfahrt zwischen Europa und Amerika dauerte um 1900 nur noch sechs Tage. Der Informationsaustausch zwischen Wien, Budapest und New York rund sechs Stunden. ${ }^{24}$ Auf die stattfindende Transmigration zwischen der Habsburgermonarchie und den Vereinigten Staaten wies auch die Berichterstattung hin: „Es ist auch überhaupt falsch von einer österreichischen Auswanderung zu sprechen, denn zu mehr als 75 Prozent handelt es sich nicht um Auswanderer, sondern Wanderer, eigentlich um Saisonarbeiter [...]. ${ }^{“ 25}$

21 Stuart Hall beschrieb ein solches Nostalgisieren und Verklären der vermeintlich besseren, vergangenen Tage mit der Konzeption eines „back-then“, in welchem er aber nicht nur verklärendes, sondern ebenso auch subversives Potential sah. Stuart Hall, Old and New Identities, Old and New Ethnicities, in: Anthony D. King (Hg.), Culture, Globalization, and the WorldSystem: Contemporary Conditions for the Representation of Identity (Minneapolis: University of Minnesota Press, 1997), 41-68.

22 Koller, Das Wiener Volkssängertum in alter und neuer Zeit, 182-187.

23 Die Studie von Annemarie Steidl, Wladimir Fischer-Nebmaier and James W. Oberly betont, dass Migration zwischen der Habsburgermonarchie und den Vereinigten Staaten um 1900 keineswegs eine einseitige Bewegung war, sondern ebenfalls als Migration von den USA nach Europa gedacht werden muss. Annemarie Steidl, Wladimir Fischer-Nebmaier and James W. Oberly, From a Multiethnic Empire to a Nation of Nations: Austro-Hungarian Migrants in the US, 1870-1940 (Innsbruck, Vienna, Bozen, 2017), 50-75. Siehe auch Annemarie Steidl, Engelbert Stockhammer, Hermann Zeitlhofer, „Relations among Internal, Continental, and Transatlantic Migration in Late Imperial Austria“, Social Sience History, 31, no.1 (2007): 61-92.

24 „Das Vermittlungswesen“, IAR, 10.6.1894, 1-3.

25 NFP, 16.1.1914, 2. 
Diese „Saisonarbeit“ betraf auch die Szene populärer Kultur, in der die amerikanischen Künstler*innen in der Monarchie als ebenso beliebte Attraktion galten, wie die Wiener und Budapester Bühnenstars jenseits des Atlantik. Zudem war die Szene eng mit Migration verbunden, da in den Varietés zu arbeiten oder sogar eine artistische Karriere einzuschlagen ein mögliches erstes Verdienstfeld für die Migrant*innen war.

Eines der ersten Volkssängerensembles, das zwischen Städten in Galizien, aber auch zu größeren Städten der Monarchie tourte, waren die Brodersänger. Wie der Name der Gruppe andeutete, kam die Gruppe ursprünglich aus der galizischen Grenzstadt Brody. Dort gründete Berl Broder, geboren als Berl Margulies (1817-1880) das Ensemble und wählte seinen Künstlernamen so, dass dieser auf den Ort verweisen sollte, von dem die Gruppe aufbrach. ${ }^{26}$ Eines der beliebtesten Lieder der Brodersänger setzte sich mit den Gründen für die Mobilität von Berl Broder und den anderen auseinander: Ikh nebekh peklmakher (Jidd. Ich unglücklicher Schmuggler). ${ }^{27}$ Berl Broder erlangte zunächst in Brody Bekanntheit, wo seine Fähigkeit zu unterhalten schnell in aller Munde war. „Als Brody die reiche Handelsstadt, infolge einer grossen wirtschaftlichen Krisis[!] arm geworden, verliess Berl die Stadt. Nun beginnen seine Wanderjahre; er durchzog mit seiner Sängergesellschaft fast alle grösseren Städte Galiziens, wo er überall gerne gehört wurde. Späterhin ging er nach Rumänien [...]. “28 Unter diesen ersten Städten, die dieses „erste reisende Volkssängerensemble“ bereiste, war Lemberg. Hier traten die Brodersänger im Lemberger Gimpl, der ersten Singspielhalle in Galizien, auf. ${ }^{29}$

An die Tradition der Brodersänger knüpften die späteren Volkssängergruppen und Varietéensemble an. Am bekanntesten war vielleicht die Vilna Trupe, die in den ersten Jahren des Ersten Weltkrieges gegründet wurde und von Vilnius über Białystok bis Warschau auftrat. ${ }^{30}$ Dass es überhaupt möglich wurde, international tätig zu sein, hing auch insofern mit der massenhaften Migration zusammen, dass nicht nur die technischen Anforderungen der Reise mit der Eisenbahn und/oder dem Schiff leichter zu bewältigen waren, sondern Mehrsprachigkeit in immer größerem Ausmaß auch über die alltägliche Kommunikation hinaus im nächsten Lebensumfeld gelebte Praxis war. Die Menschen

26 Nathan Michael Gelber, „Berl Broder: Ein Beitrag zur Geschichte der jüdischen Volkssänger“, Mitteilungen für jüdische Volkskunde 16, no. 3 (1913): 1-18, 1.

27 Börries Kuzmany, Brody: Eine Galizische Grenzstadt im langen 19. Jahrhundert (Wien, Köln, Weimar: Böhlau, 2011), 92.

28 Gelber, „Berl Broder“, 4.

29 Delphine Bechtel, „Le théatre yiddish Gimpel de Lemberg: une Odyssée oubliée“, Yod 16 (2011): 83-93.

30 S. Gelbart, 15 yor „Vilner Trupe”: Zamlung le-koved dem 15-yorikn yoyvl fun der Vilner Trupe (Lotz: o.V., 1931). 
waren zunehmend in unterschiedlichen Kontexten und zwischen verschiedenen Lebenswelten sozialisiert. Auf Artist*innen, die non-verbal unterhielten und nicht auf Sprache als Vermittlungsinstanz angewiesen waren, hatte dies natürlich geringere Auswirkung. Für diejenigen aber, die mit Sprachkomik und Gesang ihr Publikum begeistern wollten, ergaben sich mit der wachsenden Sprach- und Kulturkompetenz ihrer Zuhörer*innen neue Möglichkeiten.

Die Mobilität führte zu einer generellen Veränderung innerhalb der populären Kultur. Während die Volkssänger*innen in den vergangenen Jahrzehnten meist allein in Heurigen und Gaststätten aufgetreten waren, entstanden zum Fin de Siècle, wie im dritten Kapitel skizziert, zunehemend regelmäßige Spielstätten und es herrschte innerhalb der Szene eine rege Organisation und gute Infrastruktur. Die Künstler*innen gaben nicht mehr Einzelvorstellungen, sondern traten als Teil von Ensembles in bunt zusammengestellten, facettenreichen Programmen auf. Nun begleiteten nicht mehr die Künstler*innen das Wirtshausambiente: Sie und ihre Vorstellungen waren die Hauptattraktion und der Grund, weshalb Gäste kamen oder ausblieben. ${ }^{31}$ Die Programme dauerten meist zwei bis drei Stunden und wurden täglich zu mehreren Vorstellungszeiten, meist ab den frühen Nachmittagsstunden bis in die Nacht, angeboten. Die Eintrittspreise waren sehr gering, häufig musste gar kein Eintritt bezahlt werden. In manchen Spielstätten gab es gegen Aufpreis auch Logen.

Mit der zunehmenden Popularität dieses Angebots und der kombinierten Programme in Varietés und Singspielhallen entstanden viele neue artistische Berufe. Die Programme, die Aufführungen und die Stücke waren heterogen. Es wurden keineswegs nur noch ausschließlich Possen, Couplets oder Lieder vorgetragen. Akrobatische Darbietungen bis hin zum „Drahtseilakt“ waren ebenso Teil der Aufführungen. ${ }^{32}$ Was zählte, war das Außergewöhnliche: Mimikerinnen, Komiker*innen und „knochenlose“ Menschen oder skurrile Auftritte, die aus medizinischen Gegebenheiten - „Abnormitäten“ - Anlass zum Amüsement anderer generierten - wie etwa die Nummern des „kleinsten Zwerges“ oder der "Miniatur Athleten und Akrobaten“" ${ }^{33}$ Derartiges fand sich in Potpourris auf den „Brettl'n“ im Varieté, in der Singspielhalle und im Orpheum vereint.

$31 \mathrm{Ab}$ den 1880er Jahren ist in Zeitungsinseraten von Heurigen und Wirtshäusern zunehmend zu beobachten, dass mit der Popularität einzelner Volkssängerinnen geworben wurde, was sich langsam in längere Abende und mehrere Personen verwandelte, bis schließlich die Potpourris an Unterhaltungsprogrammen entstanden.

32 Siehe hierzu etwa IAR, 1.8.1894, 4.

33 Inserat des „kleinsten Zwerges“, IAR, 1.11.1891, 4; Inserat der „Miniatur Athleten und Akrobaten“, IAR 1.11.1894, 17. Siehe allgemein Joseph Philippi, „Das Picante in der Kunst“, IAR, 1.8.1892, 1-2. 


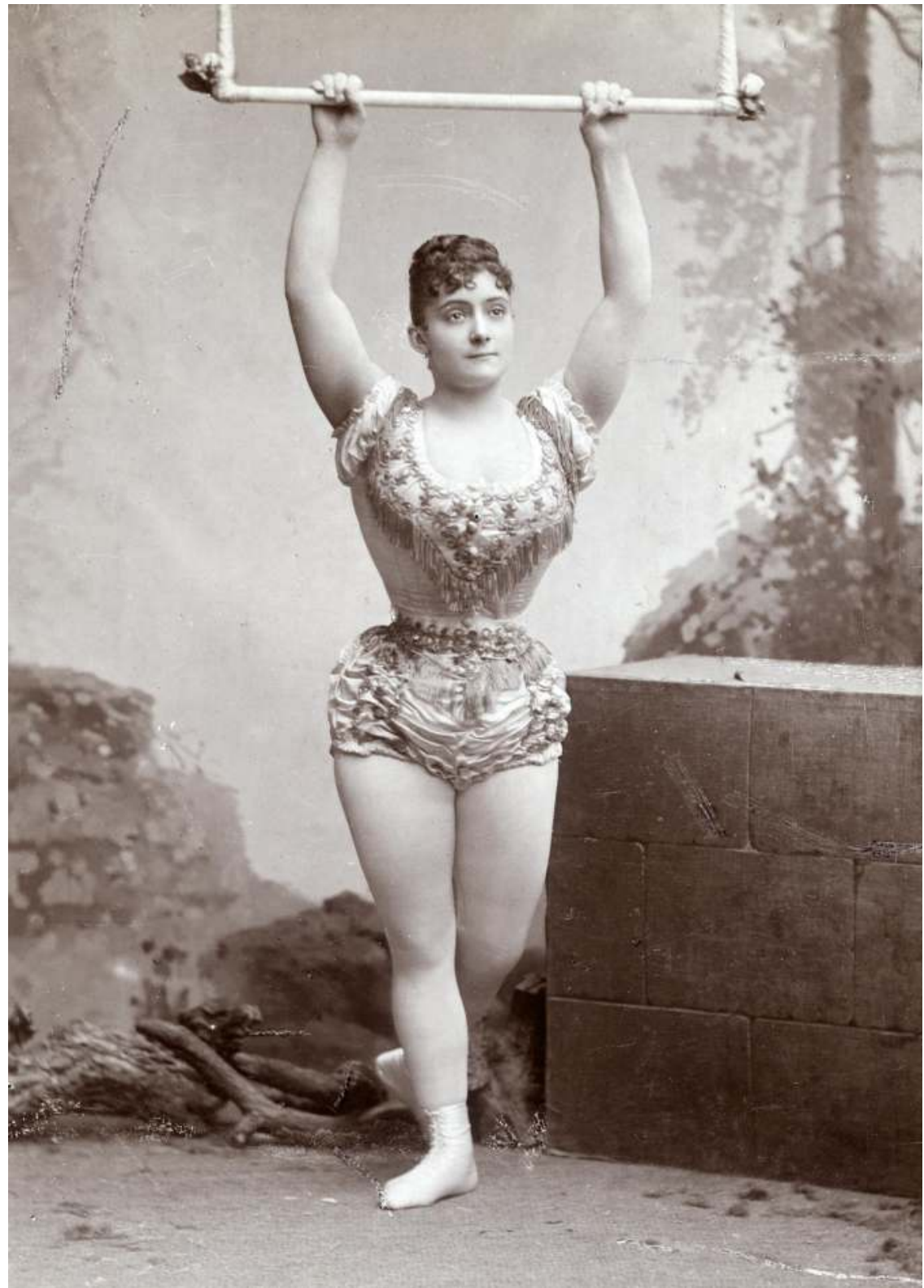

Abb. 16 Artistin in einem Wiener Varieté um 1900, Rudolf Krziwanek, Schwarz-Weiß-Abzug, Bildarchiv Austria, Pk 2814,1 
Als Teil solcher Programme aufzutreten, brachte den Künstler*innen den Vorteil ein, sich nicht mehr selbst in jeder neuen Stadt, in die sie kamen, um Aufführungserlaubnisse oder Konzessionen für Spielstätten kümmern zu müssen, sondern die bereits von der Direktion ausgehandelten Arrangements nutzen zu können. Der oben erwähnte Volkssänger Josef Koller sah in dieser Veränderung den Grund für die „neue Zeit des Volkssängerthums“. Die neue Qualität an Mobilität bewirkte ihm zufolge, dass die zuvor eher lose Unterhaltung mit humoristischen Sketches und Liedern sich immer stärker institutionalisierte. Das, was als die "neue Zeit des Volkssängerthums“ wahrgenommen wurde, war eine stärkere räumliche Anbindung der Aufführungen, die sich aus dem Wunsch, Mobilität administrativ zu vereinfachen, ergab. Die fixen Spielstätten in den Städten verfügten über Konzessionen und standen in Kontakt mit den Behörden für Aufführungsgenehmigungen. Pro fixe Konzession gab es zur Jahrhundertwende permanent etwa drei bis vier Gastauftretende. ${ }^{34}$ Man musste nur von einer Spielstätte engagiert werden und konnte schon auftreten. Gerade für reisende Künstler*innen, so Koller, sei deshalb die stärkere räumliche Institutionalisierung populärer Kultur die wichtigste Voraussetzung gewesen. ${ }^{35}$

\section{Wachstum und Untergang?}

Das Entstehen von Infrastruktur für Auftritte und die Erleichterung administrativer Tätigkeiten brachten umgekehrt auch rasch Neugründungen von Spielstätten mit sich. Von 1890 bis 1900 verdoppelte sich die Zahl an Spielstätten in der Habsburgermonarchie und in New York vervierfachte sich die Zahl sogar. Die Budapester Zeitung Internationale Artisten Revue verzeichnete bei ihrem ersten Erscheinen 1891 rund 110 „Varieté-Bühnen und KonzertEtablissements" - von New York bis Moskau und von Malmö bis Athen. Das „Fachorgan für Varieté- und Spezialitätenbühnen, Circus, Konzertetablissement, Schausteller und reisende Artisten“, so der Untertitel, kannte außerdem dreißig „reisende Theater und Arenas“, 191 „Sängerinnen“, 98 „Komiker und Sänger" und 68 „Kapellmeister und Pianisten“. ${ }^{36}$ Zur Szene mobiler Populärkultur gehörten: „Ventrioloquisten, Mimiker, Athleten, Musikalische Spezialitäten,

34 IWE, 21.12.1901, 15.

35 Ich spreche von der stärker räumlich verankerten Volkssängerszene, deren Darbietungen in den neuen Räumen auch mit artistischen Darbietungen und in Potpourris gemeinsam aufgeführt wurden, von Etablissementkultur (wiederum als räumliche Konsequenz, konnten so mehrere Künstler*innen im nun begrenzten Raum untergebracht werden). Potpourri meint hier im übertragenen Wortsinn eine bunte Zusammenstellung des Programms aus verschiedenen Nummern („Programmmix“). Siehe auch Kapitel 3.

36 Die Redaktion [Ferdinand Steiner], „An unsere geehrten Leser!“, IAR, 8.11.1891, 1. Es handelt sich hierbei um jene Zahlen, die beim ersten Erscheinen der Zeitung genannten wurden. (Für das Jahr 1891 differenzierte das Verzeichnis nicht nach Tätigkeitsorten, sondern nannte nur die Namen der Künstlerinnen.) Die Variationsbreite sieht man in den teilweise stark 
Musik-Kapellen, Ballett, Pantomime, Clowns und Excentriques, Schnellmaler, Dresseur, Gymnastiker und Akrobaten, Imitatoren, Jongleur und Equilibrist, Kantschuk, Seilkünstler, Duette, Terzette und Quartette, Velocipedisten und Skater[!], Zauberkünstler und Illusionisten“. 37

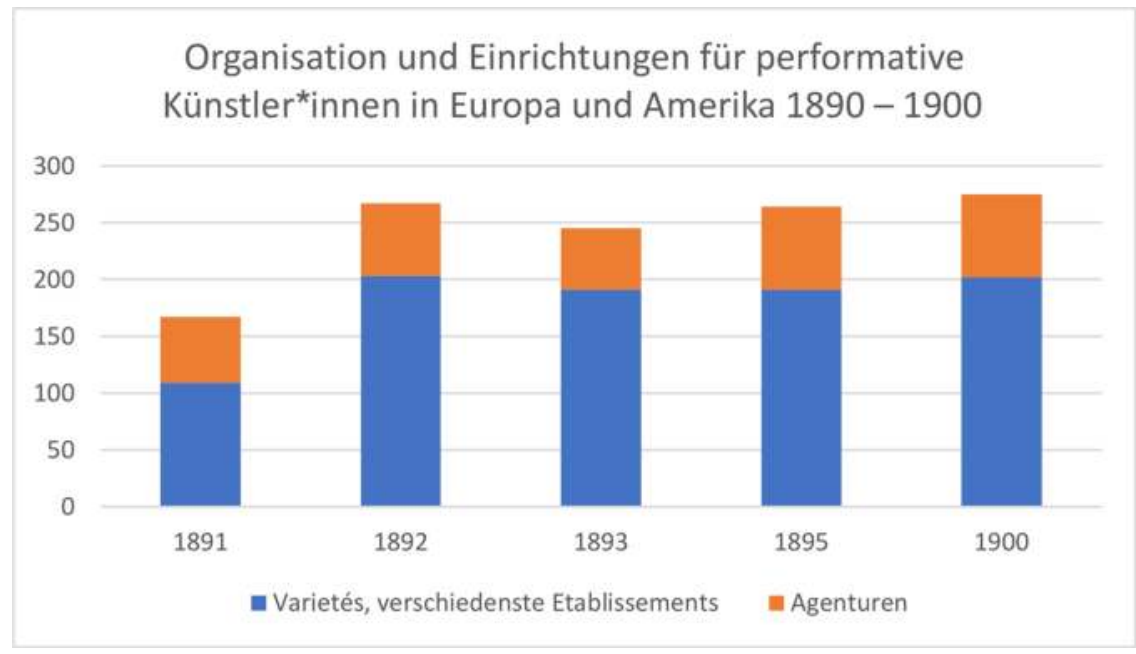

Abb. 17 Organisation und Einrichtungen der Populärkultur um 1900

Um 1900, also knapp zehn Jahre nach ihrem ersten Erscheinen, war die Internationale Artisten Revue über das Bestehen von knapp 300 Organisationen, Varietés, Etablissements und unzählbare andere Lokale für Künstler*innen in 80 Städten in Europa und den Vereinigten Staaten informiert. ${ }^{38}$

abweichenden Zahlen etwa ein Jahr später, zu dem Zeitpunkt, als die Zeitung aufgrund der enormen Nachfrage von zwei Ausgaben pro Monat auf drei expandierte. Im März 1892 sind nur mehr 19 „Kapellmeister und Pianisten“ (davon zehn aus Budapest, und einer aus Wien), 42 „Komiker und Sänger“ (davon 26 in Budapest und sieben in Wien tätig) und 86 „Sängerinen“[!] (davon 43 in Budapest und fünf in Wien tätig, was natürlich nicht als repräsentativ für die Szene, wohl aber für das schon zu Beginn bestehende Netzwerk der IAR zu sehen ist) verzeichnet. Die schwankenden Zahlen sind einerseits mit starken Diskontinuitäten in dem Berufsfeld an sich verbunden, andererseits aber natürlich auch mit der Verbreitung der Zeitung und dem Abonnement-Willen der Künstler*innen. Deshalb ist naheliegend, dass die Zahlen bei ersten Aufrufen zur Erfassung aller mobiler Künstler*innen eher relevant sind und aufgrund abnehmender Abonnements im nächsten Jahr zurückgingen.

37 Die Berufsbezeichnungen sind der Internationalen Artisten Revue entnommen.

38 Die statistische Auswertung beruht auf den Anführungen von Organisationen, Agenturen und verschiedenen Einrichtungen (Artistencafés, Singspielhallen, Varietés etc.) in der Internationalen Artisten Revue. Diese Listen fanden sich in allen Ausgaben. Für die Auswertung wurden die ersten Dezemberausgaben herangezogen (erstes Erscheinen der IAR). Damit sagt 
Doch gerade die Internationalisierung und das mit der Mobilität verbundene Wachstum der Szene hätten den Untergang einzelner Bereiche der Unterhaltungskultur und speziell der autochthonen Spielarten bedeutet. Das bereits im zweiten Kapitel zitierte Memorandum für das „Alt-Wiener Volkssängertum“ klagte die Bedrohung des vermeintlich ,authentischen Volkssängertums aus alter Zeit“ an. In dieser Hommage schrieb Joseph Koller: „Das internationale Moment begann sich auszuwirken. Man importierte Lieder aus Deutschland und England und lokalisierte sie. Die neue Geschmacksrichtung zerstörte alle Pläne der um ihre Existenz kämpfenden Volkssänger. ${ }^{\text {“39 }}$ Spätestens in den 1910er Jahren waren derartige Veränderungen als virulent wahrgenommen worden. Koller berichtete, dass die Volkssänger*innen Wiens sogar bei Kaiser Franz Joseph zu intervenieren versuchten. Das Bestreben, Mobilität und Internationalität einzudämmen, blieb jedoch erfolglos: „Nun kam der Krieg und der Notschrei der Volkssänger verhallte. “40

Derartige Untergangszenarien sind in sich freilich widersprüchlich und blieben im Darstellen der vermeintlich in Bedrohung befindlichen Gilde unreflektiert. So führte auch Koller seine Argumentation beim Versuch einer Abgrenzung der Szene ad absurdum. Nichtsdestoweniger bedingten die Untergangszenarien eine Sorge um den Verlust von Traditionen, die durch Migration, Mobilität und die damit einhergehende Plurikulturalität als im Untergang befindlich wahrgenommen wurden. Für Jüdinnen und Juden war das aufstrebende internationale Moment der Populärkultur besonders wichtig: In Wien ließen Referenzen auf, Alt-Wien' und die einstige Szene populärer Kultur dort das Fremde zunächst als exklusiv behandeln. Die zunehmend internationale Ausrichtung der populären Inhalte stand wider diese Exklusivität des vermeintlich Wienerischen und beugte auch Antisemitismus vor. ${ }^{41}$ Das Exkludierende, das durch das internationale Moment insgesamt in der öffentlichen Auseinandersetzung über die populäre Kultur in Wien, Budapest und New York zurückging, wurde allerdings dennoch in den Aufführungen artikuliert wie es Abwertung und Auflösung erfuhr. Das wird Teil der Analysen im fünften Kapitel sein.

\section{Organisation}

Die neuentstandenen Spielstätten, die unterschiedlichen artistischen Berufe und die vielen Künstler ${ }^{\star}$ innen mussten vernetzt werden. Um das Reisen der

die Auswertung natürlich zum einen im Wesentlichen etwas über die Verbreitung und Vernetzung der Internationalen Artisten Revue aus. Diese war aber vergleichbar mit der Vernetzung der anderen Organe und wird deshalb hier exemplarisch herangezogen.

39 Koller, Das Wiener Volkssängertum in alter und neuer Zeit, 190.

40 Ebda.

41 Hödl, Zwischen Wienerlied und Der kleine Kohn, 33. 
Künstler*innen zu vereinfachen und den Direktionen eine möglichst einfache Kommunikation mit potentiellen neuen Gastauftretenden zu gewähren, wurden alsbald neue Medien gegründet. Die erste Zeitung für reisende Artist ${ }^{*}$ innen in der Habsburgermonarchie war die Internationale Artisten Revue. Orientiert an Der Artist sah sich die Internationale Artisten Revue als Vertreterin der Interessen, Avantgarde im Kampf um eine Verbesserung der Lage sowie für eine soziale und gesellschaftliche Besserstellung des Standes der (international) tätigen Künstler*innen. Als „Fachorgan für Varieté- und Spezialitätenbühnen, Circus, Konzertetablissements, Schausteller und reisende Theater" wollte diese Zeitung sämtlichen mobilen Künstler ${ }^{\star}$ innen Vernetzungs- und Orientierungsmöglichkeiten bieten. Über derartige Fortschritte berichtete das Medium in den Ausgaben. ${ }^{42}$ Ein erstes Resümee 1894 lautete:

Die Fachpresse ist ein unentbehrlicher Faktor im Artisten-Leben. Sie ist die Verbindungsbrücke zwischen Direktoren und Artisten. Der wichtigste Adressenkalender für Orpheums, Chantants, Circusse und diversen anderen Vergnügungs-Etablissements. Sie fördert, in gleichem Maasse die Interessen der Direktoren, sowie auch die der Artisten, wacht mit immer offenen Augen über alle Vorgänge in der Künstlerwelt [...].[!] ${ }^{43}$

Der Anspruch der Zeitungen war es, nicht nur Informationen über Lokalitäten und Ensembles bereitzustellen, sondern die zahlreichen Etablissements und Künstler*innen zu vernetzen. ${ }^{4}$ In der Verbreitung des Fachorgans spiegelte sich alsbald der immer mobiler werdende Charakter populärer Kultur wider: Insgesamt verdoppelten sich die Agenturen und Lokale, mit denen das Fachorgan in Kontakt stand, über die Jahre seines Bestehens bis 1914 und konnte sich die Internationale Artisten Revue auf Korrespondenzen in bis zu 100 Städten berufen. ${ }^{45}$ Das wachsende Interesse an internationalen Aufführungen zeigte sich auch in der Zunahme der korrespondierenden Lokalitäten und steigenden Zahl an bezahlten Inseraten in der Internationalen Artisten Revue. Zunächst listete die Internationale Artisten Revue in einem Index sämtliche mit ihr in Korrespondenz stehende Lokalitäten auf: Das Spektrum reichte von Varietés über Singspielhallen bis hin zu kleinen Etablissements und Cafés mit Aufführungsmöglichkeiten. Noch vor dem zehnjährigen Bestehen der Zeitung nahmen diese

42 IAR, 8.11.1891, 1.

43 Arthur Falz, „Die Fachpresse“, IAR, 10.3.1894, 1-2, hier 1.

44 Angemerkt werden muss, dass diese Zahlen sich aus dem eurozentrischen Blick der Internationalen Artisten Revue ergeben und aus der inneramerikanischen Perspektive die Zahl stark nach oben korrigiert werden muss. Jedoch soll in diesem Teil das rasante Wachstum am Publikationsorgan IAR, dass sich an seinem New Yorker Pendant orientierte, nachvollzogen werden. Eine vergleichende statistische Erhebung im New York Clipper wäre wünschenswert.

45 Statistische Auswertung der Verzeichnisse der Internationalen Artisten Revue über ihre Erscheinungsjahre 1891-1914 (von der Autorin durchgeführt). 
um 1900 derart überhand, dass nur mehr vermittelnde Agenturen dokumentiert werden konnten.

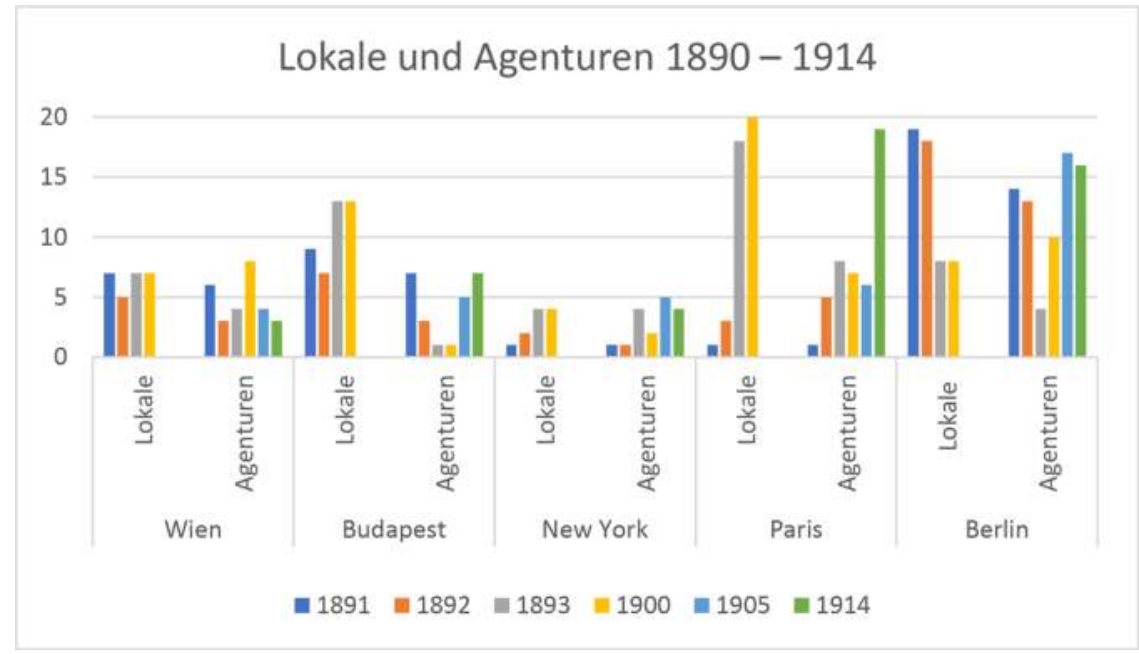

Abb. 18 Überblick über in der Internationalen Artisten Revue inserierende Lokale und Agenturen 1890-1914

Die Gründung einer derartigen Zeitung für die Habsburgermonarchie stand aber auch eng mit der Sozialisation des Herausgebers in Zusammenhang. Ferdinand Steiner war Teil einer aus der ungarischen Reichshälfte stammenden Familie, die fest in der Theaterszene verankert war und ihn von frühester Kindheit mit Künstler*innen in Kontakt brachte. Ein anderes Mitglied der Familie war Gábor Steiner (1858-1944), der viele der bekanntesten Wiener Etablissements leitete: Das Theater an der Wien, das Carltheater und, wohl am beliebtesten, die Vergnügungsstätte im Englischen Garten, als diese sich zu Venedig in Wien verwandelte. ${ }^{46}$ Es ist davon auszugehen, dass Ferdinand Steiner daher früh in Kontakt mit der Szene kam und Artistenzeitschriften wie

46 Andere Mitglieder der Steiner-Familie waren vor allem in der Wiener Szene aktiv: Gábor Steiner (1858-1944), der zum Christentum konvertierte, war selbst aktiver Schauspieler und leitete das Theater an der Wien. Später übernahm dessen Sohn, Franz Steiner, die Leitung. Gemeinsam übernahmen sie auch das Carltheater in der Praterstraße. Größte Bekanntheit erlangte Gabor Steiner aber als Leiter der Vergnügungsstätte Venedig in Wien. Klaus Hödl hebt hervor, dass in der Literatur die Steiner-Familie immer als Beispiel einer jüdischen Familie in der Unterhaltungsszene dargestellt wird. Damit stehen diese in einer Kontinuitätslinie biologistischer Argumentation. Alternative Ansätze sind das Konzept der Jewish Difference bzw. das in dieser Arbeit verwendete Paradigma der Ähnlichkeit. Zu den Problemen der Historiographie über ,jüdische' Populärkultur siehe Hödl, Zwischen Wiener Lied und Der kleine Kohn, 30, 79-80. Die Vernetzung zeigte sich auch in den Korrespondenzen unter den 
Der Artist kannte. An derartigen Zeitschriften orientierte Steiner sich dann auch bei der Gründung seines Fachorgans.

Das Pendant für die amerikanische Szene war der New York Clipper. Bereits seit 1853 erschien dieser wöchentlich in New York als „Fachschrift für amerikanische Artisten “. ${ }^{47}$ Mit dem primären Ziel, über die Theater-, Varieté- und Singspielhallenszene in den Vereinigten Staaten zu informieren, verschrieb sich das Blatt nach und nach einem internationalen Publikum. Ab den 1880er Jahren widmete es sich dem internationalen Metier reisender Künstler*innen und Artist*innen. Es gab Rubriken wie „Performers going to Europe“, in der vorab inseriert und um Stellen angesucht werden konnte. Amerikanischen Künstler*innen sollte so eine problemlose Erwerbstätigkeit in den Europa ermöglicht werden. Umgekehrt veröffentlichte der New York Clipper aber auch in Amerika spezielle Informationen für reisende Künstler*innen aus Europa und stand in regem Austausch mit der Internationalen Artisten Revue, in der das Neueste über die amerikanischen Varietés und Singspielhallen immer wieder abgedruckt wurde. ${ }^{48}$

In den Dezennien um die Jahrhundertwende wurde nach dem Beispiel der Internationalen Artisten Revue eine Vielzahl ähnlicher Zeitschriften gegründet. Beispiele für die facheinschlägigsten waren das in Wien herausgegebene Varieté, das in Budapest erscheinende Blatt Folies Caprice sowie die in den 1920er Jahren in New York herausgegebenen Vaudeville News. ${ }^{49}$ Sie berichteten über Aufführungen, griffen Kritiken und Repliken auf, sammelten Inserate rund um den Künstlerberuf und das Chantantwesen und publizierten zeitgenössische Debatten, die dann Szenemitglieder kommentierten.

Einzigartig war die Zeitung Folies Caprice. Folies Caprice erschien nicht in einer für den Druck gesetzten Form, sondern - wie viele Aufführungsmanuskripte - als lithographisch reproduzierte handschriftliche Publikation vermutlich deshalb - nur wenige Monate. Als „Zeitung unter Freunden“ gedacht, sollte ihr Name auf das gleichnamige Varieté verweisen. Herausgeber war der in der Varietészene überaus bekannte Sándor Rott (1868-1942).$^{50} \mathrm{Er}$ wollte mit diesem „Hausblatt [...] durch die Mitglieder gesammelten Beiträge

Artist ${ }^{*}$ innen. Siehe beispielsweise NAHJP, L30: Theater Wien. Sowie YIVO, RG 1843: Hebrew Actor's Union, Correspondences.

47 Mit diesem Untertitel inserierte der New York Clipper in der Internationalen Artisten Revue.

48 IAR, 8.2.1892, 10. Es gab immer auch Informationen zu Etablissements und Aufführungen in Europa, sowie Hinweise über die gängigen Verhaltensmuster bei Besuchen in Wiener oder Budapester Spielstätten. Zum Exchange Office siehe NYC, 24.6.1899, 336.

49 Das humoristisch-satirische Blatt Caprice wurde 1902 als Wochenzeitschrift in Budapest herausgegeben und widmete sich der Etablissementszene der Stadt. Die Vaudeville News erschienen 1920 bis 1929 in New York.

50 Zu Sándor Rott siehe Gluck, The Invisible Jewish Budapest, 1555-156. 
uns stets fröhlich“[!] stimmen. Im Wunsch, „intimere Räume“ als die des Varietés zu haben, um beisammen sein zu können, schuf Rott mit dem Blatt einen Raum für „Zusammenkünfte im Geiste und im Humor“. Sein Plädoyer lautete: "Suchen wir uns gegenseitig durch witzige Beiträge in Form von Erzählungen und Episoden zu amüsieren; Beleidigungen seien ausgeschlossen und alles sei nie anders, als im Scherz aufzufassen. "51 Die Zeitschrift war gewissermaßen ein Potpourri aus Tagebucheinträgen bekannter Mitglieder der Szene populärer Kultur, die den aktuellen Humor ebenso wie Fragen und Diskussionen der Unterhaltungswelt - durchaus auch kabarettistisch - kommentierten. Kleine Karikaturen sorgten für die graphische Auflockerung der verschiedenen Schriftbilder, die durch die Vielzahl an Autographen in der Zeitschrift Folies Caprice entstanden.

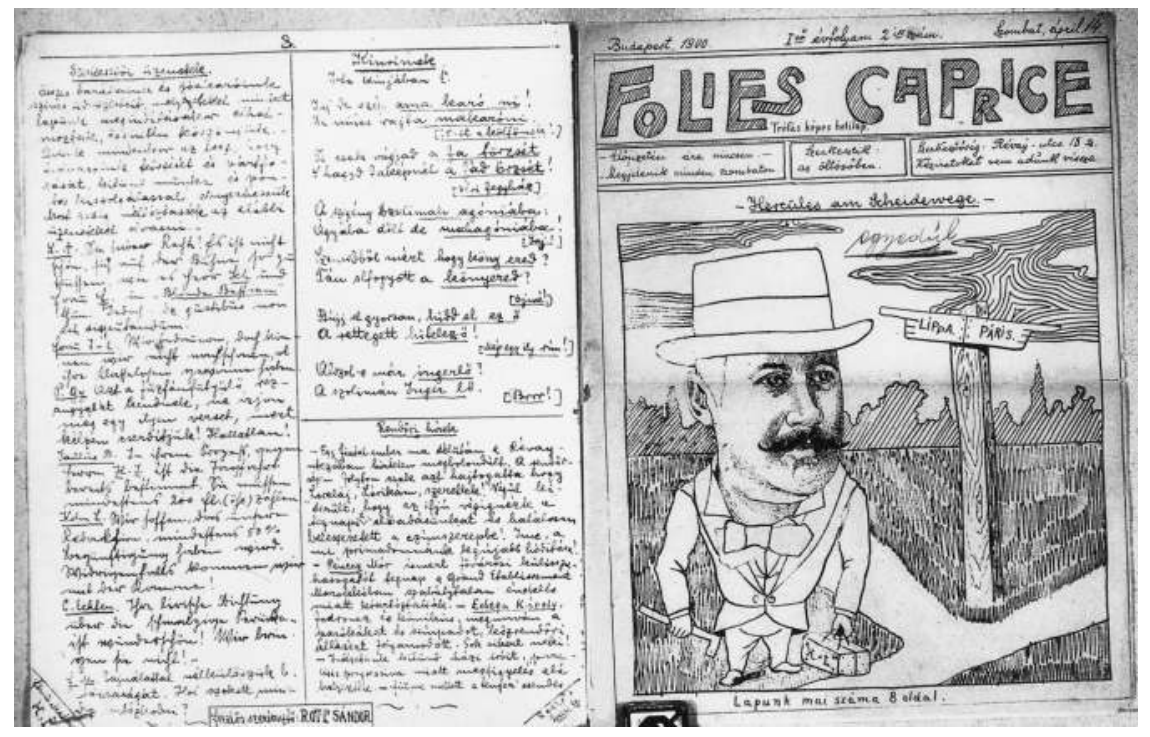

Abb. 19 Die Zeitschrift Folies Caprice erschien als lithographischer Druck 1900 in Budapest, Sammlung für Theatergeschichte der ungarischen Nationalbibliothek Széchényi

Die Mitglieder der Szene gründeten Artistenzeitungen nicht nur, um sich bei Fragen von Engagements zu vernetzen, sondern auch, um sich in sozialen Belangen auszutauschen. Bereits in ihrer ersten Ausgabe im November 1891 verwies die Internationale Artisten Revue auf Missstände und Vorbehalte gegenüber der Szene und strich diese als Grund hervor, warum es einer Fachpresse bedürfe:

51 Pt., „Eingesendetes Nachwort zum Vorwort“, Folies Caprice 1, no. 1, 7.4.1900, 2. 
Die allmähliche Ausdehnung des Artistenwesens, der sich immer mehr entwickelnde Fortschritt und das fortwährende Ringen in der Societät zur Behauptung, der bereits eroberten Position, machen ein vollkommen unabhängiges Organ, welches als Sprachrohr der vitalen Interessen des Artistenstandes gelten soll, zur dringenden Nothwendigkeit $[\ldots] .[!]^{52}$

Die Missstände, mit denen sich reisende Künstler*innen auseinandersetzen mussten, waren der Grund für die Etablierung des vorerst zweimal monatlich erscheinenden Publikationsorganes: „Das Wesen der Varietétheater, Konzertetablissements, Circusse, Schausteller und reisender Theater, krankt an hunderten Uebeln und durch Ventilierung all' dieser Uebelstände kann früher oder später eine Besserung der Situation herbeigeführt werden.[!]“53

\section{Die Distributionspraxis der Populärkultur}

Fachorgane wie die Internationale Artisten Revue stellten Informationen zu Infrastruktur, Organisation und neuen Entwicklungen (in) der Etablissementkultur sowie über Kontakte und Adressen für reisende Schauspieler*innen bereit. Man erfuhr, dass „Rudolf Wildmann [...] schnell und reell Konzessionen für Budapest und Ungarn“ besorgte, ${ }^{54}$ dass Armin Sternberg in der Kerepesi út 36 Instrumente in eigener Fabrikation herstellte, ${ }^{55}$ wo es „Vorzugspreise für Artisten“ gab ${ }^{56}$ oder wann Josef Modl oder die „französische Excentrique-Sängerin “ Paulette Rossé noch zu buchen waren. ${ }^{57}$

Dass derartige Konzessionen erfordert waren, entnahmen die Künstler*innen einem Gesetz; dieses beinhaltete u. a., dass jedes Stück zur Aufführung genehmigt werden musste. In New York waren inhaltliche Reglementierung seit dem Aufkommen der Actors Unions um die Jahrhundertwende von deren Einflussnahme geprägt. ${ }^{58}$ Ab 1900 waren Aufführungsmöglichkeiten beinahe ausschließlich an eine Mitgliedschaft in einer Actor's Union gebunden. ${ }^{59}$ Die

52 „An unsere geehrten Leser!“, IAR, 8.11.1891, 1.

53 IAR, 8.11.1891, 1. Zur Organisation populärer Kultur zwischen den deutschen Gebieten und Nordamerika siehe Antje Dietze, „Americanization of Show Business? Shifting Territories of Theatrical Entertainment in North America at the Turn of the 20th Century“, in: Gabriele Pisarz-Ramirez, Hannes Warnecke-Berger (Hg.), Spatialization Processes in the Americas (Bern, New York: Peter Lang, 2018), 193-215.

54 IAR, 8.11.1891, 10.

55 IAR, 24.12.1891, 45.

56 IAR, 8.3.1892, 11.

57 Models Inserat: IAR, 24.1.1892, 12. Rossés Inserat: IAR, 1.4.1892, 11.

58 Die Unions sammelten die eingereichten Textbücher. Aus deren Korrespondenzen können Aufschlüsse über die Entscheidungspraxis darüber, was aufgeführt wurde, gewonnen werden. Zum Beispiel YIVO, RG 1843 Hebrew Actor's Union.

59 Judith Thissen, Reconsidering the Decline of the New York Yiddish Theatre in the Early 1900s, Theatre Survey 44, no.2 (2003): 173-197, 188. 
Actors Unions waren weniger gesetzliche als gewerkschaftliche Institutionen, die es durchsetzten, dass nur ihre Mitglieder Auftrittsslots zugeteilt erhielten. Die Unions engagierten sich aber auch für die soziale und ökonomische Verbesserung der Schauspieler*innen und Artist*innen, so erwirkten sie etwa eine wesentliche Erhöhung der Gagen für die Künstlerinnen. Zudem regelten gesonderte Gesetze sowohl den Ablauf der Aufführungen als auch die aufgeführten Stoffe. In Wien und Budapest war für Aufführungsgenehmigungen die Zensurbehörde zuständig. Die Theaterordnung vom 14 . November $1850^{60}$ sah eine räumliche Anbindung für alle Arten von Aufführungen vor. Gaststättenund Spielstättenbetreibende mussten über Konzessionen verfügen. Den Inhalt der Stücke begutachtete die Zensurbehörde, die in größeren Städten Teil der Polizeidirektion war. Im Bemühen, „öffentlichen Anstand und Sittlichkeit“ zu wahren, entschied die Zensur auch über eventuelle Erwähnungen von Namen, Produkten, Firmen, Patenten etc. ${ }^{61}$

Die gesetzliche Reglementierung mit einem Konzessionsgebot für die Monarchie und einer Unionsdominanz in New York hatte zur Folge, dass sich die Kosten für Theaterbetreibende zwischen 1900 und 1910 beinahe verdreifachten. Für Genehmigungen mussten Manuskripte zu jedem neuen Stück in jeder Stadt vorgelegt werden. Künstler*innen, die an mehreren Orten auftraten, fertigten an jedem Ort erneut eine Abschrift des Bühnenmanuskripts an. Diese Abschriften besaßen folgende Funktionen: Zum einen waren sie Bewerbungsunterlagen, die bei den Spielstättenbetreibenden vorab vorgezeigt wurden, um

60 Allgemeines Reichs-Gesetz- und Regierungsblatt für das Kaiserthum Österreich 1849-1852, RGBl. 454/1850, Verordnung des Ministeriums des Inneren vom 25.11.1850, 1976-1980: Die Theaterordnung war „wirksam für Oesterreich unter und ob der Enns, Salzburg, Steiermark, Kärnthen, Krain, Tirol und Vorarlberg, Triest, Görz und Gradiska, Istrien, Dalmatien, Böhmen, Mähren, Schlesien, Galizien, Bukowina, Ungarn, Kroatien, Slavonien, die serbische Woiwodschaft mit dem Temeser Banate, die Militär-Gränzgebiete und Siebenbürgen“. Die Entscheidungsgewalt über Theateraufführungen oblag dem Bezirkshauptmann (respektive Komitatsvorstand, Delegat, Präfekt), in jenen Städten, wo es eine Polizeidirektion gab, dem Stadthauptmann oder Polizeidirektor. Für Wien war das die niederösterreichische Statthalterei. Die Länder der ungarischen Krone wurden in megye [Komitaten] verwaltet. Budapest war Teil des Komitats Pest-Pilis-Solt-Kiskun (mit Komitatssitz Budapest). Einen Überblick über die Entwicklung der Zensur nach 1900 geben Bachleitner, Ferstl, Österreichische Theaterzensur im 20. Jahrhundert, 27-50.

61 Der Bestand der Theaterzensur für die niederösterreichischen Gebiete (zu denen Wien um 1900 zählte) befindet sich im Niederösterreichischen Landesarchiv und besteht aus den der Zensurbehörde vorgelegten Textbüchern, den Zensurvermerken in den Manuskripten und teilweise auch den Akten der Zensurbehörde. NÖLA, NÖ Reg. Präs. Theater TB - Textbücher der Theaterzensur und NÖLA, NÖ Reg. Präs. Theater ZA -Zensurakten. Für die in Budapest aufgeführten Stücke nicht ortsansässiger Autor*innen befinden sich die Manuskripte als ausgegliederter Teil in der Theatersammlung der Széchényi Library. NSZL, Színháztörténeti Tár [theaterhistorische Sammlung]. 
überhaupt ein Engagement zu bekommen. ${ }^{62}$ Zum anderen mussten die Spielstättenbetreiber*innen die Manuskripte für die Aufführungserlaubnisse bei den Behörden einreichen. Nachdem sich die Ortswechsel im Kontext der Migrationsbewegungen schneller gestalteten, bedeutete es einen größeren Aufwand, die Manuskripte in entsprechender Zahl zu reproduzieren.

Den Aufwand minimieren zu können, hatte praktische Vorteile. Diese Nische erkannten einzelne Unternehmen und es etablierten sich Verlage oder Sparten von Verlagen, die für die Künstler*innen ,einzelne, nicht zum Verkaufe gedachte" Drucke beziehungsweise Kopien handgeschriebener Manuskripte anfertigten. Es handelte sich häufig um lithographische Reproduktionen und nicht um gesetzte Manuskriptseiten. Die Lithographien beinhalteten oft Aufführungsdetails, wie Bühnenarrangements, weshalb sie für die Rekonstruktion der Aufführungspraxis wertvoll sind.

Die Mobilität wirkte sich somit direkt auf die Produktions- und Distributionspraxis der Populärkultur aus. Das Wiener Verlagshaus Franz Bárd und Bruder war einer dieser Verleger. Ursprünglich im sechsten Budapester Bezirk Terézváros situiert, eröffnete es als Konsequenz der Dynamik zwischen den Städten im Dezember 1894 eine Expositur in Wien. ${ }^{63}$ Auch die Inhaber selbst reisten regelmäßig zwischen Budapest und Wien, um Aufführungen zu besuchen und mit neuen Kund ${ }^{*}$ innen in Kontakt zu treten. ${ }^{64}$

62 IAR, 24.12.1891, 46.

63 Die Niederlassung befand sich in der Kossuth Lajos utca 4 in Budapest und am Opernring 3 in Wien. Lehmann, Nachweis Protokollierte Firmen, 1910, 311.

64 Kossuth Lajos utca 4 und Wien, Opernring 3. Oder auch der Schuberthaus-Verlag, Wien Leipzig, als „Manuskript gedruckt“ - Druckerei-, Verlags- und Aktiengesellschaft vorm. R. v. Waldheim, Jos. Eberle \& Co, Wien. Meldezettel Franz Bárd, WStLA, Historische Meldeunterlagen, K1 - B-Antiquariat. 


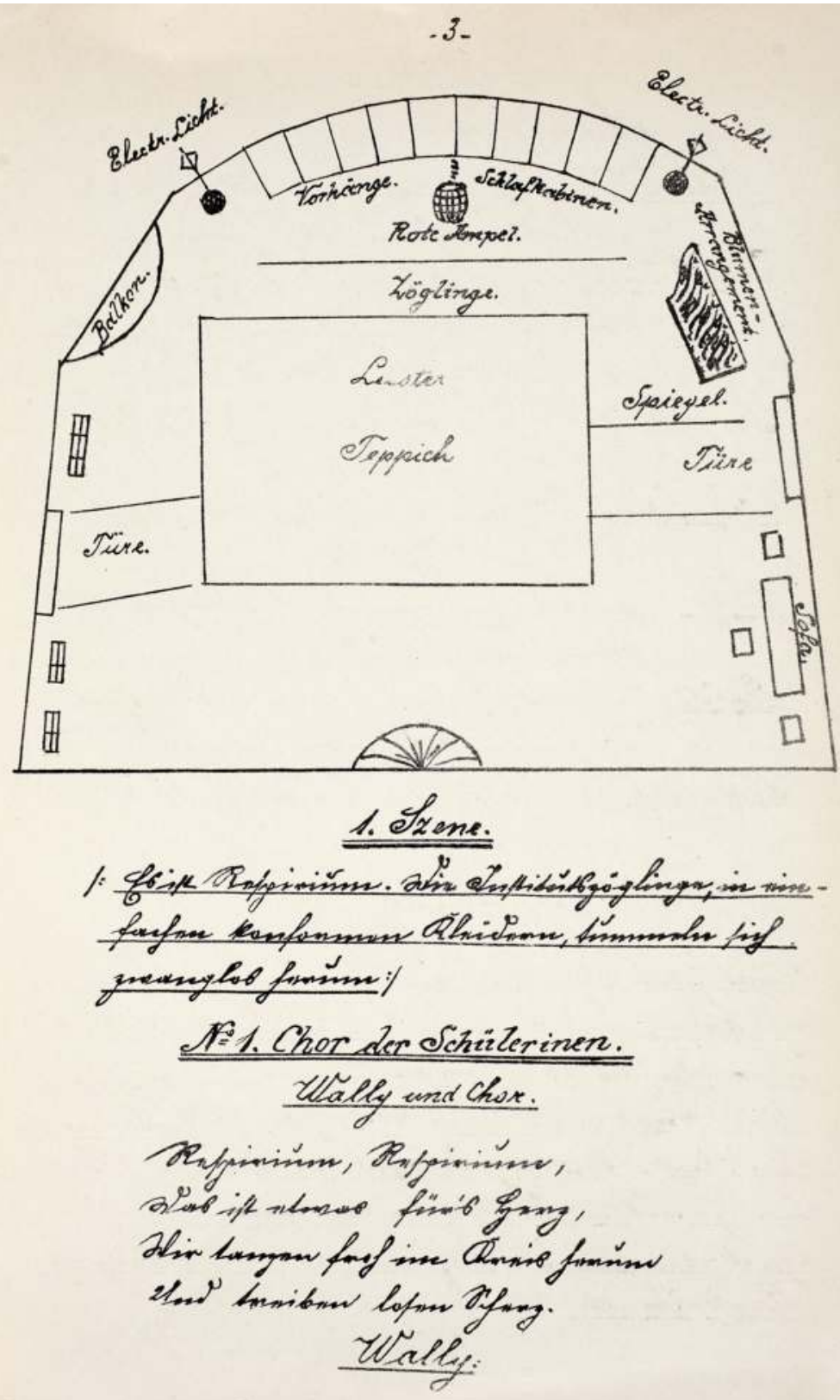

Abb. 20 Bühnenarrangement in der Lithographie eines handgeschriebenen Manuskripts, Martin Knopf, Pariser Luft, Sammlung für Theatergeschichte der ungarischen Nationalbibliothek Széchényi 
Die Künstler*innen mussten, wie dargelegt, den Spielstättenbetreiber*innen Kopien ihrer Stücke geben, damit diese die Aufführungserlaubnisse einholen konnten. Urheberrecht und Copyright-Bestimmungen stellten somit wichtige Schutzmechanismen für Künstler*innen dar. War ein Stück einmal in den Händen eines Impressarios, war es ein Leichtes, es von anderen Schauspieler ${ }^{\star}$ innen wieder aufführen zu lassen. Mit dem „Copyright Act“ von 1842 konnten Künstler*innen ihre Stücke an andere verkaufen. Von diesem Recht Gebrauch machten meist Verlagshäuser, die sich die Rechte sicherten und dann weiterverkauften. Das Zugeständnis von Urheberrecht und weiterem Schutz geistigen Eigentums oblag aber sehr stark den regionalen Schutzbestimmungen. ${ }^{65}$ Erst der „Copyright Act“ von 1909 bewirkte eine weitere Verbreitung des Wissens um die gesetzliche Schutzmöglichkeit. ${ }^{66}$ Lange Rechtsstreits, die zuvor gängige Praxis waren, nahmen ab. ${ }^{67}$

All diese Richtlinien und gesetzlichen Vorgaben waren mit finanziellem Aufwand verbunden. Die eingereichten Manuskripte mussten mit einer Zwei-

65 Scott verweist darauf, dass gerade im Handel mit Musikstücken der „Copyright Act“ von 1842 bereits wesentlichen Einfluss hatte. Frankreich etwa gestand in Artistencafés gespielten Stücken und Liedern nach der ersten Aufführung das Recht auf geistiges Eigentum, dass nicht ohne weiteres von anderen kopiert werden durfte, zu. Scott, Sounds of the Metropolis, 33-34.

66 Nachdem die Grundlage für ein 14-jähriges Copyright 1790 geschaffen wurde, gab es eine erste wesentliche Novelle 1831, die ein 28-jähriges Schutzrecht vorsah, das nochmals um 14 Jahre verlängert werden konnte. Der „US Copyright Act“ von 1909 führte das 75-jährige Copyright ein, was in einer Novelle von 1911 wesentliche Neuerungen für außeramerikanische Produktionen beinhaltete. The Law of Copyright. Including the Copyright Act 1911. London 1912. Hiervon zeugt für Stücke in Jiddisch die Marwick Collection an der Library of Congress. Nach und nach reichten auch Künstler*innen aus der Monarchie ihre lithographierten Manuskripte bei der Copyrightbehörde ein. Rückschlüsse auf die Nutzung von Copyright und Urheberrecht zu ziehen, ist dennoch vage. Meist lassen sich nur Hinweise für die von Verlagen gedruckten Duplikate finden (die fügten dann zumindest den Copyright-Vermerk ein). Zum Beispiel Siegmund Josef, Taufstein Louis und Siebert E., Das Teufelsmädchen. NSLB, NSZL, Színháztörténeti Tár: I.M.1002. Das lässt vermuten, dass gerade die Verlage auf die Schutzmöglichkeit hinwiesen - nicht zuletzt deshalb, weil das bedeuten konnte, dass eine weitere Druckversion nötig war. Inwieweit das Urheberrecht unter den Etablissements verfolgt wurde, erhob ich nicht im Rahmen dieser Untersuchung. Lediglich durch Hinweise lassen sich einzelne Schlaglichter auf diese Frage werfen. Die mediale Debatte darüber, dass eine „nicht-originale“ Gruppe unter dem Namen der Folies Caprice in Linz auftrat, ist ein solches Schlaglicht. IAR, 20.5.1905, 5.

67 Diese sind etwa dokumentiert in WStLA, Bühnenschiedsgericht, A1 - Akten. Danzer's Orpheum war eines der am häufigsten in Streitfälle verwickelte Etablissements. Über Monate zogen sich verschiedene Klagen gegen den „Re-Print“ Unternehmer Otto Eirich. WStLA, Bühnenschiedsgericht, A1 - Akten: Danzers Orpheum gegen Otto Eirich 9/1922 sowie Otto Eirich gegen Danzers Orpheum 10/1922. Zu Copyright und Urheberrecht siehe auch Scott, Sounds of the Metropolis, 31-34. 
Kronen-Marke gestempelt sein. ${ }^{68}$ Die Steuern, die an Konzessionen gebunden waren, überstiegen diesen Betrag allerdings noch um ein Vielfaches. Als besonders kostspielig wurden die für Artist ${ }^{\star}$ innen nötigen Aufwendungen in Budapest beschrieben. Denn hier in der Metropole der transleithanischen Reichshälfte habe es eine geradezu „drakonische“ Spektakelsteuer gegeben. „In keiner Grossstadt am Continente wird Seitens der Behörde ein solcher Hochdruck auf das Chantant- und Varietéwesen ausgeübt als in Budapest[!] “69, so der Aufmacher der Internationalen Artisten Revue. Insgesamt 309 Gulden mussten die Künstler*innen für Stempel-, Magistrats- und Polizeigebühren monatlich aufbringen. Hinzu kamen noch Einkommens-, Kommunal- und Staatssteuern für die Etablissements. Das führte dazu, „[... ] dass die hiesigen Directoren unter die Höchstbesteuerten der Hauptstadt rangirt werden können[! $]{ }^{“ 70}$ Im Gegensatz zur monatlichen Abrechnung in Budapest war es in Wien möglich, tageweise eine Gebühr von maximal drei Gulden abzurechnen. ${ }^{71}$

Dennoch ließen die Beschleunigungen und Erleichterungen die Szene populärer Unterhaltung florieren. Die internationale Ausrichtung und Vernetzung waren für die Betreibenden von Etablissements wie die Künstler*innen von großem Interesse. Wichtig war aber vor allem eine soziale Absicherung und Organisation innerhalb der Szene, um bei etwaigen Unfällen, Betrügereien und anderen Missständen Unterstützung zu erhalten. Da es keine staatlichen Instanzen gab, welche Versicherungen bereitgestellt hätten, bildeten sich immer mehr Vereine, die sich für Artist ${ }^{\star}$ innen einsetzten und soziale Absicherung und Alltagserleichterung boten.

\section{Vereine}

$\mathrm{Ab}$ Mitte der 1880er Jahre gründeten die Künstler*innen Vereine. ${ }^{72}$ Unter den ersten solcher Künstlervereine war der Internationale Artistenverein Der Lustige Ritter in Wien. ${ }^{73}$ In der Anfangszeit agierte der Lustige Ritter als gemeinsamer Verein für alle Artist*innen der Monarchie, besonders ihrer Residenzstädte.

68 NÖLA, NÖ Reg. Präs. Theater ZA -Zensurakten.

69 IAR, 8.11.1891, 2.

70 IAR, 8.11.1891, 2.

71 IAR, 8.11.1891, 2.

72 Scott konstatiert die Entwicklung von Artistenvereinen betreffend, dass Künstler*innen zuvor gesetzlich häufig daran gebunden waren, nur in einer Spielstätte aufzutreten. Die Vereine verfolgten teilweise auch stark Werbezwecke, weshalb sie erst mit dem Wegfall von Spielstättenbindungen relevant wurden. Zur globalen Entwicklung von Artistenvereinen siehe Scott, Sounds of the Metropolis, 20-21.

73 Hinweise zum Lustigen Ritter können nur aus Zeitungen zusammengetragen werden, da es in den Archiven keine Vereinsunterlagen gibt. Jedoch berichtete die Internationale Artisten Revue sehr intensiv über die Tätigkeit des Vereins und aktuelle Veränderungen. Meist schrieben auch die leitenden Figuren des Vereins selbst über die Stimmungslage. In der Internationalen 
Die Artist ${ }^{*}$ innen aus Budapest hatten sich in den ersten Jahren euphorisch der in Wien stationierten Institution angeschlossen. Noch vor deren zehnjährigen Bestehen gründeten sie allerdings ihre eigene Körperschaft. Als Budapester Artisten-Verein spaltete sich diese im Jahr 1900 von der Wiener Sektion ab. Neben Berichten über viele kleinere Unstimmigkeiten und temporäre Abkoppelungen von Sektionen innerhalb der Vereine in den beiden Städten traten sie aber bei großen Feierlichkeiten (zunächst noch) nach außen hin geschlossen auf. In den Vereinigten Staaten etablierten sich Associations for Traveling Vaudeville Managers und zahlreiche Circuits, die internationalen Artist*innen längere Arbeitsgenehmigungen und Engagements bieten konnten.

Die Mitgliederlisten zeigen, dass nicht nur die Szene selbst, sondern auch die Vereine ein weiteres wichtiges Interaktionsfeld von internationalen jüdischen wie nichtjüdischen Künstler*innen waren. Nach dem Motto „viribus unitis“ gründete ein Zusammenschluss bekannter Wiener und Budapester Volkssänger*innen, allen voran die jüdischen Volkssänger Josef Modl und Carl Kratzl, 1892 den Internationalen Artisten Verein Der lustige Ritter. Dem Wahlspruch "dem Humor eine Gasse, das Wohlthun als Ziel“ folgend, hielten die Statuten fest, dass Der Lustige Ritter bestrebt war, „[...] die in Wien weilenden Artisten untereinander bekannt zu machen, geselligen Verkehr herbeizuführen und verarmte oder verunglückte Artisten zu unterstützen [...]“. ${ }^{\text {74 }}$ Der Verein bezahlte zwar kein Krankengeld, war aber um die Schaffung eines „Asyls“ für alte und schwache Artist ${ }^{\star}$ innen bemüht. ${ }^{75}$ Nachdem der Künstlerberuf nicht als Gewerbe anerkannt war, konnten die Sänger*innen und Artist*innen auch auf keinerlei Versicherungsleistungen hoffen und mussten sich für ihre Versorgung selbst organisieren. ${ }^{76}$

Geleitet wurde der Verein von einem Komitee, dem ein Obmann vorstand. Nach der Gründung hatte der Singspielhallenkonzessionär Matthias Bernhard Lautzky das Amt des Obmanns für wenige Jahre inne, ${ }^{77}$ bis 1900 amtierten die bekannten Volkssänger Josef Modl $^{78}$ bzw. Franz Kriebaum, ${ }^{79}$ ehe Lautzky nach Kriebaums Tod, wieder die Funktion des Vereinsobmanns und der Schriftsteller und Gastronom Karl Kutschera die des stellvertretenden Schriftwarts des

Artisten Revue erschien im März jeden Jahres der „Jahresausweis“ [Bilanz] des Vereins. Andere Zeitungen, wie etwa das Illustrirte Wiener Extrablatt berichteten auch immer wieder über die Vereinstätigkeit.

74 Vereinsstatuten zitiert in der IAR, 10.12.1893, 5.

75 IAR, 1.8.1899, 1.

76 „Das Vermittlungswesen“, IAR, 10.6.1894, 1-3.

77 IAR, 1.10.1893, 2.

78 IAR, 20.3.1895, 6.

79 Lehmann, Nachweis Behörden, öffentliche und Private-Institute, Unterrichts-Anstalten und Vereine 1, 1900, 243 sowie 251. 
Internationalen Artisten Clubs übernahmen. ${ }^{80}$ Das Vereinslokal des Lustigen Ritters wechselte regelmäßig zwischen den Spielstätten Wiens. ${ }^{81}$

Der Tätigkeitsbereich des Lustigen Ritters blieb dabei keinesfalls nur auf Wien beschränkt. Der Verein operierte international. Und obwohl der Vereinssitz in Wien eingetragen war, forderten auch die Budapester Mitglieder ihre Kolleg*innen zum Beitritt auf: „Thuet Euch zusammen, u[nd] schliesst Euch den Wiener Brüdern an! Die ,Lustigen Ritter' werden Euch mit offenen Armen empfangen [...] $]^{\text {82 }}$ forderte die Internationale Artisten Revue die Budapester Szene 1895 auf:,,Artistenbrot! Euch brauche ich es doch wohl nicht erst zu erzählen, wie bitter und schwer es verdient wird. “83 Zunächst folgten die in Budapest tätigen Artist ${ }^{*}$ innen dem Aufruf und fanden sich zumindest für ein paar Jahre unter dem Dach des Lustigen Ritters ein.

Allerdings zersplitterte der Verein bereits in den ersten Jahren des Bestehens in verschiedene Interessensrichtungen (Unterstützung von Kindern, Betrieb eines Artistenheims). ${ }^{84}$ Der steigenden Konkurrenz und den Anforderungen der Szene geschuldet, kam es im Folgejahr zur Gründung eines Wiener Artistenverbandes. Am 20. Oktober 1893 trafen sich 150 Personen "beiderlei Geschlechts“, wie betont wurde. Dieser zweite Verein in Wien richtete sich, anders als der Lustige Ritter, expliziter an Artist*innen: „Man sah Seiltänzer und Akrobaten, Feuerverschlinger und Messerwerfer, Athleten und Zwerge, Tänzerinnen und Kautschukmänner friedlich nebeneinander. Auch die Volkssänger hatten sich zahlreich eingefunden $[\ldots . .]^{\text {“85 }}$ In der Berichterstattung zeigte sich einmal mehr, wie stark zwischen den verschiedenen performativen Berufen Austausch stattfand und gemeinsame Interessen bestanden.

Auch in diesem Verein arbeiteten Jüdinnen und Juden mit Nichtjüdinnen und Nichtjuden zusammen. Die Ziele waren ähnlich denen des Lustigen Ritters. So forcierte auch der Wiener Artistenverband die allgemeine gesellschaftliche Besserstellung der Artist*innen wie auch die Kooperation in der Durchsetzung materieller Interessen, Versicherung im Alter oder für Unglücksfälle. Für die Artist ${ }^{*}$ innen war besonders wichtig, nicht mehr, wie bisher, unter dem „Vagabunden- und Bärentreibergesetz“ zu stehen, sondern den Gewerben zuge-

80 Wahlspruch des internationalen Artisten Clubs der lustige Ritter in Wien, IAR, 1.10.1893, 10.

811893 war das Vereinslokal in Ronacher's Restaurant untergebracht. Lehmann's allgemeiner Wohnungsanzeiger, 1893, 206. Um 1900 war es in der Eschenbachgasse 2 eingetragen und 1910 dann in der Praterstraße im Artisten Café. Lehmann's allgemeiner Wohnungsanzeiger 1900, 251 bzw. 1910, 242.

82 IAR, 1.4.1895, 3.

83 OG., „Zur Gründung eines Budapester Artisten-Vereines“, IAR, 10.4.1895, 2-3, 2.

84 IAR, 10.12.1893, 4-5. Siehe auch IWE, 23.11. 1903, 16.

85 IAR, 1.11.1893, 8. 
ordnet zu werden. Neben der Pflege der Gemeinschaft unter den Künstlerinnen war die Eingrenzung von Konkurrenz eines der Hauptanliegen. ${ }^{86}$

Nach siebenjähriger Kooperation unter dem Wiener Artistenverband entschloss sich die Budapester Szene 1899, einen eigenständigen Artistenverein zu gründen. Die offizielle Eröffnung zelebrierte der neue Verein mit der Fahnenweihe im Mai des Jahres 1900. Die Präsidentschaft oblag dem bekannten Orpheumsdirektor Carl Somossy und dem Herausgeber der Internationalen Artisten Revue, Ferdinand Steiner. ${ }^{87}$ Der Verein unterstützte wiederum kranke und „invalide“ Mitglieder und war darum bemüht, „[...] dem Artistenstand Achtung zu verschaffen $[\ldots]^{\text {“ }}{ }^{88}$

Trotz der Abspaltungen einzelner Sektionen und Interessensgruppen unterstützten einander die Vereine, was etwa bei Feierlichkeiten im öffentlichen Raum zelebriert wurde. Nach acht Jahren gemeinsamer Organisation der Budapester und Wiener Artist ${ }^{*}$ innen feierte der erste Artistenverein in Budapest am 20. Mai 1900 Fahnenweihe. Beinahe alle lokalen Größen waren in dem Zusammenschluss vereinigt und internationale Kolleg*innen zollten Tribut. ${ }^{89}$ Die „Bannerweihe“ sollte auch ein von Karl Döring (1867-1907) verfasstes Gedicht begleiten, das die Parallelen zu anderen Aufzügen augenscheinlich macht. Es mutete überaus militaristisch an und verstand sich als „Kampfansage“ auf Deutsch und Ungarisch. ${ }^{90}$

Ein großes Fest mit internationaler Beteiligung, das mit einem öffentlichen Festzug über die Prachtstraßen der Metropole begann, mündete in einem feierlichen Akt im Somossy Orpheum, wo alle Gäste als Glückwunschgeste in der Tradition des „Nagelns" ${ }^{\text {"91 }}$ ein Metallstück in den neuen Fahnenstab schlugen. Abends gab es ein gemeinsames Bankett mit Tanz. Nach vielen Festreden setzten sich dann schließlich „Trinksprüche“, wie der Pester Lloyd berichtet, bis in die späten Nachtstunden fort:

Gestern fand in prunkvoll feierlicher Weise die Fahnenweihe des hiesigen Artistenvereins statt. Die festlichen Veranstaltungen begannen Vormittags[!] mit einem glänzenden Festzug, der von einer tausendköpfigen Menge begleitet, seinen Weg über die Ring- und Andrássystraße nahm. [...] Der eigentliche Akt der Fahnenweihe fand um 2 Uhr nach-

86 IAR, 1.11.1893, 8.

87 Zur Person Ferdinand Steiner siehe die Ausführungen früher in diesem Kapitel.

88 PL, 14.4.1900, 7.

89 IAR, 20.5.1900.

90 Karl Dörings Gedicht ist abgedruckt in IAR, 20.5.1900, 1.

91 Zur Tradition des „Nagelns“ siehe Florian Dering, Volksbelustigung: Eine bildreiche Kulturgeschichte von Fahr-, Belustigungs- und Geschicklichkeitsgeschäften der Schausteller vom 18. Jahrhundert bis zur Gegenwart (Nördlingen: F. Greno, 1986), 159. 
mittags im Etablissement Somossy statt. Fast sämtliche österreichisch-ungarische und viele ausländische Artistenvereine hatten Vertreter entsendet, $[\ldots] .^{92}$

Ein weiteres Beispiel für die trotz Abspaltung weiterbestehende enge Zusammenarbeit zwischen den Wiener und Budapester Sektionen war die im Oktober 1900 in Wien stattfindende Fahnenweihe des Wiener Zwölferbundes. Der Zwölferbund war ein weiterer humanitärer Artistenverein, der in den letzten Jahren des 19. Jahrhunderts gegründet worden war und dessen Mitglieder sich vielfach aus jenen des Lustigen Ritters rekrutierten. Der Zwölferbund hatte aber einen anderen Schwerpunkt. Er war besonders um die Versorgung von Kindern bemüht. ${ }^{93}$ Louis Taufstein (1870-1942), der bekannte Liedvorträger der Budapester Orpheumgesellschaft, war ein überaus aktives Mitglied beider Vereinigungen und korrespondierte rege mit den Mitgliedern in Budapest. ${ }^{94}$ Die Inszenierung der Wiener Vereinsfeier fand in ähnlicher Manier statt wie diejenige ein halbes Jahr zuvor in Budapest. In einem Bericht für die Internationale Artisten Revue hob Louis Taufstein besonders die Beteiligung des antisemitischen Wiener Bürgermeisters Karl Lueger hervor: „Der erste Nagel wurde von Bürgermeister Dr. Lueger in den Fahnenschaft eingeschlagen [...]. “95 Trotz Luegers Teilnahme an der Ehrenfeier des von prominenten jüdischen Szenemitgliedern initiierten Vereins blieben, wie die Berichterstattung hervorhob, jegliche antisemitische Ausfälligkeit aus.

Die einstimmige Unterstützung und Kooperation drohten 1901 beinahe unterbrochen zu werden. Im Dezember kam es von Seiten der ungarischen Behörden zu einem Aufführungsverbot für eine Wiener Volkssängergruppe. Daraufhin bildete sich in Wien rasant eine Interessensgruppe rund um den Konzessionär Albert Hirsch (1841-1927), die ebenso für die Wiener Spielstätten „Schutz den Einheimischen“ forderte. Es kam zu einer vermeintlich national motivierten Konkurrenz zwischen den Etablissementkünstler*innen aus Budapest und Wien. Allerdings zeigte sich schnell, dass dieser „nationale Konflikt" nicht unter den Künstler*innen bestand, sondern ein politischer Akt der Budapester Verwaltungsbehörde war, der - trotz der Weihnachtsfeiertage schon innerhalb der nächsten drei Tage aufgrund der heftigen Intervention der Budapester Varietékünstler*innen zurückgenommen werden musste. Nachdem das Gerücht umging, die Folies Caprice würden eine Expositur in Wien errichten, bot sich Albert Hirsch als deren potentieller Leiter an. Zuvor hatte

92 PL, 21.5.1900, 2.

93 IAR, 1.8.1899, 2.

94 IAR, 20.10.1900, 1-2.

95 IAR, 20.10.1900, 1. Zur rituellen Praktik der Fahnenweihe siehe Hödl, Zwischen Wienerlied und Der kleine Kohn, 45. 
sich Hirsch äußerst feindselig und ablehnend gegenüber Ensembles und Künstler*innen aus Budapest geäußert; nun nahmen ihm seine Wiener Kolleg*innen die schnelle Meinungsänderung übel. Dennoch folgte unter den Wiener Spielstättenbetreiber*innen eine heftige Diskussion, die in Wiens medialer Rezeption als „Volkssängerkrieg“ betitelt wurde. ${ }^{96}$ Aber auch hier bekannten sich 90 Prozent der Wiener Volkssänger ${ }^{\star}$ innen unverzüglich gegen Restriktionen für Gastkünstler*innen. ${ }^{97}$

Die Kooperation der Budapester und Wiener Vereine bestand weiter. 1918 wurde schließlich die Internationale Artisten Organisation gegründet, deren Hauptzweck die Verbesserung der wirtschaftlichen und sozialen Stellung der Artist*innen war. Arnold Bralah gründete den Verein, Ferdinand Leopoldi (1886-1944) und Josef Koller waren Gründungsmitglieder. ${ }^{98}$ Mit dem Sitz in der Praterstraße - dem Herzen der Wiener und internationalen Artistenszene - war dieser der „Sammelpunkt“ der Artisten. ${ }^{99}$

Das amerikanische Pendant war die Association of Traveling Vaudeville Managers, der Sam Scribner (1858-1941) vorstand und die alljährlich mehrere Versammlungen abhielt. ${ }^{100}$ Diese Vereinigung reisender Künstleragent ${ }^{*}$ innen bemühte sich, Lithographien für Manuskripte kostengünstig bereitzustellen und zwischen Etbalissementbetreibenden und Künstler*innen zu vermitteln. ${ }^{101}$ Für die reisenden Schauspieler ${ }^{\star}$ innen und Artist*innen waren die sogenannten Circuits verantwortlich. Sie waren Zusammenschlüsse mehrerer Theater unter einem Manager. So boten verschiedene Spielstätten den Artist*innen Engagements für nicht nur wenige Tage, sondern über einen längeren Zeitraum. „[D] urch sorgfältiges Vorbereiten der Reiserouten unnütze weite Reisen von einem Engagement ins andere zu verhindern" ${ }^{102}$ war das Bestreben der Circuits. Solche Vereinigungen ermöglichten längerfristige Engagements von bis zu zwei Jahren und bei guten Gagen und gestalteten somit die Migration nach USA als attraktiv. Das funktionierte so gut, dass Künstler ${ }^{\star}$ innen der sogenannten

96 Hödl, Zwischen Wienerlied und Der kleine Kohn, 86-120. Ob die Folies Caprice wirklich vorhatten, außerhalb von Sommergastspielen in Wien sesshaft zu werden, geht aus der Berichterstattung in Budapest nicht hervor.

97 „Der Volkssängerkrieg“, IWE, 26.5.1903, 9. Siehe außerdem Ausführungen in Kapitel 3.

98 Koller, Das Wiener Volkssängertum in alter und neuer Zeit, 160.

99 Freiheit, 15.9.1927, 3.

100 NYC, 24.6.1899, 338.

101 NYC, 22.6.1899, 18. Sowie Inserat „Association of Travelling Variety Managers“, NYC, 26.6.1897, 276.

102 IAR, 10.8.1913, 5. Für die „big-time-variétés“ wurde von Gagen bis zu 3500 Dollars pro Woche berichtet. Für „small-time-variétés“ weniger, jedoch ebenso von Wocheneinnahmen von bis zu 23.000 Dollars (bei zwei Spielzeiten pro Tag außer Sonntag und Eintrittspreisen von 25 Cents). 
großen Theater oft anstrebten, „einen Abstecher auf die Bretter des Variétés“ machen zu können, da ein solcher „meist nicht zu ihrem materiellen Nachteil“ gewesen sei. Die größte derartige Organisation war das United Booking Office. Den Orpheum-Circuit leitete der aus Ungarn stammende Martin Beck und der Loew-Circuit betrieb kleinere Spielstätten. ${ }^{103}$

\subsection{Jüdinnen und Juden auf der Tour}

Wenn Mendel Rottmann in den 1890er Jahren seine Programme konzipierte, tat er dies unter der Annahme, sie sowohl in Wien als auch in Budapest aufzuführen. Der Volkssänger, der in den 1910er Jahren in Wien sein eigenes Varieté eröffnen sollte, trat regelmäßig als Max Rott in den beiden Residenzstädten der Monarchie auf. Seine erste Anlaufstelle in Budapest war die Blaue Katze, als Antal Oroszi noch für diese schrieb. Mit Oroszi wechselte auch Rotts favorisierte Gastspieladresse in Budapest zum „Mustervarietéc Folies Caprice. Nachdem Rott aber regelmäßig in Budapest war, trat er auch immer wieder bei der Herzmanngruppe auf. ${ }^{104}$ Der Wiener Volkssänger und Bühnenautor Heinrich Eisenbach spielte im ,ersten Hauptstädtischen Orpheum“ (Somossys Orpheum) ebenso wie in Herzmanns Orpheum. Er stand der Budapester Szene so nahe, dass er sogar seine langjährige Partnerin Anna Ferry im Rahmen einer Gastaufführung in Somossys Orpheum im November 1893 heiratete. ${ }^{105}$ Bekannter als Max Rott, Heinrich Eisenbach oder Anna Ferry ist Ester Rokhl Kaminskas Erfolgsgeschichte als Künstlerin auf Tour. Ihre Karriere ließ Kaminska zwischen Russland, Polen und den Vereinigten Staaten von der Jahrhundertwende bis nach dem Ersten Weltkrieg erfolgreich touren. ${ }^{106}$

Für sie alle waren, wie die Bestrebungen der Vereine andeuteten, persönliche Beziehungen vor allem auch dann wichtig, wenn es auf einer Tour zu Schwierigkeiten kam. Obwohl die neue organisatorische Infrastruktur das Mobilsein erleichterte, bedeutete eine Atlantiküberquerung noch immer zahlreiche Risiken. Künstleragenturen und Varietémanager bemühten sich, gute Reiseund Arbeitskonditionen für die Künstler*innen aus der Habsburgermonarchie sowie Verträge einzuwerben, die es ihnen ermöglichten, mehrere Monate am

103 IAR, 10.8.1913, 5.

104 NSLB, Színháztörténeti Tár, Mulatók.

105 „Im Somossy Orpheum“, IAR, 1.11.1893, 9.

106 Ester Rokhel Kaminska verfasste auch Lebenserinnerungen, die 1926 in Der Moment publiziert wurden. Ester Rokhl Kaminska, Zikhroynes, Der Moment, 8.10.1926. Wie Ester Rokhl Kaminska die Entstehung moderner jiddischer Schauspielerinnen prägte siehe Alyssa Quint, The Rise of Modern Yiddish Theater (Bloomington: Indiana University Press, 2019), 140-145. 
Stück auf den New Yorker Bühnen zu arbeiten. Künstler*innen, Spielstättenund Agenturbetreiber*innen waren daher bestrebt, ein starkes internationales Netzwerk aufzubauen und ihre Erfahrungen - etwa hinsichtlich Versicherungen, einfacheren Reiserouten oder Grundlagen der Vereinsgründung - auszutauschen. Allen Bemühungen des internationalen Netzwerks in der mobilen Populärkultur zum Trotz, blieben Gräueltaten, schamlose Ausbeutung und Betrügerein nicht aus. Im Jänner 1894 wandte sich ein Artist, der gerade von einer Tour aus New York zurückgekehrt war, an seine Kolleg*innen:

Imre Fox engagirte mich in Wien im Mai 1893 für eine Tourné in Amerika und Canada auf 30 Wochen, respect. vom 2.Nov. 1893 bis 1. Mai 1894. Juni, Juli und August war ich die Koster \& Bial in New York engagirt. Am 2. Nov., Morgens fuhren wir von New York nach einem kleinen Ort, wo die erste Vorstellung stattfand; von da ab reisten wir beinahe jeden Tag, Sonnabend den 7. Nov. spielten wir in Welmington. Nach der Vorstellung reiste Imre Fox, wie er sagte, in Geschäften nach New York und sollte Montag in Bethlehem bei der Gesellschaft wieder eintreffen. Wir waren also am 9. Nov unter Leitung seines Schwagers Mr. Clark nach Bethlehem gereist. Für die Abendvorstellung wurde alles vorbereitet, das Publikum war bereits im Theater, nur unser Direktor Imre Fox war noch nicht da, wir warteten alle Züge die aus New York kamen, aber keiner brachte ihn, schliesslich waren wir gezwungen die Vorstellung abzusagen und dem $\mathrm{Pu}$ blikum das Geld zurückzugeben.[...] Da wir keinen Leiter hatten, so fuhren wir noch denselben Abend nach New-York zurück, ich begab mich sofort zu Missis Fox, unter Thränen erzählte sie mir, dass ihr Mann verschwunden, sie habe alle Hospitale durchgesucht und auch bei der Polizei nachgefragt, habe aber nirgends eine Spur von ihm gefunden. Sie war der festen Meinung, dass er ermordet worden sei. Am 10. Nov. Erst hatte sie die Gewissheit erlangt, dass er nach Europa durchgebrannt und sie aller Mittel entblösst zurückgelassen habe.[!] ${ }^{107}$

Dieser Leserbrief illustriert, wie Künstler*innen aus Europa über mehrere Stationen von Agenturen gewissermaßen durch die Vereinigten Staaten verbucht wurden. Anlaufstelle dabei blieb stets New York, wo die Tour ihren Ausgang und schließlich auch das Ende nahm. Im konkreten Fall zu früh und wegen eines Betrugs. Deshalb warnte der Verfasser in diesem Leserbrief auch seine Kolleginnen, damit diese nicht auch auf die schamlosen Tricks eines unseriösen Künstleragenten hereinfielen. Er bat die anderen Mitglieder der Szene aber auch um Hilfe bei der Suche nach Imre Fox in der Hoffnung einer Aufwandsentschädigung. Es kam also durchaus vor, dass angeheuerte Künstlerinnen in Amerika zurückgelassen wurden. In solchen Fällen kam dem internationalen Netzwerk große Bedeutung zu.

Nicht aber nur die Schaffung von Medien, sondern gerade auch die bauliche Infrastruktur, die etwa mit Artistenheimen in Budapest aufgebaut wurde, war 
eine besonders wichtige Maßnahme zur Unterstützung mobiler Künstler*innen. In Wien spielten Varietés vielfach in den Sälen von Hotels. Damit war durch die Hotelgastronomie diese wichtige Infrastruktur gegeben. So war nicht nur Verpflegung während der Vorstellungen gewährleistet, sondern auch die Unterkunft für Auftretende von auswärts fand eine einfache Antwort. In Budapest allerdings waren Varietés und Singspielhallen beinahe ausschließlich außerhalb von Hotels, in den Parterreetagen von Wohngebäuden und Ähnlichem untergebracht. Nächtigungsmöglichkeiten mussten in Budapest somit in anderer Form geschaffen werden. Hier entstanden, wie im dritten Kapitel dargelegt, rund um die Aufführungsstätten sogenannte Artistenheime. ${ }^{108}$ Diese waren dazu gedacht, auswärtigen Künstler*innen Übernachtungen zu guten Konditionen zu ermöglichen. Viele der Etablissmentbetreibenden eröffneten derartige Artistenheime, teilweise im selben Gebäude, in dem sich die Spielstätte befand, oder in nahegelegenen Gebäuden. Als Aufenthalts- und Austauschorte kam den Budapester Artistenheimen untertags große Bedeutung zu. ${ }^{109}$ Zusätzlich prägten alsbald Artistencafés, die zu „Rendezvous aller Artisten [und Artistinnen]“ dienen sollten, ${ }^{110}$ die Nachbarschaft der Etablissements und Artistenheime. Diese Entwicklung von caféartigen Taglokalen griff sodann auf Wien ${ }^{111}$ und New York über. ${ }^{112}$

108 Artistenheime etablierten sich auch in Wien, sie unterschieden sich jedoch von jenen in Budapest. In Wien waren derartige Unterbringungen eine Versorgung für kranke oder alte Szenenzugehörige. Siehe Kapitel 3.

109 IAR, 10.12.1893, 16.

110 Siehe etwa die Hinweise auf Herzmanns Artistencafé, IAR, 8.11.1891, 10.

111 Diese Entwicklung ist für New York etwas zeitversetzt ab dem ersten Jahrzehnt des 20. Jahrhunderts nachweisbar.

112 Zum Beispiel das Café Royal: An der $12^{\text {th }}$ Ecke $2^{\text {nd }}$ Avenue hatte es 1908 nach dem Betreiber Café Breslau geheißen und wurde 1910 in Café Royal umbenannt. Edna Nahshon, Café Royal, in: dies. (Hg.), New York's Yiddish Theater: From Bowery to Broadway (New York: Columbia University Press, 2016), 36-38, 37. 
Abb. 21 Inserat von Herzmanns Orpheum in der Internationalen Artisten Revue mit Bewerbung des Artistenheims und dem Hinweis auf die ungarische Version der Klabriaspartie im Folies Caprice, Internationale Artisten Revue, 10. Jänner 1894, 16, Sammlung für Theatergeschichte der ungarischen Nationalbibliothek Széchényi

Allerdings brachte die Etablierung von Räumen für mobile Künstler*innen nicht nur Vorteile mit sich. Die neuen Artistencafés und -heime beförderten Vorwürfe, dass die Betreiber der ohnehin schon „vulgären Etablissements“ dort verdeckte Prostitution gefördert hätten. Die Unterstellungen lauteten, dass sich die Schauspielerinnen in den Cafés vom Publikum aushalten ließen (was natürlich eine Umsatzsteigerung für die Leitung bedeutete) und dann für „rohe Obszönitäten“ mehr oder minder freiwillig in die oberen Räumlichkeiten verschwunden seien; ${ }^{113}$ „Zwei oder drei geheime Räume, von denen die Polizei keine Kenntnis haben konnte [...]", berichtete die Budapesti Hírlap ihren Leser ${ }^{*}$ innen. ${ }^{114}$ Solche Unterstellungen beruhten somit auf dem räumlichen Argument, dass die Nebenräume der Cafés und die Schlafräume in den

113 „Chantant und Polizei“, IAR, 8.3.1892, 1.

114 Budapesti Hírlap, 7.10.1893, 5. Die Budapesti Hírlap führt hier die Folies Caprice als Beispiel an. 
Artistenheimen natürlich - im Unterschied zu den Etablissements - der Öffentlichkeit nicht zugänglich und auch für die Staatspolizei nicht ohne direkten Anlass betretbar waren. Für den Fall der Erregung öffentlichen Ärgernisses, der Ruhestörung oder anderer Übertretungen der „Sittlichkeitsgrenze“ wurde ab April 1892 die legale Möglichkeit eingerichtet, Spielstätten die Konzession mit sofortiger Wirkung entziehen zu können. Deshalb bemühte sich die Szene intern immer stärker, derartigen Eventualitäten vorzubeugen. ${ }^{115}$
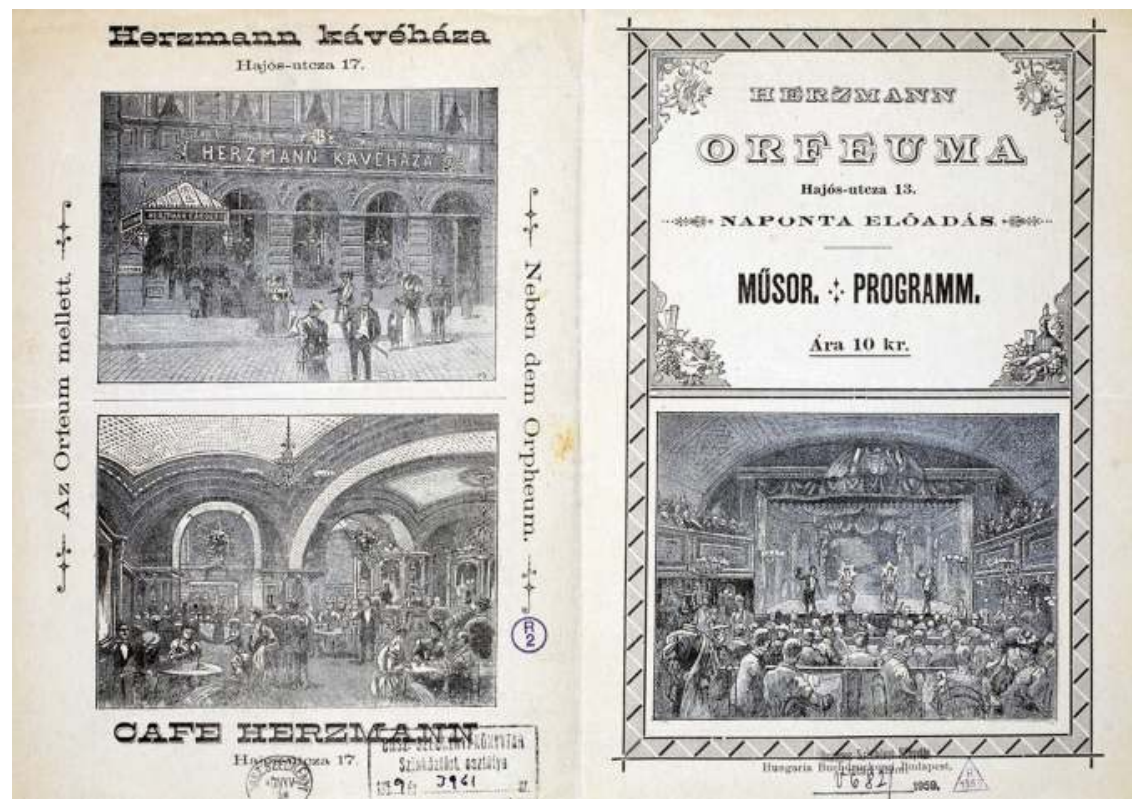

Abb. 22 Herzmanns Varieté und Artistencafé Budapest um 1900, Sammlung für Theatergeschichte der ungarischen Nationalbibliothek Széchényi

Zudem machte die Konkurrenz zwischen den einzelnen Einrichtungen die Schaffung von semiprivaten Räumen für die Künstlerinnen zur Grundlage für gegenseitige Unterstellungen, die die Mitbewerbenden aus dem Weg schaffen sollten: Der Staat, der die Etablissementszene ohnehin als subversives, bedrohliches Element wahrnahm, setzte derartige Forderungen häufig ohne Überprüfung um. Darüber hinaus benutzten die politischen Agitatoren die Unterstellung als willkommenes Argument, um die populäre Kultur, deren großer Einfluss innerhalb der Bevölkerung gerade den nationalistisch gesinnten Politikern zuwider war, zu denunzieren. In diesen Bereichen des Alltages verbrachten die Menschen viele Stunden - nun nicht mehr nur während der Aufführungen,

115 „Erste Schritte“, IAR, 8.3.1892, 1-2. 
sondern zunehmend auch zum Verweilen davor oder danach; Stunden, die vom internationalen Charakter der populären Kultur geprägt waren, und das diametrale Gegenteil der dekretierten nationalen Homogenität erfahren ließen. Die bereits angesprochenen Programme illustrierten dies anschaulich. Bereits die illustrierten Titelseiten der Programme versprachen Transgression nicht nur über nationale Positionen hinweg oder in kultureller Hinsicht, sondern auch in Hinblick auf Geschlechterrollen.

\subsection{Männliche Damen, weibliche Männer und deren Imitationen: mobile Rollenbilder}

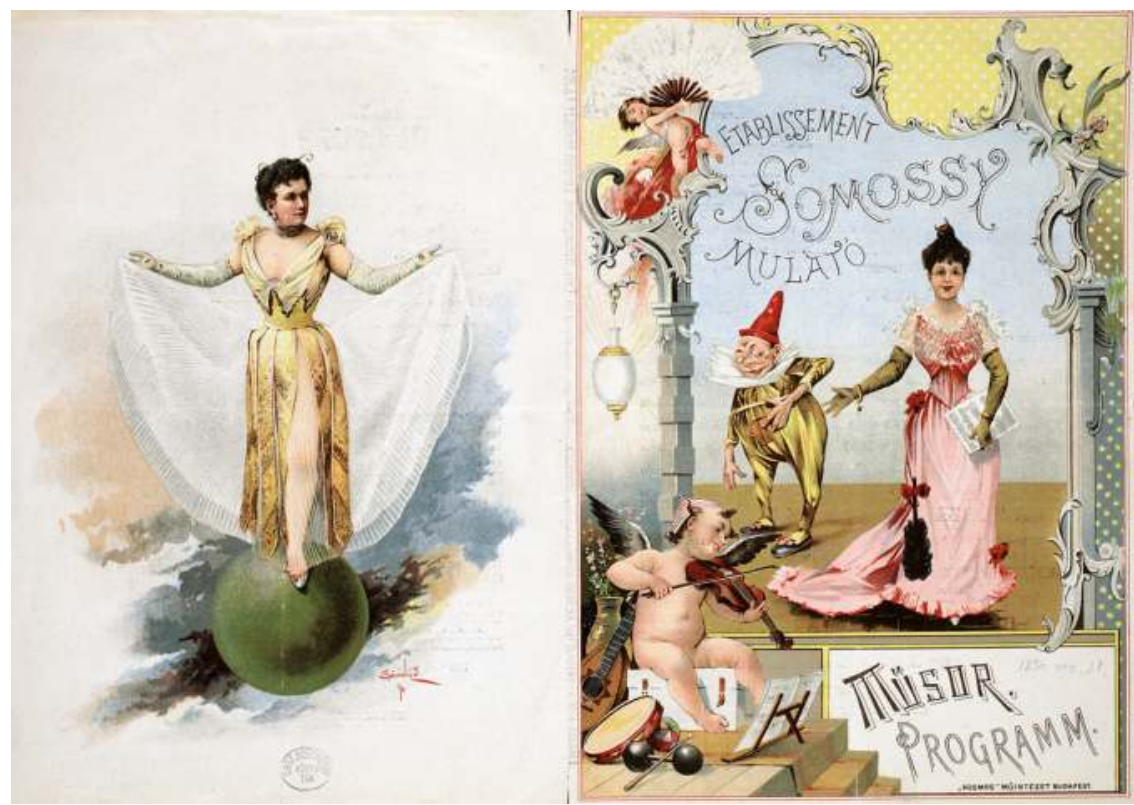

Abb. 23 Programm von Somossys Orpheum mit Engelsgestalt, Artistin, Sängerin und kleiner Pantomime, Sammlung für Theatergeschichte der ungarischen Nationalbibliothek Széchényi

Wie aber gestalteten sich die Rollen der Akteur*innen vor dem Hintergrund der Mobilität sowie der durch diese provozierten Kritik? Neidvoll schauten die Bühnen der Welt nach Budapest. Hier spross förmlich ein originelles Etablissement nach dem anderen aus dem Boden. Von den Raffinessen beeindruckt, wollten alle Schauspielerinnen die Luft der Spielstätten in der ungarischen Hauptstadt atmen und in andere Städte tragen. Die Wiener Volkssängerbühnen 
der letzten Jahrzehnte des 19. Jahrhunderts galten dahingegen als die Schmieden für die besten Gesangsartist ${ }^{\star}$ innen und Komikerinnen: Von den Wiener „Brettln“ aus gingen viele der erfolgreichsten Humorist*innen und Chansonetten in die Welt. ${ }^{116}$ Eine Besonderheit der New Yorker Szene war die Infrastruktur, die sie den reisenden Künstler*innen aus Europa bot, um auf einer Tour über längere Zeit in New York arbeiten zu können. Vor diesen Rahmenbedingungen gestalteten sich die Rollenbilder und Funktionen der Varietészene zwischen den drei Städten ähnlich. Vor allem die Vorwürfe, die der Szene gegenüber aufgrund dieser neu entstehenden Räume, die für die mobile Populärkultur wichtig waren, geäußert wurden, beeinflussten die Selbstverständnisse der Künstler*innen. Von den Verständnissen darüber, welche verschiedenen Rollen den Akteurinnen in der Populärkultur zukamen und davon, wie sich diese Rollenbilder zu den Vorwürfen verhielten, handelt der folgende Abschnitt. Dabei soll zunächst von den Volkssängern und Regisseuren die Rede sein, weiters von den Volkssängerinnen, Soubretten und Chantant-Müttern und schließlich von den Direktoren.

\section{Volkssänger, Gesangshumoristen und Komödianten}

Wer ein (,jüdischer') Volkssänger, ein Gesangshumorist oder ein Komödiant war, ist weder klar definiert noch eindeutig. Ebenso im Diffusen verlieren sich Definitionsversuche dessen, was ein Volkssänger, ein Gesangshumorist, Komödiant oder Kabarettist machte beziehungsweise worin sich diese Tätigkeiten unterschieden.

Abraham Goldfaden (1840-1908) gilt als der Begründer des jiddischen Theaters. Dass Abraham Goldfaden lange vor seiner Karriere in Literatur und Dramaturgie Volkssänger und Gesangshumorist gewesen war, ist weniger bekannt. Fabius Schach nannte Goldfaden 1901 in seiner Geschichte über das jüdische Theater einen der ersten jüdischen Volkssänger. „Goldfaden war schon lange vorher als patriotischer Volkssänger wie als Humorist bekannt, und seine Liedersammlung ,Das Jüdele‘ gehörte zu den beliebtesten. " ${ }^{117}$ Neben dieser Liedsammlung blieb Schach allerdings zurückhaltend, was die Volkssängerqualitäten des großen Literaten betraf: „Er reihte einige zugkräftige Couplets aneinander, füllte die Lücken mit irgend einer unsinnigen Erzählung aus, klebte einige Witze daran und hatte ein ,Stück. Er konnte weder Leben und Handlung, noch Charaktere in seine Stücke eintragen. ${ }^{\text {"118 }}$ Das Besondere an Goldfadens

116 IAR, 1.11.1893, 1-2.

117 Julius Schach, „Das jüdische Theater, sein Wesen und seine Geschichte“, Ost und West 1, no. 5 (1901): $347-358,350$.

118 Ebda. 


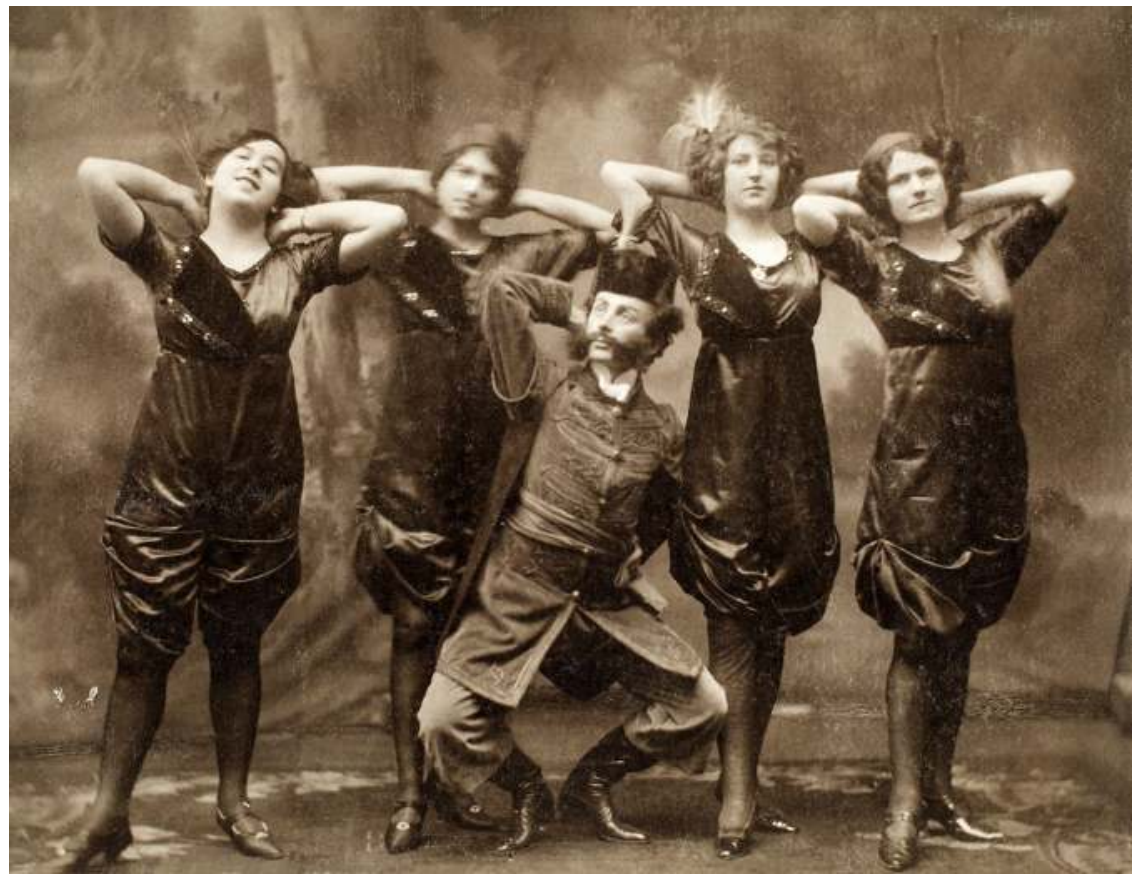

Abb. 24 Aufnahme von einem Ensemble in einem Fotoalbum von der Budapester Varietészene um 1900, Sammlung für Theatergeschichte der ungarischen Nationalbibliothek Széchényi

Dramen sei gerade die Kombination des Volkssängergeschicks mit jenen des Literaten und Dramaturgen gewesen. Samuel Meisel, der 1908 eine Geschichte des jüdischen Theaters verfasste, betonte, dass in Goldfadens dramatischem CEuvre die Kombination zwischen populärer Kultur und Literatur trefflicher nicht kulminieren hätte können: „Das Goldfadensche Theater ist Schauspielhaus, Oper, Operette, Variété und Orpheum in einer Bude. Aus ebensovielen Bestandteilen setzt sich jedes Goldfadensche Theaterstück zusammen: es ist Drama, Lustspiel, Posse, Operette und Varieté-Spezialität in einem Machwerk. "“119

Dieser vielleicht letzte ,jüdische Volkssänger“, so Arno Nadel 1916 in einer fünfteiligen Aufsatzserie über das jüdische Volkslied, sei ein „schöner Mann“ gewesen: ${ }^{120}$

119 Samuel Meisels, „Zur Geschichte des jüdischen Theaters“, Ost und West 8, no. 8-9 (1908): 509-526, 519.

120 Hierbei ist auffallend, dass Nadel, obwohl, wie der Artikel besagt, er sich an religiösen Volksliedern orientiert, als Beispiel Rosenstein bringt, der sich eben nicht mit religiösen Volksliedern beschäftigte. Aron Nadel verfasste auch den Beitrag über das jüdische Volks- 
Traurig wird man, wenn man an diesen schönen, dunklen, schwarzlockigen Mann denkt, der nun wohl auch in Amerika viele Menschen und vor allem viele Mädchen begeistert, wenn er in den Abendstunden in seinem finsteren Hotelzimmer sich einschließt und mit zitternder wundervoller Stimme [...] die herrlichsten jüdischen Volkslieder erklingen läßt.[!] ${ }^{121}$

Der letzte vermeintlich authentische jüdische Volkssänger sei er deshalb gewesen, weil im Zuge der neuen Mobilität die ,jüdischen Volkssänger“ zu Weltenbummlern wurden: „Und welch ein echter, herrlicher Zigeuner ist er! Man findet ihn in Wien, in Berlin, in Paris und London -, und vor dem Krieg war er in New-York, [... “ “122 Der Prototyp des (,jüdischen') Volkssängers war folglich ein Reisender, der gekonnt verschiedene Fertigkeiten vereine. ${ }^{123}$ Und auch dieser vielleicht letzte jüdische Volkssänger beherrschte das Vermischen bestimmter, genrespezifischer Fertigkeiten. Leo Rosenstein (1861-1921), von dem Nadel wiederum als letztem jüdischen Volkssänger sprach, war besser bekannt als Leo Stein. Er schrieb die Texte zu bekannten Operetten wie der Lustigen Witwe, der Csárdásfürstin und Wiener Blut. Er arbeitete mit Franz Lehár (1870-1948), Johann Strauss (1825-1899), Bela Jenbach (1871-1943), Emmerich Kálmán, Robert Stolz (1880-1975) und Fritz Grünbaum (1880-1941) und auch Edmund Eysler (1874-1949) auf den „Brettln“ zusammen. Und viele andere Etablissements adaptierten seine Texte. ${ }^{124}$

Gerade aber gegen diese Kombination verschiedener künstlerischer Ausdrucksformen verwehrte sich Josef Koller in der Beschreibung der Wiener Volkssänger*innen. Traditionellerweise, so Koller in seinem Führer zum Volkssängertum, waren Komiker keine Volkssänger „im wahren Wortsinne“. Seine Argumentation war jedoch widersprüchlich. Denn die Komiker, so Koller weiter, hätten durch ihr wiederholtes Auftreten im Varieté und mit ihren Liedern, Couplets und Soloszenen „weiteste Volkstümlichkeit“ erlangt. ${ }^{125}$ Max Rott,

lied für das Jüdische Lexikon. Was ein jüdisches Volkslied alles sein konnte, war ebenso diffus. Angemerkt sei allerdings, dass etwa das jüdische Lexikon darunter nicht zwingend ausschließlich das religiöse Volkslied verstand. Eine der drei möglichen Arten des jüdischen Volksliedes sei das „, coupletartige“. Nadel verortet dieses in der Badchanim-Dichtung und nennt das Jiddische als einen Aspekt. Arno Nadel, Jüdisches Volkslied, in: Georg Herlitz, Bruno Kirschner (Hg.), Jüdisches Lexikon: Ein enzyklopädisches Handbuch des jüdischen Wissens in vier Bänden, 4 (Berlin: Jüdischer Verlag, 1930), 1239-1241, 1239-1240.

121 Arno Nadel, „Jüdische Volkslieder: Religiöse Lieder“, Der Jude, eine Monatsschrift 1, no.7 (1916): 465-479, 469.

122 Ebda.

123 Den Referenzen aus dem jüdischen Volkslied ist gemein, dass Frauen nicht zu diesem Prototyp zählen.

124 R. Müller, Leo Stein, in: Österreichisches Biographisches Lexikon 13, 1815-1950 (Wien: Verlag der österreichischen Akademie der Wissenschaften, 2010), 151.

125 Koller, Das Wiener Volkssängertum in alter und neuer Zeit, 185. 
Otto Taussig, Adolf Glinger, Louis Taufstein und Heinrich Eisenbach waren nur einige wenige der bekannten Brettl- und Etablissementkünstler. Sie traten als Volkssänger, Gesangshumoristen und Komödianten auf. In verschiedensten Etablissements brachten sie ihr Repertoire auf die Bühne, das von Liedern über Couplets zu Soloszenen bis zu Einaktern reichte. In den vielfach kabarettartigen Darbietungen oder Parodien vermittelten sie ihrem Publikum Alltagspolitik, Gesellschaftszynismus und nicht selten auch Gesellschaftskritik. ${ }^{126}$

Nachdem meist ausschließlich die Männer der Etablissementszene in der bisherigen Literatur behandelt worden sind, wird die Vorstellung dieser drei Volkssänger hier kurz gehalten und geht von einer Kritik zu einem ihrer bekannten Stücke aus. ${ }^{127}$

Der Einakter ,Das letzte Leintuch', dessen Premiere es vorgestern [11. April 1913] bei den ,Budapestern' gab, ist ganz ohne Zweifel einer der besten Schwänke, die je auf der an witzigen Darbietungen gewiß nicht armen Bühne des Budapester Orpheums aufgeführt worden sind. Die bewährten Possendichter Glinger und Taussig haben in dem engen Rahmen des Einakters eine Fülle von Situationskomik und Wortwitz aufgestapelt und das Ensemble der ,Budapester' tut das Seine, um jede Pointe den vom Lachen erschütternden Publikum entsprechend zu servieren. Auch ein zweiter Einakter von Glinger und Taussig, ,Optische Täuschung ist sehr amüsant; im bunten Teile des Programmes zeigt der Herr Eisenbach im Verwandlungssketch ,Der Biererzug` wieder seine ganze vielseitige künstlerische Begabung. Herr Armin Berg singt neue originelle Couplets, die Soubrettte Risa Basté und das niedliche Fräulein Wallis bringen gleichfalls sehr hübsche Darbietungen.[! $]^{128}$

In diesem Bericht vom April 1913 schrieb das Wiener Fremdenblatt über einen Abend bei den Budapestern, an dem Adolf Glinger, Otto Taussig, Heinrich Eisenbach, Risa Basté u. a. beteiligt waren. Die Budapester Orpheumgesellschaft spielte zu dieser Zeit, wie dem Zitat entnommen werden kann, im Hotel Central in der Taborstraße 8 unter Carl Lechner. Das letzte Leintuch war nur eines der Paradestücke der Glinger-Taussigschen Produktion. ${ }^{129}$ Das Duo schrieb eine unüberschaubare Menge an Soloszenen, die von der Versicherung gegen

126 Siehe Kapitel 5.

127 Frauen und Jüdinnen in der Volkssängerszene sind in der bisherigen Literatur ein Desiderat. Wacks, Die Budapester Orpheumgesellschaft; Brigitte Dalinger, Werner Hanak-Lettner, Lisa Noggler (Hg.), Wege ins Vergnügen: Unterhaltung zwischen Prater und Stadt (Wien: Metroverlag, 2016).

128 Fremdenblatt, 5.4.1913, 16.

129 Das Textbuch ist vorhanden und Thema im Buch. Glinger, Taussig, Das letzte Leintuch. NÖLA, NÖ Reg. Präs. Theater TB - Textbücher der Theaterzensur 127/8. 
Ehebruch über Mendelsohn und Komp. bis Auf der Alm da gibt's ka Sünd' reichten. ${ }^{130}$

Das Stück Das letzte Leintuch handelte von der Affäre des WäscheKonfektionärs Emil Herzog mit der Baronin Claire Pichou. Herzog, der ein Geschäft besitzt und verheiratet ist, stolpert völlig irritiert von den amourösen Gefühlen, die er für die Baronin hegt, seit diese zum ersten Mal in Herzogs Geschäft gekommen ist, durch das Leben. Mit zwölf Personen war das Stück relativ üppig besetzt, wobei bei den kürzeren Auftritten der kleineren Rollen in einzelnen Szenen durchaus eine Person mehrere hätte besetzen können. Jedenfalls bestand es aus drei Hauptrollen, die zwei Gesangshumoristen und eine Volkssängerin respektive Soubrette übernahmen. Die Hauptfigur Herzog schläft morgens bis zehn Uhr - weshalb die Aufräumerin Wuchterl anmerkt, „so faul kann aber auch nur a Jud sein“. Auf Anweisung der Baronin hin soll er „Französisch“ lernen, wobei er sich überlegt, Französisch sei eigentlich wie „Jüdisch“[!] und sich sodann sorgt, nicht gar „Jüdisch“ anstatt Französisch zu lernen. Und er möchte unbedingt einen Kammerdiener einstellen, der seinen Stand hebt, ihn in einen "Aristokraten“ verwandelt, sein Benehmen aufpoliert und mit ihm „Französisch“ übt; denn, wie Herzog meint, alle Kammerdiener sprächen Französisch. In der Schlussszene animiert der Kammerdiener Herzog, die Baronin nicht länger warten zu lassen und feuert ihn euphorisch zur Eroberung an. Mit der Feststellung ,ich bin doch meschugge“ geht Herzog schließlich zu ihr. Als Unterstützung bittet er den Kammerdiener, ihm auf der Violine den Rákóczi-Marsch zu spielen. ${ }^{131}$

Diese „Fülle von Situationskomik und [aufgestapeltem] Wortwitz“132 und das Talent, dessen es bedurfte, jede Pointe gekonnt zu servieren, waren, wie der zuvor aus dem Vergnügungsanzeiger zitierten Kritik entnommen werden kann, Grundlage eines Publikumserfolgs. Dazu bedurfte es eines gekonnten Spagats zwischen vermeintlichen Genregrenzen und gutem Geschmack sowie der idealen Ergänzungen alter Unterhaltungstraditionen mit Neuem und Populärem. All jenen Humoristen, die das bewiesen, war die Verehrung des

130 Glinger, Taussig, Versicherung gegen Ehebruch. NÖLA, NÖ Reg. Präs. Theater TB - Textbücher der Theaterzensur 127/2. Glinger, Taussig, Mendelsohn und Komp. NÖLA, NÖ Reg. Präs. Theater TB - Textbücher der Theaterzensur 611/18. Der Originaltitel, der von der Zensurbehörde nicht zugelassen wurde, lautete Der zuckersüße Oppenheim. Sowie Glinger, Taussig, Auf da Alm da gibt's ka Sünd'. NÖLA, NÖ Reg. Präs. Theater TB - Textbücher der Theaterzensur 98/37.

131 Neben den mehr oder weniger expliziten Artikulationen jüdischer Versatzstücke referiert die Schlussszene auf das Bild des Yidl mit der Fidl, das mit einem ungarischen Nationalstereotyp überlagert wird. Glinger, Taussig, Das letzte Leintuch, 8f, 11. NÖLA, NÖ Reg. Präs. Theater TB - Textbücher der Theaterzensur 127/8.

132 Fremdenblatt, 5.4.1913, 16. 
Publikums sicher. Entwickeln könnten die Künstler dieses Talent, indem sie sich in verschiedenen Rollen erprobten und nicht nur jene übernahmen, die ihnen lagen, resümierte Karl Kutschera in einer Fachstudie über das Varieté:

Jeder Schauspieler hat sein eigenes Fach und übernimmt selten eine Rolle, die ihm nicht liegt. Das sollte er in einem kleinen Variététempel probiren. Hier heist es in einem Zeitraume von einigen Tagen einen Character einpauken und studiren, ohne Rücksicht auf Individualität, hier kann erst das Genie durchbrechen und da kann man sehen, ob Talent vorhanden ist oder nicht.[! $]^{133}$

Einer, der sein Talent erprobt hatte und der das Publikum für sich einzunehmen wusste, war Heinrich Eisenbach. Geboren am 10. August 1870, war er einer der bekanntesten Volkssänger Wiens. Besonders berühmt war er für seine „Art der Jargonbühne“. ${ }^{134}$ Das Spiel mit Stereotypen, die Imitationen der ,jüdischen und böhmischen Typen “135, war seine Spezialität. Die Rollen, die Louis Taufstein für ihn schrieb, verhalfen ihm weit über die Grenzen der Stadt hinaus zu Bekanntheit. ${ }^{136}$ Er war nicht nur einer der beliebtesten Schauspieler der Budapester Orpheumgesellschaft, er wurde 1907 auch stellvertretender Leiter des Etablissements (Direktor war zu diesem Zeitpunkt Franz Böhm). ${ }^{137}$ In Somossys und Herzmanns Orpheum in Budapest ging Eisenbach ein und aus. ${ }^{138}$ In den 1910er Jahren trat Eisenbach sogar in Filmen auf. ${ }^{139}$ Der „populaere Komiker“, wie er zu seinem 50. Todestag vom Kulturdienst Wien beschrieben wurde, ${ }^{140}$ verstarb $1923 \mathrm{im}$ Alter von 52 Jahren. ${ }^{141}$ „Gestern abends ist in seiner Wohnung der bekannte Komiker Heinrich Eisenbach gestorben. Eisenbach [war] über seine Spezialität der ,jüdischen' Rollen hinaus ein vorzüglicher Schauspieler

133 IAR, 10.11.1894, 1-2.

134 Clipping aus Neuer Freier Presse, 15.4.1923, WStLA, Biographische Sammlung Heinrich Eisenbach.

135 Koller, Das Wiener Volkssängertum in alter und neuer Zeit, 177.

136 Wacks, Budapester, 80-98.

137 WStLA, M.Abt. 104, A8/5, Feuer- und Sicherheitspolizei: Theater, Lokale: Budapester Orpheum, 1756/1907: Schreiben vom 22.10.1907.

138 IAR, 1.11.1893, 9; IAR, 24.1.1892, 2.

139 Kinematographische Rundschau, 13.8.1916, 16.

140 Kulturdienst Wien vom 7.3.1973, Blatt 120.

141 Eisenbach verstarb am 14. April 1923 in Wien. Als Alleinerbin setzte er in einem, am 25. März 1923 verfassten, Testament, seine Frau, Mizzi Eisenbach (geb. Pfleger), ein. Todesfallsaufnahme Heinrich Eisenbach, WStLA, Bezirksgericht Hietzing, A4/2 - Verlassenschaftsabhandlungen: 658/23. Mizzi Eisenbachs Schwester war die in den 1920er Jahren weltbekannt gewordene Filmschauspielerin Mia May (geb. Hermine Pfleger). Hermine Pfleger trat bereits im Alter von fünf Jahren im Wiener Jantsch Theater auf, u. a. als Herma Angelot in Operetten. Mia May heiratete den Wiener Julius Otto Mandl, besser bekannt als Joe May. 
und anerkannter Künstler [...]. “142 Bei der Beerdigung Eisenbachs in Hietzing wenige Tage später sei die gesamte Bühnenszene Wiens anwesend gewesen. ${ }^{143}$

Adolf Glinger war ebenso Schauspieler und Hausautor bei der Budapester Orpheumgesellschaft. Er wurde am 13. August 1873 in Budapest geboren. Nach seiner Tätigkeit für diverse Singspielhallen in Wien eröffnete er 1913 gemeinsam mit Otto Taussig, mit dem er eine Vielzahl der beliebtesten Etablissement-Couplets verfasste, das Varieté Max und Moritz im ersten Wiener Gemeindebezirk. Auf einem Meldezettel findet sich der Vermerk, dass Glinger vor seiner Karriere als Schriftsteller und Schauspieler als Cafetier tätig gewesen war und dass es sich bei Glinger um einen Künstlernamen handelte. ${ }^{144}$ Ein überdurchschnittlich großer Pack an Meldezetteln im Wiener Stadt- und Landesarchiv dokumentiert das bewegte Leben Glingers (und das seiner Frau).

Wie Adolf Glinger trat auch Max Rott unter einem Künstlernamen auf. Er war ein Mitglied der Herzmann-Truppe. Ebenso trat er regelmäßig bei der Budapester Orpheumgesellschaft in Wien auf. Josef Koller schrieb in dem Memorandum an „Alt Wien und seine Sänger“ Folgendes über Max Rott:

Max Rott, recte Mendel Rottmann, kam in Radimno (Galizien) im Jahre 1865 zur Welt. In den strengen Sitten der Hebräer von Haus aus erzogen, mußte Rott mit ,Ohrenlocken sowie mit dem Kaftan bekleidet gehen, was dem Jungen absolut nicht zusagte. Schon frühzeitig erregte der hübsche Liedvortrag des Kleinen Bewunderung. Rasch entschlossen verließ Rott, der für das Gewerbe wenig übrig hatte, das Elternhaus. Sein erster Besuch galt dem Friseur, der die Schmacktlocken entfernen mußte.[!] ${ }^{145}$

Das Koller-Zitat illustriert eine paradigmatische Beschreibung eines von Zeitgenoss ${ }^{\star}$ innen als jüdisch wahrgenommen Volkssängers. ${ }^{146}$ Zunächst sang sich

142 IKZ, 15.4.1923, 5.

143 NWT, 18.4.1923, 7.

144 Auf seinen Meldezetteln war Glinger als konfessionslos vermerkt. Adolf Glinger habe Hargescheimer geheißen. Meldezettel Adolf Glinger, WStLA, Historische Meldeunterlagen, K2 C-Antiquariat. Und Meldezettel Adolf Glinger Hargesheimer, WStLA, Historische Meldeunterlagen, K4 - Meldekartei. Meldezettel Adolf Glinger, WStLA, Historische Meldeunterlagen, K5 - E-Antiquariat. Todesfallaufnahme Adolf Glinger, WStLA, Bezirksgericht Innere Stadt, A4/15 - Verlassenschaftsabhandlungen: 360/47.

145 Koller, Das Wiener Volkssängertum in alter und neuer Zeit, 159.

146 Ein vergleichbares Beispiel ist der Volkssänger und spätere Direktor von Danzer's Orpheum, Franz Kriebaum. Die erste Beschreibung Kriebaums als Grünbaum stammte auch von dem hier zitierten Josef Koller. Koller, Wiener Volkssängerthum, 96. Hödl vermerkt, dass es in Forschungsarbeiten daher wesentlich sei, Matriken von Kultusgemeinden ebenso wie die Taufmatriken der Pfarren zu überprüfen, um nicht antisemitische Argumente der Jahrhundertwende beziehungsweise, wie häufig auch in der Forschung vorgegangen wurde, Kategorisierungen aus dem Nationalsozialismus zu tradieren. Hödl, Zwischen Wienerlied und Der kleine Kohn, 5f. Für die vorliegende Arbeit wurden hauptsächlich Meldekartei- 
Rott „[...] durch die größeren Gasthäuser Lembergs und Przemysls [...]“. Da es ihm gelang, mit seinen „jüdischen Volksliedern“ Beifall zu finden, „[...] konnte sich der junge Sänger gut kleiden. “147 Als Max Rott startete er dann beim Orpheum Herzmann in Budapest eine erfolgreiche Karriere im Varieté, wie Koller betonte, allerdings ohne „Schmacktlocken“ - ein äußeres Attribut, das auf die jüdische Herkunft des Protagonisten verwiesen habe und ohne den vermeintlich jüdisch klingenden Namen. „Physischer Merkmale“, so Koller, hätte Rott sich jedoch natürlich nicht entledigen können. Deshalb habe er nur ,jüdische Rollen' gespielt:

Rott spielte wohl nur die jüdischen Rollen, stattete aber die einzelnen Figuren, wie das Schlieferl in ,Leiser und Zimt ' und den Reis in der ,Klabriaspartie', sowie alle seine Typen mit so viel wahrheitsgetreuen Zügen aus, daß man mit Fug und Recht sagen konnte, daß Rott unerreicht dastand.[! $]^{148}$

Gemeinsam mit Benjamin Blatz trat er später über Jahre im Duett als „Brüder Rott“ auf. ${ }^{149}$ Der Diskurs über jüdische oder nichtjüdische Künstlernamen war dabei keineswegs etwas, dass nur die männlichen Mitglieder der Szene betraf, sondern ebenso die Künstlerinnen, wie sogleich noch Thema sein wird. Wie aber schon die Diskussion um Volkssänger, Kabarettisten und Gesangshumoristen zeigt, sind hier mehrere Aspekte von Interesse: das ,authentische, jüdische Volkslied“, das sie zunächst vortrugen und dann für eine internationale Karriere tauschten, wie auch die Wahl von Künstlernamen. Beide Phänomene waren, wie bereits im vorherigen Kapitel dargelegt, in der Internationalisierung der

en verwendet, da sie, wie ich argumentieren möchte, einer hohen Interaktion zwischen den Protagonist*innen und dem entstehenden Schriftstück unterlagen. Meldezettel wurden handschriftlich ausgefüllt und Zuschreibungen konnten in ihnen - im Vergleich zu anderen öffentlichen Dokumenten - relativ frei getätigt werden konnten. Additiv lässt sich im Vergleich mit Nachrufen und Todfallsmeldungen ein umfassenderes Bild darüber gewinnen, wie Varietédirektoren, Künstler*innen und Artist*innen wahrgenommen wurden. Rott verwies selbst im Meldezettel auf seinen vollen Namen Mendel Rottmann und sein Religionsbekenntnis Judentum. Meldezettel Max Rott, WStLA, Historische Meldeunterlagen, K1 - B-Antiquariat. Für Kriebaum etwa ist bezeichnend, dass keiner der unmittelbaren Nachrufe ihn als ,jüdischen' Künstler wahrgenommen zu haben scheint. Erst Kollers Werk, das 1930 erschien, tradierte eine solche Wahrnehmung. Nachrufe etwa in der Internationalen Artisten Revue, oder im Deutschen Volksblatt. IAR, 20.7.1900, 3; Deutsche Volksblatt (Abendausgabe), 20.7.1900, 2.

147 Koller, Das Wiener Volkssängertum in alter und neuer Zeit, 159. Die Bukowiner Rundschau dokumentierte 1899 einen Auftritt der Brüder Rott im „Theater-Varieté“ des Herrn Sami Weiß. Bukowiner Rundschau, 25.6.1899, 4.

148 Koller, Das Wiener Volkssängertum in alter und neuer Zeit, 159.

149 Siehe zum Beispiel Inserat von Herzmann's Orpheum, PL, 9.9.1891, 4. 
populären Kultur zu sehen und sind deshalb nicht als eine vermeintlich exklusive ,Assimilations'- oder ,Akkulturationsbestrebung' der Jüdinnen und Juden unter den Künstler`innen und mit ihnen einer jüdischen Kunst zu verstehen. ${ }^{150}$

\section{Die Chantant-Regisseure}

Viele Volkssänger, Humoristen, Komiker und Soubretten waren nicht nur aktiv als Schauspieler tätig, sondern inszenierten und arrangierten als rechte Hand der Direktor ${ }^{*}$ innen die Programme. Außerdem war die Sparte der sogenannten "Chantant-Regisseure“ ein häufig gewählter Berufsweg nach der aktiven Bühnenkarriere von Schauspieler ${ }^{\star}$ innen und Artist ${ }^{\star}$ innen. Ebenso üblich war es, zwischen der Position als aktiver Schauspieler und derjenigen des Regisseurs zu wechseln: Die Tätigkeit als Regisseur schloss das aktive Schauspiel nicht aus.

Regisseure genossen zeitgenössisch allerdings einen schlechteren Ruf. Das Publikum beanstandete, dass der Regisseur in Programmen und Werbeanzeigen an prominenter Stelle neben den Leitenden der Aufführungsstätten genannt wurde. Ein Regisseur habe doch eigentlich keine wirkliche Aufgabe. Oft kam es zu medialen Debatten über die vermeintliche Nicht-Funktion der Chantant-Regisseure. Dass sie nichts zu tun hätten, sei aber ein großer Irrtum; die Herausforderung für den Chantant-Regisseur läge nämlich darin, aufgrund seiner eigenen schauspielerischen Ausbildung den Direktor auf die talentiertesten Künstler*innen aufmerksam zu machen, ihr Programm gekonnt auszuwählen und den Geschmack des Publikums zu kennen. Dieses Bekenntnis zum Beruf des Chantant-Regisseurs entstammte der Feder von Louis Taufstein - einem, der selbst häufiger für Singspielhallen Stücke schrieb und Programme inszenierte sowie aktiv auftrat. Er wollte mit diesem Beitrag die Leser*innen der Artisten Revue von der Bedeutung der Regisseure überzeugen. ${ }^{151}$

Louis Taufstein war einer, der es verstand, Soloszenen, Couplets und Lieder den Künstler*innen auf den Leib zu schreiben und die Programme perfekt zu inszenieren. Der am 3. Februar 1870 in Wien geborene Coupletist war Hausautor bei der Budapester Orpheumgesellschaft. Andere Größen der Szene wie Heinrich Eisenbach lebten förmlich für seine Stücke. ${ }^{152}$ Taufstein schrieb ebenso Operetten ${ }^{153}$ und Kabaretts und war weit über die Grenzen der Monarchie hinaus bekannt. Wie so viele innerhalb der Szene, heiratete er eine Kollegin, die Sängerin Lina Löbl. Taufstein teilte aber auch ein anderes trauriges Schicksal mit so vielen seiner Kollegeninnen unter den Chantant-Regisseuren. Als immer

150 Zur Problematik der Begriffe, Assimilation` wie auch,Akkulturation` siehe die Ausführungen in der Einleitung.

151 IAR, 24.22.1891, 1-2.

152 Siehe die unzähligen Lieder und Stücke in den Beständen der Theaterzensur im NÖLA.

153 Siehe etwa WAZ, 17.8.1917, 6. 
auch politisch Schreibender stand er mit dem Austrofaschismus und Nationalsozialismus in Konflikt. Taufstein wurde politisch und rassistisch verfolgt und am 20. September 1942 im Konzentrationslager Theresienstadt ermordet. ${ }^{154}$

In Taufsteins ambitioniertem Statement für die Chantant-Regisseure erklärte er die Gründe, die er für die Konkurrenz zwischen Schauspieler, Regisseur und Direktor sah, nämlich, dass sie alle ursprünglich aus dem gleichen Feld kämen. Da der Regisseur aus dem gleichen Feld wie die Schauspieler stamme, habe er nicht nur mit einem schlechteren Ruf zu kämpfen, so Taufstein, sondern sei auch stets geheime Zielscheibe des Spottes seiner Kollegen: „Ein schneidiger Regisseur, wenn er derartiges bemerkt, muss mit besonderer Energie vorgehen, sonst wachsen ihm die Mitglieder über den Kopf [...]." ${ }^{155}$

Trotz der allgemeinen Offenheit und Modernität der Szene populärer Kultur und den vielen Möglichkeiten, in der Etablissementkultur unkonventionelle Geschlechteridentifikationen auszuformen, waren Frauen nicht in der Regisseurrolle zu finden. Allerdings ist auffallend, dass die Künstlerinnen häufig ihre eigenen Regisseurinnen waren und entsprechenden Spielraum in den Programmpotpourris erhielten, um ihr Repertoire selbst zusammenzustellen. ${ }^{156}$

\section{Von der „bodenständigen“ Volkssängerin zur Soubrette}

Die „holden Frauen“ waren bis in die 1860er Jahre aus der Szene der Volkssänger und Gesanghumoristen ausgeschlossen: „Die Herren der Schöpfung beherrschen das Gebiet der Pablatschen. Kam in den verschieden gearteten Possen eine Frauenrolle vor, mußte sie ein Mann in Verkleidung spielen. "157 Der Ausschluss von Frauen aus der populären Kultur, von dem es auch davor Ausnahmen gab, ${ }^{158}$ sollte sich aber bald ändern. Deshalb stellt der folgende Abschnitt die Entwicklung der Volkssängerin hin zur Soubrette dar, stellt Protagonistinnen vor und skizziert deren Handlungsspielräume. Warum tauschten Männer und Frauen die Rollen, wie wirkte sich das auf deren Rollenkonstruktionen aus und welche Faktoren ermöglichte das? Inwiefern steht dies in Zusammenhang mit den gesellschaftlichen Vorurteilen gegenüber Volkssängerinnen und Soubretten?

154 Die Ehe mit Löbl hielt allerdings nur kurz. WStLA, Historische Meldeunterlagen, K2 C-Antiquariat: Meldezettel, Louis Taufstein. Sowie WStLA, NSDAP Wien, Gauamt für Sippenforschung, K2/1 - Matriken der israelitischen Kultusgemeinde: Louis Taufstein. Wacks, Budapester, 126-131. Wacks, Budapester, 126-127. Siehe auch Personendatenbanken des Dokumentationsarchivs des Österreichischen Widerstands, Suche: Louis Taufstein: http:// www.doew.at/erinnern/personendatenbanken (letzter Zugriff: 13.4.2020).

155 IAR, 24.11.1891, 1-2.

156 NSZL, Színháztörténeti Tár, Programme von Varietés und Singspielhallen.

157 Koller, Das Wiener Volkssängertum in alter und neuer Zeit, 32.

158 Es gibt sehr wohl Hinweise darauf, dass Frauen auch davor schon ähnliche Berufe ausübten. 
Gewissermaßen den Urtypus der ersten Volkssängerinnen verkörperte in den 1880er Jahren, dem Chronisten der Volkssängerszene Josef Koller zufolge, die aus Budapest stammende Amalia Seidler, im Volksmund die "Seidler-Mali“ genannt. ${ }^{159}$ Amalia Seidler (auch Zeidler) spielte bei einem der großen Wiener Konzessionäre und Gesellschaftsleiter, Karl Drexler (1833-1883), der nach seiner aktiven Karriere als Schauspieler Drexler's Singspielhalle im Wiener Prater leitete. Neben dem Engagement als Sängerin, stellte dieser Amalia Seidler außerdem zur Pflege seiner verwaisten Kinder ein:

[...] Drexler nahm seine erste Sängerin, Amalia Zeidler, zur Pflege seiner verwaisten kleinen Kinder eine Kollegin ins Haus, welche nun liebevoll für die Verwaisten sorgte, die Wirtschaft als echte Hausmutter leitete und Abends[!] mit ihrer brillanten, frischen, unverwüstlichen Stimme und ihrem schneidigen Wesen die kecksten Jodler, die verblüffendsten Triller in fescher, unvergleichlicher Weise zum Besten gab. ${ }^{160}$

Die jüngste Tochter Drexlers, die Amalia Seidler großzog, war Anna Drexler. Anna Drexler sollte eine Volkssängerin der nächsten Generation werden und 1885 den berühmten Gesangskomiker Josef Modl heiraten. ${ }^{161}$

Mit Amalia Seidler, Anna Drexler und ihren bald zahlreich vorhandenen Kolleginnen mussten jedenfalls die Frauenrollen nicht mehr von Männern in Verkleidung gespielt werden. Die sich etablierenden Volkssängerinnen, so teilte die Internationale Artisten Revue ihren Leser*innen mit, waren „kecke Hausmütter", die abends die Gesellschaft unterhielten. ${ }^{162}$ In den folgenden Jahren nahm die Figur der Volkssängerin respektive Etablissementkünstlerin zunehmend obszönere Züge an. Damit einhergehend kam den Geschlechterrollen eine ungeahnte Gender-Mobilität zu. Das zuvor wegen mangelnder Frauen in der Szene notwendige Gender-Bending, nämlich das Spielen von sogenannten „Hosenrollen“ oder eigentlich „Rockrollen“, in welchen Männer Frauen mimten, etablierte sich nun bald als bewusste Inszenierung. Die Frauen gaben auf der Bühne immer öfter den Mann. Sogar, wenn Frauen und Männer in einem Stück gleichzeitig mitwirkten, gab es diese Praxis der Rolleninterpretation, die sich besonderer Beliebtheit erfreute.

Die Praxis des Gender-Bendings ist in der Forschung zur Populärkultur in Wien und Budapest völlig unbeachtet. Auch für das New York der Jahrhundertwende gibt es beinahe keine Auseinandersetzungen mit Gender-Mobilität in

159 Koller, Das Wiener Volkssängertum in alter und neuer Zeit, 32-33.

160 „Die Tragödie des ,Volkssängerthums“', IAR, 1.3.1895, 1-4.

161 IAR, 1.3.1895, 2. Josef Modl war Mitbegründer der Budapester Orpheumgesellschaft, aktiver Vereinsobmann des Internationalen Artistenvereins Der lustige Ritter und eine gefeierte Größe der Wiener wie auch Budapester Etablissementszene. Zu Modl siehe auch Hödl, Zwischen Wienerlied und Der kleine Kohn, 73 und 95.

162 IAR, 1.3.1895, 1-4. 
der Populärkultur. Warren Hoffman konstatiert, dass gerade queere Sexualität in unterschiedlichster Form die Populärkultur in Amerika spätestens ab dem Beginn des zwanzigsten Jahrhunderts prägte ${ }^{163}$ und mit Molly Picon die wohl bekannteste Inszenierung erleben sollte. ${ }^{164}$ Aber zunächst sei zur Entwicklung zurückgekommen.

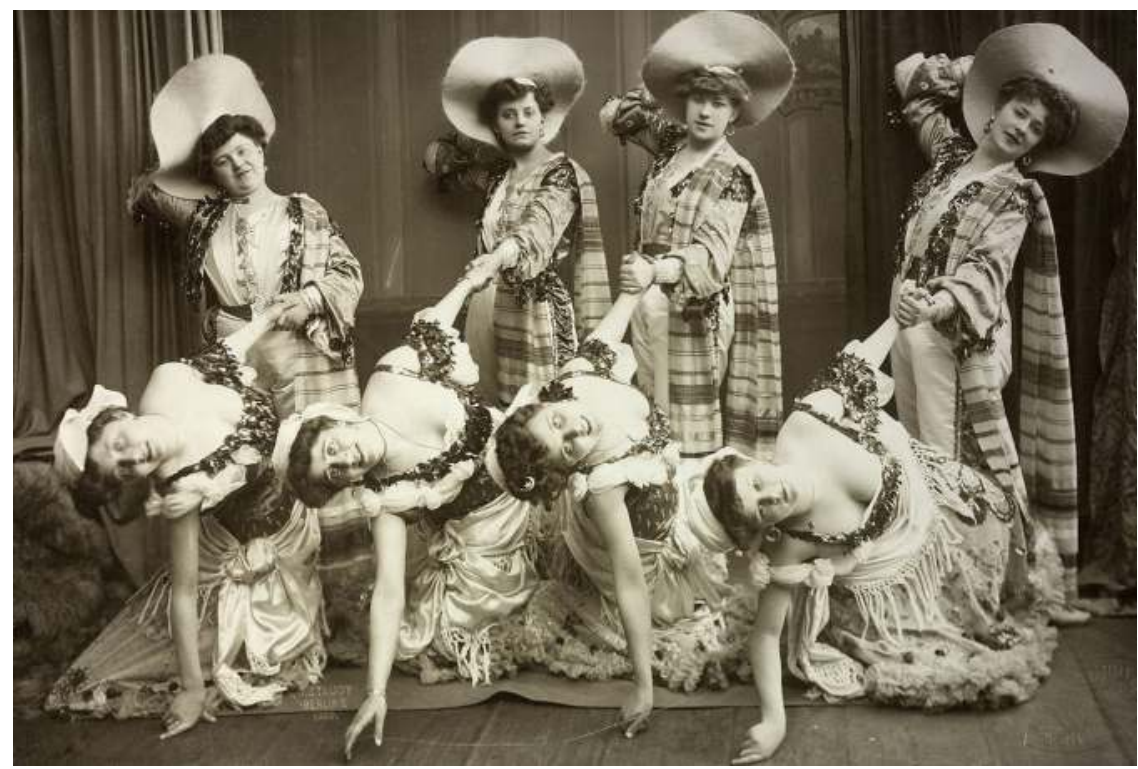

Abb. 25 Soubretten in einem Wiener Varieté um 1900, Bildarchiv Austria, Kor392-8

Von den noch als „bodenständig“ beschriebenen „Seidler Malis“ entwickelten sich die Volkssängerinnen weiter und waren bald bekannt (beziehungsweise verrufen) für ihren Sexappeal. Denn spätestens ab den 1900er Jahren traten sie in Budapest und Wien nur noch als angeblich französische Soubretten auf. Die Soubretten waren vielfach noch dieselben Darstellerinnen wie zehn Jahre zuvor. Um 1900 waren sie aber als den Männern die Sinne raubende Vamps bekannt. Als aufreizende Schauspielerinnen oder Sängerinnen prägten sie die „Bretteln“ und Orpheen Budapests, New Yorks und Wiens ebenso mit wie ihre als Komödianten oder Jargonartisten auftretenden männlichen Kollegen. Die Soubretten waren es, wie etwa die Neue Freie Presse hinwies, die den Bühnenarrangements

163 Warren Hoffman, The Passing Game: Queering Jewish American Culture (New York: Syracuse University Press, 2009), 4.

164 Zu Molly Picons Gender-Bending im Film siehe James Hoberman, Bridge of Light: Yiddish Films Between Two Worlds (Philadelphia: Temple University Press, 1995), 5. 
„eine Intimität des eigenen Schlafzimmers“ zu verleihen vermochten. In Werbungen für ihre Aufführungen bedurfte es keiner genauen Ausführung ihrer Qualitäten. Die Anzeigen verwiesen lediglich auf die allgemein „bekannten Soubretten". 165

Sie alle waren nicht mehr als Volkssängerinnen bekannt. Die internationale Bezeichnung für diese charmanten Sängerinnen wurde mit der Mobilisierung der Szene zunehmend „Soubrette“. Was eine Soubrette sein konnte, war nicht immer eindeutig. Die Brockhaus Enzyklopädie der Jahrhundertwende stellte einen unmittelbaren Zusammenhang zum lateinischen „supretta“ für Dienerin her und wies darauf hin, dass sich bald ausschließlich die Theatersprache dieses Ausdruckes bediente. Gemeint gewesen sei damit ein „listiges, verschmitztes, dienstfertiges Kammermädchen [...] wie es im Lustspiel behufs leichtfertiger Intrigen als stehender Typus gebraucht wird [... $]^{\text {“ }}{ }^{166}$ Was eine Soubrette der Jahrhundertwende noch mit einem „listigen Zimmermädchen“ zu tun habe, fragte die Internationale Artisten Revue und kam zu folgendem Schluss:

Was hat die moderne Soubrette noch von einem Kammerkätzchen an sich? Soubretten sind weibliche Bühnenkobolde, die, ob sie nun singen, plaudern oder tanzen, den Hörer und Beschauer unwillkürlich mit sich fortreissen, so, dass er sich willig allen ihren Künsten und Capriolen gefangen gebit. [...] Eine echte Variétésoubrette muss fast noch mehr Feuer wie eine Theatersoubrette haben, denn im Variété will man vor allen Dingen in animirte Stimmung versetzt sein.[! $]^{167}$

Gerade aus den Varietés der Monarchie seien dabei „verhältnismäßig die besten Soubretten“ hervorgegangen. „Die Wienerin und Pesterin zumal vereint den Chic der Pariser Soubrette, die jedoch meist allzufrei im Auftreten ist, mit einer wohlthuenden, behaglichen, herzgewinnenden Lustigkeit, die sie um sich verbreitet, und kann vor allen Dingen vortrefflich singen. " ${ }^{168}$ Unter diesen unübertrefflichen Soubretten fanden sich „Naturjodlerinnen“ ebenso wie „Pariser Chanteusen“. Viele von ihnen verführte der „Hang zu einem leichten Leben“ dazu, Soubrette zu werden. Allerdings stand diese Wahl nicht jeder offen, wie immer wieder betont wurde, denn dieser Beruf könne „eigentlich nicht gelernt werden“ ${ }^{169}$ Als Stern der Budapester Soubretten galt Cäcilie Carola, „die von der Engländerin die Anmuth, von der Französin den Chic und von der Ungarin das Temperament besitzt, dies vermengt mit einem eminent schauspielerischen

165 Neue Linzer Tagespost, 29.5.1898, 4. Die Verweise auf die bekannten Soubretten fanden sich in sämtlichen Anzeigen.

166 Brockhaus, „Soubrette“.

167 Eduard Romanowski, „Die Soubrette“, IAR, 20.6.1895, 1-2, 1.

168 Romanowski, „Die Soubrette“, 2.

169 Ebda. 
Talent $[\ldots]]^{“ 1}{ }^{170}$ Die „Excentrique-Sängerin“ trat in allen großen Variétes Budapests ebenso wie in Wiener Programmen auf, etwa gemeinsam mit Herrn Armin, dem „Verwandlungskünstler", in Pertl's Orpheum, in einem der Pratercafés oder in Danzer's Orpheum. ${ }^{171}$ Die Szene feierte sie als eine „Natur“, in der sich verschiedene „Anlagen“ bestmöglich trafen: „Angeborene Grazie und ambitiös, fleissiges Streben“ ließen sie ihr Können im „Komischen und Exzentrischen als im Hochtragischen“ erwerben und ihre ausgezeichneten Manieren die Gunst des Publikums erringen. ${ }^{172}$

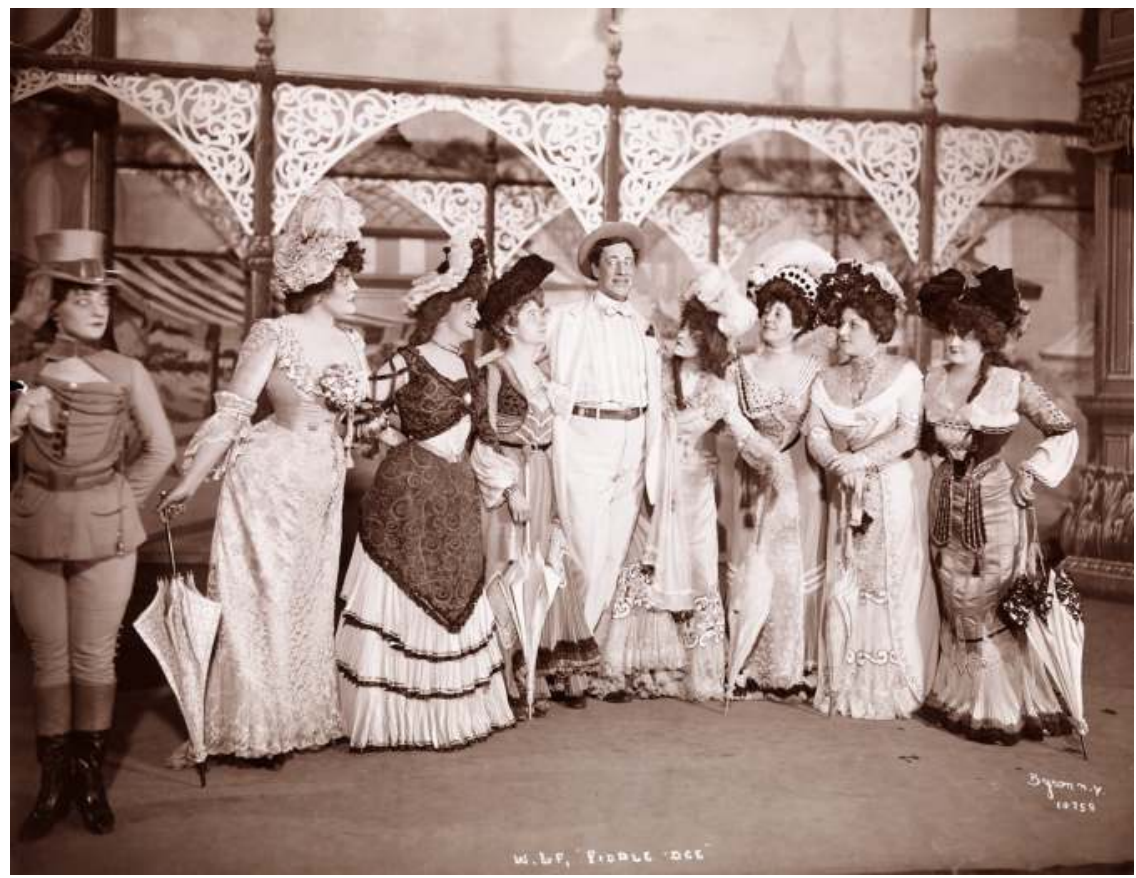

Abb. 26 Soubretten in der Aufführung Fiddle-Dee-Dee in der Weber \& Fields Music Hall New York 1901, Byron Company, Museum of the City of New York. 41.420.329

Unter den Soubretten ergab sich alsbald eine große Konkurrenzsituation, wie die Internationale Artisten Revue betonte. „Es hat sich leider im Laufe der Zeit bei vielen Costümsoubretten und Chansonettensängerinnen ein ziemlicher Wettstreit um glänzende Garderobe, Schmuckgegenstände, (Ohrgehänge, Brillanten selbst Diamanten und dergleichen) herausgebildet, dass es fast den

170 IAR, 24.12.1891, 1.

171 Kikeriki, 17.12.1893, 5 sowie Beilage.

172 IAR, 24.12.1891, 1. 
Anschein gewinnt, als sollte die Soubrette zu einem blossen Schaugegenstand erniedrigt werden“. Derartige Entwicklungen suggerierten, dass die Soubrette mehr „Schönheitsmädchen“ als Künstlerin war. Dieser Umstand müsse sich dringend ändern, da sie ihr Studium auf ihre Kunst und nicht auf ihr Äußeres verwenden sollten:

Sie [die „wirkliche Soubrette"] muss einerseits den Charakter, die Sprache und die Sprechweise der einzelnen Typen und Völker genau kennen und zu lernen bemüht sein [...], andererseits regelrecht ihre Stimme schulen, ausbilden und pflegen - auch in hygienischer Hinsicht, [...] und drittens muss eine gute Soubrette sich allerdings auch auf jene harmlosen und decenten Mittel der Koketterie verstehen, die Mutter Natur nun einmal den Frauen zugewiesen hat. Dazu gehört vor allem die tiefe Kunst des Weibes, sich mit Geschmack, wenn auch einfach zu kleiden.[! $]^{173}$

Gemäß dieser Charakteristik des Fachorgans erwartete das Publikum von Soubretten in der Monarchie somit einen „Spagat“ zwischen verschiedenen, weiblich konnotierten Eigenschaften. Soubretten sollten den Chic der aus Paris bekannten Vertreterinnen kopieren und das stimmliche Können von Opernsoubretten, wie das geschmackliche Geschick der gutbürgerlichen Salondamen vereinen. In der Diskussion um die besonderen Vorzüge wie auch Anforderungen an die Wiener und „Pester" Varietékünstlerinnen entfalteten sich präzise gesellschaftliche Normvorstellungen: Geschmack im Kleidungsstil zu beweisen, wurde mit der Floskel „tiefe Kunst des Weibes“ bezeichnet und damit als exklusiv Frauen inhärente Eigenschaft konstruiert. Obwohl das Fachorgan den Soubretten viele, für Rollenverteilungen in anderen Bereichen geradezu modernistisch anmutende Zugeständnisse machte, schlugen in den Erwartungen stereotypisiert traditionelle Haltungen durch. Gleichwohl forderte das Publikum von den Varietékünstlerinnen, dass sie den transnationalen Charakter populärer Kultur verkörperten und eben nicht etwas, wie auch immer definiertes, Nationales. All das betraf natürlich weder ausschließlich die Rollenbilder über Künstlerinnen, noch ausschließlich die Vorstellungen innerhalb der Monarchie, sondern ebenso in Amerika.

Die Soubretten an sich waren keineswegs eine exklusiv europäische Erscheinung der Zeit. Noch waren es die Rollenvorstellungen, die sich um sie aufspannten. Der Charakter der Soubrette war in Opern im 18. und 19. Jahrhundert entstanden. Jennifer Gillis beschreibt den Soubrettencharakter bereits dort als einen, der über das Potential verfügte, gesellschaftliche Machtverhältnisse auf den Kopf zu stellen. ${ }^{174}$ Und auch die populären Bühnen Amerikas such-

173 Ebda.

174 Jennifer Gillis, The Soubrette Character as an Agent of Social Change in $18^{\text {th }}$ and $19^{\text {th }}$ Century Opera Buffa and Singspiel (Diss. University of Oklahoma, 2018). 
ten ab dem letzten Jahrzehnt des 19. Jahrhunderts die „singing and dancing Soubrette[s]“, - bevorzugt jene „with specialities“ in ihrem Repertoire oder Vortrag. Aufgrund des Charmes der Soubretten sprach die Welt nicht mehr von Etablissements, sondern nur noch von „Busentempeln“. 175

Eine spätere Vertreterin der amerikanisch-jiddischen Soubretten war Molly Picon, deren Geburtsname Małka Opiekun lautete. Ihre Eltern waren als galizische Migrant*innen in den 1880er Jahren nach New York gekommen. Picons Karriere begann im Alter von zwölf Jahren. Bald fiel Picon jedoch die ihr fehlende Mehrsprachigkeit, welche die Rollen ihr abverlangten, auf, weshalb sie später gemeinsam mit ihrem Mann, Jacob Kalich, der ebenfalls Schauspieler war, immer wieder für längere Auslandsaufenthalte nach Europa ging, um unter anderem vor allem ihr Jiddisch zu perfektionieren. Denn, wie sie selbst sagte, „the Yiddish I spoke was completely bastardized, and part of our plan was for me to learn correct Yiddish, with its soft, guttural European accent. "176 Auf einer über drei Jahre andauernden Reise quer durch Europa gaben sie und ihr Mann zahlreiche Gastspiele. ${ }^{177}$

Zu den bekanntesten Soubretten Wien und Budapests, die bereits in den späten 1890er Jahren ihre Bühnenkarriere begannen und diese bis zur Machtergreifung der Nationalsozialist*innen verfolgten, gehörten Risa Basté (1879-1968) und Paula Walden (1874-1961). Risa Basté war eine jener Volkssängerinnen, die ihr Publikum auch mit männlichen Reizen zu verzaubern wusste. Risa Basté war der nom de plume von Sali Glinger (geb. Friedmann). Als jüdische Künstlerin legte auch sie sich bald einen international klingenden Namen zu. Jedenfalls wurde Sali Friedmann am 5. April 1879 in Wien geboren und heiratete den aus Budapest stammenden Schauspieler, Schriftsteller und Volkssänger Adolf Glinger. Gemeinsam spielten sie etwa für die Budapester Orpheumgesellschaft. ${ }^{178}$ Paula Walden kam am 15. August 1874 als Pauline Fleischmann

175 Siehe beispielsweise die Anzeigen im New York Clipper: NYC, 27.8.1898, 14. Zu „Busentempeln" siehe Koller, Das Wiener Volkssängertum in alter und neuer Zeit, 99.

176 Zitiert in Joshua S. Walden, Pathbreakers and Superstars, in: Edna Nahshon (Hg.), New York's Yiddish Theater: From Bowery to Broadway (New York: Columbia University Press, 2016), 102-139, 130.

177 In Wien verweilte sie 1921 und 1931 jeweils mehrere Monate. WStLA, Historische Meldeunterlagen, K2 - C-Antiquariat, Meldezettel Jacob Kalich. WStLA, Historische Meldeunterlagen, K3 - D-Antiquariat, Meldezettel Jacob Kalich. [Molly Picon ist als Ehegattin in Kalichs Meldezettel miteingetragen.] Die beiden traten auch auf den Etablissementbühnen wie der Rolandbühne auf. IKZ, 21.10.1921, 7 sowie 14.12.1921, 5.

178 Sie starb am 4.1.1968. Siehe Meldezettel Sali Sarah Friedmann, WStLA, Historische Meldeunterlagen, K2 - C-Antiquariat. Meldezettel Sali Sara Glinger Hargesheimer, geb. Friedmann, WStLA, Historische Meldeunterlagen, K4 - Meldekartei. Meldezettel Sali Risa Glinger, geb. Friedmann, WStLA, Historische Meldeunterlagen, K5 - E-Antiquariat. Todfallsaufnahme Sali Glinger, WStLA, Bezirksgericht Innere Stadt A4/3 - Verlassenschaftsabhandlungen: 46/68. 
in Wien zur Welt. Auch sie heiratete am 30. Mai 1908 einen Kollegen bei den Budapestern, Otto Taussig. Paula Walden und Risa Basté verband eine gleich enge Freundschaft wie ihre Männer, die gemeinsam, wie oben dargestellt, unzählige Stücke verfassten. Walden und ihr Mann waren bis zu dessen Tod am 2. Juli 1925 verheiratet. ${ }^{179}$ Auch sie trat als Paula Walden und damit unter einem Künstlernamen auf; ihr Meldename lautete Pauline Taussig. Und auch ein weiteres trauriges Schicksal teilte Paula Walden mit vielen ihrer Kolleg*innen: Paula Walden wurde am 18. Juni 1941 aus ihrer Wiener Wohnung in der Herminengasse 10 nach Theresienstadt deportiert. Doch sie erlebte die Befreiung des Konzentrationslagers und kam im Oktober 1945 zurück in die Wiener Leopoldstadt, ${ }^{180}$ wo sie bis zu ihrem Tod am 23. Februar 1961 lebte. Besonders ergreifend ist, dass Sali Glinger (also Risa Basté) die Todfallsmeldung von Paula Walden unterzeichnete. Auch nach ihrer Karriere auf den „Brettln“ der Welt waren die beiden Volkssängerinnen bis in die 1960er Jahre befreundet geblieben. ${ }^{181}$

\section{Der Chantant-Direktor}

Jene, die diese Soubretten bei Laune halten mussten, waren die „ChantantDirektoren“ und - wohlgemerkt auch -direktorinnen. Die Position des Direktors wurde als eine dargestellt, die eigentlich jede ${ }^{\star} r$ einnehmen konnte, egal ob Artist $^{*}$ in, Restaurateur ${ }^{*}$ in oder Cafetier. Die Internationale Artisten Revue sah allerdings als die bestmögliche Besetzung der Position des „Chantant-Direktors“, einen Artist[!]. ${ }^{182}$ Ein guter „Chantant-Direktor“ sei, wer die „Vorzüge“ seiner Artisten ${ }^{\star}$ innen, Musiker*innen, Komiker*innen und Gymnastikerinnen kenne. Mit dem Wissen um die Talente seiner Gruppe erfülle er die Erwartungen des Publikums und durch eine geschickte Zusammenstellung des Programms verstehe er es, sein Publikum immer wieder in sein Etablissement zu locken. Darüber hinaus müsse es der leitenden Person eines Etablissements gelingen, die Gruppe angemessen zu loben und zu fördern. Sollten in einer Stadt dennoch nicht genug Auftrittsmöglichkeiten für die Truppe bestehen, sei es der

Sowie Meldezettel Adolf Glinger, WStLA, Historische Meldeunterlagen, K2 -C-Antiquariat. Und Meldezettel Adolf Glinger Hargesheimer, WStLA, Historische Meldeunterlagen, K4 Meldekartei. Und Meldezettel Adolf Glinger, WStLA, Historische Meldeunterlagen, K5 E-Antiquariat. Todfallsaufnahme Adolf Glinger, WStLA, Bezirksgericht Innere Stadt A4/15 - Verlassenschaftsabhandlungen: 360/47. Sie starb am 4. Jänner 1968.

179 Vermerk auf Waldens Meldezettel. WStLA, Historische Meldeunterlagen, K2 - C-Antiquariat, Meldezettel Paula Taussig.

180 Meldezettel Paula Taussig, geb. Fleischmann, WStLA, Historische Meldeunterlagen, K4 Meldekartei.

181 Meldezettel Paula Taussig, WStLA, Historische Meldeunterlagen, K5 - E-Antiquariat.

182 IAR, 8.1.1892, 1. 
"Chantant-Direktor", der eine Tour organisieren und die Mitglieder seiner Truppe zur Teilnahme daran animieren müsse. ${ }^{183}$ Meistens sei der Komiker der Direktor der reisenden Gesellschaften gewesen. Zu fürchten habe er nur „seinen guten Freund“, den Pianisten. „Der darf nicht gereizt werden, denn in der Provinz giebt es keinen Ersatz." Die meisten Pianisten seien nur auf regelmäßige Abgeltungen aus. Einem Konkurrenzdenken innerhalb einer Gesellschaft müsse der Direktor vorbeugen, denn mit einem Machtringen wurden die häufigen Spaltungen, Wiedervereinigungen und Neugründungen von Ensembles erklärt:

[...] Manche Pianisten sind noch gefährlicher, sie haben nämlich Direktionsgelüste! [...] Mit Neid verfolgt er die Einnahmen seines Freundes und es dauert nicht lange so hat er 2-3 Mitglieder auf seiner Seite und die Verschwörung ist organisiert, die Gesellschaft zügellos. Bei solchen Vorkommnissen streicht der Komiker die Segel, denn er ist ein Schlaukopf und lässt sich zu seinem lieben Freund als Mitglied engagiren. Die Metamorphose ist vollendet und die Comödie beginnt! Die neue Firma prosperirt einige Abende. Nun fängt es aber an, in der beleidigten Brust des Komikers zu brennen, der Neid ist ein gefährlicher Faktor. Stets hat der Komiker das Publicum auf seiner Seiter, der Liebling hat grossen Anhang. Der Gedanke, sein Freund den Pianisten einzutunken wäre die grösste Genugthuung seiner Ehre. Sein Plan gelingt ihm, die Verwirrung in der Gesellschaft ist bald nicht mehr zu klären und zum Gaudium des Publikums löst sich die Truppe auf und die Provinzbewohner rufen dann im leichtsinnigen Hohn das übliche: Abzug Német![!] ${ }^{184}$

Die Bezeichnung „Chantant-Direktor“ war weder spezifisch noch nur für Inhaberinnen einer bestimmten Art von Etablissements gebräuchlich. ${ }^{185}$ Jedoch waren wesentlich mehr Männer als Frauen in leitenden Positionen. Wie die Besitzerin des Tingl-Tangels im Budapester Stadtwäldchen, von welcher Molnárs Liliom handelt, leitete etwa auch die Jüdin Minna Rott mit ihrer Schwester Sophie Ruzek ein Etablissement in Wien. ${ }^{186}$ Juliette Spiegel und Minna Moser waren andere bekannte Frauen in der Position von Varietédirektorinnen in Wien. ${ }^{187} \mathrm{Zu}$ den bekanntesten „Chantant-Direktoren“ in Budapest zählten die im dritten Kapitel vorgestellten Antal Orozzy (Folies Caprice) und Carl Somossy. ${ }^{188}$

Somossy, der Leiter des sogenannten ersten hauptstädtischen Orpheums in Budapest, war allgemein eine der bedeutendsten Persönlichkeiten für die

183 IAR, 8.1.1892, 1-2.

184 IAR, 8.1.1892, 2.

185 IAR, 8.1.1892, 1-4.

186 Hödl, Zwischen Wienerlied und Der kleine Kohn, 33, Anmerkung 130.

187 Koller, Das Wiener Volkssängertum in alter und neuer Zeit, 177.

188 Siehe die Spielstätten in diesem Kapitel. 
Entwicklung der Etablissementkultur, aber auch für soziale Fragen des Berufsstandes der internationalen Artistenszene gewesen. Somossy begann als Sekretär beim Prager Zirkus und arbeitete sich hoch. In der alten Ankerhalle hatte er das erste Varieté Ungarns eingerichtet. Um die Jahrhundertwende gelang es ihm, die bekanntesten Persönlichkeiten der internationalen Szene in seinem Orpheum zu versammeln. ${ }^{189}$ Somossy musste aber auch mit Rückschlägen kämpfen: Der bekannte Volkssänger Sándor Bródy berichtete über Somossy, dieser habe wie ein Kaiser gelebt, seine Wäsche zum Waschen nach Wien geschickt und Kleider in London gekauft. Aufgestanden sei er nie vor 12 Uhr und Mittag habe er immer gegen fünf Uhr nachmittags gemacht. In der ersten Pause im Varieté habe er sein Mittagessen eingenommen, dann habe sein Tag erst angefangen. Für seine Spielstätten habe er jeden Tag den schönsten Blumenschmuck angeschafft und Köstlichkeiten vom raffiniertesten Essen und den exquisitesten Getränken bis hin zum kostenlosen, aber doch köstlichen Amüsement serviert. Deshalb habe zu seinen Gästen nicht nur die breite Bevölkerung der ungarischen Metropole gezählt, sondern auch Magnaten wie Jenö Zichy (1837-1906). Derartige Kostspieligkeiten hätten allerdings auch dazu geführt, dass Somossy 1897 Konkurs anmelden und sein Unterhaltungsimperium wieder neu aufbauen musste. ${ }^{190}$

Boris Thomashefsky war über die Jahre ein großer Star der jiddischen Bühne, Betreiber mehrerer jiddischer Theater und ebenso Manager einer der ersten Music Halls an der Bowery. Er war als jüdischer Migrant aus Osteuropa nach New York gekommen und genoss in der Szene der Etablissements bei Jüdinnen und Juden und Nichtjüdinnen und Nichtjuden bald gleichermaßen große Beliebtheit. ${ }^{191}$ Im Zuge einer Aufführung lernte er seine spätere Frau Bessie kennen, die ebenfalls nach New York ausgewandert und Schauspielerin geworden war. ${ }^{192}$ Boris Thomashefsky hatte allerdings auch zahlreiche Affären mit anderen Schauspielerinnen. Deshalb waren er und seine Familie häufig in den Zeitungen. Thomashefskys Biographie zeigt, dass die Konkurrenz stieg, aber auch das Showbusiness nicht immer ein ganz einfaches Geschäft war. Wegen einer seiner Affären wurde er verklagt - ein Umstand, der wesentlich zu dem Konkurs, den Thomashefsky 1915 anmelden musste, beitrug. ${ }^{193}$ Er eröffnete

189 IAR, 1.11.1894, 3-7.

190 Oliver Perczel, Az éjszaka császárai (Friedmann Adolf és Somossy Károly pályaképe) [Kaiser der Nacht, ein Porträt von Adolf Friedmann und Carl Somossy, ungedrucktes Manuskript]. Ich danke Oliver Perczel für die Einsicht in das ungedruckte Manuskript.

191 Stefanie Halpern, Boris Thomashefsky: Matinee Idol of the Yiddish Stage, in: Edna Nahshon (Hg.), New York's Yiddish Theater: From Bowery to Broadway (New York: Columbia University Press, 2016), 118-127, 118-122.

192 Nahshon, A Galerie of Stars of the American Yiddish Stage, 313.

193 NYT, 28.2.1915, 10. 
später weitere Spielstätten, etwa das National Theatre an der Bowery um 1920. Als Thomashefsky im Juli 1939 starb, kamen - trotz seiner beruflichen und privaten Schwierigkeiten - Tausende von Menschen zu seiner Beerdigung und feierten den großen Theatermacher und Begründer der jiddischen Bühne in Amerika. ${ }^{194}$

Das gegenseitige Denunzieren, welches Thomashefsky am eigenen Leib erfahren musste, war eine beliebte Strategie in der Etablissementszene, sich unliebsamer Konkurrenz zu entledigen. Mit dem steigenden Angebot an Unterhaltungseinrichtungen, nahmen auch die Anzeigen unter den Direktor*innen und der Druck, Konzessionen zu erwerben, zu. „Wenn der eine Agent mit einem x-beliebigen Direktor ein Geschäft macht, rannte der Andere sofort zur Polizei, erstattete dort Anzeige, dass ein ausländischer Direktor hier weilt, der allerlei Mädchen, sub titule Sängerinen[!] engagiert [...]. “195 Derartige Anzeigen hatten sich in den meisten Fällen als falsch herausgestellt, jedoch vielfach auch zum Entzug von Konzessionen geführt. Vor allem Vorbehalte gegenüber ausländischen Direktor*innen und Schauspieler*innen nahmen zu.

\section{Die Bühne als Zone des Übergangs zwischen Rollen}

Diese Rollenentwürfe in der populären Kultur und vor allem das, was diese Künstler ${ }^{\star}$ innen auf der Bühne umsetzten, deutete zum einen auf eine für die Zeit verhältnismäßig große Gleichberechtigung zwischen Männern und Frauen hin und veranschaulicht zum anderen, dass die populären Aufführungen Übergangsbereiche zwischen vermeintlich starr getrennten Geschlechterkonstellationen zuließen. Diese modernistisch-subversive Möglichkeit fand ihren ultimativen Ausdruck um 1900 in der von den Künstler*innen populär gemachten Praxis des Gender-Bendings. Das offene Thematisieren von Sexualität und die Praxis der Rollentransgression brach nicht nur Geschlechternormen auf, sondern repräsentierte eine Lockerung allgemeiner binärer Konstrukte wie auch jenes einer vermeintlich jüdisch-nichtjüdischen Dichotomie. Allgemein wurde Sexualität im ausgehenden 19. und 20. Jahrhundert, wie der Historiker David Biale konstatiert, zu einem wesentlichen Bestandteil der kulturellen Auseinandersetzung mit dem Jüdisch-Sein. ${ }^{196}$

Neben den vermeintlich sehr stereotyp anmutenden Zuschreibungen kam den Künstler*innen in der populären Kultur - vor allem der Rolle der Soubrette - auch ungeahnt subversives Potential zu. Teil ihrer Aufführungen wurde es nämlich, auf der Bühne zunehmend Männer zu spielen. Es ging hierbei

194 NYT, 1.7.1939, 25.

195 IAR, 24.3.1892, 1.

196 David Biale, Eros and the Jews: From Biblical Israel to Contemporary America (Berkeley, Los Angeles: University of California Press, 1997), 204-209. 
aber nicht nur um die Übernahme einer eigentlich für einen Mann konzipierten Rolle, weil etwa zu wenig männliche Schauspieler greifbar gewesen wären. Nicht wie bei den in der Theatergeschichte zuvor lange üblichen sogenannten „Hosenrollen“, bei denen Männer Frauenparts übernahmen, da Frauen das Schauspielen verboten gewesen war. Bei diesen Hosenrollen gab es immer nur einen geschlechtlichen Part auf der Bühne. Ihre volle Wirkung entfaltete die performative Strategie des Gender-Bendings der Jahrhundertwende darin, dass nicht nur eine Frau eine Männerrolle übernahm, sondern auch ein Mann die Frauenrolle und beide Rollen gemeinsam - aber eben inszeniert von vermeintlich anderen Geschlecht - auf der Bühne die Szenerie gestalteten.

Über eine derartige Aufführung der Wiener Volkssängerin Risa Basté, die zuvor bereits vorgestellte "grande dame“ der Szene, gemeinsam mit dem international bekannten Man de Wirth im Varieté Roither berichtete die Neue Tagespost:

Die stärkste Zugkraft üben aber nach wie vor Herr Man de Wirth und Fräulein Risa Basté [aus], [...]. Die beiden Erstgenannten bilden einen interessanten Kontrast, Herr Man de Wirth als Dame und Fräulein Basté als Mann. Beide haben die Stärken und Schwächen des jeweilig , anderen' Geschlechts mit Erfolg studiert und liefern Copien, die vom Original kaum zu unterscheiden sind.[! ${ }^{197}$

In den folgenden Jahren verlief sich auf den Bühnen Wiens und Budapests offenbar die Praxis des fluiden Spielens mit Geschlechteridentitäten, für die Risa Basté und Paula Walden so beliebt gewesen waren. Die noch in den Jahren zuvor üblich gewesene Unabhängigkeit bei der Wahl des Geschlechts der verkörperten Rolle wurde abgelöst. In New York erfreute sie sich längerer Beliebtheit. Die Künstler*innen der amerikanischen Bühnen brachten die Praxis später wiederum nach Europa zurück. Etwa inkludierten Molly Picon und Jacob Kalich einen Rollentausch in ihr Wiener Programm. Mit Yentl („Jenkele") und anderen Klassikern traten die beiden 1921 vom Volkstheater bis zu den Wiener Kammerspielen auf. ${ }^{198}$ Teile des Wiener Publikums reagierten wie folgt:

197 Neue Linzer Tagespost, 29.5.1898, 4 [Hervorhebung im Original].

198 „An der Rolandbühne“, Illustrierte Kronen Zeitung, 14.12.1921, 5. 


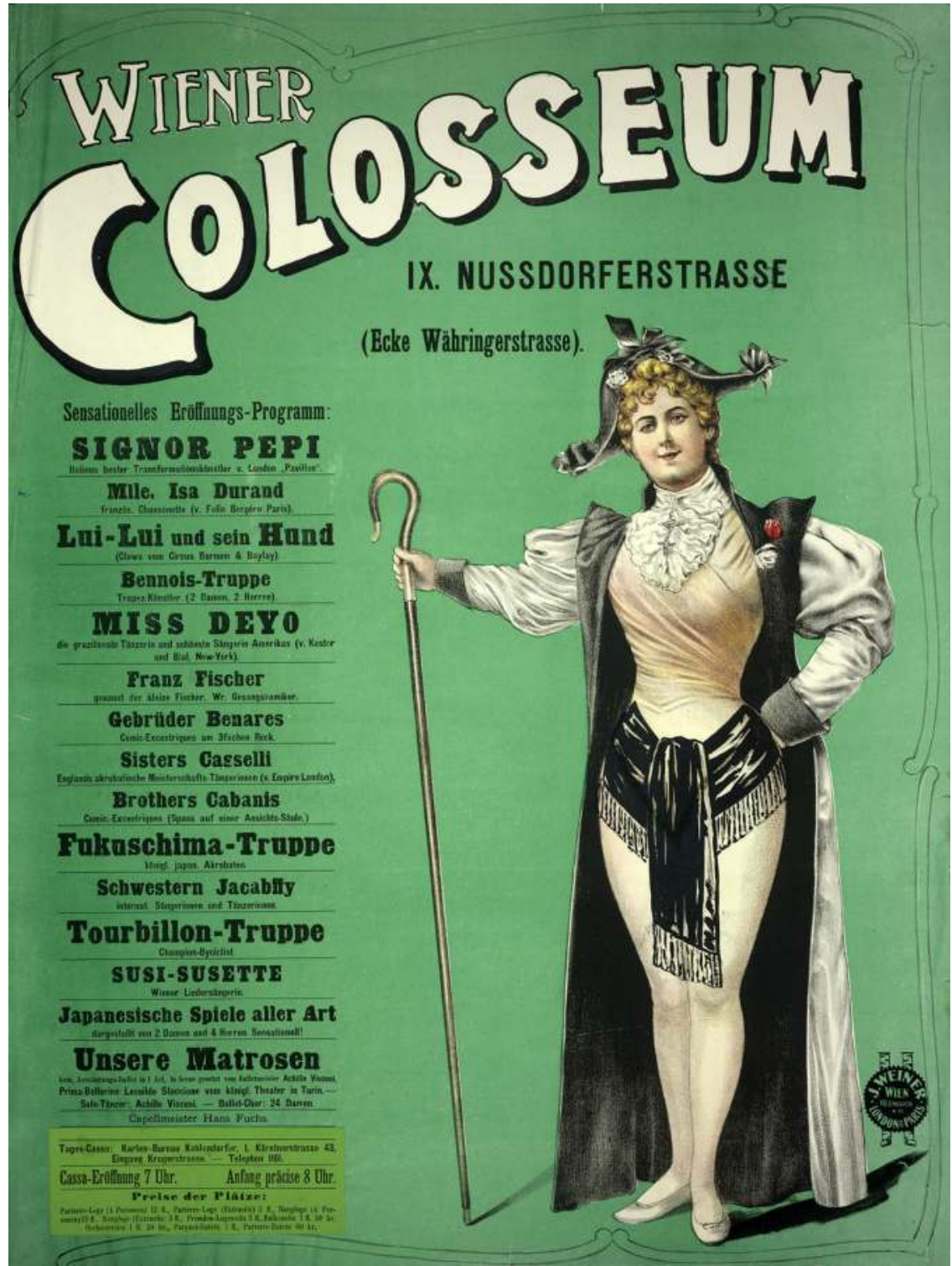

Abb. 27 Programm des Wiener Colosseums mit einer Soubrette in Aufmachung eines männlichen Bühnenparts, Jacob Weiner, Chromolithographie, Bildarchiv Austria, Pk 3003, 272 
Sondervorstellung in den Kammerspielen. Vor nahezu ausverkauftem Hause gab es am Samstag in den Kammerspielen des Deutschen Volkstheaters zwei wunderhübsche Nachmittagsstunden. Liebenswürdige amerikanische Künstler, Mr. J. Kalich und die lustige Mali Picon[!] gaben ihr Bestes zugunsten der Wiener Kinder. Es war wirklich Stimmung. ... Lieder aus dem Ghetto, Kinderlieder, reizende Duette, ... feine Chansons eröffneten den Lauschenden das jüdische Gemüt und lehrten es lieben. Mit trefflichen Temperament tanzte Mali Picon eine uns Wienern ganz fremdartige Verwandlungsnummer Broadway-Typen -, und als die reizende Künstlerin am Schluß gar eigene Imitationslieder sang, mit immer wechselnden, verblüffenden und entzückenden Einfällen in Mimik und Bewegung das Publikum mitreißend, da hatte sie in wenigen Minuten eine dankbare Gemeinde. Das Theater wurde zum Salon: während sie sang, plauderte sie in bestem gegenseitigen Verstehen mit uns Wienern, machte uns vergnügt, ja sie brachte das Parkett zum Mitsingen eines Refrains; man mochte wollen oder nicht, man mußte.[!] ${ }^{199}$

Dem Neuer Wiener Tagblatt zufolge sei das Publikum mit der noch wenige Jahre zuvor gängigen und durchaus weit verbreiteten Praxis eines Gender-Bendings auf den Bühnen der Varietés nicht (mehr) vertraut. Das Publikum Anfang der 1920er Jahre habe die Art des Wechselns zwischen Geschlechterrollen als befremdlich wahrgenommen. ${ }^{200}$

Ungeachtet der vermeintlichen Irritation des Wiener Publikums perfektionierte Molly Picon den inszenierten Rollenwechsel. Ihre wohl bekannteste Auftritt als Mann brachte sie im Film Yidl mitn Fidl (1936). Joseph Greens Film, der als kommerziell erfolgreichster jüdischer Film aller Zeiten gilt, wurde 1935 in Polen gedreht und handelt von Itke und später Yidl und ihrem Vater, die ihren Lebensunterhalt als Musiker*innen bestritten.

Yidl mitn Fidl ist eine filmische Auseinandersetzung mit der Geschichte einer reisenden Gruppe von Musikant ${ }^{*}$ innen, die jiddische Lieder und Couplets an verschiedensten Orten aufführen. In dem Film verkörperte Molly Picon als die Violinistin bzw. Fiedlerin Itke die Hauptrolle. Itke reist zunächst in Begleitung ihres Vaters und später als Teil einer Gruppe Musiker*innen umher. Auf ihrer Reise tritt sie in einer kleinen Stadt auf, als plötzlich andere Musiker mit ihrer Gruppe um die Gunst des Publikums zu konkurrieren beginnt. Es kommt zu einer direkten Konfrontation zwischen den Musiker*innen, die schließlich darin endet, dass sich alle eingestehen, gemeinsam besser zu klingen. Nach der Fusion setzen sie als Ensemble ihre Tournee fort - allerdings nicht mit Itke, sondern mit Yidl, da Itkes Vater fürchtet, eine Tournee sei für sie als Frau zu gefährlich. Die beiden anderen Musiker nehmen Itke sodann wie

199 „Sondervorstellung in den Kammerspielen“, NWT, 8.8.1921, 4.

200 Anzumerken ist, dass in den 1910er Jahren auch Travestiekünstler*innen in der Populärkultur aktiv wurden und Rollen bekleideten. Magnus Hirschfeld etwa beschäftigte sich zeitgenössisch damit. Annette F. Timm, The Politics of Fertility in Twentieth Century Berlin (Cambridge: Cambridge University Press, 2010), 46-57. 
selbstverständlich als Mann und nicht als Frau wahr; um die neue Kooperation nicht zu gefährden, spielt Itke, nun als Yidl, dieses Spiel mit. Der Umstand des Reisens erleichtert wesentlich den Wechsel zwischen den Geschlechtern. ${ }^{201}$

In der Yidl mitn Fidl konnte Picon im Wechsel der Rollen zwischen Mann und Frau verschiedene Ebenen struktureller Diskriminierungen, denen Jüdinnen und Nichtjüdinnen ausgesetzt waren, thematisieren. Als Frau wird die Musikerin zunächst so dargestellt, dass ihre Berufs- und Bewegungsfreiheit Einschnitte erfährt und sie nur in Begleitung - der ihres Vaters und später auch der anderen Ensemblemitglieder - reisen kann. Damit greift der Film die oben dargestellte Panik auf, dass allein reisende Frauen der Gefahr von Entführung und Zwangsprostitution ausgesetzt seien. Diese Angst spricht der Vater explizit an und geht deshalb schließlich mit seiner Tochter auf Reisen. Später empfiehlt er ihr die Verkleidung als Mann, damit sie sicher reisen und als Musiker ${ }^{\star}$ in ihr Geld verdienen könne.

Allerdings bricht auch ein Charakter dieses Narrativ der Panik und führt gleichzeitig die Pluralität der Praxis des Gender-Bendings vor: die Musikerin Taube, die später zu der Gruppe hinzustößt. Sie ist durch ihre Kleidung und Art des Auftritts deutlich als Frau markiert. Mit Taube erhält die Gruppe sodann umgehend mehr Aufmerksamkeit. Zwei vermeintliche Agenten wollen schließlich die Musikerin abwerben und zum Star machen, um Geld an ihr zu verdienen. Hier scheint im Film wieder der Diskurs um die Panik vor Mädchenhändlern und deren vermeintliche Verknüpfung mit der populären Kultur auf. Es steht sogleich die Frage im Raum, ob die Musikerin wohl nur in ein Abhängigkeitsverhältnis und später in die Sexarbeit gelockt werden würde. Diese Sorge bestätigt sich jedoch nicht. Taube entzieht sich der Situation, indem sie mit ihrem Freund davonläuft und eröffnet so eine Karrierechance für Itke, die diese (zunächst aus Versehen) ergreift.

Die Szene von Yidls ,Outing' als Frau ist ein Bühnenauftritt im Theater. Einerseits zeigt sich hier, wie ihre Geschichte auf der Bühne zu einer unterhaltsamen Gender-Performance wird. Ihre Erzählung über die Geschlechtertransgressionen nimmt das Publikum mit Humor und Leichtigkeit auf, es ist „köstlich amüsiert“. An dieser Szene werden auch die Freiheiten deutlich, die sich Frauen auf den Bühnen nahmen. Während Itke als Yidl im Alltag ihre Identifikation als Frau verheimlichen muss oder zumindest dazu angehalten wird, kann sie auf der fiktiven Bühne frei von der Seele sprechen. Sie zielt dabei der Inszenierung nach gar nicht auf die Unterhaltung des Publikums ab. So erzählt Itkes Auftritt unfreiwillig etwas über die Wahrnehmung von Frauen und gibt sich im

201 Migration im Kontext populärer Unterhaltung und Gendermobilität ist als Forschungsdesiderat zu sehen. Zu Migration und Queer Theorie siehe Eithen Luibhéid, „Queer/Migration: An Unruly Body of Scholarship“, GLQ 14, no.2-3 (2008): 169-190, 174. 
gleichen Moment als Frau zu erkennen. Damit verliert sie zwar ihre „Tarnung“, gleichzeitig tut sich aber mit Itkes Outing innerhalb einer heteronormativen Denkweise $^{202}$ die Beziehung zu dem männlichen Partner im Ensemble, für den sie die ganze Reise über geschwärmt hat, als eine reale Option auf.

Damit inszenierte Molly Picon gemeinsam mit Green sämtliche, in der Szene populärer Kultur in den letzten Jahrzehnten relevant gewordenen Debatten und inkludiert subversive Potentiale. Dieses filmische Dokument der 1930er Jahre lässt erahnen, was die jüdischen und nichtjüdischen Künstlerinnen in der Praxis des fluiden Geschlechterwechsels zu entwerfen und vorzuführen vermochten. Der Historiker Sander L. Gilman zeigt am Beispiel der Entwicklung der Salome (ursprünglich in Johann Strauß` Oper) für die Inszenierung von Jüdinnen auf der Bühne, dass derartigen Rollen das Potential innewohnte, sämtliche Stereotype und gesellschaftspolitischen Wirkmächte zu bündeln. ${ }^{203}$

Von den noch als „bodenständig“ beschriebenen „Seidler Malis“204 am Beginn der 1880er Jahren hatten sich die Volkssängerinnen während des folgenden Jahrzehnts zu Soubretten entwickelt, die immer größeren Gestaltungsraum hinsichtlich der Interpretation ihrer Rollen erhielten und so alsbald mit Selbstbewusstsein sowohl weibliche als auch männliche Charaktere dem Publikum vorführen konnten. So verliehen sie in ihren Stücken und Liedern soziopolitischen Themen große Brisanz. Gerade dieser Handlungsspielraum und der selbstbewusste Umgang sowie die Subversion, mit der die Soubretten ihren Handlungsspielraum nutzten, brachte allerdings auch negative Konsequenzen. In diesem, inhaltlich moderne Aushandlungen zulassenden Umfeld sahen sich die Künstler*innen alsbald mit Vorwürfen konfrontiert. Ihnen wurde unterstellt, nicht nur auf der Bühne zu unterhalten, sondern das männliche Publikum vor allem mittels sexueller Gefälligkeit für sich zu gewinnen. Dieser Vorwurf, so die Argumentation, hänge damit zusammen, dass die ersten Volkssängerinnen vor der künstlerischen Tätigkeit als Prostituierte tätig gewesen seien. Andere, die „Diven“, wie sie Josef Koller in „Das Wiener Volkssängertum“ nannte, sorgten für Gespräche durch „scharf gewürzte Lieder“ und „schlüpfrige Zoten“, „verschämte Blicke“ und „züchtige Lieder“, wie das Tanzen des Cancan, wobei „Strumpfbänder und Dessous schimmerten“. Dies habe, so Koller, natürlich

202 Michael Warner, Introduction, in: ders. (Hg.), Fear of a Queer Planet: Queer Politics and Social Theory (Minneapolis: University of Minnesota Press, 1993), vi-xxxi, x.

203 Sander L. Gilman, „Salome, Syphilis, Sarah Bernhardt and the ,Modern Jewess“, The German Quarterly 66, no. 2 (1993): 195-211, 195-201.

204 Siehe Koller, Das Wiener Volkssängertum in alter und neuer Zeit, 32-33. 
Gerüchte befördert. ${ }^{205}$ Wieder andere Volkssängerinnen hätten aber auch ihren Beruf mit Prostitution verbunden. ${ }^{206}$

Prostituierte verkörperten um 1900 Ängste vor dem „Weiblichen“, Juden jene vor dem „Weiblichen“ und „Männlichen“.207 Misogynie und Antisemitismus waren einander um die Jahrhundertwende sehr ähnlich. ${ }^{208}$ Es ist darum kein Zufall, so der Historiker Sander Gilman, dass die „exemplarischen Humoristen “ in der Kultur des Fin de Siècle Juden waren. ${ }^{209}$ Es ist auch kein Zufall, dass gerade Gruppen, in denen Jüdinnen und Juden mit Nichtjüdinnen und Nichtjuden gemeinsam auftraten, Misogynie und Antisemitismus provozierten. Ebenso scheinen die massiven Abwertungsversuche gegenüber der populären Kultur von behördlicher und politischer Seite aus nicht zufällig, war gerade die populäre Kultur - eben aufgrund ihrer Auseinandersetzung mit gesellschaftspolitisch brisanten Themen und ihrem offenen Hinterfragen von Vorurteilen und vermeintlichen Realitäten mit ihrer enormen Reichweite - ein ungern geduldetes Ventil.

\subsection{Vorbehalte gegenüber der populären Kultur}

Immer wieder drehten sich die Vorwürfe um die Frage eines „alleine Reisens“: Die für das Gender-Bending bekannte Soubretten Risa Basté und Paula Walden waren verheiratet und reisten meist mit ihren Ehemännern; Molly Picon tat desgleichen im realen Leben und entwarf ihre Reise als Musiker*in im Film auch immer in Begleitung. Sie vermied es, alleine zu reisen und doch kam die gesellschaftliche Debatte immer wieder darauf zurück. Dennoch blieben erniedrigende Vorwürfe gegenüber der Szene bestehen. Das Aufkommen von Vorwürfen wurde häufig mit dem vermeintlich fehlenden Talent der Künstlerinnen in Zusammenhang gebracht. Neben jenen Artistinnen, die von Obszönität profitierten und dem Publikum die Sinne raubten, gab es natürlich auch diejenigen, die den Ansprüchen des Publikums nicht genügten. Diese seien meist

205 Koller, Das Wiener Volkssängertum in alter und neuer Zeit, 37-45.

206 Klaus Hödl, „,Jewish History beyond binary conceptions: Jewish performing musicians in Vienna around 1900", Journal of Modern Jewish Studies 1 (2017): 1-18, 7.

207 Gilman, Freud, Race, and Gender, 28.

208 Christina von Braun, Antisemitismus und Misogynie: Vom Zusammenhang zweier Erscheinungen, in: Jutta Dick, Barbara Hahn (Hg.), Von einer Welt in die andere: Jüdinnen im 19. und 20. Jahrhundert (Wien: Brandstätter, 1993), 179-196. Siehe auch Karin Stögner, Antisemitismus und Sexismus: Historisch-gesellschaftliche Konstellationen (Baden: Nomos, 2014), 13-20; sowie zu Antisemitismus und Antifeminismus Shulamit Volkov, Das jüdische Projekt der Moderne: Zehn Essays (München: C. H. Beck, 2001), 62-81.

209 Gilman, Freud, Race, and Gender, 82. 
nicht aus freiem Wunsche dem Beruf nachgegangen, sondern aus einem Zwang. Denn viele junge Frauen wurden geradezu genötigt, eine Bühnenkarriere einzuschlagen. Die Zeitungen spielten auch hier eine Mittlerrolle und wollten zur Aufklärung von Missständen beitragen, um Vorwürfe einzudämmen. Am 24 . Februar 1892 titelte etwa die Internationale Artisten Revue „Nieder mit der Konsum-Sklaverei“:

Es ist eine oft erhärtete Thatsache, dass junge, wohl mitunter etwas leichtfertige, aber in Armuth und Noth erzogene blutjunge Mädchen, durch eitle Verblendung gewissenlosen Schacherhänden überantwortet werden, dass man ihnen den Beruf als Sängerinen[!] aufoktroirt, ohne dass sie denselben in sich fühlen, sie in die Welt, oft in ferne, halbcivilisirte Länder hinausspedirt, wovon sie sich Schätze von Gold und Edelsteinen erhoffen und gar oft nur erringen sie - Thränen der bitteren Enttäuschung oder - die lachende Schande! [! $]^{210}$

Der Bericht betont einerseits wiederum die Wichtigkeit von künstlerischer Reife und Freiheit - das „Fühlen“ der Profession und des künstlerischen Geistes. Nur das lasse letztlich zu, vor dem Publikum erfolgreich und selbstbewusst zu erscheinen. Junge, untalentierte Mädchen würden deshalb nie wirkliche Soubretten. Die Zuschauer*innen äußerten dann schlechten Künstlerinnen gegenüber sofort gnadenlos Kritik. Das Publikum verlache und verspotte die Auftretenden - insbesondere junge Frauen -, die sie nicht zur vollen Zufriedenheit unterhielten. ${ }^{211}$

Sängerinnen, die das Publikum nicht begeistern konnten, wurden als Grund für Vorbehalte gegenüber der Szene gesehen. Schuld an dieser Misere seien erstens die Eltern und zweitens die korrupten Theaterunternehmer gewesen. ${ }^{212}$ In erstem Fall machte die Presse vor allem die sogenannten „Chantant-Mütter“, die Mütter der jungen Sängerinnen, verantwortlich. „Jene, von welchen Schiller behauptet: Da werden Weiber zu Hyänen! Diese Damen sind der Schrecken aller Direktoren; machen Garderoben und Bühnenräume unsicher und stehen überall den Arbeitern im Wege. " ${ }^{213}$ Sie wollten ihre Töchter nur in den Etablissements der Stadt unterbringen. Das scheiterte vielfach unter der schlechten Rückmeldung des Publikums, das die jungen, unerfahrenen und meist ungeübten Künstlerinnen auspfiff und verlachte. Die unglücklichen und erfolglosen Frauen bekämen dann nicht selten ernstzunehmende psychische Probleme, so das Fazit des Artikels. So schenkten viele dann jeder noch so unglaubwürdigen Versprechung Glauben. ${ }^{214}$

210 „Nieder mit der Konsum-Sklaverei“, IAR, 24.2.1892, 1.

211 Als absolutes Negativbeispiel fungierte hier das Orpheum in Fiume. IAR, 24.2.1892, 2.

212 IAR, 24.2.1892, 2.

213 IAR, 20.2.1894, 1.

214 IAR, 20.2.1894, 2. 
Dass Künstlerinnen in der populären Kultur mit geheimer Prostitution in Verbindung gestanden hätten, ist dabei ein Vorwurf, der vielfach auch von der Forschung übernommen wurde. ${ }^{215}$ Allerdings ist anzumerken, dass sich dafür keine verallgemeinerbaren Belege finden. Das soll nicht heißen, dass es nicht zu verdeckter Prostitution und auch zu Affären zwischen Soubretten und Verehrern aus dem Publikum gekommen ist. Jedoch scheint die Behauptung eines allgemeinen Nahverhältnisses der Etablissements zur Prostitution unhaltbar. Eine Vielzahl der Etablissementkünstlerinnen waren mit ihren Kollegen verheiratet. ${ }^{216}$ Allgemein legt auch der Blick in die Aufführungsunterlagen das subversive Potential, das den Soubretten zukam, ein anderes Bild nahe. ${ }^{217}$ Es drängt sich die Frage auf, ob das bis zur Ekstase getriebene aufreizende Bühnenspiel entsprechende Projektionen und Phantasien veranlasste.

Unter dem Titel „Bittere Pillen“ vermittelte die Internationale Artisten Revue am 20. September 1893 ihren Leserinnen, „[d]ass eine Bretter- oder BrettelDame mehr als jedes andere weibliche Wesen der männlichen Stütze, ob nun in Form legitimen oder liberalen Rechts, bedürfe, ist selbstverständlich und durch ihr Metier gerechtfertigt, weil sie eben nur durch solche Stützen Carrière

215 Elisabeth Brauner-Berger, Volkssängertum im Wandel (Diss. Universität Wien, 1993), 53; sowie Hödl unter Verweis auf Brauner-Berger, Zwischen Wienerlied und Der kleine Kohn, 105. Brauner-Berger stellt diese Behauptung auf. Problematisch an dieser Behauptung ist, dass Brauner dafür keine Quellenbelege ausweist. Zwei Schreiben der Polizeibehörde interpretiert sie, ohne dass sich ein entsprechender Hinweis tatsächlich im Text findet, mit „[d]amit sind eindeutig die Volkssängerinnen gemeint“. Brauner-Berger, Volkssängertum im Wandel, 57. Ebenso nicht belegt ist die zweite Thematisierung des Verhältnisses von Volkssängerinnen zu Prostitution, wo Brauner-Berger behauptet, dass „[s] ie [Volkssängerinnen] verkauften ja nicht nur ihre Kunst, sondern auch ihren Körper und verdienten gut damit“. Als Paradebeispiel für eine Prostituierte und Volkssängerin führt Brauner-Berger die „Fiaker-Milli“ an. Die „Fiaker-Milli“, eigentlich Emilie Turecek (Koller, Das Wiener Volkssängertum in alter und neuer Zeit, 37), galt als eine der bekanntesten Wiener Volkssängerinnen der 1860er Jahren. Woher die Information stammt, dass sie Prostituierte gewesen sei, wird nicht angeben. Brauner-Berger, Volkssängertum im Wandel, 56. Allgemein sei zu der Verbindung von Prostitution und Volkssängerinnen angemerkt, dass sich derartige Hinweise nicht explizit finden, sondern nur implizit die in unter „Soubretten“ dargestellte Diskussion vonstatten ging. Für das Beispiel der „Fiaker-Milli“ im Besonderen lässt sich konstatieren, dass es in Folge einer widrigen Darstellung ihrer Person 1867 zu einem Gerichtsprozess gekommen war. In dem Prozessverlauf hob der Angeklagte sogar explizit hervor, dass die Darstellung nur zur Übertreibung dienen sollte und keinerlei lebensweltlicher Realität entsprach, was auch der Konsens der anderen Aussagen war. NWT, 26.11.1867, 3.

216 Franz und Marietta Kriebaum, Risa Basté und Adolf Glinger, Otto Taussig und Paula Walden, Anna Drexler und Josef Model, Fürst mit der Schwarzen Eberl Pepi, Drexler mit Amalia Seidler, Heinrich Eisenbach mit Mizzi Telmont, Josef Armin und Käthe Wachs. Siehe einerseits die Ausführungen in dieser Arbeit. Andererseits zu Kriebaum, Fürst, Model Koller, Das Wiener Volkssängertum in alter und neuer Zeit, 18, 97 und 157.

217 Siehe hierzu die Ausführungen im Kapitel 5. 
zu machen hofft. “218 Es sei daher legitim, so das Argument, dass die Schauspielerinnen mit der Presse „liebäugeln“, um gute Kritiken zu bekommen und dem männlichen Publikum „schöne Augen“ machten, solange Kunst auszuüben ihr aufrichtigster Wunsch sei. Es sei jedoch äußerst verwerflich, so der Artikel, die Kunst als Vorwand für Flirt und Anbiederung zu benutzen:

Die Commillitonen der Bühnenuntugenden mögen uns gnädigst verzeihen, wenn wir der Ansicht sind, dass eine derartige Theaterfee mehr Unglück und Schande stiftet, als zwanzig sogenannte öffentliche Kebaweiber, vulgo Lustdirnen, weil bekanntlich die Velleitäten Letzerer keinen anhaltenden sein dürfen, indem dafür polizeiliche und sonstige Organe sorgen, dass sie ihre ohnehin genügend unverschämten Grenzen nicht überschreiten.[! $]^{219}$

Die Diskussion in der Internationalen Artisten Revue veranschaulicht einen wahrgenommenen Unterschied zwischen Varietédamen und sogenannten „Dirnen“. Dem „Unverfangen von Lüsten“ sollten sich die „Bretteldamen“ nicht hingeben, da Kunst ihr höchstes Anliegen zu sein habe. Die „Dirnen“ bräuchten einen gesetzlichen Aufseher, damit ihre Lüste nicht ausuferten. Den Varietédamen hingegen sprach die Diskussion gewissermaßen das Recht auf sexuelle Selbstbestimmung zu, zumindest solange diese keine ausbeuterische Komponente habe. Denn,

[d]ie Künstlerin oder Artistin lebe aber ihrem Bühnen- oder Podium-Gewerbe und nachdem auch in ihrem Busen ein warmfühlendes Herz schlägt, so sei auch ihr, wie jedem anderen Weibe gegönnt, der Liebe zu pflegen: allein ihr Gewerbe nur dazu zu benützen, um vom Ertrage körperlicher Reize schmarotzend die in ihre Netze fallenden Gimpel umbarmherzig[!] zu plündern, dass sei ihr ebenso wie der gewöhnlichen Lustdirne verboten. $^{220}$

In dieser Diskussion um „Dirnen“ und Varitékünstlerinnen klangen viele misogyne Topoi der Zeit durch: Nur körperliche Reize zu verwenden und unbeholfene Opfer zu überwältigen, sei ihr verboten, denn der Mann im Publikum vermöge ohnehin nicht, gegen seine Lüste anzukommen. Die Frau dürfe von ihren Stärken als Verführerin nicht „schmarotzen“.221

Um dem schlechten Ruf der Etablissements entgegenzuwirken, war die Szene bemüht, jedem Missbrauch ihres Kunstgewerbes vorzubeugen. Um zu vermeiden, dass vermeintliche Agent ${ }^{*}$ innen, Ensembleleitende oder Direktor ${ }^{\star}$ innen Frauen auf dem Wege einer „Karriere“ in die Prostitution lockten, schalteten

218 „Bittere Pillen“, IAR, 20.9.1893, 1-2, 1.

219 IAR, 20.8.1893, 2.

220 IAR, 20.9.1892, 2.

221 Ebda. 
die Künstlerinnen sogar warnende Inserate in Zeitungen, sobald ihnen Derartiges zur Kenntnis gelangte. Am 30. November 1891 schickte eine Delegation reisender Künstler*innen einen offenen Brief an die Internationale Artisten Revue.

WARNUNG. Wir unterzeichnende Artisten warnen alle Collegen u[nd] hauptsächlich Colleginnen ein Engagement in das hierortige Chántant ,Imperial' (Hotel Concordia) zu acceptieren: der Besitzer desselben Ivan Robeff, ist laut k. u. k. Consulatsprotocoll wegen Mädchenhandel angeklagt, da er eine ihm missliebige Artistin (G. G. aus Wien) um rascher zu seinem Vorschuss zu kommen, in ein hiesiges öffentliches Haus verkaufen wollte, und nur den raschen Einschreiten des löbl[ichen] Consulates ist es zu danken, dass benannte Artistin noch bei Zeiten gerettet wurde.[! $]^{222}$

Die Solidarität und das Engagement, das die Artist*innen in diesen Belangen an den Tag legten, waren beachtlich. Unmittelbar nach Bekanntwerden des Sachverhaltes kündigten alle im Engagement des Etablissements stehenden Künstler*innen ihre Position. Umgehend wandten sie sich an die internationalen Medien, um ihre Kolleg*innen vor einem ähnlichen Schicksal zu bewahren. „Da nun dieser Ehrenmann alle Artisten verloren hat, wird er wahrscheinlich den Versuch machen, durch eine zweite Person in Budapest oder Wien zu engagiren; wir empfehlen daher diese Zeilen der Beachtung aller Artisten so wie Agenten.[! ] ${ }^{\text {“223 }}$ Der Brief wurde vom Kapellmeister Emil Rosé und neun weiteren Unterzeichnenden am 30. November 1891 aus Sofia abgeschickt und bereits in der nächsten Ausgabe der Internationalen Artisten Revue, am 8. Dezember 1891. veröffentlicht.

Diese kämpferische Reaktion auf die Vorkommnisse in Sofia zeigt mehrerlei auf: Zum einen, dass Sexarbeit in Varietés innerhalb der Szene nicht akzeptiert war, und zum anderen, dass Wien und Budapest wichtige Umschlagpunkte für Engagements in anderen Teilen der Monarchie waren. Außerdem illustrieren die Vorkommnisse, dass sich einige Protagonist ${ }^{\star}$ innen der Szene strikt gegen Derartiges wehrten. Gleichermaßen bewies der Brief der Artist*innen den starken Zusammenhalt; Berufsgenoss ${ }^{\star}$ innen sollten davor bewahrt werden, Opfer jener dreisten Gestalten zu werden, die die Popularität des Gewerbes auszunützen versuchten.

222 „Warnung“, IAR, 8.12.1891, 32.

223 Ebda. 


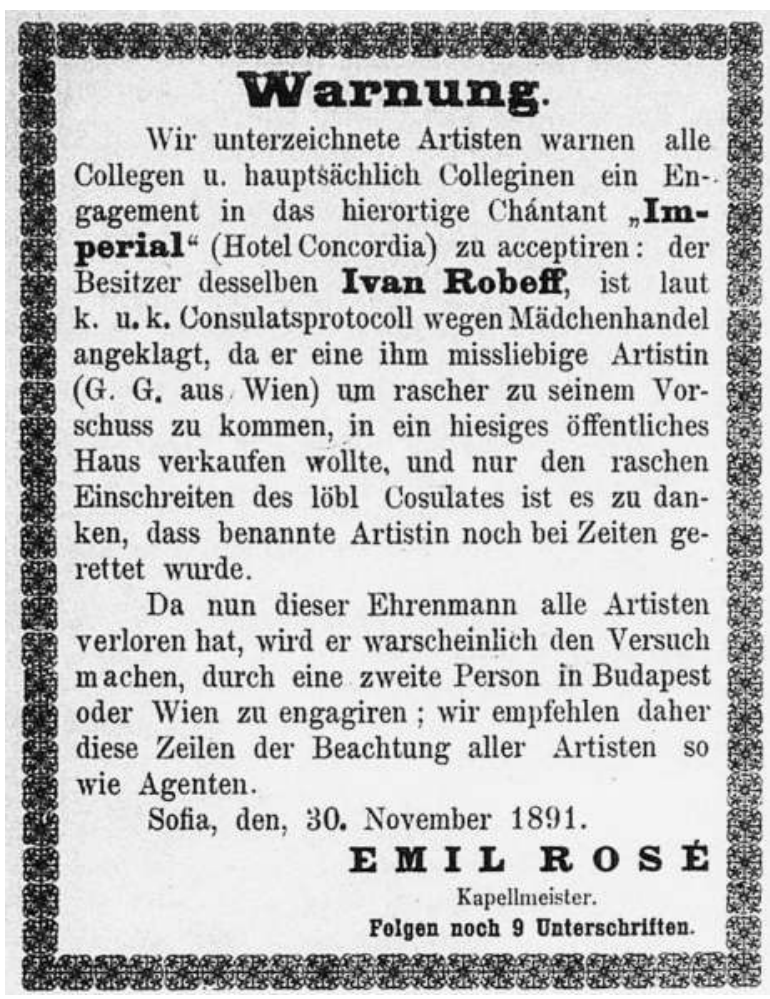

Abb. 28 Inserat „Warnung“ von mobilen Künstler*innen um vor vermeintlichen Engagements zu warnen, Internationale Artisten Revue, 8. Dezember 1891, Sammlung für Theatergeschichte der ungarischen Nationalbibliothek Széchényi

Auch wenn sich die Szene selbst vehement gegen die dargestellten Vorwürfe, wie die Nutzung der „privaten Räume“ zur Prostitution, oder dass die Sängerinnen lediglich an schnellem Geld und nicht seriöser Kunst interessiert seien, zu wehren versuchte, degradierten die genannten Unterstellungen die populäre Kultur. ${ }^{224}$ All diese Vorwürfe hingen eng mit dem sich zunehmend mobilisierenden Charakter populärer Kultur zusammen. Im dritten Kapitel dieses Buches habe ich dargelegt, dass die Vorwürfe an die Räume, die für reisende Künstler*innen geschaffen wurden, gebunden waren. Dieses Kapitel illustrierte, dass gerade der Charme und das Subversive der Künstlerinnen, das vom Publikum nachgefragte internationale Flair ausmachte und das dieses regelrecht von den Schauspielerinnen einforderte, Vorwürfe beförderten. Ein weiteres,

224 IAR 8.3.1892, 1. Die Internationale Artisten Revue reagierte auch auf den Artikel in der Budapesti Hírlap (der in gleicher Form auch in den Magyar Újság gedruckt wurde). IAR, 10.10.1893, 1 sowie 20.10.1893, 1 . 
in diesem Kontext zu sehendes Beispiel war der im dritten Kapitel behandelte „Volkssängerkrieg“. Hier wurde aus Angst vor der Expansion des Budapester „Mustervarietés“ Folies Caprice ein weitgreifender Konflikt innerhalb der Szene geschürt. $^{225}$

All diese Vorwürfe, die Mobilität habe negative Auswirkungen, bezogen sich alsbald auch auf die Inhalte. Gerade für das ,jüdischen Theater“ sei dies der Untergang gewesen:

In seinen neuen Pflanzstätten konnte das jüdische Theater keine Fortschritte machen und musste zu einem Provinztheater werden. Namentlich in Amerika, wo alles Geschäft und Humbug ist, musste aus der jüdischen Bühne ein tragischkomisches Zwitterding werden. Man braucht nur die widerlichen Theaterzettel der jüdischen Institute in New York mit ihren Jahrmarktsankündigungen zu lesen, um zu wissen, wess[!] Geistes Kind dort das jüdische Theater ist. [...] Er schmiert daher alles Mögliche zusammen und taufte die unmöglichsten Dinge in Judenstücke um. ${ }^{226}$

Nahm also die Gesellschaft das transnationale Flair und die Mobilität der populären Kultur als Bedrohung wahr? Oder - um zurückzukommen auf die zuvor formulierte Frage -, bekam das Publikum Angst vor der Mobilität populärer Kultur?

Mit einem flüchtigen Blick ließe sich das bejahen. Die Möglichkeiten, die die populäre Kultur eröffnete, waren vielfältig: $\mathrm{Ob}$ das Reisen und eine internationale Karriere oder das Aneignen neuer Vorstellungen von Geschlechterrollen: Die populäre Kultur vermochte es, bestehende Wertvorstellungen, gesellschaftliche Normen und Zugehörigkeiten umzudrehen und erreichte damit breite Bevölkerungsschichten auch über Grenzen politischer Systeme hinweg. Frauen konnten auf der Bühne plötzlich einen Mann spielen, obwohl der Rollentausch viele Jahre - nämlich, als es für Frauen noch als unschicklich galt, auf Bühnen aufzutreten und deshalb verboten war - nur Männern vorbehalten war. Der Blick in die Inhalte, die die populäre Kultur diskutierte, im nächsten Kapitel verstärkt dieses zunächst als naheliegend erscheinende Bejahen.

225 Zum „Volkssängerkrieg“ siehe Hödl, Zwischen Wienerlied und Der kleine Kohn, 105.

226 Schach, Das jüdische Theater, 355. 


\section{Die urbanen „Busentempel“ als Möglichkeitsräume}

Antisemitismus und Erotisierung, Gender-Bending und produktives

Miteinander?

statt Musentempel ,Busentempel

- Reichspost über Etablissements $1899^{1}$

Der Inhaber des Hotels, in dem die Offiziere logierten, ein gewisser Brodnitzer [...] machte den Spielsaal auf. Er hängte einen großen Zettel an die Fensterscheibe des Cafés. Er verkündete, daß er Spiele jeder Art bereit halte, eine Musikkapelle allabendlich bis in die Morgenstunden ,konzertieren' lassen werde und ,Tingel-Tangel-Sängerinnen von Ruf' engagiert habe. Die ,Renovierung' des Lokals begann mit den Konzerten der Musikkapelle, die aus acht zusammengeklaubten Musikern bestand. Später traf die sogenannte ,Nachtigall aus Mariahilf‘ ein, ein blondes Mädchen aus Oderberg. Sie sang Walzer von Lehár, dazu das gewagte Lied: ,Wenn ich in der Liebesnacht in den grauen Morgen wandre..., ferner als Zugabe: ,Unter meinem Kleidchen trag' ich rosa Dessous voller plis .... ${ }^{2}$

In diesem Ausschnitt aus Radetzkymarsch flocht Joseph Roth ein paradigmatisches Unterhaltungsszenario, das die in den vorherigen Kapiteln beschriebenen Entwicklungen zusammenfasst, ein: In einem Hotel wird eine Spielstätte eröffnet, als ersten Schritt der Sanierung „klaubt“ der Direktor acht reisende Artisten zusammen und krönt seine neue Truppe mit einer charismatischen Sängerin, einer Soubrette, die mit pikanten Texten zu den Melodien bekannter Klassiker das Publikum anlocken soll. Rund um die Bühne, auf der die „TinglTangel-Sängerin" auftritt, schrieb Joseph Roth, sind in dem Lokal mehrere Kartentische aufgestellt. Auf ihnen finden regelmäßig Kartenpartien, vermutlich Tarock, statt. Damit hatte Roth einen perfekten Entwurf eines erfolgreichen Vergnügungsetablissements geliefert: Ein Szenario, das so erfolgreich war, dass es selbst Stoff für die populäre Kultur wurde.

In einem der bekanntesten Stücke der Jahrhundertwende ging es um eine solche Kartenpartie in einer Gaststätte. Die Klabriaspartie erzählt von vier Männern, die nichts anderes machen, als Karten zu spielen. Die bekannteste Fassung ging auf den bereits mehrmals erwähnten jüdischen Varietéschreiber und Singspielhallenkonzessionär Antal Oroszi zurück. Das Stück hat, dramaturgisch gesehen, keine Handlung: Der Ausgang der Kartenpartie ist ebenso

1 Reichspost, 6.4.1899, 9.

2 Joseph Roth, Radetzkymarsch [1932] (Köln: Anaconda, 2012), 214-215. 
wenig von Relevanz wie das Geschehen um diese herum. Interessant und unterhaltsam war lediglich das Gespräch der Kartenspieler. Die durchaus derben Witze, die spitzfindigen Pointen und die amüsanten Anekdoten behandeln dabei nur allzu illustrativ Begegnungen zwischen Juden, Jüdinnen, Nichtjuden und Nichtjüdinnen.

Aufgrund des großen Erfolgs dieses Themas waren bald alle Varietés $\mathrm{Bu}$ dapests und Wiens an Antal Oroszis Stück interessiert und adaptierten es in verschiedene Sprachen. ${ }^{3}$ Rechte für dessen Verwendung machten sich die Singspielhalleninhaber*innen mit dem Autor unter der Hand aus, ein für den Umgang mit Urheberrechten im Bereich der populären Kultur innerhalb der Monarchie durchaus üblicher Vorgang. Allerdings hatte in diesem Fall die Wiener Polizei etwas gegen die Übernahme:

Die ,Klabrias-Partie, die in jüngster Zeit so populär gewordene burleske Posse, war in Wien Gegenstand eines literarischen Eigenthums-Prozesses. Der Verfasser ist bekanntlich Herr Orossi. Als nun eine Gesellschaft mit Budapester Kräften, geführt von Herrn Freiwirth unter der Direktion des Singspielhallen Inhabers Lautzky, nach Wien kam, nahm sie das Werk Orossi's ,Die Klabrias-Partie, nach Wien zur Aufführung mit und sicherte dem Verfasser einen materiellen Gewinn zu. Die Wiener Polizeibehörde verbot jedoch wegen der vielen enthaltenen Pikanterien das Stück und Freiwirth lies die ,Klabiras-Partie‘ für Wiener Verhältnisse umarbeiten.[!] ${ }^{4}$

Mit dieser Umarbeitung „für Wiener Verhältnisse“ war dann allerdings der Autor Oroszi nicht einverstanden, denn die Adaption entsprach nicht seinem Sinn von gutem Amüsement. „Der Bearbeiter machte es sich jedoch, so behauptet Orossi, recht bequem, indem er einfach die Pikanterien wegstrich und die kernigen Spässe, wie die drollige Situation beibehielt “ 5

Das Stück erlangte deshalb eine derartige Popularität, weil eine solche Kartenpartie in jedem Hotel oder Gasthaus hätte stattfinden können - in jedem guten Lokal, wie Roth schrieb, waren Kartentische und -spieler zu finden -,

3 Einige Beispiele für in Wien aufgeführte Adaptierungen des Stückes waren Josef Philippi, Die Klabrias Parthie im Atschanit Dorf. NÖLA, NÖ Reg. Präs. Theater TB - Textbücher der Theaterzensur 050/08 (aufgeführt 1896 in der Singspielhalle von Karl Steidler); Josef Armin, Im Banne der Karten - Der Klabrias-Spieler. NÖLA, NÖ Reg. Präs. Theater TB Textbücher der Theaterzensur 117/10 (aufgeführt bei der Budapester Orpheumgesellschaft 1901); sowie Adolf Bergmann, Die Klabriaspartie: Eine Kaffeehaus-Szene. NÖLA, NÖ Reg. Präs. Theater TB - Textbücher der Theaterzensur 155/05 (aufgeführt im Max und Moritz 1920). Siehe Abbildung 10 Titel- und Rückseite eines Programmes der Folies Caprice mit u. a. der Klabriaspartie auf Deutsch und Ungarisch um 1900, Sammlung für Theatergeschichte der ungarischen Nationalbibliothek Széchényi - .

4 „Die Klabrias-Partie - ein literarisches Streitobjekt“, IAR, 8.12.1891, 27.

5 Ebda. 
und weil ein Großteil des Publikums selbst schon Teil einer solchen Kartenpartie gewesen war. Es blieb nicht nur bei der Inszenierung des Stückes als Die Klabriaspartie, sondern es kam auch zu einer Vielzahl von Adaptionen an verschiedene, zeitrelevante Diskurse wie etwa denjenigen der Migration. So ging auch Die Klabriaspartie auf Reisen und wurde unter dem Aufhänger „Das Leben ist nur ein Kartenspiel“ etwa 1894 als Die Klabriaspartie von Chicago im Etablissement Imperial in Budapest aufgeführt. ${ }^{6}$

Reiseerfahrungen, wie sie das Stück Die Klabriaspartie thematisierte, brachte einer der bekannten jiddischen Literaten auf den Punkt. „Du lieber Gott, was man unterwegs alles erlebt", begann Scholem Alejchem eine Aufsatzsammlung. Er selbst sei „ein Reisender"7 schreibt Alejchem und charakterisiert die Besonderheit zeitlicher und räumlicher Erfahrung des Reisens wie folgt: „Da ich soviel unterwegs bin, geschieht es mir sehr oft, daß ich ganze Tage herumsitze und keinen Finger rühre. Es gibt einfach nichts zu tun. " 8 Unterwegs gebe es zwar viel zu erleben, das Reisen selbst aber rufe eine irritierte Wahrnehmung von Zeit, Raum und der eigenen Person hervor. Die Entdeckung der Besonderheiten des Unterwegsseins sowie der von üblichen Gewohnheiten abweichenden Wahrnehmung der räumlichen und zeitlichen Umgebung teilte nicht nur Scholem Alejchem, sondern auch viele andere Künstler*innen mit ihren Zeitgenoss ${ }^{\star}$ innen. Unabhängig davon, welchen Mobilitätsmustern sie folgten oder aus welchen Gründen sie unterwegs waren: Die Bezeichnung, die Scholem Alejchem dafür fand, ist eine treffende. Sie alle waren „Handlungsreisende ${ }^{\text {“9 }}$ Diese verschiedensten Erfahrungen bei Handlungsreisen fanden sich reflektiert in der Populärkultur der Zeit und wurden bei Adaptionen wie jener der Klabriaspartie in den Etablissements miteinander geteilt.

Von derartigen Stück- und Liedadaptionen und wie Mobilität diese beeinflusste, handelt dieses Kapitel. Der Frage, wie die Autor ${ }^{*}$ innen das Reisen in populäre Stücke und Lieder einflochten, so wie das in den verschiedenen Fassungen der Klabriaspartie geschah, geht das Kapitel mithilfe von weiteren Beispielen nach. Aspekte der Transnationalität und des interkulturellen Transfers werden anhand dreier Motive, die in Couplets, Liedern und anderen populären Stücken besonders rekurrent waren, herausgearbeitet: Reisen, Beziehungen und Intimes. Selbstredend ist, dass diese Motive natürlich auch ineinanderflossen. ${ }^{10}$ Die Zeitgenoss ${ }^{\star}$ innen erkannten sie als geeignet, um verschiedene

6 D. K., „Etablissement Imperial“, IAR, 20.1.1894, 5.

7 Scholem Alejchem, Eisenbahngeschichten, 7.

8 Ebda.

9 Scholem Alejchem, Eisenbahngeschichten, 8.

10 Diese drei Motive wählte die Autorin aus der systematischen Sichtung des breiten Korpus unterschiedlicher Manuskripte (Textbücher), die um die Jahrhundertwende von den im dritten 
jüdisch-nichtjüdische Beziehungen und kulturelle Verflechtungen zu diskutieren. Wie interpretierte die populäre Kultur ihre eigene und die Mobilität ihres Publikums? Welche Funktionen erfüllten das Reisen, das Intime und Beziehungen in populären Stücken und wie veränderten Künstler*innen diese Motive, um sie in Budapest, New York und Wien auf die Bühne zu bringen? In der Beantwortung dieser Fragen werden zunächst die Motive anhand ausgewählter Stücke vorgestellt und dann hinsichtlich der Repräsentation von „Ähnlichkeit“ und/oder „Differenz“ analysiert.

\subsection{Singen, Spielen und Erzählen darüber, „was man unterwegs alles erlebt“"}

Die Klabriaspartie wurde zu einem Paradebeispiel von einem Stück, das die neue Mobilität immer wieder aufgriff. Wie es dem Stück gelang, das Publikum zu begeistern, zeigte die Rezeption der zuvor erwähnten Inszenierung als Klabriaspartie von Chicago in Budapest. ${ }^{11}$ Hermann Rosenzweig (1886-1941) schrieb diese neue Fassung von Oroszis Klassiker. Ihren Premierenabend feierte sie am 11. Jänner 1894 im Etablissement Imperial. „Die seit Langem erwartete Rückkehr der Klabrias-Kompagnie von Chicago ist am 11. d. M. [Jänner] im Beisein eines sehr zahlreichen Publikums vor sich gegangen und sie wusste auch jetzt dieselbe Theilnahme für sich zu erwecken, als gelegentlich der lustigen Hinreise. "[!] ${ }^{12}$ Nachdem schon im Jahr davor ein Reisemotiv in das pikante Stück über eine Kartenpartie eingeflochten worden war - einer der Kartenspieler ging auf Reisen verloren -, verschlug die neuerliche Adaption die restliche Runde auf eine einsame Insel.

Die jetzige Handlung spielt auf einer entlegenen Insel des Oceans, wohin die schiffbrüchige Reisegesellschaft vom Schicksal verschlagen wurde, welches Malheur aber das Wiedersehen der drei Klabriasspieler herbeiführte, die sich auch nicht lange besinnend zu einer gemüthlichen Partie zusammensetzten, noch dazu auf blosser Erde.[! $]^{13}$

Kapitel vorgestellten Spielstätten und Akteur*innen bei der Zensurbehörde oder der Hebrew Actor's Union eingereicht wurden oder in einem Nachlass erhalten blieben und in Berichterstattungen, Zeitungen und Textbüchern dieser Akteur ${ }^{\star}$ innen und Spielstätten besonders häufig vorkamen.

11 D. K., „Etablissement Imperial“, IAR, 20.1.1894, 5.

12 Ebda.

13 Ebda. 
Aus der Kritik, die detailgenau die Aufmachung der Szene schilderte und darüber berichtete, was für Lacher sorgte, geht hervor, was die Inszenierung zum Erfolg machte:

Wir sehen u. a. auch eine Amazonentruppe aufmarschiren und exerziren, die sich aus durchwegs schönen Damen in schmucken Panzerkostümen bestehend, sehr hübsch ausnimmt und die Armee des Herzogs von Quaquaqua bildet. Gespielt wurde brillant. Dieses Mal ist Herr Eisenbach der Hauptheld des ganzen Stückes, er bot als Mandolássi de Pattanyos (alias Dolfi Krachmandel) in Indianerkleidung mit seinem gestotterten Ungarisch-Deutsch eine recht drollige Figur. Herr Grossmann (Lippi Saftgrün), Herr Kohler (Maxi Grünzweig), Herr Baumann (Isidor Propeller), Herr Schneider (Menasche Regenwurm) und Herr Proksch als Enkel von Columbus waren gestalten von unwiderstehlicher Komik und lieferten im Spiel gleich Gutes. So manches paprizirte Witzwort, manch scharfes Wortspiel wird wiederum von hier aus seinen Flug durch die Stadt nehmen und das Lob des ungenannten und doch bekannten Verfassers der jüngsten Klabriaspartie verkünden, zu deren Text sich noch eine flotte Musik gesellt.[! $]^{14}$

In seiner Adaption des Kartenspiels auf einer einsamen Insel benannte der Budapester jüdische Autor Hermann Rosenzweig die fünf Hauptcharaktere der früheren Versionen der Klabriaspartie, nämlich Dolfi Krachmandel, Lippi Saftgrün, Maxi Grünzweig, Isidor Propeller, Menasche Regenwurm, um. Sie wurden zu dem lange vor den vier anderen schiffbrüchig gewordenen Mandolássi de Pattanyos und Herrn Grossmann, Herrn Kohler, Herrn Baumann und Herrn Schneider. Der als böhmisch entworfene Charakter Herr Proksch behielt seinen ursprünglichen Namen. Erhalten blieb die bekannte Szene des Kartenspiels, um die Rosenzweig sodann neue Witze und Couplets um das Motiv von Mobilität erschuf.

Ein anderer Prototyp des Reisenden, eines vermeintlich jüdischen Vagabunden, entwickelte Louis Taufstein in der Figur des „Commis Voyageur“. Taufstein ließ diesen etwa in einer Soloszene, die er 1901 erstmals inszenierte, auftreten. Mit der Begrüßung „hab die Ehr' mich vorzustellen / bin ein commis vojageur [...]“ tritt der Protagonist, ein Handelsreisender, in dem Stück mit dem Titel Der Reisende vor das Publikum. In den ersten Sätzen des Entréeliedes beschreibt sich dann der „Commis Vojageur“: „[...] von der allerfeinsten Gattung, / bin geschickt und tüchtig sehr, / bin gereist für feine Firmen / für so manches feines Haus / bin versirt in allen Branchen / kenn mich überall gut aus".[!] ${ }^{15}$ So macht das Stück die Alltäglichkeit der Mobilität um 1900 zum Gegenstand; eine Mobilität, die Alltag jüdischen und nichtjüdischen Lebens geworden war.

14 Ebda.

15 Taufstein Louis, Der Reisende. NÖLA, NÖ Reg. Präs. Theater TB - Textbücher der Theaterzensur $117 / 4$. 
Das Motiv „jüdischen Reisens“ besitzt eine lange reale und fiktive Tradition. Es wurde vielfach in der Literatur aufgegriffen und hat sich einmal mehr im Kontext der Massenmigration in einen Topos verwandelt. ${ }^{16}$ So viele unterschiedliche Gründe (Umher-)Reisen haben konnte, so vielschichtig (und nicht ausschließlich positiv) waren die Bilder über Reisende, Umherfahrende und Migrierende. ${ }^{17}$ Wie der "Commis Vojageur“ in dem Taufsteinschen Stück reisten Volkssänger*innen und Ensembles um 1900 zwischen Städten. Auch sie waren "gemeine Reisende" und die Praxis des Reisens beeinflusste ihre Aufführungen und das Aufgeführte. Es ist daher nicht weiter erstaunlich, dass sie das Phänomen „Reisen“ oft in Stücken oder Liedern aufgriffen. Dabei wurde „Reisen“ mannigfaltig aufgefasst.

Im gegenwärtigen Denken ist „Reisen“ häufig mit einem Ortswechsel, üblicherweise zu Erholungszwecken, verbunden. Reisen ist aber auch Praxis in Migrationsprozessen. ${ }^{18}$ Es kann auch, wie im Fall des Reisenden im erwähnten Stück und im Alltag vieler Künstler ${ }^{\star}$ innen um 1900, der Profession geschuldet, also beruflich bedingt, sein. ${ }^{19}$ In den Stücken konnte der dynamische Charakter des Unterwegsseins ebenso zum Katalysator geistiger Beweglichkeit des Publikums werden. Gemeinsam war den Stücken und Liedern, dass sie, unterschiedlich interpretiert und inszeniert, auf das Reisen rekurrierten. Ob als tatsächlicher Wechsel von physischen Orten oder im Singen und Nachdenken darüber - Reisen eröffnete einen hochreflexiven Raum. Es ist gewissermaßen das bewusste Erleben eines Schwellenzustandes. Die postcolonial studies beschreiben Aushandlungen derartiger Schwellenzustände als ein Auseinandersetzen mit einem „Dazwischen“. ${ }^{20}$ Diesem „Dazwischen“ wird besondere Bedeutung für die Konstitution von Kulturen zugeschrieben. Der Kulturwissenschafter Homi Bhabha, in der Antwort darauf, wo Kulturen entstehen und ausgehandelt werden, verortet dies in den Zwischenräumen: „[...] in-between

16 Es sei nur kurz auf die bekannten jiddischen Erzählungen Scholem Alejchems, Jizchok Leib Perez' oder etwa Joseph Roths Juden auf Wanderschaft verwiesen. Zu den unterschiedlichen Sujets ,jüdischer Reisen“ siehe im Allgemeinen DeKoven Ezrahi, Booking Passage; sowie darin By Train, by Ship, by Subway, 103-130.

17 Korbel, Reisen in Wiener Volkssängerstücken: Ähnlichkeit als Analysekategorie jüdischnichtjüdischer Beziehungen, in: Norbert Honsza, Przemysław Sznurkowski (Hg.), Identitätsdiskurs im deutsch-jüdischen Dialog (Frankfurt am Main, Bern, Bruxelles u. a.: Peter Lang, 2017), 189-204.

18 Schlör, „Solange wir auf dem Schiff waren, hatten wir ein Zuhause“, 226-246.

19 James Clifford betonte die Bedeutung des Hinterfragens unterschiedlicher, wie er es nennt, „Kulturen des Reisens“. James Clifford, Traveling Cultures, in: Lawrence Grossberg, Cary Nelson, Paula A. Treichler (Hg.), Cultural Studies (London, New York: Routledge, 2009), 96-112.

20 Peter Burke, Cultural Hybridity (Cambridge: Cambridge University Press, 2014). 
spaces provide the terrain für elaborating strategies of selfhood - singular or communal $[\ldots . . .]^{“ 21}$

Die urbanen Räume der Populärkultur ermöglichten die Konstitution solcher Zwischenräume. In den Auseinandersetzungen mit diesem „Dazwischen“ über das Spielen mit Situationen des Reisens und ihrem metaphorischen Gebrauch in den Aufführungen wurden nicht nur geographische Verhältnisse von Ferne und Nähe ausgelotet, sondern es wurde auch ein Interaktionsraum für jüdischnichtjüdische Beziehungen eröffnet. ${ }^{22}$ Die Aufführungen - Theater spielen - bot den Rahmen, Wirklichkeiten zu erzeugen und Deutungsoptionen vorzuführen. Vor dem Hintergrund des Reisens konnten die Künstler*innen verschiedene ,jüdische ${ }^{c}$ Identifikationen artikulieren, repräsentieren und aushandeln. ${ }^{23}$

\section{Die Folie des Reisens}

Wovon handeln die Stücke, die sich mit Reisen auseinandersetzten? Welche Rückschlüsse über Mobilität im ausgehenden 19. und frühen 20. Jahrhundert und welches Bild darüber können aus populären Stücken gewonnen werden? Beginnen wir die Betrachtung mit fünf Stücken, die zwischen 1897 und 1903 uraufgeführt wurden. Während das Stück Der Reisende über die alltägliche Berufserfahrung eines in vielen Bereichen tätigen Händlers Aufschluss gab, informierte das Stück Der Reisekoffer (Couplet) ${ }^{24}$ über die Handlungsempfehlungen - Annehmliches und Unanständiges - für die reisende Frau. Die Reise nach Paris (Quodlibet) ${ }^{25}$ erzählte von der Faszination der Moderne, dargestellt durch den Besuch eines Wiener Ehepaars auf der Pariser Weltausstellung. Den kolonialen Entdeckergeist und die damit verbundene Einfalt der Gesellschaft spitzte der Volkssänger Eisenbach in dem Stück Der Afrikareisende (Soloszene) ${ }^{26} \mathrm{zu}$. Gleichzeitig diente hier das Verhandeln von Kolonialismus auch der Diskussion jüdisch-nichtjüdischer Beziehungen. Ein Wiener Quartett in Amerika (Posse

21 Bhabha, The Location of Culture, 2.

$22 \mathrm{Zu}$ Spielstätten populärer Kultur als jüdisch-nichtjüdische Interaktionsräume siehe Hödl Klaus, „Jiddisches Theater als jüdisch-nichtjüdisches Interaktionsfeld: Einführung in das Themenheft", Transversal 8, no. 2 (2007): 3-15.

23 Physische Ortswechsel gehen mit individuellen und kollektiven Dislokationen und Lokationen einher. Das Aushandeln dieser geschieht immer in wechselseitigen Prozessen zwischen dem vermeintlich ,Eigenen' und dem vermeintlich ,Anderen'

24 Risa Basté, Liedertexte. NÖLA, NÖ Reg. Präs. Theater TB - Textbücher der Theaterzensur $117 / 24$.

25 Louis Taufstein, Die Reise nach Paris. NÖLA, NÖ Reg. Präs. Theater TB - Textbücher der Theaterzensur 116/23.

26 Heinrich Eisenbach, Der Afrikareisende. NÖLA, NÖ Reg. Präs. Theater TB - Textbücher der Theaterzensur 116/3. 
mit Gesang in fünf Bildern ${ }^{27}$ brachte die Schwierigkeiten der Emigration eines Ensembles, in dem Jüdinnen und Juden und Nichtjüdinnen und Nichtjuden gemeinsam auftraten, in die Vereinigten Staaten auf die Bühne. ${ }^{28}$

Das Stück Der Reisende (Soloszene) ${ }^{29}$ reichte Louis Taufstein mit einem Dringlichkeitsvermerk versehen - es sollte so bald wie möglich zur Aufführung kommen - für die Singspielhalle M. B. Lautzky, also die Budapester Orpheumgesellschaft in Wien, am 25. April 1901 bei der k. u. k. Behörde für Theaterzensur ein. ${ }^{30}$ Diese kam seinem Wunsch nach. Bereits am darauffolgenden Tag erhielt Heinrich Eisenbach, der das Stück vortragen sollte, eine eingeschränkte Erlaubnis. ${ }^{31}$ Im Stück stellt sich der jüdische Volkssänger Heinrich Eisenbach dem Publikum als ein reisender Alleskönner vor. Im Entréelied präsentiert dieser - der "Commis Voyageur" - seine Fertigkeiten und erweckt so den Eindruck, er wolle dem Publikum etwas von einem weit umhergereisten Gelehrten erzählen. „Commis Voyageur", was entweder „gemeiner Reisender" oder „Geschäftsreisender" meinen konnte, zu sein, bedeutet in dem Stück aber nicht nur Weltkenntnisse privater, sondern vor allem beruflicher Natur zu haben:

Gold und Silber und Juwelen / Kleiderstoffe, feinste Warn' / Hosenträger, Merschaumspitzen/ Hab' vertreten Schuh' sogar, / Krägen, Hemden und Konsorten, / Hab ich auf den Markt gebracht / Porzellan und Nähmaschinen / Hab' in Leinwand auch gemacht. / Möbel, Spiegel, Busenschützen/ Zwirrn und Nadln, Blechgeschirr / Regenschirm und Champagner / kauft am besten man bei mir![!] ${ }^{32}$

Sogleich offenbart der Reisende auch die Qualitäten eines professionellen umherfahrenden Händlers: ${ }^{33}$

Wer a guter Reisender sein will, der muss vor allem verstehen, die Leut a Loch im Bauch reinzureden, freilich muss a Reisender auch wissen, was er redt. Wann am z.b. die Kund-

27 Jantsch Heinrich, Ein Wiener Quartett in Amerika. NÖLA, NÖ Reg. Präs. Theater TB Textbücher der Theaterzensur 469/7.

28 Zur „Weltbühne Wien“ siehe Brigitte Dalinger, Interkulturalität: Kulturtransfer und Theaterwissenschaften, in: Ewald Mengel, Ludwig Schnauder, Rudolf Weis (Hg.), Weltbühne Wien (Approaches to Cultural Transfer 1) (Trier:WVT, 2010), 105-116.

29 Taufstein Louis, Der Reisende. NÖLA, NÖ Reg. Präs. Theater TB - Textbücher der Theaterzensur $117 / 4$.

30 Ebda.

31 Vermerk der k.k. Polizei-Direktion Pr. 13, 26.4.1901, unterzeichnet von S. Klose NÖLA, NÖ Reg. Präs. Theater ZA - Zensurakten, Z. 24/2P.13.

32 Louis Taufstein, Der Reisende. NÖLA, NÖ Reg. Präs. Theater TB - Textbücher der Theaterzensur 117/4. Sehr oft finden sich Schreibfehler: Mit Busenschützen waren vermutlich Busenstützen gemeint.

33 Händler meinte gewissermaßen einen mobilen Vertreter oder Verkäufer, der durchaus auch (aber nicht zwangsläufig) auf ein einzelnes Produkt spezialisiert sein konnte. 
schaft a Grabstein bestellt, so darf der Reisende nicht sagen: Es soll mich freuen, recht bald wieder mit Ihren geschätzten Auftrag beehrt zu werden, sonst kann es ihm passieren, daß er statt a Auftrag a paar gute fraß /: Ohrfeigen :/ bekommt.[! $]^{34}$

Die Soloszene, die aus Entréelied (mit Endreimen) und Prosa besteht, erzählt dann vielmehr über die - sexuellen - Missgeschicke im beruflichen Alltag des „Commis Voyageurs“: Sigi Mauldrescher, so sein Name, beginnt seine Ausbildung als „Praktikant“ mit fünf Gulden Monatslohn. Diese Arbeit, lässt er das Publikum wissen, hat er aufgrund seiner „Platzkenntnisse“, also wegen seines Wissens um die örtlichen Gegebenheiten, bekommen. Anders als sein „böhmischer Chef“, ist er bereits in seiner Praktikantenzeit der einzige, der arbeitet. Während der Chef ständig isst, was Sigi ihm zuvor besorgen muss, schrubbt dieser Fußböden. Statt Dank und Anerkennung habe er anstelle einer Verköstigung nur die plumpe Aussage zu hören bekommen, er solle doch den „Gummi von den Briefmarken lutschen“.

Dem angespannten Verhältnis zu seinem Arbeitgeber steht jenes zu seiner Chefin gegenüber, mit der er überaus gut auskommt. Sie bewundert die „Leistungsfähigkeit und jugendliche Kraft" des Protagonisten: Für seine Fähigkeiten beim „Nummerieren“ lobe sie ihn besonders. Gerade dieses Talent wird jedoch zum Problem, als der Chef beim "gemeinsamen Nummerieren“ mit der Chefin dazukommt und ihn kurzerhand entlässt. Der Protagonist sieht das aber positiv - denn schließlich gelangt er dadurch zu einer wichtigen Erkenntnis für sein Mobilsein und seine zukünftige Karriere: „Ferner muß a Reisender, wann er wohinkommt, vor allem mit'n Hausknecht Freundschaft schließen. Kommt es dann zum Hinauswerfen, so kann man auf a sanfte Behandlung rechnen."[! $]^{35}$

Nicht darum verlegen, sich in der Welt umzusehen, hat der „Commis Voyageur" Glück und findet seine nächste Anstellung in einer Wäschereifabrik als Aufseher von fünfzig „Mädln“. Für ihn sei das eine Kleinigkeit - zumindest so lange, bis er auch jetzt wieder mit einer „Probirmamsell[!]“ intensiver zusammenzuarbeiten beginnt. Bald muss es dasselbe Ende wie zuvor nehmen, denn „[k]ann sich dann a Mensch zamreißen? Richtig bin ich hinaus geworfen worden. “[! $]^{36}$ Es folgt eine Anstellung als Vertreter für eine Weingroßhandlung, die für ihren schlechten Wein bekannt ist. Sigis verkäuferischem Talent ist dies nicht abträglich. Er verkauft einer Kundschaft den Wein als Präsent für deren Schwiegermutter. Als sich der Kunde jedoch nach kurzer Zeit meldet und ihn in tiefer Dankbarkeit wissen lässt, dass er ihm bei der Beseitigung

34 Louis Taufstein, Der Reisende. NÖLA, NÖ Reg. Präs. Theater TB - Textbücher der Theaterzensur 117/4.

35 Ebda.

36 Ebda. 
der Schwiegermutter behilflich gewesen sei, kann er der Tätigkeit aus moralischen Gründen nicht länger nachgehen. Sigi Mauldrescher hat schlussendlich Glück und kommt zu einer beliebteren Firma, in der er sein Geschick und seine Tüchtigkeit entfalten kann. Ob das dann auch das Ende seiner Reise ist, bleibt allerdings offen.

Das Stück Der Reisende interpretiert Reisen als Erwerb von Fertigkeiten und Lebensweisheiten. Für den „gemeinen Reisenden“ meint das eine Reise durchs Leben. Am Beginn steht ein Bruch zwischen Vorstellungen über weltbürgerliches Reisen und Reisen im beruflichen Alltag. Mobil wird der Protagonist zuerst immer dann, wenn er eine Anstellung verliert. Später wird Reisen Teil seines Berufes. „Beruflich Reisender“ ist dabei jedoch eine beschönigende Bezeichnung für jemanden, der allgemeinhin eher als Umherfahrender (Händler) bezeichnet wurde. Der Beruf der Umherfahrenden bzw. das Bild davon war vor allem mit den östlichen Gebieten der Monarchie (Galizien, Bukowina) assoziiert ${ }^{37}$ und nicht zuletzt mit Kriminalität und Betrügerei in Verbindung gesehen. ${ }^{38}$ Im Stück wird diese Verbindung zwischen Mobilität und Kriminalität über die „fehlende Bodenständigkeit“ der Umherfahrenden, die es nicht vermochten, sich irgendwo zu „verwurzeln“, hergestellt. In diesem Sinne steht die Konstitution des Bildes des „Commis Voyageurs" in Verbindung zu der um die Jahrhundertwende florierenden Metapher, Jüdinnen und Juden seien sogenannte „Luftmenschen“. Ursprünglich von der jiddischen Literatur geprägt, war die Formel um die Jahrhundertwende in innerjüdischen Diskursen zunehmend zur sozialökonomischen Kritik an der gesellschaftlichen Situation geworden. Umgekehrt sahen Antisemit*innen in der Metapher eine Bestätigung ihrer Vorstellungen über die vermeintliche jüdische Abstraktheit und ,fehlende Bodenständigkeit. ${ }^{39}$ Diese evoziert das Stück zudem über das Beschreiben der Tätigkeiten Sigi Mauldreschers als nicht eindeutig benennbare ,jüdische Berufe“40

37 Die ökonomischen Auswirkungen der Erschließung Galiziens mit der Eisenbahn wurden bereits in der Einleitung dargestellt.

38 Christoph Daxelmüller, „Das Mauscheln“, in: Julius H. Schoeps, Joachim Schlör (Hg.), Antisemitismus: Vorurteile und Mythen (München, Zürich: Piper, 1996), 143-152, 147.

39 Die Entwicklung der Metapher von Jüdinnen und Juden als „Luftmenschen“ beschrieb Nicolas Berg. Nach der soziologisch und ökonomisch kritischen Verwendung um die Jahrhundertwende drückte bald der Zionismus seine Ablehnung gegenüber der sogenannten Assimilation mittels dieser Metapher aus. Nicolas Berg, Luftmenschen, in: Dan Diner (Hg.), Enzyklopädie jüdischer Geschichte und Kultur 3 (Stuttgart, Weimar: Metzler, 2012), 571-572. Nicolas Berg, Luftmenschen: Zur Geschichte einer Metapher (toldot Essays zur jüdischen Geschichte und Kultur 3) (Göttingen, Bristol: Vandenhoeck \& Ruprecht, 2014), 9-19.

40 "Jüdische Berufe" entwickelte sich wie Reisen zu einem gängigen Topos in der Literatur im Kontext der jüdischen Massenmigration. Zum Beispiel Scholem Alejchem, Eisenbahngeschichten, 17-19. 


\section{Stereotype, Vorurteile und Kolonialismus}

Verweisend auf das Stereotyp über vermeintliche Luftmenschen konzipierte der Autor Louis Taufstein einen bewussten Gegensatz zwischen den von dem Protagonisten beschriebenen, vermeintlich typisch jüdischen, Tätigkeitsfeldern und der Benennung des Protagonisten: Im Stück stellt der Protagonist zuerst seine Tätigkeiten vor. Erst dann bittet er um die Erlaubnis auch sich vorstellen zu dürfen, „Haben die Ehre, guten Abend meine Hochachtung, bin so frei mich ganz Ergebenst vorzustellen, mein Name ist Sigi Mauldrescher "[!] ${ }^{41}$ Den antisemitischen Vorstellungen über vermeintlich jüdische Namen entgegnend wählt der Autor Taufstein den vermeintlich typisch nichtjüdischen Namen Sigi Mauldrescher. Damit konterkariert er den mit dem Anspielen auf jüdische Berufe evozierten Diskurs über ,Jüdisch-Seinc. Die Namensgebung des Protagonisten impliziert aber auch einen subversiven zweiten Bruch mit Klischees. Die Namenswahl Siegfried (Kurzform Sigi) galt als besonders „übertriebene Konvertitenmoral“ und „Ausdruck der nie erreichbaren Assimilation“. ${ }^{42}$ Zudem beinhaltet die Wortkombination des Nachnamens Mauldrescher eine Referenz auf das antisemitische Stereotyp des vermeintlich jüdischen Mauschelns.

Taufstein inszeniert somit zuerst einen Bruch mit dem stereotypisierten umherfahrenden jüdischen Händler. Durch die Benennung ergibt sich eine Distanz zum vermeintlichen ,Jüdisch-Sein' Gleichzeitig erfolgt mit der Distanzierung erst recht wieder eine Assoziation mit einem anderen antisemitischen Stereotyp, dem der „,assimilierten“ Jüdinnen und Juden - der „übertriebenen Konvertiten“. Taufstein stellte nicht nur das vermeintlich ,Jüdische“ des Klischees über Umherfahrende in Frage, sondern ebenso ein vermeintlich über Namen erkennbares ,Nicht-Jüdisch-Sein. Das Stück führt damit die Absurdität der Assimilationsdebatte vor, indem es deren Widersprüchlichkeit dem Publikum in der Charakterisierung Sigi Mauldreschers Schritt für Schritt vor Augen führt.

Eine Mehrfachbesetzung von sich überlagernden Klischees findet auch in der Verknüpfung von beruflichem Alltag und Sexualität statt. Ebenso kommt es in der plötzlichen, auf ein glückliches Ende hinauslaufenden Wendung auf den ersten Blick zu einem Handlungsbruch. Den einzigen Zugewinn an Fähigkeiten stellt die gewonnene Lebenserfahrung dar. Dieser Lebenserfahrung, erworben auf der Reise durchs Leben, kann der bislang auf ungeschickte Weise in missliche Lagen gekommene unfreiwillige Reisende es schließlich verdanken, dass er sich in einen erfolgreichen Reisenden verwandelt. Eine Wende, die nötig ist, um einen Bogen zum Entréelied spannen zu können und die als Legitimation dafür

41 Louis Taufstein, Der Reisende. NÖLA, NÖ Reg. Präs. Theater TB - Textbücher der Theaterzensur 117/4.

42 Bering, Der „jüdische“ Name, 159-161. 
dient, dass der Vortragende überhaupt über die Qualitäten eines Reisenden berichten darf: Denn wer möchte von einem erfolglosen Reisenden über die Herausforderungen des Metiers erfahren?

Einen erfolgreichen „Bildungsreisenden“ macht das Stück Der Afrikareisende zum Thema. Auch in dieser Soloszene, die wieder für Heinrich Eisenbach geschrieben und am 13. Februar 1899 bei der Zensurbehörde eingereicht wurde, scheint es, ähnlich wie im Stück Der Reisende, auf den ersten Blick um berufliches Reisen zu gehen. Begrüßt wird das Publikum mit den Worten: „Grüß Gott, mei liebe Heimatstadt / Jetzt bin ich wieder da / Ich komm jetzt mit der Eisenbahn / direkt aus Afrika. / Die Leut bleiben auf der Gassen steh'n / Und schaun's mich alle an, / das is der Wenzl Jerabek / der weltberühmte Mann!“43

In Der Afrikareisende erzählt die fiktive Figur Wenzl Jerabek, deren Benennung auf ein weitverbreitetes Stereotyp über tschechische Namen verwies, ${ }^{44}$ von dem beruflichen Werdegang, der beim Schustermeister Pospischall im zehnten Wiener Gemeindebezirk begann. Mehr, als dass sich der Protagonist, seit er diese Praktikantenstelle verlassen hat, mit „Afrikanisten“ beschäftigt, erfährt das Publikum aber auch in diesem Stück nicht über die Profession, sondern wird im Schwank über Vorurteile und deren vermeintliche Realität aufgeklärt. So eröffnet der Protagonist die Szene mit der Feststellung, nur weil er sich mit „Afrikanisten“ beschäftige, müsse sich niemand vor ihm fürchten, denn er sei ja ein „behm“ - also ein Böhme: „Sie brauchens schon nit von mir zu fürchten, warum ich a bißl wild ausschau I thu Ihnen nix i bin ja a behm! Wenzl Jerabek heiß ich und beschäftig mich mit Afrikanisten!"[! $]^{45}$

Im weiteren Verlauf des Stückes verliert er kein Wort über seine Arbeit, sondern erzählt Buntestes; etwa über das Essen, das er (nicht) bekommt: Von „Schweinsbeuschel, Roßbratel bis Stiefelsohlen“[!] standen sämtliche „Köstlichkeiten" der Wiener Küche auf dem Speiseplan. Das Bild der böhmischen Frauen, die als Kindermädchen in Wien arbeiteten, ${ }^{46}$ konterkarierend, beschwert er sich, dass er bei seinem ersten Meister für das Aufziehen der Kinder verantwortlich sei und damit der einzige, der arbeite: „Alle zwa Stunden hab i dem Pomperlatsch Milch geben müssen, aber nur aus'n Flaschl, anders war mir selbstständli nit mögli!"[!! ${ }^{47}$ Eines Tages gibt er dem Kleinkind versehentlich

43 Heinrich Eisenbach, Der Afrikareisende. NÖLA, NÖ Reg. Präs. Theater TB - Textbücher der Theaterzensur 116/3.

44 Wenzel/Vaclav war ein weit verbreiteter tschechischer Name. Der Landesheilige ist der Heilige Vaclav.

45 Heinrich Eisenbach, Der Afrikareisende. NÖLA, Theaterzensur Textbücher 1899-1901, Kt. $116 / 3$

46 John, Lichtblau, Schmelztiegel, 27.

47 Heinrich Eisenbach, Der Afrikareisende. NÖLA, NÖ Reg. Präs. Theater TB - Textbücher der Theaterzensur 116/3. 
anstelle der Milch- die Spiritusflasche zu trinken. Der Meister echauffiert sich über dieses „Missgeschick“ und Wenzl ist gezwungen, sich eine neue Arbeit zu suchen. Das gestaltet sich schwieriger als gedacht. Über die schrecklichen Dinge, die er ertragen muss, informiert er das Publikum über eine „Behandlung mit dem spanischen Röhrl“ und „[s]o was lasst sie aber a bem nit gfallen, und deswegen hab i mir denkt, packst deine sieben Zwetschken zsamm, und wirst a Afrikareisender". 48

Deshalb setzt er seine Migration fort und begibt sich auf eine - fiktive - Reise nach Afrika. Bei der ungefähren Verortung des fernen Kontinents greift er auf für das Publikum bekannte Distanzen zurück. Der Weg nach Afrika sei ihm zufolge „vielleicht no amal so weit wie bis auf Gaslau“. Kaum im vermeintlichen Afrika angelangt, kehrt sich die Perspektive auf das Essen um und er wird selbst zur potentiellen Nahrung: Ein „böhmischer Löwe“ und ein afrikanischer Stamm wollen ihn „fressen“. Wenzel hat aber letztlich Glück, denn er kann die Tochter des Häuptlings durch sexuelle Gefälligkeiten und ein Eheversprechen überzeugen, ihn frei zu lassen. Kaum in Sicherheit und zurück in Europa, bricht Wenzel allerdings das Eheversprechen, weil er sich doch um eine „Bähmin“[!] umsehen wolle.

In dem Stück Der Afrikareisende ist das Motiv des Reisens in vielerlei Hinsicht mit Mobilität verbunden. Zunächst am Beginn mit der der Figur implizierten Migration von Böhmen nach Wien und mit dem Schauplatzwechsel von Wien nach Afrika. Dann dient Mobilität der Horizonterweiterung, die dem Protagonisten später, zurück in Wien, zu Ruhm verhilft und ihn legitimiert, als Erzähler vor ein Publikum zu treten. Vor dem Versetzen der Stereotype an einen vermeintlich weit entfernten Ort, setzt sich die Soloszene, wie schon das erste vorgestellte Stück, mit Überbetonungen und mehrfachen Überschreibungen über die Diskurse der Zeit hinweg. Einerseits laufen die weit verbreiteten Stereotype über „böhmische Kindermädchen“, „faule Böhmen“, die „,ewig mürrischen Wiener" sowie das Leben und die Menschen in Afrika ineinander. Andererseits bricht die mehrfache Überlagerung gemeinsam mit der Selbstpositionierung und -repräsentation diese Stereotype. Im Exotisierungsdiskurs der Zeit stehend, imaginiert der als „ungebildeter Böhme“ stigmatisierte Charakter des Hauptprotagonisten die Menschen in Afrika als „menschenfressend“ und „nackt“. Gleichzeitig schlägt aber auch eine Ambivalenz und Ironie der Soloszene durch. Wenzl Jerabek bezeichnet sich umgekehrt selbst als „Bem“. Er beschäftigt sich als „Afrikanist“ mit dem „ultimativ Fremden“. Er sei wiederum „ungefährlich“, weil er eben „Bem“ sei. Die Ambivalenz und Ironie der Figur kommt also immer wieder durch, stellt das Stück doch in den Raum, vor dem vermeintlich „Fremden“ nicht Angst haben zu müssen. Außerdem versucht es die ganzen

48 Ebda. 
- unvorteilhaften - Eigentümlichkeiten des „Eigenen“ aufzudecken. Die „anderen Böhmen“ stereotypisiert der indirekt selbst als „böhmisch“ entworfene Charakter als arbeitsscheu und den ganzen Tag essend. Wenzel und im ersten Stück Sigi geben sich zwar als das Gegenteil aus, unterminieren das aber mit ihrem Verhalten. Mit der Auseinandersetzung über den Afrikareisenden ist das Stück zudem eine zeitgenössische Referenz auf die ethnologischen Vorträge, die von Personen, die Afrika bereist hatten, in den Städten Europas gehalten wurden. Mit kolonialistischem Blick auf den „fernen Kontinent“ berichteten sie über das „fremde Unzivilisierte“ ${ }^{49}$ Wollten die Künstler*innen also im Darstellen dieser unterschiedlichen problematischen Diskurse das Publikum dazu bringen, sich und die alltäglichen Stereotype zu hinterfragen?

Das Stück operiert entlang eines schmalen Grades einer doppelten Abwertung und gelungenen Subversion. Zunächst scheint es die Gegenposition des Stereotypisierten einzubringen, macht diese aber im gleichen Moment auch lächerlich. Das subversives Potential entpuppt sich aber gerade in dieser vermeintlich doppelten Parodie. Denn es verwendet Stereotype, die vermutlich viele im Publikum ebenso vertraten. Die Stereotype bilden für die Künstlerinnen die Basis für einen gemeinsamen Erfahrungshorizontes mit dem Publikum. Diesen können sie dann subversiv nutzen. Indem sie die Stereotype als nur in anderen erkennbar zeigen, treiben sie die im Gebrauch der Pauschalierung liegende Ignoranz auf die Spitze. In der Popularität der Stücke zeigt sich, dass die Künstler*innen trotzdem zum Publikum, das der eigentliche Adressat der Ironie war, Empathie aufzubauen und es für ihre Anliegen zu gewinnen vermochten.

\section{Gender und gesellschaftliche Normen}

Diese Strategie wandten nicht nur die männlichen Kollegen, sondern auch die Soubretten an. Das Lied Der Reisekoffer reichte die Soubrette Risa Basté als Teil einer ihrer Liedersammlungen 1902 bei der Zensurbehörde ein. In ihm schilderte sie die Perspektive einer jungen Reisenden. Ziel und Ausgangspunkt der Reise der Protagonistin im Stück ist nicht weiter von Bedeutung und kommen nur implizit in der Erwähnung eines Besuchs bei der Tante vor. Im Fokus des kurzen Liedes stehen vielmehr eine junge Frau und das Versprechen an deren Tante. Sie hat versprochen, sie werde auf dem Weg im Frauenabteil reisen, um keinesfalls in Kontakt mit Männern zu treten. Da es allerdings in gemischten Abteilen doch viel unterhaltsamer sei, bricht sie das der Tante gegebene Wort in der Annahme, die Tante werde nie davon erfahren.

49 Wie auch in den anderen Städten wurden in Budapest, New York und Wien immer wieder Vorträge von „Afrikareisenden“ (die teils auch in Theatersälen stattfanden) angekündigt. Siehe zum Beispiel PL, 9.3.1894, 7; NYC, 2.11.1889, 568 oder NWJ, 16.9.1897, 12. 
So verlebt die Reisende eine "gesellige“ Fahrt im gemischten Abteil und kommt in Kontakt mit einem allein reisenden Mann. Das lässt die Reise wie im Flug vergehen. Als sie dann am Ziel einen Blick in ihren Koffer wirft, fällt sie beinahe in Ohnmacht: „Von einer Reise komm ich das sieht man mir doch an / Auch ein Malheur ganz fürchterlich passiert mir auf der Bahn / Ein Herr saß in der Ecke nachts manch Wort ich mit ihm plausch / Da hat im Eifer des Gefechts Gepäck mit mir vertauscht. “50 Anstatt ihrer Toiletteartikel hält sie Herrengarderobe in Händen. So bleibt ihr nur übrig, das Publikum zu fragen „Wer hilft mir blos auf'ne Idee? Wie kommt sowas ins Frauencoupé“.[! $]^{51}$ In dem kurzen, dreistrophigen Lied vermerkte Risa Basté Notizen zur Aufführungspraxis, die uns wissen lassen, dass sie während des Vortrags Herrenkleidungsstücke zeigte. Sie hielt etwa eine Herrenkrawatte, als sie Folgendes sang: „Wenn ich so zur Tante komm und sie das geschaut / Sieht sie gleich für so etwas bin ich doch nicht gebaut / für so was hab' ich doch nicht die mindeste Figur / Ach du lieber Gott, was sag ich ihr dann nur"[!]. ${ }^{52}$

Für die Aufführung der Liedersammlung, Teil derer dieses Lied war, erhielt die Singspielhalle und damit Risa Basté am 3. Juli 1902 einen positiven Bescheid der Zensurbehörde. Die Singspielhallenleitung wurde jedoch dafür verantwortlich gemacht, dafür Sorge tragen zu müssen, dass es zu keinen verfänglichen Szenen beim Vortrag des Liedes käme. ${ }^{53}$

Die kokett singende Risa Basté wollte mit den herumliegenden und herumfliegenden Damen- und Herrenkleidungsstücken auf der Bühne eine Szene entstehen lassen, die jener aus Schlafzimmern in privaten Momenten glich. Gleichzeitig verweist diese Szene auf intime und private Momente von Reisen respektive Migration. Migrant*innen wie Reisende befördern in ihren Koffern wichtige Habseligkeiten und emotionsbesetzte persönliche Gegenstände. Das Abhandenkommen eines Koffers ist viel mehr als lediglich der Verlust von Gegenständen. Insbesondere für Migrant*innen, die sich am Beginn der Migration entscheiden müssen, welche Dinge des bisherigen Lebens sie in die neue Welt mitnehmen wollen und können, bedeutet der Koffer ein Behältnis für eine große Zahl an Identifikationspunkten und geschätzten Besitztümern. In ihm transportieren sie wichtige persönliche Gegenstände, deren Abhandenkommen als dementsprechend unangenehm, schmerzlich und dislozierend erlebt wird. Auch Scholem Alejchem thematisierte in seinen kurzen Anekdoten über das

50 Risa Basté, Liedertexte. NÖLA, NÖ Reg. Präs. Theater TB - Textbücher der Theaterzensur $117 / 24$.

51 Ebda.

52 Ebda.

53 Vermerk der Zensurbehörde zu Liedertexten Risa Basté, 3.7.1902, unterzeichnet Rehl. Risa Basté, Liedertexte. NÖLA, NÖ Reg. Präs. Theater TB - Textbücher der Theaterzensur 117/24. 
Reisen gerade diesen Umstand und die Bedeutung des Koffers auf Reisen. ${ }^{54}$ Darauf, wie die Soubrette einen solchen Koffer geschickt in ihrer Performanz einsetzte, um Tabuisiertes anzusprechen, kommt die Analyse gleich noch zurück.

\section{Inszenierung von Gefahren des Unterwegsseins}

Die Gefahren und die Ängste von Migrierenden thematisiert das Stück Ein Wiener Quartett in Amerika. Es steht an der Schwelle von beruflichem Reisen und Reisen im Kontext von Migration. Im August 1898 wies das Neue Wiener Journal darauf hin, dass das Stück Ein Wiener Quartett in Amerika ${ }^{55}$ am Jantsch Theater in Vorbereitung war. ${ }^{56}$ Heinrich Jantsch hatte das Stück bereits im Jahr zuvor bei der Zensurbehörde eingereicht. ${ }^{57}$ Als er den Bescheid mit der Genehmigung erhielt, befand sich sein Wiener Volkstheater im Prater ${ }^{58}$ gerade im Umbau. Deshalb kam es erst nach der Wiedereröffnung der Spielstätte in der Sommersaison 1898 zur Uraufführung des Migrationsszenarios eines Quartetts, das in Amerika Wienerlieder spielen und damit erfolgreich werden wollte. ${ }^{59}$

Als „Posse mit Gesang in 5 Bildern“ konzipiert, entwirft das Stück fünf verschiedene Szenarien von Künstler*innen, die aus Europa in die Vereinigten Staaten aufbrechen. Während die ersten beiden Bilder vom Chicago zur Zeit der Weltausstellung erzählen, handelt das dritte Bild von der Adaptionsfähigkeit des Wienerliedes an das amerikanische Publikum und verlagert die Handlung des Stückes von Chicago nach New York. Die erste Szene dieses dritten Bildes beginnt im Vorzimmer des österreichischen Konsuls in New York. Eine Gruppe von „Auswanderern beiderlei Geschlechts“ aus der Monarchie findet sich ein, um sich darüber zu beschweren, dass sie unter Vorspiegelung falscher Tatsachen in das „Land der unbegrenzten Möglichkeiten“ gelockt worden sind. „Amerika ein reiner Schwindel / Natürlich, - ein Schwindel! - a Fopperei“, lassen sie es durch das Vorzimmer hallen. Weder Reichtum noch großen Besitz habe ihnen die Migration bisher eingebracht. Dafür wollen die Migrant*innen nun einen

54 Scholem Alejchem, Eisenbahngeschichten, 237.

55 Heinrich Jantsch, Ein Wiener Quartett in Amerika. NÖLA, NÖ Reg. Präs. Theater TB Textbücher der Theaterzensur 469/7.

56 NWJ, 21.8.1898, 7.

57 NÖLA, NÖ Reg. Präs. Theater ZA - Zensurakten: 1897/6460 K 35, Ein Quartett in Amerika.

58 Jantsch's Wiener Volkstheater im Prater (kurz Jantsch Theater) war die Nachfolgeeinrichtung des Fürst Theaters im Prater. 1898 verfügte das Jantsch Theater über 600 Sitz- und 190 Stehplätze. Lehmann, Sitzpläne der Wiener Theater- und Concert-Säle 1898, 36. Die Loge kostete acht Kronen, ein Sitzplatz zwischen einer und zwei Kronen, auf Stehplätzen am zweiten Rang konnte man für 30 Heller die Aufführungen sehen. Lehmann, Sitzpläne der Wiener Theaterund Concert-Säle 1898, 29.

59 NWJ, 21.8.1898, 7. 
Ausgleich. Der Konsulatsbeamte versucht, die Gruppe zu beruhigen, denn der Konsul soll schließlich nicht gestört werden. Diese Vorstellungen seien vor zwanzig Jahren noch Realität gewesen, mittlerweile aber leider nicht mehr. Leider hat der Beamte damit wenig Erfolg, die Meute will endlich wissen, wo denn das Land sei, „wo ma’s Gold aus der Erd außergrabt?“

Eine andere Ausgangssituation bei ihrer Ankunft in New York findet eine Musikergruppe aus Wien vor. Ein amerikanischer Farmer hat das Quartett für eine Tournee nach Amerika eingeladen. Die Finanzierung dafür sichert der Farmer zu und hinterlegt Geld für die Vier, das sie bei ihrer Ankunft nur am Konsulat abholen müssten. Das Quartett macht sich mit dem Devisenschein im Gepäck mit dem Schiff auf nach New York. Während der Überfahrt werden sie allerdings von vier anderen Migranten belauscht, die so von dem Scheck und dem in New York hinterlegten Geld erfahren. Kaum ist das Ensemble in Ellis Island von Bord gegangen und hat die Einreiseprozedur überstanden, steht das Quartett mit seinem Gepäck da und überlegt, wie es den Weg zum Konsulat finden könne. Unbemerkt stehlen ihnen derweil die anderen Migranten die Instrumente und Koffer. Obwohl die vier unter guten Voraussetzungen gestartet sind, stehen sie schließlich ohne Ausweise und Habseligkeiten da.

Als identitätslos und ohne Instrumente auch als zukunftslos beschrieben, machen sich die vier Unbemittelten aus Wien in Richtung Konsulat auf, um dort das ihnen widerfahrene Verbrechen zu melden. Die Diebe kommen ihnen allerdings auch dabei zuvor und beheben das für das Quartett hinterlegte Geld. Während die vier Musiker sich durch die Wirren der Migration mäandern, ist der Diebesbande ein guter Start in der goldenen Medine sicher. Und auch das Konsulat schenkt dem „richtigen“ Quartett keinen Glauben. Schlimmer noch, weil sich die Männer nicht ausweisen können, werden sie sodann selbst für die Betrüger gehalten. Aus Angst, zu verhungern, „gesteht“ dann zu allem Übel einer der vier für ein in Aussicht gestelltes Frühstück den Diebstahl, den sie gar nicht begangen haben. Es dauert so noch eine Weile, bis das Quartett den Konsulatsbeamten von seinem tatsächlichen Schicksal überzeugen kann. Das gelingt schließlich, als die Instrumente auftauchen, die die Ganoven mangels Verwendungsmöglichkeit zurückgelassen haben. Das Quartett hat nun die Möglichkeit, zu beweisen, dass es das Wienerlied spielen kann. Bei der Darbietung altbekannter und populärer Melodien erkennt eine andere Migrantin das berühmte Quartett aus der Monarchie; ein Beweis, der die vier schließlich ihre „Identität“ wiedererlangen lässt.

Das Stück porträtiert damit sehr eindringlich die Gefahren, die eine Tournee für Künstler*innen bedeuteten konnte. Auch wenn die Fahrt über den Atlantik zur Jahrhundertwende nicht mehr ein schwer zu bewältigendes Unternehmen darstellte - dauerte die Überfahrt kaum eine Woche und waren Tickets zu durchaus erschwingbaren Preisen zu haben -, stellten vor allem 
die unbekannten Herausforderungen, ein vielfaches Vermissen von gesetzlichen Sicherheiten und Interessensvertretungen lange ein großes Hindernis dar, um sich problemlos an den neuen Auftrittsorten zurechtzufinden. Das Stück Ein Wiener Quartett in Amerika entwirft über dieses Gefühl der Unsicherheit während einer Mobilität treffende Sittenbilder.

Das Stück vermittelt umgekehrt implizit auch, dass die Künster*innen, so sie ihr Geschäft beherrschten, nichts zu fürchten hätten; sie machten sie irgendwie ihren Weg und würden in der Habsburgermonarchie wie in den Vereinigten Staaten für Auftritte engagiert. Denn schließlich ließen sie ihre Lieder Wiedererkennung finden. Dieses Zurückfinden zu sich selbst in der als völlig unbekannt dargestellten neuen Umgebung illustriert das Stück zum Schluss mit dem Rückgewinn der Identität in Form der Ausweispapiere.

Eine weitere Art der Interpretation des Reisens in der populären Kultur generierte das Stück Die Reise nach Paris. Dieses verband das Reisen mit technischer Innovation und gesellschaftlichem Fortschritt. Weltausstellungen, wie jene in Chicago boten Komiker*innen, Sänger*innen und anderen Künstler*innen schon lange viele Themen zur Auseinandersetzung. Analog handelte Die Reise nach Paris von einem Parisaufenthalt zum Besuch der Weltausstellung 1900. ${ }^{60}$ Während Chicago 1893 Veranstaltungsort war, beherbergte Paris 1900 den beliebten Publikumsmagneten, wo „Populäres“ ebenso wie die neuesten Erfindungen präsentiert wurden. Eines der Highlights der Pariser Weltausstellung 1900 war das "rollende Trottoir“. Dieses beeindruckte so sehr, dass Referenzen darauf die populäre Kultur in den Jahren nach der Jahrhundertwende geradezu überfluteten. So rekurrierte auch das Lied Die Reise nach Paris darauf und spannte dabei einen Bogen von bürgerlichem Reisen bis zum Einfluss des französischen Ideals auch auf die populäre Kultur insgesamt. ${ }^{61}$

Das Lied von Louis Taufstein war Teil einer größeren Liedersammlung, die am 29. September 1900 bei der Zensurbehörde eingereicht worden war und eine Genehmigung zur Aufführung in der Singspielhalle Lautzky am 3. Oktober 1900 erhielt. In ihm lässt Taufstein ein Wiener Ehepaar in die „Hauptstadt der Liebe" reisen. Allerdings nicht, um sich die typischen Sehenswürdigkeiten anzusehen. Zum Zeitpunkt der Reise ist Paris gerade die Gastgeberstadt der Weltausstellung; außerdem giert das Paar nach der Unterhaltungsszene der französischen Hauptstadt. So erlebt das bürgerliche Ehepaar auf seiner Reise Tanzabende in Paris und promeniert am "rollenden Trottoir“, dem Highlight der Weltausstellung. Auf dem Höhepunkt der Reise kommt es schließlich nicht

60 Zur Beschreibung der Weltausstellung siehe Baedeker, Paris 1900, Anhang.

61 Augenscheinlich wird dieser Blick in einer Vielzahl der Benennungen von Spielstätten: die Blaue Katze, die Folies Caprice, die Folies Comiques etc. 
mehr umhin, die Freizügigkeit der Pariser Männer und die exorbitant hohen Kosten, die dieser Parisaufenthalt mit sich bringt, zu erkennen und zu beklagen.

O Paris, vergessen kann man es nie / Drum ruhen wir jetzt chapau claque allons fromage de brie / Ja wir fahren mit dem Schnellzug 1. Claß', / über Berg u. Thal, zu sausen durch die Welt/ ist sehr schön doch kostet es einen Haufen Geld. / An der Seine der lieblich schönen / ist die Stadt Paris gelegen / Diese Seine die riecht nach Moschus, / unser Wien ist nichts dagegen.[! $]^{62}$

Das Lied transportiert die Bewegung des Zuges „über Berg und Thal“ und die sinnliche Verortung der Hauptstadt Frankreichs an der Seine ebenso wie das „Vogelhäusel“-große Hotelzimmer und die Preise in der Stadt. Schließlich illustriert das vier Seiten lange Quodlibet, dass nicht nur sprichwörtlich, sondern auch tatsächlich die monitären Mittel knapp werden konnten: In einem Pariser Lokal wird der Protagonist Opfer von Taschendieben, die seine Geldbörse entwenden. Aus der misslichen Lage muss ihm seine Ehefrau helfen und sich einen „französischen Kavalier" - oder besser gesagt dessen Portemonnaie angeln. Allerdings hilft auch das nicht wirklich und das Paar ist gezwungen, aus monetärer Not die Stadt der Weltausstellung früher als gedacht wieder zu verlassen. Die Rückreise lässt die beiden schließlich die Vorzüge Wiens erkennen. Der Wehmut, die „moderne Welt", für die Paris stand, wieder verlassen und in den Alltag zurück zu müssen, setzen sie die Konfrontation mit der Realität entgegen.

Wir fuhren heim dann gewöhnlich dritter Claß, / Dann ganz stier war'n wir, ja sowas is ka Spaß. / Bald war'n wir in der Wienerstadt, / die für uns so viel Reize hat, / u. riefen froh u. glücklich aus, / am allerschönsten is zu Haus, / und es endet, auf diese Weise / unsere große Ausstellungsreise / Wir kennen jetzt das Pariser Leben / gehen nimmer hin, denn Wien bleibt Wien![! $]^{63}$

Das Motiv des Reisens in Liedern populärer Kultur greift folglich auch einen Blick auf Reisen der Bourgeoisie auf, wie etwa den Besuch der Weltausstellung. Einen solchen Parisaufenthalt entwarfen die Künstler*innen als ultimativen Ausdruck einer modernen, weltoffenen und kosmopolitischen Haltung und zeigten im gleichen Moment auch schon wieder die Grenzen dieser auf, wenn es darum ging, negative Erfahrungen auf Reisen zu machen. Das Stück wollte dem Publikum die Wehmut, Paris nicht sehen zu können, nehmen, indem es negative Klischees mit der Rückkehr in die Stadt des Wiener Charmes kontrastiert. Schlussendlich blieb nichts mehr, als „Wien bleibt Wien“ hinzuzufügen.

62 Louis Taufstein, Die Reise nach Paris. NÖLA, NÖ Reg. Präs. Theater TB - Textbücher der Theaterzensur 116/23.

63 Ebda. 
Wie das Stück Die Reise nach Paris zeigt, griff die populäre Kultur zeitgenössische Diskurse über technischen Fortschritt und urbanes Lebensgefühl der Zukunft nur zu gerne auf. Die Sehenswürdigkeiten auf der Weltausstellung in Paris wurden mannigfaltig diskutiert. Erfindungen wie das sogenannte „rollende Trottoir“ repräsentierten ein neues urbanes Bewegungsgefühl und eine moderne Adaption des Flanierens. Es war gewissermaßen Wirklichkeit gewordene Utopie. Stadtbürger ${ }^{\star}$ innen gemütlicheren Typs konnten sich auf diesem bewegten Gehsteig durch die Stadt bewegen und gleichzeitig einen Kaffeeplausch führen. Körperliche Ruhe verunmöglichte es nicht mehr, sich dennoch im urbanen Raum zu bewegen und sich das urbane Umfeld anzueignen. Was zuvor in Kutschen erprobte Praxis der privaten Fortbewegungsart war, fand im „rollenden Trottoir“ nun eine Weiterbewegungsmöglichkeit für die breite Öffentlichkeit. Eine Idee, die auch den populären Künstler ${ }^{\star}$ innen gefiel und die sie mit allen teilen wollten.

\subsection{Populärkultur als interkultureller und kosmopolitischer Raum}

Der neue Bewegungsdrang der Menschen schlug sich als Motiv in der Populärkultur nieder. Es war die Mobilität der Migrant*innen, die gesellschaftliche Bewegung symbolisierte. Es erlangte Reisen auch da als bürgerliches Phänomen Beliebtheit. Die kleine Sommerfrische in nahen Erholungsgebieten, wie in den Wiener oder den Buda(pester) Bergen, repräsentierte Reisen für jedermann: „[a]lle Welt reist[e]“, so Theodor Fontane (1819-1898). ${ }^{64}$ Und die Besucher*innen der Etablissements begaben sich in den Aufführungen mit den Stücken auf Reisen. ${ }^{65}$ Wie die bisher dargelegten Beispiele zeigten, interpretierten die Stücke das Motiv des Reisens als Praxis verschiedener Arten von Mobilität ${ }^{66}$ unterschiedlich: als Praxis in Migrationsprozessen, als Ausdruck eines bürgerlichen Lebensstils, als berufsbedingt und dem persönlichen Aufstieg dienend aber auch als Bewegung und Katalysator zwischen Bekanntem und Unbekannten. Doch welche Schlüsse lassen sich daraus über die Assoziationen von und mit Reisen gewinnen? Warum griffen Künstler*innen gerade dieses Motiv auf? Verbarg sich dahinter eine besondere Strategie, und wenn ja, was sollte die Metapher des Reisens bewirken? Wie können die Evidenz und Funktion von

64 Theodore Fontane, Unterwegs und wieder daheim (München: Nymphenburger Verlagshandlung, 1972), 7. Der Aufsatz Modernes Reisen, aus dem die Textpassage stammt, wurde 1894 publiziert.

$65 \mathrm{Zu}$ Reisen als populäres Gesellschaftsphänomen siehe Hermann Bausinger, Populäre Kultur zwischen 1850 und dem Ersten Weltkrieg, in: Kaspar Maase, Wolfgang Kaschuba (Hg.), Schund und Schönheit: Populäre Kultur um 1900 (Wien, Köln, Weimar: Böhlau, 2001), 29-45, 40-42.

66 Schlör, „Solange wir auf dem Schiff waren, hatten wir ein Zuhause“, 229-232. 
Stereotypen in Verbindung mit Reisen interpretiert werden? Und was lässt sich daraus im Hinblick auf die Konstitution von Identifikationen und Kulturen schließen?

Wie und was in der Kultur verhandelt wird - wenn etwa Autor*innen bewusst die Reise als Motiv verwenden, um kontroverse Inhalte thematisieren zu können -, behandelt die kulturwissenschaftliche Forschung unter der Perspektive von „Kultur als Übersetzung“. 67 Die Theater können insofern als Räume der Transformation gesehen werden, als sie ständig aus gesellschaftlichen Debatten und persönlichen Erlebnissen neue Produkte erzeugten. ${ }^{68}$ In den Theatern übersetzten die Künstler ${ }^{*}$ innen zwischen Lebenswelten und Erfahrungshorizonten. ${ }^{69}$ „Übersetzung meint in diesem Zusammenhang einen Prozess kultureller Vermittlung und ist „[...] aus dem linguistisch-textlichen Paradigma herausgelöst und als eine unverzichtbare Praxis einer Welt wechselseitiger Abhängigkeiten und Vernetzungen erkannt“, so Doris Bachmann-Medick. ${ }^{70}$ „Kultur“ wird nicht als etwas Monolithisches, sondern als etwas (Ver-)Mittelndes und Interagierendes zwischen kulturellen Assoziationen und Identifikationen gedacht. ${ }^{71}$ Was in einem bestimmten Umfeld als „typisch französisch“, „typisch weiblich“ oder „typisch jüdisch“ markiert wird, ergibt sich im Austausch mit anderen Assoziationen darüber und im Dialog der Vielzahl an Vorstellungen.

$67 \mathrm{Zu}$ Kulturtransfer und kultureller Übersetzung in der Historiographie über Jüdinnen und Juden siehe die Beiträge in Wolfgang Schmale, Martina Steer (Hg.), Kulturtransfer in der jüdischen Geschichte (Frankfurt, New York: Campus, 2006).

68 Zur Neukonzeption der Transformationsforschung sowie zur Problematik des Begriffs kultureller Übersetzung siehe Petra Broomans, Sandra van Voorst, Introduction, in: dies. (Hg.), Rethinking Cultural Transfer and Transmission: Reflections and New Perspectives (Studies on Cultural Transfer \& Transmission 4) (Groningen: Barkhuis, 2012), 9-14 sowie Boris Buden, Kulturelle Übersetzung: Einige Worte zur Einführung in das Problem, in: ders., Stefan Nowotny (Hg.) Übersetzung: Das Versprechen eines Begriffs (Wien: Turia + Kant, 2008) und Michaela Wolf, „Kulturelle Übersetzung“ - Spielwiese für übersetzerische Beliebigkeit oder Spielarten von Übersetzung „nach Babel“? in: Hiroshi Yamamoto, Christine Ivanovic (Hg.), Übersetzen - Transformation: Umformungsprozesse in/von Texten, Medien, Kulturen (Würzburg: Konigshausen \& Neumann, 2010), 44-55.

69 Brigitte Dalinger, „Interkulturalität: Kulturtransfer und das jüdische Theater“, Transversal 8, no.2 (2007): 15-36.

70 Bachmann-Medick, Cultural Turns, 239.

71 Ebda., 246. Federico Italiano, Michael Rössner, Translatio/n: An Introduction, in: dies. (Hg.), Translatio/n: Narration, Media and the Staging of Differences (Bielefeld: Transcript, 2012), 9-18, 10-12. Ansgar Nünning, Towards Transnational Approaches to the Study of Culture: From Cultural Studies and Kulturwissenschaften to a Transnational Study of Culture, in: Doris Bachmann-Medick (Hg.), The Trans/national Study of Culture: A Translational Perspective (Berlin, Boston: De Gruyter, 2016), 23-49, 23-27. 
Mit dem Verständnis von „Kulturen als Übersetzung“ ist die Entdeckung von Zwischenräumen in den postkolonialen Theorien verbunden. ${ }^{72}$ Diese Zwischenräume sind bisher als liminale Übergangsbereiche, dritte Räume und andere abstrakte (und damit vage) Konstrukte beschrieben worden. ${ }^{73}$ Diese Vagheit macht ihre methodische Erschließung schwierig. Doris Bachmann-Medick schlägt deshalb vor, Übergangsbereiche als Übersetzungsräume zu verstehen: „[... ] als Gestaltungsräume von Beziehungen, von Situationen, ,Identitäten ' und Interaktionen durch konkrete kulturelle Übersetzungsprozesse“ ${ }^{74}$ Moritz Csáky spricht über die Konstitution von Kulturen in solchen Zwischenräumen mit der Metapher Kultur als Kommunikationsraum. Eine solche Perspektive mache, so Csáky, die Metropolen der Habsburgermonarchie als die plurikulturellen Gefüge, die sie waren, beschreibbar. ${ }^{75}$

Die Metapher des Reisens verkörpert eine solche Zwischenraumqualität. Reisen repräsentiert augenscheinlich sowohl den Charakter des Aufeinandertreffens von Bekanntem mit weniger Bekanntem. Im Reisen schwingt die Notwendigkeit von Mittelung und Interaktion mit dem Umfeld, um bekannt zu werden, mit. Reisen ist aber auch ein Ausdruck des Dazwischenseins, eines Unterwegsseins, nicht mehr am Ort der Abreise, Punkt A, aber auch noch nicht angekommen an der Zieldestination, Punkt B, zu sein. Das Spektrum dessen, was auf einer Reise passieren kann, ist unbegrenzt. Was sich also im Dazwischen ergibt, offeriert tausende Möglichkeiten. Nicht zuletzt kann Reisen im Großen

72 Bhabha, The Location of Culture, 6-10

73 Turner beschreibt Zwischenräume als liminal spaces. Victor Turner, The Anthropology of Performance (New York: PAJ Publications, 1987). Was Homi Bhabha als „dritten Raum“ - ein liminaler Raum zur Artikulation - beschreibt, sieht er als Grundlage überhaupt erst dafür, dass Differenz in irgendeiner Form artikuliert und damit Raum gegeben werden kann. Auch er betont, dass der „dritte Raum“ erst die diskursiven Bedingungen für Äußerungen konstituiert, die sodann Grundlage der Konstitution von Kulturen werden. Bhabha, The Location of Culture, $50-56$.

74 Bachmann-Medick, Cultural Turns, 247.

75 In einem Kommunikationsraum wird die Semantik von „Objekten“ auf Basis zwischenmenschlicher Interaktionen konstituiert. Was welche Bedeutung bekommt, ist demnach ein kollektives und individuelles Aushandeln von Machtverhältnissen. Csáky, Das Gedächtnis der Stadt, 101; sowie Moritz Csáky, Das Gedächtnis Zentraleuropas: Kulturelle und literarische Projektionen auf eine Region (Wien, Köln, Weimar: Böhlau, 2019). In dieser Beschreibung der Konstitution von Kultur kommt ein wesentlicher Unterschied zwischen den deutschsprachigen Kulturwissenschaften und dem an den britischen Ansätzen der Cultural Studies orientierten Zugängen zutage. Die Cultural Studies, ausgehend vom Birminghamer Center for Contemporary Cultural Studies, lenkten den Fokus auf alltäglicher Populärkultur, während die Kulturwissenschaften dazu tendieren, den Kulturbegriff semiotisch zu erweitern. Doris Bachmann-Medick, The Trans/national Study of Culture: A Translational Perspective, in: dies. (Hg.), The Trans/national Study of Culture: A Translational Perspective (Berlin, Boston: De Gruyter, 2016), 1-22, 2-5. Nünning, Towards Transnational Approaches, 26-27. 
oder im Kleinen geschehen; es ist etwas, das den meisten zur Jahrhundertwende ein Begriff war - eben auch wegen der sich ändernden Qualität an Mobilität durch die Massenmigration. Der Gebrauch des Reisens als Metapher reüssierte deshalb nicht nur wegen seinem natürlichen Naheverhältnis zu Mobilität, sondern gerade auch wegen seiner Zwischenraumqualität, die es ermöglichte, tagespolitische Themen und gesellschaftsbrisante Fragen aufzugreifen.

Bei der Diskussion und Reflexion darüber, was in Zwischenräumen verhandelt wird und was die Übersetzung von Kultur konstituiert, ist die Betonung von Differenz omnipräsent. Homi Bhabha und andere Wissenschafter*innen des postcolonial turn proklamieren, dass die Konstitution von Kultur und kultureller Mittelung auf dem Aushandeln von Differenzen beruht. ${ }^{76}$ Ein Beispiel einer solchen Argumentation ist die Diskussion um Jewish Difference: Im Gemeinsamen von Jüdinnen und Juden und Nichtjüdinnen und Nichtjuden ließen sich - mehr oder weniger intensiv und vordergründig - Jewish Difference(s) ausmachen. ${ }^{77}$

In der Populärkultur kommt es hinsichtlich eines Aushandelns von Differenz zu einer einigermaßen paradoxen Situation. Zunächst erwecken die Überpräsenz von Stereotypen und das immer wieder auf die Spitze getriebene Kontrastieren von Kulturen in den Stücken den Eindruck, dass überwiegend Differenzen präsent seien. Die vorgestellten Stücke illustrieren, dass die populäre Kultur im Allgemeinen und das Motiv des Reisens, durch die von ihm evozierten Verortungsprozesse, im Besonderen für das Verhandeln von Stereotypen Raum bot. Sie bedienen unterschiedliche Zugänge zu Reisen. Geschäftliches Reisen beinhaltete vorwiegend berufliche Klischees und ,exotisierende' Stereotype im Zusammenhang mit einem ungewöhnlichen Beruf. Beim Reisen einer Frau ging es um die Auseinandersetzung mit Sittlichkeitsvorstellungen und schließlich auch um ein Weltenbummeln oder touristisch-bildungsbürgerliches Reisen. Dabei verhandelten die Künstler*innen Stereotype der Bourgeoisie, die es sich leisten konnte, auf Sommerfrische, zur Verwandtschaft oder nach Frankreich zu fahren. Reisen bedeutete in den Stücken aber auch, eine Beweglichkeit im Blick auf Stereotype und Kategorisierungen zuzulassen.

76 Bhabha, The Location of Culture, 56.

77 Daniel und Jonathan Boyarin sind von der Prämisse ausgegangen, dass „[...] a Jewish subjectposition founded on generational connection and its attendant anamnestic responsibilities and pleasures affords the possibility of a flexible and nonhermenetic critical Jewish identity". Boyarin, Boyarin, Diaspora: Generation and the Ground of Jewish Identity, 701. Boyarin, Boyarin, So Whats's New, vii-xxii; Hödl, From Acculturation to Interaction, 84-87; Silverman, Reconsidering the Margins, 103-120. 


\section{3 (Jüdischer) Humor und Ähnlichkeit}

Populärkultur war und ist aber nicht nur an der Reflexion und Umkehr von Stereotypen interessiert; sie versucht ebenso, ein breites Publikum in ihren Bann zu ziehen. Wie gesellschaftspolitische Kritiken und soziokulturelle Auseinandersetzungen artikuliert werden, muss wohldurchdacht sein, um eben populär, also beliebt bei einem größeren Publikum, zu sein und zu bleiben. ${ }^{78}$ Das zweite Kapitel legte die Bedeutung von Amüsement in der Unterhaltung um die Jahrhundertwende dar; es thematisierte jenen Anspruch, dass die Menschen unterhalten werden und sich amüsieren wollten. Das bedeutet umgekehrt aber, dass die Stücke, um populär zu sein, diesen Zweck erfüllen mussten. ${ }^{79}$ Dabei auch kritisch, provokant und direkt sein zu können, bedurfte eines großen Talents. Hätten die Stücke und Lieder nicht unterhalten, wäre die Nachfrage nach ihnen oder den jeweiligen diese vortragenden beziehungsweise verfassenden Künstler*innen rasch gesunken. Das hätte den Künstler*innen die Lebensgrundlage entzogen. Was machte also die Populärkultur amüsant und wie übersetzten die Künstler*innen brisante Inhalte, um kontroversielle Blicke auf diese verhandeln oder gar Gesellschaftskritik äußern zu können?

Für Sigmund Freud (1856-1939) bedarf es, um „unterhalten zu werden“ und „sich zu amüsieren“ verschiedener Aspekte. Er benennt drei Arten des Amüsements: Witz, Komik und Humor. Zunächst trennt Freud zwischen dem Witz und der Komik: „Der Witz wird gemacht, die Komik wird gefunden, und zwar zu allererst an Personen, erst in weiterer Übertragung auch an Objekten, Situationen $\mathrm{u}[\mathrm{nd}] \mathrm{d}[\mathrm{er}] \mathrm{gl}\left[\right.$ eichen]. ${ }^{\text {(80 }}$ Witz und Komik treten nicht ausschließlich

78 Das meint natürlich nicht, dass die Beschreibung dieser Stücke beziehungsweise ihre Zuordnung zur Populärkultur per se den Rückschluss erlauben beziehungsweise, dass argumentiert werden kann, dass sie populär waren. Nachdem die derartigen Strategien des Aufgreifens und des Adaptierens von Motiven sowie des Umgangs mit Stereotypen kontinuierlich weiterbestanden, lässt dies jedoch den Rückschluss zu, dass diese Strategien erfolgreich waren und der Popularität keinen Abbruch taten - vielleicht diese sogar förderten.

79 Levine, Highbrow Lowbrow, 4-9 und 33. Levine betont, dass er nicht zur grundsätzlichen Aufgabe dieser Kategorien aufruft. Vielmehr hinterfragt er deren rigide Erstellung. In Vorstellungen betreffend die Hierarchisierung von Kultur sei die Frage der sozialen Klassen omnipräsent. Levine fragt, warum etwa nicht ein ästhetisches Gefühl der Gegenwart, die Aussage von kulturellen Ausdrucksformen und ihre Funktionsweise oder die Verteilung eines Kulturprodukts in die Bewertung (positiv) miteinbezogen werde. Wegweisende Arbeiten publizierte hierzu Jonathan Hess, der etwa den Zusammenhang zwischen der ,middlebrow Literatur und deutsch-jüdischer Identität untersuchte. Die Auflösung dieser Dichotomie Hoch- und Populärkultur bzw. highbrow und lowbrow war stark von Sorkins Arbeiten zur Hinterfragung von Minderheit und Mehrheit beeinflusst. Hess, Middlebrow Literature, 11-14.

80 Sigmund Freud, Der Witz und seine Beziehung zum Unbewussten/Der Humor, herausgegeben von Peter Gay [1905/1927] (Frankfurt am Main: Fischer, 2009), 193. Zu Freud und Gender 
getrennt auf, sondern gemeinsam oder stehen zumindest in Beziehung zueinander. Der Witz kann auch auf die Komik zurückgreifen. Die Komik bedient sich entweder des Naiven oder der Zote, gelegentlich auch der Zukunftsvision. Damit die Komik „gefunden“ werden kann, bedarf es der Möglichkeit eines „Sichhineinversetzens“. Die Situation müsse die Haltung eines „Verstehenwollens" evozieren. ${ }^{81}$ Komik und Witz gegenüber positioniert Freud den Humor. Humor sei ein egoistisch motivierter Lustgewinn. Er biete Lust, ohne ein Gros an Gefühlen investieren zu müssen. „Mich, den unbeteiligten Zuhörer, trifft gewissermaßen eine Fernwirkung der humoristischen Leistung des Verbrechers; ich verspüre, vielleicht ähnlich wie er, den humoristischen Lustgewinn. " ${ }^{82}$

Empathie zur dargestellten Situation, zur porträtierten Person oder zum Geschehen aufbauen zu können, sei die Grundvoraussetzung für Amüsement. Deswegen teilten allen drei Formen des Amüsements - Witz, Komik und Humor - die Grundbedingung, dass ein Hineinversetzen in das Dargestellte, ein Empfinden beziehungsweise eine Bereitschaft zum Erkennen von Ähnlichkeit evoziert werden müsse. Laut Freud geschieht dies beim Humor auf Kosten anderer, Witz und Komik bedürfen einer gewissen Selbstironie und Vorstellungskraft. Die Lust (am Amüsement und der Unterhaltung sowie die Lust durch sie) sei unmittelbare Folge dieses Erkennens von Ähnlichkeit. Mit dieser Lust und dem Suchen nach ihr spielten die Künstler*innen in der populären Kultur. Sie verstanden es gekonnt, abzuwägen, wie viel Vorstellungskraft dem Publikum abverlangt werden konnte. Mit Pointen, die sie häufig auf eigene Kosten servierten, gelang es ihnen das volle subversive Potential der Unterhaltungskultur zu entfalten.

Was aber meint, im Amüsement eine Ähnlichkeit aufzubauen? Um nachvollziehen zu können, welche Faktoren abzuwägen für die Künstler*innen wichtig war, folgen hier zunächst Überlegungen zum Ähnlichkeitsdenken. Walter Benjamin (1892-1940) beschäftigte sich mit der Bedeutung von Ähnlichkeitswahrnehmungen in dem im Herbst 1933 verfassten Aufsatz über Die Lehre vom Ähnlichen. Darin bezeichnete Benjamin die Fähigkeit, Ähnlichkeit zu produzieren und wahrzunehmen, als eine der größten Leistungen des Menschen. ${ }^{83}$

siehe Gilman Sander L., Freud, Race, and Gender (Princeton: Princeton University Press, 1993).

81 Freud, Der Witz und seine Beziehung zum Unbewußten,193-200 sowie 209-211.

82 Freud, Der Humor, 253. Hierin sah Freud aber auch eine Lustüberspitzung, die ins Großartige und Erhabene abdrifte - „den Triumpf des Narzissmus“. Ebda., 254.

83 Walter Benjamin, Die Lehre vom Ähnlichen, in: ders., Gesammelte Schriften 2, 1, herausgegeben von Rudolf Tiedemann und Hermann Schweppenhäuser (Frankfurt am Main: Fischer, 1977), 204-213. Siehe Kapiteleingangszitat. Dorothee Kimmich weist darauf hin, dass kognitive Lernprozesse über Ähnlichkeitswahrnehmungen ablaufen. Kimmich, Ins Ungefähre, $9-12$. 
Laut Benjamin sei „Ähnlichkeit [...] eine ,Figur des Kontinuierlichen, Übergänglichen. Sie bedarf zwar der Markierung von Differenzen, stellt aber nie einen Bruch oder Gegensatz dar" ${ }^{\text {"84 }}$ Diese Produktivität, die einem Denken in Differenzen Ähnlichkeit addiert, und daran interessiert ist, warum und wie Ähnlichkeiten und Differenzen im Alltag aufgebaut werden, griffen postmoderne Ansätze auf. Anil Bhatti und Dorothee Kimmich heben hervor, dass das Produzieren von Ähnlichkeit Teil einer bewussten Inszenierung wie in der populären Kultur sein kann. Das ist für die populärkulturelle Praxis eine wichtige Prämisse, denn sie legt die Frage nahe, ob Populärkultur - als massengesellschaftliches Phänomen - nicht überhaupt erst populär war, weil sie auch Ähnlichkeiten in den vermeintlich so evident dargestellten Differenzen erkennbar machte.

Die starke Präsenz von Differenz in Narrativen ist nicht zuletzt in den Forschungsinteressen begründet. In den letzten Jahrzehnten kam Auseinandersetzungen mit „Identität(en)“ besondere Aufmerksamkeit zu. Dabei rückte „Alterität“ (das „Andere“) als wesentliche - da wahrscheinlich einzige Komponente - von Identitätskonstruktionen in den Mittelpunkt von Fragestellungen. ${ }^{85}$ So hat sich „Differenz" zu einer weitverbreiteten Analysekategorie entwickelt, die allerdings unweigerlich Grenzen schafft und Dichotomien erzeugt. ${ }^{86}$ Seit den 2010er Jahren hat die Forschung zu hinterfragen begonnen, ob nicht auch in den Differenzkonstruktionen Ähnlichkeitswahrnehmungen entscheidender seien als die Differenzierung. Diese müsse unweigerlich in Relation zu etwas Bekanntem gesetzt werden. Beeinflussen Vorstellung über und Imagination des ,Anderen' als das ,Eigene` ähnlich seiende Kategorisierungen stärker als das als unbekannt Wahrgenommene? Die Forschung um Bhatti und Kimmich argumentiert, dass die Imagination des ,Anderen' auf einer bekannten Referenz - auf etwas, wozu Ähnlichkeit hergestellt werden könne - aufbaut. Ähnlichkeit, so das Argument, ist der Referenzrahmen, der verwendet wird, um jene Differenz anzugeben, in der das ,Andere vom ,Eigenen ${ }^{c}$ abweiche. ${ }^{87}$ Differenzen bestehen folglich und werden auch nicht negiert. Sie sind aber graduell und stets von mehr oder weniger Ähnlichkeiten begleitet. Klaus Hödl konstatierte, dass „Ähnlichkeit zwischen Menschen oder Kollektiven bedeutet, dass es we-

84 Bhatti, Kimmich, Einleitung, 14.

85 Doris Bachmann-Medick, Cultural Turns, 184-185, 206-207.

86 In den Jüdischen Studien der Ansatz Jewish Difference. Siehe Fußnote 77.

87 Bhatti, Kimmich, Einleitung, 15-17. Sabine Müller, Tractatus, „Schmäh“ und Sprachkritik: Überlegungen zu einer alternativen Genealogie der Wiener Moderne, in: András F. Balogh, Christoph Leitgeb (Hg.), Mehrsprachigkeit in Zentraleuropa (Wien: Praesens, 2012), 229-254, 237-242. 
der eine völlige Unterscheidbarkeit noch eine gänzliche Angleichung zwischen ihnen gibt". 88

Was bedeutet dann ein Erkennen von Ähnlichkeit für humorvolle Auseinandersetzungen mit Jüdisch-Sein? Viele der Gruppen spielten mit kulturellen Artikulationen von Jüdisch-Sein ebenso wie mit antisemitischen Stereotypen. ${ }^{89}$ Wie kann das verstanden werden? Wie nutzten die Autor*innen und Schauspieler*innen Differenzerfahrungen des Publikums? Die Theaterwissenschafterin Eva Krivanec illustriert, dass Antisemitismus bewusst zur Verhöhnung von Antisemiten benutzt wurde. ${ }^{90}$ Hödl schreibt dazu, dass jüdisch-nichtjüdische Volkssängergruppen sogar antisemitischen Diskursfiguren völlig neue Konnotationen hinzufügten und ihre negative Charakteristik ins Positive wandten. ${ }^{91}$ Wenn jüdische und nichtjüdische Volkssänger*innen mit vermeintlich jüdischen Ausdrücken spielten oder stereotyp dargestellte „jüdische Charaktere“ mimten, erfüllte dies die unterschiedlichsten Funktionen. Es diente aber nicht der Schaffung einer totalen Opposition zwischen Jüdinnen und Juden und Nichtjüdinnen und Nichtjuden. Betreffend den Einsatz von Schmäh hebt die Literaturwissenschafterin Sabine Müller einerseits die Möglichkeit zur Identitätsbehauptung, und anderseits seine Funktion zum „lachenden Aushandeln“ mit „offenen“ Möglichkeiten zum Handlungsanschluss hervor. Insbesondere für den (Wiener) „Schmäh“ konstatiert Müller eine grenzwertige Stellung zwischen „Fremdenfeindlichkeit“ und „Fehlerfreundlichkeit“. Müller bezieht dies bereits auf Hugo von Hofmannsthal, der in einer Rede hervorstrich, dass, bei aller Heftigkeit der Aussagen, der Humor auch immer mit einer gewissen „Zwinkernden Selbstironie“ einhergehe. ${ }^{92}$ Der „Schmäh“ operiere mit einer Identifikation - jüdisch, männlich, weiblich, national etc. - zunächst so, dass sie als different und ausschließlich bei anderen wahrgenommen wird. Dann lässt der Schmäh die gleiche - vermeintliche - Differenz auch im „Eigenen“ auftauchen. Damit knüpfen die Überlegungen an Freuds Analyse der Funktion von Witz, Komik und Humor an. „Schmäh“, Amüsement und Humor bauen in diesem Sinne die Brücke zwischen den beiden Positionen: Sie führen die

88 Hödl, Zwischen Wienerlied und Der kleine Kohn, 187.

89 Korbel, Populärkultur und Antisemitismus, 17-37.

90 Eva Krivanec, „Krank und wieder gesund gelacht...“: Jüdisches Unterhaltungstheater in Wien und Berlin zwischen 1910 und 1918, in: Christine Haug, Franziska Mayer, Madleen Podewski (Hg.), Populäres Judentum: Medien, Debatten, Lesestoffe (Conditio Judaica 76, Studien und Quellen zur deutsch-jüdischen Literatur- und Kulturgeschichte) (Tübingen: Max Niemeyer Verlag, 2009), 103-120.

91 Klaus Hödl, „,Der kleine Kohn` on the Jewish Stage: Performative Strategies to Fight AntiSemitism in Vienna around 1900“, Leo Baeck Institute London - Report of Activities 60, no. 1 (2015): 123-140.

92 Müller, Tractatus, „Schmäh“ und Sprachkritik, 229-254. 
als different wahrgenommene Identifikation auch als eigene und damit dem Publikum vertraute vor, wodurch eine Abgrenzung zum dargestellten ,Anderen schwierig, paradox bis unmöglich wird. In den populären Stücken der Jahrhundertwende spielten jüdische und nichtjüdische Autor*innen gleichermaßen mit Idiomatik und Themen, die verschiedenen Identifikationen zugeordnet waren. Die Funktion von Theater, dem Publikum einen Spiegel vorzuhalten, wurde dabei genutzt, um diese vielen Facetten, die hinter Differenzwahrnehmungen stehen, erkennbar zu machen. Für den jüdischen Humor in der populären Kultur schlage ich daher vor, das komplexe Zusammenspiel von antisemitischen Stereotypen und Aushandlungen eines Jüdisch-Sein genauer zu betrachten. ${ }^{93}$

Aufführungen sind etwas Performatives; Differenz- und Ähnlichkeitswahrnehmungen zu generieren, ebenso. Bedeutungen entstehen im Zusammenspiel von Publikum, Schauspieler ${ }^{\star}$ innen, allen anderen Objekten und dem Raum. Bedeutungsaushandlungen vollziehen sich immer wieder neu. Und so ist Lust an Aufführungen ephemer, weil Ähnlichkeit zu erkennen an die Flüchtigkeit der Situationen gebunden ist; Ähnlichkeit muss immer wieder neu generiert werden. Die Kulturwissenschafterin Aleida Assmann spricht dementsprechend von der „Performanz der Ähnlichkeit“. Assmann meint damit, dass sich Differenz und Ähnlichkeit im gegenseitigen Wechselspiel ergeben und ,immer wieder auf- bzw. abgebaut" werden. In der Interaktion zwischen Publikum und Schauspieler*innen können Feindbild und Ähnlichkeit nahe beieinanderliegen. ${ }^{94}$

Populärkultur setzt eine breite Basis an Identifikationsmöglichkeiten voraus. Wenn sich das Publikum in einer maximalen Differenz - ohne jeglichen Bezug herstellen zu können - sähe, gäbe es keine Grundlage für Amüsement und keine Basis des Verstehens von Komik oder des Partizipierens am Humor. Denn es käme, nach Freud, zu keinem Lustgewinn. Unlust wäre die Folge und das Dargebotene würde nicht populär. Somit stellt sich die Frage, welche Funktion Differenzmarkierungen, wie etwa der übertriebenen, vielfach antisemitischen Zeichnung von Charakteren in den populären Stücken zukam. Zugespitzt formuliert: Bauen diese Differenzmarkierungen auf einer „Ähnlichkeit der Differenz" auf?

Die Metapher des Reisens verwenden die Stücke immer, um einen Abstand zwischen dem Protagonisten oder der Protagonistin, durch die das Publikum

93 Ich beziehe mich hier auf Lisa Silverman, die explizit betont, dass die Interpretation jüdischnichtjüdischer Beziehungen über eine teleologische Sicht auf Antisemitismus hinausreichen müsse und fragen sollte, warum etwa antisemitische Einstellungen in ihnen vorkommen und welche Funktion diese sodann erfüllen. Lisa Silverman, „Beyond Antisemitism: A Critical Approach to German-Jewish Cultural History“, Nexus: Essays in German Jewish Studies 1, no.1 (2011): 27-45.

94 Assmann, Ähnlichkeit als Performanz, 167-168, 171-173. 
das Stück oder Lied erlebt, und dem Thema - Migration, Geschlechterrollen, Bürgertum - zu schaffen. Im Lied Der Reisekoffer greift Risa Basté die Konvention der damaligen Zeit, dass Frauen nicht gemeinsam mit Männern reisen sollen, auf. Basté entwirft aber die gemeinsame Reise von Männern und Frauen als unterhaltsamer. Das expliziert die Künstlerin in dem Stück soweit, dass sie das Unterhaltsame aus der Frage, was sie denn nun - also nach der Reise mit Männergarderobe anfangen könnte, generiert. Vor dieser amüsanten Szene muss sich die Protagonistin darüber Gedanken machen, wie ein solcher Eklat gesellschaftlich legitimierbar sei - würde ihre Tante, zu der sie unterwegs ist, das niemals dulden. Gleichzeitig ist es dabei zentral, dass sie nicht nur Frauen oder Männer, sondern das gesamte Publikum mit ihren Überlegungen abholt. Es ist augenscheinlich, dass sie dafür um die Jahrhundertwende nicht die Unterscheidbarkeit von Geschlechtern anzweifelte. ${ }^{95}$ Vielmehr macht sie Aspekte sämtlicher Geschlechterrollen für ihr Publikum nachvollziehbar und das, was die Forschung mit dem Ähnlichkeitsparadigma beschreibt - nämlich Differenz nicht „über Bord zu werfen“, sondern sie „jenseits ihres Gegensatzes zur Identität“ neu zu konzipieren. ${ }^{96}$ Im Couplet Die Reise nach Paris konstruierte Louis Taufstein einen Blick von außen, nämlich von Wiener*innen auf die französische Hauptstadt. Wie nach Paris reisende Wiener*innen die Stadt, die Bevölkerung und die Kultur imaginierten und mit welchen Stereotypen dies einherging, ist das Thema. ${ }^{97}$ Ein Wiener Quartett in Amerika erzählt von den Schwierigkeiten, die berufliche Migration mit sich bringen kann und kontrastiert gleichzeitig das Bild von beruflich Migrierenden mit dem der breiten Masse jener, die ohne konkrete Angebote, in der Hoffnung nach einem besseren Leben von Europa nach Amerika (und vielfach auch wieder zurück) ${ }^{98}$ gingen. ${ }^{99}$ Die Stücke Der Reisende und Der Afrikareisende handeln von beruflich bedingter Migration von als böhmisch entworfener Protagonisten, die jeweils mit einen vorurteilsbehafteten Blick auf die eigene Umwelt dem Publikum einen Spiegel vorhalten.

Indem sie auf Vorurteile referieren, verfolgen die Stücke und Lieder dieselbe Strategie: Sie erzeugen zunächst immer eine vermeintlich totale Differenz zum stereotypisierten Charakter, ehe die Künstler*innen eine humoristische

95 Risa Basté, Liedertexte. NÖLA, NÖ Reg. Präs. Theater TB - Textbücher der Theaterzensur 117/24.

96 Andreas Langenohl, Ähnlichkeit als differenztheoretisches Konzept: Zur Reformulierung der Modernisierungstheorie, in: Bhatti, Kimmich, Ähnlichkeit, 105-127, 106.

97 Louis Taufstein, Die Reise nach Paris. NÖLA, NÖ Reg. Präs. Theater TB - Textbücher der Theaterzensur 116/23.

98 Steidl, Fischer-Nebmaier, Oberly, From a Multiethnic Empire to a Nation of Nations, 50-75.

99 Heinrich Jantsch, Ein Wiener Quartett in Amerika. NÖLA, NÖ Reg. Präs. Theater TB Textbücher der Theaterzensur, TB - Textbücher der Theaterzensur 469/07. 
Wende damit evozieren, dass sich in dieser Differenz doch Gemeinsamkeiten und Ähnlichkeiten ergeben. Ein Wiener Quartett in Amerika thematisiert sämtliche Stereotype über Migrant*innen aus der Monarchie in den Staaten aus der Sicht der reisenden Künstler ${ }^{\star}$ innen, die mit anderen Migrant ${ }^{\star}$ innen in Kontakt kamen. Die vier Künstler, die auf dem Ozeandampfer mit den anderen Migrant ${ }^{\star}$ innen gemeinsam nach Amerika fahren, berichten aus ihrer Perspektive von der Ankunft auf Ellis Island, wo sie ihre Musikinstrumente und ihre „Mitreisenden“ die Koffer mit den Habseligkeiten, die in die Emigration mitgenommen werden konnten, durch das Einreiseprozedere zu bringen versuchen. Zunächst scheint der Blick der Musikanten auf die anderen Migrant ${ }^{\star}$ innen geprägt von einer Distanz. Im Abhandenkommen der Musikinstrumente wird aber sehr schnell die (keinesfalls rein allegorische) Bedeutung dieser Fracht klar, wenn in ihrem Verlust nicht nur ein Besitz verloren geht, sondern mit ihm „die Identität der Musiker“. Der Reisende und Der Afrikareisende greifen aus dem Alltag bekannte Klischees auf, um den am Beginn der Reise zunächst unbekannten Raum, in den sich der Reisende begibt, zu beschreiben. Der arbeitssuchende Reisende, der sich selbst als „Behm“, also Böhme, bezeichnet, fühlt sich vor allem an negative Attribute über die böhmische Bevölkerung der Monarchie erinnert. Sich selbst weist der Protagonist nur positiv konnotierte Klischees zu, die negativ konnotierten hingegen dem ,Anderen': Der arbeitsscheue „behm“ ist der Chef, der fleißige „behm“ der Protagonist selbst. $\mathrm{Ab}$ diesem Zeitpunkt werden nicht mehr nur negative Seiten des Stereotyps erkennbar. Auch schlägt in der zugespitzten und offensichtlichen Zuschreibung des Negativen zum ,Anderen' einerseits Selbstironie und anderseits auch gewissermaßen ein Anspruch auf Selbstreflexion durch, indem gerade in der Kurzsichtigkeit, Negatives nur im ,Anderen' zu erkennen, das Komische erzeugt wird. Diese Ambivalenz des Gebrauches von Stereotypen und das Nebeneinanderstehen von positiven wie negativen Seiten eines Stereotyps wird in der Darstellung des Chefs und der Chefin des Protagonisten evident: Während er seinen Chef als arbeitsscheuen Tschechen stereotypisiert, stellt er die tschechische Chefin als positive Figur dar, die sein Talent erkenne und schätze; er etabliert eine Beziehung der ihm eigentlich in den früheren Beschreibungen diametral gegenüberstehenden tschechischen Arbeitgeberin.

Die Stücke ließen so Mehrfachzuschreibungen, die die Differenz der ,Anderen' in der Wahrnehmung des ,Eigenen' sichtbar machten, augenfällig werden. Damit generierten die Künstler ${ }^{\star}$ innen eine Aufführungserfahrung, die nahe an der Alltagserfahrung ihres Publikums war. Denn plurikulturelle Gesellschaften, wie es alle Migrationsgesellschaften sind und somit auch jene der Habsburgermonarchie und der Vereinigten Staaten waren, „[...] basier[en] auf der Ähnlichkeitslogik, auf Überlappungen, Polyglossie und Synkretismus, und das steht jenseits der Eigen-Fremd-Logiken von Assimilation oder Authentizität. 
[...] Statt des harten Prinzips des, Entweder-oder' wird das fluide Prinzip des ,Sowohl-als-auch bevorzugt “ ${ }^{100}$ Dieser Prämisse von Anil Bhatti folgend, war es gerade diese permanente Erfahrung, nicht entweder Differenz oder totale Gleichheit zu einem Gegenüber zu empfinden, die die Menschen in Wien, Budapest und New York täglich machten und somit auch in der populären Kultur anzuwenden verstanden.

Derartige Mehrfachzuordnungen und Bedeutungsüberschreibungen bezogen sich nicht nur auf nationale Stereotype, sondern brachten ebenso die fluide Aushandlung dessen, was um 1900 als ,jüdisch“ gesehen wurde, in den Diskurs ein. Welche Rolle Sprache in dieser Verhandlung zukam, illustriert das Stück Der Afrikareisende. Es vermischt Wiener Dialekt und "Jargon" und addierte noch gängige Floskeln des Tschechischen, wenn etwa der Protagonist seine Ausführungen mit Zwischenrufen wie „dobre Noz![!, gute Nacht] oder „to je dobre“ [das ist gut] verstärkt. Hier wird das performative Aushandeln von Ähnlichkeitswahrnehmungen zu jüdischen Identifikationen vor allem über Idiomatik, zu Stereotypen über Referenzen auf zeitgenössische Diskurse hergestellt.

In Afrika is a große große Wiesen. Do segns ka Bam, ka Strauch, ka Wirtshaus, nit amol i Gasbeleuchtung habns dort, das is die jüdische Wüste Sahrah! Amol wie i auf der Sahrah umanandgstiegen bin, hör ich mit amol fürcherliche Gebrüll, und richtig kummta von weiten mächtige Löwe auf mi zug'sprungen. No, hab i ma denkt, jetzt dobre Noz! Wissens, bem fürcht sie nit gar so leicht, aber ganz alleinig mit a Löwm das is ka Klanikkeit nit! Als dann der Löwe rennt auf mi zu, reißt Pappen auf, so groß wie bei uns äußre Burgthor, und will mi fressen. In meiner Angst fang ich auf Böhmisch zum schrein an: Strć Prst, skrsk, krk! Wie das Löwe Hört, macht er Maul zu, fangt An zum lachen, schaut mi freundschaftli an, dann draht er sie um Und geht ganz pomali furt. Und wie i mi den Kerl genauer anschau, sich i, daß er zwa Schwafeln hat. Er war böhmische Löwe, Landsmann meiniges.[! ${ }^{101}$

Die populäre Kultur porträtierte damit nicht nur die Lebenswirklichkeit einer von dem Wechselspiel aus „Differenz“ und „Ähnlichkeit“ lebenden plurikulturellen Gesellschaft, sondern auch den besonderen Stellenwert, den die Alltagsmehrsprachigkeit darin einnahm. Für die Menschen, die in Wien, Budapest oder New York um 1900 lebten, war es der wahrscheinliche Fall, mit mehr als

100 Bhatti, Plurikulturalität, 176-177.

101 Heinrich Eisenbach, Der Afrikareisende. NÖLA, NÖ Reg. Präs. Theater TB - Textbücher der Theaterzensur 116/3. In der Habsburgermonarchie um die Jahrhundertwende waren neben antisemitischen Stereotypen jene über die böhmische Bevölkerung am meisten verbreitet. Pressler, Jüdisches und Antisemitisches in der Wiener Volksunterhaltung, 63-67. Eines der bekanntesten Werke, das mit (anti)böhmischen Stereotypen spielt, ist sicherlich Jaroslav Hašeks Soldat Schwejk. Jaroslav Hašek, Die Abenteuer des braven Soldaten Schwejk, 2 Bd. (Hamburg: Rowohlt, 1960/61). 
einer Sprache aufgewachsen zu sein und bestimmte Floskeln anderer Sprachen für den alltäglichen Gebrauch zu beherrschen und unhinterfragt wie selbstverständlich im Alltagssprachgebrauch zu verwenden. So war es keine Seltenheit, dass Ungarisch als Erstsprache, Deutsch als Schulsprache und beispielsweise Tschechisch als Verhandlungssprache zur Sprachrealität der Budapester oder Wiener Bevölkerung gehörten, ebenso, wie die New Yorker Bevölkerung in einer Mischung von Yiddisch, English und Italienisch keine Besonderheit ausmachte. Erst die zunehmenden Nationalismen waren darum bemüht, diese polyglotte Sprachrealität des Alltags zu negieren. ${ }^{102}$

Wie lebensnotwendig sich eben nicht die eine Sprache, wie von den Nationalisten proklamiert, sondern das Beherrschen verschiedener Sprachen (in unterschiedlichen Elaboriertheitsstufen) erwies, zeigt das Stück Der Afrikareisende. Hier wird das Aushandeln zwischen einer Differenzierung und einer Identifikation mit dem Tschechischen im Zusammentreffen in der, ,jüdischen Wüste " mit einem Löwen, der den Protagonisten fressen will, evident. ${ }^{103}$ Als er zu dem Löwen ,strc prst skrs krk”(steck den Finger in den Rachen) sagt, beginnt dieser zu lachen, ihn freundschaftlich anzublicken und wendet sich schließlich ab. Wenzl Jerabek erklärt das dem Publikum folgendermaßen: „Und wie i ma den Kerl genauer anschau, sich i, daß er zwa Schwafeln hat. Er war böhmischer Löwe, Landsmann meiniges. “104 Die antiböhmischen Stereotype gehören ebenso zum Denken des Protagonisten wie das Hoffen und Fluchen auf Tschechisch und ein in prekären Situationen (wie der lebensgefährlichen Begegnung mit dem Löwen) auftauchender tschechischer Patriotismus, vielleicht sogar Nationalismus. Damit zeigt sich nicht nur einmal mehr, wie sich sprachliche Vielfalt, nationale Diskurse und Zuschreibungen des ,Jüdischen“ überlappten, sondern auch, dass deren vermeintliche Opposition als realitätsfern erkannt wurde. Das Zusammentreffen mit dem Löwen kann als paradigmatischer Ausdruck dafür gesehen werden, dass in einer absolut fremden Situation, in der üblicherweise nur Differenzempfindung erwartet werden würde, doch auch Bekanntes und Ähnliches spontan artikuliert werden können: Als sich nämlich der Löwe um-

102 Dass die Bemühungen, alltägliche Mehrsprachigkeit zu negieren, nicht erfolglos blieben, spiegelt sich nach wie vor eindringlich in den historiographischen Narrativen, die sich über die Habsburgermonarchie finden, wider. Siehe hierzu Zahra, „Imagined Noncommunities“, 93-119. Zur Funktion von Sprachvariationen und Mehrsprachigkeit in Stücken siehe Bill Ashcroft, Gareth Griffiths, Helen Tiffin, The Empire Writes Back: Theory and Practice in Post-colonial Literatures (London, New York: Routledge, 2002), 50-76.

103 David Rechter, „Ethnicity and the Politics of Welfare: The Case of Habsburg Austrian Jewry“, Simon Dubnow Institute Yearbook 1 (2002): 257-276.

104 Siehe Wappentier des Königreichs Böhmen. Heinrich Eisenbach, Der Afrikareisende. NÖLA, NÖ Reg. Präs. Theater TB - Textbücher der Theaterzensur 116/3. 
dreht und der Protagonist seine zwei Schwänze sieht und ihn als böhmischen Löwen erkennt. ${ }^{105}$

Die Stücke und Lieder spielen immer wieder mit Zuschreibungen des „Jüdischen“. Im Stück Der Afrikareisende etwa wird durch einen suggerierten Verständnisfehler die „Wüste Sahara“ zur jüdischen „Wüste Sarah“. 106 Der wienerisch-tschechische Protagonist gibt vor, die fremde Lokalisation in Afrika zu kennen, indem er eine „bekannte“ Komponente hinzufügt und sie zur vermeintlichen „Wüste Sarah“ macht und den ihm bekannten Namen als ,jüdischen" Namen kategorisiert. Über diese Assoziationen schafft der Protagonist Verortungsmöglichkeiten im unbekannten Raum und dadurch auch Anknüpfungspunkte für das Publikum. Die ,jüdische Wüste“ bringt aber noch etwas mit ein: Im zeitgenössischen Diskurs galt das Sprechen über die "jüdische Wüste" als Referenz auf Palästina und den Zionismus. ${ }^{107}$

Die genannten Beispiele von populären Liedern und Stücken geben somit Aufschluss über den kommunikativen Umgang mit Differenzen, die über das Phänomen „Reisen“ in seinen unterschiedlichen Interpretationsformen verhandelt wurden. ${ }^{108}$ Scheint es auch zunächst so, als würde ausschließlich das ,Andere verhandelt, beziehen sich die aufgeworfenen Vorstellungen über Differenzen immer zurück auf den Protagonisten oder die Protagonistin im Stück. Das macht Normen umkehrbar und gewissermaßen re-interpretierbar. Nicht im ausschließlichen Rekurrieren auf Differenzen funktionieren die Stücke, sondern in einem Ausloten von „Gleichheit" und „Unterschied“. Die Stücke und Lieder erweitern so Lesarten von nationalen Stereotypen ebenso wie Vorstellungen über ,Jüdischkeit' oder Geschlechternormen.

Die Aufforderung, Ansprüche, Wertvorstellungen und Vorurteile über Geschlechterrollen und Gesellschaft zu reflektieren, führt die Sängerin des Liedes Der Reisekoffer vor. Als Dame des Bürgertums lebt sie den Spaß der Reise im gemischt-geschlechtlichen Abteil aus. Aus der Misere, dabei erwischt zu werden, gestaltet die Sängerin eine amüsante Szene, in der sie es zudem vermag, sämtliche Ansprüche, die an Frauen um die Jahrhundertwende gestellt wurden, als lächerlich vorzuführen. Auch in Der Reisekoffer dient der Blick auf Mobilität dem Ausloten unterschiedlicher Stereotype. Die Konzeption der Szene als Reise einer Nichte zu ihrer Tante spiegelt Vorstellungen über die Bourgeoisie wider. Die Gedankenwelt, die sich der Protagonistin durch ihre Reisebekanntschaft eröffnet, greift dahingegen Diskurse über Geschlechterrollen und -normen auf.

105 Heinrich Eisenbach, Der Afrikareisende. NÖLA, NÖ Reg. Präs. Theater TB - Textbücher der Theaterzensur 116/3.

106 Ebda.

107 Ich möchte mich bei Frank Stern für den Hinweis darauf bedanken.

108 Kimmich, Orte der Ähnlichkeit, 189. 
Zunächst verspricht die Nichte ihrer Tante, alleine und im Frauenabteil des Zuges zu reisen, jedenfalls jeden Kontakt zu Männern zu meiden. ${ }^{109}$

Das Versprechen, das die Nichte ihrer Tante gibt (nämlich als alleinreisende Frau vorsichtig zu sein und keinesfalls in Kontakt mit Männern zu treten) ist im Zusammenhang mit dem zeitgenössischen Problem des Mädchenhandels zu sehen. Männer, die mit Mädchen und jungen Frauen unweit von deren Zuhause in Kontakt traten und sie überzeugten oder überwältigten, mit ihnen zu kommen und als Prostituierte für sie zu arbeiten, prägten das Bild des umherfahrenden Mädchenhändlers, des ,jüdischen Mädchenhändlers“. Zum einen entstand das Stereotyp des ,jüdischen Mädchenhändlers“, weil viele der Opfer der Menschenhändler Jüdinnen und Juden waren. Zum anderen nährten aber gerade auch antisemitische Vorurteile eine in den Debatten als ,jüdisch“ bezeichnete Gefahr. Die Aufregung darüber bestand vor allem daraus, zu debattieren, wie Frauen vor dem ,jüdischen Mädchenhändler “ beschützt werden könnten. ${ }^{110}$ Jedenfalls führte eine gehäufte Zahl an Vorkommnissen dieser Art - die vom willentlichen Mitkommen wie unwillentlichen Entführungen von Mädchen und jungen Frauen reichten - zu einer Panik. ${ }^{11}$ Gemeinsam mit anderen (im vorherigen Kapitel aufgezeigten) Gefahren, zeigte die Angst davor, man selbst oder die Töchter könnten Opfer des Mädchenhandels werden und in Bordelle in den östlichen und südöstlichen Gebieten Europas oder Südamerikas verschleppt werden, dass das Reisen zunehmend als ein Gefahren Ausgesetztsein empfunden wurde.

Obwohl Reisen als gefährlich erlebt wurde, bedeutete es ebenso Abenteuer. Trotz der Angst und den Vorbehalten, Frauen allein reisen zu lassen, herrschte offensichtlich auch Einigkeit darüber, dass eine Reise im „gemischten Abteil“ viel vergnüglicher war. Deshalb setzte sich die Protagonistin über das Versprechen hinweg und musste schließlich darüber nachdenken, was sie denn nun am Ende der Reise mit einer Krawatte und Hosenträgern anfangen solle. Die Komposition der Szene erschöpft sich folglich nicht in einer vermeintlichen Dichotomie von männlichen und weiblichen Stereotypen. Vielmehr zeigt die Protagonistin im Vorführen ihrer aufkommenden Gedanken, dass sich die Konstruktion von Geschlechternormen und -klischees wechselseitig zwischen allen Geschlechterkonstruktionen ergibt. So bleibt die Sängerin nicht nur dabei, sich zu fragen, was sie nun mit den Habseligkeiten des Mannes machen solle; sie monologisiert auch darüber, wie ihre männliche Reisebekanntschaft mit dem Strumpfband und dergleichen in ihrem Koffer wohl umgehen werde. Für

109 Peter W. Marx, Ein theatralisches Zeitalter: Bürgerliche Selbstinszenierungen um 1900 (Tübingen: Francke, 2008), 226-240.

110 Stauter-Halsted, „A Generation of Monsters“, 25-35.

111 Wingfield, The World of Prostitution, 10-12. 
den als weiblich ausgewiesenen Charakter haben folglich die Erfahrungen des als männlich entworfenen Gegenpartes eine ebenso wesentliche Bedeutung wie das Selbst, das sich für den Inhalt des Koffers schämt. ${ }^{112}$ Dabei zeigt das Lied Der Reisekoffer die Subversivität, die die vermeintlich banal erscheinenden Inhalte populärer Kultur innehatten. Risa Basté gelang mit dem Lied und der Art, wie sie es vorführte, ein modernistisch rebellischer Akt. Um 1900 galt es für Frauen als unschicklich, über Kleidungsstücke von Männern zu sprechen. Stefan Zweig schrieb davon, dass sogar eigene Ausdrücke kreiert wurden um Gemeintes, nicht Sagbares trotzdem adressieren zu können.

[I]mmer schien der damaligen Welt der ,Anstand' in tödlicher Gefahr: bei jeder Geste, bei jedem Wort. Vielleicht wird man heute noch verstehen, daß es in jener Zeit als Verbrechen gegolten, wenn eine Frau bei Sport oder Spiel eine Hose angelegt hätte. Aber wie die hysterische Prüderie begreiflich machen, daß eine Dame das Wort ,Hose damals überhaupt nicht über die Lippen bringen durfte? Sie mußte, wenn sie schon der Existenz eines so sinngefährlichen Objektes wie einer Männerhose überhaupt Erwähnung tat, dafür das unschuldige ,Beinkleid' oder die eigens erfundene ausweichende Bezeichnung ,Die Unaussprechlichen' wählen. ${ }^{113}$

Um nicht mit der Zensurbehörde in Konflikt zu geraten, sang die Volkssängerin also nicht von den Dingen, die sie nach dem schnellen Aufbruch und der Verwechslung des Koffers vorfand. Sie hatte die Gegenstände zur Illustration dabei. So musste sie nicht die Worte benutzen und konnte doch direkt darauf rekurrieren. Gleichzeitig macht sie sich darüber lustig, dass sie das Wort für das Kleidungsstück nicht verwenden durfte.

Eine andere Strategie, auf negative Stereotype und Redewendungen zu verweisen, verfolgten die Volkssänger*innen mit deren impliziter Verwendung. Sie inkludierten sie unterschwelliger und beiläufiger, also dem Gebrauch von Stereotypen im Alltag nahekommend. Wie etwa die ,jüdische Wüste“ im zuvor diskutierten Stück Der Afrikareisende, ließen sie hie und da gängige Klischees über die „böhmische Arbeitsmoral“, „böhmische Gepflogenheiten“ und Ähnliches fallen. In der Reise nach Paris wird das etwa mit der Feststellung „[w]ie ich in die Taschen greif, da is die Brieftasch weg, / Im Gedräng da hat mir scheint, wer hätt so was gedacht, / ein Pariser Gauner ein böhmischen Zirkel g'macht [...] "illustriert. ${ }^{114}$ „Einen böhmischen Zirkel machen“ war eine Redensart, die im ausgehenden 19. Jahrhundert die Ausübung eines Taschendiebstahls

112 Risa Basté, Liedertexte. NÖLA, NÖ Reg. Präs. Theater TB - Textbücher der Theaterzensur $117 / 24$.

113 Zweig, Die Welt von Gestern, 93-94.

114 Louis Taufstein, Die Reise nach Paris. NÖLA, NÖ Reg. Präs. Theater TB - Textbücher der Theaterzensur 116/23. 
bedeutete und als Anspielung auf die Vorbehalte gegenüber der tschechischen Bevölkerung Wiens entstand. ${ }^{115}$ In diesem Wiener Volkssängerstück verwendet der Protagonist die ihm und dem Publikum geläufige Zuordnung sodann für die Beschreibung der nicht bekannten Pariser Umstände und damit sich das Publikum eine Vorstellung darüber machen konnte, was ein Pariser Gauner tat. Das sollte die Situation erklären und für Amüsement sorgen.

Die populären Lieder und Stücke referierten ständig auf geteilte Lebenswelten von Jüdinnen und Juden und Nichtjüdinnen und Nichtjuden. Zum einen spielten die Künstler*innen mit als ,jüdisch“ Konzipiertem. Zum anderen griffen sie antisemitische Stereotype auf, verwendeten Floskeln und Assoziationen. Derartige Referenzen waren in allen Stücken evident. An anderer Stelle verwendeten die Künstler*innen „Jargon“, Wiener Dialekt und das sogenannte „Jiddeln“, - also eine Mischung aus Jiddisch und dem restlichen Wiener, Budapester und New Yorker Sprachenpolyglott -, an der wieder nächsten variierten sie jiddische/,jüdische Ausdrücke (eppes, euweh etc.) oder flochten Ausrufe wie „bist du meschugge“ ein. ${ }^{116}$ Die Künstler*innen verwendeten derartige Phrasen und Redewendungen weder als außergewöhnlich noch zur Markierung einer Differenz. Vielmehr benutzten sie sie so, wie im alltäglichen Hörund Sprachgebrauch gewöhnt, nämlich selbstverständlich und beiläufig. Gibt es in den Stücken mehrere Personen, kommt es nicht zu einer expliziten $\mathrm{Zu}-$ weisung eines spezifischen Wortschatzes zu einzelnen Figuren, sondern einer gleichmäßigen Verwendung des bunt gemischten Wortschatzes von allen, lediglich die Intensität konnte variieren. Damit illustrieren die Volkssänger*innen sehr deutlich, dass nicht ein Monolingualismus verschiedene ethnisch oder national abzugrenzende Gruppen einte, sondern gerade im Sprachgebrauch die Plurikulturalität der Städte ihren Ausdruck fand und erst recht keine getrennt jüdische und nichtjüdische Aufführungsrezeption existierte.

Eine ähnliche Funktion wie das Einpflegen von jüdischen und anderen Stereotypen erfüllte das latente Verwenden von sexuellen Anspielungen, die Künstlerinnen in den Stücken mehr oder weniger offensichtlich artikulieren. In Der Afrikareisende geschieht das mit einem kolonialistischen Blick auf die vermeintlich afrikanische Frau. Diese stellt das Stück als Mittel zum Zweck dar. Solange sich der Protagonist in einer Notlage befindet und auf die Hilfe der „Tochter des Stammeshäuptlings" angewiesen ist, verspricht er, sie mit nach Europa zu nehmen und zu heiraten. Zurück in Wien, sucht er sich aber lieber eine „Böhmin“, die mit abwertenden Klischees über tschechische Frauen denunziert wird:

115 Zur Redewendung und ihrer karikaturistischen Darstellung über Tschech*innen siehe Becher, Österreicher und Tschechen in der Karikatur, 42.

116 Andreas Nachama, Jiddisch im Berliner Jargon: Oder: Hebräische Sprachelemente im deutschen Wortschatz (Berlin: Jaron, 2007). 
I bin scho auf der afrikanischen Speisekarte g'stande. Sie, das is Ihnen ka Annehmlichkeit! In Wienerstadt in Café Edison hab i immer klane Schwarze zu mir genommen, und jetzt hättens sollen füllen die klane Schwarzen mie verspeisen! Der Häuptling hat sie schon Magen eingricht auf mie Schwarzscherzl und die Frau die is wieder auf's vordere g'flog'e. Aber in der Nacht is Tochter von Häuptling zu mir kummen, und hat gsagt, wann i’s mitnimm nach Europa als meine Frau, so schenkt mir Freiheit. I hab ihr natürlich alles Mögliche versprochen, aber wie i dann frei war, hab i mir denkt: Kannst mi gern hab’n, schwarze Stiefelwichs! Und nächste mal. mirs wieder dan Kitzlichen Punkt bei mir berührt, und von Heiraten ang'fangt hat, bin i ihr durchgangen. So, jetzt bin i wieder in Wienastadt, und heirat wollte Bähmin mit Massa Penise. Vielleicht wissens mir passende Parthie?[!] ${ }^{117}$

In Der Reisende spricht der Volkssänger über die körperliche Beziehung zwischen ihm, dem Praktikanten, und seiner Chefin, die umgangssprachlich mit „Nummerieren“ ausgedrückt wird. Das „Nummerieren“, also die Affäre, löst überhaupt erst die Mobilität des Reisenden in dem Stück aus und setzt diese auch fort, denn in der nächsten Anstellung scheitert er wieder wegen seiner unersättlichen Lust und muss mobil bleiben. Schließlich gelangt er aber trotzdem als Reisender zu Lebensweisheit und beruflichen Fertigkeiten. Die Reisende in Der Reisekoffer ist aufgrund einer gesellschaftlichen Konvention mobil, die den Besuch der Tante vorsah und als Ausdruck bürgerlichen Reisens interpretiert werden kann. Dabei veranlasst sie aber das Interesse an Männern, nicht im Frauenabteil zu reisen. Und schließlich ist es auf der Reise nach Paris dem Einsatz der Ehefrau des Protagonisten zu verdanken, dass das Wiener Ehepaar sich aus der misslichen Lage ohne Geld zu sein befreien kann: Mit ihren Reizen und sexuellen Versprechungen angelt sich die Frau einen französischen Kavalier, der ihre Rechnung begleicht.

Überhaupt bot sich die Situation des Reisens in ihren unterschiedlichen Ausdrucksformen dazu an, Intimität zu thematisieren, war sie doch gerade im Unterwegssein ständig auf die Probe gestellt. Zudem bot sich Intimität an, um unterschiedlich intensive Beziehungen zwischen Jüdinnen und Juden und Nichtjüdinnen und Nichtjuden zu diskutieren.

\subsection{Beziehungen und das Intime}

In den frühen Morgenstunden des 10. April 1836 wurde in Manhattan die Leiche von Helen Jewett (1813-1836) gefunden. Ein gelegtes Feuer sollte verschleiern, dass die „Edelhure“ erschlagen wurde. Zwei Männer wurden angeklagt, wer

117 Heinrich Eisenbach, Der Afrikareisende. NÖLA, NÖ Reg. Präs. Theater TB - Textbücher der Theaterzensur 116/3. 
aber Helen Jewetts Mörder gewesen war, konnte nie eindeutig geklärt werden. Des Mordes angeklagt war der 19-jährige Richard Robinson. Aufgrund seiner Bekanntschaft zu politisch einflussreichen Leuten wurde jedoch nie eine Strafe verhängt. Die Berichterstattung im New York Herald entfachte eine Diskussion darüber, ob Robinson tatsächlich unschuldig war und ob es rechtmäßig sei, einen Mord, auch wenn „lediglich“ an einer Prostituierten, nicht zu sühnen. Die Meinungen der Presse und der Öffentlichkeit gingen auseinander. Die Öffentlichkeit diskutierte wochenlang darüber. ${ }^{118}$ Der Fall Helen Jewett entwickelte sich zu einem der ersten bekannten Beispiele für eine Auseinandersetzung mit Sexualität und Prostitution im öffentlichen Raum. Neu an der Diskussion über den Mord an der Prostituierten war, dass viele Menschen Stellung für die Prostituierte bezogen und intime Erfahrungen plötzlich als Diskussionsgut in der Gesellschaft angekommen waren: Kampagnen wurden gestartet, es kam zu Interventionen und Diskussionen über „low- and upscale prostitution“, also über Sexarbeit auf der Straße und in noblen Bordellen. ${ }^{119}$

\section{Die jüdische Straßensängerin - Adaptionen des Bildes der Varitédame/Volkssängerin}

Die Varieté- und Etablissementszene New Yorks griff rund fünfzig Jahre später diese Diskussion wieder auf. Sie sollte das Bild von der ,jüdischen Straßensängerin“ nachhaltig prägen. Zu diesem Zeitpunkt war von dieser offenen Diskussion über Sexualität und Prostitution, die der Fall Helen Jewett evoziert hatte, nicht mehr viel übrig. Die Szene populärer Kultur an der Bowery griff die Themen "Sexualität und Prostitution“ sodann wieder auf. Boris Thomashefsky holte die Themen in die Theater, als er 1903 für das People's Theatre eine Adaption von Victor Hugos Glöckner von Notre Dame schrieb. Er ließ Victor Hugos Glöckner von Notre Dame zur jüdischen Straßensängerin in New York werden ${ }^{120}$ und griff Prostitution im Kontext von Straßenmusik, Bettelwesen und Street Arabs (Straßenkindern) an der Lower East Side auf. Thomashefsky war dafür bekannt, Klassiker nicht nur in ,jüdische“, sondern auch in Migrationskontexte zu setzen. So adaptierte er Hugos Glöckner von Notre Dame ebenso wie Shakespeares Hamlet und andere Werke zum Beispiel als Hamlet oder der Yeshiva Schüler an Alltagsszenen an der New Yorker Lower East Side. ${ }^{121}$

118 Cohen, „The Mystery of Helen Jewett“, NYT, 6.8.1899, 10.

119 The Bowery Boys, Who killed Helen Jewett: A mystery by gaslight (New York, Radiosendung ausgestrahlt am 17.2.2017); Cline Cohen Patricia, The murder of Helen Jewett (Newport Beach: Books on Tape, 1998).

120 NYPL, Dorot Jewish Division, Theater Collection: Thomashefsky Boris, Der bes hamedresh unter der erd, oder, die Yudishe shtrassen zengerin, P (Ms. Yid. 20).

121 Halpern, Boris Thomashefsky, 122. 
In diesem Stück steht den sonst als betörende Bühnenvamps agierenden weiblichen Charakteren die ,jüdische Straßensängerin in New York“ gegenüber. In Thomashefskys Version des Glöckners wurde die Straßensängerinnen an der Bowery zum Inbegriff von „lowscale prostitution“. Zudem stellt sie eine neue Form des Bettelns, eine Art Verbindung zwischen Bettelwesens und der Populärkultur, dar. Das Stück bekam den Titel Der Beit Hmdrsh ointer der erd oder da Idishe Shtroßen Zengerin (Straßensängerin) und wurde am 4. Jänner 1903 erstmals als Einakter, dann in neuer und kürzerer Version 1907, schließlich 1928 als Kurzposse aufgeführt. ${ }^{122}$

Das Stück handelt von einem jüdischen Straßenmädchen, das verwaist bei einem Rabbi an der Bowery aufwächst. Dem Titel Die Lehrjahre in der Hölle, oder das Dasein als jüdische Straßensängerin gerecht werdend, ist die verwaiste Hauptprotagonistin ab dem jungen Erwachsenenalter dazu gezwungen, in den Straßen zu singen, um sich einen Lebensunterhalt zu verdienen. Bald allerdings singt sie nicht mehr nur für ihr Publikum, sondern muss, um nicht zu verhungern, sexuelle Dienste anbieten. Zur Zeit der Erstaufführung des Stückes hatte Prostitution an der Lower East Side im Allgemeinen und an der Bowery im Besonderen massiv zugenommen. Allein entlang der Bowery gab es innerhalb von zehn Blöcken rund 70 Stätten der Prostitution. ${ }^{123}$ Das Werben um potentielle Kunden in den Straßen ging beinahe schon aggressiv zu. Unabhängig von Tages- oder Nachtzeit warben die Prostituierten für eine "gute Zeit" mit ihnen. ${ }^{124}$

Im Stück gibt es insgesamt zwölf Charaktere. Alle, außer die der ,jüdischen Straßensängerin" Florendin, sind zugleich als italienische wie auch jüdische Charaktere entworfen: Dona Estela de Sillva oder Ester de Shlomo, Tsiperania oder Tsiporah. Die Figuren unterliegen zudem der schon angesprochenen Praxis des Gender-Bendings. Ein paar sind sowohl als Frauen- als auch Männerrollen (Rafael oder Rafaela) konzipiert. Außerdem können andere Charaktere (außer Florendin) von Männern oder Frauen gespielt werden: Schauspielerinnen konnten die Männerrollen verkörpern, wie auch Schauspieler die Frauenrollen spielen konnten; das heißt Ester de Shlomo konnte von einem Mann verkörpert werden.

122 J. Greenfield bearbeitete das Manuskript für die Aufführung einer gekürzten Version ab 7. März 1907. Aufgrund der Anmerkungen im Manuskript kann vermutet werden, dass Greenfield nur etwa zwei Drittel der Figuren übernahm. Im Manuskript vermerkte Max Friedländer, dass er die Version von Mai 1925 bearbeitete.

123 Gilfoyle verzeichnet für die Bowery zwischen 1900 und 1909 zumindest 56 Stätten der Prostitution mehr als noch in den 1880er Jahren. Timothy Gilfoyle, City of Eros: New York City, Prostitution, and the Commercialization of Sex, 1790-1920 (New York, London: W.W. Norton, 1992), siehe Abbildungen 9 und 10 auf 200-201.

124 Gilfoyle, City of Eros, 215-218. 
Florendin, die in den "Gossen“ von einem Reb (jidd. Rabbi) aufgezogen wird, muss jederzeit für mögliche Geldgeber verfügbar sein. Diese Art des Einkommens rund um sexuelle Gefälligkeiten für Männer in den Straßen wird Dreh- und Angelpunkt einer Diskussion im Stück, in Folge derer schließlich der Straßensängerin das Recht auf Liebe abgesprochen wird: Drei „edle Damen“, die zu einer Theateraufführung an die Bowery, eine Straße neben der Wohnund Arbeitsstätte der jüdischen Straßensängerin, gekommen sind, beobachten eine Szene im täglichen Arbeitsleben von Florendin. Sie sind über den Umstand entsetzt, dass sie für Geld tanzt und singt und mit Männern in ihrem Verschlag verschwindet. Daraufhin beginnen sie ein Gespräch mit der Straßensängerin. Besonders echauffieren sich die edlen Damen darüber, dass die Straßensängerin es wagt, bei einem solchen Treiben von Liebe zu singen:

Florendin: noch eines soll ich singen? Ich weiß - das eine, ein Neues, was abends alle meine Verehrer zu hören lieben. [...]

Tsipora [ein Dienstmädchen von Donna Estela/Ester de Shlomo]: Zu [singen] von Liebe? Soll das heißen du bist verliebt?

Florendin: Ich? Und verliebt? Wie soll das zusammenpassen? Wer wird das Liebe nennen, von einer armen Straßensängerin, einer Bettlerin, die ihr Brot durch Singen und Tanzen in der Gasse verdient. Wenn ein junger Mann besoffen ist [...] Verliebt? Ich ha ha ha. Dann könnte man eine Geschichte von mir als Narr erzählen.[!] ${ }^{125}$

In weiterer Folge des Gesprächs sprechen sie der Straßensängerin - letztlich wegen ihres Migrationshintergrundes - das Recht auf Liebe ab. Zurückkommend auf die Praxis des Gender-Bendings erscheint besonders spannend, dass gerade die Hauptrolle aus der üblichen breiten Praxis der Geschlechterbesetzungen hinausfiel. Die Regienotiz sah vor, dass Florendin tatsächlich von einer Frau verkörpert werden sollte. Der Autor zielte somit auf eine bewusste Hinterfragung der Rolle der jüdischen Migrantin, ihrer Tätigkeit als Straßensängerin, ein Bild, das eng verbunden war mit jenem der Volkssängerin und das Assoziationen mit Prostitution wieder aufgriff. Verlagert in den neuen Kontext der Rolle und in Zusammenhang mit dem Faktum, dass auch an der Lower East Side „sex sells" weit verbreitet war, trug das Stück zu einer Diskussion des Rollenbildes bei.

Die Gesprächssituation zwischen den edlen Damen, die auch von Männern verkörpert werden konnten, stellt eine besondere Aushandlung von Geschlechterverhältnissen dar: Sie diskutieren mit der Straßensängerin über das Verhalten

125 Thomashefsky Boris, Der bes hamedresh unter der erd, oder, die Yudishe shtrassen zengerin, P (Ms. Yid. 20). NYPL, Dorot Jewish Division, Theater Collection. 
anderer Männer gegenüber Immigrantinnen. ${ }^{126}$ Die Intention, die den sogenannten „Hosenrollen“ zugrunde liegt, kann im Sinne einer bestmöglichen Aneignung maximaler Geschlechterdifferenz interpretiert werden. In Hosenbeziehungsweise Kleiderrollen wollen die Schauspieler ${ }^{*}$ innen die sogenannte „Kopie des ,Anderen““ bestmöglich darstellen und als möglichst ähnlich verkaufen; um dann die Ähnlichkeit (gegebenenfalls) in der Inszenierung bewusst brechen und als Differenz darstellen zu können.

Neben Armut und Prostitution machte Thomashefsky die Vorlieben der Bewohner*innen der „Jewtown“ zum Thema des Stückes. Damit brachte er, neben Armut und Prostitution in der Straßensängerinnenszene, auch die Bedeutung von Unterhaltung im Alltag auf die Bühne des People's Theatre. Das Stück ist Teil der Theaterszene und benutzt die Charaktere, um über die Populärkultur zu reflektieren. Einerseits, in dem es den Einfluss von Migration auf die Unterhaltungsszene anspricht, andererseits aber vor allem im Hinblick darauf, wie diejenigen, die sich damit den Lebensunterhalt verdienen mussten, negativ beäugt werden. Das Stück zeigt nämlich, wie die sogenannten „Edlen“ (der Teil der New Yorker Bevölkerung ohne Migrationshintergrund) sich über die Künstlerinnen in den Straßen, auf ihren Wegen in die Theater, wo sie sich sodann von ihnen unterhalten ließen, äußerten.

Somit kann die zweite Erzählebene als Verweis auf die Situation des Publikums vor und nach den Aufführungen gelesen werden. Als gewissermaßen reale Erzählwelt wird selbige subversiv genutzt und gibt den sonst nur als Unterhaltungsfaktoren wahrgenommen Akteur ${ }^{\star}$ innen eine Stimme. ${ }^{127}$ Denn die Theater und Music Halls an der Bowery wurden nicht ausschließlich von Migrant ${ }^{\star}$ innen besucht und die Stücke konnten als Sprachrohr der Migrant ${ }^{\star}$ innen fungieren. Die Besucher ${ }^{\star}$ innen ohne Migrationshintergrund sind im Stück als „Edle“ dargestellt. Im zeitgenössischen Diskurs kritisierten sie die Populärkultur meist und nahmen die Akteur*innen kaum bis gar nicht als Individuen wahr. Die aus der Perspektive Florendins erlebte Erzählung im Stück macht ihr Schicksal zum Teil einer Ich-Wahrnehmung des Publikums und so zu einer erlebbaren Ähnlichkeit. Der Raum der Aufführung ermöglicht ein Statement

126 Für dieses Reflektieren über alte und neue Traditionen und Rollenvorstellungen boten die New Yorker Bühnen viel länger Raum als die Wiens und Budapests. Eine der bekanntesten Inszenierungen des Rollenwechselns ist verbunden mit der Schauspielerin Molly Picon. Siehe Kapitel 3.

127 Gayatri Chakravorty-Spivak, Can the Subaltern Speak? Postkolonialität und subalterne Artikulation, mit einer Einleitung von Hito Steyerl (Es kommt darauf an 6) (Berlin, Wien: Turia+Kant 2014)., 12-16. Zum inkludierenden Potential von Transferprozessen zwischen sozialen Gruppen siehe Katharina Scherke, Kulturelle Transfers zwischen sozialen Gruppierungen, in: Federico Celestini, Helga Mitterbauer (Hg.), Ver-rückte Kulturen: Zur Dynamik kultureller Transfers (Stauffenburg Discussion 22) (Tübingen: Stauffenberg, 2011), 99-116. 
der sonst „Ungehörten“. So können auch die Akteurinnen der Populärkultur ihre Lesart etwa des Stereotyps der vermeintlich jüdischen Straßensängerin artikulieren. Das Wechselspiel von Genderdiversität durch Ähnlichkeitsreferenzen und das Auftreten von traditionell interpretierten Geschlechterrollen eröffnen hier ein subversives Potential.

Das Stück vermischt folglich verschiedenste religiöse wie kulturelle Identifikationen. Der Rabbi etwa verweist auf religiöse Tradition. Die Figur sorgt für das verwaiste Kind und steht damit für Fürsorge und Sittlichkeit, institutionalisiert im Judentum. Damit war die Figur die personifizierte Referenz auf die Bedeutung jüdisch-religiöser Tradition. Der Rabbi spricht Jiddisch ebenso wie Englisch und ein paar Floskeln Italienisch und Spanisch. Im Entwurf der Szene an der Bowery (dem Teil des Broadways an der Lower East Side), trifft die Figur des Rabbi auf die moderne plurikulturelle Welt der Migrant*innen aus verschiedenen Teilen Europas. Die Einbettung der Szene in den Alltag der Straßensängerin kreiert Eindrücke vom Leben der Migrant ${ }^{\star}$ innen dort. Ebenso erinnert ihre Tätigkeit als Straßensängerin an die Unterhaltungsszene und an die vielen kulturell ,jüdischen“ Identifikationen. Die Benennung der anderen Charaktere spiegelt die mehrfache Überlagerung von vermeintlich nationalen Kontexten wider und führt zudem die Unzulänglichkeit eindeutiger Geschlechterzuordnungen vor. ${ }^{128}$

Wie diese Adaptionen - das Neuaufgreifen, Erweitern, Anpassen, Umstrukturieren, Verändern - von Stücken zeigen, birgt bei dieser Art der Übersetzung nicht die Frage nach einem Original, sondern der Prozess an sich das subversive Potential. Nach Homi Bhabha gehe es dabei nicht um die Frage nach einem Original, das sodann adaptiert werde oder Bestätigung erfahren müsse.

$[\mathrm{T}]$ ranslation is also a way of [...] imitating an original in such a way that the priority of the original is not reinforced but by the very fact that it can be simulated, copied, transferred, transformed, made into a simulacrum and so on: the original is never finished or complete itself. [...] What this really means is that cultures are only constituted in relation to that otherness internal to their own symbol-forming activity which makes them decentered structures - though that displacement or liminality opens up the possibility of articulating different, even incommensurable cultural practices and priorities. ${ }^{129}$

128 Zur mehrfachen Codierung, Überlagerung und Umdeutung von Stereotypen siehe Federico Celestini, Um-Deutung: Transfers als Kontextwechsel mehrfach kodierbarer kultureller Elemente, in: ders., Herlga Mitterbauer (Hg.), Ver-rückte Kulturen: Zur Dynamik kultureller Transfers (Stauffenburg Discussion 22) (Tübingen: Stauffenberg, 2011), 37-52, 44-48.

129 Jonathan Rutherford, The Third Space: Interview with Homi Bhabha, in: ders. (Hg.), Identity: Community, Culture, Difference (London: Lawrence \& Wishart, 1990), 207-221, 210. 
Stuart Hall schreibt dazu, dass kultureller Austausch und Übersetzen überhaupt kein Original kennen. Übersetzungen seien kontinuierliche Prozesse von Wiederartikulation und ein Setzen von Ideen in neue Kontexte. ${ }^{130}$

\section{Operettenadaptionen}

Ein anderes Beispiel, wie unterschiedliche sprachliche Kontexte und kulturelle Affiliationen ineinanderliefen, bietet die internationale Rezeptionsgeschichte des vermeintlich ungarischen Csárdás. In Form von Emmerich Kálmáns Erfolgsoperette Die Csárdásfürstin machte sich der Csárdás in den Varietés Budapests und Wiens ebenso gut wie an der Bowery in New York. Ähnlich wie Victor Hugos Glöckner von Notre Dame wurde auch die Csárdásfürstin für die Etablissements der Bowery adaptiert. Dieses Stück ist eine Allegorie auf die Figur der Volkssängerin respektive Soubrette in der Szene populärer Kultur ein Stoff, der das Publikum zu faszinieren schien.

In der ersten Version, von den Wiener und Budapester Autoren Leo Stein und Bela Jenbach geschrieben und von Emmerich Kálmán vertont, wurde die Operette zuerst unter dem Titel Alles für die Liebe bei der Zensur in Wien 1915 eingereicht. ${ }^{131}$ Das Stück handelt von einem jüdischen Orpheum aus Budapest, das eine Reise nach Amerika plant, um auf Tournee zu gehen und der Liebesgeschichte zwischen Edwin und der Varietésängerin Silva. Edwin, der Sohn des Fürsten von Weylersheim, möchte Silva heiraten. Als er allerdings seinem Vater erzählt, eine Varietésängerin heiraten zu wollen, kommen sämtliche gesellschaftlichen Konventionen zur Sprache. Eine emotionale Diskussion über die vermeintlichen unehrenhaften Verbindungen zwischen der Varietészene und anderen Vergnügungsmilieus kommt auf. Silva nimmt deshalb Abstand von der Heirat und will schließlich beleidigt nach Amerika abreisen. Mit diesem Szenensetting legten die Autoren der Csárdásfürstin nicht nur eine zeitnahe Auseinandersetzung mit der Orpheum- und Varietészene der Monarchie und deren Prägung durch die Themen Migration und Mobilität vor. Es gelang ihnen auch, den Wandel des Bildes der Volkssängerin zur Varietésängerin und Soubrette sowie die Tätigkeit der Künstler*innen zwischen der Monarchie und New York einzufangen.

130 Stuart Hall, Cultural Studies and the Politics of Internationalization: An Interview with Stuart Hall by Kuan-Hsing Chen, in: ders., David Morley (Hg.), Critical Dialogues in Cultural Studies (London, New York: Routledge, 2005), 393-409, 394: „Translation is a continuous process of re-articulation and re-contextualization, without any notion of primary origin."

131 Leo Stein, Bela Jenbach, Emmerich Kálmán, Es lebe die Liebe (die Csárdásfürstin). NÖLA, NÖ Reg. Präs. Theater TB - Textbücher der Theaterzensur 672/08. 
Die Csárdásfürstin wurde als Di tshardash firstin ${ }^{132}$ dem New Yorker Publikum vorgestellt. Die Operette in vier Akten in einer jiddisch-englischen (Yinglish) Übersetzung der späten 1910er Jahre adaptierte den Kontext des Stückes teilweise an die Lebensumstände in der "goldenen medine“. Um das amerikanische Publikum besser anzusprechen, wurde der Beginn neugestaltet. Die Tournee des Ensembles wird aus der amerikanischen Perspektive betrachtet; das Publikum geht im Stückverlauf nicht von Europa nach Amerika mit, sondern erlebt von Amerika aus, wie das Ensemble aus der Monarchie kommt. Damit sich das Publikum auch vorstellen kann, woher die Künstler*innen stammten und wie sie „drüben“ lebten, fügte der Autor ein vermeintlich typisches Stimmungsbild der „österreichischen“ Idylle ein.

Hei a heiei is mein heimatsland is oif di berge weit / Hea oh hea ganz hoikh oiben dort mein wiegele shteht. / Dort wo es pliht shen das edelweis. / Dort wo es glenst stes der shnee un eiz. / Hea ah hea klofen hertser wild un heiss. / Wenn a siebenbirger meidel libt sikh in dir eiz. / Nit zum shpasen nur ganz ernst zogt zie: di bist mein.[!] ${ }^{133}$

Jenem Teil des Publikums ohne Migrationserfahrung wurde mit dem bekannten Einstiegslied die eigentliche „Location“ des Ensembles vorgestellt und nahegebracht. Das weitere Stück hindurch blieb die Csárdásfürstin unverändert.

Wie die Beispiele der Aufführungen von der Csárdásfürstin und der Straßensängerin zeigten, variierte das Vorgehen in der Neuinszenierung populärer Stücke. Ein weiteres der bekanntesten Beispiele für eine derartige Adaption populärer Handlungen war das abermalige Aufgreifen und Neuinterpretieren von Abraham Goldfadens berühmter Operette Shulamit. Diese erlangte vor der Jahrhundertwende in New York Bekanntheit. Wenig später fand sie sich in kleineren und größeren Adaptionen auf den Bühnen der Monarchie. Für ein kleines Theater in Budapest wurde das Stück 1898 auf Ungarisch entworfen. Dass die Szene nicht an einen derartigen Erfolg der ungarischen Produktion glaubte, zeigte die Berichterstattung in den Zeitungen. Das Wiener Fremdenblatt berichtete über diese Aufführungen des eigentlich jiddischen Theaterstücks.

Am hiesigen ungarischen Theater wurde heute das seltene Jubiläum der hundertsten Aufführung des biblischen Singspiels, Shulamith' vor ausverkauftem Hause gefeiert. Es ist dies der erste Fall, daß ein musikalisches Werk auf einer Budapester Bühne in einer Saison hundert Aufführungen erlebte und wird die Bedeutung dieses Ereignisses noch da-

132 Emmerich Kálmán, Di tshardash firstin, Übersetzung von Julius Adler P (Ms. Yid. 105). NYPL, Dorot Jewish Division, Theater Collection: Da das Manuskript größtenteils nur transliteriert wurde, ist an dieser Stelle die jiddische Transkription zitiert.

133 Emmerich Kálmán, Di tshardash firstin, Übersetzung von Julius Adler P (Ms. Yid. 105). NYPL, Dorot Jewish Division, Theater Collection. 
durch erhöht, daß dasselbe Werk unmittelbar vorher an einer kleinen Bühne in Ofen im bescheidensten Rahmen 121mal in Szene ging.[!] ${ }^{134}$

121 erfolgreiche Aufführungen erlebten nur wenige Produktionen, weshalb Goldfadens Operette sogleich an die großen Theater der Stadt ging. Nachdem es bereits in der ungarischen Metropole enorme Beliebtheit erlangt hatte, sollte Shulamit als Export der Budapester populären Kultur nach Wien gehen. Nachdem das „biblische Singspiel“ schon diesen großen Erfolg gefeiert hatte, kam es im Sommer 1899 als Sommergastspiel ans Jantsch Theater im Wiener Prater. Sein Debüt in Wien feierte das Stück zunächst als Sulamith - Jeruzsalem leánya (ungar. Shulamit, Tochter Jerusalems) auf Ungarisch. ${ }^{135}$ In den nächsten Jahren sollte es in Wien zu mehreren Neuinszenierungen auf Ungarisch und Deutsch kommen. Hierfür adaptierte man jedoch nicht mehr die Einbettung oder Konzeption. Vielmehr vertraute man auf jenen Entwurf, der sich in Budapest als erfolgreich erwies und übertrug diesen - voraussetzend, es gäbe uneingeschränkte Übersetzbarkeit - sprachlich. ${ }^{136}$

Wie die Autor*innen mit dem Transfer von Stücken zwischen den verschiedenen Aufführungsumgebungen umgingen, variierte. Die Metapher des Reisens, der Mobilität und Bewegung ließ das Publikum eine Veränderung erwarten. So konnte eine kulturelle Übersetzung von einer sprachlichen Adaption zur vollständigen Neuinterpretation von Handlungsumfeld und Kontext, Neubenennungen von Charakteren oder lediglich der Übernahme der im Stück transportierten Moral reichen. Die Adaption der Csárdásfürstin war ein Beispiel für die Übernahme eines gesamten Stückes mit kleineren inhaltlichen Adaptionen. Anders als Thomashefskys Straßensängerin, bei deren Adaption lediglich die Idee des vermeintlich unliebsamen Charakters im städtischen Alltag, dem man zwar begegnet und wahrnimmt, aber mit dem man nicht in Kontakt tritt und daher verschiedene Vorbehalte schürt, erhalten blieb. Dennoch spielten die Künstler*innen mit der Bekanntheit des Bildes der Varietésängerin ebenso wie der Straßensängerin, um dem Publikum das Anknüpfen zu erleichtern. Dass die Künstler*innen damit erfolgreich waren, bewies nicht zuletzt auch

134 Fremdenblatt, 1.5.1899.

135 Goldfaden Abrahám, Sulamith - Jeruzsalem leánya [Shulamit - Tochter Jerusalems]. NÖLA, NÖ Reg. Präs. Theater TB - Textbücher der Theaterzensur 471/9.

136 Goldfaden Abrahám, Sulamith - Jeruzsalem leánya [Shulamit - Tochter Jerusalems]. NÖLA, NÖ Reg. Präs. Theater TB - Textbücher der Theaterzensur 274/02; Goldfaden Abrahám, Shulamit, die Tochter aus Jerusalem. NÖLA, NÖ Reg. Präs. Theater TB - Textbücher der Theaterzensur 1915/1178 K 55. Zu Übersetzbarkeit und Unübersetzbarkeit siehe Emily Apter: Against World Literature: On the Politics of Untranslateability (London: Verso, 2013), 3. Zu Weltliteratur siehe Ashcroft, Griffiths, Tiffin, Postcolonial Studies, 279-280. 
die Auseinandersetzung mit dem Bild der populären Künstlerin, wie sie in der Straßensängerin und in der Csárdásfürstin stattfand.

\section{Die Volkssängerin an der Bowery?}

Die populäre Kultur eröffnete insbesondere für Künstlerinnen einen Handlungsspielraum, der allerdings nicht immer nur zu positiven Bewertungen, wie im vorherigen Kapitel aufgezeigt, beitrug. Die Varietésängerinnen vermochten auf der Bühne, Geschlechterstereotype aufzubrechen und so ihr Publikum für sich zu gewinnen. Die facettenreichen Dimension, die in der Figur der Varietésängerin oder populären Künstlerin aufeinandertrafen, waren der Grund dafür, dass die Figur selbst immer wieder in Stücken aufgegriffen wurde, um sich mit deren Rolle in der populären Kultur auseinanderzusetzen.

Die Repräsentation des Bildes der Volkssängerin, die über die Jahre zur Varietésängerin und Soubrette wurde, reichte von der als passiv dargestellten Person bis zur „Macherin“ als diejenige in Künstlergruppen, die zu Erfolg führte und vor dem Scheitern bewahrte. Die Breite der als Volkssängerin entworfenen Charaktere reichte von der zur Prostitution gezwungenen Migrantin (wie in der Straßensängerin) bis hin zur umschwärmten Csárdásfürstin. In der Csárdásfürstin war die Figur der Varietésängerin so entworfen, dass sie dem Bild der Soubretten der Zeit entsprach. Während Florendin als Straßensängerin meist passiv dargestellt war, war Silva als aktiver Charakter des Stückes entworfen. Silva bestimmt, dass das Ensemble die Stadt verlässt und auf Tournee geht, sie entscheidet, wo die Gruppe auftritt und was dem Publikum vorgeführt wird. Von ihr ist das Ensemble abhängig, denn ohne sie wäre die Tournee zum Scheitern verurteilt. Ebenso abhängig von ihr ist der männliche Hauptprotagonist Edwin, der bemüht ist, alles zu tun, um die schöne Sängerin zurückzugewinnen. Die Repräsentation der Volkssängerin in der Inszenierung besaß den breiten Handlungsspielraum, der den Soubretten in der populären Kultur zukam.

\subsection{Das Private im Unterwegssein}

Die Entwicklung des Bildes der reisenden Soubrette und Debatten über Prostitution und Sexualität im Kontext von Migration trafen sich in Diskussionen über räumliche Aspekte des Unterwegsseins. Ob auf einem Schiff, im Zug oder bei der Ankunft in den Städten: Gerade die Frage danach, wo genächtigt werden konnte, war brisant. Das zeigte sich nicht zuletzt in den Debatten über die Unterkünfte für reisende Künstler*innen, die sogenannten „Artistenheime“, die sogleich als Stätten geheimer Prostitution verunglimpft wurden. ${ }^{137}$

137 Siehe Kapitel 4. 
Unterkünften auf Reisen kam einen ambivalenter Ruf zu. Hotels galten als gefährlich. Kriminalität war in ihnen keine Seltenheit. Übernachtungen bargen außerdem erhebliche Gesundheitsrisiken: Als 1874 das luxuriöse Grand Hotel in Stockholm eröffnete, galt es als erstes Hotel, das die Bettbezüge zwischen den Gästen bei der Neubesetzung der Zimmer wechselte. Als Raum zur Übernachtung ist ein Hotel ein privater Bereich in einem öffentlichen Umfeld. Ob es tatsächlich privat war, hing letztlich von den monetären Mitteln, die in eine Unterkunft investiert werden konnten, ab. Jedenfalls aber stand die Frage der Nächtigungsvariante in einem Spannungsfeld von Notwendigkeit und Gefahr.

Die populäre Kultur entdeckte die Ambivalenz der Frage nach Privatheit und privaten Räumen und nutzte sie, um gesellschaftspolitisch relevante Fragen zu diskutieren. Das Nächtigungsmotiv wurde dabei ebenso breit beleuchtet wie das Bild der Volkssängerin: In populären Liedern und Stücken inszenierten die Künstler*innen Schlafunterkünfte als Räume der Familie auf Reisen, als einen privaten Ort für Liebende, die sich nirgendwo sonst treffen konnten und in anderen Situationen als Lusthaus für Prostitution. Die Stücke benannten zum einen die vielen unterschiedlichen Funktionen dieser Räume ebenso, wie sie zum anderen die Ambivalenz der Beziehungen, die sich in den Übernachtungsstätten ereigneten, als Folie für Reflektion durch Amüsement nutzten. Räume wie Hotels können als sogenannte „non-lieux“ beschrieben werden; als Orte beziehungsweise Nicht-Orte - die an Bedeutung verlieren, weil die Tätigkeiten, der die Menschen an ihnen nachgehen, Priorität haben. ${ }^{138}$ Die Stücke griffen häufig die besondere Qualität des Hotels und Schlafcoupés auf, um die Eigenheit der Übernachtungsräume auf Reisen in Spiegelflächen unterschiedlichster Beziehungen zu verwandeln. In diesem Sinne ist die diesem Abschnitt zugrundeliegende Annahme, dass sich gerade die „Nicht-Ort“-Qualität von derartigen Übernachtungsräumen in den Etablissementstücken als Zwischenraum für das Aushandeln von verschiedenartigen Beziehungen - sexuellen, familiären und beruflichen - anbot. ${ }^{139}$ Die Stücke repräsentieren, wie die Gesellschaft über Privatheit und Intimität auf Reisen dachte und was darüber imaginiert wurde. Sie illustrieren pointiert, welche Normen es gab und deuten damit an, weshalb Menschen, die besonders häufig unterwegs waren, oft delikaten Vorwürfen ausgesetzt waren.

Die Stücke Im Schlafcoupé und Ein Hotel in Budapest gehen unterschiedlich mit der Privatheit des jeweiligen Übernachtungsraumes um: Während

138 Augé, Nicht-Orte, 40-43. Clifford, Traveling Cultures, 96.

139 Damit unterscheidet sich die vorliegende Interpretation von der eigentlichen Beschreibung von Nicht-Orten. In der Praxis der Tätigkeiten in ihnen habe nach Marc Augé nämlich ein Aushandeln gerade keine Rolle gespielt. Das hier verfolgte Argument lautet aber, dass in der Transformation des Hotel- bzw. Übernachtungsraums in den performativen Stücken diese „Nicht-Ort“-Qualität die Funktion als Zwischenraum evoziert. 
Boris Thomashefsky in der jüdischen Straßensängerin explizit das Leben auf der Straße ohne Privatheit (und sogar die Absprache des Rechts auf eine) solche thematisierte, geht es in den im Folgenden behandelten Stücken um die verschiedenen Zwecke von Übernachtungsräumen während des Unterwegsseins. Allen Orten ist gemeinsam, dass sie eigentlich der Nächtigung dienen. Damit schaffen sie aber auch das Gefühl einer privaten Sphäre, die zur Folie für Aushandlungen verschiedener Beziehungen wird: zwischen Reisepartner ${ }^{\star}$ innen, zwischen (betrogenen) Ehepartner*innen, zwischen Liebenden ebenso wie zwischen Jüdinnen und Juden und Nichtjüdinnen und Nichtjuden.

\section{Nächtigen unterwegs - Erfundene, verhinderte oder gelebte Intimität?}

„Menschen waren es gewohnt, unterwegs zu sein und wussten daher mit der Frage der Nächtigung bestens umzugehen", könnte eine der Kernaussagen der populären Kultur lauten. Diese arbeiteten der Wiener Possendichter und Volkssänger Louis Taufstein und sein Budapester Kollege Erich Urban für eine Aufführung in der ungarischen Metropole heraus. ${ }^{140}$ Die Musik zu dieser kurzen Operette schrieb Martin Knopf. ${ }^{141}$ In diesem Stück wählten Taufstein und Urban einen mobilen Übernachtungsraum, das Schlafcoupé im Zug, als Mittelpunkt der Handlung. Die Autoren entwickelten eine Szene, in der sie mehrere Reisende am Morgen nach einer Nacht unterwegs porträtierten. Als der Schaffner zu sehr früher Stunde an die Tür des Schlafabteils klopft, findet er alle noch schlafend vor. Als Antwort erhält er: „Kein Wunder - wir modernen Menschen sind es ja gewöhnt, den grössten Teil unseres Lebens auf Reisen $\mathrm{zu}$ verbringen, fühlen uns also im rollenden Eisenbahnzuge ebenso wohl und sicher, als im Bette daheim. “" ${ }^{142}$ Diese Feststellung geht in das erste Lied über, das die Bedeutung von Reisen als bürgerliches Phänomen darstellt - denn, wer etwas "gelten wolle“, der reist:

Der Arme, der an der Scholle klebt, / Wird nicht für voll genommen, / Wer etwas gelten will, der strebt / /: Recht viel herumzukommen.:/ / Er ist zwar irgendwo zuhause. / Doch nur pro forma, denn bekannterweise / Ist schliesslich er jahrein, jahraus / /: Ja doch stets auf der Reise. :/ Erst gestern sass der moderne Mann / Noch in Paris ganz heiter, / Heute kommt er schon in London an. / /: Nach Rom geht's morgen weiter :/ / Dann rasch nach Wien, weil es so nah, / Nach Hamburg, wo er niemals noch gewesen, / Von dort geht's nach Amerika / Und dann zu den Chinesen:/ Adler, der durch die Lüfte flieht [!] / Wolke, die rasch vorüberzieht, / Ihr kennt niemals Ruhe und nicht Rast, / Ihr seid gar nirgends

140 Taufstein Louis, Urban Erich, Im Schlafcoupé. NSLB, NSZL, Színháztörténeti Tár: I.M. 4322.

141 Die Rechte für das Stück lagen bei Dr. O.F. Eirich, Hof- und Gerichtsadvocat in Wien, Praterstrasse 38 sowie bei Dr. Matron Sándor in Budapest, Bécsi utca 1.

142 Taufstein Louis, Urban Erich, Im Schlafcoupé. NSLB, NSZL, Színháztörténeti Tár: I.M. 4322. 
lang zu Gast. / Euch scheint die Welt nur eng und klein, / Euch tun wirs gleich, Euch ganz allein, / Jagen und Leiben / Nirgends verweilen / Soll unsre Losung sein![! $]^{143}$

Das Stück greift folglich zum einen die Präsenz von Debatten über die Mobilität der Gesellschaft auf. Zum anderen ist es eine Anekdote über Privatsphäre auf Zugreisen im Schlafcoupé. Ein auf Kriegsfuß stehendes Ehepaar, das seit fünf Jahren getrennt lebt, ist auf einer Reise gemeinsam im Schlafabteil unterwegs. Besonders zweisame Stunden verbringen die beiden allerdings nicht. Der Mann spricht seine Frau auf ihre ihm bekannte Affäre an. Im Streit stellt der Ehegatte fest, dass er sie, sobald sie am Ziel der Reise angekommen seien, verlassen wolle. Die Ehefrau ist ihm aber einen Schritt voraus, erwartet sie doch ein Kind von ihrer Affäre. Diese Situation ist für sie gesellschaftlich jedoch nicht vertretbar. Aus diesem Grund hat sie, wie sich herausstellt, die gemeinsame Reise in einem Schlafcoupé arrangiert. Als ihr der Mann sein Wissen um ihre Liasson eröffnet, erpresst sie ihn geschickt mit der gesellschaftlich angenommenen Privatheit einer solchen Reise: Sie verrät ihm, dass „er“ Vater wird. „[Er:] Was? Nachdem wir fünf Jahre getrennt lebten? Ich bin verraten, entehrt!“ Die Protagonistin verwendet die gemeinsame Fahrt im Schlafabteil und die Vorstellungen über die Intimitäten einer solchen Reise als Mittel zur Erpressung des Ehemannes, um ihm das Kind, das sie erwartet, anzudichten:

[Sie:] Keineswegs, mein Freund. Wir kommen sogleich nach Marseilles, wo mich meine lieben Verwandten erwarten. Die werden nun Gelegenheit haben zu sehen und zu hören, dass wir Beide allein eine Nacht im Schlafcoupé verbracht haben, werden die Sache der Welt weiter erzählen und ...[! $]^{144}$

Wie schon im Stück Der Reisekoffer der Soubrette Risa Basté zeigen sich hier gesellschaftliche Vorstellungen über moralisches Reisen gegenüber unmoralischem Verhalten unterwegs. Eine gemeinsame Nachtreise im Schlafcoupé war folglich im Sinne eines offensichtlichen Beweises einer romantischen Beziehung zwischen Mann und Frau suggerierbar. Verheirateten Paaren brachte das zwar keine üblen Nachreden ein. Im Fall von Taufstein und Urbans Stück stellte es den Ehepartner aber vor vollendete Tatsachen. Geschickt inszeniert, kann die Ehefrau ihren Seitensprung tarnen und dem Ehemann ein Kind andichten.

In der Posse Ein Hotel in Budapest oder gestörte Schäferstunden geht es viel direkter zu. Das Stück wurde 1905 für die Wiener Singspielhalle Carl Lechner bei der Zensurbehörde eingereicht. ${ }^{145}$ In ihm kommt ein Fremder in Begleitung

143 Ebda.

144 Ebda.

145 O.A., Ein Hotel in Budapest. NÖLA, NÖ Reg. Präs. Theater TB - Textbücher der Theaterzensur 119/19. 
einer Dame von seinem Zimmer und wird vom Hotelier gefragt: „Hoffentlich waren die Herrschaften zufrieden?" Der Gast antwortet, in jeder Hinsicht zufrieden gewesen zu sein und dankt zum Abschied. Der Hotelier entgegnet darauf: „O bitte, bitte, dies haben schon sehr viele Leute gesagt. Mein Hotel ist - unberufen - in den besten und allerbesten Kreisen sehr gut eingeführt. " ${ }^{\text {"146 In }}$ der sehr vergnüglichen Unterkunft in Budapest steht nämlich Diskretion an allererster Stelle, denn es sei nicht nur das unterhaltsamste, sondern gleichzeitig auch das verschwiegenste Hotel der Stadt. Meist suchen dieses aber nicht Reisende, sondern, wie der Hotelier hervorhebt, die besten Kreise der Budapester Gesellschaft auf. Ein Gast, der das Hotel für eine Nacht buchen wolle, werde aufs Unfreundlichste hinausgeworfen, denn dieses Hotel buche man nur für wenige Augenblicke und sicher niemals mit seinem Ehemann oder seiner Ehefrau. Dass es dabei diskret zugehe, sei dem extra engagierten taubstummen Personal zu verdanken.

Das Stück inszeniert verschiedene Szenen in dem Budapester Hotel mit den bekanntesten Persönlichkeiten der Stadt - Frauen und Männer gleichermaßen. Untereinander kennt man sich aus den Korridoren. Nur die jeweiligen Lebenspartner*innen wissen nicht um die - meist bezahlten - Affären ihrer Ehemänner beziehungsweise Ehefrauen. In dieses routinierte bunte Treiben verirrt sich eines Tages ein Reisender, der in der Unterkunft tatsächlich nächtigen will. Er wird zum Zeugen des Geschehens und zum Ansprechpartner für das doch nicht so zufriedene Personal. Ihm wird erzählt, wie lange das alles schon so gut laufe und wie wunderbar der Austausch und das Vergnügen in diesem Hotel in Budapest sei. Das gut laufende Geschäft unterbricht plötzlich ein unerwarteter Brand im Hotel. Alle Anwesenden drohen plötzlich in ihrem Treiben enttarnt zu werden. Deshalb wird zunächst überlegt, die Feuerwehr nicht zu rufen, sondern das Hotel besser völlig in Flammen aufgehen zu lassen - im schlimmsten Fall mit den Menschen. Schließlich entscheiden sich die Hotelgäste und -betreibenden doch dagegen und rufen um Hilfe.

Das im Stück porträtierte Geschehen rekurriert auf einen Brand in Budapest im Sommer 1903. Mitten im Herzen der Metropole, an der Kerepesi út, wo sich unter anderem das Varieté Folies Caprice befand, hatte ein vierstöckiges Gebäude Feuer gefangen. Außergewöhnlich schnell war es beinahe völlig niedergebrannt und bald griffen die Flammen auf die umliegenden Gebäude über. In diesen befand sich unter anderem das Warenhaus Goldberg und das als dubiose Einrichtung verrufene „Hotel Orient“. Aufgrund der vielen Menschen, die sich zum Zeitpunkt des Brandes in den Gebäuden aufhielten, gestaltete sich die Rettungsaktion bei dem Großbrand gestaltete sich als besonders spektakulär.

146 Ebda. 
Viele mussten aus den Fenstern springen, um nicht Opfer der Flammen zu werden. Dennoch forderten die Brandherde im Goldberg'schen Warenhaus und im Hotel zahlreiche Tote und konnten erst nach einigen Stunden gelöscht werden. Die Zahl der Opfer blieb aber unbekannt, weil nicht ausmachbar war, wie viele Personen sich in dem Warenhaus und Hotel tatsächlich aufhielten. ${ }^{147}$ Noch viele Monate später wurde immer wieder an den „großen Brand in Budapest“ erinnert. $^{148}$

Die Inszenierung dieser Rettungs- und gleichzeitig Enthüllungsaktion um das Hotel im Stück gibt Einblick in ein performatives Aushandeln von Jüdisch-Sein. Denn einer der beiden Feuerwehrmänner wird „als Jude gespielt “ ${ }^{\text {"149 }}$ und tritt mit „Scholem Alechem“[!] (hebrä. „Friede sei mit euch“) in die Untergangsszene, gefolgt von dem Hinweis „die Zeit ist teuer“. Obwohl sich ihm gegenüber alle skeptisch verhalten, rettet der jüdische Feuerwehrmann die Menschen. Diese fürchten indes, dass, da einer der Feuerwehrmänner nun auch „noch Jude“ ist, das Treiben in dem Hotel erst recht zu Tage komme. Schließlich aber führt die großartige Rettungsleistung des jüdischen Feuerwehrmannes dazu, dass sich eine der Hauptfiguren des bunten Treibens im Hotel zu erkennen gibt: Als ihn der nichtjüdische Feuerwehrmann retten will, sagt er: „Danke. Zu dem da (zeigt auf den zweiten Feuerwehr[!]) hab ich mehr Vertrauen weil er auch aner von unsre Leut ist [... “ "150 Letztendlich erklärt die Posse „der Jude“ habe vollstes Vertrauen innerhalb der „Hotelgesellschaft“ gewonnen.

Das Stück verhandelt nicht nur den als Schlafstätte getarnten Raum als Schauplatz von im öffentlichen Diskurs angepragerten Verhalten, sondern ebenso das Verhältnis von antisemitischen Stereotypen und sich performativ ergebender Ähnlichkeit in jüdisch-nichtjüdischen Beziehungen. Im Entschluss, sich vom jüdischen Feuerwehrmann wegen dessen „Leistung“ retten lassen zu wollen, nimmt das populäre Stück pointiert das Akkulturationsnarrativ aufs Korn. Es zeigt, dass schon zeitgenössisch die Absurdität des „erbrachten Beitragsdenkens“ verlächerlicht wurde. Die Nichtjüdinnen und Nichtjuden artikulierten dann Ähnlichkeit, wenn sie einen Beitrag von Jüdinnen und Juden erkannt und geschätzt hätten. Das bedeutet nicht, dass diese Antisemitismus vollständig aufgegeben hätten. Für diese Ambivalenz steht im Stück die anfängliche Abneigung und Skepsis dem jüdischen Feuerwehrmann gegenüber und schließlich die Wende und die Hinneigung zu ihm aufgrund seiner Taten.

147 „Ein schrecklicher Brand in Budapest“, Arbeiterwille, 26.8.1903, 3.

148 Siehe etwa „Eine furchtbare Brandkatastrophe in Christiania“, Feuerwehrsignale, 5.10.1903, 13.

149 Anmerkung im Textbuch.

150 O.A., Ein Hotel in Budapest. NÖLA, NÖ Reg. Präs. Theater TB - Textbücher der Theaterzensur 119/19 [Klammer im Original]. 
Gleichzeitig ist die Person des Hoteliers Folie dafür, dass, wenn der Diskurs über das Jüdisch-Sein einer Person nicht im antisemitischen Vorurteil stecken blieb, sich überhaupt nicht die Frage nach einer Leistung und folglich Anpassung gegenüber der Nichtjüdinnen und Nichtjuden stellte. Denn Begegnung und Interaktion zwischen Jüdinnen und Juden und Nichtjüdinnen und Nichtjuden waren alltäglich und selbstverständlich. In der Übertreibung dieser Frage und dem Vorführen der Lächerlichkeit des Vorurteils verweist das Stück darauf und dass jüdisch-nichtjüdische Interaktion nicht permanent kommentiert wurde. ${ }^{151}$

Die Privatheit unterwegs erfüllte somit verschiedene Zwecke: In Ein Hotel in Budapest traf sich die Budapester Mittelschicht, die mit einer besonderen Vorliebe Affären pflegte. Durch die Ausnahmesituation eines Brandes muss plötzlich befürchtet werden, dass Informationen an die Außenwelt gelangen könnten, dass also die Privatheit des Raumes gefährdet sei. Im Stück Im Schlafcoupé nutzt die schwangere Ehefrau das Wissen um das gesellschaftliche Bild der Intimität einer Zugreise bei Nacht aus, um ihrem Ehemann ein Kind unterzujubeln. Das Bild darüber, dass in einem Schlafcoupé scheinbar nicht gereist werden konnte, ohne dass die Reisenden untereinander intim würden, veranlasste die Frau mit ihrem Ehemann den Zug zu nehmen. Hier schließt sich auch wieder der Kreis zum Stück Der Reisekoffer, in dem die Tante der Protagonistin verbieten wollte, in einem gemischten Abteil zu reisen.

151 Ernst Petra, Übersetzen und jüdische Kulturen - eine Annäherung, in: dies., Hans-Joachim Hahn, Hoffmann Daniel, Salzer Dorothea M. (Hg.), trans-lation - trans-nation - transformation: Übersetzen und jüdische Kulturen (Schriften des Centrums für Jüdische Studien 21) (Innsbruck, Wien, Bozen: Studienverlag, 2012), 13-38. 


\section{Zusammenfassung}

In den hier vorgestellten Stücken, die in Wien, Budapest oder New York aufgeführt wurden, standen Reisen, Beziehungen und Intimes in unterschiedlichen Verhältnissen zwischen beruflichem und privatem Alltag. Das Unterwegssein an sich reagierte auf veränderte Zeit- und Raumwahrnehmungen. Die Stücke illustrierten zudem, wie die Populärkultur gesellschaftliche Normen sowie Vorurteile ansprach, zerpflückte und umkehrte.

Die Metapher von Mobilität, Reisen und Unterwegssein in den Etablissementstücken und -liedern um 1900 stellte verschiedene Dislokationen - physische ebenso wie berufliche, persönliche etc. - zur Diskussion. Durch eine Verlagerung in weit entfernte, vermeintlich neutrale Räume konnten Grenzen von Ethnizität, Religion oder Gender und politische Probleme wie Nationalismus oder Antisemitismus angesprochen werden. ${ }^{1}$ Das Reisen als ein Unterwegssein, das solche Entwurzlungen hervorruft und neue Lokationen verhandelt, bot sich dafür an: Reisen bedingt eine Konfrontation mit neuen, (vorerst) nicht bekannten Situationen. Darin treffen Menschen und Praktiken, die einander zunächst unbekannt sind und als fremd wahrgenommen werden, aufeinander. Es gilt sodann, Bezüge herzustellen. Aufgrund der räumlichen Veränderung ist das leichter möglich. Darum konnten die Stücke vor dem Motiv der Mobilität verschiedene Identifikationsangebote ausloten. Die Qualität und Intensität der Auseinandersetzung mit dem vermeintlich ,Anderen, das einen auf der Reise erwartete, waren natürlich unterschiedlich. Analog dazu muss die Frage, inwieweit verschiedene Personen, die die Aufführungen besuchten, Referenzen und Assoziationen lesen und verknüpfen konnten, offenbleiben.

Die populären Stücke repräsentierten zeitgenössische Diskurse und gaben Einblick in abweichende Meinungen, Lesarten und Interpretationen. Der kolonialistische Blick auf Afrika war in einer Vielzahl an Vorträgen von Europäern, die „ferne Länder“ bereisten und sodann über „Land und Leute" berichteten, repräsentiert. Diesen zeitgenössischen Blick eines vermeintlichen Afrikareisenden thematisierte das Stück Der Afrikareisende. Es spielt mit diesem Blick Europas auf die „Stämme Afrikas“ ebenso wie mit Stereotypen der Monarchie, über Migration und Mobilität. Schienen auf den ersten Blick die Differenz zu dem als , anders' Dargestellten zu überwiegen, machte das Stück ebenso Altbekanntes sichtbar. Diese Strategie verfolgten auch die anderen Stücke. Sie zeigten immer zwei Lesarten von Stereotypen auf: Die eine, dergemäß die Stücke die Stereotype plump aufgriffen und aus dem Zeitverständnis heraus behandelten.

1 Diese Strategie fand sich auch in utopischen Texten. Siehe hierzu Ulrich E. Bach, Tropics of Vienna: Colonial Utopias of the Habsburg Empire (New York: Berghahn, 2016). 
Und eine andere, nach der die Stücke dem Publikum den eigenen monolithischen Zugang vor Augen führten. Die Stücke hielten dem Publikum so einen Spiegel vor, indem sie sich über die Naivität jener, die sich unhinterfragt mit solchen Stereotypen ausdrückten und positionierten, ironisierten.

Das Gleiche gilt für Zuschreibungen von Jüdisch-Sein: Was in der Verortung der afrikanischen Wüste als ,jüdische Sahrah" artikuliert wurde oder sich in der beiläufigen Einflechtung vermeintlich ,jüdischer“ Ausdrücke niederschlug, wies auf die gemeinsame Gestaltung des Alltags von Jüdinnen, Juden und Nichtjüdinnen, Nichtjuden hin. Der Umstand, dass die populäre Kultur das wie selbstverständlich dem Publikum transportierte, deutete wiederum auf deren Subversivität hin. Wenn Nichtjüdinnen und Nichtjuden Jüdinnen und Juden spielten, hieß das nicht, dass sie eine totale Opposition zwischen jüdisch und nichtjüdisch generierten und umgekehrt. In den vorgestellten Beispielen wurden immer wieder auch Ähnlichkeiten aufgezeigt. Anstatt Entwürfe als exklusiv darzustellen, wiesen sie „partielle Übereinstimmungen“ auf. ${ }^{2}$ Das zeigte sich auch im Umgang mit den negativen Stereotypen. Es fehlte zwar nicht an antisemitischen Stereotypen, jedoch waren diese keineswegs die einzigen, die aufgegriffen wurden. Die Künstler*innen warfen ebenso Stereotype über nationalisierte Lesarten, über Geschlechter etc. ein. Gleichzeitig kehrten die Stücke und Lieder zwischen Selbst- und Fremdironie die Lesart der Stereotype um.

Sowohl in der Monarchie als auch in New York boten die Stücke Raum für ein Querlesen der Stereotype und Rollenbilder. Vor dem Hintergrund, dass jeder der Texte, die aufgeführt werden wollten, der Zensur vorgelegt werden musste, bot sich Reisen als gefundener Aufhänger für eine Reinterpretation von Stereotypen und Rollenbildern an. Die Metapher der Mobilität und des Reisens bot die Möglichkeit, Stereotype und das ,Andere außerhalb der Monarchie zu verorten und somit für die Zensur unproblematisch erscheinen zu lassen: Der "Commis Voyageur" reiste zwischen nicht näher bestimmten Orten umher. Die Kriminalität gegenüber dem Wiener Quartett ereignete sich in New York und die Geldbörse wurde dem Wiener Touristen in Paris gestohlen. Repräsentiert als Reise durchs Leben, führte Mobilität den Erwerb von Lebensweisheit und Können vor. In New York, wo über Aufführungserlaubnisse die Actors Unions entschieden, konnten Dinge direkter angesprochen werden. Zum einen zur Reflexion und zum anderen als Hinweis zur Hinterfragung des Bildes über die Populärkultur fungierte die Darstellung von Mobilität beziehungsweise Migration in der Figur der jüdischen Straßensängerin in dem Stück Der Beit Hmdrsh ointer der erd oder da Idishe Shtroßen Zengerin von Boris Thomashefsky. Mit

2 Hödl, Zwischen Wienerlied und Der kleine Kohn, 187. 
dem Stück bot Thomashefsky einen Raum für die Diskussion von Populärkultur und Prostitution. Es setzte sich mit dem Leben auf der Straße und der Verdienstmöglichkeit von Migrant*innen in der Populärkultur auseinander und wies darauf hin, dass diejenigen, die gerne die Theater besuchten, sich abwertend über die Produzent*innen von Populärkultur äußerten.

In vielen Lebensgeschichten wurde die Phase der Mobilität als zu Fertigkeiten führend oder in eine sexuelle Beziehung mündend inszeniert. Das explizite Hervorheben der Veränderung von Biographien durch Mobilität kann auch als ein Hinweis an das Publikum auf die Veränderbarkeit der Gegenwart interpretiert werden. Rund um Mobilität stellte die Frage nach Privatheit und Intimität ein zentrales Thema dar. Wo und wie genächtigt werden konnte, war breit diskutiert. Die Hotels und Übernachtungsräume waren paradigmatische Nicht-Orte. In ihnen ist das Aushandeln von Beziehungen nicht von Relevanz, sondern steht die Praxis des Tuns im Vordergrund. Das Übernachtungsabteil in dem Stück Das Schlafcoupé verhalf einem zerstrittenen Ehepaar zu einem gemeinsamen Kind: Die schwangere Ehefrau nutzte das Bild über das Reisen in Schlafcoupés, um behaupten zu können, mit ihrem Ehemann geschlafen zu haben und nicht zu ihrer Affäre stehen zu müssen. In Ein Hotel in Budapest fungierte die Unterkunftsmetapher als Überleitung zum Stundenhotel für die gehobene Budapester Gesellschaft. Damit erfüllten Räume wie Hotels oder Zugabteile den Zweck, zur Verhandlungsfläche von Beziehungen und gesellschaftlichen Normen zu werden.

Außerdem waren alle Stücke Interaktionsfelder von Jüdinnen, Juden und Nichtjüdinnen und Nichtjuden und ein Spiegel der wechselseitigen Beziehungen zwischen ihnen. ${ }^{3}$ Die Konzeption der Stücke spiegelte die plurikulturelle Zusammensetzung des Publikums wider. Die Populärkultur zeigt zudem, dass Stereotype gleichermaßen von Nichtjüdinnen und Nichtjuden wie Jüdinnen und Juden aufgegriffen wurden und sie diese somit gemeinsam verhandelten. Von einem performativen Konzept von Theater ausgehend, lässt sich abschließend folgern, dass die Aufführungen somit einen Raum für ein gemeinsames Aushandeln von Identitäten zwischen Jüdinnen und Juden und Nichtjüdinnen und Nichtjuden darstellten. ${ }^{4}$

$3 \mathrm{Zu}$ der Bedeutung von Text als „space“ in den Jüdischen Studien siehe Charlotte Elisheva Fonrobert, Vered Shemtov, „Introduction: Jewish Conceptions and Practices of Space“, Jewish Social Studies 11, no.3 (2005): 1-8, 2; sowie Kapitel 3.

4 Erika Fischer-Lichte prägte maßgeblich das Verständnis von Theater als performativen Raum: Bedeutungen in Aufführungen werden somit nicht lediglich zwischen den Schauspieler*innen auf der Bühne verhandelt, sondern zu einem entscheidenden Teil vom Publikum mitbestimmt. Fischer-Lichte, Performativität, 37-44 und 53. 



\title{
Nachspiel - Am American Scenic Railway durch Wien
}

\author{
Populäre Kultur um 1900 als Hoffnung, Vision oder Dystopie?
}

\author{
„Dem Muthigen gehört die Welt“ \\ Josef Modl bei der Gründung der Budapester \\ Orpheumgesellschaft $1889^{1}$
}

Als 1909 die erste Hochschaubahn im Wiener Prater eröffnete, blickte diese sprichwörtlich und in mehrerlei Sinn aus der Monarchie nach Amerika. Diese Hochschaubahn erhielt den Namen American Scenic Railway. Allerdings sollte nicht nur der Name, sondern ebenso die bauliche Rundumkonstruktion die Vergnügungsfahrt von etwa einer Meile Länge zu einer Fernreise durch die amerikanischen Rocky Mountains machen. Rund um die Gleise der - damals ungesicherten - Sitzwagons erstreckte sich ein Bergmassiv, das die Kulisse des Stephansdoms und der dahinter auftauchenden Weinberge als Blick in ein fernes Wien erscheinen lassen musste. Mit einer Fahrt konnten die Gäste nicht nur schnelles Vergnügen erleben, sondern ebenso in die vermeintliche Ferne schweifen - eine Idee, die den Besucher*innen des Wiener Praters imponierte. ${ }^{2}$

Die Hochschaubahn war eine besondere Attraktion. Die erste Hochschaubahn war Teil des Vergnügungsareals im Prater, das Englischer Garten oder Kaisergarten genannt und jährlich neugestaltet wurde. ${ }^{3}$ Das von dem Amerikaner Lamarcus Adna Thompson (1848-1919) in Auftrag gegebene Spektakel orientierte sich an jener Achterbahn, die der Pionier des Achterbahnbaus 1884 auf Coney Island eröffnet hatte und der das Erscheinungsbild der Stadt - insbesondere vom Meer aus, für alle ankommenden Migrant*innen - prägen sollte. Die Coney Island Scenic Railroad wurde Vorbild für das fahrende Vergnügen in Freizeitparks. Der nach ihrem Vorbild erbaute American Scenic Railway diente sodann als Inspiration für die Holzachterbahn, die rund zehn Jahre später im Budapester Stadtwäldchen eröffnen sollte und bis in die 2010er Jahre dort zu sehen war. ${ }^{4}$

1 Der Humorist, 5.7.1889, 5.

2 Plan vom Englischen Garten mit American Scenic Railway. WStLA, M.Abt. 104, A8/16 Feuer- und Sicherheitspolizei: Theater, Lokale: Wiener Vergnügungspark Kaisergarten, Plan Kaisergarten Saison 1913.

3 Siehe hierzu Kapitel 3.

4 Die Budapester historische Achterbahn aus Holz von 1922 im Vidámpark im Budapester Stadtwäldchen sollte eines jener Relikte der populären Kultur des beginnenden 20. Jahrhunderts sein, das am längsten überdauerte. Der „Budapester Prater“, wie der Vidámpark im Volksmund 


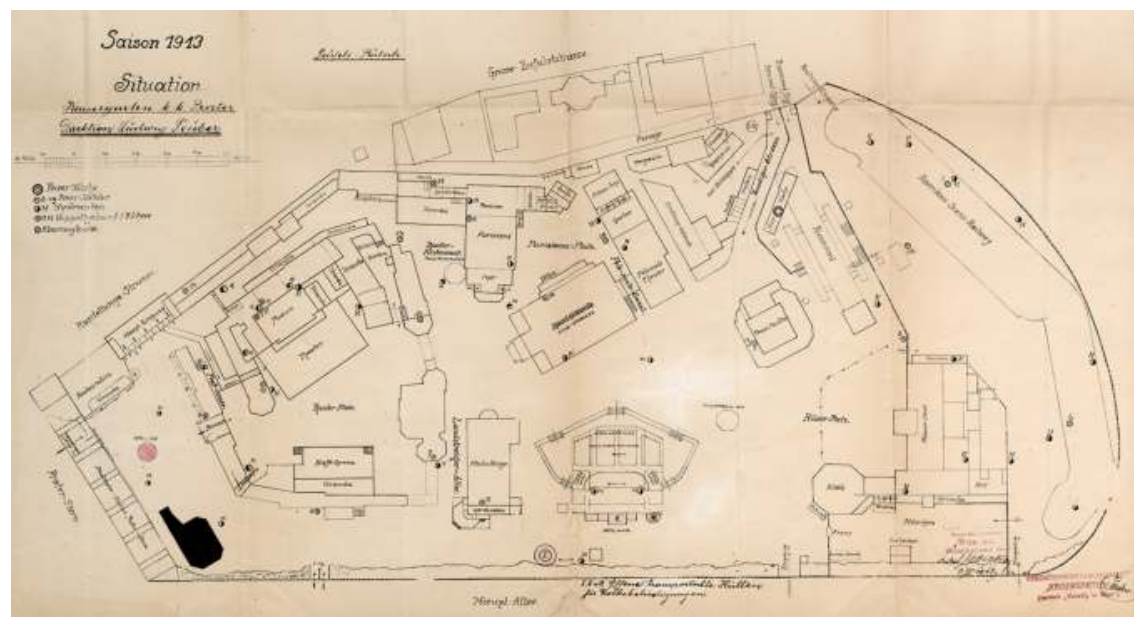

Abb. 29 Plan vom Prater mit Café, Varieté Parisisana, Kino Varieté und American Scenic Railway, Wiener Stadt- und Landesarchiv

Der American Scenic Railway im Wiener Prater war ein paradigmatisches Beispiel für die Entwicklungen in der populären Kultur um 1900: Die Hochschaubahn war im internationalen Austausch und gegenseitiger Beeinflussung entstanden. Sie verkörperte Bewegung und war ein innovativer Begegnungsraum für unterschiedlichste Menschen - geradezu visionär. Breite Teile der Wiener Bevölkerung teilten das Erlebnis des Amüsements auf der Fahrt. Emil Ranzenhofers (1864-1930) ${ }^{5}$ Illustration zeigt eindrucksvoll, wie plural die Kundschaft auf der Hochschaubahn war und Jüdinnen und Juden hier mit Nichtjüdinnen und Nichtjuden den Alltag gemeinsam bestritten. In unmittelbarer Nähe der Hochschaubahn befand sich Präuschers Panoptikum, ein „Museum und Panopticum“, das historische Szenen ebenso wie „Menschenbilder“ in Figurenform (gewissermaßen Vorgänger von Madame Tussauds) ausstellte und so die Welt ins Kleine projizieren wollte. Beim nächsten Eingang konnten die Menschen ins Lustspieltheater stolpern, ein paar Schritte weiter in den Sommermona-

liebevoll genannt wurde, sollte am 9. November 2012 geschlossen werden. Die Hochschaubahn wurde schließlich 2015 abgerissen.

5 Gedruckt wurde die Graphik von und Jacob Weiners (1864-1940). Emil Ranzenhofer hinterließ mit seinen künstlerischen Werken viele Eindrücke vom alltäglichen jüdischen und nichtjüdischen Leben in Wien. Von Ranzenhofer stammt u. a. eine der bekanntesten Darstellungen des Innenraums im Leopoldstätter Tempel (Inneres der Synagoge in der Tempelgasse, Aquarell, 1902). 


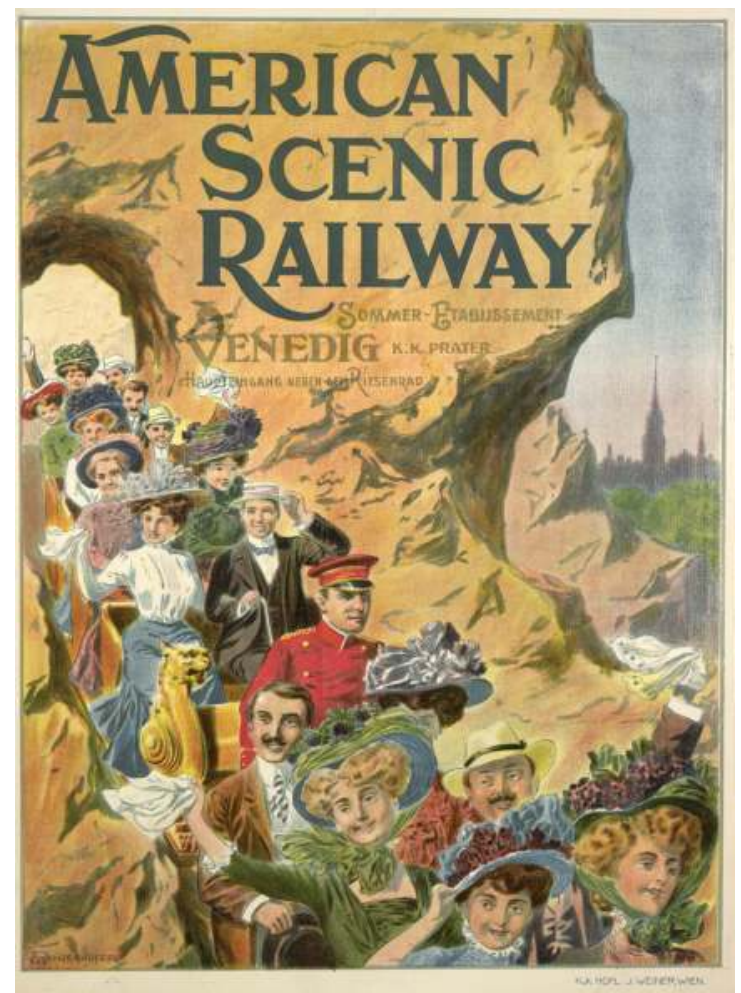

Abb. 30 Ranzenhofer, American Scenic Railway, k.u.k. Prater, Venedig in Wien, Farblithographie um 1900, Albertina DG2003/1086

ten ins Sommeretablissement, einer Freiluftbühne, auf der Soubretten und Gesangshumoristen gastierten. ${ }^{6}$

Auf die Tour verfolgte die Bewegung der populären Kultur zwischen der Habsburgermonarchie und Amerika im Allgemeinen und von Jüdinnen und Juden sowie den Transformtionen und Artikulationen von Jüdisch-Sein in der Unterhaltung im Besonderen. Singspielhallen, Varietés und wie sich die Etablissements sonst nannten, die um 1900 überall zu finden waren, tauchten die Städte in ein internationales Licht. Die Räume populärer Kultur luden ihr Publikum, zu dem Jüdinnen und Juden ebenso gehörten wie Nichtjüdinnen und

6 O.A., Führer durch H. Präuschers Panopticum Wien k.u.k. Prater 140 (Wien: Verlag von H. Präuscher, 1892); o.A., Führer durch das anatomische, pathologische und ethnologische Museum von H. Präuschers Nachfolgern (Wien: Verlag von H. Präuschers Nachfolgern, [ohne Jahresangabe]). 
Nichtjuden, zum Verweilen ein, zum Lachen und dazu, gemeinsam Visionen zu leben.

$\mathrm{Zu}$ diesen Visionen gehörte das Übernehmen von einem Jüdisch-Sein ebenso wie das Hantieren mit antisemitischen Stereotypen, die sich im Gelächter auflösen sollten. Die Metapher der Mobilität und des Reisens verwendeten die Künstlerinnen, um hierzu Beweglichkeit in den Köpfen ihres Publikums $\mathrm{zu}$ evozieren. Besonderer Beliebtheit erfreute sich das Spiel mit nationalen, ethnischen, sozialen, religiösen u. a. Stereotypen und Identifikationen. Wenn Jüdinnen und Juden mit scheinbar antisemitischen Stereotypen unterhielten, „Böhmen“, „Ungarn“ oder „Afrikaner“ darstellten oder bourgeoisen Attitüden nachfühlten, war ein Publikumshit fast garantiert. Die Ebenen der Interpretation und Lesarten dieser Lieder und Stücke waren komplex, vielschichtig und keineswegs stringent. Es konnten als ,jüdisch“ konnotierte Zuschreibungen entworfen oder (angelehnt an antisemitische Diskurse der Zeit) neue Rollen entwickelt werden, um mit der Inszenierung den dahinterstehenden Antisemitismus kritisch zu hinterfragen. In der Transgression von Geschlecht, Stereotypen und Kategorisierungen erwies sich die populäre Kultur als fruchtbarer geradezu visionärer - Zwischenraum.

Die Nachfrage nach köstlichem Amüsement und die neue Mobilität stellten aber auch Rollenbilder in der populären Kultur infrage. Die in der Einleitung zitierte Anekdote in der Internationalen Artisten Revue forderte die Mitglieder der Szene populärer Kultur nicht nur dazu auf, auf Tour zu gehen. Sie strich zudem hervor, wie wichtig die weibliche Volkssängerin, die sich zur Soubrette entwickelt hatte, war. Die Etablissementdirektor*innen mussten Geschick beweisen, um immer in gutem Austausch mit internationalen Künstlerinnen zu stehen und das beste Programm anbieten zu können. Nur so verhinderten sie, in der Flut an Stätten des Amüsements unterzugehen. Die Soubrette wie der Gesangsakrobat mussten es verstehen, ihre Inhalte so aufzubereiten, dass das Publikum in der jeweiligen Stadt ihr Talent erkennen und lieben konnte. Das Publikum forderte immer mehr, dass Soubretten wie Volkssänger die „Charakteristika des jeweils anderen Geschlechts“ perfekt beherrschten, um auf der Bühne das andere Geschlecht darzustellen. Die populären Künstler*innen entwickelten die subversive Strategie eines Gender-Bendings, das sodann herkömmliche $\mathrm{Zu}$ schreibungen von Geschlecht auch abseits der Bühnen fraglich erscheinen ließ. Und dennoch verstummten nicht die Unterstellungen, diese Künstler ${ }^{\star}$ innen - vor allem die Frauen unter ihnen - betrieben nur seichte „Schwankkunst" zum Schein zur Verhüllung von Sexarbeit, in den berüchtigten „zwei oder drei geheimen Räumen im ersten Obergeschoss" der Etablissements. ${ }^{7}$

7 Budapesti Hírlap, 7.10.1893, 5. 
Ungemindert der Tatsache, dass es berechtigte Hinweise auf Fälle gab, wo Künstlerinnen in vermeintliche Engagements gelockt wurden, sind derartige Vorwürfe auch aus dem Einfluss, den die populäre Kultur um 1900 bekam und den vor allem politische Eliten nicht gerade schätzten, zu erklären. Beispiele, wie die Reaktionen der Varietés und Artist ${ }^{\star}$ innen auf die ungarische Theaterordnung von 1895 zeigen dies. Die Reform intendierte zwar eine nationale Homogenisierung, bewirkte jedoch das Gegenteil: Die Volkssänger^innen aus Wien arbeiteten noch stärker mit den ungarischsprachigen Künstler ${ }^{\star}$ innen aus Budapest zusammen, die Programme und das Publikum wurden immer bunter. Auch jemand, der nicht Deutsch, Jiddisch oder Ungarisch sprach, oder diese Kultur im Alltag ablehnen würde, konnte plötzlich Teil einer mehrsprachigen Aufführung werden.

Die Populärkultur erwies sich als ein Bereich einer breiten Teilhabe von Jüdinnen und Juden und damit als ein wesentlicher Bereich jüdisch-nichtjüdischer Interaktion. Die Praxis der Aneignung von Künstlernamen, die (wider die weitverbreitete Annahme) Nichtjüdinnen und Nichtjuden im gleichen Ausmaß pflegten wie Jüdinnen und Juden, ist ein Beispiel, wo sich die vermeintlich gefährliche Seite der populären Kultur enthüllte. Es ging bei der Praxis der Wahl von Künstlernamen nämlich nicht darum, ein Jüdisch-Sein zu überwinden, sondern darum, den internationalen Charakter der populären Kultur zu leben. Obwohl Jüdinnen und Juden die Populärkultur in großem Ausmaß prägten, fällt eine - im Verhältnis zu den anderen vehement antisemitischen zeitgenössischen Diskursen - paradoxe Unterrepräsentanz im zeitgenössischen Sprechen über jüdische Akteurinnen in der Populärkultur auf.

Die populäre Kultur stand aber auch zwischen Alltag und vermeintlicher Irrealität des Amüsements. Die Etablissements sind Teil des Alltäglichen und eröffnen zugleich Räume des Außergewöhnlichen. Die Stücke konstituierten sich in einem Dazwischen von lebensweltlicher Referenzialität und den performativen bzw. erzählten Räumen, die sie ermöglichten. Sie konnten Inhalte ansprechen, die in der vermeintlich realen Welt nur schwer sagbar gewesen wären. Die politischen Akteure und andere Opponent ${ }^{\star}$ innen modernistischer Ansichten erkannten jedoch, dass die populäre Kultur Brücken in die Realität schlug. Sie wussten um ihr subversives Potential und begegneten diesem mit Vorbehalt und Denunziationen.

„Dem Muthigen gehört die Welt", ${ }^{8}$ war das Lebensmotto und der Künstlergrundsatz von Josef Model, der die Budapester Orpheumsgesellschaft in Wien mit den Stars aus Budapest gründete. Die in Auf die Tour vorgestellten Protagonist ${ }^{\star}$ innen waren mutig und haben buchstäblich die Welt mit ihrer Kunst

8 Der Humorist, 5.7.1889, 5. 
erobert und die Welt mit ihrer Kunst in vielerlei Hinsicht von Kleinkariertheit, Vorurteil und Vermeintlichkeit zu befreien vermocht. Nicht zuletzt deshalb wurden viele der Protagonist*innen Opfer des Nationalsozialismus. Auch der American Scenic Railway tat seine letzte Fahrt 1944. 


\section{Abkürzungsverzeichnis}

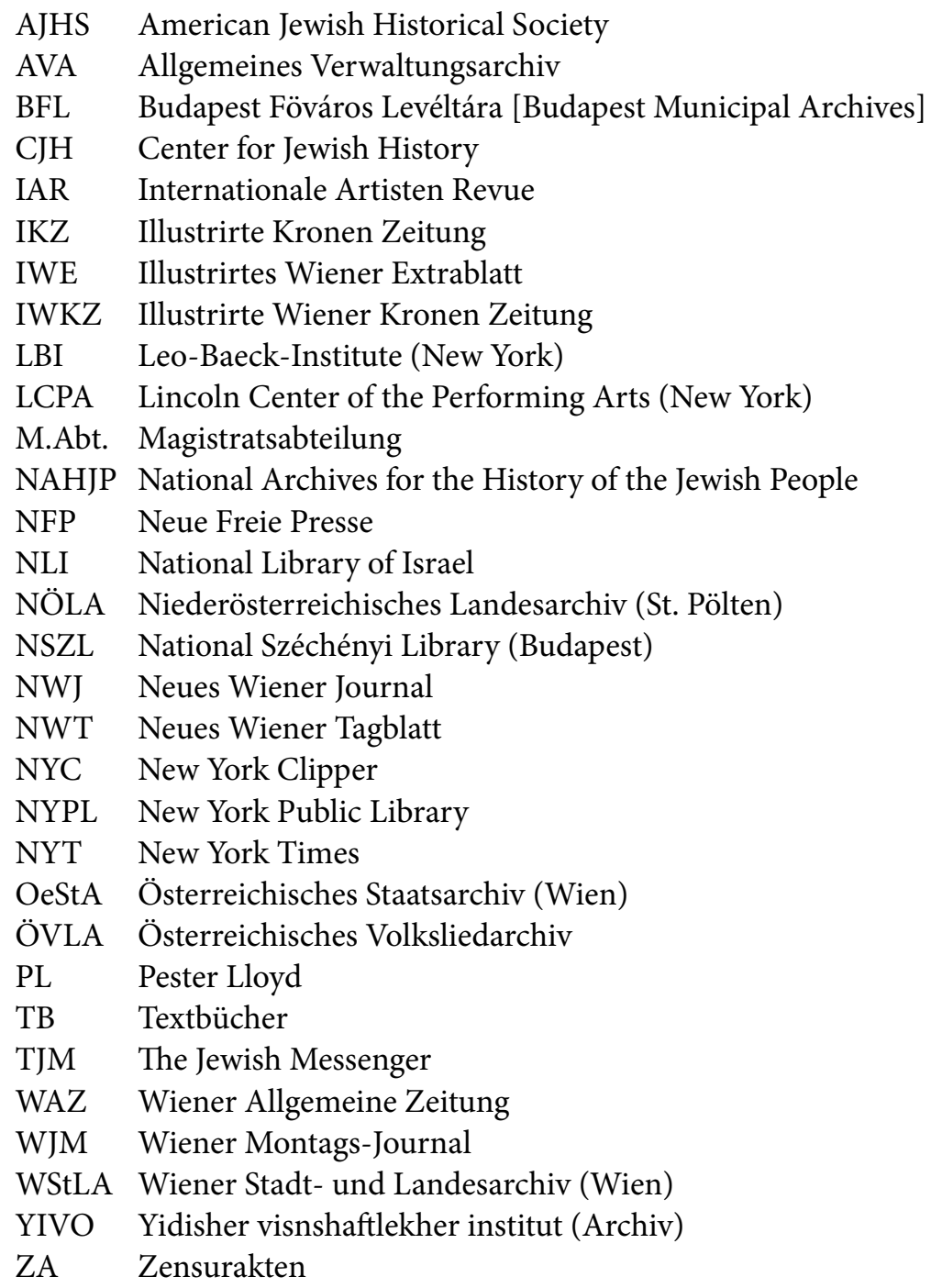





\section{Literaturverzeichnis}

Anbinder, Tyler, Five Points: The 19th-Century New York City Neighborhood that Invented Tap Dance, Stole Elections, and Became the World's Most Notorious Slum (New York: Free Press, 2001).

Andlauer, Teresa, Die jüdische Bevölkerung im Modernisierungsprozess Galiziens 1867-1914 (Menschen und Strukturen, HistorischSozialwissenschaftliche Studien 11) (Frankfurt am Main, New York: Peter Lang, 2001).

Adorno, Theodor W., Max Horkheimer, Dialektik der Aufklärung: Philosophische Fragmente (Frankfurt am Main: Suhrkamp, 2016).

Alejchem, Scholem, Eisenbahngeschichten, herausgegeben, aus dem Jiddischen übersetzt und mit einem Nachwort von Gernot Jonas (Frankfurt am Main: Jüdischer Verlag, 1996).

Alweltlikher idishn kultur-kongres (Hg.), Idisher teater in aeirupe zwishn beide welt-malkhmot (New York: Forward, 1971). [Das Jiddische Theater zwischen den Weltkriegen]

Anderson, Benedict, Imagined Communities: Reflections on the Origin and Spread of Nationalism (London: Verso, 2016).

Apter, Emily, Against World Literature: On the Politics of Untranslatability (London: Verso, 2013).

Ashcroft, Bill, Gareth Griffiths, Helen Tiffin, Postcolonial Studies: The Key Concepts (New York, Oxon: Routledge, 2013).

Ashcroft, Bill, Gareth Griffiths, Helen Tiffin, The Empire Writes Back: Theory and Practice in Post-colonial Literatures (London, New York: Routledge, 2002).

Aschheim, Steven E., „Between East and West: Reflections on Migration and the Making of German-Jewish Identity, 1800-1880“, Studia Rosenthalia 23 (1989): 77-87.

Aschheim, Steven E., „German History and German Jewry: Boundaries, Junctions and Interdependence“, Leo Baeck Institute Year Book 43 (1998): 315-322.

Assmann, Aleida, Ähnlichkeit als Performanz: Ein neuer Zugang zu Identitätskonstruktionen und Empathie-Regimen, in: Anil Bhatti, Dorothee Kimmich (Hg.), Ähnlichkeit: Ein kulturtheoretisches Paradigma (Konstanz: Konstanz University Press, 2015), 167-186.

Augé, Marc, Nicht-Orte (München: C. H. Beck, 2014).

Bach, Ulrich E., Tropics of Vienna: Colonial Utopias of the Habsburg Empire (New York: Berghahn, 2016). 
Bachleitner, Norbert, Paul Ferstl, Österreichische Theaterzensur im 20. Jahrhundert: Ein Abriss ihrer Entwicklung und eine Fallstudie zur Zensur englischer Stücke während des Ersten Weltkriegs, in: Ewald Mengel, Ludwig Schnauder, Rudolf Weis (Hg.), Weltbühne Wien 2: Rezeption anglophoner Dramen auf Wiener Bühnen des 20. Jahrhunderts (Trier:WVT, 2010), 27-50.

Bachleitner, Norbert, Michaela Wolf, ÜbersetzerInnen als „gatekeepers“?: (Selbst-)Zensur als Voraussetzung für die Aufnahme in das literarische Feld der späten Habsburgermonarchie, in: Denise Merkle, Carol O’Sullivan, Luc Van Doorslaer, Michaela Wolf (Hg.), The Power of the Pen: Translation \& Censorship in Nineteenth Century Europe (Representation - Transformation 4) (Wien, Berlin: LIT, 2010), 29-54.

Bachmann-Medick, Doris, Cultural Turns: Neuorientierungen in den Kulturwissenschaften (Hamburg: Rowohlt, 2014).

Bachmann-Medick, Doris, The Trans/national Study of Culture: A Translational Perspective, in: dies. (Hg.), The Trans/national Study of Culture: A Translational Perspective (Berlin, Boston: De Gruyter, 2016), 1-22.

Bachmann-Medick, Doris (Hg.), The Trans/national Study of Culture: A Translational Perspective (Berlin, Boston: De Gruyter, 2016).

Bailey, Peter, Popular Culture and Performance in the Victorian City (Cambridge, New York: Cambridge University Press, 2003).

Bartal, Israel, Imagined Geography: The Shtetl, Myth, and Reality, in: Steven T. Katz (Hg.), The Shtetl: New Evaluations (New York: New York University Press, 2007), 179-192.

Battegay, Caspar, Judentum und Popkultur: Ein Essay (Bielefeld: Trasnskript, 2012).

Bausinger, Hermann, Populäre Kultur zwischen 1850 und dem Ersten Weltkrieg, in: Kaspar Maase, Wolfgang Kaschuba (Hg.), Schund und Schönheit: Populäre Kultur um 1900 (Wien, Köln, Weimar: Böhlau, 2001), 29-45.

Bechtel, Delphine, „Le théatre yiddish Gimpel de Lemberg: une Odyssée oubliée“, Yod 16 (2011): 83-93.

Becker, Tobias, Inszenierte Moderne: Populäres Theater in Berlin und London 1880-1930 (Berlin: De Gruyter, 2014).

Beckermann, Ruth, Die Mazzesinsel: Juden in der Leopoldstadt 1918-1938 (Wien: Löcker, 1992).

Beller, Steven, Wien und die Juden 1867-1938 (Böhlaus Zeitgeschichtliche Bibliothek 23) (Wien, Köln, Weimar: Böhlau, 1993).

Benjamin, Walter, Die Lehre vom Ähnlichen, in: ders., Gesammelte Schriften 2,1, herausgegeben von Rudolf Tiedemann und Hermann Schweppenhäuser (Frankfurt am Main: Fischer, 1977), 204-213. 
Berg, Nicolas, Bilder von Luftmenschen, in: Dan Diner (Hg.), Synchrone Welten: Zeitenräume jüdischer Geschichte (Göttingen: Vandenhoeck \& Ruprecht, 2005), 199-224. [= Bilder von Luftmenschen]

Berg, Nicolas, Luftmenschen, in: Dan Dinner (Hg.), Enzyklopädie jüdischer Geschichte und Kultur 3 (Stuttgart, Weimar: Metzler, 2012), 571-572. [= Luftmenschen]

Berg, Nicolas, Luftmenschen: Zur Geschichte einer Metapher (toldot Essays zur jüdischen Geschichte und Kultur 3) (Göttingen, Bristol: Vandenhoeck \& Ruprecht, 2014). [= Zur Geschichte einer Metapher]

Berkowitz, Joel, Barbara Henry (Hg.), Inventing the Modern Yiddish Stage: Essays in Drama, Performance, and Show Business (Detroit, Michigan: Wayne State University Press, 2012).

Bering, Dietz, Der ,jüdische“ Name, in: Julius Schoeps, Joachim Schlör (Hg.), Antisemitismus: Mythen und Vorurteile (München, Zürich: Piper, 1996), 153-166.

Bhabha, Homi K., The Location of Culture (London, New York: Routledge, 2004).

Bhatti, Anil, Dorothee Kimmich, Einleitung, in: dies. (Hg.), Ähnlichkeit: Ein kulturtheoretisches Paradigma (Konstanz: Konstanz University Press, 2015), $7-32$.

Bhatti, Anil, Dorothee Kimmich, Introduction, in: dies. (Hg.), Similarity: A Paradigm for Culture Theory (New Delhi: Tulika Books, 2018), 1-24.

Bhatti, Anil, Dorothee Kimmich (Hg.), Ähnlichkeit: Ein kulturtheoretisches Paradigma (Konstanz: Konstanz University Press, 2015).

Bhatti, Anil, Plurikulturalität, in: Johannes Feichtinger, Heidemarie Uhl (Hg.), Habsburg neu denken: Vielfalt und Ambivalenz in Zentraleuropa, 30 kulturwissenschaftliche Stichworte (Wien, Köln, Weimar: Böhlau, 2016), 171-180. Bhatti, Anil, Dorothee Kimmich (Hg.), Similarity: A Paradigm for Culture Theory (New Delhi: Tulika Books, 2018).

Biale, David, „Confessions of an Historian of Jewish Culture“, Jewish Social Studies, New Series 1, no. 1 (1994): 40-51.

Biale, David, Preface, in: ders. (Hg.), Cultures of the Jews: A New History (New York: Schocken Books, 2002), xvii-xxxiii.

Biale, David (Hg.), Cultures of the Jews: A New History (New York: Schocken Books, 2002).

Biale, David, Eros and the Jews: From Biblical Israel to Contemporary America (Berkeley, Los Angeles: University of California Press, 1997).

Billings, John S., Department of the Interior, Vital statistics of New York City and Brooklyn: Covering a Period of Six Years Ending May 31, 1890 (Washington: US GPO, 1894). 
Blaseio, Gereon, Pompe Hedwig, Ruchatz Jens (Hg.), Popularisierung und Popularität (Köln: DuMont, 2005).

Bolker, Joan L., A Room of One's Own Is Not Enough, in: dies. (Hg.), The Writer's Home Companion: An Anthology of the World's Best Writing Advice, from Keats to Kunitz (New York: Penguin Books, 1997), 183-200.

Bolker, Joan L. (Hg.), The Writer's Home Companion: An Anthology of the World's Best Writing Advice, from Keats to Kunitz (New York: Penguin Books, 1997).

Botz, Gerhard, Ivar Oxaal, Michael Pollak, Nina Scholz (Hg.), Eine zerstörte Kultur: Jüdisches Leben und Antisemitismus in Wien seit dem 19. Jahrhundert (Wien, Köln, Weimar: Böhlau, 2002).

Böhme, Hartmut, Christof Rapp, Wolfgang Rösler (Hg.), Übersetzung und Transformation (Berlin, Boston: De Gruyter, 2007).

Bourdieu, Pierre, Distinction: A Social Critique of the Judgment of Taste (Cambridge: Harvard University Press, 1984).

Bourdieu, Pierre, „The Social Space and the as Genesis of Groups“, Theorie and Society 14, no. 6 (1985): 723-744.

Bourdieu, Pierre, Soziologische Fragen: Über einige Eigenschaften von Feldern (Frankfurt am Main: Suhrkamp, 1993).

Bourdieu, Pierre, Sozialer Raum und „Klassen“: Zwei Vorlesungen (Frankfurt am Main: Suhrkamp, 1995).

Boyarin, Daniel, Jonathan Boyarin, „Diaspora: Generation and the Ground of Jewish Identity“, Critical Inquiry 19, no. 4 (1993): 693-725.

Boyarin, Daniel, Jonathan Boyarin, Introduction - So Whats's New? in: dies. (Hg.), Jews and other Differences: The New Jewish Cultural Studies (Minneapolis: University of Minnesota Press, 1997), vii-xxii.

Boyarin, Daniel, Jonathan Boyarin (Hg.), Jews and other Differences: The New Jewish Cultural Studies (Minneapolis: University of Minnesota Press, 1997). Boyer, John W., Political Radicalism in Late Imperial Vienna: Origins of the Christian Social Movement, 1848-1897 (Chicago: University of Chicago Press, 1981).

Brauch, Julia, Anna Lipphardt, Gelebte Räume - Neue Perspektiven auf jüdische Topographien, in: Petra Ernst, Gerald Lamprecht (Hg.), Jewish Spaces: Die Kategorie Raum im Kontext kultureller Identitäten (Schriften des Centrums für Jüdische Studien 17) (Innsbruck, Wien, Bozen: Studienverlag, 2010), 13-32.

Brauch, Julia, Anna Lipphardt, Alexandra Nocke, Exploring Jewish Spaces: An Approach, in: dies. (Hg.), Jewish Topographies: Visions of Space, Traditions of Place (Burlington, Hampshire: Ashgate, 2008), 1-26.

Brauch, Julia, Anna Lipphardt, Alexandra Nocke (Hg.), Jewish Topographies: Visions of Space, Traditions of Place (Burlington, Hampshire: Ashgate, 2008). 
Braun, Christina von, Antisemitismus und Misogynie: Vom Zusammenhang zweier Erscheinungen, in: Jutta Dick, Barbara Hahn (Hg.), Von einer Welt in die andere: Jüdinnen im 19. und 20. Jahrhundert (Wien: Brandstätter, 1993), 179-196.

Brauner-Berger, Elisabeth, Volkssängertum im Wandel (Diss. Universität Wien, 1993).

Brinkmann, Tobias, „German Jews?“: Reassessing the History of NineteenthCentury Jewish Immigrants in the United States, in: Ava F. Kahn, Adam D. Mendelsohn (Hg.), Transnational Traditions: New Perspectives on American Jewish History (Detroit: Wayne State University Press, 2014), 144-164.

Brinkmann, Tobias (Hg.), Points of Passage: Jewish Transmigrants from Eastern Europe in Scandinavia, Germany, and Britain 1880-1914 (New York, Oxford: Berghahn, 2013).

Brinkmann, Tobias, „Points of Passage: Reexamining Jewish Migration from Eastern Europe after 1880“, in: ders. (Hg.), Points of Passage: Jewish Transmigrants from Eastern Europe in Scandinavia, Germany, and Britain 1880-1914 (New York, Oxford: Berghahn, 2013), 1-26.

Broomans, Petra, Sandra van Voorst, Introduction, in: dies. (Hg.), Rethinking Cultural Transfer and Transmission: Reflections and New Perspectives (Studies on Cultural Transfer \& Transmission 4) (Groningen: Barkhuis, 2012), 9-14.

Broomans, Petra, Sandra van Voorst (Hg.), Rethinking Cultural Transfer and Transmission: Reflections and New Perspectives (Studies on Cultural Transfer \& Transmission 4) (Groningen: Barkhuis, 2012).

Brubaker, Rogers, Frederick Cooper, „Beyond ,Identity“, Theory and Society 29 (2000): 1-47.

Brubaker, Rogers, Ethnicity without Groups (Cambridge, London: Harvard University Press, 2006).

Buden, Boris, Kulturelle Übersetzung: Einige Worte zur Einführung in das Problem, in: ders., Stefan Nowotny (Hg.) Übersetzung: Das Versprechen eines Begriffs (Wien: Turia + Kant, 2008).

Buden, Boris, Stefan Nowotny (Hg.) Übersetzung: Das Versprechen eines Begriffs (Wien: Turia + Kant, 2008).

Burke, Peter, Cultural Hybridity (Cambridge: Cambridge University Press, 2014).

Bułat, Mirosława M., Kaminski-Theater, in: Dan Diner (Hg.), Enzyklopädie jüdischer Geschichte und Kultur 3 (Stuttgart, Weimar: Metzler), 313-316.

Butler, Judith, Performative Akte und Geschlechterkonstitution, in: Uwe Wirth (Hg.), Performanz: Zwischen Sprachphilosophie und Kulturwissenschaften (Frankfurt am Main: Suhrkamp, 2002), 301-320. 
Buzinkay, Géza, Budapesti Karikatúrák [Budapest in Karikaturen], in: Dozsa Katalin F., Egy nagyváros születése: Pest, Buda, Obuda az egyesites idejen [Die Geburt der Großstadt: Oder Pest, Buda und Óbuda zur Zeit der Vereinigung] (Budapest: Budapesti Torteneti Muzeum, 1998), 101-103.

Celestini, Federico, Um-Deutung: Transfers als Kontextwechsel mehrfach kodierbarer kultureller Elemente, in: ders., Helga Mitterbauer (Hg.), Ver-rückte Kulturen: Zur Dynamik kultureller Transfers (Stauffenburg Discussion 22) (Tübingen: Stauffenberg, 2011), 37-52.

Celestini, Federico, Mitterbauer Helga (Hg.), Ver-rückte Kulturen: Zur Dynamik kultureller Transfers (Stauffenburg Discussion 22) (Tübingen: Stauffenberg, 2011).

Certeau, Michel de, Praktiken im Raum, in: Jörf Dünne, Stephan Günzel (Hg.), Raumtheorie: Grundlagentexte aus Philosophie und Kulturwissenschaften (Frankfurt am Main: Suhrkamp, 2015), 343-353.

Chakravorty-Spivak, Gayatri, Can the Subaltern Speak? Postkolonialität und subalterne Artikulation, mit einer Einleitung von Hito Steyerl (Es kommt darauf an 6) (Berlin, Wien: Turia+Kant 2014).

Clifford, James, Traveling Cultures, in: Lawrence Grossberg, Cary Nelson, Paula A. Treichler (Hg.), Cultural Studies (London, New York: Routledge, 2009), 96-112.

Cline Cohen, Patricia, The murder of Helen Jewett (Newport Beach: Books on Tape, 1998).

Csáky, Moritz, Das Gedächtnis der Städte: Kulturelle Verflechtungen - Wien und die urbanen Milieus in Zentraleuropa (Wien, Köln, Weimar: Böhlau, 2010).

Csáky, Moritz, Das Gedächtnis Zentraleuropas: Kulturelle und literarische Projektionen auf eine Region (Wien, Köln, Weimar: Böhlau, 2019).

Csáky, Moritz, Hybride Kommunikationsräume und Mehrfachidentitäten: Zentraleuropa um 1900, in: Elisabeth Röhrlich (Hg.), Migration und Innovation um 1900: Perspektiven auf das Wien der Jahrhundertwende, unter Mitarbeit von Agnes Meisinger (Wien, Köln, Weimar: Böhlau, 2016), 65-97.

Csendes, Peter, Sipos András, Budapest und Wien: Technischer Fortschritt und urbaner Aufschwung im 19. Jahrhundert (Budapest, Wien: Franz Deuticke, 2003).

Csontos, Katalin, Az elsö székesfövárosi múzezn [Das erste Museum in der Landeshauptstadt], in: Dozsa Katalin F., Egy nagyváros születése: Pest, Buda, Obuda az egyesites idejen [Die Geburt der Großstadt: Oder Pest, Buda und Óbuda zur Zeit der Vereinigung] (Budapest: Budapesti Torteneti Muzeum, 1998), 123-133.

Dalinger, Brigitte, „Interkulturalität: Kulturtransfer und das jüdische Theater“. Transversal 8, no. 2 (2007): 15-36. 
Dalinger, Brigitte, Interkulturalität: Kulturtransfer und Theaterwissenschaften, in: Ewald Mengel, Ludwig Schnauder, Rudolf Weis (Hg.), Weltbühne Wien 1 (Approaches to Cultural Transfer 1) (Trier: WVT, 2010), 105-116.

Dalinger, Brigitte, „Verloschene Sterne“: Geschichte des jüdischen Theaters in Wien (Wien: Picus, 1998).

Dalinger, Brigitte, Werner Hanak-Lettner, Lisa Noggler (Hg.), Wege ins Vergnügen: Unterhaltung zwischen Prater und Stadt (Wien: Metroverlag, 2016).

Daxelmüller, Christoph, „Das Mauscheln“, in: Julius H. Schoeps, Joachim Schlör (Hg.), Antisemitismus: Vorurteile und Mythen (München, Zürich: Piper, 1996), 143-152.

DeKoven, Ezrahi Sidra, Booking Passage: Exile and Homecoming in the Modern Jewish Imagination (Berkeley: University of California Press, 2000).

Delius, Annette, Intimes Theater: Untersuchungen zu Programmatik und Dramaturgie einer bevorzugten Theaterform der Jahrhundertwende (Kronberg: Scriptor, 1976).

Dering, Florian, Volksbelustigung: Eine bildreiche Kulturgeschichte von Fahr-, Belustigungs- und Geschicklichkeitsgeschäften der Schausteller vom 18. Jahrhundert bis zur Gegenwart (Nördlingen: F. Greno, 1986).

Dietze, Antje, Americanization of Show Business? Shifting Territories of Theatrical Entertainment in North America at the Turn of the 20th Century, in: Gabriele Pisarz-Ramirez, Hannes Warnecke-Berger (Hg.), Spatialization Processes in the Americas (Bern, New York: Peter Lang, 2018), 193-215.

Diner, Dan (Hg.), Synchrone Welten: Zeitenräume jüdischer Geschichte (Göttingen: Vandenhoeck \& Ruprecht, 2005).

Diner, Hasia, Yiddish New York, in: Edna Nahshon (Hg.), New York's Yiddish Theater: From Bowery to Broadway (New York: Columbia University Press, 2016), 50-63.

Dozsa, Katalin F., Egy nagyváros születése: Pest, Buda, Obuda az egyesites idejen [Die Geburt der Großstadt: Oder Pest, Buda und Óbuda zur Zeit der Vereinigung] (Budapest: Budapesti Torteneti Muzeum 1998).

Eichinger, Barbara, Frank Stern (Hg.), Wien und die jüdischen Erfahrungen 1900-1938: Akkulturation - Antisemitismus - Zionismus (Wien, Köln, Weimar: Böhlau, 2009).

Engelmann, Jan (Hg.), Die kleinen Unterschiede: Der Cultural Studies-Reader (Frankfurt am Main, New York: Campus, 1999).

Engelmann, Jan, Simon Frith, „Unscharfe Grenzmarkierungen“: Gespräch zwischen Simon Frith und Jan Engelmann, in: ders. (Hg.), Die kleinen Unterschiede: Der Cultural Studies-Reader (Frankfurt am Main, New York: Campus, 1999), 170-174.

Ernst, Petra, Hans-Joachim Hahn, Daniel Hoffmann, Dorothea M. Salzer (Hg.), trans-lation - trans-nation - trans-formation: Übersetzen und jüdische Kul- 
turen (Schriften des Centrums für Jüdische Studien 21) (Innsbruck, Wien, Bozen: Studienverlag, 2012).

Ernst, Petra, Gerald Lamprecht (Hg.), Jewish Spaces: Die Kategorie Raum im Kontext kultureller Identitäten (Schriften des Centrums für Jüdische Studien 17) (Innsbruck, Wien, Bozen: Studienverlag, 2010).

Ernst, Petra, Übersetzen und jüdische Kulturen - eine Annäherung, in: dies., Hans-Joachim Hahn, Hoffmann Daniel, Salzer Dorothea M. (Hg.), translation - trans-nation - trans-formation: Übersetzen und jüdische Kulturen (Schriften des Centrums für Jüdische Studien 21) (Innsbruck, Wien, Bozen: Studienverlag, 2012), 13-38.

Farkas, Julius von, Die Strukturen der geistig führenden Schicht Ungarns, 1867-1900, in: Ungarische Jahrbücher 19 (1939), 11-50.

Faßmann, Heinz, Die Bevölkerungsentwicklung 1850-1910, in: Helmut Rumpler, Peter Urbanitsch (Hg.), Die Habsburgermonarchie 1848-1918, Band 9/1 Lebens- und Arbeitswelten in der industriellen Revolution (Wien: Verlag der österreichischen Akademie der Wissenschaften, 2010), 159-184.

Feichtinger, Johannes, Uhl Heidemarie (Hg.), Habsburg neu denken: Vielfalt und Ambivalenz in Zentraleuropa, 30 kulturwissenschaftliche Stichworte (Wien, Köln, Weimar: Böhlau, 2016).

Fink, Iris, Roland Knie, Überlandpartie! Kabarett auf Sommerfrische (Wien, Köln, Weimar: Böhlau, 2018).

Fischer-Lichte, Erika, Performativität: Eine Einführung (Edition Kulturwissenschaften 10) (Bielefeld: Transcript, 2012).

Fischer, Rolf, Entwicklungsstufen des Antisemitismus in Ungarn 1867-1939: Die Zerstörung der magyarisch-jüdischen Symbiose (München: R. Oldenburg, 1988).

Fiske, John, Reading the Popular (London, New York: Routledge, 2011).

Fiske, John, Understanding Popular Culture (London, New York: Routledge, 2011).

Flusser, Vilém, Von der Freiheit des Migranten: Einsprüche gegen den Nationalismus (Hamburg: CEP Europäische Verlagsanstalt, 2013).

Fonrobert, Charlotte Elisheva, Shemtov Vered, „Introduction: Jewish Conceptions and Practices of Space“, Jewish Social Studies 11, no. 3 (2005): 1-8.

Fontane, Theodor, Unterwegs und wieder daheim (München: Nymphenburger Verlagshandlung, 1972).

Freud, Sigmund, Der Witz und seine Beziehung zum Unbewussten/Der Humor, herausgegeben von Peter Gay (Frankfurt am Main: Fischer, 2009).

Frojimovics, Kinga, Géza Kormoróczy, Viktória Pusztai, Andrea Strbik, Jewish Budapest: Monuments, Rites, History (Budapest, New York: Central European University Press, 1999). 
Gassert, Philipp, Transnationale Geschichte, Version: 2.0. in: DocupediaZeitgeschichte, 29.12.2012, https://docupedia.de/zg/Transnationale_Geschichte_Version_2.0_Philipp_Gassert (letzter Zugriff: 13.4.2020).

Gartner, Lloyd P., „The Great Jewish Mass Migration - Its East European Background“, Tel Aviver Jahrbuch für Deutsche Geschichte 27 (1998): 107-133.

Gatrell, Peter, Philippe Nivet, Refugees and Exiles, in: Jay Winter (Hg.), The Cambridge History of the First World War, Civil Society 3 (Cambridge: Cambridge University Press, 2014), 186-215.

Geisthövel, Alexa, Bodo Mrozek, Einleitung, in: dies. (Hg.), Popgeschichte, Band 1: Konzepte und Methoden (Bielefeld: Transcript, 2014).

Geisthövel, Alexa, Bodo Mrozek (Hg.), Popgeschichte, Band 1: Konzepte und Methoden (Bielefeld: Transcript, 2014).

Gelbart S., 15 yor „Vilner Trupe“: Zamlung le-koved dem 15-yorikn yoyvl fun der Vilner Trupe (Lotz: o. V., 1931).

Gelber, Nathan Michael, „Berl Broder: Ein Beitrag zur Geschichte der jüdischen Volkssänger", Mitteilungen für jüdische Volkskunde 16, no. 3 (1913): 1-18.

Gilfoyle, Timothy, City of Eros: New York City, Prostitution and the Commercialization of Sex 1790-1920 (New York, London: W.W. Norton, 1992).

Gillis, Jennifer, The Soubrette Character as an Agent of Social Change in $18^{\text {th }}$ and $19^{\text {th }}$ Century Opera Buffa and Singspiel (Diss. University of Oklahoma, 2018).

Gilman, Sander L., Freud, Race, and Gender (Princeton: Princeton University Press, 1993).

Gilman, Sander L., „Salome, Syphilis, Sarah Bernhardt and the ,Modern Jewess“", The German Quarterly 66, no. 2 (1993): 195-211.

Glossy, Carl, Zur Geschichte der Wiener Theatercensur (Wien: Carl Konegen, 1896).

Gluck, Mary, „Jewish Humor and Popular Culture in Fin-de-Siècle Budapest“, Austrian History Yearbook 34 (2008): 1-21.

Gluck, Mary, Popular Bohemia: Modernism and Urban Culture in Nineteenth Century Paris, Cambridge 2008.

Gluck, Mary, „The Budapest Flâneur: Urban Modernity, Popular Culture, and the 'Jewish Question' in Fin-de-Siècle Hungary", Jewish Social Studies 10, no. 3 (204): 1-22.

Gluck, Mary, The Invisible Jewish Budapest: Metropolitan Culture at the Fin de Siècle (Wisconsin: University of Wisconsin Press, 2016).

Gorin, Bernhard, Di geshikhte fun yidshen teater: zwei tausend yahr 2 (New York: Literarischer Ferlag, 1918).

Grosch, Nils, Carolin Stahrenberg (Hg.), „Im weißen Rößl“: Kulturgeschichtliche Perspektiven (Populäre Kultur und Musik 19) (Münster, New York: Waxmann, 2016). 
Grossberg, Lawrence, What's going on? Cultural Studies und Popularkultur (Wien: Turia + Kant, 2000).

Hall, Stuart, David Morley (Hg.), Critical Dialogues in Cultural Studies (London, New York: Routledge, 2005).

Hall, Stuart, Cultural Studies and the Politics of Internationalization: An Interview with Stuart Hall by Kuan-Hsing Chen, in: ders., David Morley (Hg.), Critical Dialogues in Cultural Studies (London, New York: Routledge, 2005), 393-409.

Hall, Stuart, Ethnizität: Identität und Differenz, in: Jan Engelmann (Hg.), Die kleinen Unterschiede: Der Cultural Studies-Reader (Frankfurt am Main, New York: Campus, 1999), 83-98.

Hall, Stuart, Old and New Identities, Old and New Ethnicities, in: Anthony D. King (Hg.), Culture, Globalization, and the World-System: Contemporary Conditions for the Representation of Identity (Minneapolis: University of Minnesota Press, 1997), 41-68.

Halpern, Stefanie, Boris Thomashefsky: Matinee Idol of the Yiddish Stage, in: Edna Nahshon (Hg.), New York's Yiddish Theater: From Bowery to Broadway (New York: Columbia University Press, 2016), 118-127.

Hašek, Jaroslav, Die Abenteuer des braven Soldaten Schwejk, 2 Bde. [1920a-1923] (Hamburg: Rowohlt, 1960/61).

Haug, Christine, Franziska Mayer, Madleen Podewski (Hg.), Populäres Judentum: Medien, Debatten, Lesestoffe (Conditio Judaica 76, Studien und Quellen zur deutsch-jüdischen Literatur- und Kulturgeschichte) (Tübingen: Max Niemeyer Verlag, 2009).

Heltai, Jenö, A kerepesi út, in: A Hét, Társaldalmi, Irodalmi és Müvészeti Közlöny 4, no. 25 (1893), 18.6.1893.

Hess, Jonathan M., Middlebrow Literature and the Making of German-Jewish Identity (Stanford: Stanford University Press, 2010).

Hirschfeld, Ludwig, Wo sind die Zeiten ...: Zehn Jahre Wien in Skizzen (Wien: Anstalt, 1921).

Hoberman, James, Bridge of Light: Yiddish Films Between Two Worlds (Philadelphia: Temple University Press, 1995).

Hobsbawm, Eric, Terence Ranger, The Invention of Tradition (Cambridge, New York: Cambridge University Press, 2013).

Hödl, Klaus, Als Bettler in die Leopoldstadt: Galizische Juden auf dem Weg nach Wien (Wien, Köln, Weimar: Böhlau, 1994).

Hödl, Klaus, „,Der kleine Kohn' on the Jewish Stage: Performative Strategies to Fight Anti-Semitism in Vienna around 1900“, Leo Baeck Institute London Report of Activities 60, no. 1 (2015): 123-140.

Hödl, Klaus, „From Acculturation to Interaction: A New Perspective on the History of the Jews in Fin-de-Siècle Vienna"', Shofar 25, no. 2 (2007): 82-103. 
Hödl, Klaus, Galizische Juden und Jüdinnen in Wien: Einige Gründe für deren Stereotypisierung, in: Elisabeth Röhrlich (Hg.), Migration und Innovation um 1900: Perspektiven auf das Wien der Jahrhundertwende (Wien, Köln, Weimar: Böhlau, 2016), 221-241.

Hödl, Klaus, „,Jewish History‘ beyond Binary Conceptions: Jewish Performing Musicians in Vienna around 1900“, Journal of Modern Jewish Studies 1 (2017): 1-18.

Hödl Klaus, „,Jewish History' as part of ,general history‘: A comment“, Medaon 12, no. 22 (2018): 1-4.

Hödl, Klaus, „Jiddisches Theater als jüdisch-nichtjüdisches Interaktionsfeld: Einführung in das Themenheft", Transversal 8, no. 2 (2007): 3-15.

Hödl, Klaus (Hg.), Nicht nur Bildung, nicht nur Bürger: Juden in der Populärkultur (Schriften des Centrums für Jüdische Studien 23) (Bozen, Innsbruck, Wien: Studienverlag, 2013).

Hödl, Klaus, Vom Shtetl an die Lower East Side: Galizische Juden in New York (Wien, Köln, Weimar: Böhlau, 1991).

Hödl, Klaus, „The Quest for Amusement: Jewish Leisure Activities in Vienna circa 1900", Jewish History and Culture 14, no. 1 (2014): 1-17.

Hödl, Klaus, Wiener Juden - jüdische Wiener: Identität, Gedächtnis und Performanz im 19. Jahrhundert (Schriften des Centrums für Jüdische Studien 9) (Bozen, Innsbruck, Wien: Studienverlag, 2006).

Hödl, Klaus, Zwischen Wienerlied und Der kleine Kohn. Juden in der Wiener populären Kultur um 1900 (Jüdische Religion, Geschichte und Kultur 27) (Göttingen: Vandenhoeck \& Ruprecht, 2017).

Hoffman, Warren, The Passing Game: Queering Jewish American Culture (New York: Syracuse University Press, 2009).

Hollitzer, Carl, Gerstenbrand Alfred, Wiener Köpfe in der Karikatur: Worte von Julius Buer (Wien: Elbmühl Papierfabriken und Graphische Industrie, 1928).

Holzinger, Sarah, Die Darstellung von Juden und Jüdinnen im Humoristischen Volksblatt „Kikeriki“ (Dipl. Arbeit, Universität Graz, 2015).

Honsza, Norbert, Przemysław Sznurkowski (Hg.), Identitätsdiskurs im deutschjüdischen Dialog (Frankfurt am Main, Bern, Bruxelles u. a.: Peter Land, 2017).

Horkheimer, Max, Kritische Theorie: Eine Dokumentation (Frankfurt am Main: Suhrkamp, 1968).

Italiano, Federico, Micahel Rössner, Translatio/n: An Introduction, in: dies. (Hg.), Translatio/n: Narration, Media and the Staging of Differences (Bielefeld: Transcript, 2012), 9-18.

Italiano, Federico, Rössner Michael (Hg.), Translatio/n: Narration, Media and the Staging of Differences (Bielefeld: Transcript, 2012). 
James, Edmund, The Immigrant Jew in America (New York: B.F. Buck \& Company, 1907).

John, Michael, Albert Lichtblau, Schmelztiegel Wien einst und jetzt: Zur Geschichte und Gegenwart von Zuwanderung und Minderheiten (Wien, Köln, Weimar: Böhlau, ${ }^{2}$ 1993).

John, Michael, Vielfalt und Heterogenität: Zur Migration nach Wien um 1900, in: Elisabeth Röhrlich (Hg.), Migration und Innovation um 1900: Perspektiven auf das Wien der Jahrhundertwende (Wien, Köln, Weimar: Böhlau, 2016), 23-64.

Judson, Pieter M., Tara Zahra, „Introduction“, Austrian History Yearbook 43 (2012): 21-27.

Judson, Pieter M., The Habsburg Monarchy: A New History (Cambridge: Cambridge University Press, 2016).

Kahn, Ava F., Adam D. Mendelsohn (Hg.), Transnational Traditions: New Perspectives on American Jewish History (Detroit: Wayne State University Press, 2014).

Kaminska, Ester Rokhl, Zikhroynes, in: Der Moment, 8.10.1926.

Kaps, Klemens, Ungleiche Entwicklung in Zentraleuropa: Galizien zwischen überregionaler Verflechtung und imperialer Politik, 1772-1914 (Wien, Köln, Weimar: Böhlau, 2015).

Karady, Victor, Gewalterfahrung und Utopie: Juden in der europäischen Moderne, aus dem Französischen von Judith Klein (Frankfurt am Main: Fischer, 1999).

Kassal-Mikula, Renata, Alt-Wien unter dem Demolierungskrampen: Wiens Innenstadt nach 1858, in: Wolfgang Kos, Christian Rapp (Hg.), Alt-Wien: Die Stadt, die niemals war (Wien: Czernin, 2004), 46-61.

Kastantinovíc, Zoran, Vom Werden einer Metropole: Anmerkungen zum Thema „Wien als Magnet“, in: Gertraud Marinelli-König, Nina Pavlova (Hg.), Wien als Magnet? Schriftsteller aus Ost-, Ostmittel- und Südosteuropa über die Stadt (Wien: Verlag der österreichischen Akademie der Wissenschaften, 1996), 21-33.

Kikeriki (Hg.), Kohn-Lexikon, Wien 1895. [Zweite Auflage 1900 und dritte Auflage 1904].

Kimmich, Dorothee, Ins Ungefähre: Ähnlichkeit und Moderne (Konstanz: Konstanz University Press, 2017).

Koller, Josef, Das Wiener Volkssängertum in alter und neuer Zeit: Nacherzähltes und Selbsterlebtes, mit Biographien, Episoden, Liedern, zahlreichen Abbildungen und Porträts nach zeitgenössischen Bildern aus dem Volkssängerleben (Wien: Gerlach und Wiedling, 1931).

Konrád, Miklós, Music Halls and Jewish Identities in Budapest at the Turn of the Century, in: Jurgita Šiaučiūnaitè-Verbickienè, Larisa Lempertienè 
(Hg.), Jewish Space in Central and Eastern Europe: Day-to-Day History (Cambridge: Cambridge Scholars Publishing, 2009), 143-155.

Korbel, Susanne, „Jews, Mobility, and Sex: Popular Entertainment between Budapest, Vienna, and New York around 1900“, Austrian History Yearbook 51 (2020): 220-242.

Korbel, Susanne, Populärkultur und Antisemitismus um 1900 oder: Warum „Kohn zehrt“?, in: Réka Sentyváni, Béla Teleky (Hg.), Brüche, Kontinuitäten, Konstruktionen. Mitteleuropa im 20. Jahrhundert (Wien: New Academic Press, 2017), 17-37.

Korbel, Susanne, Reisen in Wiener Volkssängerstücken: Ähnlichkeit als Analysekategorie jüdisch-nichtjüdischer Beziehungen, in: Norbert Honsza, Przemysław Sznurkowski (Hg.), Identitätsdiskurs im deutsch-jüdischen Dialog (Frankfurt am Main, Bern, Bruxelles u. a.: Peter Lang, 2017), 189-204.

Korbel, Susanne, Lukas Nievoll, Thomas Stoppacher (Hg.), Rethinking Jewish and non-Jewish Relations, Jewish Culture and History 21, no. 1 (2020).

Körösy, József, Budapest Székesfőváros Halandósága az 1901-1905 években és annak okai [Die Sterblichkeit in Budapest in den Jahren 1901-1905 und ihre Ursachen] (Budapest: Grill, 1902).

Kos, Wolfgang, Christian Rapp (Hg.), Alt-Wien: Die Stadt, die niemals war (Wien: Czernin, 2004).

Koschorke, Albrecht, Ähnlichkeit: Valenzen eines post-postkolonialen Konzepts, in: Anil Bhatti, Dorothee Kimmich (Hg.), Ähnlichkeit: Ein kulturtheoretisches Paradigma (Konstanz: Konstanz University Press, 2015), 35-46.

Krivanec, Eva, „Krank und wieder gesund gelacht...": Jüdisches Unterhaltungstheater in Wien und Berlin zwischen 1910 und 1918, in: Christine Haug, Franziska Mayer, Madleen Podewski (Hg.), Populäres Judentum: Medien, Debatten, Lesestoffe (Conditio Judaica 76, Studien und Quellen zur deutschjüdischen Literatur- und Kulturgeschichte) (Tübingen: Max Niemeyer Verlag, 2009), 103-120.

Krivanec, Eva, „Sammelbecken und Sprungbrett: Die Freie jüdische Volksbühne in Wien -Lebenswege ihrer ProtagonistInnen zwischen Theater und Film, zwischen Europa und Übersee“, Transversal 8, no. 2 (2007): 37-50.

Kuzmany, Börries, Brody: Eine galizische Grenzstadt im langen 19. Jahrhundert (Wien, Köln, Weimar: Böhlau, 2011).

Lackner, Nini, Hans Pemmer, Der Prater einst und jetzt. (Leipzig, Wien: Jugend und Volk, 1935).

Laidlaw, Walter, Population of the City of New York 1890-1930 (New York: The Cities Census Committee, 1932).

Langenohl, Andreas, Ähnlichkeit als differenztheoretisches Konzept: Zur Reformulierung der Modernisierungstheorie, in: Anil Bhatti, Dorothee Kimmich (Hg.), Ähnlichkeit: Ein kulturtheoretisches Paradigma (Konstanz: Konstanz 
University Press, 2015), 105-127.

Lässig, Simone, Miriam Rürup, Introduction: What Made a Space „Jewish“? Reconsidering a Category of Modern German History, in: dies. (Hg.), Space and Spatiality in Modern German-Jewish History (New York: Berghahn, 2017), 1-20.

Lässig, Simone, Miriam Rürup Miriam (Hg.), Space and Spatiality in Modern German-Jewish History (New York: Berghahn, 2017).

Lefebvre, Henri, The Production of Space, translated by Donald NicholsonSmith (Oxford, Cambridge: Blackwell, 1991).

Lehmann, Adolph, Adolph Lehmanns allgemeiner Wohnungs-Anzeiger, nebst Handels- u. Gewerbe-Adressbuch für d. k.k. Reichshaupt- u. Residenzstadt Wien u. Umgebung. Wien 1890-1922. [jährliche Ausgabe; an entsprechender Stellen mit Jahreszahl und Band ausgewiesen]

Lehmann, Lilli, Mein Weg, herausgegeben von Michael Holzinger (Berlin: Contumax Hofenberg, 2014).

Levine, Lawrence W., Highbrow Lowbrow: The Emergence of Cultural Hierarchy in America (Cambridge, London: Harvard University Press, 2002).

Levine, Lawrence W., „The Folklore of Industrial Society: Popular Culture and Its Audiences“, The American Historical Review 97, no. 5 (1992): 1369-1399.

Loewy, Hanno, Jukebox Jewkbox! Ein jüdisches Jahrhundert auf Schellack \& Vinyl (Hohenems: Verlag des jüdischen Museums, 2014).

Löw, Martina, Raumsoziologie (Frankfurt am Main: Suhrkamp, 2015).

Löw, Martina, „The Constitution of Space: The Structuration of Spaces Trough the Simultaneity of Effect and Perception“, European Journal of Social Theory 11, no. 1 (2008): 25-49.

Löw, Martina, Weidenhaus Gunter, „Boarders that Relate: Conceptualizing Boundaries in Relational Spaces“, Current Sociology Monograph 65, no. 4 (2017): 553-570.

L'Office Central Royal Hongrois de Statistique, Annuaire Statistique Hongrois (Budapest: Athenaeum, 1932).

Luibhéid Eithen, „Queer/Migration: An Unruly Body of Scholarship“, GLQ 14, no.2-3 (2008): 169-190.

Lukacs, Georg, Schriften zur Literatursoziologie: Ausgewählt und eingeleitet von Ludz Peter (Neuwied: Luchterhand, 1961).

Lukacs, John, Budapest, 1900: A város és kultúrája [Von der Stadt und ihrer Kultur] (Budapest: Európa, 1991).

Lukacs, John, Ungarn in Europa: Budapest um die Jahrhundertwende (Berlin: Siedler, 1990).

Lukas, Scott A. (Hg.), A Reader in Themed and Immersive Spaces (Pittsburgh: Carnegie Mellon ETC Press, 2016). 
Maase, Kaspar, Grenzenloses Vergnügen: Der Aufstieg der Massenkultur 1850-1970 (Frankfurt am Main: Fischer, 1997).

Maase, Kaspar, Wolfgang Kaschuba (Hg.), Schund und Schönheit: Populäre Kultur um 1900. (Wien, Köln, Weimar: Böhlau, 2001).

Maase, Kaspar, Einleitung: Schund und Schönheit: Populäre Kultur um 1900, in: ders., Wolfgang Kaschuba (Hg.), Schund und Schönheit: Populäre Kultur um 1900 (Wien, Köln, Weimar: Böhlau, 2001), 9-28.

Mann, Barbara E., Space and Place in Jewish Studies (Piscataway: Rutgers University Press, 2012). [= Space and Place in Jewish Studies]

Mann, Barbara E., Space and Place, in: Laurence Roth, Nadia Valman (Hg.), The Routledge Handbook of Contemporary Jewish Cultures (London, New York: Rutgers University Press, 2015), 183-194. [= Space and Place]

Marinelli-König, Gertraud, Nina Pavlova (Hg.), Wien als Magnet?: Schriftsteller aus Ost-, Ostmittel- und Südosteuropa über die Stadt (Wien: Verlag der Osterreichischen Akademie der Wissenschaften, 1996).

Marx, Peter W., Ein theatralisches Zeitalter: Bürgerliche Selbstinszenierungen um 1900. (Tübingen: Francke, 2008).

Meisels, Samuel, „Zur Geschichte des jüdischen Theaters“, Ost und West 8, no. 8-9 (1908): 509-526.

Mengel, Ewald, Ludwig Schnauder, Rudolf Weis (Hg.), Weltbühne Wien 1: Approaches to Cultural Transfer (Trier:WVT, 2010).

Mengel, Ewald, Ludwig Schnauder, Rudolf Weis (Hg.), Weltbühne Wien 2: Rezeption anglophoner Dramen auf Wiener Bühnen des 20. Jahrhunderts (Trier: WVT, 2010).

Menzel, Julia, „Meine Frau hat sich göttlich amüsiert“: Das weiße Rößl im Spiegel zeitgenössischer Satirezeitschriften, in: Nils Grosch, Carolin Stahrenberg (Hg.), „Im weißen Rößl“: Kulturgeschichtliche Perspektiven (Populäre Kultur und Musik 19) (Münster, New York: Waxmann, 2016), 117-132.

Meisels, Samuel, „Zur Geschichte des jüdischen Theaters“, Ost und West 8, no. 8-9 (1908): 509-526.

Mettauer, Philipp, Barbara Staudinger (Hg.), „Ostjuden“: Geschichte und Mythos (Bozen, Innsbruck, Wien: Studienverlag, 2015).

Meysels, Theodor F., Bummel durch Alt-Wien (Wien: Franz Leo, 1936).

Middell, Matthias, Hannes Siegrist (Hg.), Dimensionen der Kultur- und Gesellschaftsgeschichte (Festschrift für Hannes Siegrist zum 60. Geburtstag) (Leipzig: Leipziger Universitäts Verlag, 2007).

Middell, Matthias, Kulturtransfer und transnationale Geschichte, in: ders., Hannes Siegrist (Hg.), Dimensionen der Kultur- und Gesellschaftsgeschichte (Festschrift für Hannes Siegrist zum 60. Geburtstag) (Leipzig: Leipziger Universitäts Verlag, 2007), 49-69. 
Molnár, Ferenc, Liliom: Vorstadtlegende in sieben Bildern und einem szenischen Prolog [1909] (Wien, Leipzig: Deutsch-österreichischer Verlag, 1912). Müller, R., Leo Stein, in: Österreichisches Biographisches Lexikon 13, 1815-1950 (Wien: Verlag der österreichischen Akademie der Wissenschaften, 2010), 151.

Müller, Sabine, Tractatus, „Schmäh“ und Sprachkritik: Überlegungen zu einer alternativen Genealogie der Wiener Modernen, in: András F. Balogh, Christoph Leitgeb (Hg.), Mehrsprachigkeit in Zentraleuropa (Wien: Praesens, 2012), 229-254.

Müller, Sabine, Wiener Schmäh, in: Johannes Feichtinger, Heidemarie Uhl (Hg.), Habsburg neu denken: Vielfalt und Ambivalenz in Zentraleuropa, 30 kulturwissenschaftliche Stichworte (Wien, Köln, Weimar: Böhlau, 2016).

Myrs, Margaret, Searching for Data about Ladies' Orchestras, in: Pirkko Moisala, Beverly Diamond (Hg.), Music and Gender (Illinois: University of Illinois Press, 2000), 189-213.

Nachama, Andreas, Jiddisch im Berliner Jargon: Oder: Hebräische Sprachelemente im deutschen Wortschatz (Berlin: Jaron, 2007).

Nadel, Arno, Jüdisches Volkslied, in: Georg Herlitz, Bruno Kirschner (Hg.), Jüdisches Lexikon: Ein enzyklopädisches Handbuch des jüdischen Wissens in vier Bänden, 4 (Berlin: Jüdischer Verlag, 1930), 1239-1241.

Nadel, Arno, „Jüdische Volkslieder: Religiöse Lieder“, Der Jude, eine Monatsschrift 1, no. 2 (1916): 112-122.

Nadel, Arno, „Jüdische Volkslieder: Religiöse Lieder“, Der Jude, eine Monatsschrift 1, no. 3 (1916): 182-194.

Nadel, Arno, „Jüdische Volkslieder: Religiöse Lieder“, Der Jude, eine Monatsschrift 1, no. 4 (1916): 255-267.

Nadel, Arno, „Jüdische Volkslieder: Religiöse Lieder“, Der Jude, eine Monatsschrift 1, no. 5 (1916): 326-339.

Nadel, Arno, „Jüdische Volkslieder: Religiöse Lieder“, Der Jude, eine Monatsschrift 1, no. 7 (1916): 465-479.

Nahshon, Edna, Café Royal, in: dies. (Hg.), New York's Yiddish Theater: From Bowery to Broadway (New York: Columbia University Press, 2016), 36-38.

Nahshon, Edna (Hg.), New York's Yiddish Theater: From Bowery to Broadway (New York: Columbia University Press, 2016).

Nünning, Ansgar, Towards Transnational Approaches to the Study of Culture: From Cultural Studies and Kulturwissenschaften to a Transnational Study of Culture, in: Doris Bachmann-Medick (Hg.), The Trans/national Study of Culture: A Translational Perspective (Berlin, Boston: De Gryter, 2016), 23-49.

Osterhammel, Jürgen, „Transnationale Gesellschaftsgeschichte: Erweiterung oder Alternative?“, Geschichte und Gesellschaft 27 (2001): 464-479. 
Osterhammel, Jürgen, Ähnlichkeit - Divergenz - Konvergenz: Für eine Historiographie relationaler Prozesse, in: Anil Bhatti, Dorothee Kimmich (Hg.), Ähnlichkeit: Ein kulturtheoretisches Paradigma (Konstanz: Konstanz University Press, 2015), 75-92.

O.A., Führer durch H. Präuschers Panopticum Wien k.u.k. Prater 140 (Wien: Verlag von H. Präuscher, 1892).

O.A., Führer durch das anatomische, pathologische und ethnologische Museum von H. Präuschers Nachfolgern (Wien: Verlag von H. Präuschers Nachfolgern, [ohne Jahresangabe]).

O.A., Wirtschaftliche Zustände Galiziens in der Gegenwart: 6 Vorträge gehalten aus Anlass der Studienreise der Wiener Freien Vereinigung für staatswissenschaftliche Fortbildung nach Krakau und Galizien (Wien: Braumüller, 1913.)

Oxaal, Ivar, Die Juden im Wien des jungen Hitler: Historische und soziologische Aspekte, in: Gerhard Botz, ders., Michael Pollak, Nina Scholz (Hg.), Eine zerstörte Kultur: Jüdisches Leben und Antisemitismus in Wien seit dem 19. Jahrhundert (Wien: Czernin, 2002), 46-64.

Patka, Marcus G., Stalzer Alfred (Hg.), Alle meschugge? Jüdischer Witz und Humor (Wien: Jüdisches Museum Wien, 2013).

Patka, Marcus G., Die Budapester Orpheumgesellschaft - Eine Bühne für den Jargon, in: ders.., Alfred Stalzer (Hg.), Alle meschugge? Jüdischer Witz und Humor (Wien: Jüdisches Museum Wien, 2013), 84-89.

Plunz, Richard, A History of Housing in New York City (New York: Columbia University Press, 1990).

Pohanka, Reinhard, „Der Väter Burgen liess sie schleifen...“: Stadtplanung 1848-1918 in Wien und Budapest, Legitimation und Nationalismus, in: Wolfgang Kos, Christian Rapp (Hg.), Alt-Wien: Die Stadt, die niemals war (Wien: Czernin, 2004), 71-76.

Pressler, Gertraud, Jüdisches und Antisemitisches in der Wiener Volksunterhaltung, in: Michael Weber, Thomas Hochrader (Hg.), Identität und Differenz: Beiträge zur vergleichenden und systematischen Musikwissenschaft (Musicologica Austriaca 17) (Wien: Musikwissenschaftlicher Verlag, 1998), 63-82.

Pulzer, Peter G. J., Die Entstehung des modernen Antisemitismus in Deutschland und Österreich 1867-1914 (Göttingen: Vandenhoeck \& Ruprecht, 2004).

Quint, Alyssa, The Rise of Modern Yiddish Theater (Bloomington: Indiana University Press, 2019).

Rahden, Till van, „Juden und die Ambivalenz der bürgerlichen Gesellschaft in Deutschland von 1800-1933“, Transversal 1 (2004): 33-61.

Rahden, Till van, Weder Milieu noch Konfession: Die situative Ethnizität der deutschen Juden im Kaiserreich in vergleichender Perspektive, in: Olaf Blaschke, Frank-Michael Kuhlemann (Hg.), Religion im Kaiserreich: Milieu, 
Mentalitäten, Krisen (Gütersloh: Gütersloher Verlagshaus, 1996), 409-434. Rechter, David, „Ethnicity and the Politics of Welfare: The Case of Habsburg Austrian Jewry“, Simon Dubnow Institute Yearbook 1 (2002): 257-276.

Resch, Andreas, Die Wiener Kulturwirtschaft um 1910 und die Partizipation von Juden, Tschechen und „Staatsfremden“, in: Elisabeth Röhrlich (Hg.), Migration und Innovation um 1900: Perspektiven auf das Wien der Jahrhundertwende (Wien, Köln, Weimar: Böhlau, 2016), 119-171.

Richers, Julia, Jüdisches Budapest: Kulturelle Topographien einer Stadtgemeinde im 19. Jahrhundert (Wien, Köln, Weimar: Böhlau, 2009).

Riis Jacob, How the Other Half Lives: Studies among the Tenements of New York, herausgegeben von Leviatin David (Boston: Bedford \& St. Martins, 2011).

Rischin, Moses, The Promised City: New York's Jews 1870-1914 (Cambridge, London: Harvard University Press, 1977).

Röhrlich, Elisabeth (Hg.), Migration und Innovation um 1900: Perspektiven auf das Wien der Jahrhundertwende (Wien, Köln, Weimar: Böhlau, 2016).

Roßbach, Nikola, Wien parodiert: Theatertexte um 1900 (Wien: Praesens, 2007).

Rosman, Moshe, How Jewish is Jewish History? (Oxford: The Littman Library of Jewish Civilization, 2007).

Roth, Joseph, Hiob: Roman eines einfachen Mannes, in: ders. Werke in drei Bänden, Bd. 2 [1930] (Köln, Berlin: Kiepenheuer \& Witsch, 1956).

Roth, Joseph, Juden auf Wanderschaft [1927] (München: Dtv, 2015).

Roth, Joseph, Radetzkymarsch [1932] (Köln: Anaconda, 2012).

Roth, Laurence, Valman Nadia (Hg.), The Routledge Handbook of Contemporary Jewish Cultures (London, New York: Routledge, 2015).

Rozenblit, Marsha L., „A Note on Galician Jewish Migration to Vienna“, Austrian History Yearbook 19 (1983): 143-152.

Rozenblit, Marsha L., Jews of Vienna 1867-1914: Assimilation and Identity (Albany: State University of New York Press, 1983).

Rozenblit, Marsha L., Jewish Ethnicity in a New Nation-State: The Crisis of Identity in the Austrian Republic, in: Michael Brenner, Derek Penslar (Hg.), In Search of Jewish Community: Jewish Identities in Germany and Austria 1918-1933 (Bloomington, Indianapolis: Indiana University Press, 1998), 134-153.

Rozenblit, Marsha L., Reconstructing a National Identity: The Jews of Habsburg Austria during World War I (New York, Oxford: Oxford University Press, 2004).

Ruchatz, Der Ort des Populären, in: Gereon Blaseio, Hedwig Pompe, Jens Ruchatz (Hg.), Popularisierung und Popularität (Köln: DuMont, 2005), 139-145. 
Rutherford, Jonathan (Hg.), Identity: Community, Culture, Difference (London: Lawrence \& Wishart, 1990).

Rutherford Jonathan, The Third Space: Interview with Homi Bhabha, in: ders. (Hg.), Identity: Community, Culture, Difference (London: Lawrence \& Wishart, 1990), 207-221.

Sakai, Naoki, Der Ort von Vergleich und Transnationalität: Ein Plädoyer für vergleichende Geschichtswissenschaft, in: Anil Bhatti, Dorothee Kimmich (Hg.), Ähnlichkeit: Ein kulturtheoretisches Paradigma (Konstanz: Konstanz University Press, 2015), 129-152.

Sandrow, Nahma, Popular Yiddish Theatre: Music, Melodrama and Operetta, in: Edna Nahshon (Hg.), New York's Yiddish Theater: From Bowery to Broadway (New York: Columbia University Press, 2016), 64-83.

Schach, Julius, „Das jüdische Theater, sein Wesen und seine Geschichte“, Ost und West 1, no. 5 (1901): 347-358.

Scherke, Katharina, Kulturelle Transfers zwischen sozialen Gruppierungen, in: Celestini Federico, Mitterbauer Helga (Hg.), Ver-rückte Kulturen: Zur Dynamik kultureller Transfers (Stauffenburg Discussion 22) (Tübingen: Stauffenberg, 2011), 99-116.

Schivelbusch, Wolfgang, Geschichte der Eisenbahnreise: Zur Industrialisierung von Raum und Zeit im 19. Jahrhundert (Frankfurt am Main: Fischer Taschenbuch Verlag, 2000).

Schlögl, Friedrich, Wienerisches: Kleine Culturbilder aus dem Volksleben der alten Kaiserstadt an der Donau (Wien, Teschen: Prochaska, 1883).

Schlör, Joachim, „Auf der Suche nach dem Ort des Judentums“, Kritische Berichte 24, no. 3 (1996): 6-12.

Schlör, Joachim, „,Solange wir auf dem Schiff waren, hatten wir ein Zuhause‘: Reisen als kulturelle Praxis im Migrationsprozess jüdischer Auswanderer“, Voyage - Jahrbuch für Reise- und Tourismusforschung 10 (2014): 226-246.

Schmale, Wolfgang, Martina Steer (Hg.), Kulturtransfer in der jüdischen Geschichte (Frankfurt, New York: Campus, 2006).

Schmale, Wolfgang, Erkenntnisinteresse der Kulturtransferforschung, in: ders., Steer Martina (Hg.), Kulturtransfer in der jüdischen Geschichte (Frankfurt, New York: Campus, 2006), 23-41.

Schnitzler, Arthur, Die griechische Tänzerin: Frühe Erzählungen [1902] (Berlin: Verlag der Nation, 1985).

Schnitzler, Arthur, Jugend in Wien: Eine Autobiografie [1968] (Frankfurt am Main: Fischer Taschenbuch Verlag, 2012).

Schoeps, Julius H., Schlör Joachim (Hg.), Antisemitismus: Vorurteile und Mythen (München, Zürich: Piper, 1996).

Schorske, Carl E., Fin De Siècle Vienna: Politics and Culture (New York: Vintage Books, 1981). 
Schumann, Jana, Von „jüdischem Humor“ und „verjudeter Kunst“: Konzeptionen jüdischer Identität und der Populärkulturdiskurs, in: Klaus Hödl (Hg.), Nicht nur Bildung, nicht nur Bürger: Juden in der Populärkultur (Schriften des Centrums für Jüdische Studien 23) (Bozen, Innsbruck, Wien: Studienverlag, 2013), 91-102.

Scott, Derek B., Sounds of the Metropolis: The 19th Century Popular Music Revolution in London, New York, Paris and Vienna (New York, Oxford: Oxford University Press, 2008).

Sen, Arijit, Silverman Lisa (Hg.), Making Place: Space and Embodiment in the City. (Bloomington: Indiana University Press, 2014).

Sen, Arijit, Silverman Lisa, Introduction Embodied Placemaking: An Important Category of Critical Analysis, in: dies. (Hg.), Making Place: Space and Embodiment in the City. (Bloomington: Indiana University Press, 2014), 1-17. Šiaučiūnaitè-Verbickienè, Jurgita, Lempertienė Larisa (Hg.), Jewish Space in Central and Eastern Europe: Day-to-Day History (Cambridge: Cambridge Scholars Publishing, 2009).

Silber, Michael K., Budapest. YIVO Encyclopedia of Jews in Eastern Europe. http://www.yivoencyclopedia.org/article.aspx/Budapest (letzter Zugriff: 12.11.2018).

Silverman, Lisa, Becoming Austrians: Jews and Culture between the World Wars (Oxford: Oxford University Press, 2012).

Silverman, Lisa, „Beyond Antisemitism: A Critical Approach to German-Jewish Cultural History“. Nexus, Essays in German Jewish Studies 1, no. 1 (2011): $27-45$.

Silverman, Lisa, Jewish Memory, Jewish Geography: Vienna before 1938, in: Arjiit Sen, dies. (Hg.), Making Place: Space and Embodiment in the City (Bloomington: Indiana University Press, 2014), 173-197.

Silverman, Lisa, „Reconsidering the Margins: Jewishness as an Analytical Framework“, Journal of Modern Jewish Studies 8, no. 1 (2009): 103-120.

Snyder, Robert W., Voice of the City: Vaudeville and Popular Culture in New York (New York, Oxford: Oxford University Press, 1989).

Statistische Abteilung des Wiener Magistrats, Statistisches Jahrbuch der Stadt Wien für das Jahr 1890 (Wien: Magistrat, 1892).

Statistische Abteilung des Wiener Magistrats, Statistisches Jahrbuch der Stadt Wien für das Jahr 1900 (Wien: Magistrat, 1902).

Statistische Abteilung des Wiener Magistrats, Statistisches Jahrbuch der Stadt Wien für das Jahr 1910 (Wien: Magistrat, 1912).

Statistische Abteilung des Wiener Magistrats, Statistisches Jahrbuch der Stadt Wien für das Jahr 1929 (Wien: Magistrat, 1931).

Stauter-Halsted, Keely, The Devil's Chain: Prostitution and Social Control in Partitioned Poland (Ithaca, London: Cornell University Press, 2015). 
Stauter-Halsted, Keely, „A Generation of Monsters: Jews, Prostitution, and Racial Purity in the 1892 L'viv White Slavery Trail“, Austrian History Yearbook 38 (2007): 25-35.

Steer, Martina, Einleitung: Jüdische Geschichte und Kulturtransfer, in: Wolfgang Schmale, dies. (Hg.), Kulturtransfer in der jüdischen Geschichte (Frankfurt, New York: Campus, 2006), 10-22.

Steidl, Annemarie, Wladimir Fischer-Nebmaier, James W. Oberly, From a Multiethnic Empire to a Nation of Nations: Austro-Hungarian Migrants in the US, 1870-1940 (Innsbruck, Wien, Bozen: Studienverlag, 2017).

Steidl, Annemarie, Engelbert Stockhammer, Hermann Zeitlhofer, „Relations among Internal, Continental, and Transatlantic Migration in Late Imperial Austria“, Social Science History, 31, no. 1 (2007): 61-92.

Stieg, Gerald, Sein oder Schein: Die Österreich-Idee von Maria Theresia bis zum Anschluss (Wien, Köln, Weimar: Böhlau, 2016).

Stögner, Karin, Antisemitismus und Sexismus: Historisch-gesellschaftliche Konstellationen (Baden: Nomos, 2014).

Storch, Ursula, Das Pratermuseum: 62 Stichwörter zur Geschichte des Praters (Wien: Museen der Stadt Wien, 1993).

Szívós, Erika, „Introduction: Historic Jewish Spaces in Central and Eastern European Cities“, East Central Europe 42 (2015): 139-162.

Terpitz, Olaf, An Enclave in Time? Russian-Jewish Berlin Revisited, in: Jörg Schulte, Olga Tabachnikova, Peter Wagstaff(Hg.), The Russian Jewish Diaspora and European Culture 1917-1937 (Leiden, Boston: Brill, 2012), 179-199.

Timm, Annette F., The Politics of Fertility in Twentieth Century Berlin (Cambridge: Cambridge University Press, 2010).

The Bowery Boys, Who killed Helen Jewett: A Mystery by Gaslight (New York, Radiosendung ausgestrahlt am 17.2.2017).

Thissen, Judith, Early Yiddish Vaudeville in New York City, in: Edna Nahshon (Hg.), New York's Yiddish Theater: From Bowery to Broadway (New York: Columbia University Press, 2016), 248-254.

Thissen, Judith, Liquor and Leisure: The Business of Yiddish Vaudeville, in: Berkowitz Joel, Henry Barbara (Hg.), Inventing the Modern Yiddish Stage: Essays in Drama, Performance, and Show Business (Detroit, Michigan: Wayne State University Press, 2012), 184-201.

Thissen, Judith, Reconsidering the Decline of the New York Yiddish Theatre in the Early 1900s, Theatre Survey 44, no. 2 (2003): 173-197.

Thissen, Judith, Should a Married Woman Visit a Yiddish Music Hall? In: Digital Yiddish Theatre Project, 2016, https://yiddishstage.org/should-amarriedwoman-visit-a-yiddish-music-hall (letzter Zugriff: 13.4.2020).

Thomashefsky, Boris, Mayn lebns-geshikhte [Meine Lebensgeschichte] (New York: Trio Press, 1937). 
Troy, Shari, On the Play and on the Playing: Theatricality as Leitmotif in the Purimshpil of the Bobover Hasidim (Ungedr. Diss.: City University New York, 2002).

Trumbull, White, WM. Igelhart, The World's Columbian Exhibition: Chicago 1893 [Katalog zur Weltausstellung in Chicago 1893] (Philadelphia, St. Louis: P. W. Ziegler \& Co., 1893).

Twardowski, Julius, Industrialisierung Galiziens. In: Wirtschaftliche Zustände Galiziens in der Gegenwart: 6 Vorträge gehalten aus Anlass der Studienreise der Wiener Freien Vereinigung für staatswissenschaftliche Fortbildung nach Krakau und Galizien (Wien: Braumüller, 1913).

Tuan, Yi-Fu, Space and Place: The Perspective of Experience (Minneapolis: University of Minnesota Press, 2001).

Turner, Victor, The Anthropology of Performance (New York: PAJ Publications, 1987).

Ungarisches statistisches Zentralamt, Ungarisches statistisches Jahrbuch, neue Folge 18, im Auftrage des kön. ung. Handelsministers (Budapest: Athenaeum, 1910).

University of Southampton, Parkes Institute: Research, Migration. http:// www.southampton.ac.uk/parkes/research/migration.page? (letzter Zugriff: 5.1.2017).

Vari, Alexander, Nation-Building and Globalization in the Budapest Orpheum and Cabaret World (1890-1914): Vortrag gehalten auf der Konferenz der Association for Slavic, East European and Eurasien Studies. Washington 2016.

Várkonyi, István, Ferenc Molnár and the Austro-Hungarian „Fin de siècle“ (New York: Peter Lang, 1992).

Veigl, Hans, Lachen im Keller: Kabarett und Kleinkunst in Wien 1900 bis 1945 (Graz: Österreichisches Kabarett Archiv, 2013).

Vogel, Shane, The Scene of Harlem Cabaret: Race, Sexuality, Performance (Chicago: University of Chicago Press, 2009).

Volkov, Shulamit, Das jüdische Projekt der Moderne: Zehn Essays (München: Beck, 2001).

Vries, Petra de, „'White Slaves' in a Colonial Nation: The Dutch Campaign Against the Traffic in Women in the Early Twentieth Century", Social and Legal Studies 14, no. 1 (2005): 39-60.

Wacks, Georg, Die Budapester Orpheumgesellschaft: Ein Varieté in Wien 1889-1919 (Wien: Holzhausen, 2002).

Wacks, Georg, Ein Abend bei den Budapestern, in: Brigitte Dalinger, Werner Hanak-Lettner, Lisa Noggler (Hg.), Wege ins Vergnügen: Unterhaltung zwischen Prater und Stadt (Wien: Metroverlag, 2016), 34-39. 
Walden, Joshua S., Molly Picon: Darling of Second Avenue, in: Edna Nahshon (Hg.), New York's Yiddish Theater: From Bowery to Broadway (New York: Columbia University Press, 2016), 128-139.

Warnke, Nina, „Immigrant Popular Culture as Contested Sphere: Yiddish Music Halls, the Yiddish Press, and the Process of Americanization, 1900-1910", Theatre Journal 48, no. 3 (1996): 253-277.

Warnke, Nina, Patriotn and Their Stars: Male Youth Culture in the Galleries of the New York Yiddish Theatre, in: Joel Berkowitz, Barbara Henry (Hg.), Inventing the Modern Yiddish Stage: Essays in Drama, Performance, and Show Business (Detroit, Michigan: Wayne State University Press, 2012), 161-183.

Warner, Michael, Introduction, in: ders. (Hg.), Fear of a Queer Planet: Queer Politics and Social Theory (Minneapolis: University of Minnesota Press, 1993), vi-xxxi.

Wingfield, Nancy M., The World of Prostitution in Late Imperial Austria (New York, Oxford: Oxford University Press, 2017).

Winter, Rainer, Spielräume des Vergnügens und der Interpretation: Cultural Studies und die kritische Analyse des Populären, in: Jan Engelmann (Hg.), Die kleinen Unterschiede: Der Cultural Studies-Reader (Frankfurt am Main, New York: Campus, 1999), 35-48.

Wistrich, Robert, Laboratory for World Destruction: Germans and Jews in Central Europe (Lincoln, London: University of Nebraska Press, 2007).

Wistrich, Robert, Die Juden Wiens im Zeitalter Kaiser Franz Josephs (Wien, Köln, Weimar: Böhlau, 1999).

Wistrich, Robert, The Jews of Vienna in the Age of Franz Joseph (New York, Oxford: Oxford University Press, 1989).

Wobick-Segev, Sarah, Homes away from Home: Jewish Belonging in TwentiethCentury Paris, Berlin, and St. Petersburg (Stanford: Stanford University Press, 2018).

Wolf, Michaela, „Kulturelle Übersetzung“ - Spielwiese für übersetzerische Beliebigkeit oder Spielarten von Übersetzung „nach Babel“? in: Hiroshi Yamamoto, Christine Ivanovic (Hg.), Übersetzen - Transformation: Umformungsprozesse in/von Texten, Medien, Kulturen (Würzburg: Konigshausen \& Neumann, 2010), 44-55.

Woolf, Virginia, A Room of One's Own (London: Hogarth, 1929).

Yamamoto, Hiroshi, Ivanovic Christine (Hg.), Übersetzen - Transformation: Umformungsprozesse in/von Texten, Medien, Kulturen (Würzburg: Konigshausen \& Neumann, 2010).

Zahra, Tara, ,Imagined Noncommunities: National Indifference as a Category of Analysis", Slavic Review 69, no. 1 (2010): 93-119. 
Ziegler, J. W., The World's Columbian Exhibition [Katalog zur Weltausstellung in Chicago 1893] (Chicago 1893).

Zweig, Stefan, Die Welt von Gestern [1941] (Frankfurt am Main: S. Fischer, 2014). 


\section{Personen- und Sachregister}

A

Actors Unions 33, 128, 129, 230

Adler, Emanuel 65

Adler, Jacob 97-99

Ágai, Adolf 75

Ähnlichkeit 29, 30, 102, 180, 201, 202, 204, 206, 207, 217, 227, 230

- -swahrnehmungen 201,202, 204, 207

Akkulturation 25-27, 84

- -snarrativ 109,227

Akkulturationsbestrebung 153

Akrobat ${ }^{*}$ innen $\quad 25,32,55,119,122$,

135,236

Alt-Budapest 16

Alterität 202

Alt-Wien 16, 37, 38, 53, 103, 123

Alweltlikher idishn Kultur-Kongres

92

American Scenic Railway 233-235, 238

Amüsement $9,10,15,20,35,41$,

$53,54,57,63,75,76,100,116,117$,

$119,178,200,201,203,204,212$,

223, 234, 236, 237

- köstliches 55, 57, 163, 236

Anderson, Benedict 28

Antisemitismus $10,20,25,32,49$,

$102,109,123,170,203,227,229$,

236

- moderner 49

Apollo Theater 105-107

Armin, Josef 78, 83, 84

Artistenheime $17,25,31,54,82,83$,

135, 140-143, 222

Artistenverein 136
- Budapester Artisten-Verein 134, 136

- Circuits 134, 138, 139

- Internationale Artistenverein Der Lustige Ritter Wien 133, 137

- Wiener Artistenverband 136

- Wiener Zwölferbund 137

Assimilation 25-27, 84, 85, 92, 94,

153, 187, 206

Association of Traveling Vaudeville

Managers 138

\section{B}

Basté, Risa 148, 160, 161, 165, 170, 190, 191, 205, 211, 225

Bauakt 34

Bauer, Julius 35

Belgrad 111, 112

Benjamin, Walter 201, 202

Bettgeher*innen 9,35

Bevölkerungswachstum 21, 35, 38

Bhatti, Anil 29, 202, 207

Blaue Katze 75, 76, 78, 139

Blumenthal, Oscar 91

Böhmen 32, 39, 189, 190, 236

Bourdieu, Pierre 109

Bowery 9, 42, 45, 46, 53, 55, 73, 95, 97-99, 101, 102, 107, 163, 164, 214-219, 222

Brigittenau 47

Broadway 9, 45, 91, 95, 167, 218

Broder, Berl 118

Brodersänger 118

Bronx 45

Brubaker, Rogers 27

Budapester Orpheumgesellschaft

69-73, 78, 79, 81, 83, 104, 105, 107, 
$108,137,148,150,151,153,160$,

$184,233,237$

Budapesti Hírlap 142

Buenos Aires 116

Bukowina 21, 22, 186

C

Café Imperial $\quad 75,114$

Café Reklame s. Nestroyhof

Chantant-Mutter $\quad 32,114,145,171$

Chantant-Regisseur 153, 154

Circuits s. Artistenverein

Cohen, Gary 28

Colosseum 56, 106, 166

Coney Island 233

Coney Island Scenic Railroad 233

Cooper, Frederick 27

Copyright 132

- Act 132

Couplet 25, 54, 115, 119, 145, 147, $148,151,153,167,179,181,183$, 205

Csáky, Moritz 16, 198

D

Das letzte Leintuch $\quad 148,149$

Das Schlafcoupé 231

Demographie s. Bevölkerungswachstum

Der Afrikareisende $183,188-190$, 205-209, 211, 212, 229

Der Artist (Zeitschrift) 112, 124, 126

Der Beit Hmdrsh ointer der erd oder da Idishe Shtroßen Zengerin 215, 230

Der Empfindsame $\quad 114,115$

Der kleine Kohn 78

Der Reisekoffer $\quad 183,190,205,209$, 211, 213, 225, 228

Der Reisende $181,183,184,186$, $188,205,206,213$
Die Csárdásfürstin $\quad$ 147, 219-222

Die Juden (Lessing) 68

Die Klabriaspartie $78,87,93,142$, 152, 177, 179-181

Die Reise nach Paris $183,194,196$, 205

Differenz 28, 29, 32, 57, 102, 180, 199, 202-207, 209, 212, 217, 229

- Geschlechterdifferenz 217

Dilettantentheater $s$. Nestroyhof

Drexler's Singspielhalle 155

E

Ein Hotel in Budapest 223, 225, 228, 231

Ein Wiener Quartett in Amerika $183,192,194,205,206$

Eisenbach, Heinrich $\quad 81-83,108$, $139,148,150,153,181,183,184$, 188

Eisenbahn 21, 41, 116, 118, 188, 224

Eldorado Theatre 98, 99

Ellis Island 193, 206

Englischer Garten s. Prater

Erzsébetváros 46, 50, 53

Etablissement Armin $\quad 75,78,84$

Etablissement Imperial $\quad 179,180$

Etablissement Somossy 137, s. Somossys Orpheum

Eysler, Edmund 147

$\mathbf{F}$

Fellner, Ferdinand 81

Ferry, Anna 81, 139

Feuerpolizei $34,68,69$

Fiakerlied 87,88

Fischs Varieté 75

Fiske, John 19

Fleischmann, Pauline s. Paula Walden

Flusser, Vilém 23 
Folies Caprice $40,51,52,75,76, \quad$ Herzmanns Orpheum $75,83,84$, $78-80,84,87,88,91,93,104,105$, $139,142,150$

$111,126,127,137,139,142,162$, 176,226

Folies Comiques 64, 65, s. auch Nestroyhof

Freizeit 18, 55, 63

Hess, Jonathan 19, 27

Heurigen 74, 107, 119

highbrow 19

Hiob 43

Hirsch, Albert 137

Freud, Sigmund 200, 201, 203, 204

Hochkultur 9, 19, 24, 106, 109

Friedmann, Sali s. Risa Basté

Fürst, Johann 63

Fürsts Singspielhalle 64

G

Galizien $21,22,39,73,118,151$, 186

Hödl, Klaus 24, 27, 28, 107, 109, 202, 203

Hofmannsthal, Hugo von 9, 203

Hollywood 9

Hotel Central 72, 107, 108, 148

Hotel Stefanie $70,72,73,107$

Hugo, Victor 214, 219

Gartner, Lloyd 22

Gassenhauer 18, 25

Gender-Bending 10, 20, 32, 155, $164,165,167,168,170,215,216$, 236

Geschlechterrollen $\quad 10,20,27,32$, $115,144,155,167,176,205,209$, 218

Gesellschaftskritik 20, 148, 200

Glinger, Adolf 107, 148, 151, 160

Glinger, Sali s. Risa Basté

Gluck, Mary 24, 47, 75, 76, 107, 109

Goldene Medine 22

Goldfaden, Abraham 145, 146, 220, 221

Gorin, Jacob 99

Grand Theatre 97

Groschenroman 18, 50

Grünbaum, Fritz 147

H

Handlungsreisend 116, 179

Harlem 45, 107

Helmer, Hermann 81

Heltai, Ferenc 46

Heltai, Jenő 40
I

Identifikation $20,25,27-30,32,57$, $103,154,168,183,191,197,203$, 204, 207, 208, 218, 229, 236

Identität $27,61,193,194,198,202$, 205, 231

Identitäten 27, 165

Im Schlafcoupé 223, 225, 228

Im weißen Rößl 91

Imperial Music Hall $\quad 99,100$

Internationalität $\quad 9,83,85,112,123$

J

Jargon 25, 45, 93, 102, 150, 156, 207, 212

Jenbach, Bela $\quad 147,219$

Jewett, Helen 213, 214

Jewish Difference $28,29,199$

Jewish Messenger 37, 48, 49

Jiddisch $11,25,33,93,97,99,102$, $160,167,179,212,218,220,237$,

s. auch jiddisches Theater

jiddische Literatur 186

jiddische Music Hall 99 


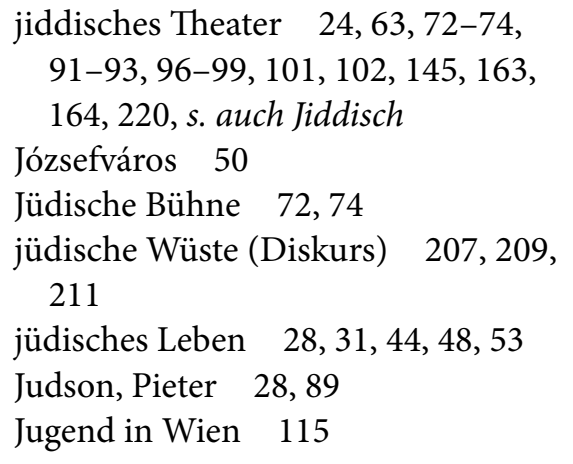

\section{K}

Kadelburg, Gustav 91

Kaiser Ferdinand Nordbahnhof s. Nordbahnhof

Kaisergarten 233, s. Prater

Kalich, Jacob 74, 160, 165, 167

Kálmán, Emmerich 9, 147, 219

Kaminska, Ester Rokhl 73, 139

Kaminska, Ida 73

Kerepesi út $\quad 40,76,78,128,226$

Kikeriki 50

Kimmich, Dorothee 29, 202

Kinematographie $63,70,105$

Koller, Josef $\quad 53,117,121,123,138$, 147, 151, 152, 155, 169

Kolonialismus 20, 183, 190, 212, 229

Kommunikationsraum 198

Koster and Bials Concert Hall 100, 101,140

Kriebaum, Franz 76, 134

Kriebaum, Marietta 76

Künstlerberuf $\quad 126,134$

Kutschera, Karl $84,85,114,134$, 150

L

Lautzky, Matthias Bernhard 71, 72, 134, 178, 184, 194

Lechner, Carl 71, 103, 148, 225
Lefebvre, Henri $\quad 58,59$

Lehár, Franz 147, 177

Lemberg 118, 152

Lemberger Gimpl 118

Leopoldi, Ferdinand 138

Leopoldstadt $47,48,50,53,63,64$, 161

Leopoldstädter Tempel $\quad 64,65,70$

Lessing, Gotthold Ephraim 68

Levine, Lawrence 18,19

Lilliom 41

Lithographie 126, 127, 131, 138, 166,235

48, London Theatre 99

Löw, Martina 58-60, 62

lowbrow 19

Lower East Side $\quad 43-45,50,53,94$, 96, 98, 109, 214-216, 218

Lueger, Karl 46, 49, 137

Lukacs, György 67

\section{M}

Mädchenhandel $111,115,174,210$

Mähren 39

makom 61, 62, s. auch Ort

Massenkultur 18, 116

Massenmigration $9,21,22,48,50$, 182, 199

Max und Moritz (Varieté) 107, 108, 151

Mazzesinsel 48, 63

middlebrow 19

Migration $16-19,22,23,31,35,43$, $44,50,94,102,109,118,123,138$, 179, 184, 189, 191-193, 196, 205, 206, 214, 216, 217, 219, 220, 222, 229, 230, s. auch Massenmigration

- Binnenmigration 22

- Massenmigration 182, 199

- Migrationsbewegung 21-23, 93, 130 
- Migrationsgesellschaft 206

- Transmigration 23, 117

Misogynie 25, 170, 173

Modl, Josef $\quad 71,103,128,134,155$, 233

Möglichkeitsraum 19, 20, 29

Molnár, Ferenc 9, 41, 162

Museum of Modern Art 9

Musikhalle 9

\section{N}

Nahshon, Edna 24

Narrativ 9, 10, 27-29, 60, 92, 96, $101,106,109,168,202,227$ national indifference 28,89

Nationalismus 28, 89, 208, 229

Nestroyhof $64-70,74,105,107$

Nestroysäle s. Nestroyhof

Neumann, Ferenc s. Ferenc Molnár

Nordbahnhof 47, 48, 50, 63, 107

0

Old-New York 16

Oroszi, Antal $78,84,103,139,177$, 178, 180

Orozzy Anton s. Antal Oroszi

Orozzy, Antal s. Antal Orozsi

\section{$\mathbf{P}$}

Pastor, Tony 97

People's Theatre 97, 99, 214, 217

Performanz 62, 192, 204, s. auch Performativität

Performativität $10,28,30,32,33$, 58, 105, 135, 165, 204, 207, 227, 237, s. auch Performanz

Picon, Molly $74,156,160,165$, 167-170

Plurikulturalität $94,96,102,123$, 212

Polish Jews 43
Posse $25,54,83,91,119,146,154$,

$178,183,192,215,225,227$

Prater $18,31,41,47,48,63,64,75$, $80,103,104,106,107,155,192$, 221, 233, 234

Präuschers Panoptikum 234

Prostitution 10, 20, 31, 111-113, 142, 168-170, 172, 173, 175, 210, 214-217, 222, 223, 231

Purimspiel 97

Q

queere 156

R

Radetzkymarsch 177

Richter-Roland, Emil $\quad$ 65, 74, 108

Richter-Roland, Josefine 108

Riis, Jacob 44, 45, 50, 94, 95

Romeo Kohn und Julie Lewi 78

Rosenstein, Leo 147, 219

Rosenzweig, Hermann $\quad$ 180, 181

Rosman, Moshe 29

Roth, Joseph $\quad 43,44,46,48,63,177$, 178

Rott, Max $\quad 79,88,139,147,151,152$

Rott, Minna 162

Rott, Sándor 126, 127

Rottmann, Mendel s. Max Rott

Ruzek, Sophie 162

\section{$\mathbf{S}$}

Schlafcoupé $\quad 223-225,228,231$

Schnitzler, Arthur 114, 115

Scholem Alejchem 15, 97, 116, 179,

191, 227

Schönberg, Arnold 9

Schönerer, Georg von 49

Schorske, Carl E. 9

Schundliteratur 18

Schwank 18, 80, 91, 148, 188, 236

Seidler, Amalia 155 
Sexarbeit $168,174,214,236$, s. auch

Prostitution

Shulamit 220, 221

Silverman, Lisa 28

Singer, Carl s. Károly Somossy

Singer, Mendel $\quad 42,43$

Sofia 174

Sommeretablissement $31,80,104$, 235, s. auch Prater

Somossy Orpheum 136

Somossy, Carl s. Károly Somossy

Somossy, Károly $\quad 80,81,84,103$,

136, 162, 163

Somossys Orpheum $71,75,81,90$, $139,144,150$

Stadtwäldchen $s$. Városliget

Stein, Leo s. Leo Rosenstein

Steiner, Ferdinand $\quad 75,125,136$

Steiner, Gábor 125

Stolz, Robert 147

Straßensängerin 214-218, 220-224, 230

T

Taufstein, Louis $\quad 137,148,150,153$, $154,181,184,187,194,205,224$, 225

Taussig, Otto $\quad 107,148,151,161$

Taussig, Pauline s. Paula Walden

Taverne 31

Thalia Theatre 97,98

Theaterordnung $86,88-91,129,237$

Theaterzensur 33, 184

Thomashefsky, Boris 97-99, 103, $163,164,214,215,217,221,224$, 230

Thompson, Lamarcus Adna 233

Tieber, Ben 106

Tingel-Tangel 74, 177

Toni Pastor's Music Hall 99

Tuan, Yi-Fu 59
$\mathbf{U}$

Übersetzung $10,11,220$

- kulturelle 32,63, 197-199, 218, 219, 221

Unionsdominanz 129

Urban, Erich 224

\section{V}

Varieté Roither 165

Városliget $18,41,46,83,162,233$

Venedig in Wien $80,103,125,235$

Vienna $1900 \quad 9$

Vígszínház Theater 41

Vilna Trupe 73, 118

Volkssängerin $\quad 32,76,145,149$, 154-157, 160, 161, 165, 169, 170, $211,216,219,222,223,236$

Volkssängerkrieg $92,138,176$

Volkssängertum $16,53,117,123$, 147, 169

\section{W}

Walden, Paula $\quad 160,161,165,170$

Warenhaus Goldberg 226

Washington Square Park 18

Weiser, Jacques 111,113

Weltausstellung 52, 194, 195

- Chicago 192, 194

- Paris 183, 194, 196

Wiener Fiakerlied s. Fiakerlied

Windsor Theatre 73, 97, 98

Wurstelprater s. Prater

\section{Y}

Yentl 165

Yidl mitn Fidl $\quad$ 167, 168

Z

Zahra, Tara $27,28,89$

Zensur 18, 33, 58, 129, 188, 190-192, 194, 211, 219, 225, 230, s. auch Theaterzensur 
Zentralstelle für die Überwachung Zweig, Stefan 37, 38, 211

des Mädchenhandels $111 \quad$ Zwischenraum 182, 183, 223, 236

Zichy, Jenö 163

Zwischenraumqualität $\quad 198,199$ 